\title{
The Impacts of the Net Stress and Stress Shadow on the Productivity of Marcellus Shale Horizontal Well
}

\author{
Mohamed El Sgher \\ mnel1980@yahoo.com
}

Follow this and additional works at: https://researchrepository.wvu.edu/etd

Part of the Petroleum Engineering Commons

\section{Recommended Citation}

El Sgher, Mohamed, "The Impacts of the Net Stress and Stress Shadow on the Productivity of Marcellus Shale Horizontal Well" (2021). Graduate Theses, Dissertations, and Problem Reports. 8321.

https://researchrepository.wvu.edu/etd/8321

This Dissertation is protected by copyright and/or related rights. It has been brought to you by the The Research Repository @ WVU with permission from the rights-holder(s). You are free to use this Dissertation in any way that is permitted by the copyright and related rights legislation that applies to your use. For other uses you must obtain permission from the rights-holder(s) directly, unless additional rights are indicated by a Creative Commons license in the record and/ or on the work itself. This Dissertation has been accepted for inclusion in WVU Graduate Theses, Dissertations, and Problem Reports collection by an authorized administrator of The Research Repository @ WVU.

For more information, please contact researchrepository@mail.wvu.edu. 
The Impacts of the Net Stress and Stress Shadow on the Productivity of Marcellus Shale Horizontal Well

Mohamed El Sgher

Dissertation submitted

to the Benjamin M. Statler College of Engineering and Mineral Resources at West Virginia University

in partial fulfillment of the requirements for the degree of

Doctor of Philosophy

in Petroleum and Natural Gas Engineering

Kashy Aminian, Ph.D., Chair

Samuel Ameri, Professor

H. Ilkin Bilgesu, Ph.D.

Timothy Carr, Ph.D.

Zamirian, Mehrdad, Ph.D.

Department of Petroleum and Natural Gas Engineering

Morgantown, West Virginia

2021

Keywords: Stress Shadowing, Geomechanical Factors, Hydraulic Fracture, Natural

Fracture (Fissure), and Marcellus Shale

Copyright 2021 Mohamed El Sgher 


\section{ABSTRACT \\ The Impacts of the Net Stress and Stress Shadow on the Productivity of Marcellus Shale Horizontal Well Mohamed El Sgher}

Shale gas development has become a crucial part of the global oil and gas industry in recent years, especially in North America. Even though the application of horizontal drilling and hydraulic fracturing techniques have successfully unlocked considerable reserves of natural gas in shale-gas reservoirs, production rates from unconventional reservoirs decline more rapidly than conventional reservoirs. This is because production from a reservoir results in an increase in net stress due to a reduction in the pore pressure, while overburden pressure remains constant. This leads to the reduction in permeability of both the matrix and the fissures, as well as the conductivity of the hydraulic fractures. Furthermore, the propagation of a fracture cause stress change in the vicinity of the fracture, commonly known as stress shadow. Stress shadow influences the properties of the subsequent hydraulic fracture stages and results in less-than-optimal production.

The objective of this study was to investigate the impact of the net stress changes and the stress shadow on gas production from a horizontal well with multiple hydraulic fractures completed in Marcellus Shale. In addition, the impacts of stage (cluster) spacing, treatment size, treatment sequencing, and the formation mechanical properties on the gas recovery are investigated. The available information from a Marcellus Shale horizontal well including well logs data, diagnostic fracture injection test (DFIT), and fracture stimulation treatment data were analyzed to determine the formation mechanical properties, minimum horizontal stress, instantaneous shut-in pressure (ISIP), process zone stress (PZS), and leak-off mechanism. The results of the analysis were utilized as the inputs for a commercial hydraulic fracturing software to predict the hydraulic fracture properties influenced by stress shadowing.

A reservoir model for a horizontal well with multi-stage hydraulic fractures in Marcellus Shale was developed using the published Marcellus Shale properties. The results of the published laboratory studies on Marcellus shale core plugs provided the foundation for evaluating the geomechanical factors which quantify the impact of net stress on the permeability of the matrix and fissure as well as the fracture conductivity. The geomechanical factors as well as the predicted hydraulic fracture properties, were then incorporated in the reservoir model. A commercial reservoir simulation software was then utilized to predict the production performance of the developed Marcellus Shale horizontal well model. The results were then compared to the production history of the horizontal well for evaluation and verification. Finally, The model was finally used to perform a number of parametric studies.

The inclusion of geomechanical factors and stress shadow provided an accurate prediction of the gas production from the horizontal well under study. Geomechanical factors have a significant impact on gas production from Marcellus Shale, particularly at the early stage of the production (2-5 years). The fissure permeability geomechanical factor has the most impact on the production. Additionally, the propped fracture conductivity geomechanical factor is influenced by the fracture half-length and initial fracture conductivity. The impact of propped hydraulic fracture 
conductivity geomechanical factor is more prominent in the formations with low Young's modulus. The stress shadowing has a negative effect on gas production. The stress shadowing effects were found to be dependent on fracture spacing. This research finds that stress shadowing effects can be reduced by increasing the distance between the neighboring fracture stages. Furthermore, the predicted fracture grows vertically upward in Marcellus Shale if the stress shadowing effects are ignored. Moreover, the stress shadowing impact on the gas production increases as the volume of the injected fluid and the sand amount per stage are increased. The impact of the stress shadowing appears to be lower for simultaneous fracturing as compared to sequential fracturing. This research finds that the hydraulic fracture properties and gas recovery from Marcellus shale improve as Poisson's ratio decreases. However, the production enhancement due to the lower Poisson's ratio can be obscured by stress shadowing when the stage spacing is close. Additionally, this research finds that the gas recovery is influenced significantly by the fracture half-length and less significantly by non-uniform fracture-length. 


\section{DEDICATION}

My parents, whose loving spirit sustains me still;

And to my wife, for unlimited support in my life; And to my kids who provide me the feeling of happiness of motherhood. 


\section{ACKNOWLEDGMENTS}

First and foremost, I would like to especially thank my mentor and committee chairperson Dr. Kashy Aminian for all the support and guidance he provided for my academic, research, and professional development. Also, for his caring guidance and help in writing my dissertation.

I would like to express my sincere gratitude to Prof. Samuel Ameri, the head of the Department of Petroleum and Natural Gas Engineering at West Virginia University, for all the support and guidance he provided for my academic and professional development.

I appreciate all the guidance and comments which I have received from my supervising committee members, Dr. H. Ilkin Bilgesu, Dr. Tim Carr, and Dr. Zamirian, Mehrdad. For their invaluable support and valuable advice and suggestions

Last but far from least, I would like to express my deep appreciation, gratitude, and love for my wife, who supported me throughout this journey. Without her, I could never have made it to where I am today 


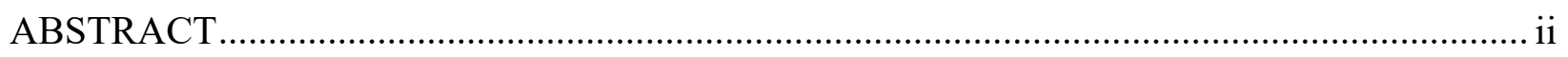

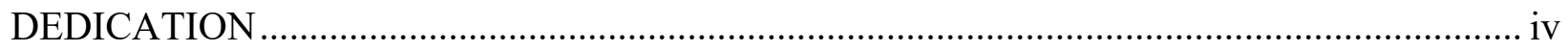

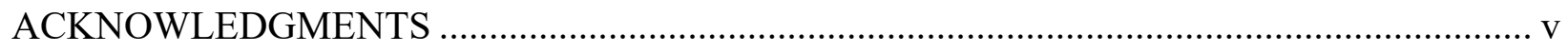

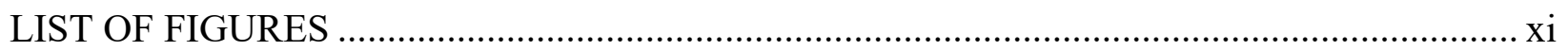

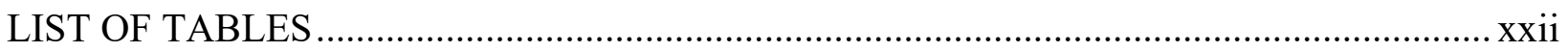

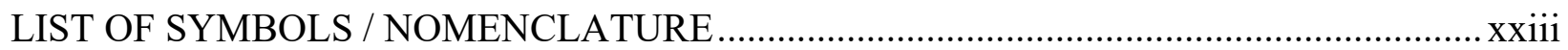

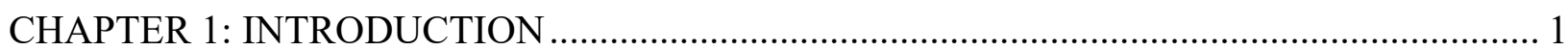

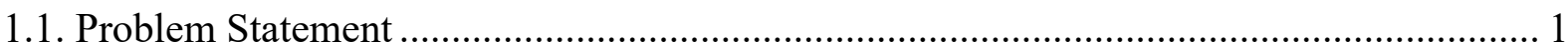

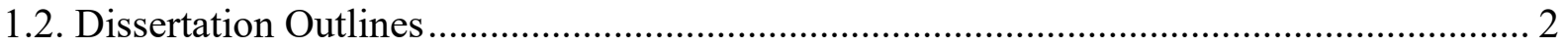

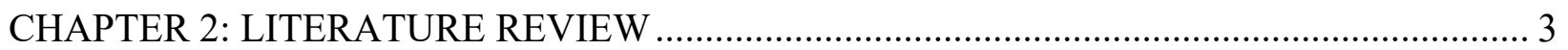

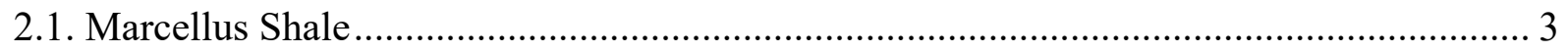

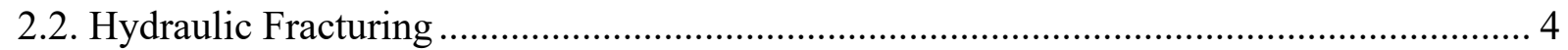

2.3. Impact of Stress on the Propped Fracture Conductivity ………........................................ 5

2.4. Impact of Stress on the Fissure Permeability ............................................................. 9

2.5. Impact of Stress on the Matrix Permeability ............................................................... 10

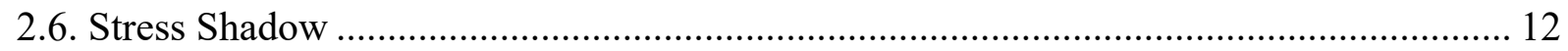

2.7. Rock Mechanics Properties.......................................................................................... 13

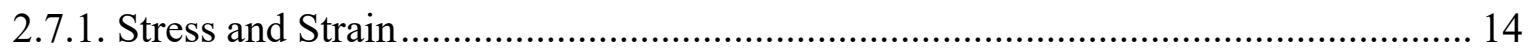

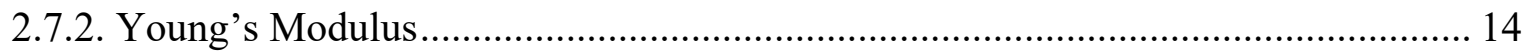

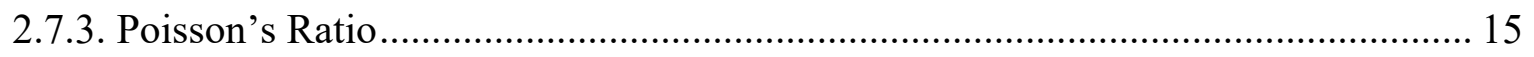

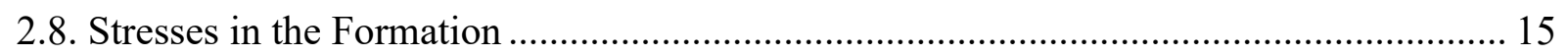

2.8.1. Minimum Horizontal Stress .................................................................................. 17

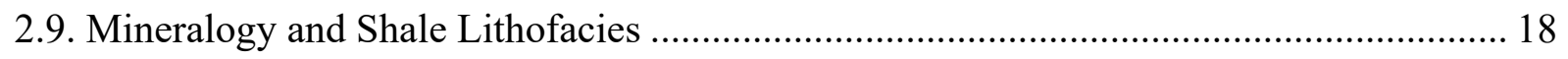

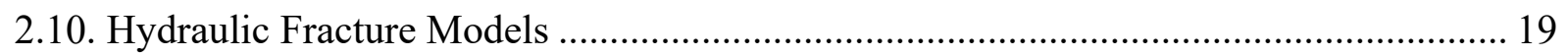

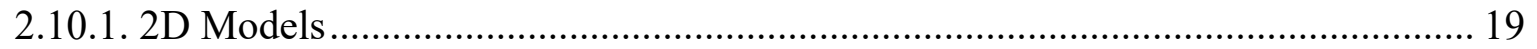

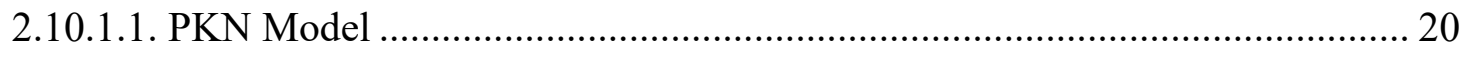

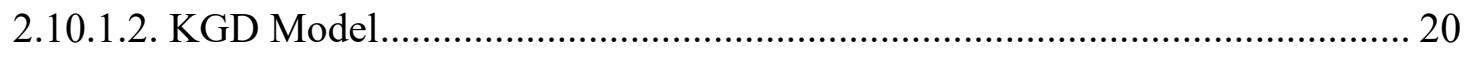

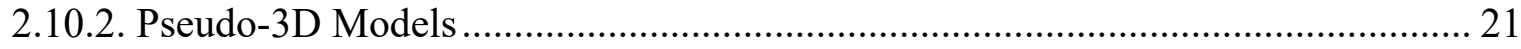

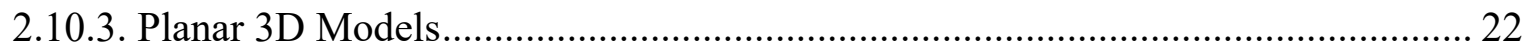

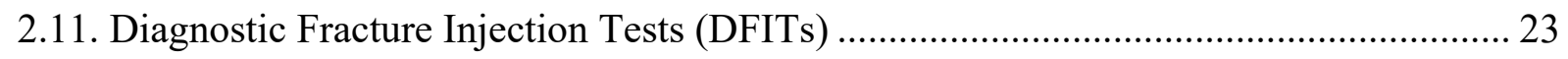

2.12. Contribution of Hydraulic Fracture Stage to Production ................................................. 24 


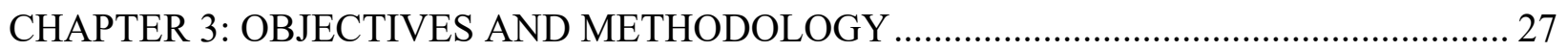

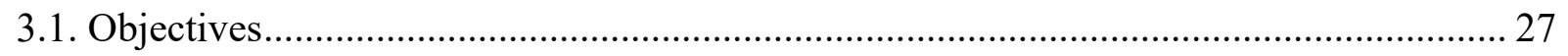

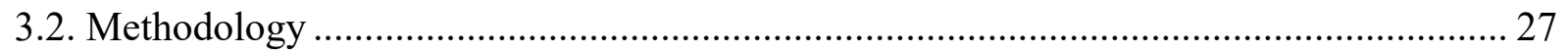

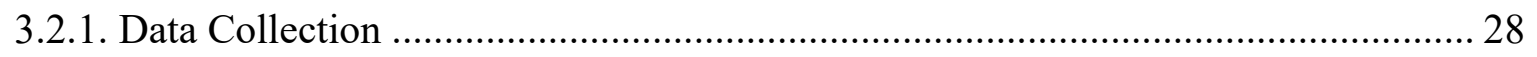

3.2.1.1. Data Collected from Well MIP-6H............................................................ 29

3.2.1.2. Data Collected from Well MIP-3H.............................................................. 30

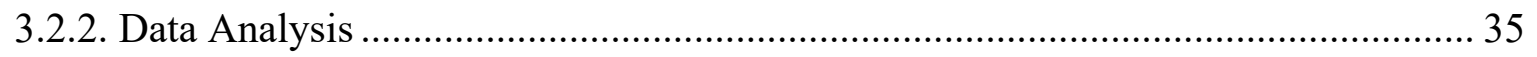

3.2.2.1. FMI Log Interpretations.......................................................................... 35

3.2.2.2. Quanta Geo Borehole Image Log Interpretations ......................................... 35

3.2.2.3. Sonic Scanner Log Interpretations ................................................................. 35

3.2.2.4. Microseismic Interpretations..................................................................... 38

3.2.2.5. Diagnostic Fracture Injection Test Interpretations........................................... 38

3.2.2.6. Stress Regime Evaluation .......................................................................... 41

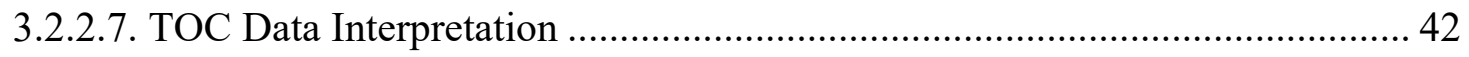

3.2.3. Prediction of the Fracture Properties .................................................................... 44

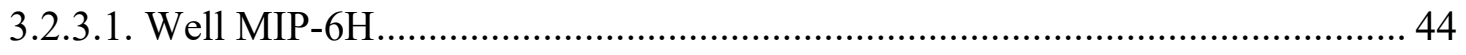

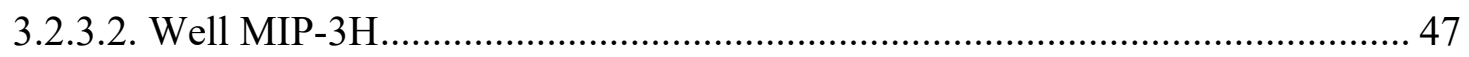

3.2.4. Reservoir Model Development for Wells MIP-6H and MIP-3H........................... 48

3.2.5. Impact of Geomechanical Factors..................................................................... 50

3.2.5.1. Matrix and Fissure Permeability Geomechanical Factors ............................. 50

3.2.5.2. Hydraulic Fracture Geomechanical Factor ...................................................... 53

3.2.5.3. Impact of Geomechanical Factor (Propped Fracture Conductivity) (MIP-6H)

3.2.5.4. Impact of Geomechanical Factors (Matrix, Fissure, and propped) (MIP-6H) 53

3.2.5.5. Impact of Geomechanical Factors (Matrix, Fissure, and propped) and Gas

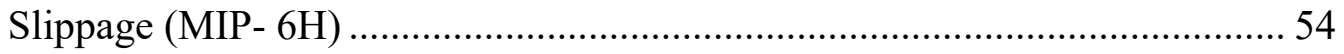

3.2.6. Impact of Stress Shadowing and Geomechanical Factors (Matrix, Fissure, and propped) (MIP-6H) ..................................................................................... 55

3.2.7. Parametric Studies to Investigate the Impact of Fracture Half-Length Including NonUniform Fracture Half-Length on the Gas Recovery............................................ 55

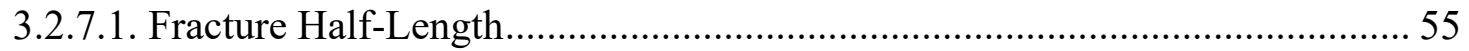


3.2.7.2. Non-Uniform Fracture Half-Length.

3.2.8. Parametric Studies to Investigate the Impact of the Geomechanical Factors on Gas Recovery. 56

3.2.8.1. Parametric Studies for Geomechanical Factor (Propped Fracture Conductivity)

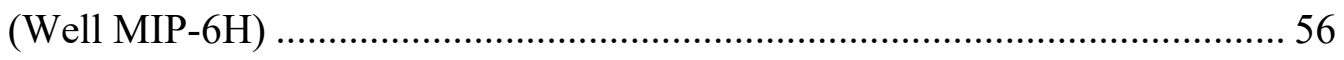

3.2.8.2. Parametric Studies for Geomechanical Factors (Matrix, Fissure, and propped) (Well MIP-6H). 57

3.2.8.3. Parametric Studies for Geomechanical Factors (Matrix, Fissure, and propped) and Gas Slippage (MIP-6H).

3.2.9. Parametric Studies to Investigate the Impact of the Reservoir and Treatment Parameters on the Degree of Stress Shadowing and the Gas Recovery from Marcellus Shale. 58

3.2.9.1. Parametric Studies for Well MIP-6H ........................................................ 58

3.2.9.2. Parametric Studies for Well MIP-3H ........................................................... 59

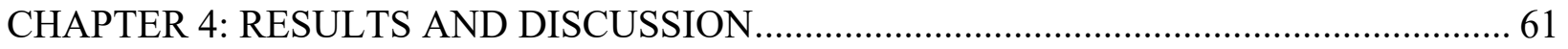

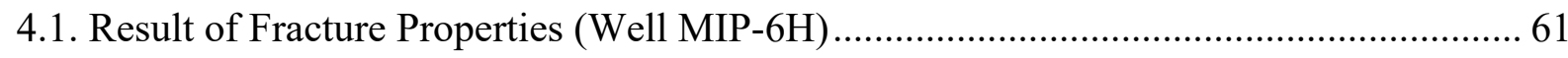

4.2. Impact of Geomechanical Factor (Propped Fracture Conductivity).................................... 61

4.3. Impact of Geomechanical Factors (Matrix, Fissure Permeability, and Propped Fracture

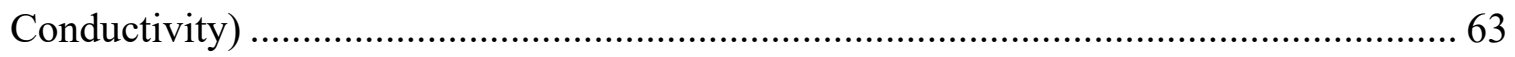

4.4. Impact of Geomechanical Factors and Gas Slippage (Well MIP-6H) ............................ 67

4.5. Impact of Stress Shadowing and Geomechanical Factors ................................................ 70

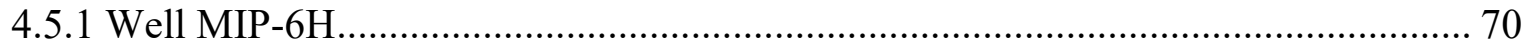

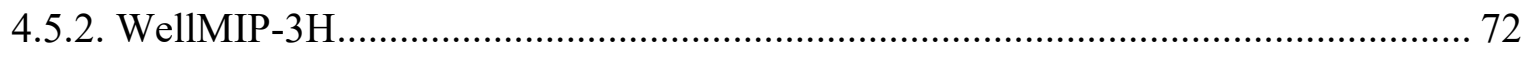

4.6. Resuts of Parametric Studies for Fracture Half-length and Non-uniform Fracture Half-

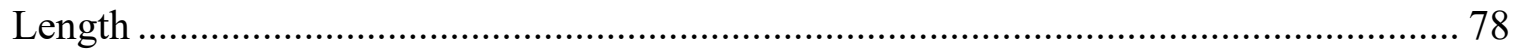

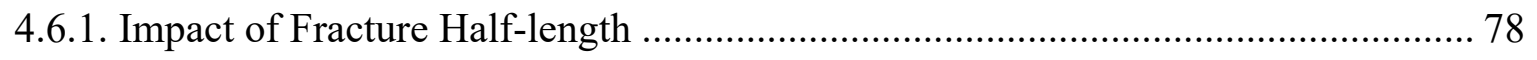

4.6.2. Effect of Non-uniform Fracture Half-Length ....................................................... 79

4.7. Resuts of Parametric Studies with Geomechanical Factor (Propped Hydraulic Fracture)

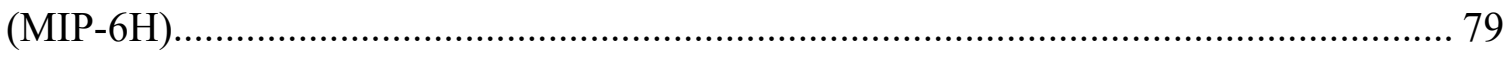

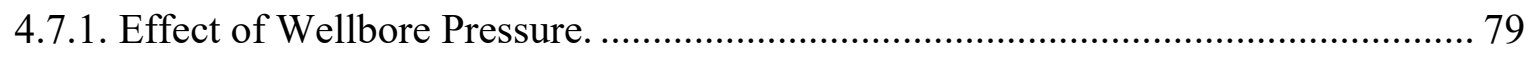

4.7.2. Effect of Fissure Permeability........................................................................... 80 


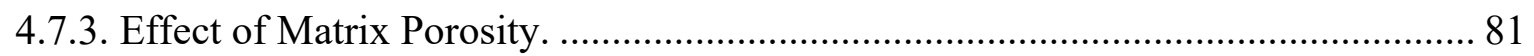

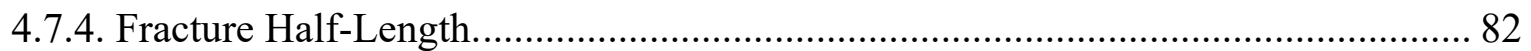

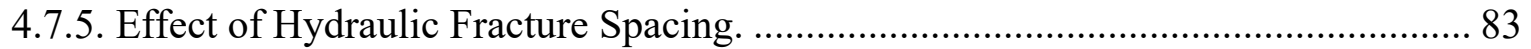

4.8. Results of Parametric Studies with Geomechanical Factors (Matrix, Fissure, and Hydraulic Fracture) for Well MIP-6H .................................................................................. 86

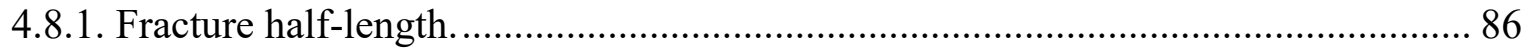

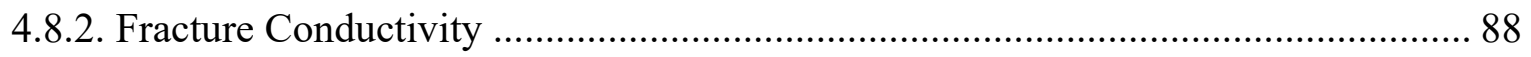

4.8.3. Fracture Stage Spacing..................................................................................... 91

4.8.4. Fissure Permeability ........................................................................................... 95

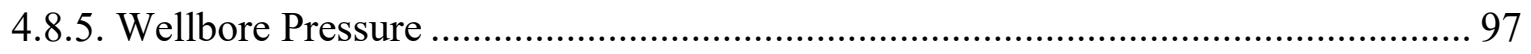

4.9. Results of Parametric Studies with Geomechanical Factors (Matrix, Fissure, and Hydraulic Fracture) (MIP-6H) ................................................................................................. 101

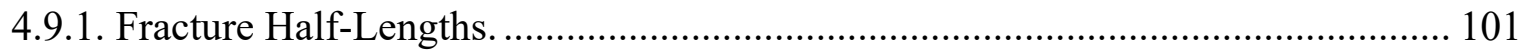

4.9.2. Initial Fracture Conductivity............................................................................. 103

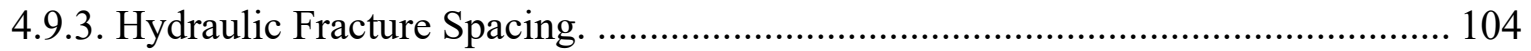

4.10. Results of Parametric Studies (Stress Shadowing) ………........................................ 107

4.10.1. Impact Fracture Spacing on Stress Shadowing and Gas Recovery (Well MIP-6H) 107

4.10.2. Impact of the Treatment Size on Stress Shadowing and Gas Recovery (MIP-6H).

4.10.3. Impact Treatment Sequencing on Stress Shadowing and Gas Recovery (Well MIP$6 \mathrm{H})$ 117

4.10.4. Impact of the Poisson's Ratio on Gas Recovery (Well MIP-6H)......................... 119

4.10.5. Impact Stress Shadowing on Fracture Properties (Well MIP-3H)...................... 120

4.10.6. Impact Cluster Spacing on Stress Shadowing and Gas Recovery (MIP-3H) ...... 121

4.10.7. Impact Cluster Spacing on Fracture Conductivity (Well MIP-3H) ..................... 125

4.10.8. Impact Treatment Design on Stress Shadowing and Gas Recovery (MIP-3H) ... 127

4.11. The Relationship between the Production Logging Tool Results (PLT) and Resistive Fractures (Fissures) and Fracture Conductivity per Stage along Horizontal Length...... 128 4.12. Comparison Gas Production Percentage per Section from the Production Logging Tool (PLT)....... 130 
4.13. The Relationship between the Total Organic Carbon (TOC) and Resistive Fractures (Fissures) and Production Logging Tool (PLT) per Stage along Horizontal Length ..... 131

CHAPTER 5: Conclusions and Recommendations .......................................................... 133

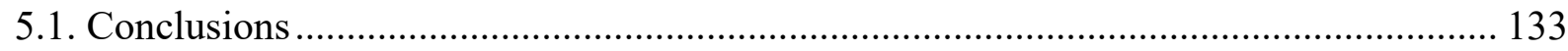

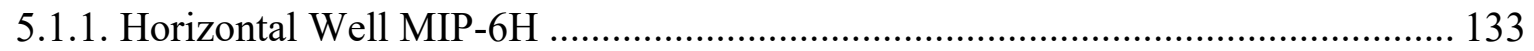

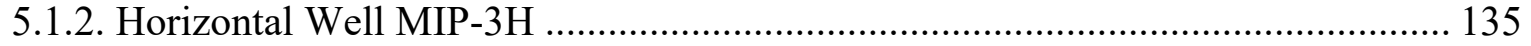

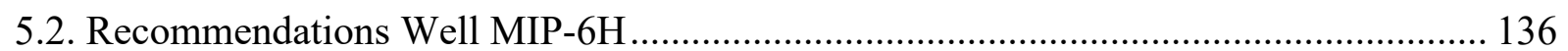

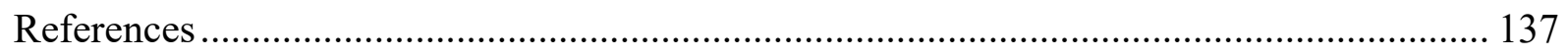

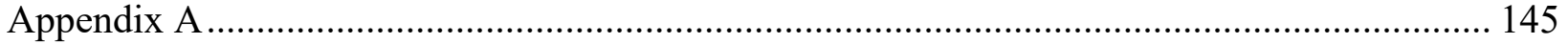




\section{LIST OF FIGURES}

Figure 2.1: Shows Extent of Marcellus Shale (Bentek, 2015) .................................................... 3

Figure 2.2: Shows Stratigraphy from North-Central West Virginia To Southeastern New York (Modified from Carter et al., 2011 and Zagorski et al., 2012.) .................................. 4

Figure 2.3: Marcellus Shale Hydraulic Fracture ("Fracking," 2013) ………………..................... 5

Figure 2.4: Brunell Hardness Numbers for Various Shale Reservoirs in North America (After

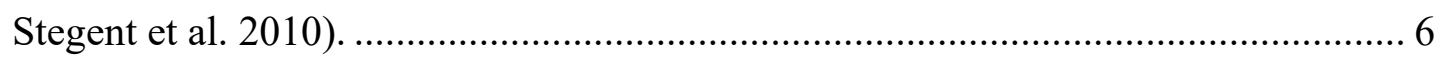

Figure 2.5: Measured Propped Fracture Conductivity for Elimsport Samples (After McGinley et

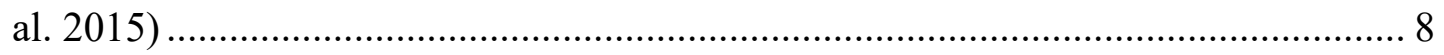

Figure 2.6: Measured Propped Fracture Conductivity for Allenwood Samples (After McGinley et

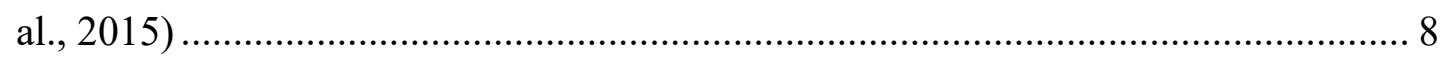

Figure 2.7: Effect of Young's Modulus and Net Stress on Conductivity of Un-Propped Fractures (After Cipolla et al. 2008). 10

Figure 2.8: The Impact of Net Stress on the Absolute Permeability of the Marcellus Shale (after

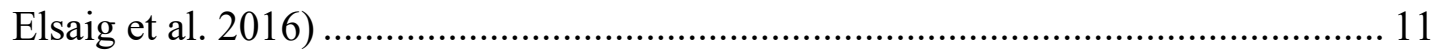

Figure 2.9: Evaluation of Fissure Closure Stress (after Elsaig et al. 2016 .................................. 11

Figure 2.10: (a) illustrates Stress Shadow (b) illustrates Effect of the Second Stage by Stress

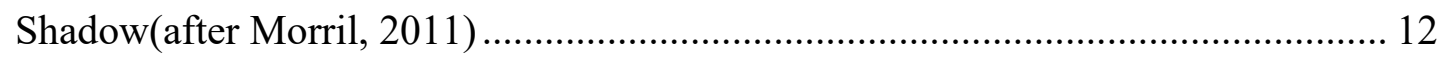

Figure 2.11: Stress Shadow Impact Middle Cluster ............................................................... 13

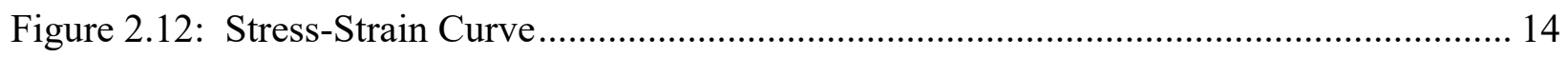

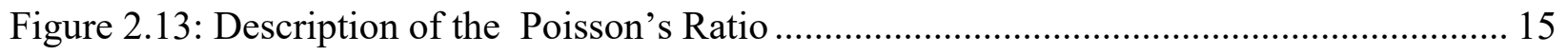

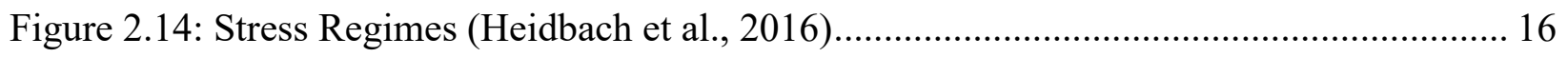

Figure 2.15: Multiple Transverse Fractures (Left) and Longitudinal Fracture (Right) (M.J.

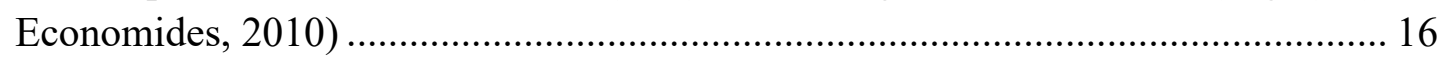

Figure 2.16: Mineralogy and Lithofacies for 3H \& 4H Wells (Paronish et al., 2016) .................. 19

Figure 2.17: Fracture Geometry in PKN Model (Economides \& Nolte, 2000)............................ 20

Figure 2.18: Fracture Geometry in KGD Model (Valk and Economides 1995) .......................... 21

Figure 2.19: Lumped Pseudo-3D model (Adachi et al. 2007) …….......................................... 22

Figure 2.20: Cell-based Pseudo-3D model (Adachi et al. 2007) ……………………................. 22

Figure 2.21: Typical DFIT Test Response (Wang et al., 2017)................................................ 23

Figure 2.22: G-Function Derivative Analysis - Leakoff Mechanisms after Craig et al. (2000)... 24

Figure 2.23: Vertical Extension of the Hydraulic Fracture in Marcellus Shale (Fisher et al. 2010) 26

Figure 3.1: MSEEL Site Illustrating the Well Locations (El Sgher et al. 2018) .......................... 28

Figure 3.2: Well Trajectory with a Variation of Gamma Ray along the Horizontal Section of Well

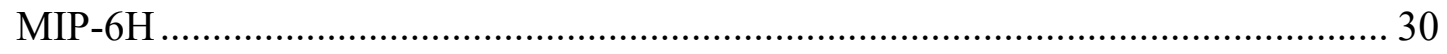

Figure 3.3: Comprehensive Suite of Logs from the Vertical Section of the Well MIP-3H Track 1Gamma Ray; Track 2- Deep Resistivity; Track 3- DTCO (Compressional Sonic), and Track 4- Bulk Density 31 
Figure 3.4: The Vertical Distribution of Microseismic Events (Carr et al., 2019) ...................... 33

Figure 3.5: Production Logging Tool Results for MIP-3H................................................... 34

Figure 3.6: (a) Drilling-Induced Fractures Orientation, (b) Breakouts Orientation ................... 36

Figure 3.7: Minimum and Maximum Horizontal Stress Orientation for MIP-3H.................... 36

Figure 3.8: Number and Type of Natural Fracture Observed Along the MIP-3H Lateral. ......... 37

Figure 3.9: (a) Rose Diagram Showing the Orientation (b) Schmidt Upper Hemisphere Projection Showing the Dip of The Resistive Continuous Fracture Observed along the Length of MIP-3H Lateral 37

Figure 3.10: Gamma-Ray, Young's Modulus, Passion's Ratio, Number of Resistive Continuous Fracture (Fissures), and Natural Fracture Density (P10) along the MIP-3H Lateral. 38

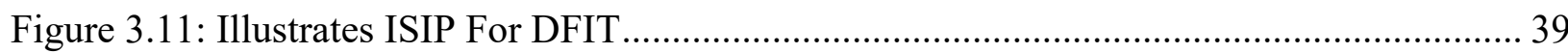

Figure 3.12: G-Function Plot Illustrating the Fissure Opening (FO) and Closure (C) for DFIT . 40

Figure 3.13: Square Root Plot for DFIT .............................................................................. 40

Figure 3.14: The Fissure Leak-Off Analysis ................................................................. 41

Figure 3.15: Stress Polygon for MIP-3H................................................................... 42

Figure 3.16: TOC Derived by Schmoker's Method (Blue) and TOC from the Core (Red)........ 43

Figure 3.17: Predicted TOC (\%) along the Horizontal Section of the Well MIP-3H................. 44

Figure 3.18: Illustrates Well MIP-6H Before Geosteering and After Geosteering .................... 45

Figure 3.19: Vertical Biot's Coefficient, Static and Dynamic Young's Modulus, Poisson's Ratio, Pore Pressure, Overborne Pressure, and Minimum Horizontal Stress Calculated from the Well Logs MIP-3H................................................................................ 46

Figure 3.20: A Matched Pressure Between Model and Actual Values for Stage 6 for MIP-6H. Dotted Pressure Curve (blue) Represents the Actual Surface Treating Pressure (Treatment Pressure in The Plot Legend), Whereas the Connected Pressure Curve (blue) Represents the Model Surface Treating Pressure (Well Pressure in The Plot Legend).................................................................................................. 46

Figure 3.21: A Matched Pressure between Model and treatment Data for Stage 7 For MIP-3H. Dotted Pressure Curve (Purple) Represents the Actual Surface Treating Pressure (Treatment Pressure in the Plot Legend), Whereas the Continuous Pressure Curve (Purple) Represents the Model Surface Treating Pressure (Well Pressure in the Plot Legend).

Figure 3.22: A Matched Pressure between Model and Actual Values for Stage 28 For MIP-3H. Dotted Pressure Curve (Purple) Represents the Actual Surface Treating Pressure (Treatment Pressure in the Plot Legend), Whereas the Connected Pressure Curve (Purple) Represents the Model Surface Treating Pressure (Well Pressure in the Plot Legend) ........................................................................................... 48

Figure 3.23: Wellbore Pressures for Well MIP-3H ......................................................... 49

Figure 3.24: Effect of Net Stress on Fissure Permeability.................................................. 51

Figure 3.25: Matrix and Fissure Permeability Multiplier ................................................... 51 
Figure 3.26: Permeability Multiplier for Gas Gas Slippage ............................................... 52

Figure 3.27: The Multiplier for Fissure Permeability ....................................................... 52

Figure 3.28: Propped Conductivity Multiplier For Fracture .............................................. 53

Figure 3.29: Illustrates Eleven Non-Uniform Fracture Half-Length Configurations .................. 56

Figure 4.1:Predicted Production Rates for MIP-6H with Geomechanical Factor (Hydraulic Fracture) for Four Years

Figure 4.2: Gas Flow Rate for 15 Years with and without Considering Geomechanical Factor for

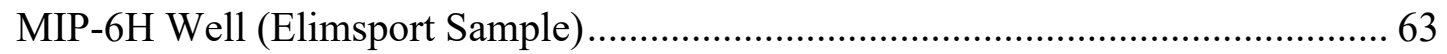

Figure 4.3: Cumulative Gas Production with and without Geomechanical Factor .................... 63

Figure 4.4: Predicted Production Rates for Well MIP-6H with Geomechanical Factors (Matrix,

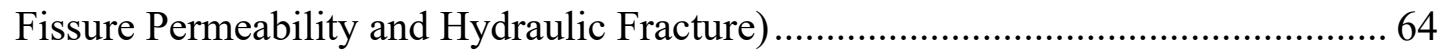

Figure 4.5: The Predicted 20-Year Gas Flow Rates for Well MIP-6H ................................... 65

Figure 4.6: Cumulative Gas Production for Well MIP-6H................................................... 66

Figure 4.7: Percentage Reduction in Gas Recovery Due to Geomechanical Factors .................. 66

Figure 4.8: Comparison of the Predicted and Actual Production for MIP-6H (1473 days) ......... 67

Figure 4.9: Production History for Well MIP-6H Water ProductionRate .................................. 68

Figure 4.10: The Predicted 10-Year Gas Flow Rates for Well MIP-6H ................................... 69

Figure 4.11: The Impact of Different Geomechanical Effects on the Predicted Gas Flow Rates 70

Figure 4.12: Gas Flow Rate with, without Stress Shadowing Effects, and without Geomechanical Factors for MIP-6 H Well ............................................................................... 71

Figure 4.13: Impact of Stress Shadowing on Cumulative Gas Production................................. 72

Figure 4.14: (a) Shows Upward vs. Downward Height Growth Per Stage (b) Illustrates the Height Asymmetry for MIP-3H Well (StimMap Evaluation Report Generated by

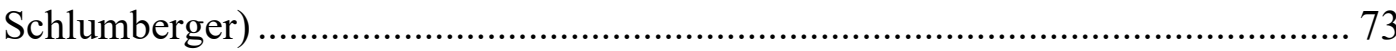

Figure 4.15: Illustrates the Fracture Length from Microseismic Interpretations (StimMap Evaluation Report generated by Schlumberger) ............................................. 73

Figure 4.16: Max Fracture Height per Stage for MIP-3H Well from Fracture Modeling (GOHFER) 74

Figure 4.17: Max Half-Length per Stage and Max Gross Fracture Length per Stage for MIP-3H Well from Fracture Modeling (GOHFER) ....................................................... 74

Figure 4.18: Fracture Height for all Stages and High Proppant Concentration (purple color) at Bottom of Fracture for MIP-3H well ........................................................... 75

Figure 4.19: Illustrates Average Fracture Conductivity .......................................................... 76

Figure 4.20: Illustrates Fracture Properties for Stage 1 with 5 Clusters .................................... 76

Figure 4.21: Shows the Average and Maximum Fracture Conductivity ................................. 77

Figure 4.22: Cumulative Gas Production for Different Production Profiles for MIP-3H ........... 78

Figure 4.23: Illustrates Fracture Half-Length $\mathrm{X}_{\mathrm{f}}$ vs. Cumulative Gas..................................... 78

Figure 4.24: Cumulative Gas Production with and without Geomechanical Factor for Wellbore Pressure 1000 Psia. 80 
Figure 4.25: Cumulative Gas Production with and without Geomechanical Factor for Wellbore Pressure 1500 Psia. 80

Figure 4.26: Cumulative Gas Production with and without Geomechanical Factor for Fissure Permeability $0.004 \mathrm{md}$ 81

Figure 4.27: Cumulative Gas Production with and without Geomechanical Factor for Fissure Permeability $0.006 \mathrm{md}$ 81

Figure 4.28: Cumulative Gas Production with and without Geomechanical Factor for Matrix Porosity 0.02 . 82

Figure 4.29: Cumulative Gas Production with and without Geomechanical Factor for Matrix Porosity 0.06 . 82

Figure 4.30: Cumulative Gas Production with and without Geomechanical Factor for Fracture

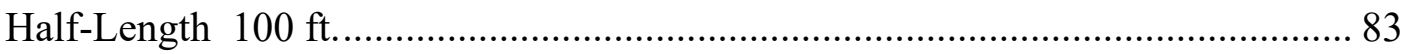

Figure 4.31: Cumulative Gas Production with and without Geomechanical Factor for Fracture Half-Length $300 \mathrm{ft}$.. 83

Figure 4.32: Cumulative Gas Production with and without Geomechanical Factor for Hydraulic Fracture Spacing $260 \mathrm{ft}$. 84

Figure 4.33: Cumulative Gas Production with and without Geomechanical Factor for Hydraulic Fracture Spacing $180 \mathrm{ft}$. 84

Figure 4.34: Cumulative Gas Production with and without Geomechanical Factor for Hydraulic Fracture Spacing $180 \mathrm{ft}$. 85

Figure 4.35: Critical Parameters that Influence the Stress-Dependent Propped Hydraulic Fracture Conductivity 85

Figure 4.36: Cumulative Gas Production for Fracture Half-Length $350 \mathrm{ft}$ and Percentage Reduction in Gas Recovery Due to Geomechanical Factors 87

Figure 4.37: Cumulative Gas Production for Fracture Half-Length $400 \mathrm{ft}$ and Percentage Reduction in Gas Recovery Due to Geomechanical Factors. 87

Figure 4.38: Cumulative Gas Production for Fracture Half-Length $450 \mathrm{ft}$ and Percentage Reduction in Gas Recovery Due to Geomechanical Factors....

Figure 4.39: Pressure Distribution after 2 Years of Production for Different Fracture Half Lengths. 88

Figure 4.40: Percentage Reduction in Gas Recovery for Different Fracture Half Lengths Due to Geomechanical Factors. 88

Figure 4.41: Cumulative Gas Production for Fracture Conductivity $20 \mathrm{md}-\mathrm{ft}$ and Percentage Reduction in Gas Recovery Due to Geomechanical Factors 89

Figure 4.42: Cumulative Gas Production for Fracture Conductivity $10 \mathrm{md}-\mathrm{ft}$ and Percentage Reduction in Gas Recovery Due to Geomechanical Factors 89

Figure 4.43: Cumulative Gas Production for Fracture Conductivity $5 \mathrm{md}-\mathrm{ft}$ and Percentage Reduction in Gas Recovery Due to Geomechanical Factors 90

Figure 4.44: Pressure Distribution after 2 Years of Production for Different Fracture Conductivity 90 
Figure 4.45: Percentage Reduction in Gas Recovery for Different Fracture Conductivities Due to Geomechanical Factors.

Figure 4.46: Cumulative Gas Production for Fracture Spacing of $260 \mathrm{ft}$. with 8 Stages and Percentage Reduction in Gas Recovery Due to Geomechanical Factors .

Figure 4.47: Cumulative Gas Production for Fracture Spacing of $180 \mathrm{ft}$. with 8 Stages and Percentage Reduction in Gas Recovery Due to Geomechanical Factors ................ 92

Figure 4.48: Cumulative Gas Production for Fracture Spacing of $100 \mathrm{ft}$. with 8 Stages and....... 92

Figure 4.49: Pressure Distribution after 2 Years of Production for Different Fracture ............... 92

Figure 4.50: Percentage Reduction in Gas Recovery for Different Fracture Spacings with 8 Stages

Due to Geomechanical Factors

Figure 4.51: Cumulative Gas Production for Fracture Spacing of $260 \mathrm{ft}$. with 10 Stages and Percentage Reduction in Gas Recovery Due to Geomechanical Factors ................ 94

Figure 4.52: Cumulative Gas Production for Fracture Spacing of $180 \mathrm{ft}$. with 14 Stages and Percentage Reduction in Gas Recovery Due to Geomechanical Factors ................ 94

Figure 4.53: Cumulative Gas Production for Fracture Spacing of $100 \mathrm{ft}$. with 23 Stages and Percentage Reduction in Gas Recovery Due to Geomechanical Factors ............... 94

Figure 4.54: Pressure Distribution after 2 years of Production for Different Fracture Spacing with Increasing Number of Stages. ...................................................................... 95

Figure 4.55: Percentage Reduction in Gas Recovery for Different Fracture Spacings and Stages Due to Geomechanical Factors. 95

Figure 4.56: Cumulative Gas Production for Fissure Permeability 0.002 md. with 8 Stages and Percentage Reduction in Gas Recovery Due to Geomechanical Factors ............... 96

Figure 4.57: Cumulative Gas Production for Fissure Permeability 0.004 md. with 8 Stages and Percentage Reduction in Gas Recovery Due to Geomechanical Factors ................ 96

Figure 4.58: Cumulative Gas Production for Fissure Permeability 0.006 md. with 8 Stages and Percentage Reduction in Gas Recovery Due to Geomechanical Factors ............... 96

Figure 4.59: Pressure Distribution after 2 Years of Production for Different Fissure Permeability 97

Figure 4.60: Percentage Reduction in Gas Recovery for Different Fissure Permeability Due to Geomechanical Factors. 97

Figure 4.61: Cumulative Gas Production for Wellbore Pressure 800 Psia and Percentage Reduction in Gas Recovery Due to Geomechanical Factors 98

Figure 4.62: Cumulative Gas Production for Wellbore Pressure 1200 Psia and Percentage Reduction in Gas Recovery Due to Geomechanical Factors . 98

Figure 4.63: Cumulative Gas Production For Wellbore Pressure 1500 Psia and Percentage Reduction in Gas Recovery Due to Geomechanical Factors ................................ 98

Figure 4.64: Pressure after 2 Years of Production for Various Wellbore Pressures................... 99

Figure 4.65: Percentage Reduction in Gas Recovery for Different Wellbore Pressures Due to Geomechanical Factors 99 
Figure 4.66: Critical Parameters That Influence the Impact of Fissure Permeability Geomechanical Factors on Gas Recovery.

Figure 4.67: Critical Parameters That Influence Propped Fracture Conductivity Geomechanical Factors on Gas Recovery. 100

Figure 4.68: Critical Parameters That Influence Matrix Permeability Geomechanical Factors on Gas Recovery. 101

Figure 4.69: Effect of Fracture Half-length on the Cumulative Gas and the Production Rates (Case $1 \mathrm{Xf}=380 \mathrm{ft}$.) 102

Figure 4.70: Effect of Fracture Half-length on the Cumulative Gas and the Production Rates . 102

Figure 4.71: Effect of Fracture Half-length on the Cumulative Gas and the Production Rates (Xf = $500 \mathrm{ft}$.)

Figure 4.72: The Influence of Fracture Half-Length on the Stress-Dependent Fissure Permeability 103

Figure 4.73: Impact Initial Fracture Conductivity (5 md-ft.) on the Cumulative Gas Production and Gas Rates 103

Figure 4.74: Impact Initial Fracture Conductivity (25 md-ft.) on the Cumulative Gas Production and Gas Rate. 104

Figure 4.75: The Influence of Initial Fracture Conductivity on the Stress-Dependent Fissure Permeability 104

Figure 4.76: Impact of Fracture Stage Spacing on the Cumulative and Gas Rate (80 ft. with 30 stages. 105

Figure 4.77: Impact of Fracture Stage Spacing on the Cumulative and Gas Rate (140 ft. with 18 stages.) 105

Figure 4.78: Impact of Fracture Stage Spacing on the Cumulative and Gas Rate (260 ft. with 11 stages.) 106

Figure 4.79: Effect of Fracture Spacing on the Stress-Dependent Fissure Permeability........... 106

Figure 4.80: Impact of Stress Shadowing on Cumulative Gas Production for Hydraulic Fracture Spacing of $100 \mathrm{ft}$ 108

Figure 4.81: Impact of Stress Shadowing on Cumulative Gas Production for Hydraulic Fracture Spacing of $150 \mathrm{ft}$. 108

Figure 4.82: Impact of Stress Shadowing on Cumulative Gas Production for Hydraulic Fracture Spacing of $200 \mathrm{ft}$. 109

Figure 4.83: Impact of Stress Shadowing on Cumulative Gas Production for Hydraulic Fracture Spacing of $250 \mathrm{ft}$. 109

Figure 4.84: Impact of Stress Shadowing on Cumulative Gas Production for Hydraulic Fracture Spacing of $350 \mathrm{ft}$. 110

Figure 4.85: Impact of Stress Shadowing on Cumulative Gas Production for Hydraulic Fracture Spacing of $400 \mathrm{ft}$. 110

Figure 4.86: Impact of Stress Shadowing on Cumulative Gas Production for Hydraulic Fracture Spacing of $450 \mathrm{ft}$ 111 
Figure 4.87: Cumulative Gas Production with and without Stress Shadowing Effects for 20 Years 111

Figure 4.88: Percentage Reduction in 20-year Gas Recovery Due to the Stress Shadowing ..... 112 Figure 4.89: Impact of Stress shadowing on Fracture Volume for Different Treatment Sizes per Stage for Stage Spacing of $150 \mathrm{ft}$

Figure 4.90: Impact of Stress shadowing on Fracture Volume for Different Treatment Sizes per Stage for Stage Spacing of $300 \mathrm{ft}$. 114

Figure 4.91: Impact of Stress Shadowing on Fracture Volume for Different Treatment Sizes per Stage for Stage Spacing of $450 \mathrm{ft}$. 114

Figure 4.92: Impact of the Stress Shadowing on Fracture Volume for Various Stage Spacing and Treatment Sizes 115

Figure 4.93: Impact of Stress Shadowing on Cumulative Gas Production for Different Treatment Sizes 115

Figure 4.94: Impact of Stress Shadowing on Cumulative Gas Production for Different Treatment Sizes 116

Figure 4.95: Impact of Stress Shadowing on Cumulative Gas Production for Different Treatment Sizes 116

Figure 4.96: Impact of the Stress Shadowing on Gas Recovery for Various Stage Spacing and Treatment Sizes 117

Figure 4.97: Cumulative Gas Production for Simultaneous and Sequential Fracturing for Stage Spacing $150 \mathrm{ft}$ 118

Figure 4.98: Cumulative Gas Production for Simultaneous and Sequential Fracturing for Stage Spacing $300 \mathrm{ft}$ 118

Figure 4.99: Cumulative Gas Production for Simultaneous and Sequential Fracturing for Stage Spacing $450 \mathrm{ft}$ 119

Figure 4.100: Impact of Passion's Ratio on Cumulative Gas Production for Different Stage Spacing 120

Figure 4. 101: Slurry and Flow Rate with Stress Shadowing Effects for Different Clusters in Stage 1. 121

Figure 4. 102: Slurry and Flow Rate without Stress Shadowing Effects for Different Clusters in Stage 1 . 121

Figure 4. 103: Average Fracture Width with and without Stress Shadowing for.................... 122

Figure 4. 104: Average Fracture Half-Length with and without Stress Shadowing for ............ 123

Figure 4. 105: Average Fracture Height with and without Stress Shadowing........................ 123

Figure 4. 106: 10-year Cumulative Gas Production with and without Stress Shadowing......... 124 Figure 4. 107: Gas Production Change Compared to the Base Case for Different Cluster Spacings. 124

Figure 4. 108: Change in Total Fracture Volume Compared to the Base Case for Different Closer Cluster Spacings. 125

Figure 4. 109: Fracture Conductivity with and without Stress Shadowing ............................ 126 
Figure 4. 110: Average Fracture Conductivity and 10-year Cumulative Gas Production..... 126

Figure 4. 111: Total Fracture Volume with Stress Shadowing and 10-year Cumulative Gas Production for Different Cluster Spacing ..................................................... 127

Figure 4. 112:Total Fracture Volume for Different Fracturing Fluid Volume per Stage .......... 128 Figure 4. 113: Percentage Reduction in 10-year Gas Recovery Due to the Stress Shadowing Effects 128

Figure 4.114: Illustrates Maximum Fracture Conductivity and Production Log Tool (PLT) ... 129 Figure 4.115: Illustrates The Relationship Between The Production Log Tool (PLT) and ...... 129 Figure 4.116: Shows Number of Resistive Continuous Fractures (Fissures) and Natural Resistive Continuous Fractures Density for Stages 5, 10 and 15 ............................... 130

Figure 4.117: Shows the Gas Production Percentage by Section.......................................... 131

Figure 4. 118: Relationship Between Average (TOC) per Stage along Horizontal Length with Natural Fractures (Fissures) per Stage ............................................................. 132

Figure 4.119:Relationship Between Average TOC per Stage Along Horizontal Length with Production Logging Tool (PLT) per Stage 132

Figure A1: Sage 1 treatment data with a matched pressure between model and actual values. Dotted pressure curve represents the actual surface treating pressure (surface pressure in the plot legend), whereas the connected pressure curve represents the model surface treating pressure (well pressure in the plot legend). ........................................ 146

Figure A2: Sage 2 treatment data with a matched pressure between model and actual values. Dotted pressure curve represents the actual surface treating pressure (surface pressure in the plot legend), whereas the connected pressure curve represents the model surface treating pressure (well pressure in the plot legend).

Figure A3: Sage 3 treatment data with a matched pressure between model and actual values. Dotted pressure curve represents the actual surface treating pressure (surface pressure in the plot legend), whereas the connected pressure curve represents the model surface treating pressure (well pressure in the plot legend). 148

Figure A4: Sage 4 treatment data with a matched pressure between model and actual values. Dotted pressure curve represents the actual surface treating pressure (surface pressure in the plot legend), whereas the connected pressure curve represents the model surface treating pressure (well pressure in the plot legend). 149

Figure A5: Sage 5 treatment data with a matched pressure between model and actual values. Dotted pressure curve represents the actual surface treating pressure (surface pressure in the plot legend), whereas the connected pressure curve represents the model surface treating pressure (well pressure in the plot legend). 150

Figure A6: Sage 6 treatment data with a matched pressure between model and actual values. Dotted pressure curve represents the actual surface treating pressure (surface pressure in the plot legend), whereas the connected pressure curve represents the model surface treating pressure (well pressure in the plot legend). 151 
Figure A7: Sage 7 treatment data with a matched pressure between model and actual values. Dotted pressure curve represents the actual surface treating pressure (surface pressure in the plot legend), whereas the connected pressure curve represents the model surface treating pressure (well pressure in the plot legend). 152

Figure A8: Sage 8 treatment data with a matched pressure between model and actual values. Dotted pressure curve represents the actual surface treating pressure (surface pressure in the plot legend), whereas the connected pressure curve represents the model surface treating pressure (well pressure in the plot legend). 153

Figure A9: Sage 1 treatment data with a matched pressure between model and actual values. Dotted pressure curve represents the actual surface treating pressure (surface pressure in the plot legend), whereas the connected pressure curve represents the model surface treating pressure (well pressure in the plot legend). 155

Figure A10: Sage 2 treatment data with a matched pressure between model and actual values. Dotted pressure curve represents the actual surface treating pressure (surface pressure in the plot legend), whereas the connected pressure curve represents the model surface treating pressure (well pressure in the plot legend). 156

Figure A11: Sage 3 treatment data with a matched pressure between model and actual values. Dotted pressure curve represents the actual surface treating pressure (surface pressure in the plot legend), whereas the connected pressure curve represents the model surface treating pressure (well pressure in the plot legend).

Figure A12: Sage 4 treatment data with a matched pressure between model and actual values. Dotted pressure curve represents the actual surface treating pressure (surface pressure in the plot legend), whereas the connected pressure curve represents the model surface treating pressure (well pressure in the plot legend). 158

Figure A13: Sage 5 treatment data with a matched pressure between model and actual values. Dotted pressure curve represents the actual surface treating pressure (surface pressure in the plot legend), whereas the connected pressure curve represents the model surface treating pressure (well pressure in the plot legend). 159

Figure A14: Sage 6 treatment data with a matched pressure between model and actual values. Dotted pressure curve represents the actual surface treating pressure (surface pressure in the plot legend), whereas the connected pressure curve represents the model surface treating pressure (well pressure in the plot legend). 160

Figure A15: Sage 7 treatment data with a matched pressure between model and actual values. Dotted pressure curve represents the actual surface treating pressure (surface pressure in the plot legend), whereas the connected pressure curve represents the model surface treating pressure (well pressure in the plot legend). 161

Figure A16: Sage 8 treatment data with a matched pressure between model and actual values. Dotted pressure curve represents the actual surface treating pressure (surface pressure in the plot legend), whereas the connected pressure curve represents the model surface treating pressure (well pressure in the plot legend). 162 
Figure A17: Sage 9 treatment data with a matched pressure between model and actual values. Dotted pressure curve represents the actual surface treating pressure (surface pressure in the plot legend), whereas the connected pressure curve represents the model surface treating pressure (well pressure in the plot legend). 163

Figure A18: Sage 10 treatment data with a matched pressure between model and actual values. Dotted pressure curve represents the actual surface treating pressure (surface pressure in the plot legend), whereas the connected pressure curve represents the model surface treating pressure (well pressure in the plot legend). 164

Figure A19: Sage 11 treatment data with a matched pressure between model and actual values. Dotted pressure curve represents the actual surface treating pressure (surface pressure in the plot legend), whereas the connected pressure curve represents the model surface treating pressure (well pressure in the plot legend). 165

Figure A20: Sage 12 treatment data with a matched pressure between model and actual values. Dotted pressure curve represents the actual surface treating pressure (surface pressure in the plot legend), whereas the connected pressure curve represents the model surface treating pressure (well pressure in the plot legend). 166

Figure A21: Sage 13 treatment data with a matched pressure between model and actual values. Dotted pressure curve represents the actual surface treating pressure (surface pressure in the plot legend), whereas the connected pressure curve represents the model surface treating pressure (well pressure in the plot legend). 167

Figure A22: Sage 14 treatment data with a matched pressure between model and actual values. Dotted pressure curve represents the actual surface treating pressure (surface pressure in the plot legend), whereas the connected pressure curve represents the model surface treating pressure (well pressure in the plot legend). 168

Figure A23: Sage 15 treatment data with a matched pressure between model and actual values. Dotted pressure curve represents the actual surface treating pressure (surface pressure in the plot legend), whereas the connected pressure curve represents the model surface treating pressure (well pressure in the plot legend). 169

Figure A24: Sage 16 treatment data with a matched pressure between model and actual values. Dotted pressure curve represents the actual surface treating pressure (surface pressure in the plot legend), whereas the connected pressure curve represents the model surface treating pressure (well pressure in the plot legend). 170

Figure A25: Sage 17 treatment data with a matched pressure between model and actual values. Dotted pressure curve represents the actual surface treating pressure (surface pressure in the plot legend), whereas the connected pressure curve represents the model surface treating pressure (well pressure in the plot legend).

Figure A26: Sage 18 treatment data with a matched pressure between model and actual values. Dotted pressure curve represents the actual surface treating pressure (surface pressure in the plot legend), whereas the connected pressure curve represents the model surface treating pressure (well pressure in the plot legend). 
Figure A27: Sage 19 treatment data with a matched pressure between model and actual values. Dotted pressure curve represents the actual surface treating pressure (surface pressure in the plot legend), whereas the connected pressure curve represents the model surface treating pressure (well pressure in the plot legend). 173

Figure A28: Sage 20 treatment data with a matched pressure between model and actual values. Dotted pressure curve represents the actual surface treating pressure (surface pressure in the plot legend), whereas the connected pressure curve represents the model surface treating pressure (well pressure in the plot legend). 174

Figure A29: Sage 21 treatment data with a matched pressure between model and actual values. Dotted pressure curve represents the actual surface treating pressure (surface pressure in the plot legend), whereas the connected pressure curve represents the model surface treating pressure (well pressure in the plot legend). 175

Figure A30: Sage 23 treatment data with a matched pressure between model and actual values. Dotted pressure curve represents the actual surface treating pressure (surface pressure in the plot legend), whereas the connected pressure curve represents the model surface treating pressure (well pressure in the plot legend). 176

Figure A31: Sage 24 treatment data with a matched pressure between model and actual values. Dotted pressure curve represents the actual surface treating pressure (surface pressure in the plot legend), whereas the connected pressure curve represents the model surface treating pressure (well pressure in the plot legend).

Figure A32: Sage 25 treatment data with a matched pressure between model and actual values. Dotted pressure curve represents the actual surface treating pressure (surface pressure in the plot legend), whereas the connected pressure curve represents the model surface treating pressure (well pressure in the plot legend). 178

Figure A33: Sage 26 treatment data with a matched pressure between model and actual values. Dotted pressure curve represents the actual surface treating pressure (surface pressure in the plot legend), whereas the connected pressure curve represents the model surface treating pressure (well pressure in the plot legend).

Figure A34: Sage 27 treatment data with a matched pressure between model and actual values. Dotted pressure curve represents the actual surface treating pressure (surface pressure in the plot legend), whereas the connected pressure curve represents the model surface treating pressure (well pressure in the plot legend). 180

Figure A35: Sage 28 treatment data with a matched pressure between model and actual values. Dotted pressure curve represents the actual surface treating pressure (surface pressure in the plot legend), whereas the connected pressure curve represents the model surface treating pressure (well pressure in the plot legend). 181 


\section{LIST OF TABLES}

Table 2.1: Mechanical Properties of the Marcellus shale Samples (after McGinley et al. 2015) . 7

Table 3.1: Treatment Design Parameters for the First Fracture Stage....................................... 29

Table 3.2: Hydraulic Fracture Parameters for Well MIP-3H .................................................. 32

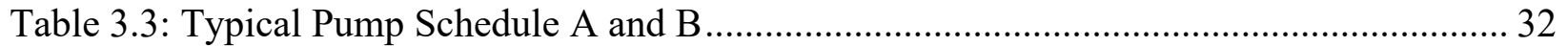

Table 3.4: Typical Pump Schedule C and D ..................................................................... 33

Table 3.5: Pyrolysis Data from Source rock analyzer, Core depth of 7445 to 7557 '................. 34

Table 3.6: Well MIP-3H DFIT Analysis ......................................................................... 41

Table 3.7: Basic Model Parameters for MIP-6H and MIP-3H .............................................. 50

Table 3.8: Parameters and Their Values Used for Parametric StudiesGeomechanical factor

(Hydraulic fracture) ..................................................................................... 57

Table 3.9: Parameters and Their Values Used for Parametric Studies Geomechanical Factors

(Matrix, Fissure and Propped Fracture Conductivity) ......................................... 57

Table 3.10: Parameters and Their Values Used for Parametric Studies Geomechanical Factor

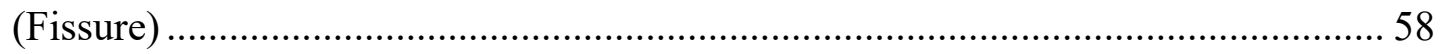

Table 3.11: Parameters and Their Values Used for Parametric Studies ..................................... 59

Table 3.12: Pump Schedule C For MIP-3H (Base Case)......................................................... 60

Table 3.13: Cluster Spacings and the Number of Fractures Used for Sensitivity Analysis ........ 60

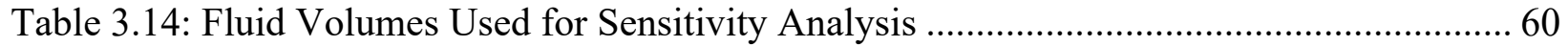

Table 4.1: Hydraulic Fracture Properties for MIP-6H......................................................... 61

Table 4.2: History Matching Parameters for MIP-6H With Geomechanical Factor................... 62

Table 4.3: Estimated Hydraulic Fracture Half-length for Well MIP-6H................................... 64

Table 4.4: Estimated Fracture Half-length obtained from History Matching............................. 68

Table 4.5: Fracture Properties with and without Stress Shadowing Effects for Well MIP-6H.... 71

Table 4.6: Hydraulic Fracture Geometry ........................................................................ 79 


\section{LIST OF SYMBOLS / NOMENCLATURE}
A: $\quad$ Area, in $^{2}$
DTC: Compressional travel time, $\mu \mathrm{sec} / \mathrm{ft}$
DTS: $\quad$ Shear travel time, $\mu \mathrm{sec} / \mathrm{ft}$
E: $\quad$ Young's modulus, MMpsi
$E_{\mathrm{d}}$ : $\quad$ Dynamic Young's modulus, MMpsi
$\mathrm{E}_{\mathrm{s}}$ : $\quad$ Static Young's modulus, MMpsi
$\mathrm{E}_{\mathrm{h}} \quad$ Horizontal Young's modulus, psi
$\mathrm{E}_{\mathrm{v}} \quad$ Vertical Young's modulus, psi
F: $\quad$ Force,lbs
$\Delta L: \quad$ Deformation, $\mathrm{ft}$
$1_{0,1} \quad$ Orginal Length, $\mathrm{ft}$
Pc: $\quad$ Closure pressure, psi
$\mathrm{P}_{\mathrm{p}}$ : $\quad$ Pore pressure, $\mathrm{psi}$
R: $\quad$ Shear to compressional velocity ratio
$\mathrm{t}$ : Transverse stress exponent, dimensionless
W : $\quad$ Fracture width
$Z_{s}: \quad$ Distance from the fracture face, in
Z: $\quad$ Depth, in
$\alpha: \quad$ Biot's coefficient, dimensionless
$\alpha_{\mathrm{h}}$ : Horizontal Biot's coefficient, unitless
$\alpha_{\mathrm{v}}$ : $\quad$ Vertical Biot's coefficient, unitless
$\varepsilon: \quad$ Strain, dimensionless
$\varepsilon_{\mathrm{h}}$ : Regional horizontal tectonic strain, microstrain
$\varepsilon_{x}: \quad$ Lateral strain, dimensionless
$\varepsilon_{Z}: \quad$ Longitudinal strain, dimensionless
$\rho: \quad$ Rock density, $1 \mathrm{bm} / \mathrm{in}^{3}$
$\rho_{b}: \quad$ Bulk density, $\mathrm{g} / \mathrm{cm}^{3}$
$\rho_{f}: \quad$ Density of the fluid, ppg
$v: \quad$ Poisson's ratio, dimensionless
$v_{\mathrm{d}}: \quad$ Dynamic Poisson's ratio, dimensionless
$v_{\mathrm{h}}$ : Horizontal Poisson's ratio, dimensionless
$v_{v}: \quad$ Vertical Poisson's ratio, dimensionless 
$\sigma: \quad$ Stress, Psi

$\sigma_{\mathrm{H}}: \quad$ Max Horizontal Stress, Psi

$\sigma_{\mathrm{h}}: \quad$ Min Horizontal Stress, Psi

$\sigma_{t}: \quad$ Regional horizontal tectonic stress, $\mathrm{psi}$

$\sigma_{v}: \quad$ Vertical stress, psi

$\phi \quad$ Efeect porosity, dimensionless 


\section{CHAPTER 1: INTRODUCTION}

\subsection{Problem Statement}

The shale gas development has become an internationally crucial part of the oil and gas industry during recent years, particularly in North America. Considerable reserves of natural gas in shale-gas reservoirs have been revealed through the application of horizontal drilling and hydraulic fracturing techniques. Petrophysical properties of shale-gas reservoirs are complex. Shale is a fine-grained sedimentary rock, which consists of consolidated clay-sized particles leading to low porosity and ultra-low permeability. Additionally, shales are comprised of a substantial amount of organic matter (kerogen), which serves as both reservoir rock and source rock. The limited pore space of the shale can store gas within the free state, whereas the organic material stores gas within the absorbed state.

Unconventional

Marcellus Shale has been producing gas in the Appalachian Basin since the late 1800s; however, only recently has it become a major producer. In 2004, Range Resources, using new drilling and fracturing techniques, began producing gas from a Marcellus Shale well in Washington County, Pennsylvania (Zagorski et al., 2012). Through May 2015, more than 8600 horizontal Marcellus Shale wells have been drilled in the Appalachian Basin (Pennsylvania, West Virginia, and limited portions of eastern Ohio) (Zagorski et al., 2017). Marcellus Shale represents a significant resource within the northeastern United States. It is both a large reserve, with an estimated 30 to 300 trillion cubic feet (TCF) of recoverable gas, and is close to some of the largest prospective markets in the country.

The major technology uses to achieve substantial economic production from shale gas reservoirs by utilizing horizontal wells with multiple hydraulic fractures. The hydraulic fracturing application to create a high conductivity pathway in shale gas reservoirs has led to an extreme increase in economically recoverable hydrocarbons from ultra-low permeability shale reservoirs. The hydraulic fracturing treatment in the horizontal wells is accomplished in stages. Diagnostic data in the field, however, has shown that, in most cases, not all stages contribute equally to the total production (Fisher et al. 2004; Molenaar et al. 2011).

One of the factors, which could result in this unequal contribution, is the stress shadow. The creation of a hydraulic fracture causes the in-situ stresses in the formation to change which impacts the properties of the subsequent hydraulic fracture. This phenomena is referred to as "stress shadowing." Additionally, rock properties, such as Poisson's ratio, Young's modulus, and the presence of the fissure, impact the geometry of a created hydraulic fracture. 
Unconventional formations, such as Marcellus Shales, have an abundance of clay minerals in their matrices, which are aligned by gravity during the deposition. This alignment of clay and other minerals creates fine-scale layering. As a consequence, the shale is anisotropic. This anisotropy is also influenced by in-situ stresses. In-situ stresses include overburden pressure and horizontal stress. As gas is produced from the reservoir, the pore (gas) pressure decreases while the overburden pressure remains constant. Therefore, the net stress increases. This leads to a reduction in the permeability, for both matrix and fissure, as well as hydraulic fracture compaction and conductivity impairment. Each of these geomechanical factors negatively impacts the ultimate gas recovery.

Neglecting the impact of the stress changes during hydraulic fracturing and production can lead to over-estimation of the gas recovery from the shale reservoirs. Therefore, it is essential to investigate the long-term production behavior of the horizontal wells with multiple hydraulic fractures in ultra-low permeability formations. More specifically, the impact of non-uniform hydraulic fracture stage contribution to gas production from the shale reservoirs caused by the stress shadowing and geomechanical factors will be investigated in this study. This investigation is significant because it has the potential to improve the efficiency of hydrocarbon production from horizontal wells in the Appalachian basin and elsewhere in the United States.

\subsection{Dissertation Outlines}

The dissertation is organized into four main chapters. Chapter one provides an introduction, problem statement, and objectives. Chapter two is the literature review, and it describes the work by previous authors. This includes the impact of stress on the propped fracture conductivity, fissure permeability, and matrix permeability. Furthermore, stress shadowing, rock mechanical properties, diagnostic fracture injection tests (DFIT), and the contribution of the hydraulic fracture stage to production will be addressed. Chapter three provides the methodology and detailed description of the GOFHER fracturing simulation software and CMG reservoir simulation software. Chapter four presents the results and the discussion. Chapter four is followed by the conclusion, references citations, and Appendix (A) 


\section{CHAPTER 2: LITERATURE REVIEW}

\subsection{Marcellus Shale}

Marcellus Shale is a Devonian formation which is located primarily in the Appalachian Basin from southern New York through northeastern and western Pennsylvania and West Virginia, into Maryland and Ohio (Zagorski et al., 2017), as is shown in Figure 2.1. The Marcellus Shale, which covers an area of approximately 95,000 square miles across six states in the northeastern U.S., has an average thickness of $50 \mathrm{ft}$ to 200 feet. Furthermore, the depth of the Marcellus production zone is between 5,000 ft to 9,000 feet. The Marcellus Shale formation is located in the lower part of the Hamilton Group, which is bound below by the lower Devonian Onondaga and above by the middle Devonian Tully Limestone, as seen in Figure 2.2. Marcellus shale is divided into members, the upper Marcellus Oatka Creek Shale and lower MarcellusUnion Springs Shale, which are separated by Cherry Valley-Purcell Limestone. Furthermore, the reservoir temperature in the Marcellus Shale is measured to be around $150^{\circ} \mathrm{F}$. Marcellus Shale is a black shale which is brittle, soft, and carbonaceous with beds of carbonate solidifications and limestone, as well as high Pyrite content. The kerogen in Marcellus Shale is primarily Type II with a mixture of Type III (Weary 2000). Furthermore, clay content in Marcellus Shale is 10 to $45 \mathrm{wt} \%$, and total organic carbon (TOC) ranges from 2 to $20 \mathrm{wt} \%$ (Boyce et al. 2010).

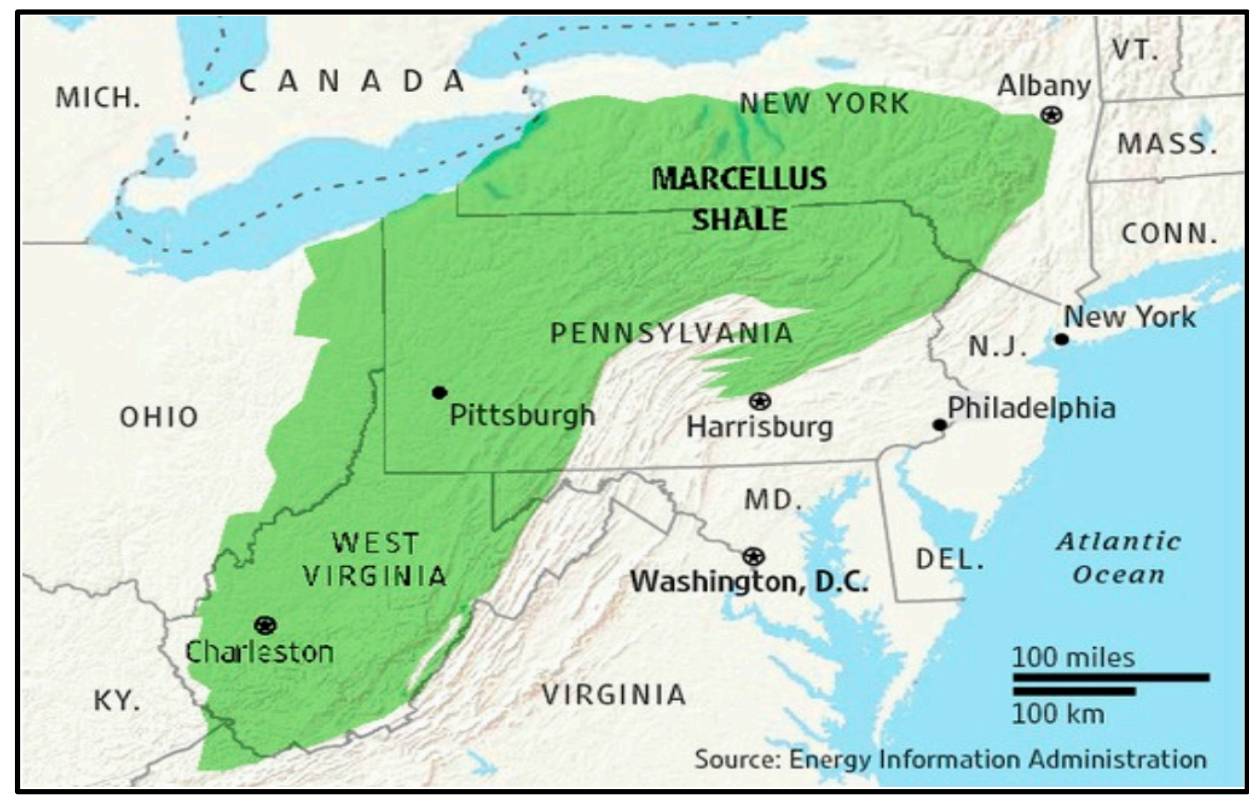

Figure 2.1: Shows Extent of Marcellus Shale (Bentek, 2015). 


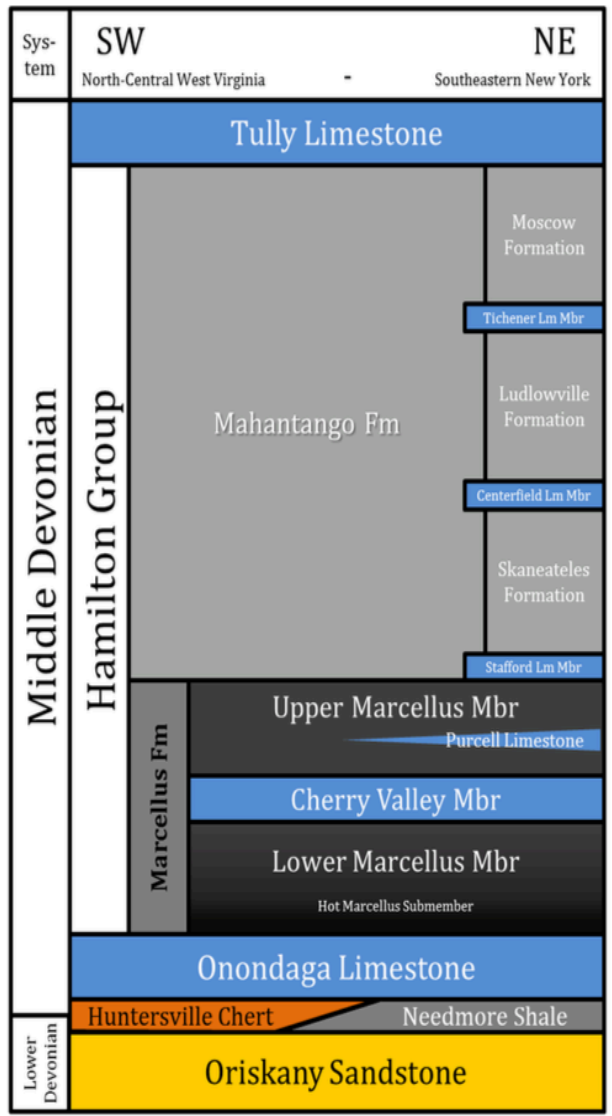

Figure 2.2: Shows Stratigraphy from North-Central West Virginia to Southeastern New York (Modified from Carter et al., 2011 and Zagorski et al., 2012).

\subsection{Hydraulic Fracturing}

A hydraulic fracture treatment is performed by injecting fluid into the wellbore to increase the downhole pressure to a value which is greater than the fracture pressure of the formation rock. This increase in pressure causes the formation to crack, allowing the injected fluid to enter and deepen the crack farther into the formation. After this, a solid proppant, such as sand, is pumped into the fractures to prevent the cracks from closing after the injection is complete, as illustrated in Figure 2.3. Fracture treatment in the Marcellus Shale is typically performed using 2,500 - 20,000 barrels of water and 25,0000-75,0000 pounds of sand proppant at an injecting rate ranging from 25 to 100 barrels per minute (Bruner and Smosna, 2011).

The propped fracture becomes a high permeability conduit which allows the gas to flow to the well. Additionally, The transmissibility measure of fluid through a fracture is known as fracture conductivity, which is defined as the product of the fracture width and the fracture permeability. 


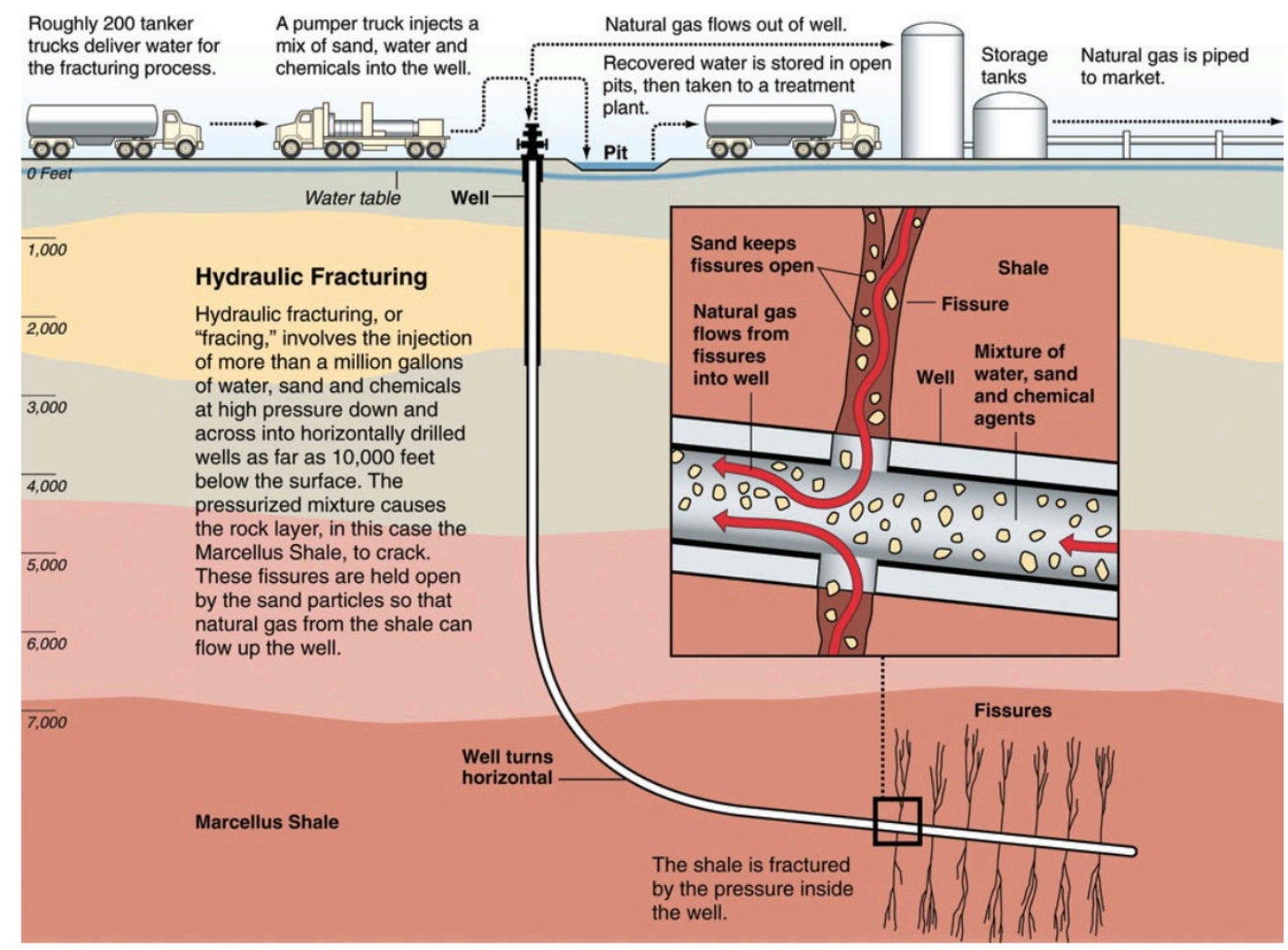

Figure 2.3: Marcellus Shale Hydraulic Fracture (“Fracking," 2013).

\subsection{Impact of Stress on the Propped Fracture Conductivity}

As unconventional reservoirs become the world's major energy source, it is essential to understand the mechanisms which impact the production performance. Hydraulic fracture closure is one of the mechanisms that cause significant reductions in gas recovery. The increase in the net stress, which accompanies the production, leads to proppant embedment in softer rock and proppant crushing in hard rock (Fan et al., 2010). This phenomenon is prevalent in the Marcellus Shale, which is considered a ductile shale because of its low Young's modulus. Additionally, the Marcellus Shale is a relatively soft formation, which is indicated by the Hardness Number as shown in Figure 2.4 (Stegent et al., 2010).

Huitt and Mcglothlin (1958) indicated that proppant which is under the weight of overburden would embed rather than crush. Volk et al. (1981) studied various variables which are related to proppant embedment, including proppant distribution, proppant size, proppant concentration, closure pressure, formation hardness, and surface roughness. They observed that the propped fracture would close due to embedment of proppant if the proppant drops less than 50 percent of a monolayer in shale formations. 


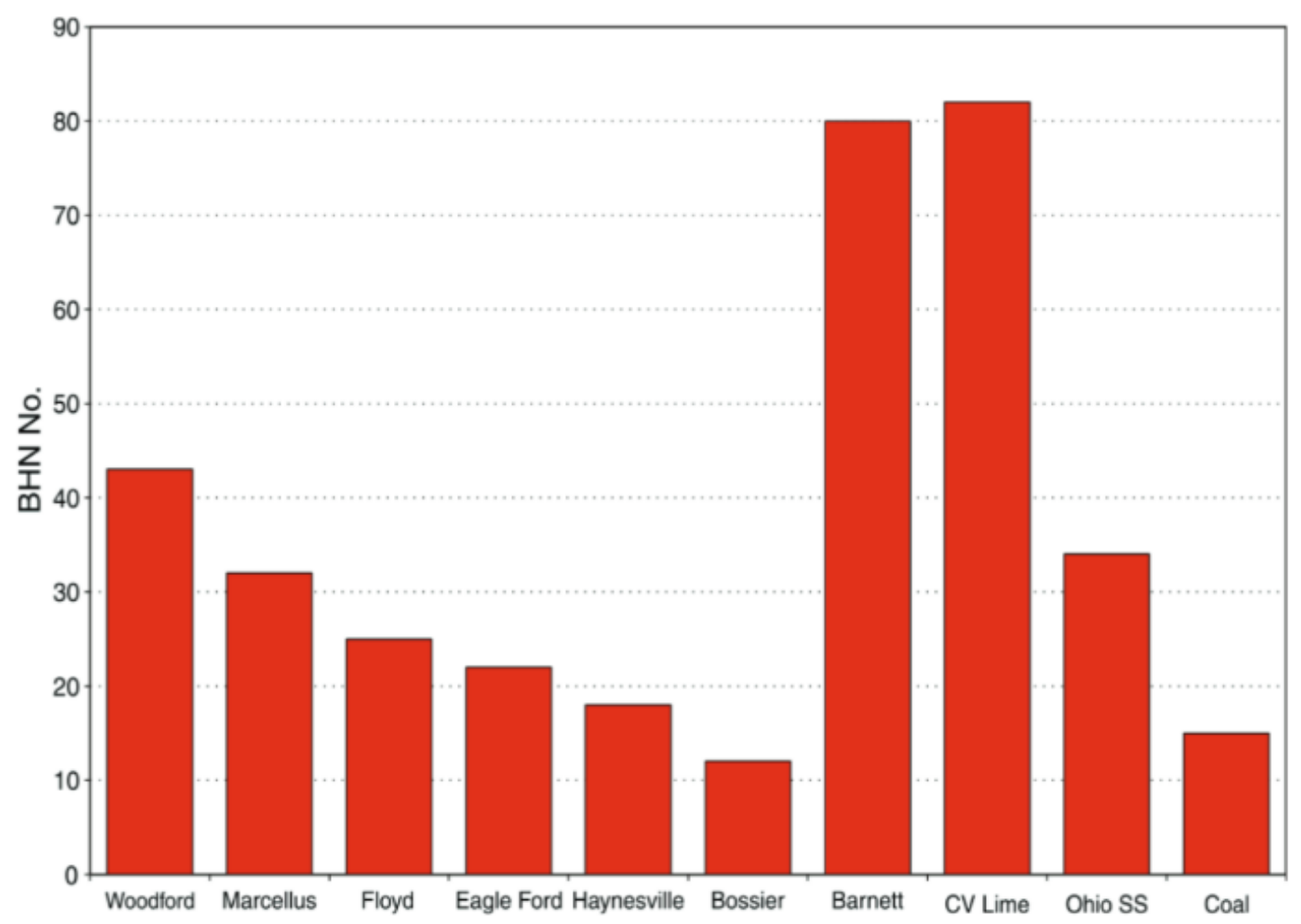

Figure 2.4: Brunell Hardness Numbers for Various Shale Reservoirs in North America (After Stegent et al. 2010).

Lacy et al. (1997) performed experimental research on fracture conductivity and embedment in soft formations. They found that embedment was primarily affected by proppant size, rock type, strength, concentration, and closure stress. Guo et al. (2008) established a measurement and analysis system of proppant embedment. They determined that stiffer rock samples would have less proppant embedment than softer rock samples. Pope et al. (2009) observed that the degree of proppant embedment into the formation increases when Young's modulus is low in shale formations. Terracina et al. (2010) determined that fracture conductivity decreases with the increasing closure pressure due to proppant embedment. Alramahi and Sundberg (2012) conducted laboratory experiments to study the embedment of proppant and its influence on hydraulic fracture conductivity. Rock mineralogy and mechanical properties were considered during these laboratory experiments. They observed that conductivity loss and high proppant embedment was present for samples with low static Young's modulus and high clay content. Furthermore, based on their experiments, they developed a correlation between proppant embedment and Young's modulus at any specific stress, which can be used to determine the loss of hydraulic fracture conductivity. Zhang et al. (2013) measured the hydraulic fracture conductivity in Barnett Shale outcrop samples. They studied both induced and natural fractures for unpropped and propped fracture conductivity. 
Additionally, they studied the effects of proppant concentration and size on fracture conductivity. They found that higher proppant concentration and the rock properties impact the decrease of fracture conductivity. Aditionally, Guzek (2014) and Briggs (2014) performed similar experiments on Fayetteville Shale and the Eagle Ford outcrop samples, respectively. They confirmed the Zhang et al. (2013) conclusion that as proppant concentrations increase, the importance of the rock properties decreases.

McGinley et al. (2015) performed various experiments to measure the propped hydraulic fracture conductivity as a function of the net stress in the Marcellus Shale. The core plugs that were utilized in their study were collected at two diverse locations (Elimsport and Allenwood). Moreover, the core plugs were cut parallel and perpendicular to the bedding planes in order to examine the impact of anisotropy on hydraulic fracture conductivity. They determined that fractures parallel to the bedding planes have lower fracture conductivity than those perpendicular to the bedding planes. Nevertheless, they related this behavior to mechanical property anisotropy instead of surface topography or roughness. Table 2.1 summarizes the mechanical properties of the core plugs which were utilized in their study.

Table 2.1: Mechanical Properties of the Marcellus Shale Samples (after McGinley et al. 2015).

\begin{tabular}{|c|c|c|}
\hline Property & Elimsport & Allenwood \\
\hline$E_{h}$ & $1.1 \times 10^{6} \mathrm{Psi}$ & $3.99 \times 10^{6} \mathrm{Psi}$ \\
\hline$E_{V}$ & $2.32 \times 10^{6} \mathrm{Psi}$ & $4.41 \times 10^{6} \mathrm{Psi}$ \\
\hline$v_{h}$ & 0.256 & 0.202 \\
\hline$v_{V}$ & 0.283 & 0.161 \\
\hline
\end{tabular}

The measured propped fracture conductivity for Elimsport and Allenwood samples as a function of closure Stress (net stress) are illustrated in Figures 2.5 and 2.6, respectively. For the vertical (bed-parallel) samples, Elimsport demonstrated a decline constant of $4.60 \times 10^{-4} \mathrm{psi}^{-1}$, slightly larger than Allenwood's decline constant of $3.77 \times 10^{-4} \mathrm{psi}^{-1}$. Likewise, for the horizontal (bed-perpendicular) samples, the decline rate for Allenwood is $4.456 \times 10^{-4} \mathrm{psi}^{-1}$, while Elimsport's rate is $1.03 \times 10^{-3} \mathrm{psi}^{-1}$. McGinley et al. (2015) concluded that the decline rate for the fracture conductivity is contrarily related to Young's modulus. 


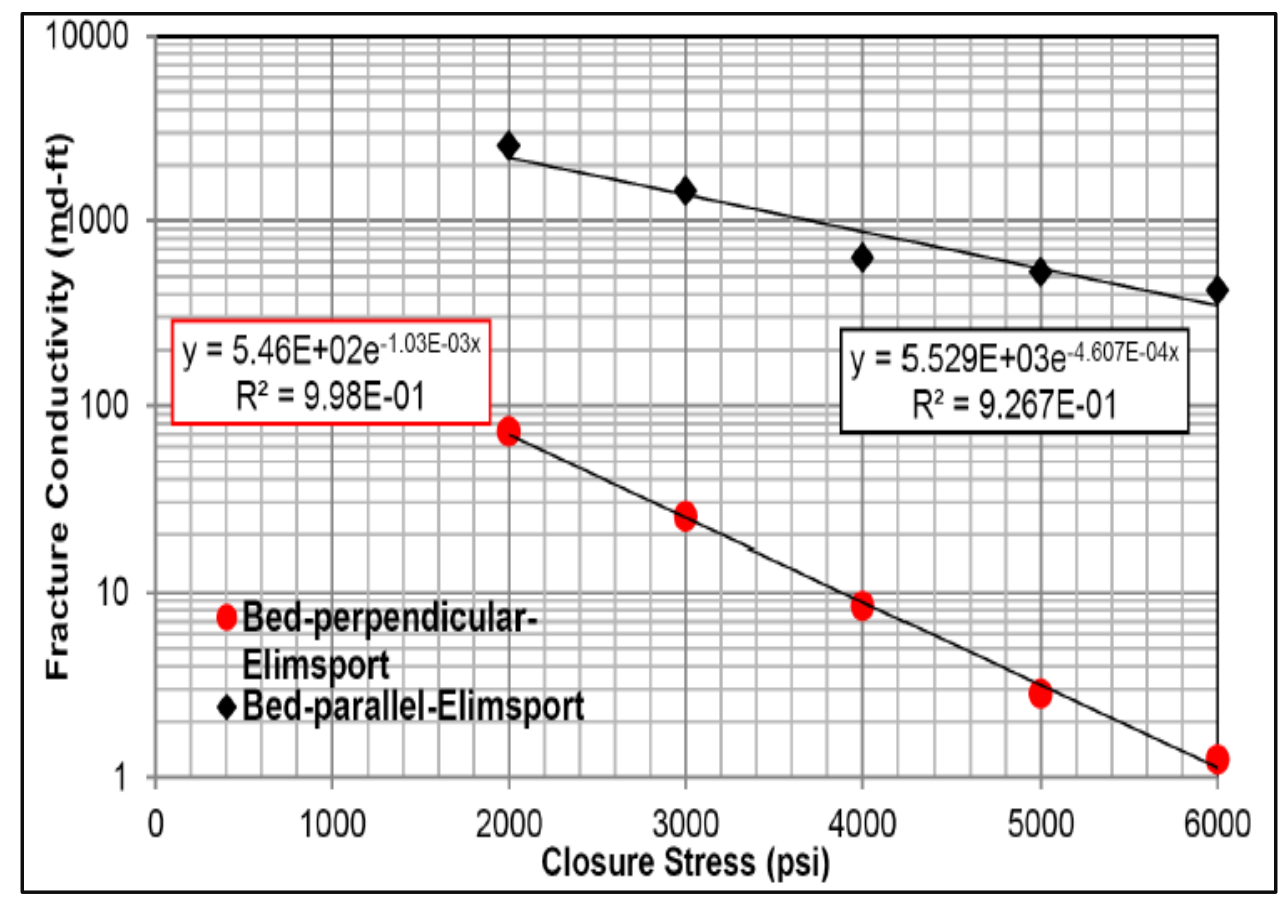

Figure 2.5: Measured Propped Fracture Conductivity for Elimsport Samples (After McGinley et al., 2015).

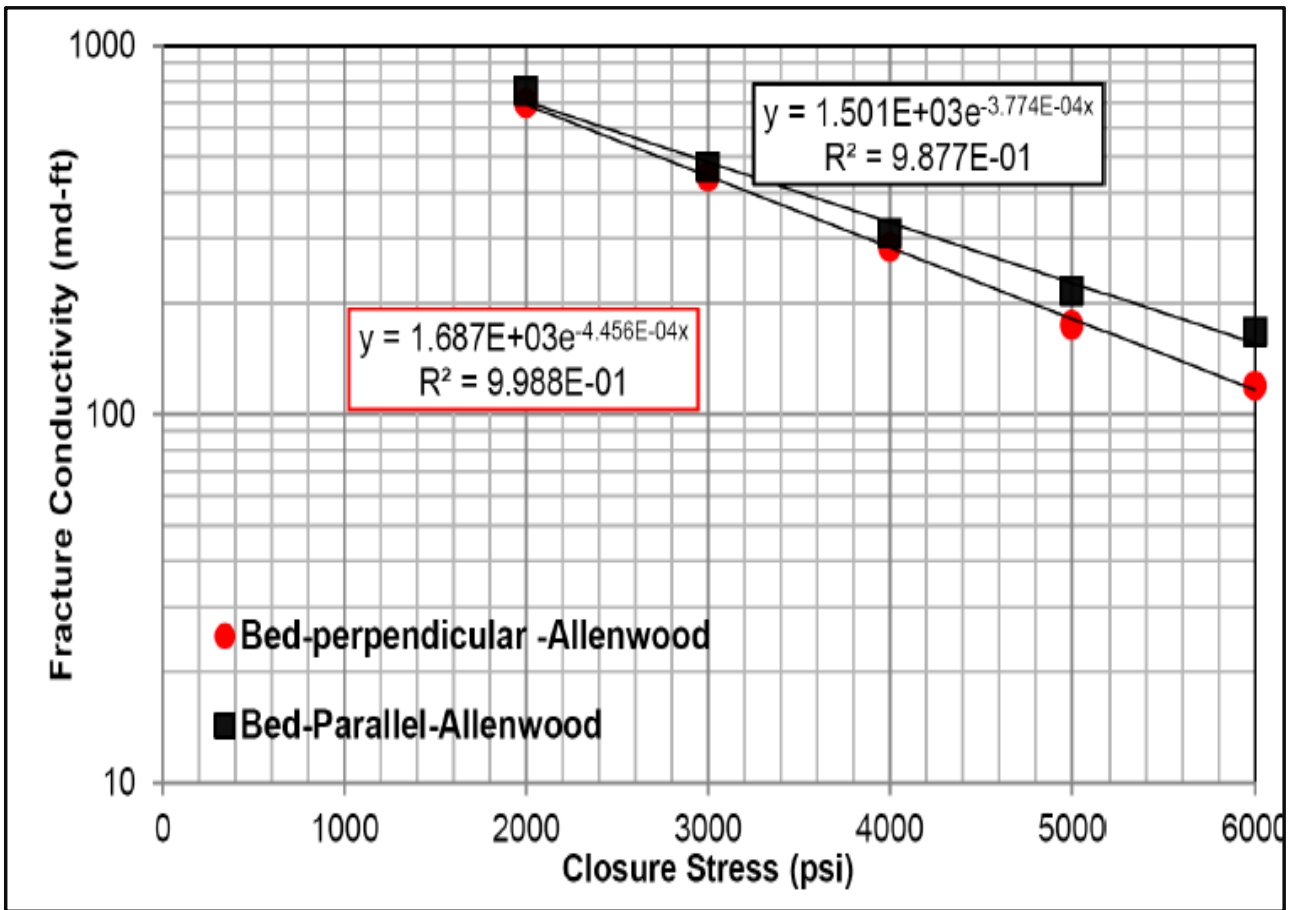

Figure 2.6: Measured Propped Fracture Conductivity for Allenwood Samples (After McGinley et al., 2015). 


\subsection{Impact of Stress on the Fissure Permeability}

The correlation between fissure permeability and net stress has been comprehensively studied by numerical modeling or experimentation (Pedrosa 1986; Best and Katsube 1995; Davies et al. 1999; Raghavan and Chin 2002; Tao et al. 2009). Gutierrez et al. (2000) studied the stress-dependent permeability of demineralized fractures in shale. They concluded that the fissure permeability decreases as the effective normal stress increases. Raghavan and Chin (2004) presented correlations to evaluate the stress-induced productivity loss in stress-sensitive reservoirs. Conversely, their focus was on the investigation of the impact of stress-dependent matrix permeability, not the fissure permeability, on production performance. Bustin et al. (2008) observed that the degree of permeability reduction with confining pressure is lower in carbonate or consolidated sandstone than in shale. Their measurements displayed an exponential relation between the shale permeability and the net stress for the Barnett, Ohio, Muskwa, and Woodford Shales.

Cipolla et al. (2010) numerically investigated the fissure closure effects on production. Their simulations demonstrated that the well productivity in many shale gas reservoirs can be reduced because of insufficient fissure conductivity. For shale formations with higher Young's modulus, such as the Barnett Shale, the ultimate gas recovery can be decreased by $10 \%$. However, for shale reservoirs with lower Young's modulus, such as Marcellus and Haynesville Shales, the decrease in ultimate gas recovery could be drastically higher. Cho et al. (2013) unitized the experimental data from Bakken cores to calibrate the correlations which were proposed by Raghavan and Chin (2004). They modified correlations and used them to investigate the impact of fissure permeability on the shale gas reservoirs' productivity.

Laboratory data which is published by Fredd et al. (2001), showed the effect of the stress on partially propped and un-propped fracture conductivity with high Young's modulus for a formation. Cipolla et al. (2008) extrapolated the data of Fredd et al. to lower Young's modulus, as shown in Figure 2.7. 


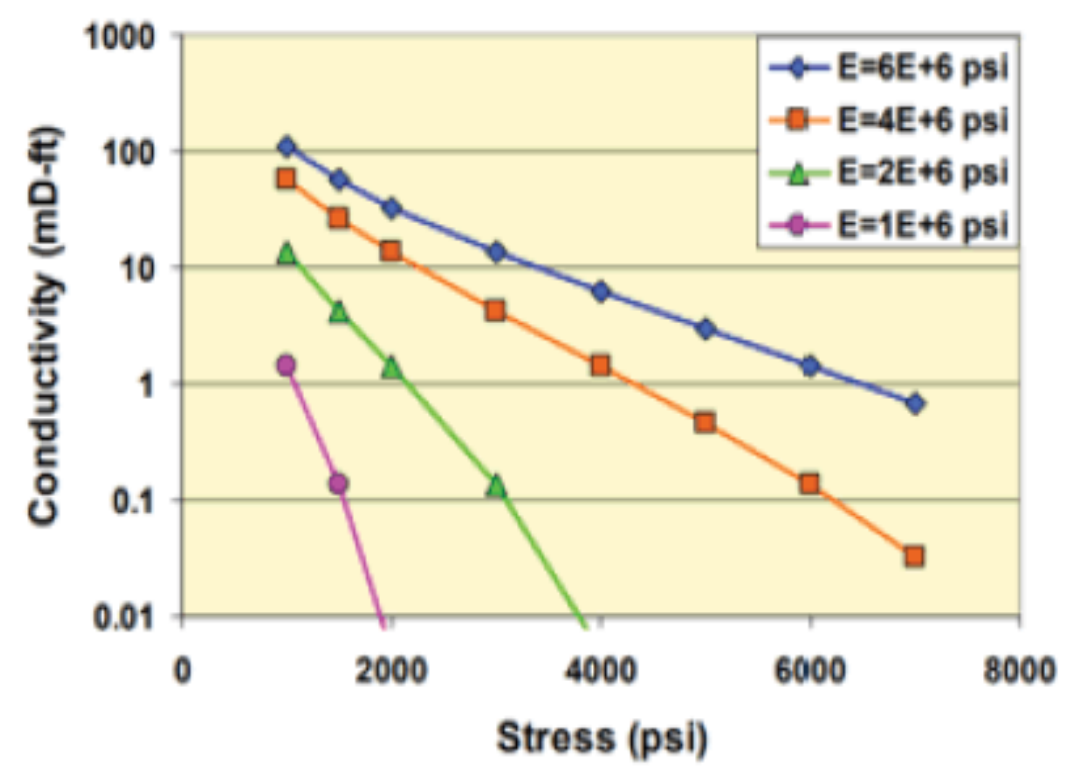

Figure 2.7: Effect of Young's Modulus and Net Stress on Conductivity of Un-Propped Fractures (After Cipolla et al. 2008).

\subsection{Impact of Stress on the Matrix Permeability}

Naturally fractured reservoirs are characterized by fractures and matrix systems, which are more sensitive to stress variants than non-fractured formations (Lian et al., 2012). Heller et al. (2014) measured matrix permeability of the shale as a function of net pressure by using helium under different pore pressures. The six core samples from the Barnett, Marcellus, Eagle Ford, and Montney formations were analyzed by Heller et al. The studies considered the entire range of the data representing matrix permeability.

More recently, a laboratory set-up, PPAL (Precision Petrophysical Analysis Laboratory) has provided accurate and repeatable measurements of the Marcellus shale petrophysical properties (Zamirian et al., 2015 and Elsaig et al., 2016). The key advantages of PPAL include the ability to measure the permeability of the shale core plugs under a wide range of pore and confining pressures. Elsaig et al. (2016) measured the absolute permeability of Marcellus shale core plugs at four different pore pressures and seven different net stress values, from 1,300 to $7,000 \mathrm{psi}$. In these experiments, the absolute permeability of the shale core plug was determined at each net stress by the application of the double slippage correction. Figure 2.8 illustrates the impact of net stress on the absolute permeability determined during these experiments. As the stress increases, the fissures that are more sensitive to stress close down. The closure of the fissures causes a major reduction in the measured permeability of the core plug. Once all the fissures are closed, the permeability reduction is only the result of the matrix compression. 
If $\mathrm{k}$ is the permeability measured at a specific stress $(\mathrm{P})$, and $\mathrm{k}_{\mathrm{o}}$ is the permeability measured at the lowest stress $\left(\mathrm{P}_{\mathrm{o}}\right)$ values, a linear trend is observed when $\left(\mathrm{k} / \mathrm{k}_{\mathrm{o}}\right)^{1 / 3}$ is plotted against $\ln \mathrm{P} / \mathrm{P}_{\mathrm{o}}$ (Walsh 1981). Figure 2.9 illustrates this plot for the above-mentioned Marcellus shale core plug (Elsaig et al., 2016). The differences in the compressibility of the fissures and the matrix result in two straight lines on this plot. The stress where these two lines intersect represents the fissure closure stress.

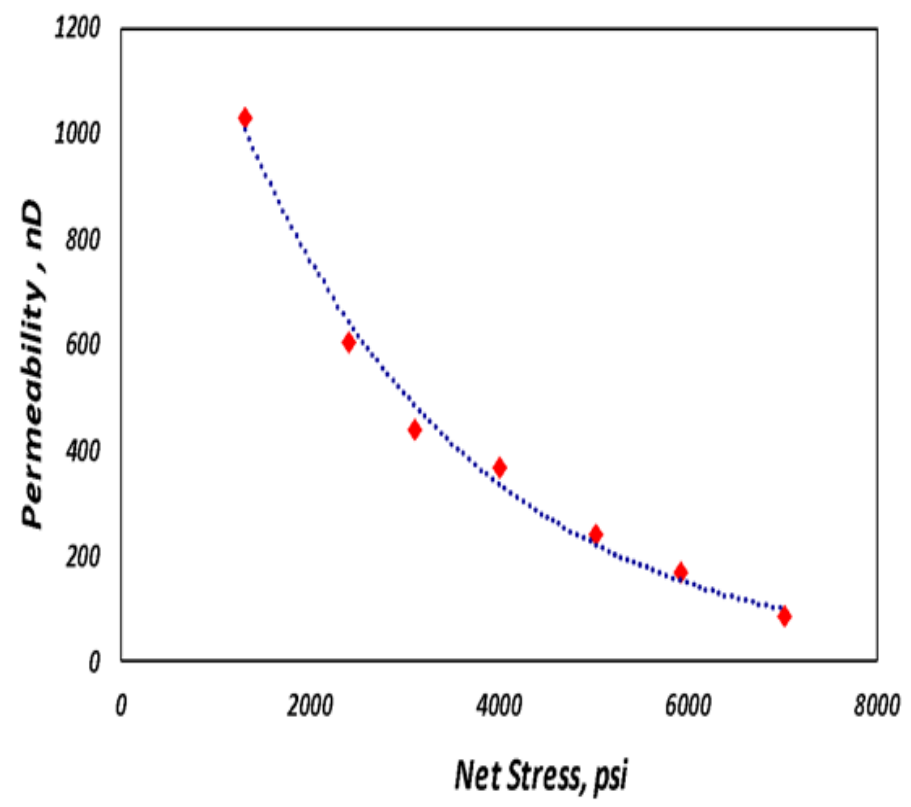

Figure 2.8: The Impact of Net Stress on the Absolute Permeability of the Marcellus Shale (after Elsaig et al., 2016).

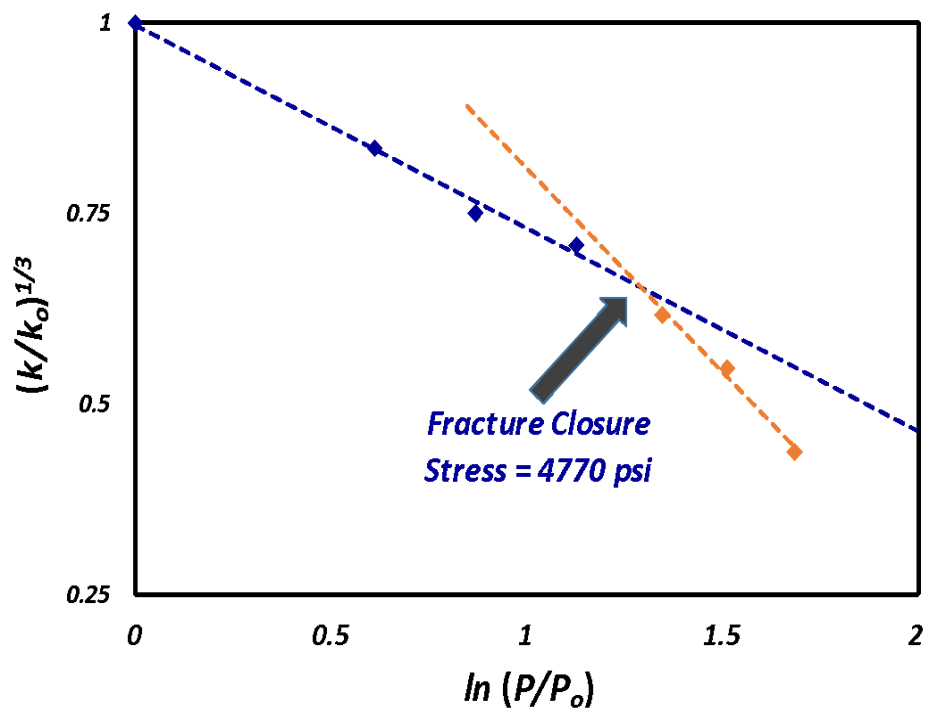

Figure 2.9: Evaluation of Fissure Closure Stress (after Elsaig et al., 2016). 


\subsection{Stress Shadow}

Horizontal wells in unconventional reservoirs are generally completed with multiple hydraulic fractures. Hydraulic fractures provide enormous fracture surface area, which leads to more significant production in an ultra-low permeability reservoir. Furthermore, during the hydraulic fracturing treatment, the initial fracture propagates in the direction of the minimum horizontal stress in the formation. The propagating fracture causes a stress change in its vicinity, commonly known as a "stress shadow," as seen in Figure 2.10 (a). Consequently, the second fracture propagates against higher horizontal stress, limiting its propagation and impacting this stage's properties, mainly the width, as seen in Figure 2.10 (b). The additional stress caused by the shadowing $(\sigma)$ is related to the net pressure, fracture width, and Young's modulus given by the deformation solution (Barree, 2015):

$$
\sigma=\frac{w E}{12 Z_{s}^{t}}
$$
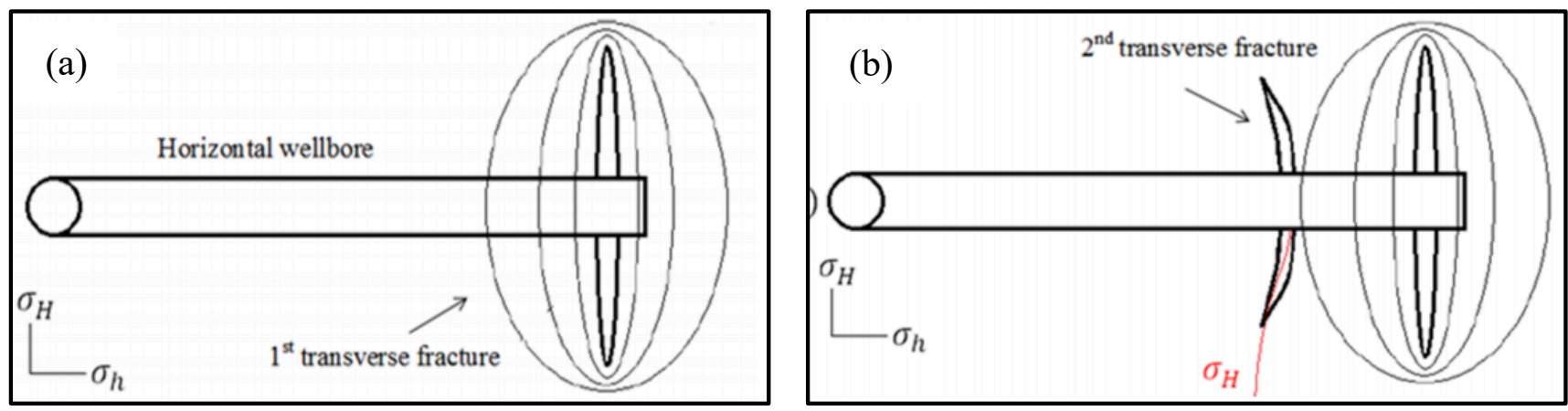

Figure 2.10: (a) Illustrates Stress Shadow (b) Illustrates Effect of the Second Stage by Stress Shadow (after Morril, 2011).

Furthermore, the stress shadow increases breakdown pressure and may even prevent the subsequent stage from initiating. Therefore, any hydraulic fracture propagates against closure stress, which its magnitude is impacted by the cumulative stress shadow from all the preceding fractures. (Fisher et al. 2004). Stress shadowing impacts are crucial in hydraulic fracture design and have therefore been studied by many authors. They found that fractures in the middle stages are shorter and narrower than those on the ends due to stress shadowing (Gemanovich et al. 1997; Fisher et al., 2004; Olson, 2008; Abass et al., 2009; Meyer and Bazan, 2011; Kresse et al., 2013) as seen in Figure 2.11. Fisher et al. (2004) concluded that stress shadowing prevents the fracture from propagating in close vicinity of other fracture 


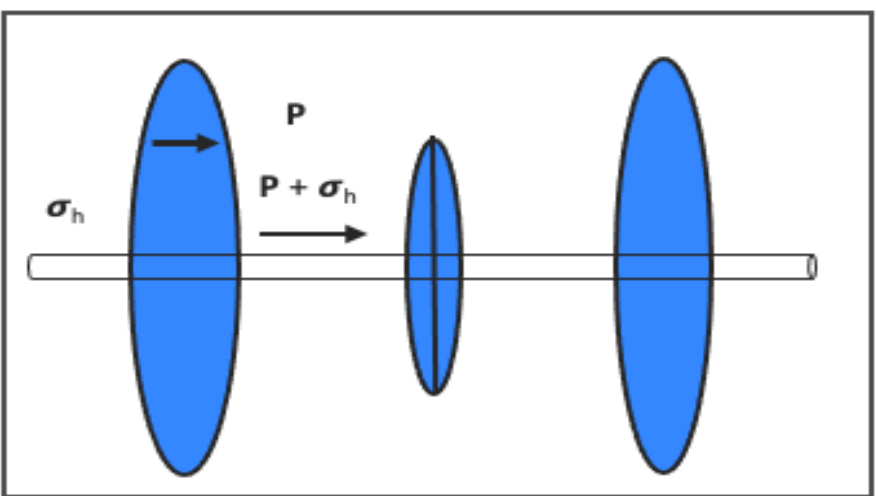

Figure 2.11: Stress Shadow Impact Middle Cluster.

Soliman et al. (2004) have shown that creating a hydraulic fracture changes in-situ stress in its surroundings, which affects the subsequent hydraulic fractures created. Singh and Miskimins (2010) suggested that an increase in spacing between the fractures reduces the interference and causes a minor increase in breakdown pressure for fracture initiation. The number and spacing of fractures influences fracture geometry (fracture length and width) due to mechanical interactions (Cheng, 2009). Roussel and Sharma (2010) indicated that decreasing fracture spacing could increase the stress shadowing impacts throughout the formation. They recommended that fracture spacing should be determined based on a distance that minimizes the shadowing effect from the previous fractures.

In unconventional reservoirs with ultra-low permeability, it is essential to closely space the hydraulic fracture stages to drain the reservoir efficiently. However, the fracture geometry and the gas recovery efficiency in the Marcellus Shale can be significantly impacted when stages are closely spaced (E1 Sgher et al. 2019a and 2019b).

\subsection{Rock Mechanics Properties}

Elastic mechanical properties of rocks (Young's Modulus and Poisson's Ratio) are essential, because they control the geometry of a created hydraulic fracture, and these elastic properties can be determined both statically and dynamically. Furthermore, mechanical rock properties are necessary to estimate minimum horizontal stress.

Laboratory core measurement of these properties can be time-consuming and costly. However, it is easier and faster to obtain the dynamic mechanical properties of a rock by taking advantage of sonic wave velocities. The quality of the reservoir's stress analysis can be related to the basic measurements of compressional velocity (Vp), shear velocity (Vs), and formation density $(\rho b)$. 


\subsubsection{Stress and Strain}

Stress is defined as the force (F) applied to a surface of a cross-sectional area (A), and calculated by Equation 2.2. The Strain is defined as the resulting deformation (change in length) divided by the original length before applying the stress and can be calculated by Equation 2.3. Applied stress can be in the form of tension or compression, where each form results in a different strain response.

$$
\begin{gathered}
\sigma=\frac{F}{A} \\
\varepsilon=\frac{\Delta L}{L_{0}}
\end{gathered}
$$

\subsubsection{Young's Modulus}

Young's Modulus is a measure of the stress needed to generate a specific deformation and represents the formation's stiffness. Static Young's modulus is determined by measuring the strain of a core under uniaxial stress loading in the laboratory. It is the slope of the linear portion of the stress-strain curve (Elastic Zone) as illustrated in Figure 2.12 and given by Equation 2.4. also, the slope is an indication of the stiffness of the material.

$$
E=\frac{\Delta \sigma}{\Delta \varepsilon}
$$

Once the stress exceeds the yield point, as illustrated in Figure 2.12, the material deforms plastically

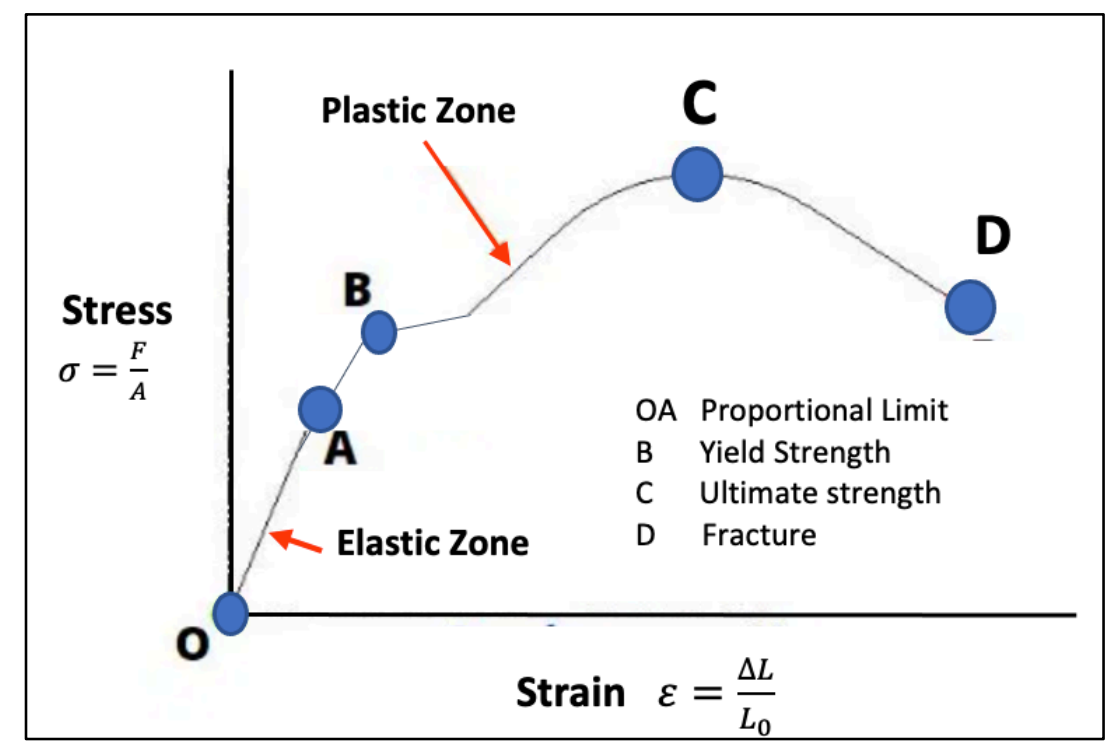

Figure 2.12: Stress-Strain Curve. 


\subsubsection{Poisson's Ratio}

Poisson's ratio expresses the ratio of lateral strain to a longitudinal strain of a rock sample when subjected to stress under axial loading conditions. Poisson's ratio is defined by Equations 2.5, 2.6, and 2.7 and is illustrated graphically in Figure 2.13. Its values range from $0-0.5$.

$$
\begin{gathered}
v=\frac{\varepsilon_{x}}{\varepsilon_{z}} \\
\varepsilon_{x}=\frac{\Delta D}{D_{1}} \\
\varepsilon_{Z}=\frac{\Delta_{L}}{L_{1}}
\end{gathered}
$$

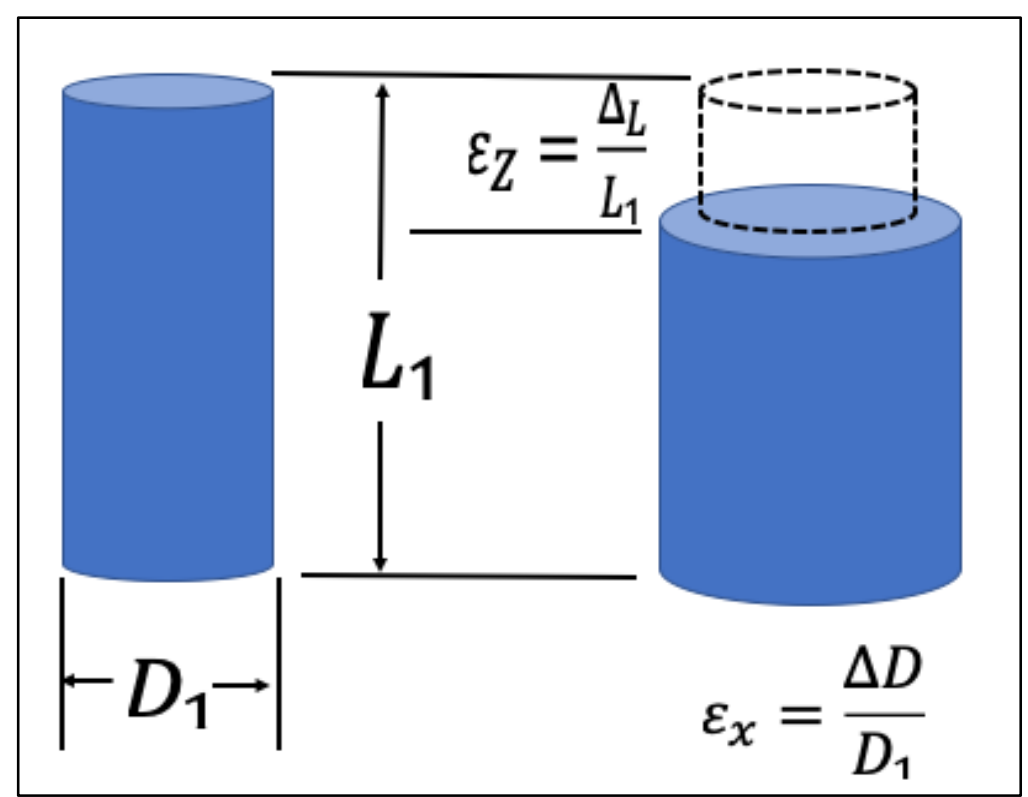

Figure 2.13: Description of the Poisson's Ratio.

\subsection{Stresses in the Formation}

The principal stresses in the subsurface include minimum horizontal stress $\sigma_{h, \min }$ maximum horizontal stress $\sigma_{H, \max }$, and overburden stress $\sigma_{v}$. Minimum horizontal stress $\sigma_{h, \min }$, and maximum horizontal stress $\sigma_{H, \max }$, are the stresses acting on the formation horizontally in the x-y plane perpendicular to the overburden stress $\sigma_{v}$. These three principal stresses control the fracture propagations and orientation. These stresses are defined as the greatest, intermediate, and the least stresses or $\sigma_{1}, \sigma_{2}$, and $\sigma_{3}$, respectively. Three principal stresses are not always oriented in the same direction due to historical tectonic movement. 
Figure 2.14 illustrates three stress regimes, including normal fault, strike-slip fault, and thrust fault. The vertical stress is the largest principal stress for normal faults, the intermediate principal stress for strike-slip faults, and the smallest principal stress for the thrust faults. There are two types of hydraulic fractures, longitudinal and transverse fractures, as illustrated in Figure 2.15. If the horizontal well is drilled perpendicular to the minimum horizontal stress, the created fracture will be longitudinal. However, if the horizontal well is drilled parallel to the minimum horizontal stress, the created fractures will be perpendicular to the horizontal well; i.e., transverse fractures.

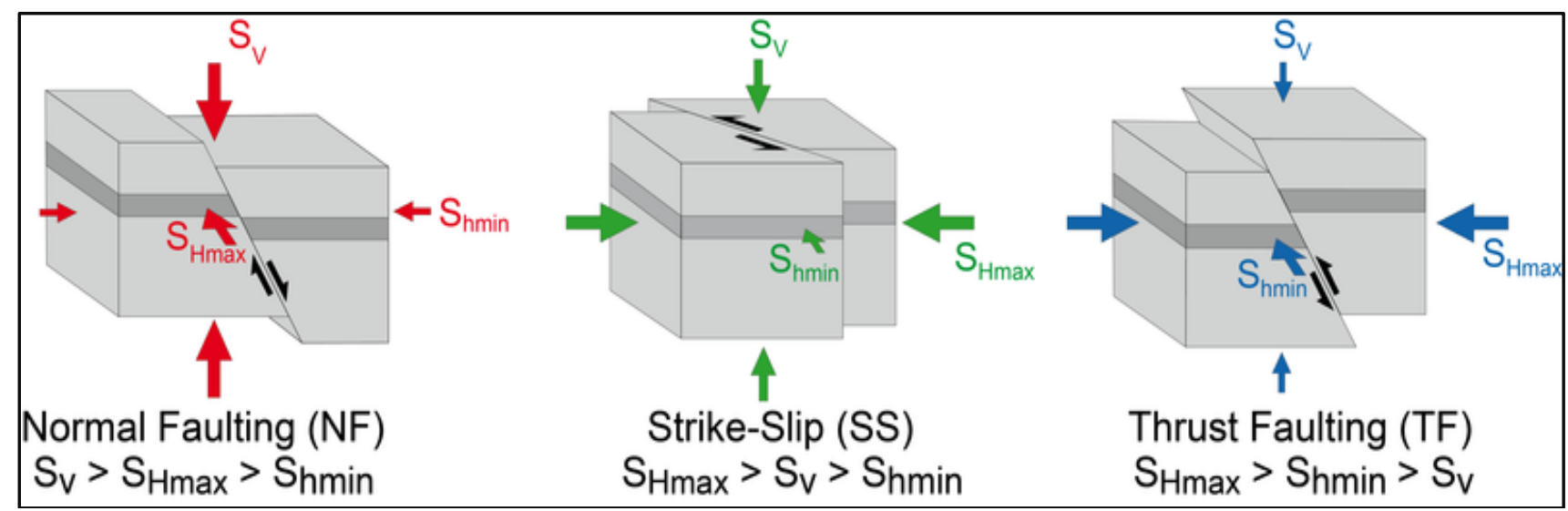

Figure 2.14: Stress Regimes (Heidbach et al., 2016).

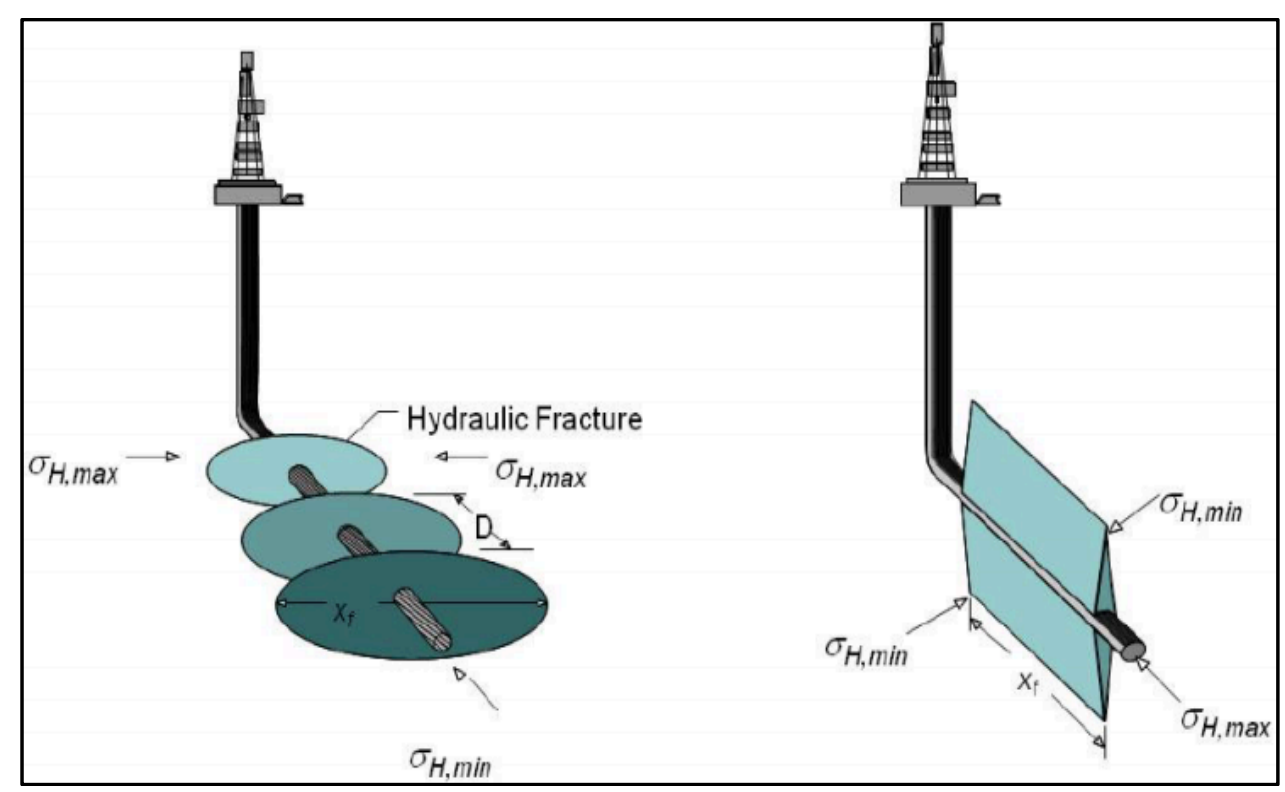

Figure 2.15: Multiple Transverse Fractures (Left) and Longitudinal Fracture (Right) (M.J. Economides, 2010). 


\subsubsection{Minimum Horizontal Stress}

GOHFER performs the necessary calculations to determine the mechanical rock properties and minimum horizontal stress. Brief descriptions of the calculations performed by GOHFER are provided here. The minimum horizontal stress is determined by the following equation (Barree et al., 2009)

$$
\sigma_{h}=P_{C}=\left(\frac{v}{1-v}\right)\left[\sigma_{v}-\alpha_{v} P_{p}\right]+\alpha_{h} P_{p}+\varepsilon_{h} E+\sigma_{t}
$$

Where:

$$
\begin{aligned}
& \sigma_{h}=\text { Minimum horizontal stress, psi } \\
& v=\text { Poisson's Ratio, fraction } \\
& E=\text { Young's Modulus, mpsi } \\
& \sigma_{v}=\text { Overburden pressure, psi } \\
& P_{p}=\text { Pore pressure, psi } \\
& \alpha_{v}=\text { Vertical Biot's coefficient, dimensionless } \\
& \alpha_{h}=\text { Horizontal Biot's coefficient, dimensionless } \\
& \varepsilon_{h}=\text { Regional horizontal tectonic strain, microstrain } \\
& \sigma_{t}=\text { Regional horizontal tectonic stress, psi }
\end{aligned}
$$

The dynamic Poisson's ratio and Young's modulus are determined from the sonic logs using the equations below (Barree et al. 2009):

$$
\begin{aligned}
& v=\frac{(R-2)}{(2 R-2)} \\
& E=13447 \rho_{b} \frac{(3 R-4)}{\left(D T C^{2} R(R-1)\right)}
\end{aligned}
$$

Where:

$$
\begin{aligned}
& \rho_{b}=\text { bulk density } \\
& R=\left(\frac{D T S}{\mathrm{DTC}}\right)^{2}
\end{aligned}
$$

DTS and DTC are the reciprocals of the compressional and shear acoustic wave velocities, respectively. The static Young's modulus for shale gas samples is obtained by the following equation (Eissa and Kazi, 1988)

$$
\log \left(E_{s}\right)=\log \left(\rho_{b} E_{d}\right)-0.55
$$


The results can be scaled as needed to match available (correct) core data. The static Poisson's ratio is generally assumed to be the same as the dynamic Poisson's ratio.

The horizontal Biot's coefficient in Equation 2.8 is assumed one. However, the vertical Biot's coefficient is obtained from effective porosity $(\phi)$ using the following correlation (Barree, 2018):

$$
\alpha_{v}=A * \phi^{b}
$$

$A$ and $b$ are fitting parameters. Generally, $A$ and $b$ are assumed to be 1 and 0.1 , respectively. However, they can be adjusted to match any core observations in the area.

The overburden pressure gradient is determined from the overburden stress $\sigma_{\mathrm{V}}$. The magnitude of $\sigma_{\mathrm{V}}$ can be derived by integrating the density log from the surface to a certain depth of interest (Zoback, 2007)

$$
\sigma_{\mathrm{V}}=\int_{0}^{D} \rho(z) g d z
$$

Where

$$
\begin{aligned}
& \sigma_{\mathrm{V}}=\text { overburden stress, } \mathrm{psi} \\
& \rho=\text { overlying rock density, } 1 \mathrm{bm} / \mathrm{in}^{3}, \\
& \mathrm{~g}=\text { gravitational acceleration, } \mathrm{in} / \mathrm{s}^{2} \\
& \mathrm{z}=\text { depth, in }
\end{aligned}
$$

\subsection{Mineralogy and Shale Lithofacies}

Advanced logging tools such as spectral gamma, lithoscanner, and nuclear magnetic resonance, and $\mathrm{X}$-ray diffraction (XRD) are calibrated with the core data and used to estimate the shale mineralogy. Figure 2.16 shows mineralogy distribution in the vertical section for two Marcellus Shale (Well MIP-3H and MIP4H) wells (Paronish et al., 2016). Marcellus interval consists of six shale lithofacies based on the organic content and mineralogy (Paronish et al., 2016) as shown in Figure 2.16. Organic Mudstone, Organic Siliceous Shale, Organic Mixed Shale, Gray Mixed Shale, Gray Siliceous Shale, and Gray Mudstone are the six different facies units. It must be pointed out that the brittleness in Shale facies depends on the mineralogy. Organic Mudstone and Gray Mudstone facies are more ductile due to higher clay content, and Organic Siliceous and Gray Siliceous shale are more brittle due to higher quartz content. 
The lateral variation in facies is distinguished between the two wells based on lateral mineralogy changes. As a result, it is essential to understand mineralogy distribution along the horizontal length in Marcellus Shale before hydraulic fractures are created.

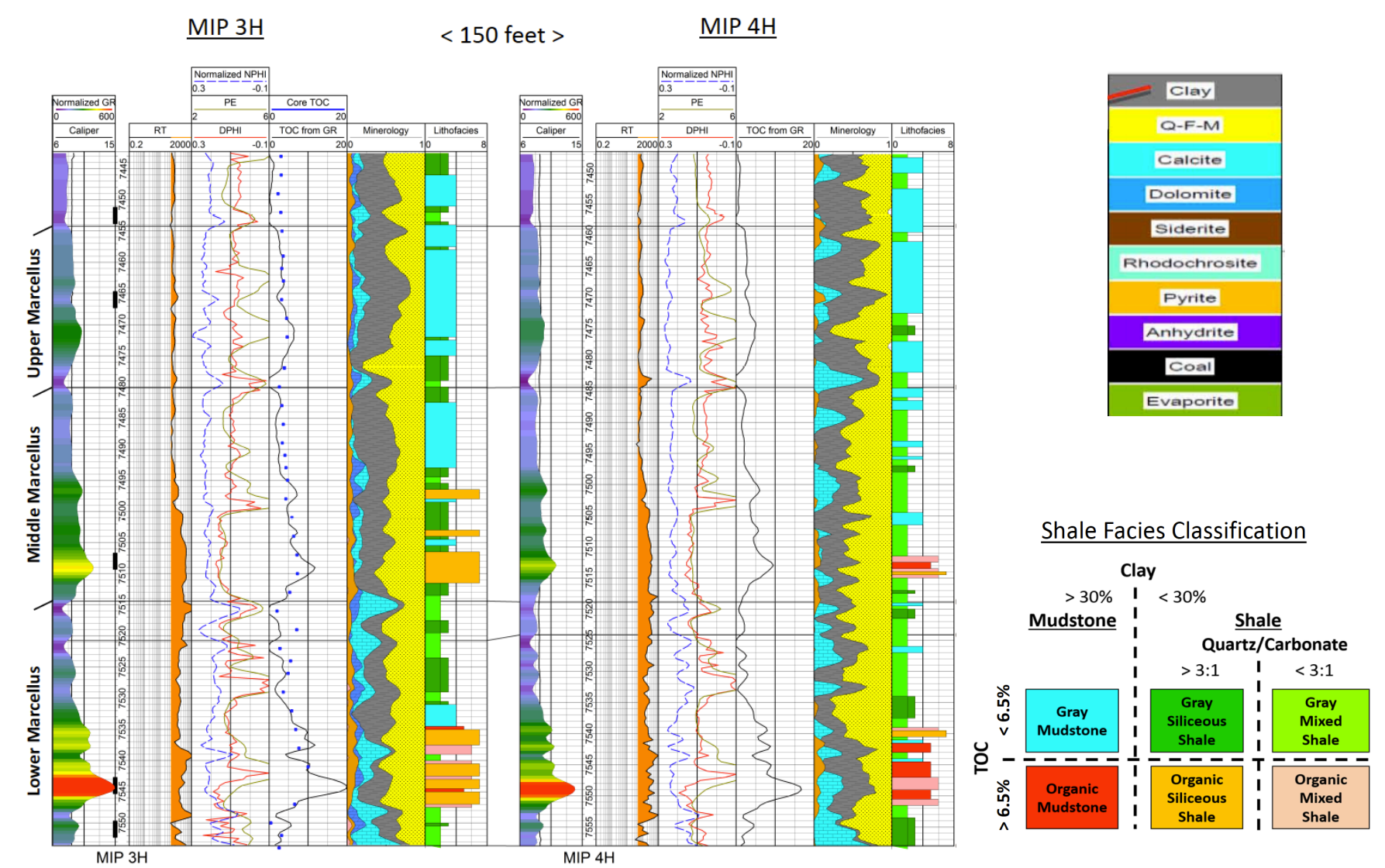

Figure 2.16: Mineralogy and Lithofacies for $3 \mathrm{H} \& 4 \mathrm{H}$ Wells (Paronish et al., 2016).

\subsection{Hydraulic Fracture Models}

Many models have been developed for estimating the properties of hydraulic fracture, including height, length, and conductivity. These models include two-dimensional (2D), pseudo three-dimensional (P3D) (e.g MFrac/MShale), and planar-3D (e.g GOHFER and StimPlan) Models.

\subsubsection{D Models}

Most two-dimensional (2D) fracture propagation models assume that the fracture height is independent of the fracture length and is assumed to be constant. Fracture width and length are computed based on the fracturing fluid volume. Two well-known fractures which are widely used in the industry are Perkins-Kern-Nordgren (PKN) (Perkins and Kern, 1961; Nordgren, 1972) and Kristonovich-Geertsma-de 
Klerk (KGD) (Khristianovitc and Zheltov, 1955; Geertsma and de Klerk, 1969). These models (PKN and KGD) assume that fluid flow with Newtonian fluids is one-dimensional and travels along the length of the fracture (Economides and Nolte 2000). Furthermore, both models assume that the rock is a homogeneous, isotropic linear elastic solid.

\subsubsection{PKN Model}

Perkins and Kern (Perkins and Kern, 1961) initially developed equations to calculate fracture length and fracture width with a constant fracture height. Later, Nordgren (Nordgren, 1972) modified their model. PKN model is usually applied when the fracture length is much greater than the fracture height $\left(\mathrm{X}_{\mathrm{f}}>>\mathrm{h}_{\mathrm{f}}\right)$ and PKN model considers the vertical plane strain. Moreover, the PKN model has elliptical cross-sections in the horizontal and vertical direction, respectively, as shown in Figure 2.17.

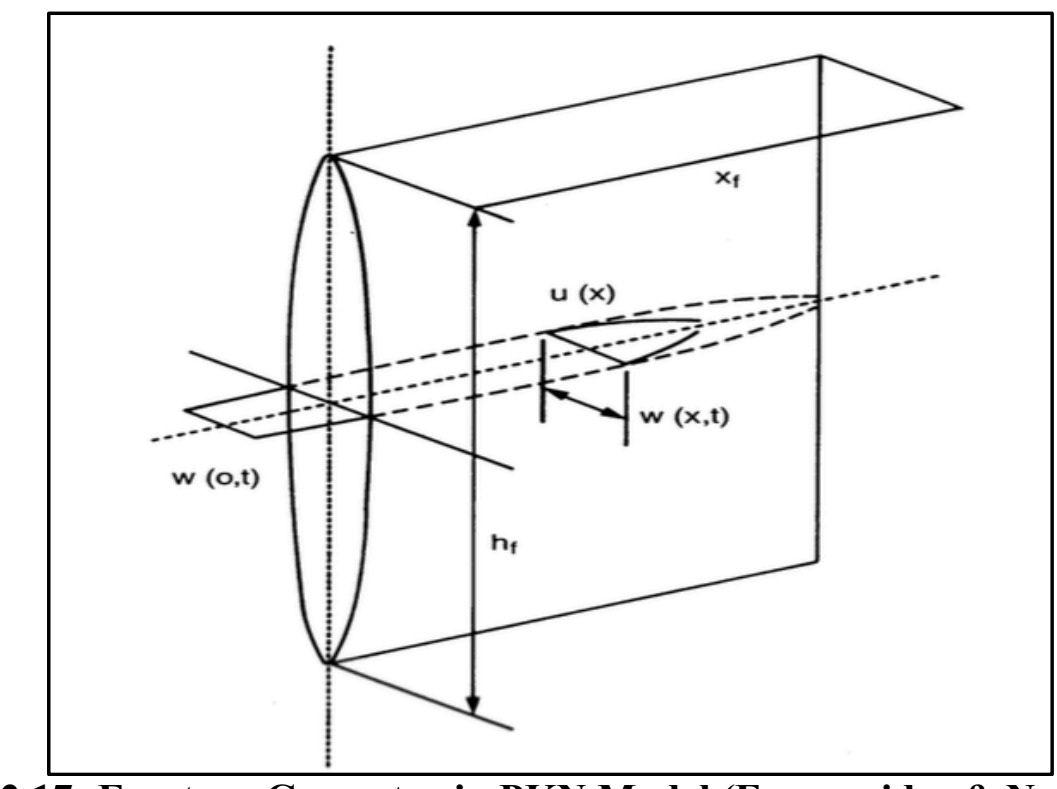

Figure 2.17: Fracture Geometry in PKN Model (Economides \& Nolte, 2000).

\subsubsection{KGD Model}

Khristianovitch, and Zheltov (Khristianovitch and Zheltov, 1955), and Geertsma and de Klerk (Geertsma and de Klerk, 1969) developed KGD model. The KGD model is more reliable if fracture height is more than the fracture length $\left(\mathrm{X}_{\mathrm{f}}<<\mathrm{h}_{\mathrm{f}}\right)$. Furthermore, the KGD model considers horizontal plane strain. An elliptical horizontal cross-section and rectangular vertical cross-section are assumed, as can be seen in Figure 2.18 


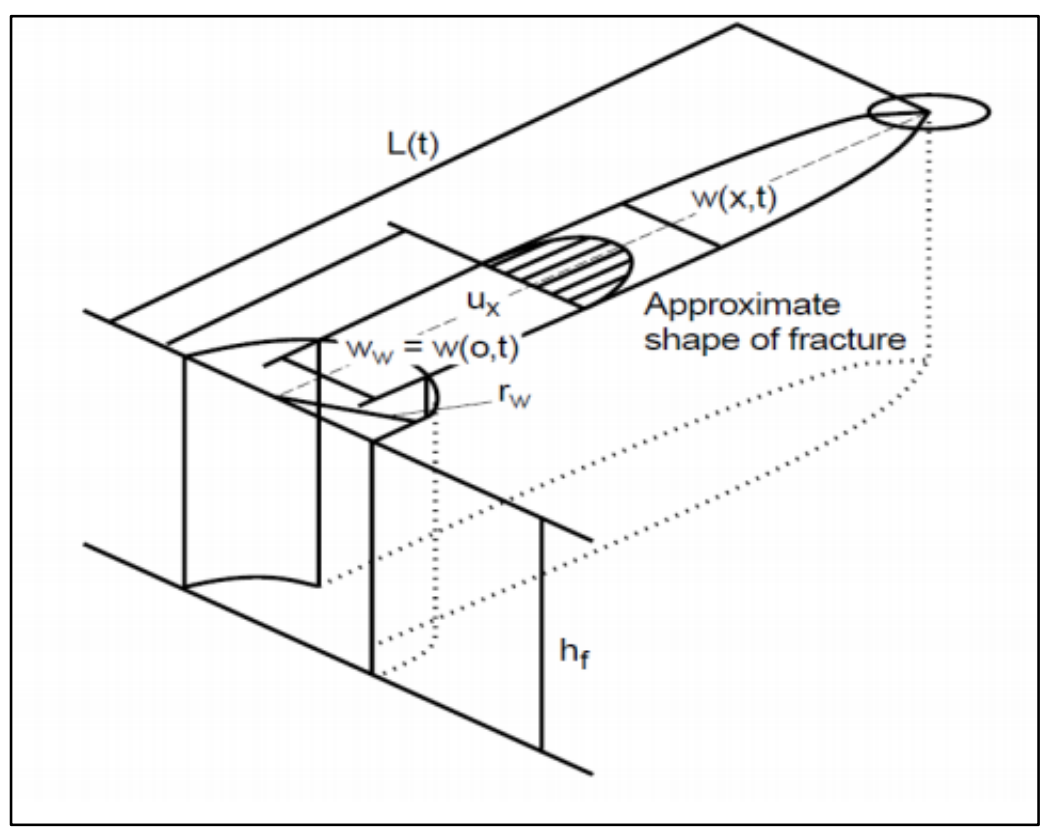

Figure 2.18: Fracture Geometry in KGD Model (Valk and Economides 1995).

\subsubsection{Pseudo-3D Models}

Most pseudo-3D (P3D) models use the basic assumptions of the PKN model with the exception of the constant fracture height. The fracture height is calculated based on the position and injection time. Moreover, P3D models assume horizontal fluid flow. The major assumptions of these models are that the fracture length is greater than the fracture height, which is a significant difference between the P-3D and the $2 \mathrm{D}$ models

Furthermore, the P3D models developed in the 1980s have two classifications, cell-based and lumped models. In a cell-based P3D model (Settari and Cleary, 1982) the fracture is divided into several elements or cells that are perpendicular to direction of the fracture length. Each cell can have a different height, as shown in Figure 2.19. This approach is consistent with the basic assumption used in PKN. Plane strain assumption is made for each vertical cross-section to simplify the elastic equation. The fracture opening width is directly related to the local fluid pressure and decoupled from the neighborhood's pressures, significantly simplifying the elasticity equation. Vertical flow is neglected, the stress intensity factors at fracture top and bottom tips, and fracture width can be directly computed analytically for a layered medium with piecewise constant stress. The case of a lump-based model (Cleary, 1980; Cleary et al., 1983) is illustrated in Figure 2.20. In this approach of the geometry of the fracture is assumed to consists two half-eclipses joined at the centers. 


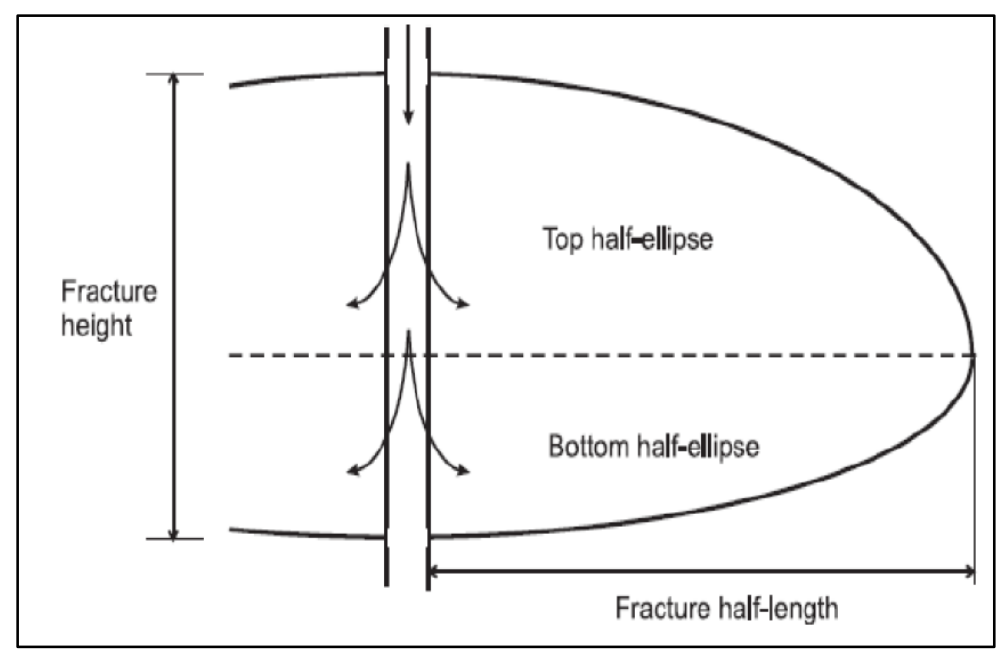

Figure 2.19: Lumped Pseudo-3D model (Adachi et al. 2007).

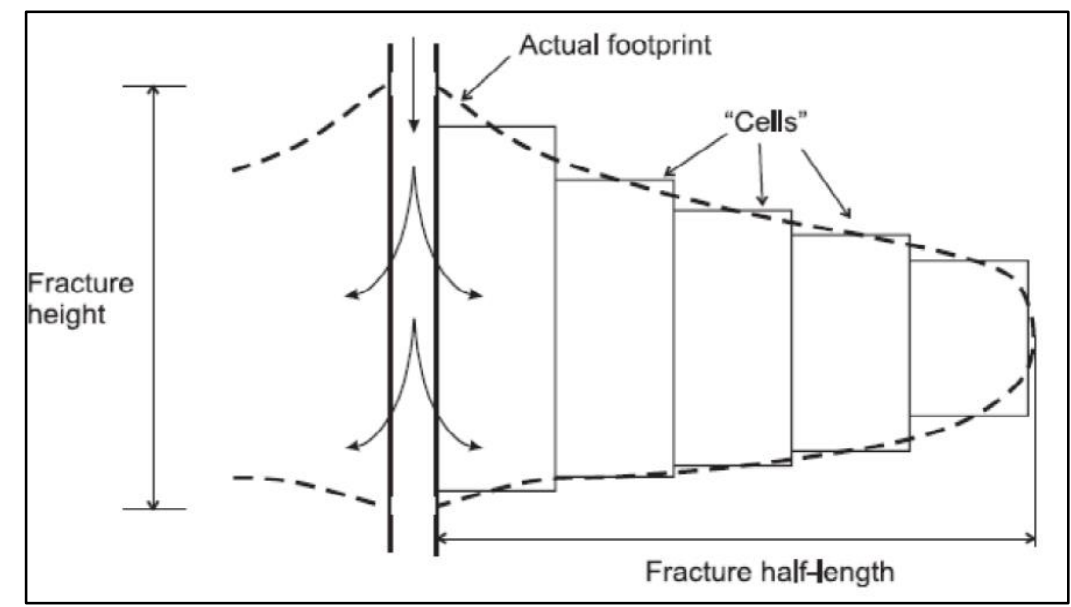

Figure 2.20: Cell-based Pseudo-3D model (Adachi et al. 2007).

Dontsove and Peirce (2015) developed a P-3D model which accounts for viscous height growth, fracture toughness in the lateral direction, and non-local elasticity. This approach is based on the cell-based P3D model with equilibrium height growth.

\subsubsection{Planar 3D Models}

Planar 3D models are considered to be more accurate than P-3D models. GOHFER software, which stands for Grid Oriented Hydraulic Fracture Extension Replicator, is a planar 3-D geometry fracture simulator with a fully coupled fluid/solid transport simulator. Furthermore, GOHFER utilizes the finite difference method, and the rock properties are assigned at each node of the finite-difference grid, enabling it to capture rock heterogeneity in both vertical and lateral directions. This model was validated with PKN and GKD models, and a good match was obtained when the same input data were used. Furthermore, GOHFER is able to incorporate stress shadowing effects when multiple fractures are modeled. 


\subsection{Diagnostic Fracture Injection Tests (DFITs)}

Diagnostic Fracture Injection Tests (DFITs), also known as minifracs or fracture calibration tests, have become one of the prevalent and practical pressure transient tests for ultra-low permeability reservoirs, which have become the focus of production in the last decade. The DFIT uses a small injected volume of water (or gas) into a reservoir to create a hydraulic fracture. Consequently, the wellhead is shut-in, and the pressure is recorded during the pressure fall-off that follows fluid loss due to fracture closure. Figure 2.21 shows a typical example of a DFIT Test. It is essential to correctly analyze and interpret DFIT data to obtain the necessary fracture design and reservoir parameters. Fracture design and reservoir parameters include instantaneous shut-in pressure (ISIP), closure stress, pore pressure, fluid efficiency, reservoir flow capacity, and fracture leak mechanisms that estimate before and after fracture closure pressure, as seen in Figure 2.21.

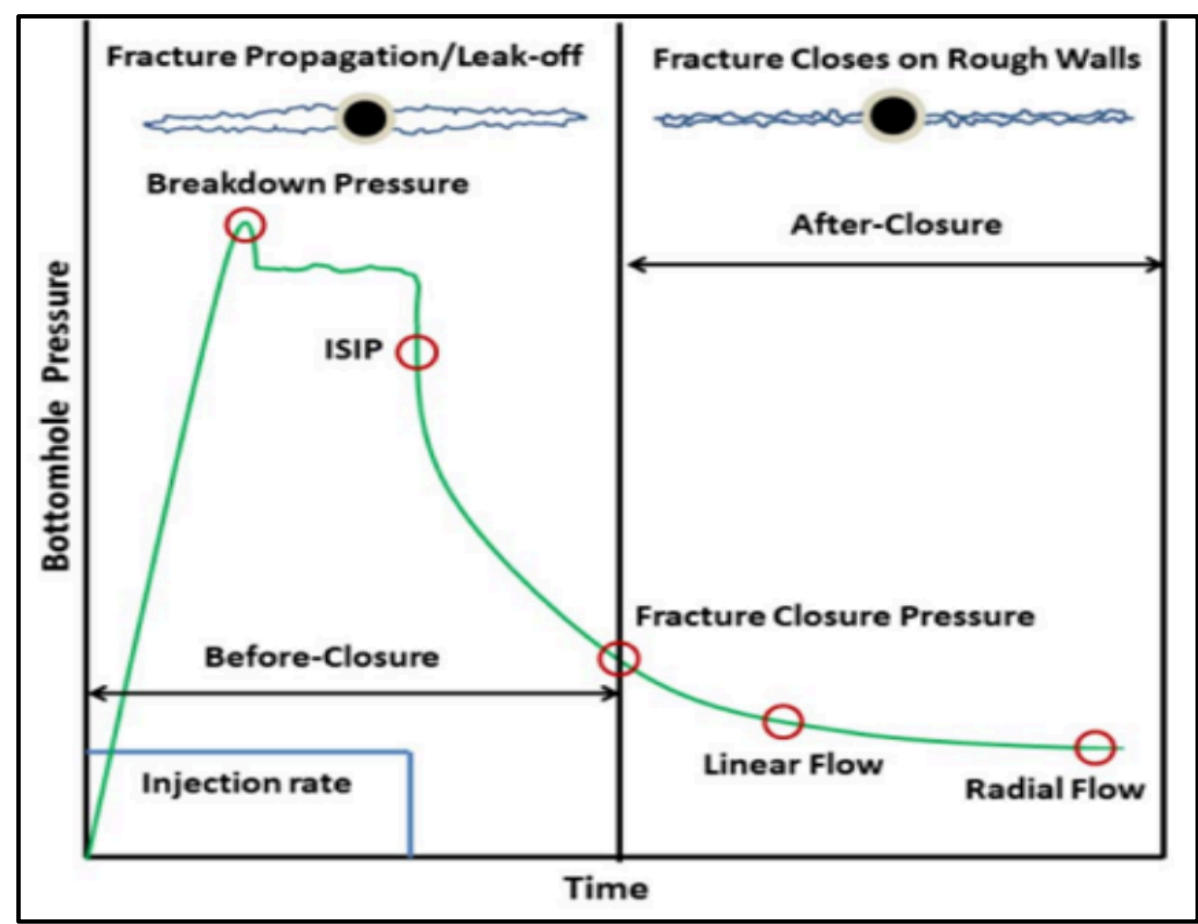

Figure 2.21: Typical DFIT Test Response (Wang et al., 2017).

Additionally, the G-function and its derivatives are the primary tools for analyzing shut-in pressures. While other diagnostic techniques such as log-log pressure derivate, the square root of time and their diagnostic derivatives provide validation and a consistent method of determining closure pressure. The Gfunction plot is the most popular method, as it is used to identify the opening of natural fractures (fissures) and to calculate the closure stress (Barree et al., 2009). When a hydraulic fracture intersects natural fractures (fissures), the leak-off rate will increase dramatically after the injection pressure exceeds the fissure closure pressure, causing the fissures to dilate (Barree et al. 1996; Barree 2018). There are four leaks off 
mechanisms, as seen in Figure 2.22, which include normal leak-off (no fissures), pressure-dependent leakoff (PDL), fracture tip extension, and height recession (Barree et al., 2009).
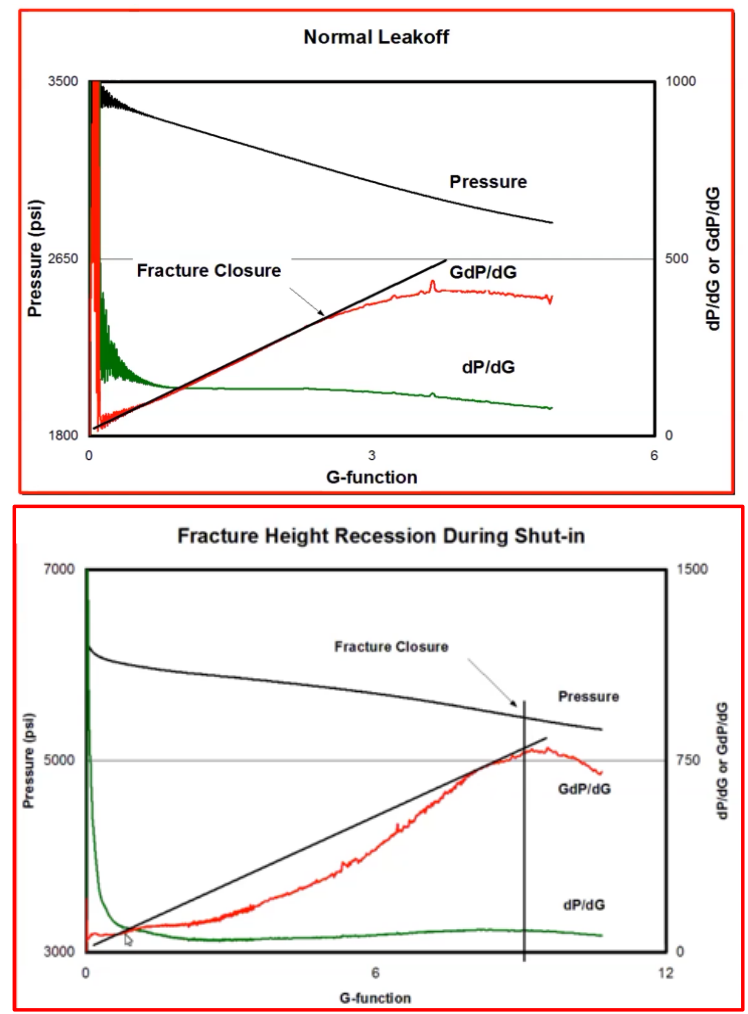
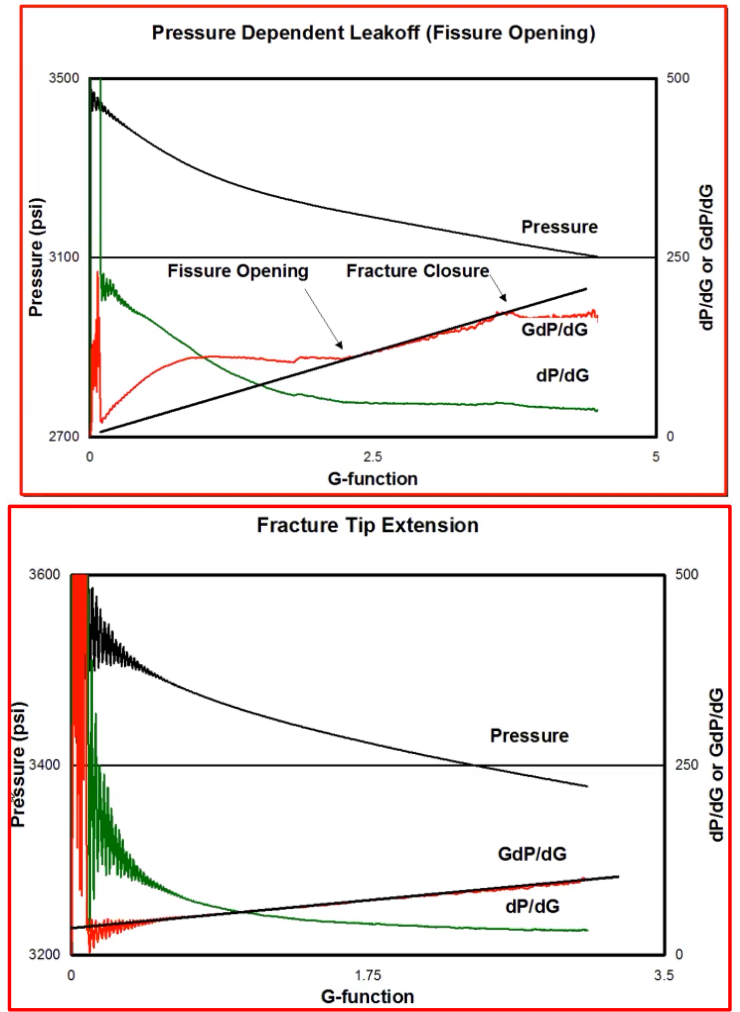

Figure 2.22: G-Function Derivative Analysis - Leakoff Mechanisms after (Craig et al. 2000)

\subsection{Contribution of Hydraulic Fracture Stage to Production}

In the United States, shale gas reservoirs have become a prosperous resource of the natural gas reserve. The key aspect of successfully growing this resource is the use of horizontal drilling and hydraulic fracture technology. This technique creates a conductive pathway into the wellbore for the hydrocarbon flow. Additionally, a horizontal well with multiple hydraulic fractures improves hydrocarbon recovery in shale reservoirs.

The horizontal wells are completed in stages, and then each stage is fractured. However, diagnostic field data has shown that some stages have not accomplished dominant fractures (Fisher et al. 2004 Molenaar et al. 2011). The production variability from the horizontal length of the well has been investigated in many studies. Cipolla et al. (2011a) used a statistical analysis of 100 production logs from geometrically completed horizontal wells, and their results pointed out that only $60 \%$ of perforation clusters contribute to production. Miller et al. (2011) and Slocombe et al. (2013) studied production logs for over 100 horizontal shale-gas wells, concluding that there is variability within the length of the horizontal, and 
only $64 \%$ of perforation clusters contributed to the total production. Chorn et al. (2014) analyzed production performance for 100 wells drilled in the Barnett Shale and observed significant production variability. Furthermore, Spain et al. (2015) discovered that 40-60\% of perforation clusters produce minimum amounts of gas or not produce gas at all. Ugueto et al. (2016) found that solely 50-60\% of the perforation clusters were appropriately stimulated or produced at substantial rates based on fiber-optic diagnostics.

Lateral heterogeneity of the reservoir properties, which include rock quality, reservoir mineralogy, and facies alteration over a short distance, affects fracture propagation. Additionally, natural fractures (fissures) distribution within shale has a substantial impact on horizontal stimulation. Many researchers have observed that there is significant variation in reservoir properties existing along with the lateral interval. This variation present along the lateral interval could affect the initiation and propagation of hydraulic fractures and the fracture productivity of the well. Researchers observed the variation by using microseismic data, image logs, and sonic logs along the horizontal length. Hydraulic fractures propagate in the path of least resistance; subsequently, it is crucial to isolate low-stress zones from high-stress zones and unfractured zones from naturally fractured zones to maximize stimulation effectiveness (Baihly et al., 2010; Wutherich et al. 2012). Furthermore, Figure 2.23 shows hundreds of fracture stages distributed from left to right, showcasing deepest to shallowest. Obviously, the hydraulic fracture extends upward rather than downward because the Onondaga Limestone below the Marcellus Shale acts as a fracture barrier (Fisher et al., 2010). Suarez-Rivera et al. (2011) and Serajian and Ghassemi (2011) showed that shale intervals that have low clay content are easier to fracture hydraulically, both during drilling and stimulation, and this is based on fracture initiation pressures and borehole image data encountered during stimulation. Additionally, Waters et al. (2006) determined that clay-rich intervals are likely to show higher horizontal stresses. Consequently, hydraulic fracture initiation and proppant placement become more challenging in these zones. 


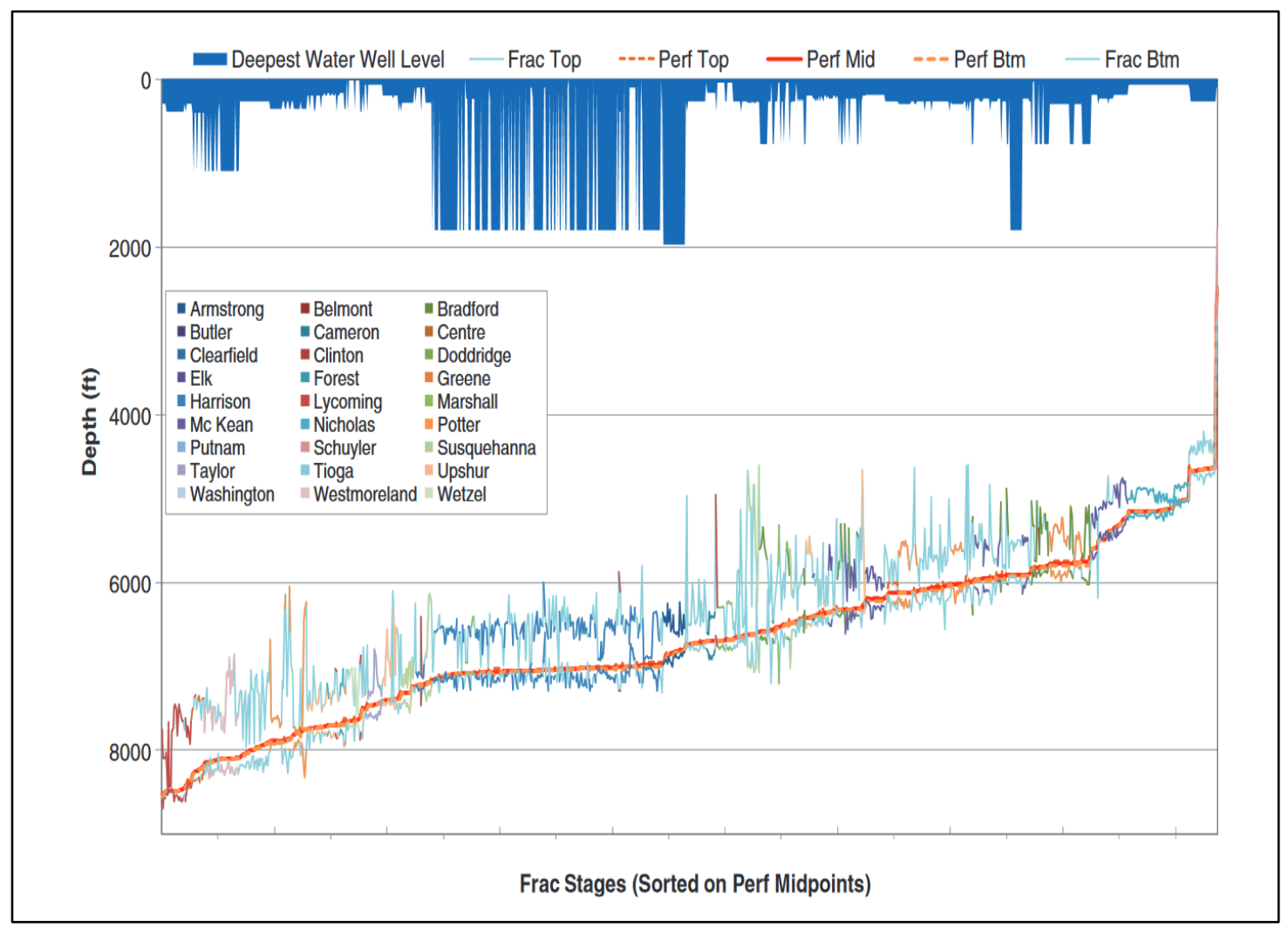

Figure 2.23: Vertical Extension of the Hydraulic Fracture in Marcellus Shale (Fisher et al., 2010).

Additionally, there have been many studies to evaluate the hydraulic fracture geometry from microseismic data. However, these approaches fall short in presenting actual fracture geometry and fracture conductivity because microseismic data shows only a small portion of the complete hydraulic fracture deformation (Maxwell et al., 2013; Cipolla and Wallace, 2014). Therefore, microseismic data cannot determine the location of proppant or fracture conductivity distribution (Cipolla et al., 2011b and 2012). Furthermore, Diagnostic Tools such as Radioactive Tracer, Fracture Mapping Tools, Fiber Optics, and Production Logging are qualitative and strictly limited by the non-uniqueness of the interpretation. Moreover, Various authors have performed studies to determine fracture properties, such as fracture conductivity and fracture half-length (Aboaba and Cheng, 2010; Yu and Sepehrnoori, 2014). Nevertheless, all these studies have considered shale gas reservoirs that include hydraulic fractures with uniform configurations. 


\section{CHAPTER 3: OBJECTIVES AND METHODOLOGY}

\subsection{Objectives}

This research aims to investigate the impact of geomechanical factors and stress shadowing on gas production from a horizontal well with multiple hydraulic fractures completed in Marcellus Shale. The specific objectives of this research study relative to a horizontal well with multiple hydraulic fractures are:

1. To evaluate the long-term production performance

2. To investigate the impact of fracture half-length, including non-uniform fracture half-length, on the gas recovery.

3. To investigate the impact of geomechanical factors (net stress changes) and slippage (pore pressure changes) on gas production

4. To investigate the impact of the stress shadowing on gas production

5. To investigate the impact stage spacing, treatment size, treatment sequencing, and the mechanical formation properties on the degree of stress shadowing and the gas recovery.

\subsection{Methodology}

To accomplish the objective of this study, a methodology consisting of the following steps was implemented:

1. Collect and analyze data to characterize the geophysical and geomechanical formation properties

2. Predict the fracture properties impacted by the stress shadowing using GOHFER fracturing simulation software.

3. Model development in reservoir simulations software (CMG)

4. Investigate the impact of geomechanical factors and non-uniform hydraulic fractures on gas recovery from a horizontal well

5. Investigate the impact of stress shadowing on gas recovery from the horizontal well.

6. Conduct parametric studies to investigate the impact of fracture half-length, including non-uniform fracture half-length, on the gas recovery.

7. Conduct parametric studies to investigate the impact of the geomechanical factors on gas recovery.

8. Conduct parametric studies to investigate the impact of the reservoir and treatment parameters on the degree of stress shadowing and the gas recovery from Marcellus Shale. 


\subsubsection{Data Collection}

The data collected and analyzed were mainly obtained from the Marcellus Shale Energy and Environment Laboratory (MSEEL). MSEEL is a multidisciplinary research site which has been developed to achieve a better understanding of the Marcellus Shale through the application of advanced geoscientific, engineering, and environmental technologies. The site is operated by Northeast Natural Energy (NNE) and contains 4 horizontal Marcellus Shale wells (Wells MIP-3H, 4H, 5H, and 6H) and a vertical science well (MIP-SW) as depicted in Figure 3.1. The vertical scientific observation well (MIP-SW) was drilled in order to obtain subsurface data and for microseismic monitoring.

The data from two horizontal wells (MIP-6H, and MIP-3H) and the vertical scientific observation well (MIP-SW) at MSEEL were used in this study. A significant amount of advanced technical information $h$ including well logs, image logs, diagnostic fracture injection test (DFIT), fracturing treatment data, is available from MIP-3H. The measurements on the core plugs from the science well performed with PPAL (Elsaig et al. 2016) were used to establish the basic shale properties.

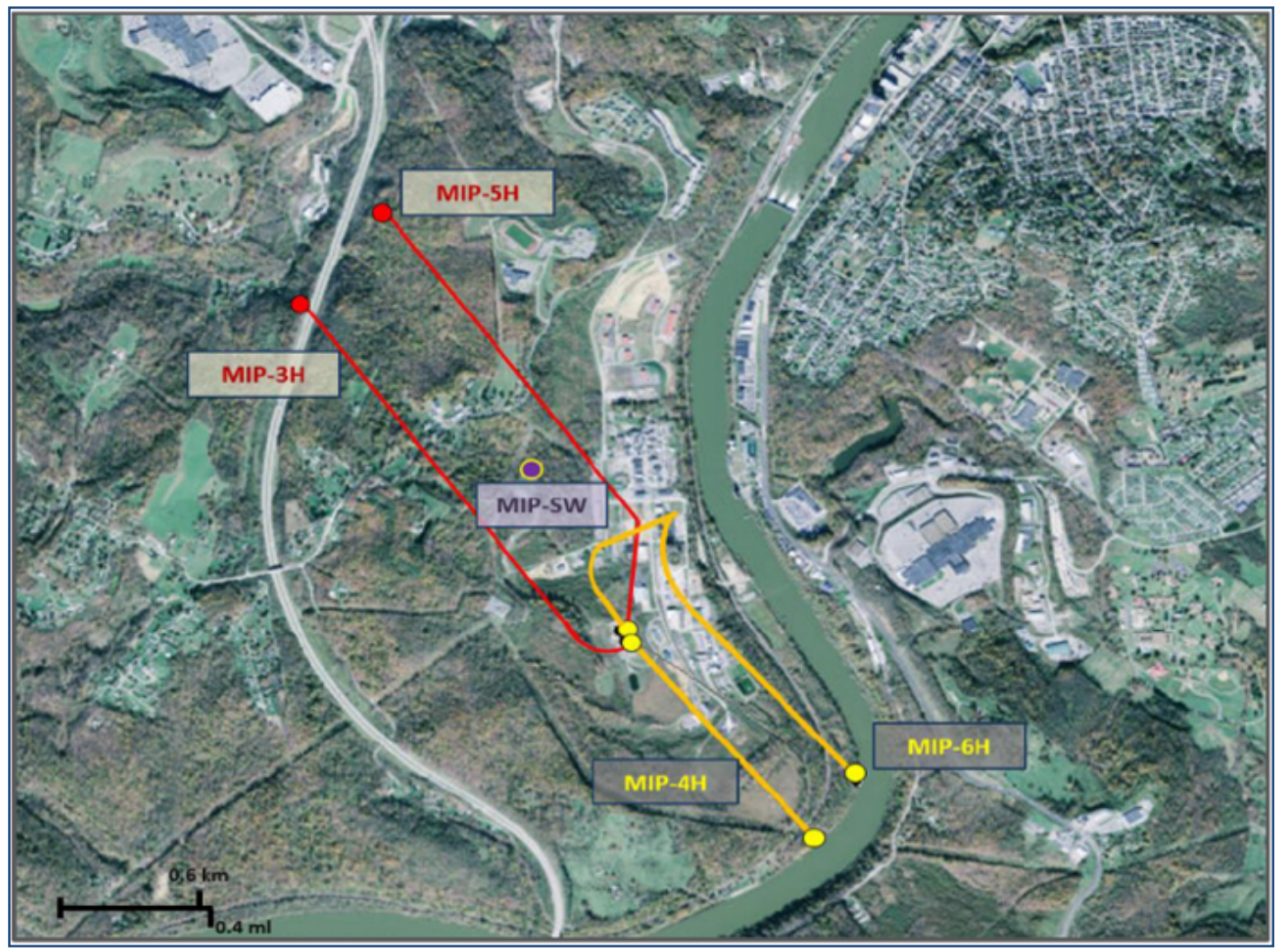

Figure 3.1: MSEEL Site Illustrating the Well Locations (EI Sgher et al., 2018). 


\subsubsection{Data Collected from Well MIP-6H}

The following data were available and were collected for the study:

1. Fracture Treatment Data: Well MIP-6H had been stimulated with eight fracture stages over a lateral length of 2,380 ft. The fracture treatment for MIP-6H used a pump rate of $80 \mathrm{bpm} .339,172$ gallons of a slick water; 1500 gallons of acid; 36,175 gallons linear 2000; and 400,000 lb of sand, which included 100,000 lb of 100 mesh and 300,000 lb of 40/100 mesh were used in each stage. The typical fracture treatment design parameters are provided in Table 3.1.

2. Well Log Data: Well log data which was required to estimate minimum horizontal stress from the well MIP-6H in the vertical section were unavailable. However, the available Gamma-Ray, Resistivity, Density, Neutron, and Acoustic well log data from well MIP-3H were utilized to evaluate well MIP-6H.

3. Figure 3.2 shows a variation of Gamma-Ray along the horizontal section of well MIP-6H with well trajectory in the vertical direction. The thickness of the pay zone of the Marcellus shale is around 90 feet, starting from $7460 \mathrm{ft}$. to $7555 \mathrm{ft}$.

4. Production Data: The production data for 1473 days (12/2011 to 12/2015) were available.

Table 3.1: Treatment Design Parameters for the First Fracture Stage.

\begin{tabular}{|c|c|c|c|c|c|c|}
\hline stage No & $\begin{array}{l}\text { Slurry } \\
\text { Rate } \\
\text { (bpm) }\end{array}$ & $\begin{array}{l}\text { Stage } \\
\text { Liquid } \\
\text { Volume } \\
\text { (U.S.gal) }\end{array}$ & Stage Type & Fuild Type & Prop Type & $\begin{array}{r}\text { Prop Conc. } \\
\text { (lbm/gal) }\end{array}$ \\
\hline 1 & 10 & 4200 & Brk/Rate & Slickwater & & \\
\hline 2 & 10 & 1500 & Acid & $15 \% \mathrm{HCl}$ & & \\
\hline 3 & 80 & 75000 & Pad & Slickwater & & \\
\hline 4 & 80 & 16666 & Prop & Slickwater & $100 \%$ Sand, White, $100 \mathrm{~m}$ & 0.25 \\
\hline 5 & 80 & 16666 & Prop & Slickwater & 100\%Sand, White, $100 \mathrm{~m}$ & 0.5 \\
\hline 6 & 80 & 16666 & Prop & Slickwater & 100\%Sand, White, $100 \mathrm{~m}$ & 0.75 \\
\hline 7 & 80 & 16666 & Prop & Slickwater & $100 \%$ Sand, White, $100 \mathrm{~m}$ & 1 \\
\hline 8 & 80 & 16666 & Prop & Slickwater & $100 \%$ Sand, White, $100 \mathrm{~m}$ & 1.5 \\
\hline 9 & 80 & 16670 & Prop & Slickwater & $100 \%$ Sand, White, $100 \mathrm{~m}$ & 2 \\
\hline 10 & 80 & 26662 & Prop & Slickwater & 100\%Sand, White, 40/70 & 0.5 \\
\hline 11 & 80 & 26662 & Prop & Slickwater & 100\%Sand, White, 40/70 & 0.75 \\
\hline 12 & 80 & 26662 & Prop & Slickwater & 100\%Sand, White, 40/70 & 1 \\
\hline 13 & 80 & 26662 & Prop & Slickwater & $100 \%$ Sand, White, $40 / 70$ & 1.5 \\
\hline 14 & 80 & 26662 & Prop & Slickwater & 100\%Sand, White, 40/70 & 2 \\
\hline 15 & 80 & 26662 & Prop & Slickwater & 100\%Sand, White, 40/70 & 2.5 \\
\hline 16 & 80 & 26683 & Prop & Linear 2000 & $100 \%$ Sand, White, $40 / 70$ & 3 \\
\hline 17 & 80 & 10584 & Prop & Linear 2000 & Flush & \\
\hline
\end{tabular}




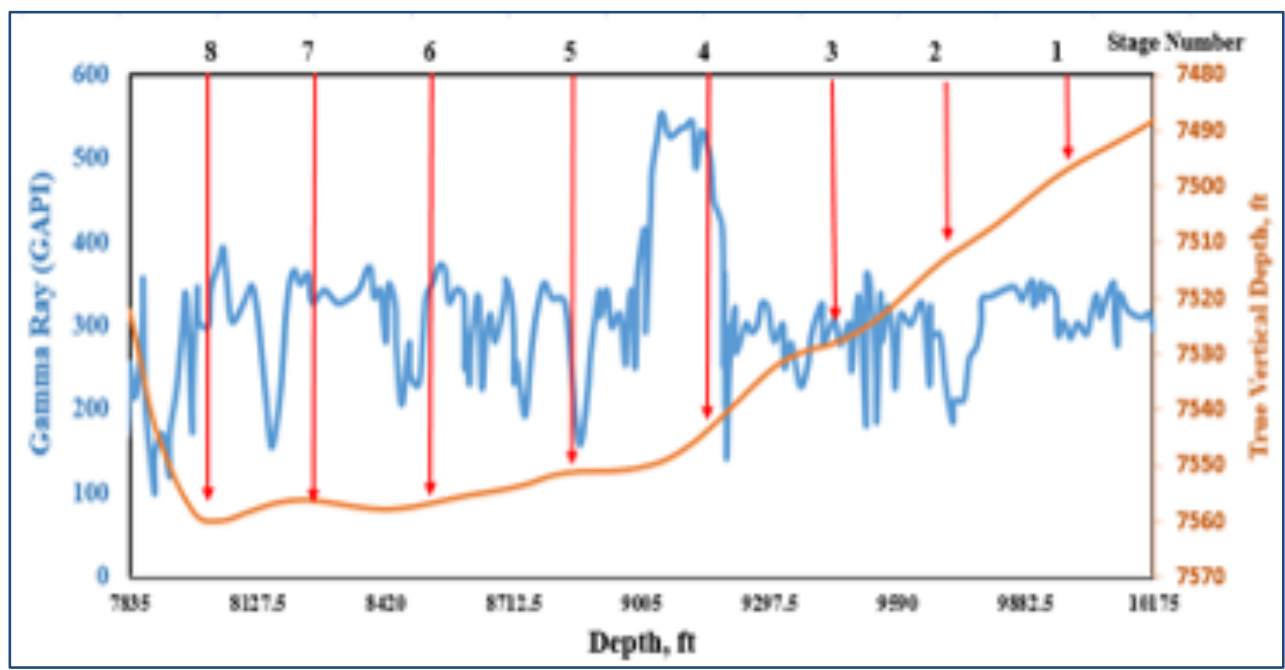

Figure 3.2: Well Trajectory with a Variation of Gamma-Ray along with the Horizontal Section of Well MIP-6H.

\subsubsection{Data Collected from Well MIP-3H}

The following data were available and were collected for the study:

1. A comprehensive suite of logs including Gamma-Ray, Resistivity, Density, Neutron, and Acoustic logs from the vertical section of the well is illustrated in Figure 3.3

2. Scanner logs from the lateral section.

3. Formation Micro Imager (FMI) log from the vertical section.

4. Quanta Geo borehole image log from the lateral section.

5. Diagnostic fracture injection test (DFIT).

6. Fracture Treatment Data: The well was stimulated with 28 fracture stages in 5 sections over a lateral length of 5800 feet. Tables 3.2 through 3.4 show the typical fracture treatment parameters.

7. Microseismic data, recorded during the treatment of Well MIP-3h at the well MIP-SW, as shown in Figure 3.4.

8. Production logging test results as illustrated in Figure 3.5.

9. TOC Measurements: There were a total of 47 samples taken from roughly every $3 \mathrm{ft}(1 \mathrm{~m})$ for TOC measurements with 5 repeat samples to confirm accuracy. Furthermore, total organic carbon (TOC) was determined from the MIP3H core using the source rock analyzer (SRA) as provided in Table 3.5.

10. The production data for $(12 / 2015$ to $12 / 2019)$ were available. 


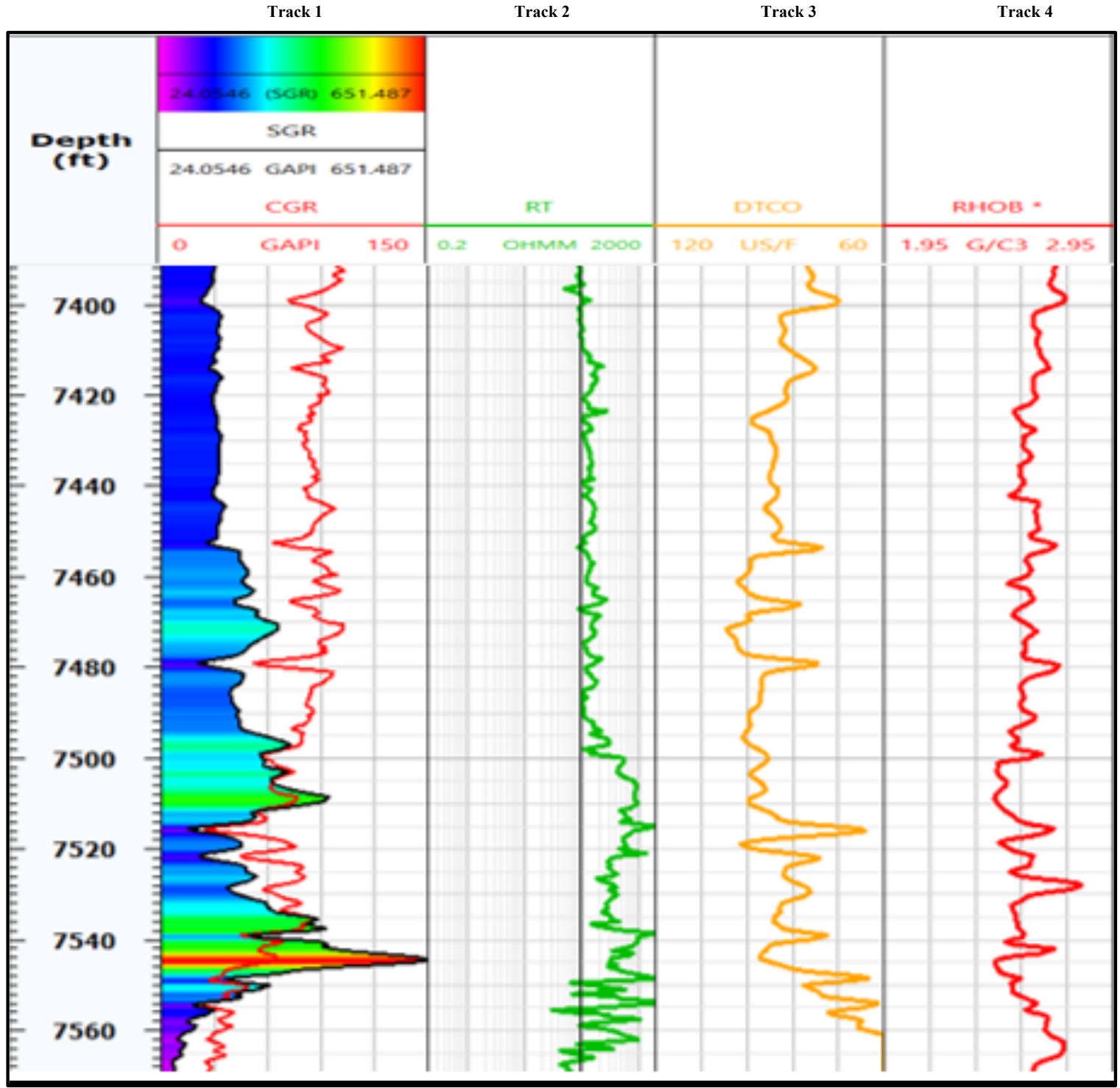

Figure 3.3: Comprehensive Suite of Logs from the Vertical Section of the Well MIP-3H Track 1Gamma Ray; Track 2- Deep Resistivity; Track 3- DTCO (Compressional Sonic), and Track 4- Bulk Density. 
Table 3.2: Hydraulic Fracture Parameters for Well MIP-3H.

\begin{tabular}{|c|c|c|c|c|c|c|}
\hline \multicolumn{2}{|c|}{ Sections } & Stages & Pump & $\begin{array}{c}\text { Clusters } \\
\text { per }\end{array}$ & Total & $\begin{array}{c}\text { Shot } \\
\text { Density }\end{array}$ \\
\hline \multirow{6}{*}{$\mathbf{A}$} & \multirow{6}{*}{ 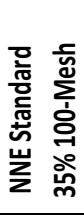 } & 1 & A & 5 & 50 & 10 \\
\hline & & 2 & A & 5 & 50 & 10 \\
\hline & & 3 & $\mathrm{~A}$ & 5 & 50 & 10 \\
\hline & & 4 & A & 5 & 50 & 10 \\
\hline & & 5 & A & 5 & 50 & 10 \\
\hline & & 6 & A & 5 & 50 & 10 \\
\hline \multirow{6}{*}{ B } & \multirow{6}{*}{ 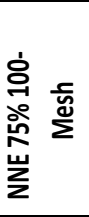 } & 7 & $\mathrm{~B}$ & 5 & 50 & 10 \\
\hline & & 8 & $\mathrm{~B}$ & 5 & 50 & 10 \\
\hline & & 9 & $\mathrm{~B}$ & 5 & 50 & 10 \\
\hline & & 10 & $\mathrm{~B}$ & 5 & 50 & 10 \\
\hline & & 11 & $\mathrm{~B}$ & 5 & 50 & 10 \\
\hline & & 12 & B & 5 & 50 & 10 \\
\hline \multirow{7}{*}{ C } & \multirow{7}{*}{ 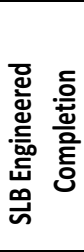 } & 13 & A & 5 & 30 & 6 \\
\hline & & 14 & A & 5 & 30 & 6 \\
\hline & & 15 & $\mathrm{C}$ & 4 & 24 & 6 \\
\hline & & 16 & $\mathrm{C}$ & 4 & 24 & 6 \\
\hline & & 17 & C & 4 & 32 & 8 \\
\hline & & 18 & C & 4 & 32 & 8 \\
\hline & & 19 & $\mathrm{C}$ & 4 & 24 & 6 \\
\hline \multirow{2}{*}{ D } & \multirow{2}{*}{ 产 } & 20 & $\mathrm{D}$ & 5 & 40 & 8 \\
\hline & & 21 & D & 4 & 32 & 8 \\
\hline \multirow{7}{*}{$\mathbf{E}$} & \multirow{7}{*}{ 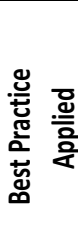 } & 22 & $\mathrm{C}$ & 4 & 40 & 10 \\
\hline & & 23 & $\mathrm{C}$ & 4 & 40 & 10 \\
\hline & & 24 & A & 5 & 40 & 8 \\
\hline & & 25 & A & 5 & 40 & 8 \\
\hline & & 26 & A & 5 & 40 & 8 \\
\hline & & 27 & $\mathrm{~A}$ & 5 & 40 & 8 \\
\hline & & 28 & A & 5 & 40 & 8 \\
\hline
\end{tabular}

Table 3.3: Typical Pump Schedule A and B.

\begin{tabular}{|c|c|c|c|c|c|c|c|c|}
\hline \multicolumn{7}{|c|}{ MIP 3H Schedule A, 440,000 Lbs (35\% 100 Mesh) } \\
\hline Stage & $\begin{array}{c}\text { Stage } \\
\text { PPA }\end{array}$ & $\begin{array}{c}\text { Proppant } \\
\text { Type }\end{array}$ & Fluid Type & $\begin{array}{c}\text { Clean } \\
\text { Fluid } \\
\text { (gal) }\end{array}$ & $\begin{array}{c}\text { Clean } \\
\text { Fluid } \\
(\text { Bbls) }\end{array}$ & $\begin{array}{c}\text { Slurry } \\
\text { Rate } \\
(B P M)\end{array}$ & $\begin{array}{c}\text { Proppant } \\
\text { Mass } \\
\text { (lbs) }\end{array}$ & $\begin{array}{c}\text { Cum. } \\
\text { Proppant } \\
\text { (lbs) }\end{array}$ \\
\hline 1 & Rate & & SlickWater & 840 & 20 & 15 & & \\
\hline 2 & Acid 15\% & & Acid 15\%HCL & 3,000 & 71 & 15 & 0 & \\
\hline 3 & Pad & & SlickWater & 42,000 & 1,000 & 90 & 0 & \\
\hline 4 & 0.25 & 100 & SlickWater & 13,200 & 314 & 90 & 3,300 & 3,300 \\
\hline 5 & 0.50 & 100 & SlickWater & 14,000 & 333 & 90 & 7,000 & 10,300 \\
\hline 6 & 0.75 & 100 & SlickWater & 18,533 & 441 & 90 & 13,900 & 24,200 \\
\hline 7 & 1.00 & 100 & SlickWater & 23,100 & 550 & 90 & 23,100 & 47,300 \\
\hline 8 & 1.50 & 100 & SlickWater & 35,267 & 840 & 90 & 52,900 & 100,200 \\
\hline 9 & 2.00 & 100 & SlickWater & 27,500 & 655 & 90 & 55,000 & 155,200 \\
\hline 10 & 0.50 & $40 / 70$ & SlickWater & 24,000 & 571 & 90 & 12,000 & 167,200 \\
\hline 11 & 0.75 & $40 / 70$ & SlickWater & 18,533 & 441 & 90 & 13,900 & 181,100 \\
\hline 12 & 1.00 & $40 / 70$ & SlickWater & 18,500 & 440 & 90 & 18,500 & 199,600 \\
\hline 13 & 1.50 & $40 / 70$ & SlickWater & 32,400 & 771 & 90 & 48,600 & 248,200 \\
\hline 14 & 2.00 & $40 / 70$ & SlickWater & 46,200 & 1,100 & 90 & 92,400 & 340,600 \\
\hline 15 & 2.50 & $40 / 70$ & SlickWater & 23,120 & 550 & 90 & 57,800 & 398,400 \\
\hline 16 & 3.00 & $40 / 70$ & SlickWater & 13,867 & 330 & 90 & 41,600 & 440,000 \\
\hline 17 & & Flush & SlickWater & 12,000 & 286 & 90 & 0 & \\
\hline & & Tota/s & & 354,060 & 8,430 & - & 440,000 & - \\
\hline
\end{tabular}

\begin{tabular}{|c|c|c|c|c|c|c|c|c|}
\hline \multicolumn{7}{|c|}{ NNE, MIP 3H Schedule B, 440,000 Lbs (75\% 100 Mesh) } \\
\hline Stage & $\begin{array}{c}\text { Stage } \\
\text { PPA }\end{array}$ & $\begin{array}{c}\text { Proppa } \\
\text { nt Type }\end{array}$ & Fluid Type & $\begin{array}{c}\text { Clean } \\
\text { Fluid } \\
\text { (gal) }\end{array}$ & $\begin{array}{c}\text { Clean } \\
\text { Fluid } \\
\text { (Bbls) }\end{array}$ & $\begin{array}{c}\text { Slurry } \\
\text { Rate } \\
\text { (BPM) }\end{array}$ & $\begin{array}{c}\text { Proppant } \\
\text { Mass } \\
\text { (lbs) }\end{array}$ & $\begin{array}{c}\text { Cum. } \\
\text { Proppant } \\
\text { (lbs) }\end{array}$ \\
\hline 1 & Rate & & SlickWater & 840 & 20 & 30 & & \\
\hline 2 & Acid 15\% & & Acid 15\%HCL & 3,000 & 71 & 15 & 0 & \\
\hline 3 & Pad & & SlickWater & 25,000 & 595 & 90 & 0 & \\
\hline 4 & 0.25 & 100 & SlickWater & 22,000 & 524 & 90 & 5,500 & 5,500 \\
\hline 5 & 0.50 & 100 & SlickWater & 33,000 & 786 & 90 & 16,500 & 22,000 \\
\hline 6 & 0.75 & 100 & SlickWater & 36,667 & 873 & 90 & 27,500 & 49,500 \\
\hline 7 & 1.00 & 100 & SlickWater & 46,200 & 1,100 & 90 & 46,200 & 95,700 \\
\hline 8 & 1.50 & 100 & SlickWater & 40,333 & 960 & 90 & 60,500 & 156,200 \\
\hline 9 & 2.00 & 100 & SlickWater & 41,250 & 982 & 90 & 82,500 & 238,700 \\
\hline 10 & 2.50 & 100 & SlickWater & 36,520 & 870 & 90 & 91,300 & 330,000 \\
\hline 11 & 1.50 & $40 / 70$ & SlickWater & 7,333 & 175 & 90 & 11,000 & 341,000 \\
\hline 12 & 2.00 & $40 / 70$ & SlickWater & 11,000 & 262 & 90 & 22,000 & 363,000 \\
\hline 13 & 2.50 & $40 / 70$ & SlickWater & 17,600 & 419 & 90 & 44,000 & 407,000 \\
\hline 14 & 3.00 & $40 / 70$ & SlickWater & 11,000 & 262 & 90 & 33,000 & 440,000 \\
\hline 15 & & Flush & SlickWater & 12,000 & 286 & 90 & 0 & 440,000 \\
\hline & & Totals & & 343,743 & 8,184 & - & 440,000 & - \\
\hline
\end{tabular}


Table 3.4: Typical Pump Schedule C and D.

\begin{tabular}{|c|c|c|c|c|c|c|c|c|}
\hline \multicolumn{7}{|c|}{ NNE, MIP 3H Schedule C, 360,000 Lb (35\% 100 Mesh) } \\
\hline Stage & $\begin{array}{c}\text { Stage } \\
\text { PPA }\end{array}$ & $\begin{array}{c}\text { Proppant } \\
\text { Type }\end{array}$ & Fluid Type & $\begin{array}{c}\text { Clean } \\
\text { Fluid } \\
\text { (gal) }\end{array}$ & $\begin{array}{c}\text { Clean } \\
\text { Fluid } \\
\text { (Bbls) }\end{array}$ & $\begin{array}{c}\text { Slurry } \\
\text { Rate } \\
\text { (BPM) }\end{array}$ & $\begin{array}{c}\text { Proppant } \\
\text { Mass } \\
\text { (lbs) }\end{array}$ & $\begin{array}{c}\text { Cum. } \\
\text { Proppant } \\
\text { (lbs) }\end{array}$ \\
\hline 1 & Rate & & SlickWater & 840 & 20 & 15 & & \\
\hline 2 & Acid 15\% & & Acid 15\%HCL & 3000 & 47.61905 & 15 & 0 & \\
\hline 3 & Pad & & SlickWater & 42000 & 1000 & 72 & 0 & \\
\hline 4 & 0.25 & 100 & SlickWater & 12000 & 285.7143 & 72 & 3000 & 3000 \\
\hline 5 & 0.5 & 100 & SlickWater & 12000 & 285.7143 & 72 & 6000 & 9000 \\
\hline 6 & 0.75 & 100 & SlickWater & 15200 & 361.9048 & 72 & 11400 & 20400 \\
\hline 7 & 1 & 100 & SlickWater & 18900 & 450 & 72 & 18900 & 39300 \\
\hline 8 & 1.5 & 100 & SlickWater & 28866.67 & 687.3016 & 72 & 43300 & 82600 \\
\hline 9 & 2 & 100 & SlickWater & 22500 & 535.7143 & 72 & 45000 & 127600 \\
\hline 10 & 0.5 & $40 / 70$ & SlickWater & 18800 & 447.619 & 72 & 9400 & 137000 \\
\hline 11 & 0.75 & $40 / 70$ & SlickWater & 15066.67 & 358.7302 & 72 & 11300 & 148300 \\
\hline 12 & 1 & 40170 & SlickWater & 15100 & 359.5238 & 72 & 15100 & 163400 \\
\hline 13 & 1.5 & 40170 & SlickWater & 26466.67 & 630.1587 & 72 & 39700 & 203100 \\
\hline 14 & 2 & $40 / 70$ & SlickWater & 37800 & 900 & 72 & 75600 & 278700 \\
\hline 15 & 2.5 & $40 / 70$ & SlickWater & 18900 & 450 & 72 & 47250 & 325950 \\
\hline 16 & 3 & $40 / 70$ & SlickWater & 11350 & 270.2381 & 72 & 34050 & 360000 \\
\hline 17 & & Flush & SlickWater & 12000 & 285.7143 & 72 & 0 & \\
\hline & & Totals & & 298,790 & 7,090 & - & 360,000 & - \\
\hline
\end{tabular}

\begin{tabular}{|c|c|c|c|c|c|c|c|c|}
\hline \multicolumn{7}{|c|}{ NNE, MIP 3H Schedule D, 440,000 Lbs SLB VEF } \\
\hline Stage & $\begin{array}{c}\text { Stage } \\
\text { PPA }\end{array}$ & $\begin{array}{c}\text { Proppa } \\
\text { nt Type }\end{array}$ & Fluid Type & $\begin{array}{c}\text { Clean } \\
\text { Fluid } \\
\text { (gal) }\end{array}$ & $\begin{array}{c}\text { Clean } \\
\text { Fluid } \\
\text { (Bbls) }\end{array}$ & $\begin{array}{c}\text { Slurry } \\
\text { Rate } \\
\text { (BPM) }\end{array}$ & $\begin{array}{c}\text { Proppant } \\
\text { Mass } \\
\text { (lbs) }\end{array}$ & $\begin{array}{c}\text { Cum. } \\
\text { Proppant } \\
\text { (lbs) }\end{array}$ \\
\hline 1 & Rate & & SlickWater & 840 & 20.00 & 15 & & \\
\hline 2 & Acid 15\% & & Acid 15\% HCL & 3000 & 47.62 & 15 & 0 & \\
\hline 3 & Pad & & SlickWater & 40000 & 952.38 & 90 & 0 & \\
\hline 4 & 0.25 & 100 & SlickWater & 8800 & 209.52 & 90 & 2200.00 & 2200 \\
\hline 5 & 0.50 & 100 & SlickWater & 11000 & 261.90 & 90 & 5500.00 & 7700 \\
\hline 6 & 0.75 & 100 & SlickWater & 11733.33 & 279.37 & 90 & 8800.00 & 16500 \\
\hline 7 & 1.00 & 100 & VF105 & 16500 & 392.86 & 90 & 16500.00 & 33000 \\
\hline 8 & 2.00 & 100 & VF105 & 22000 & 523.81 & 90 & 44000.00 & 77000 \\
\hline 9 & 3.00 & 100 & VF105 & 25666.67 & 611.11 & 90 & 77000.00 & 154000 \\
\hline 10 & 1.00 & 40170 & VF105 & 22000 & 523.81 & 90 & 22000.00 & 176000 \\
\hline 11 & 2.00 & $40 / 70$ & VF105 & 19800 & 471.43 & 90 & 39600.00 & 215600 \\
\hline 12 & 3.00 & $40 / 70$ & VF105 & 33733.33 & 803.17 & 90 & 101200.00 & 316800 \\
\hline 13 & 4.00 & $40 / 70$ & VF105 & 19800 & 471.43 & 90 & 79200.00 & 396000 \\
\hline 14 & 5.00 & 40170 & VF105 & 8800 & 209.52 & 90 & 44000.00 & 440000 \\
\hline 15 & & Flush & & 12000 & 285.71 & 90 & 0 & 440000 \\
\hline & & Totals & & 255,673 & 6,064 & - & 440,000 & - \\
\hline
\end{tabular}

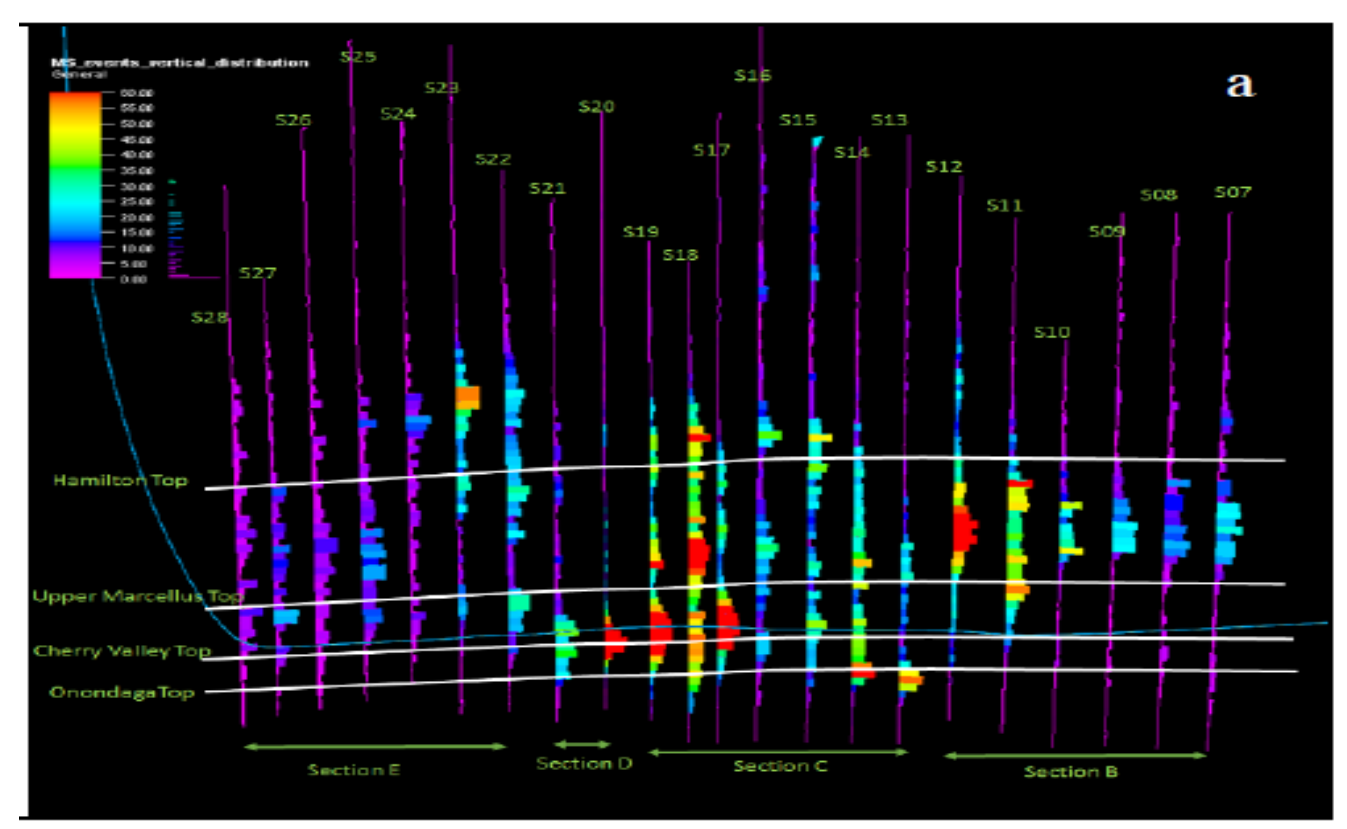

Figure 3.4: The Vertical Distribution of Microseismic Events (Carr et al., 2019). 
Table 3.5: Pyrolysis Data from Source Rock Analyzer, Core depth of 7445 to 7557'

\begin{tabular}{|c|c|c|}
\hline \multirow{2}{*}{ ID } & Depth & TOC \\
\cline { 2 - 3 } & ft & \% \\
\hline MIP 3H-01 & 7445 & 3.04 \\
\hline MIP 3H-02 & 7448 & 3.07 \\
\hline MIP 3H-03 & 7451 & 2.27 \\
\hline MIP 3H-04 & 7454 & 3.01 \\
\hline MIP 3H-05 & 7457 & 3.34 \\
\hline MIP 3H-06 & 7460 & 3.62 \\
\hline MIP 3H-07 & 7462 & 3.22 \\
\hline MIP 3H-08 & 7464 & 3.66 \\
\hline MIP 3H-09 & 7467 & 3.19 \\
\hline MIP 3H-10 & 7470 & 4.45 \\
\hline MIP 3H-11 & 7473 & 4.54 \\
\hline MIP 3H-12 & 7476 & 5.16 \\
\hline MIP 3H-13 & 7479 & 3.73 \\
\hline MIP 3H-14 & 7482 & 2.6 \\
\hline MIP 3H-15 & 7485 & 3.26 \\
\hline MIP 3H-16 & 7488 & 3.6 \\
\hline MIP 3H-16 & 7488 & 3.19 \\
\hline MIP 3H-17 & 7491 & 3.31 \\
\hline MIP 3H-18 & 7493 & 4.01 \\
\hline MIP 3H-19 & 7495 & 4.23 \\
\hline MIP 3H-2O & 7498 & 4.78 \\
\hline MIP 3H-21 & 7501 & 4.3 \\
\hline MIP 3H-22 & 7504 & 5.92 \\
\hline MIP 3H-23 & 7507 & 6.34 \\
\hline MIP 3H-24 & 7510 & 7.21 \\
\hline MIP 3H-25 & 7513 & 7.18 \\
\hline MIP 3H-26 & 7516 & 5.07 \\
\hline MIP 3H-27 & 7519 & 1.8 \\
\hline MIP 3H-28 & 7522 & 7.25 \\
\hline MIP 3H-29 & 7525 & 2.72 \\
\hline MIP 3H-30 & 7527 & 5.55 \\
\hline MIP 3H-31 & 7529 & 4.76 \\
\hline MIP 3H-32 & 7532 & 3.53 \\
\hline MIP 3H-33 & 7535 & 5.87 \\
\hline MIP 3H-34 & 7538 & 6.86 \\
\hline MIP 3H-34 & 7538 & 6.54 \\
\hline MIP 3H-35 & 7541 & 7.7 \\
\hline MIP 3H-36 & 7544 & 9.88 \\
\hline MIP 3H-36 & 7544 & 9.2 \\
\hline MIP 3H-37 & 7547 & 10.9 \\
\hline MIP 3H-37 & 7547 & 10.13 \\
\hline MIP 3H-38 & 7550 & 7 \\
\hline MIP 3H-39 & 7553 & 0.44 \\
\hline MIP 3H-40 & 7555 & 3.17 \\
\hline MIP 3H-4O & 7555 & 2.88 \\
\hline MIP 3H-41 & 7557 & 2.55 \\
\hline MIP 3H-41 & 7557 & 2.37 \\
\hline
\end{tabular}

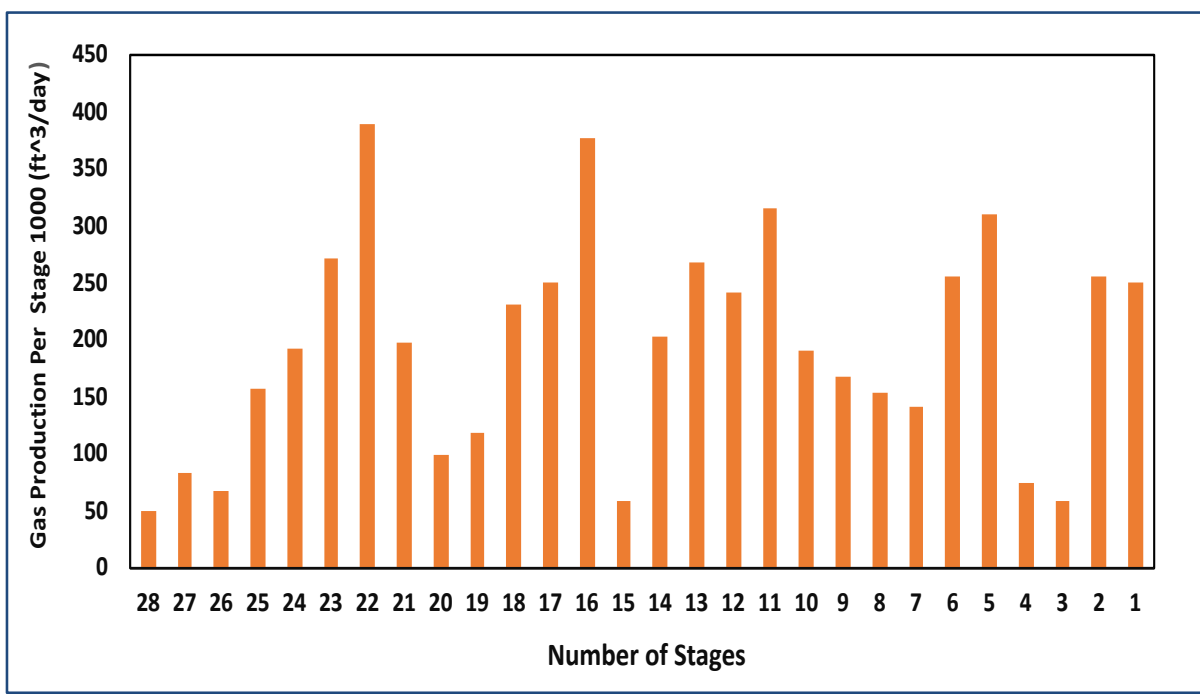

Figure 3.5: Production Logging Tool Results for Well MIP-3H. 


\subsubsection{Data Analysis}

\subsubsection{FMI Log Interpretations}

Rock failure at the borehole wall creates drilling-induced fractures (Aadnoy \& Bell, 1998) and borehole breakouts (Bell \& Gough, 1979). The interpretation of the FMI log from Well MIP-3H, as shown in Figure 3.6 (a), indicates that drilling-induced fractures, which are present below the Marcellus Shale, are oriented $\mathrm{N} 57^{\circ} \mathrm{E}$. Drilling-induced fracture oriented in the same direction as the maximum horizontal stress $\left(\mathrm{S}_{\mathrm{Hmax}}\right)$. Furthermore, the breakouts observed above the Marcellus Shale are oriented N36 W, as can be seen in Figure 3.6 (b), and their direction is the same as the minimum horizontal stress $\left(\mathrm{S}_{\mathrm{hmim}}\right)$ direction. Well MIP-3H was drilled in the direction of the minimum horizontal stress $\left(\mathrm{N} 36^{\circ} \mathrm{W}\right)$. Therefore, the transverse hydraulic fractures are initiated perpendicular to the wellbore, as shown in Figure 3.7.

\subsubsection{Quanta Geo Borehole Image Log Interpretations}

Quanta Geo borehole image log provides the number, type, density, and orientation of the natural fractures. Figure 3.8 shows the type and the number of different fractures which were obtained from Quanta Geo log. The continuous resistive fractures, when an oil-based mud is used, are considered to be the open natural fractures (fissures) in the shale. As can be seen from Figure 3.8, 1609 resistive continuous fractures were identified along the lateral section of the well. Figures 3.9a (Rose diagram) and 3.9b (Schmidt plot) illustrate the orientation, dip, and azimuth of the resistive continuous fractures.

\subsubsection{Sonic Scanner Log Interpretations}

Figure 3.10 illustrates the gamma-ray, Young's modulus, Poisson's Ratio, the number of fractures, and natural fracture density (P10) along the horizontal section of the well. Young's modulus and Poisson's

Ratio were calculated from the sonic scanner log measurements. The number of natural fractures and fracture density (P10) are obtained from Quanta Geo log. 


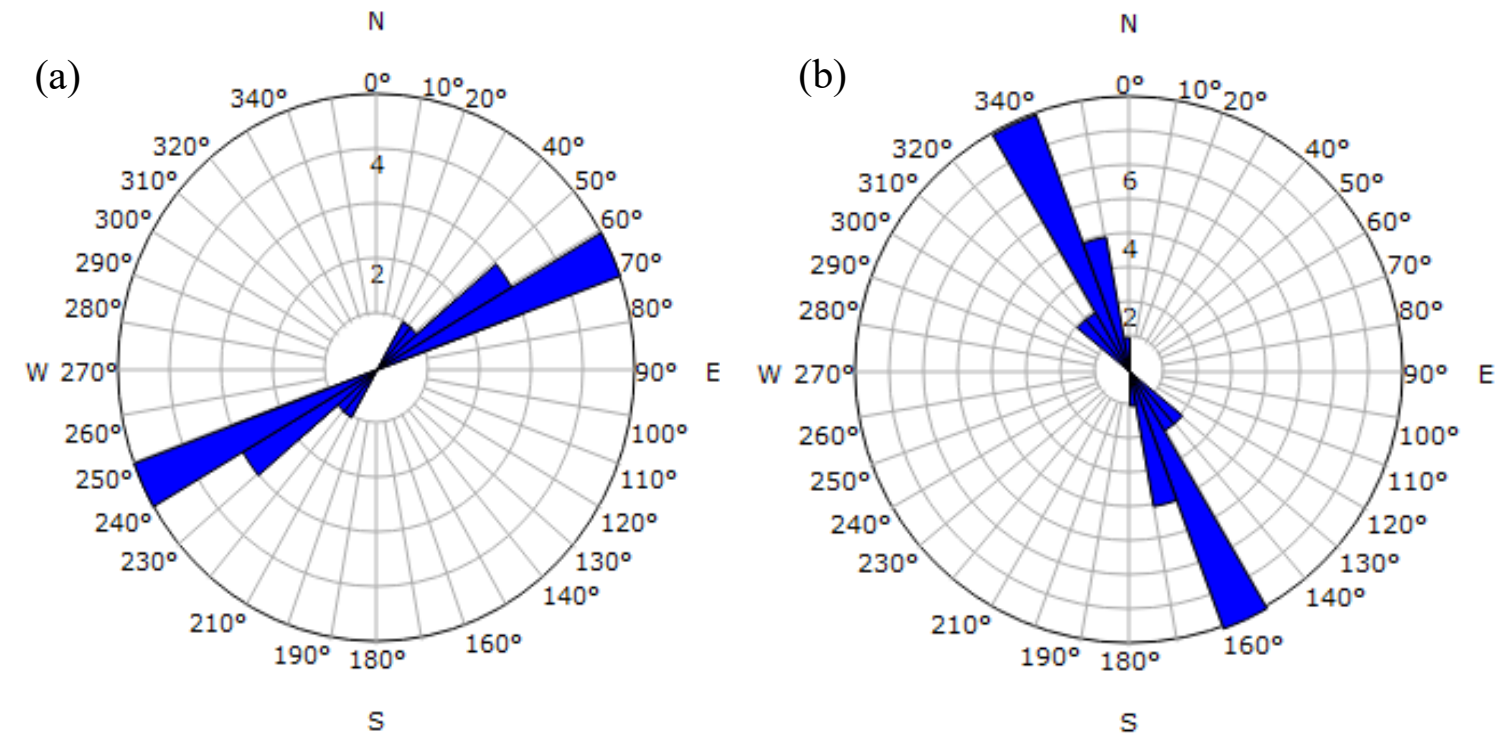

Figure 3.6: (a) Drilling-Induced Fractures Orientation, (b) Breakouts Orientation.

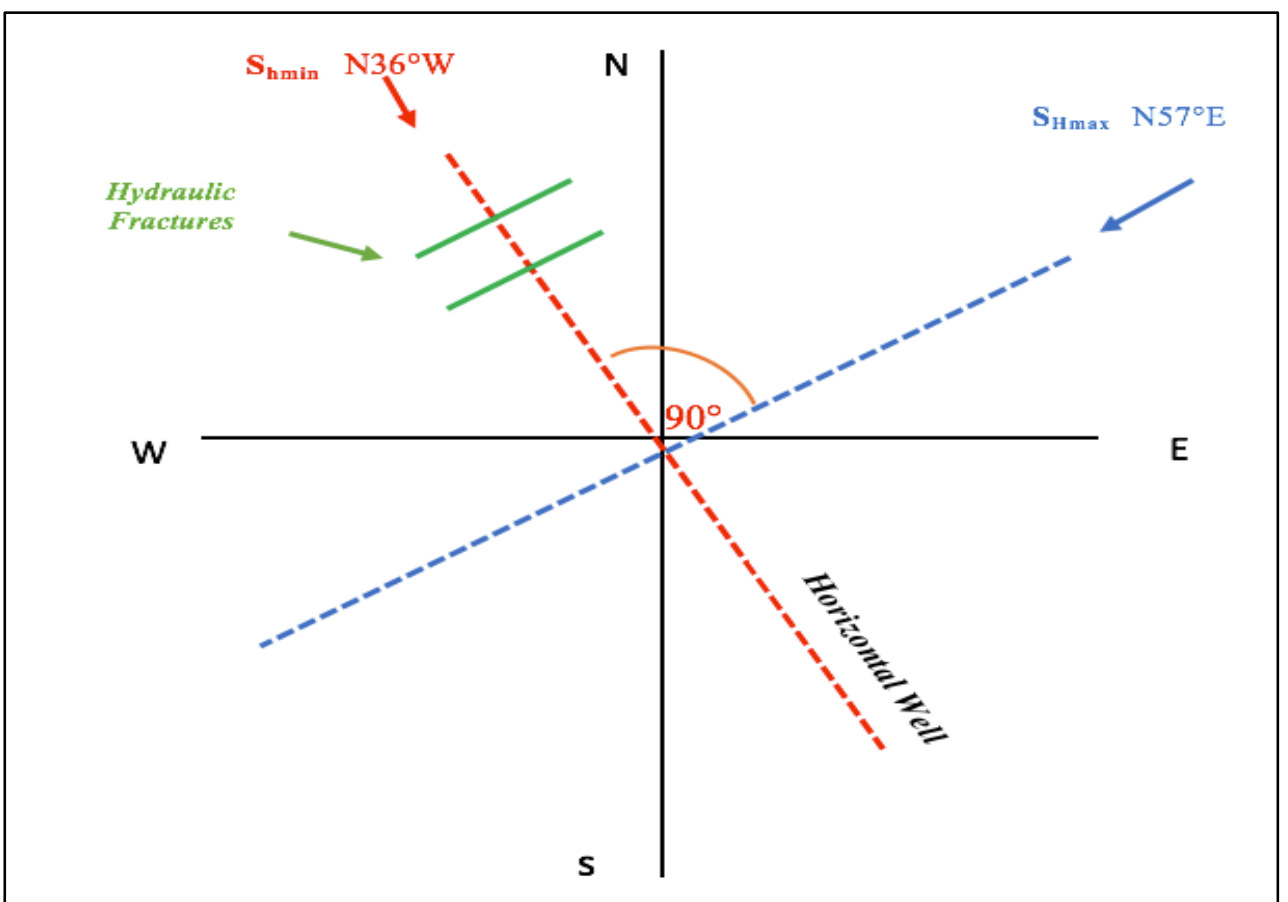

Figure 3.7: Minimum and Maximum Horizontal Stress Orientation for Well MIP-3H. 


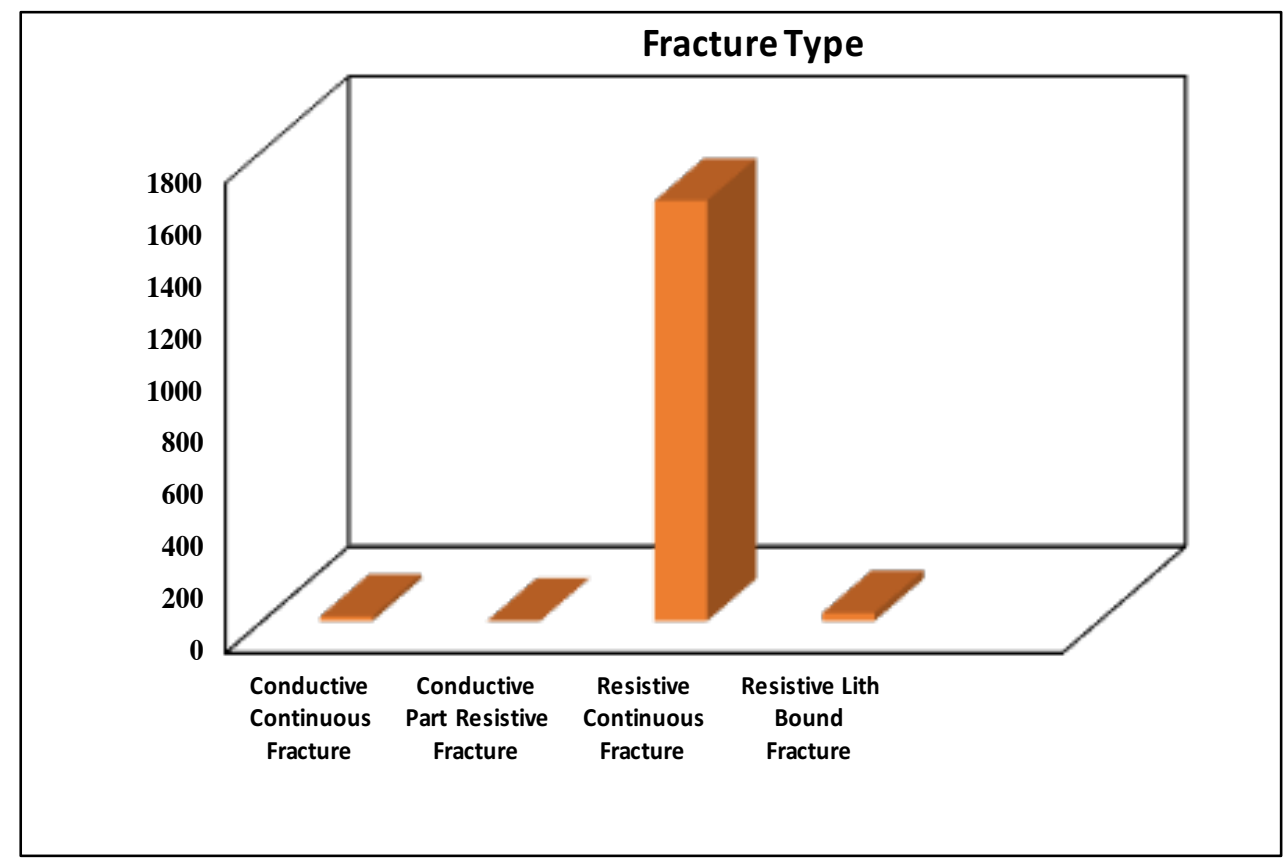

Figure 3.8: Number and Type of Natural Fracture Observed along the MIP-3H Lateral.

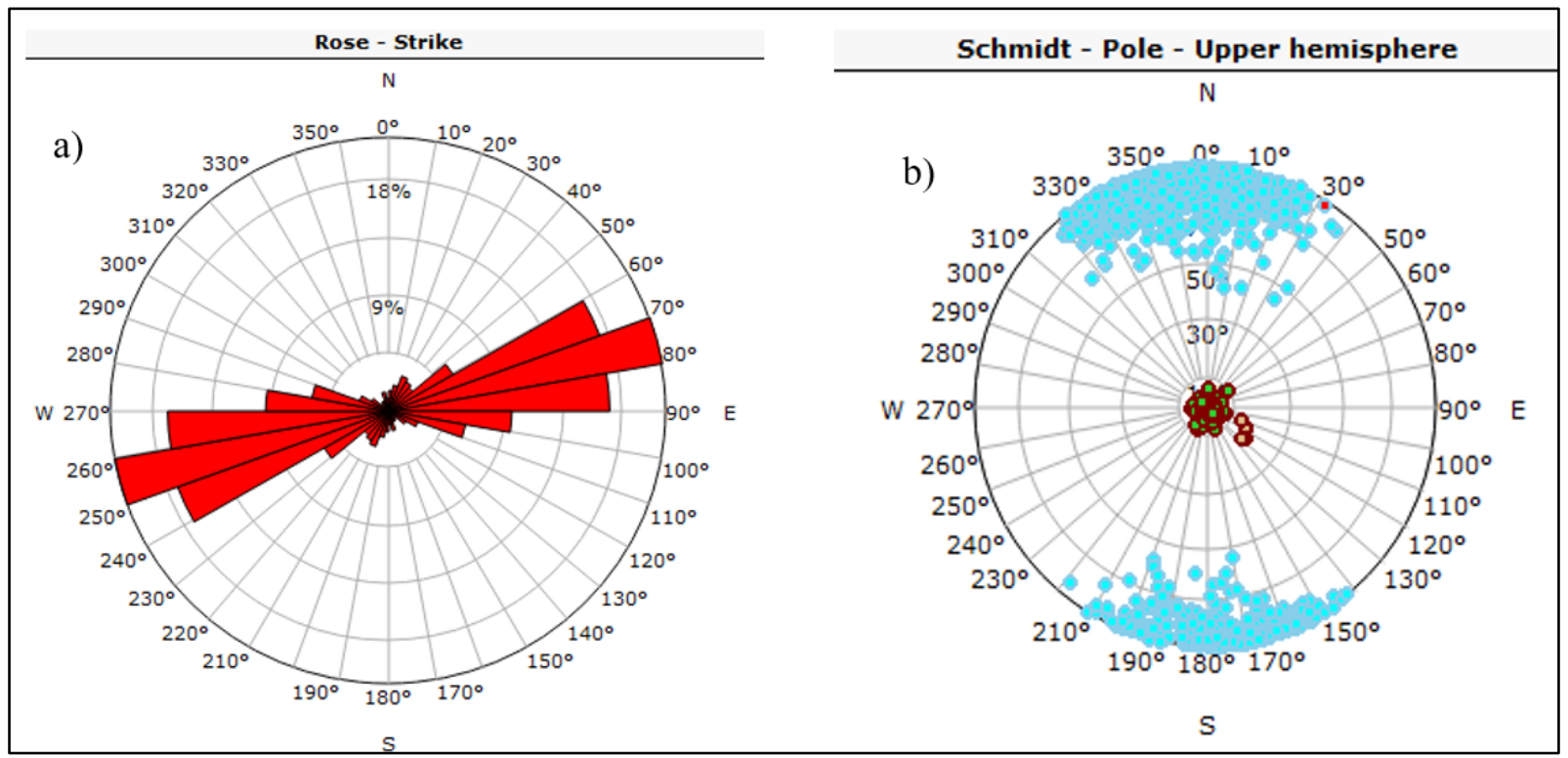

Figure 3.9: (a) Rose Diagram Showing the Orientation (b) Schmidt Upper Hemisphere Projection Showing the Dip of the Resistive Continuous Fracture Observed along the Length of MIP-3H Lateral. 


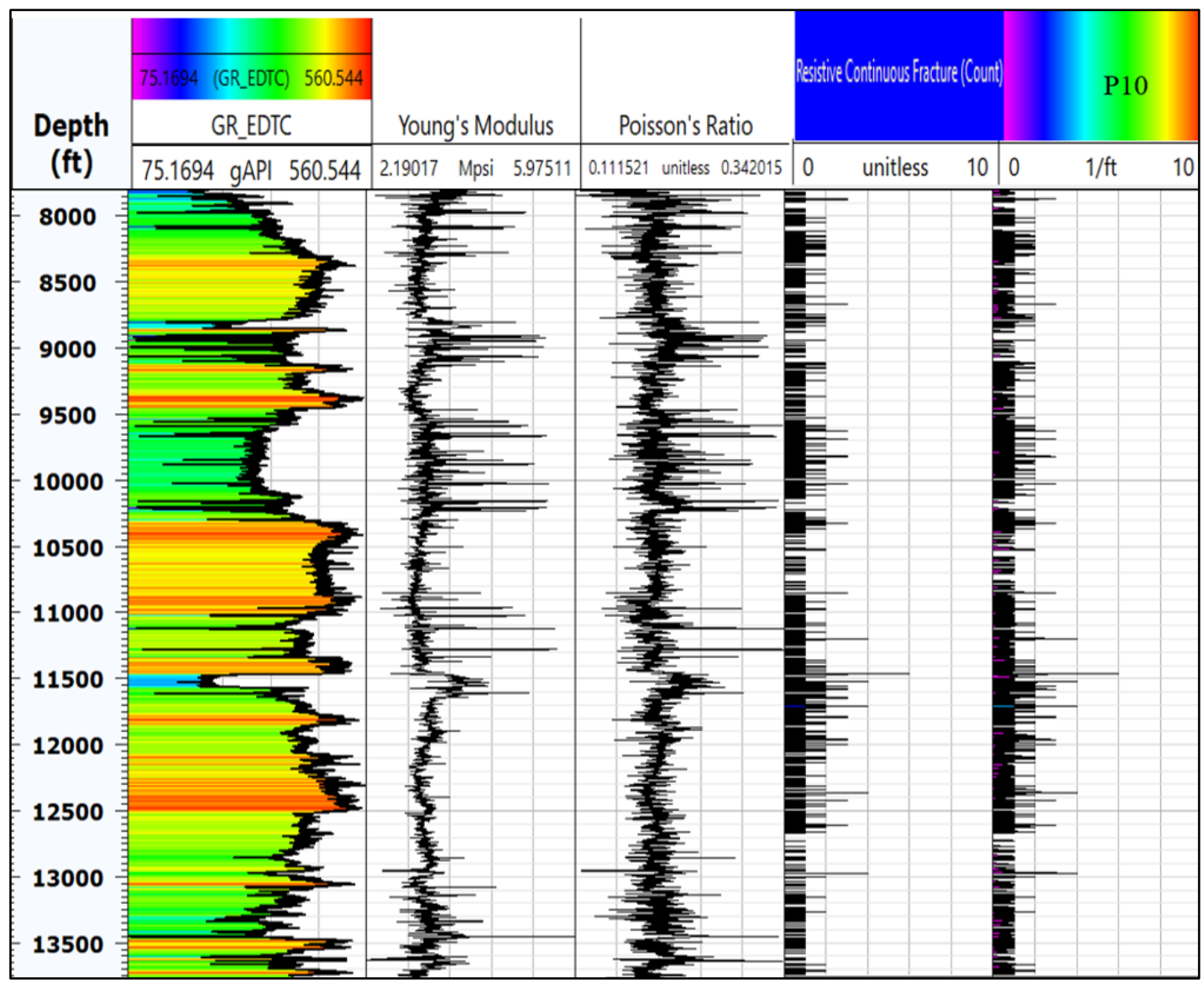

Figure 3.10: Gamma-Ray, Young's Modulus, Poisson's Ratio, Number of Resistive Continuous Fracture (Fissures), and Natural Fracture Density (P10) along the MIP-3H Lateral.

\subsubsection{Microseismic Interpretations}

Microseismic monitoring is considered to be a reliable technology for evaluating the hydraulic fracture growth during the treatment (Maxwell, 2012). It is particularly useful for identification of the outof-zone fracture growth, detection of the fault activation, and evaluation of the fracture orientation (Maxwell, 2012). The orientation of the fracture in well 3- $\mathrm{H}$ appeared to be $\mathrm{N} 59^{\circ} \mathrm{E}$ based on the interpretation of the Microseismic events (Wilson et al. 2018). The Microseismic events, as illustrated in Figure 3.4, indicated that the most fracture stages had significant upward growth and limited downward growth.

\subsubsection{Diagnostic Fracture Injection Test Interpretations}

A diagnostic fracture injection test (DFIT) was conducted in well MIP-3H. The instantaneous shutin pressure (ISIP) was obtained by extrapolating the best fit straight line through the recorded pressure values during the falloff period (after shut-in). The extrapolated value for ISIP is $5188 \mathrm{psi}$ at the surface and $8388 \mathrm{psi}$ at the bottomhole. Figure 3.11 shows the extrapolated line on the pressure curve for the determination of ISIP. Figure 3.12 shows the pressure (blue curve), first derivative (green curve), and G- 
Function or semi-log derivative (red curve). The closure pressure ( $\mathrm{C}$ on the plot) was determined at the deviation point of the semi-log derivative curve from the straight line. The square root plot, illustrated in Figure 3.13, supports the closure stress determined from the G-function plot. It can be observed from Figure 3.12 that the hump in the G-Function lies above the straight line drawn from the origin. Therefore, it can be concluded that fracture is characterized by the pressure-dependent leak-off. This indicates the presence of natural fractures (fissure) intersected by the hydraulic fracture. Additionally, the fissure opening (FO on the plot) is characterized by the return to straight-line, while the closure pressure is identified by the departure from the straight-line. Furthermore, it is clear from Figure 3.12 that the G Function plot (red curve) reaches peak after the fracture closes, which indicates that the fracture closes.

Figure 3.14 is a plot of the leak-off ratio as a function of the bottomhole pressure. The slope of the straight line is the pressure-dependent leak-off (PDL) coefficient. Furthermore, process zone stress (PZS), which is the difference between the instantaneous shut-in pressure (ISIP) and closure pressure (PC), was determined from DFIT analysis. PZS impacts the fracture width and height. The higher the process zone stress (PZS) is, the higher the fracture width. Table 3.6 summarizes the parameters, which were obtained from the DFIT analysis.

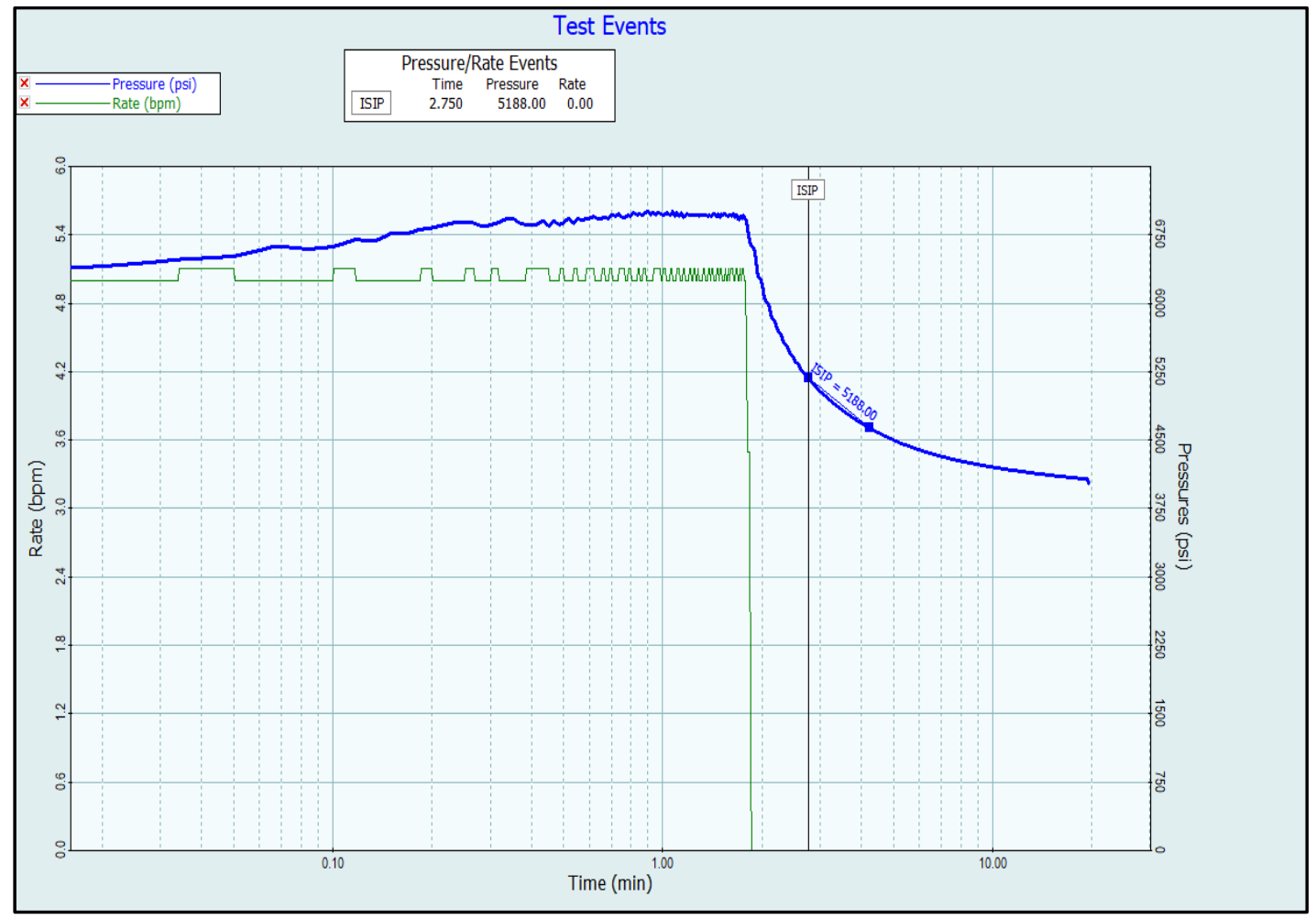

Figure 3.11: Illustrates ISIP for DFIT. 


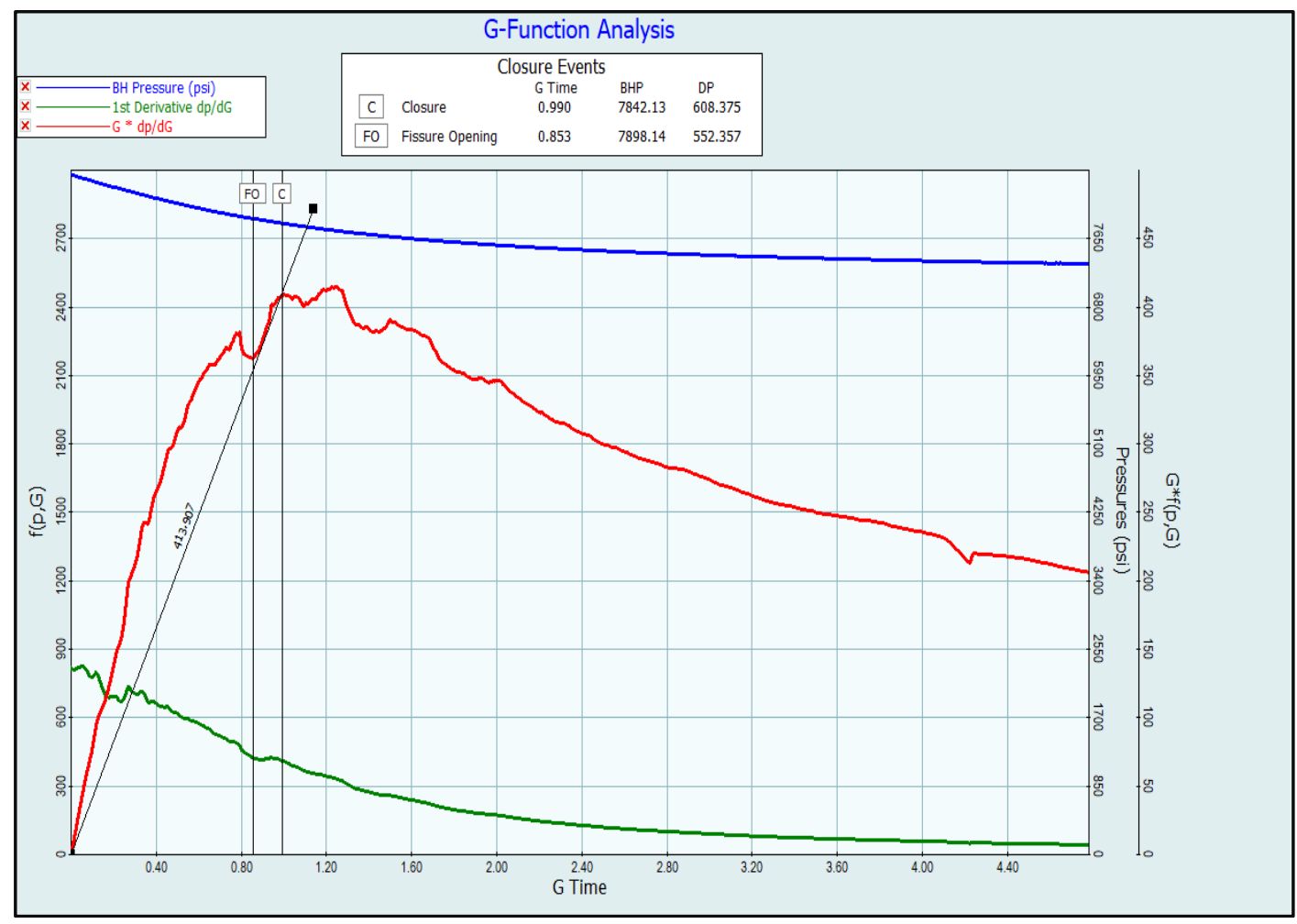

Figure 3.12: G-Function Plot Illustrating the Fissure Opening (FO) and Closure (C) for DFIT.

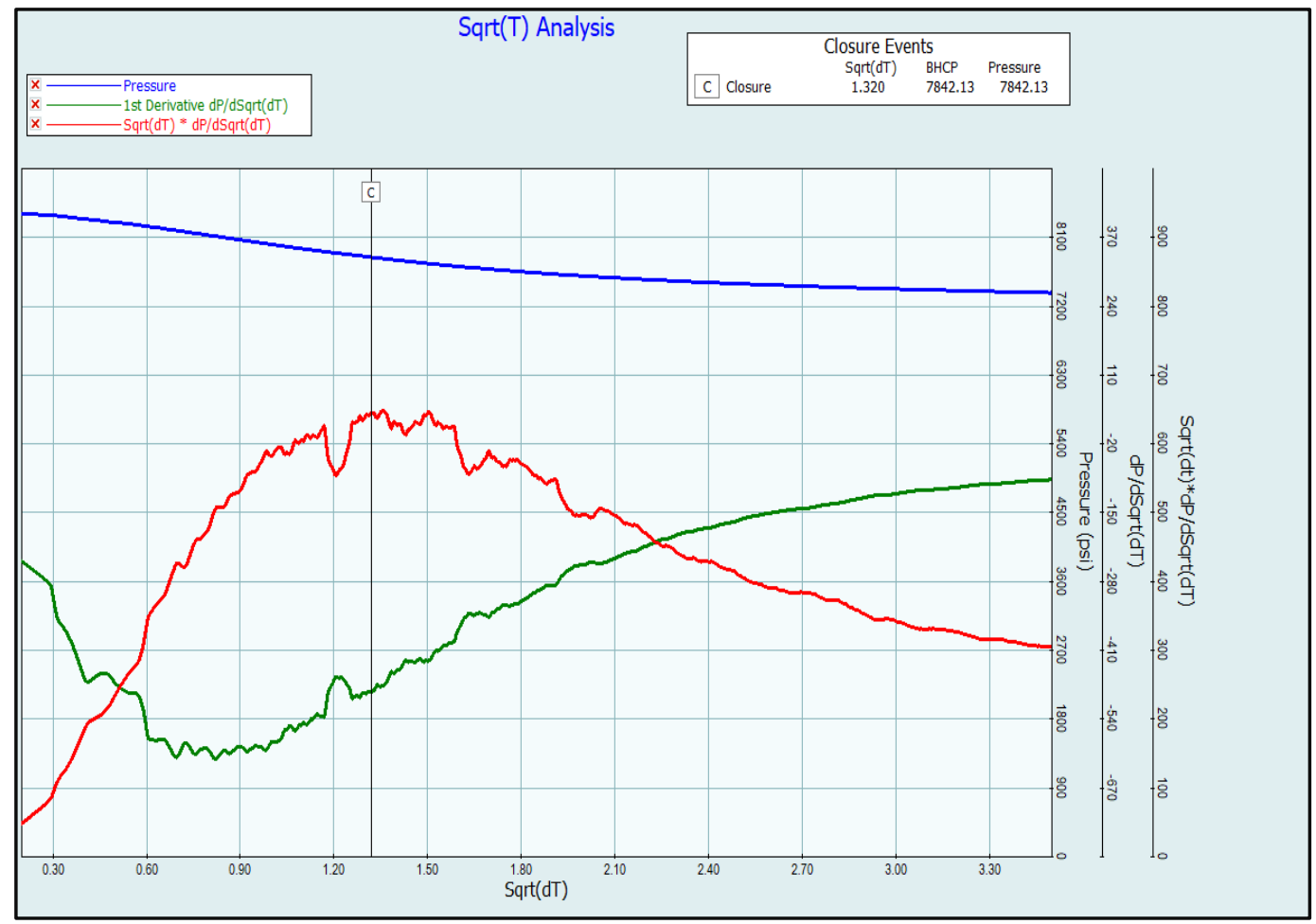

Figure 3.13: Square Root Plot for DFIT. 


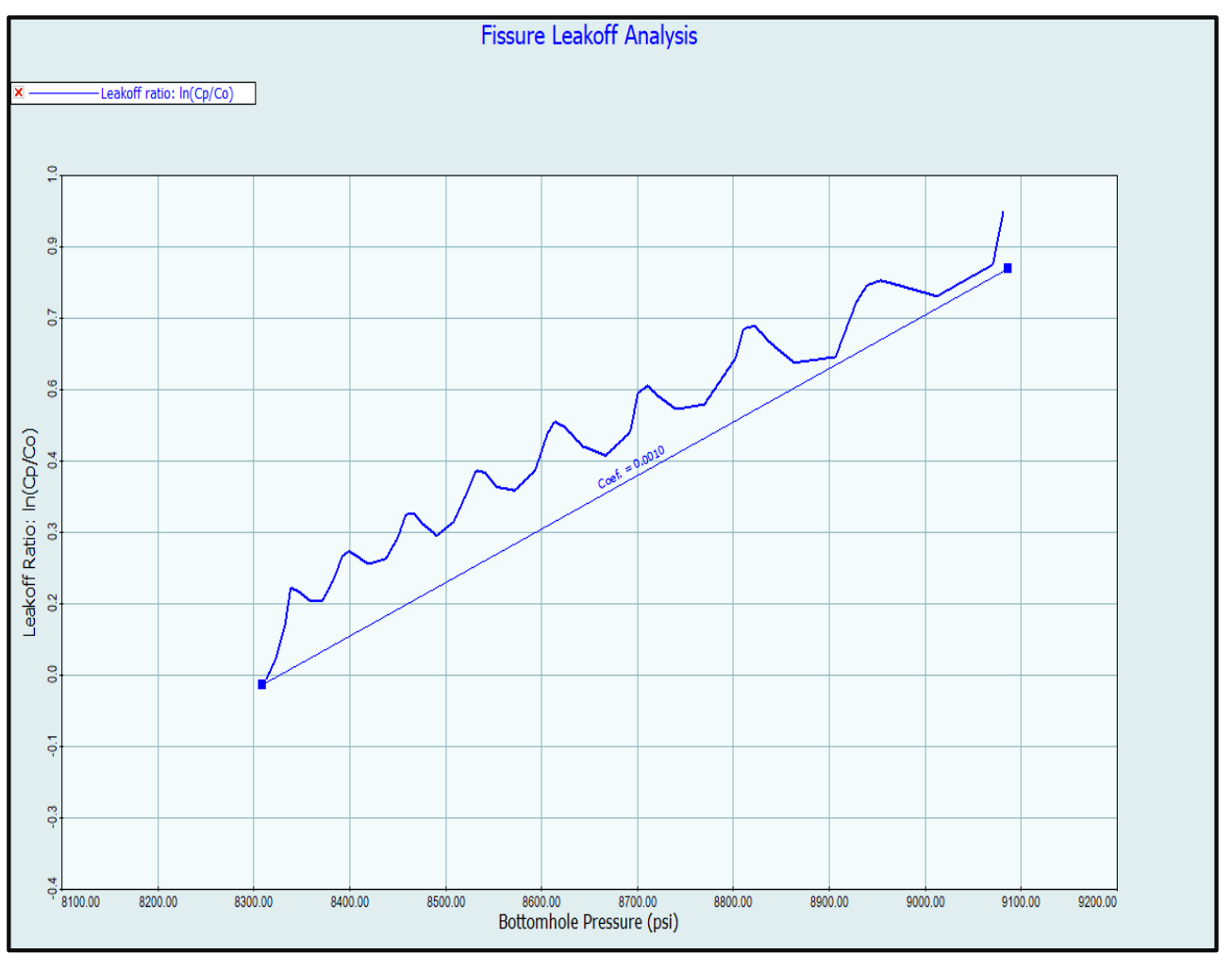

Figure 3.14: The Fissure Leak-Off Analysis.

Table 3.6: Well MIP-3H DFIT Analysis.

\begin{tabular}{|l|c|c|}
\hline \multicolumn{3}{|c|}{ DFIT Results } \\
\hline \multicolumn{1}{|c|}{ Parameters } & Values & Units \\
\hline Instantaneous Shut-In Pressure (ISIP) & 8388 & Psi \\
\hline Closure Pressure (Pc) & 7842 & PSI \\
\hline Leakoff Type & Pressure Dependent & \\
\hline PDL Cofficient & 0.001 & $1 / \mathrm{psi}$ \\
\hline Process Zone Stress (PZS) =(ISIP-Pc) & 546 & Psi \\
\hline
\end{tabular}

\subsubsection{Stress Regime Evaluation}

Figure 3.15 illustrates the stress polygon (Moss and Zoback,1990) created to determine the stress regime by using the equations from 3.1-3.3.

Normal faulting (NF): $S_{v}>S_{H \max }>S_{\text {hmin }}$

$$
\frac{\sigma_{1}}{\sigma_{3}}=\frac{S_{v}-P_{p}}{S_{h m i n}-P_{p}} \leq\left\{\left(\mu^{2}+1\right)^{\frac{1}{2}}+\mu\right\}^{2}
$$

Strike Slip Faulting (SS): $S_{H \max }>S_{v}>S_{h \min }$ 


$$
\frac{\sigma_{1}}{\sigma_{3}}=\frac{S_{H \max }-P_{p}}{S_{h \min }-P_{p}} \leq\left\{\left(\mu^{2}+1\right)^{\frac{1}{2}}+\mu\right\}^{2}
$$

Strike Slip Faulting (SS): $S_{H \max }>S_{h \min }>S_{v}$

$$
\frac{\sigma_{1}}{\sigma_{3}}=\frac{S_{H \max }-P_{p}}{S_{v}-P_{p}} \leq\left\{\left(\mu^{2}+1\right)^{\frac{1}{2}}+\mu\right\}^{2}
$$

The coefficient of friction, pore pressure, and magnitudes of overburden stress $\left(\mathrm{S}_{\mathrm{v}}\right)$ are parameters that are required to build the stress polygon. The overburden pressure was estimated to be 8800 psi by integrating density log data. The pore pressure gradient was estimated to be $0.65 \mathrm{psi} / \mathrm{ft}$ from the sonic scanner log. The coefficient of friction $(\mu)$, which is critically stressed along with preexisting fractures, is 0.6 and has a cohesion $\left(\mathrm{S}_{\mathrm{o}}\right)$ of zero (Zoback, 2007). Figure 3.15 indicates that the value of minimum horizontal stress is 6300 psi. The minimum horizontal stress estimated from DFIT is less than the overburden pressure and the stress anisotropy $\left(\mathrm{S}_{\mathrm{Hmax}}-\mathrm{S}_{\mathrm{hmin}}\right)$, which was estimated to be 400 psi from the sonic scanner log. Therefore, it is concluded that the stress regime is a normal fault.

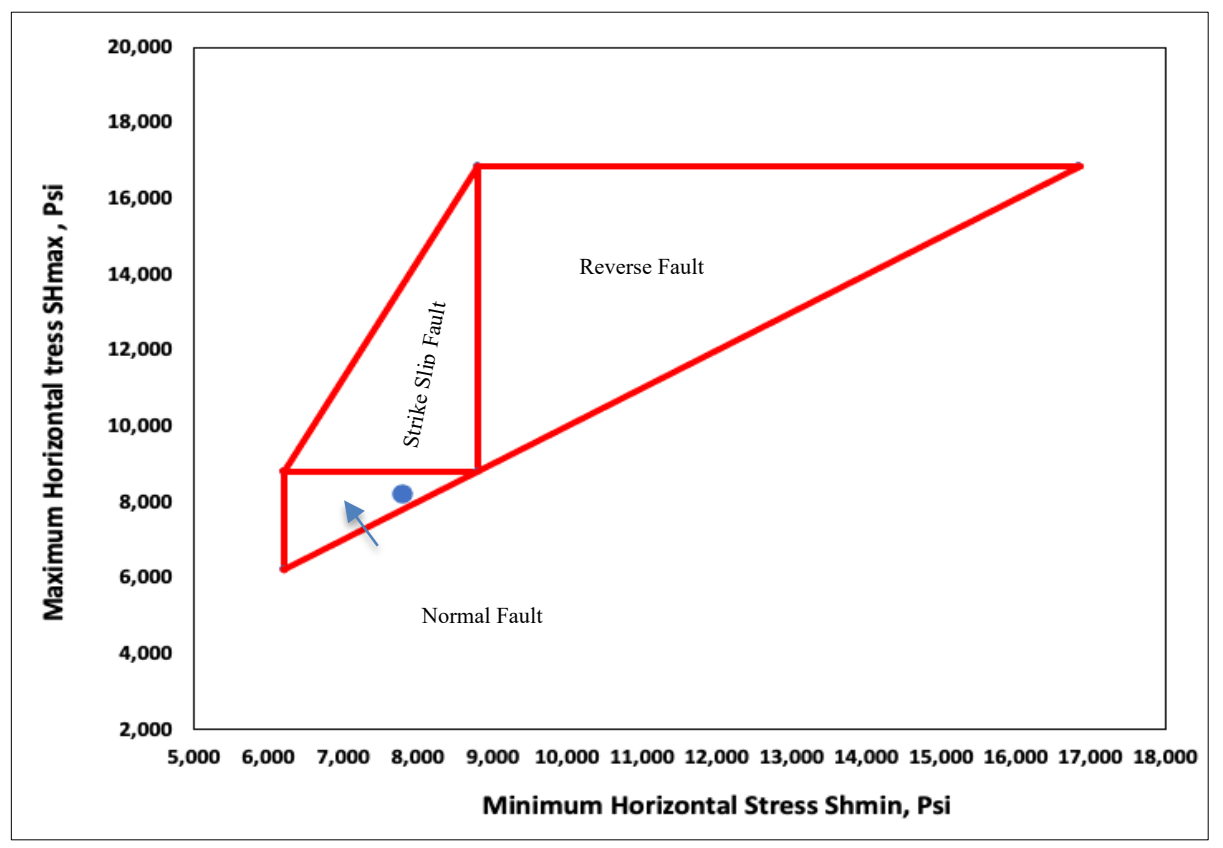

Figure 3.15: Stress Polygon for MIP-3H.

\subsubsection{TOC Data Interpretation}

Numerous methods exist to determine TOC from the well logs. In this study, Schmoker's Method was used to derive TOC from the well logs. Schmoker's method computes TOC from the bulk density logs and is the most common method used to calculate TOC as follows: 


$$
\text { TOC }=\frac{54.49}{\rho_{b}}-57.261 \quad \ldots \ldots \ldots .3 .4
$$

Where

TOC is Total Organic Carbon in wt.\%

$\rho b \quad$ is the bulk density in $\mathrm{g} / \mathrm{cm}^{3}$

TOC obtained from the core data were then used to calibrate TOC derived from well logs. Figure 3.16 illustrates TOC, determined by Schmoker's Method in the vertical section and calibrated with TOC from the core data. Schmoker's method underpredicts TOC in the lower Marcellus. However, it closely predicts TOC in the upper and middle Marcellus

Finally, Schmoker's method, calibrated with core data, was used to determine TOC from the well logs in the horizontal section of the well. Figure 4.17 illustrates the TOC distribution in horizontal length, which was predicted by Schmoker's Method.

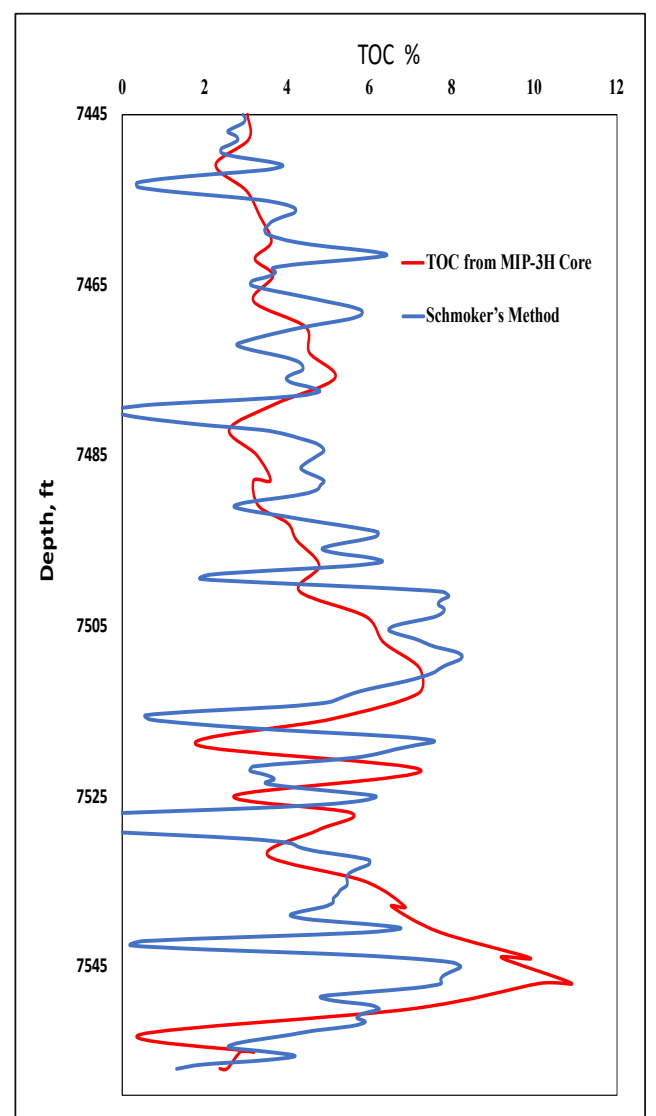

Figure 3.16: TOC Derived by Schmoker's Method (Blue) and TOC from the Core (Red). 


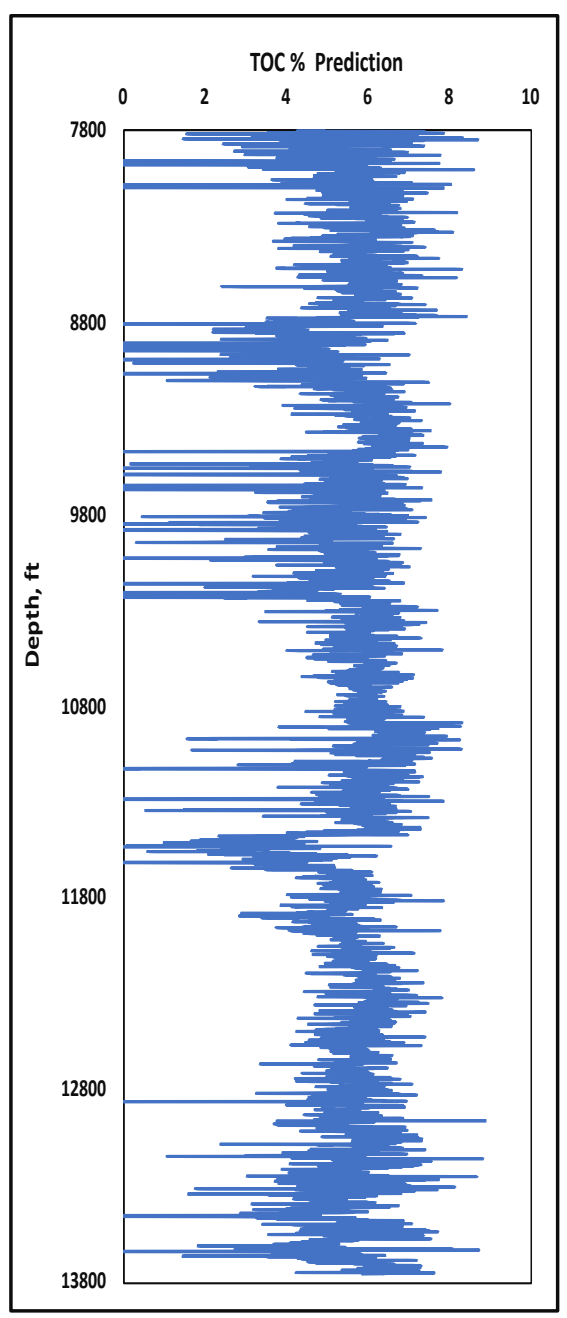

Figure 3.17: Predicted TOC (\%) along with the Horizontal Section of the Well MIP-3H.

\subsubsection{Prediction of the Fracture Properties}

\subsubsection{Well MIP-6H}

GOHFER 3D, which is considered to be the most accurate fracture simulator in the industry, was used in this study to predict the hydraulic fracture properties. All the tools necessary for unconventional well completion design, analysis and optimization including stress shadowing are incorporated in this software. A model for MIP-6H was built by uploading the logs from well MIP-3H and pore pressure gradient into GOHFER model. Since the log data were from well MIP-3H vertical section, they were converted to fit the horizontal section of the well MIP-6H through geosteering. Geosteering is performed by following similar GR signatures in both wells to assure that the horizontal section is in the correct zone, as illustrated in Figure 3.18. 


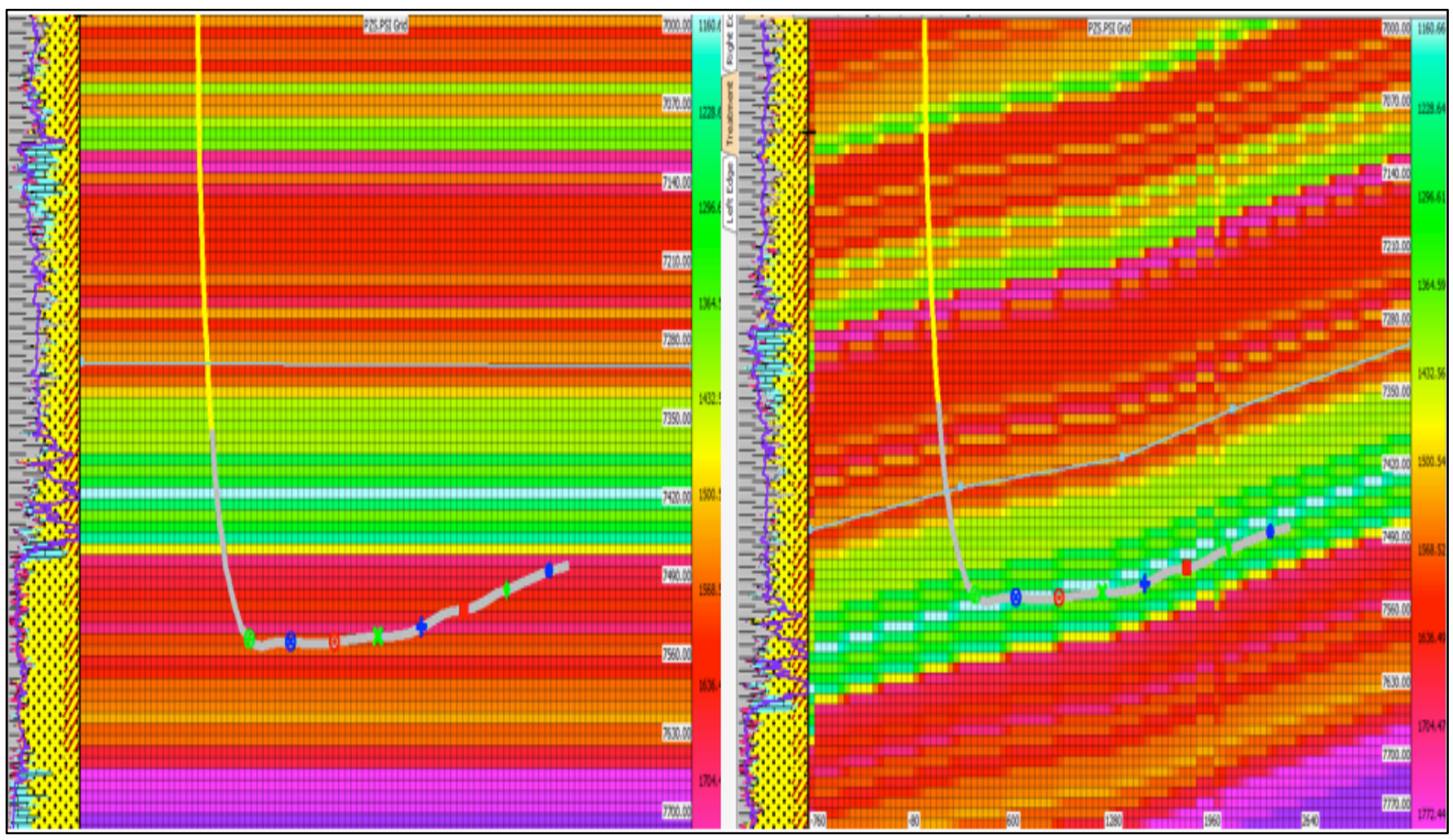

Figure 3.18: Illustrates Well MIP-6H Before Geosteering and After Geosteering.

Minimum horizontal stress $\left(\sigma_{h}\right)$ is obtained within the reservoir interval by assuming "zero" regional stress or strain. Figure 3.19 illustrates the calculated results by GOHFER based on the well MIP-3H log data as was explained previously. The pore pressure gradient was estimated to be $0.65 \mathrm{psi} / \mathrm{ft}$. from the sonic scanner $\log$

The process zone stress (PZS) has a significant impact on the fracture width and height. The higher is PZS, the higher the fracture width would be. PZS, which was obtained from well log was calibrated to the DFIT. The minimum horizontal stress was determined from the log data by assuming "zero" regional stress or strain and was also calibrated with the results of the DFIT.

Upon development of the model for Well MIP-6H, the fracture treatment data for each stage was entered in the model, and design parameters such as the friction factor and coefficient of discharge were modified to match the actual treating pressures. Figure 3.20 shows the treating pressure match for Stage 6 for Well-6H. The treatment plots for all stages are provided in Appendix A, from Figures A.1 to A.8. Finally, the fracture properties, including fracture half-length, fracture height, and fracture conductivity, were predicted with both by including and excluding the stress shadowing. 

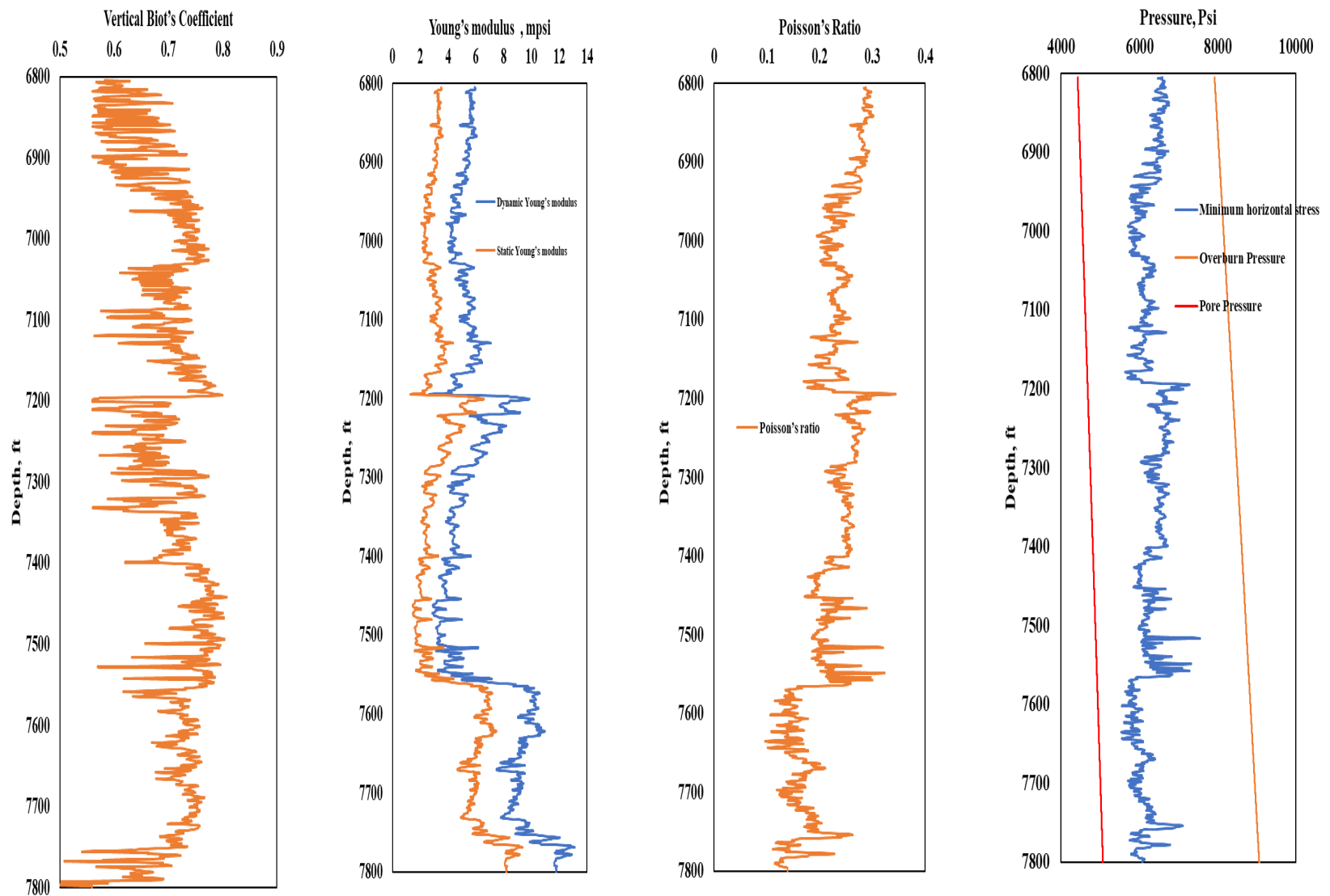

Figure 3.19: Vertical Biot's Coefficient, Static and Dynamic Young's Modulus, Poisson's Ratio, Pore Pressure, Overborne Pressure, and Minimum Horizontal Stress Calculated from the Well Logs MIP-3H.

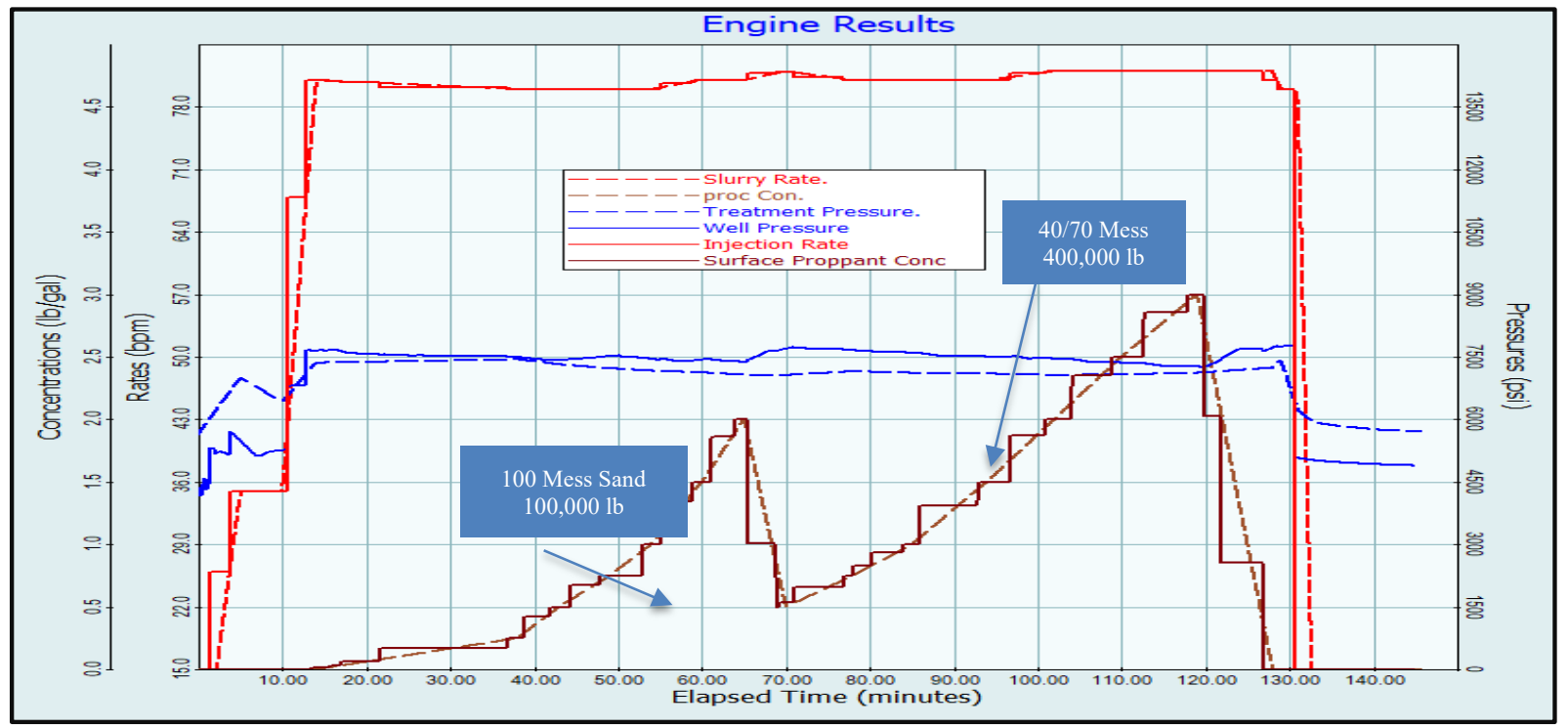

Figure 3.20: A Matched Pressure Between Model and Actual Values for Stage 6 for MIP-6H. Dotted Pressure Curve (blue) Represents the Actual Surface Treating Pressure (Treatment Pressure in The Plot Legend), Whereas the Connected Pressure Curve (blue) Represents the Model Surface Treating Pressure (Well Pressure in The Plot Legend). 


\subsubsection{Well MIP-3H}

A model for MIP-3H was developed by entering the results of the well log analysis from the vertical and lateral sections of the well into GOHFER software. Geosteering was performed to ensure that the horizontal section is in the correct zone. GOHFER can also perform the necessary calculations to determine the minimum horizontal stress, as shown in Figure 3.19. The minimum horizontal stress values were then adjusted to match the value obtained from DFIT analysis. The fracture treatment data for each stage was entered in the model, and design parameters such as the friction factor and discharge coefficient were modified to match the actual treating pressures. Figures 3.21 and 3.22 illustrate matched pressure between model and actual values for stage 7 and stage 28. These stages have different treatment designs. The treatment plots for all stages are provided in Appendix A.

As mentioned earlier, microseismic events suggested that height growth to be mainly upward from Marcellus shale. Therefore, the minimum horizontal stress in the zone below Marcellus shale (Onondaga Limestone) was increased to accommodate the upward fracture growth. Finally, the fracture properties, including fracture half-length, fracture height, and fracture conductivity, were predicted by including and excluding the stress shadowing impacts. The impact of stress shadowing could be significant when the fractures are closely spaced. The formation of mechanical properties control the degree of stress shadowing.

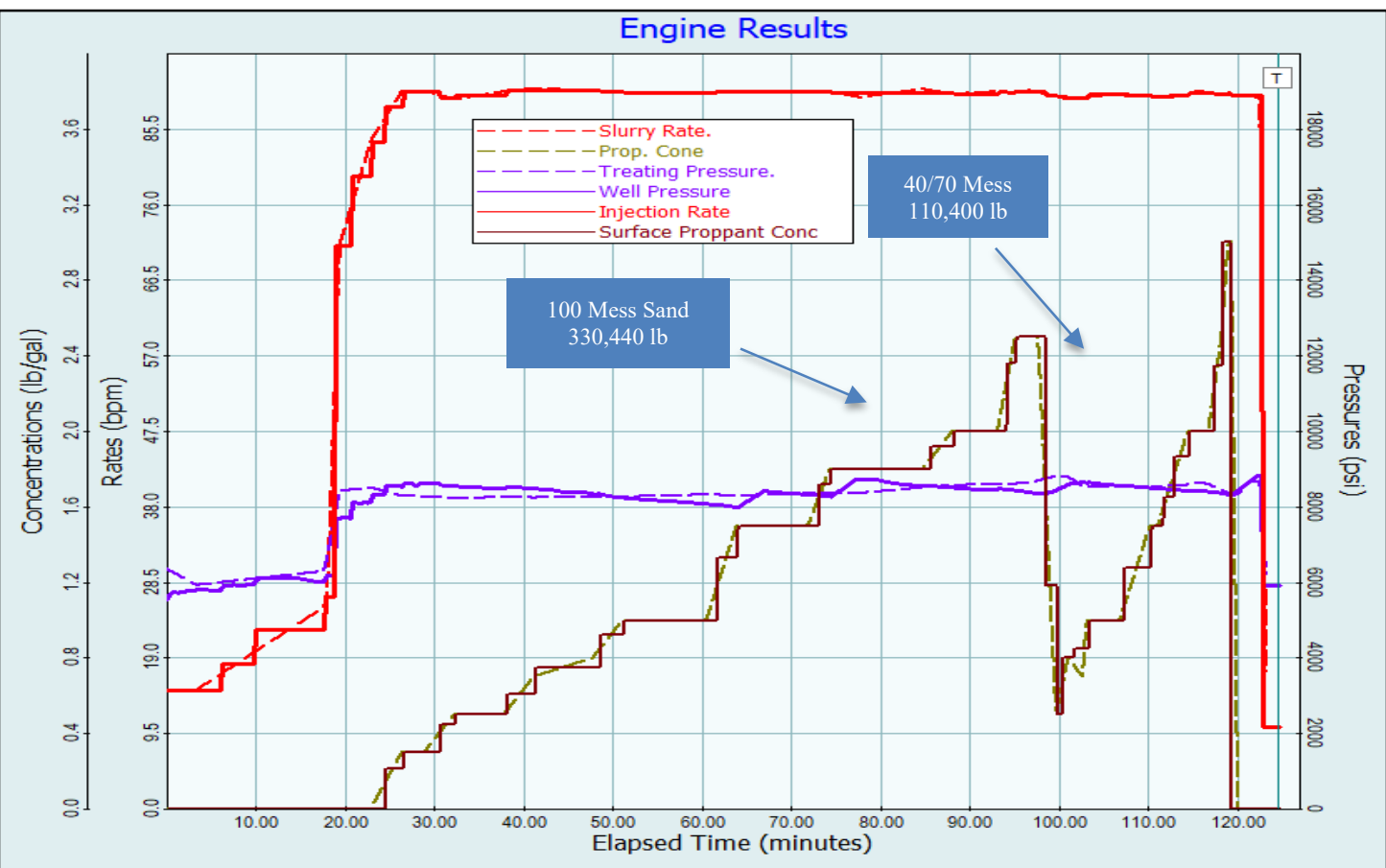

Figure 3.21: A Matched Pressure between Model and treatment Data for Stage 7 For MIP-3H. Dotted Pressure Curve (Purple) Represents the Actual Surface Treating Pressure (Treatment Pressure in the Plot Legend), Whereas the Continuous Pressure Curve (Purple) Represents the Model Surface Treating Pressure (Well Pressure in the Plot Legend). 


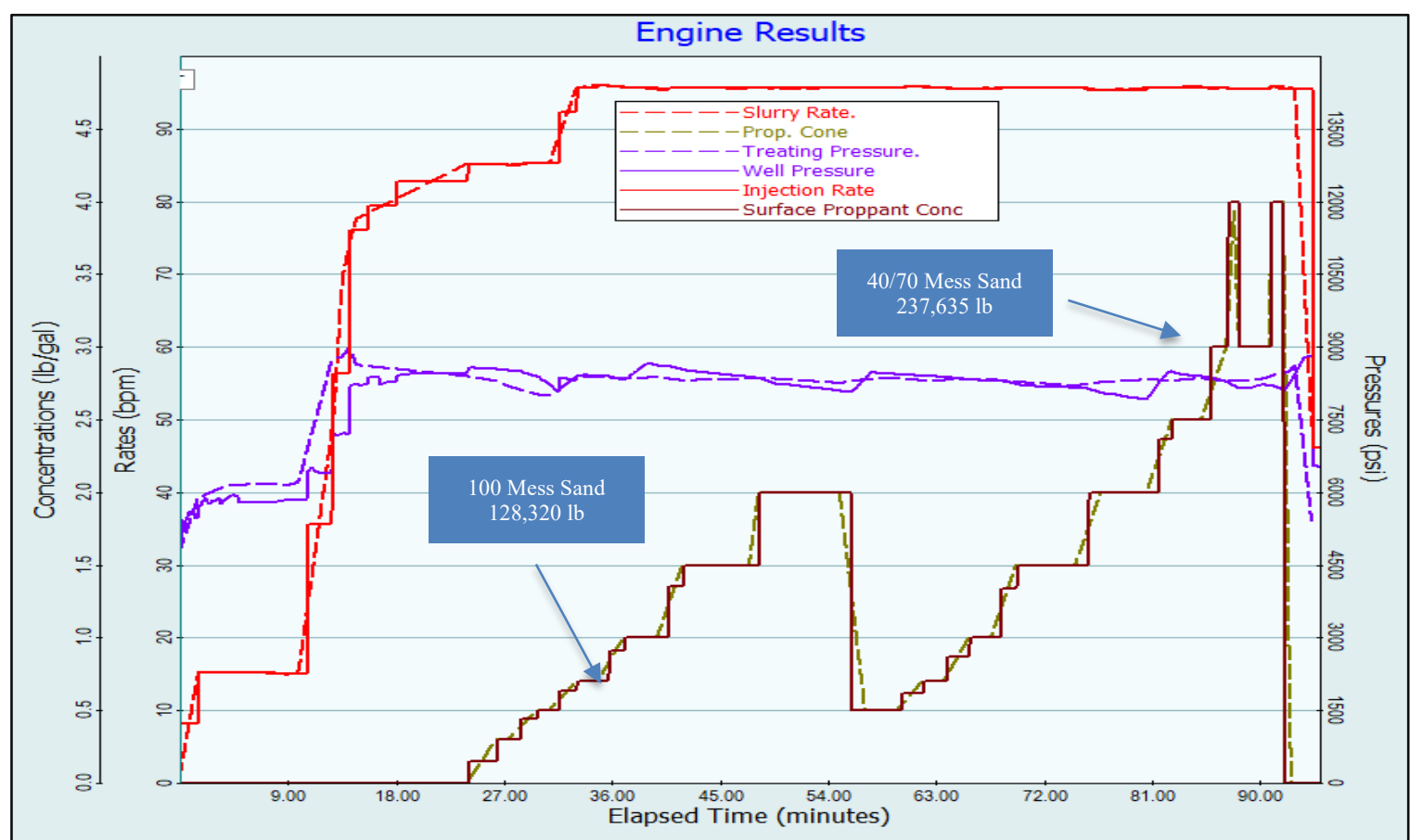

Figure 3.22: A Matched Pressure between Model and Actual Values for Stage 28 For MIP-3H. Dotted Pressure Curve (Purple) Represents the Actual Surface Treating Pressure (Treatment Pressure in the Plot Legend), Whereas the Connected Pressure Curve (Purple) Represents the Model Surface Treating Pressure (Well Pressure in the Plot Legend).

\subsubsection{Reservoir Model Development for Wells MIP-6H and MIP-3H}

A reservoir simulation software (CMG-GEM, 2019) was employed to predict the production performance of the well under study based on the predicted hydraulic fracture properties. The reservoir was modeled as a dual permeability system to efficiently and accurately simulate the transient gas production from the hydraulically fractured horizontal well in shale gas reservoirs (Rubin, 2010; Cipolla et al., 2010). The dual permeability model was used in this study. In the dual permeability model, the fluid can flow at the same time through the fracture and matrix to wellbore. Furthermore, the fluid can travel from the matrix to the fractures and from the fractures to the matrix. To accurately predict the gas flow from the matrix to bi-wing hydraulic fractures, local grid refinement (LGR), with logarithmic grid spacing, was employed. Furthermore, non-Darcy effects were included for transient gas flow in hydraulic fractures.

Marcellus shale petrophysical properties were obtained from the measurements on the core plugs. The core plugs were obtained from the science well. The measurements on the core plugs were performed using Precision Petrophysical Analysis Laboratory (PPAL) set-up (Elsaig et al. 2016). PPAL provided accurate and repeatable values for Marcellus absolute permeability through the application of the double 
slippage correction (Zamirian et al. 2015). The Langmuir constants for Marcellus shale obtained from the core plug porosity measurements using different gases (Zamirian et al. 2015) were incorporated in the base models for both wells MIP-6H, and MIP-3H. The natural fractures (fissures) distribution in reservoir simulation for well MIP-3H was estimated from the Quant Geo log interpretations, as discussed earlier, was incorporated in the base models for well MIP-3H. The wellbore pressures for the well MIP-3H. was calculated from the tubing pressure data and was used as constraints in the simulation model. Figures 3.23 shows wellbore pressures for the well MIP-3H.

Table 3.7 summarizes the basic model parameters for both of the wells MIP-6H, and MIP-3H. Relative permeability curves for flow in the shale matrix were generated using the Corey Model. For natural fractures and hydraulic fracture, relative permeability curves were assumed to be straight-line, which is a common practice in many reservoir simulators (CMG. 2019).

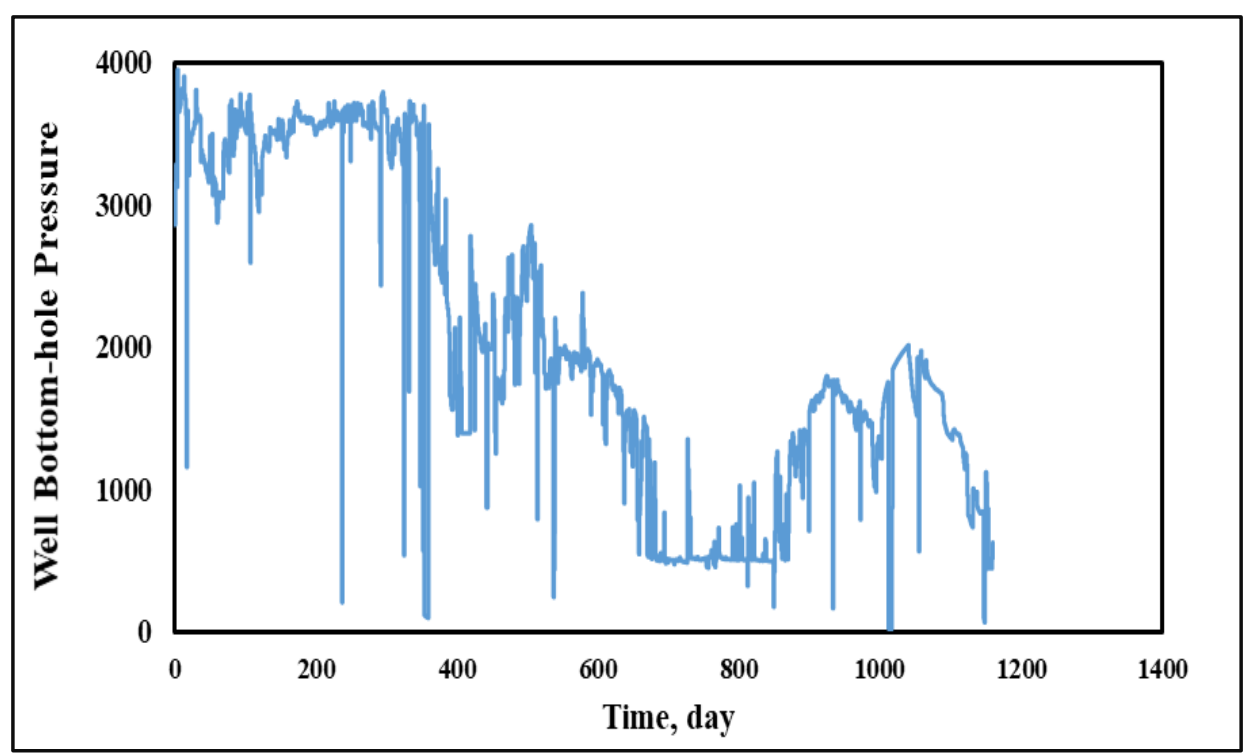

Figure 3.23: Wellbore Pressures for Well MIP-3H. 
Table 3.7: Basic Model Parameters for MIP-6H and MIP-3H.

\begin{tabular}{|l|c|c|}
\hline Reservoir Parameters & Values & Units \\
\hline Model Dimensions (MIP-3H) & 6500 Length $\times 1500 \mathrm{Width} \times 90 \mathrm{Height}$ & $\mathrm{ft}$. \\
\hline Model dimensions (MIP-6H) & 4000 Length $\times 1000 \mathrm{Width} \times 90 \mathrm{Height}$ & $\mathrm{ft}$. \\
\hline Initial Reservoir Pressure & 4700 & $\mathrm{psia}$. \\
\hline Fissure Porosity & 0.0001 & Fraction \\
\hline Matrix Porosity & 0.04 & Fraction \\
\hline Fissure Permeability i,j, $\mathrm{k}$ & $0.001,0.001,0.0001$ & $\mathrm{md}$ \\
\hline Matrix Permeability i, j, k & $0.0004,0.0004,0.00004$ & $\mathrm{md}$ \\
\hline Water Saturation & 0.15 & Fraction \\
\hline Rock Density & 120 & $\mathrm{lb} / \mathrm{ft}^{3}$ \\
\hline Langmuir Pressure & 240 & $\mathrm{psi}$ \\
\hline Langmuir Volume & 0.03 & $\mathrm{gmol} / \mathrm{lb}$ \\
\hline
\end{tabular}

\subsubsection{Impact of Geomechanical Factors}

In this study, we consider the geomechanical effects associated with the matrix permeability, fissure permeability, and hydraulic fracture conductivity, as well as the gas slippage on the productivity of the shale.

\subsubsection{Matrix and Fissure Permeability Geomechanical Factors}

The experimental results by Elsaig et al. (2016) were utilized to develop a relation between the matrix permeability and the net stress. It should be noted that the absolute permeability values given in Figure 2.8 are the combination of the matrix and fissure permeability values. Based on the experimental results, Elsaig et al. (2016) concluded that the fissures are completely closed at stress values higher than 4770 psi. Therefore, the permeability values measured at stress values higher than 4770 psi, represent only the matrix permeability. These permeability values were utilized to develop the relation between matrix permeability and net stress. Subsequently, the fissure permeability can be estimated by subtracting matrix permeability from the total permeability. Figure 3.24 illustrates the fissure permeability as a function of net stress. 


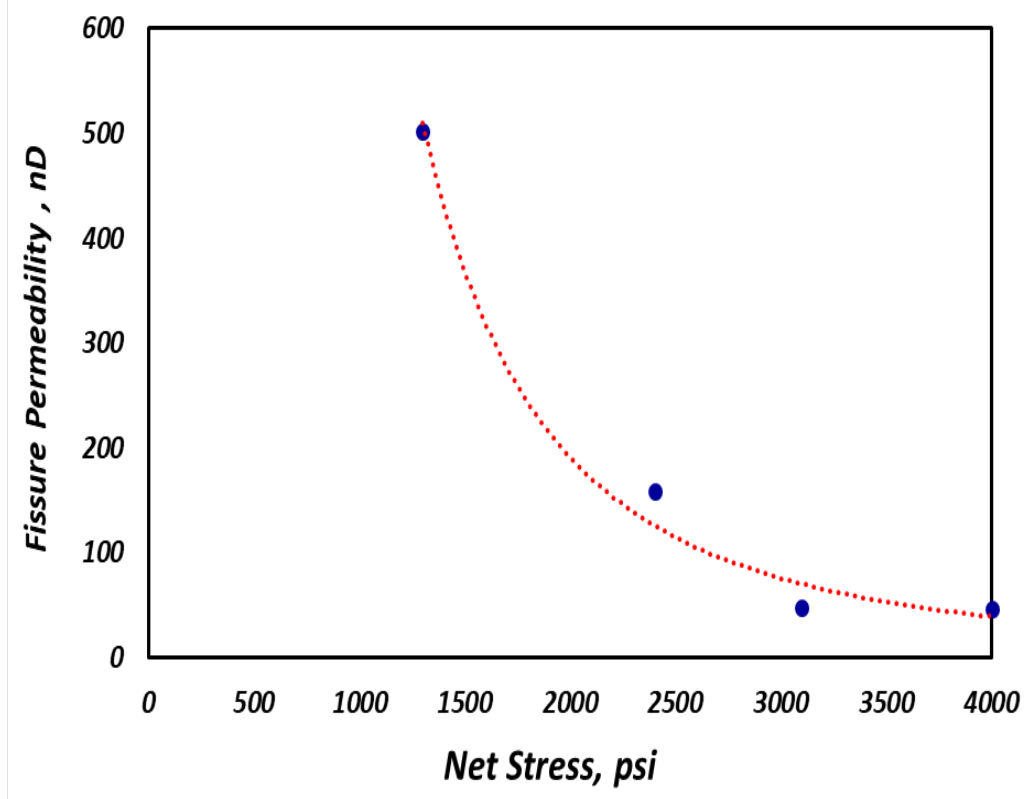

Figure 3.24: Effect of Net Stress on Fissure Permeability.

The initial net stress was estimated to be 2000 psi for Marcellus Shale. The matrix and fissure permeability values at 2000 psi in Figures 2.8 and 3.24 are considered as the initial matrix and fissure permeability. The maximum net stress was estimated to be $6800 \mathrm{psi}$. The matrix and fissure permeability values between 2000 psi and 6800 psi were then normalized and converted to permeability multipliers as a function of the reservoir pressure (pore pressure). The matrix and fissure permeability multipliers that were used in the reservoir model are provided in Figure 3.25.
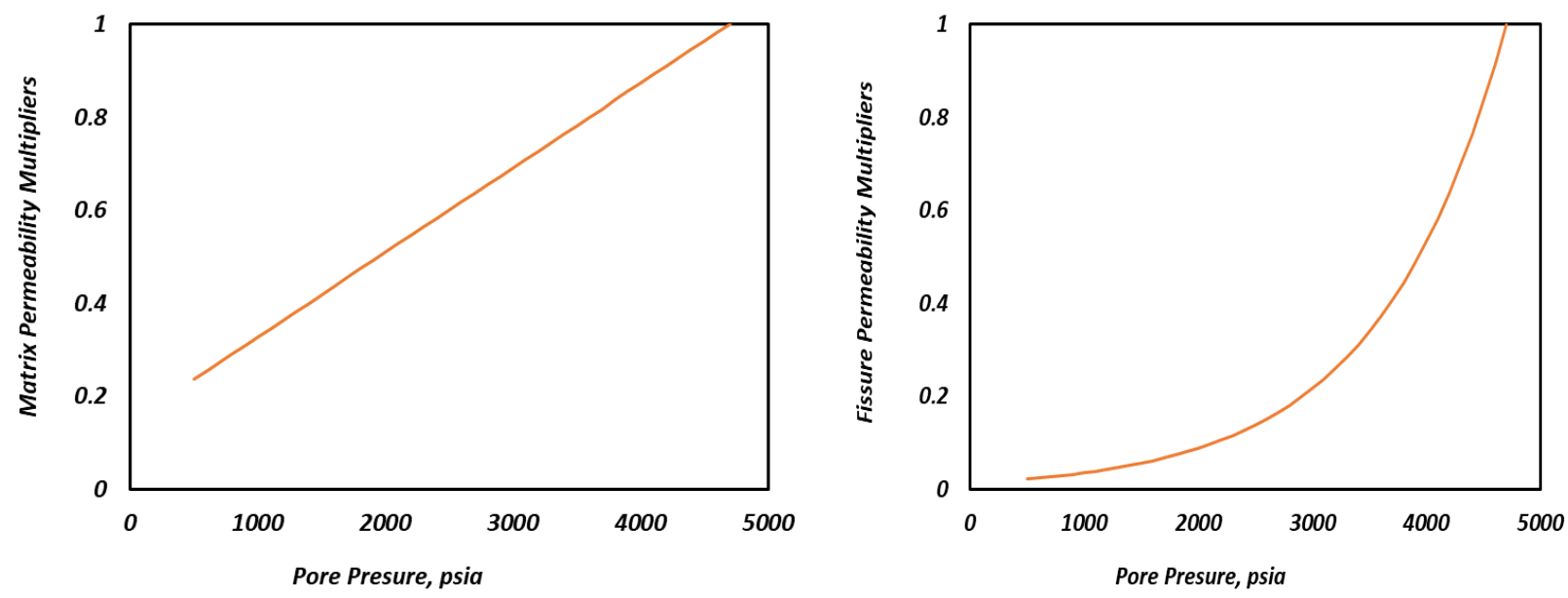

Figure 3.25: Matrix and Fissure Permeability Multiplier. 
The double-slippage relation was utilized in this study to account for gas slippage impact on the permeability as a function of the pore pressure. Figure 3.26 illustrates the permeability multiplier for the gas slippage.

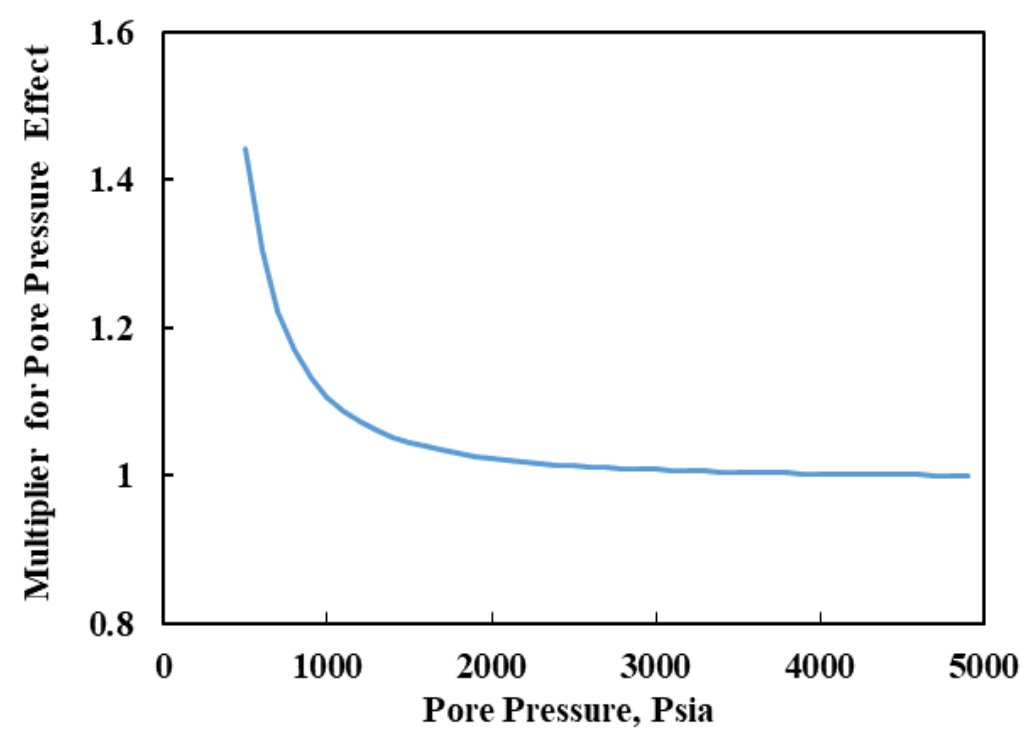

Figure 3.26: Permeability Multiplier for Gas Slippage.

Furthermore, Cipolla et al. (2008) results were utilized in this study to develop a relation between fissure permeability and net stress. Since Marcellus Shale is a relatively soft formation (Stegent et al. 2010), the curve for Young's modulus of $2 \mathrm{E}+6 \mathrm{psi}$ was used here. The un-propped fracture conductivity value at 2000 psi was considered as the initial fissure conductivity. The fissure permeability multipliers are then developed in a similar manner as for the matrix permeability multiplier. Figure 3.27 shows the multiplier for the fissure permeability.

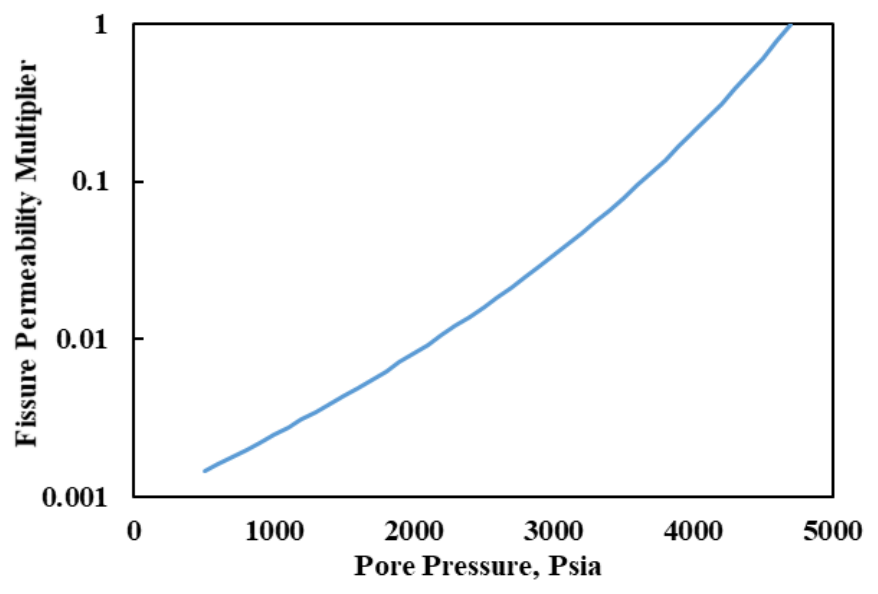

Figure 3.27: The Multiplier for Fissure Permeability. 


\subsubsection{Hydraulic Fracture Geomechanical Factor}

McGinley et al. (2015) results for Elimsport samples were utilized in this study to develop a relation between the hydraulic fracture conductivity and the net stress. The measurement results for Elimsport samples were considered because the anisotropy impacts are more pronounced. Figures 3.28 shows the multiplier for the hydraulic fracture conductivity.

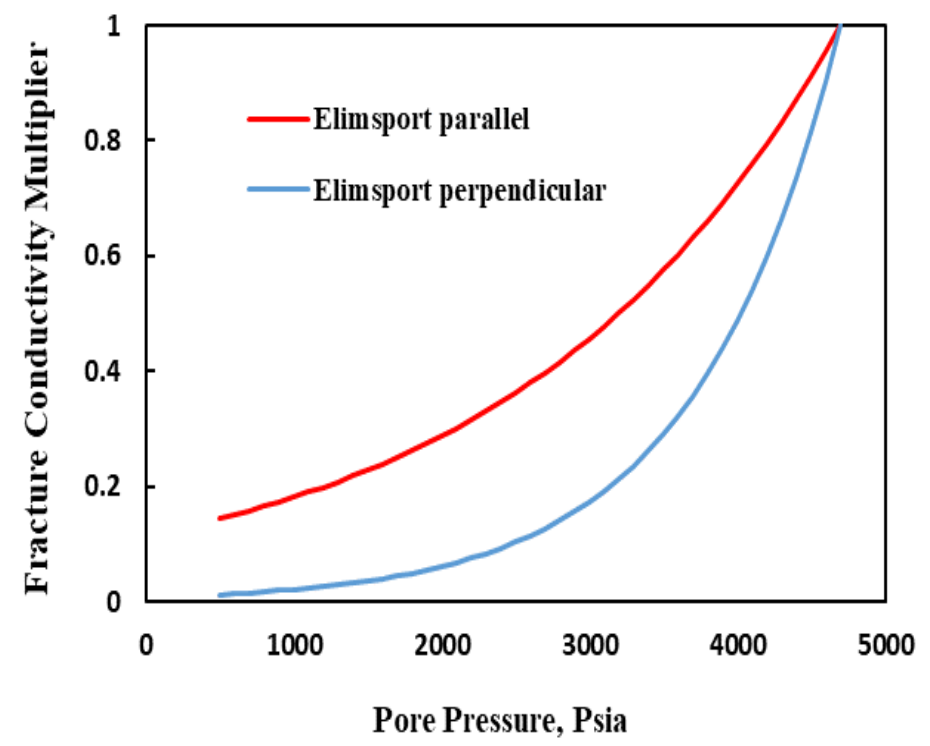

Figure 3.28: Propped Conductivity Multiplier for Fracture.

\subsubsection{Impact of Geomechanical Factor (Propped Fracture Conductivity) (MIP-6H)}

To investigate the impact of Geomechanical factor (propped fracture conductivity) on gas production, the geomechanical factor (propped fracture conductivity) was excluded from the model for well MIP-6H and the entire production history was simulated for comparison purposes.

The geomechanical factor for hydraulic fracture was obtained from experimental results by McGinley et al. (2015) and was used only in the model, as mentioned earlier.

\subsubsection{Impact of Geomechanical Factors (Matrix, Fissure, and propped) (MIP-6H)}

To investigate the impact of the stress-dependent matrix, and fissure permeability and propped fracture conductivity on the results of production history matching the following four cases were considered for well $(6 \mathrm{H})$ :

1. All geomechanical factors (stress-dependent matrix permeability, fissure permeability, and the propped fracture conductivity) were included in the model. 
2. The geomechanical factors only for matrix and fissure permeability were included in the model.

3. The geomechanical factors only for matrix permeability and propped fracture conductivity were included in the model.

4. The geomechanical factors only for fissure permeability and propped fracture conductivity were included in the model.

To investigate the impact of geomechanical factors (Matrix, Fissure, and Propped Fracture Conductivity) on gas production, the geomechanical factors were excluded from matched model for well MIP-6H (case 1) and the entire production history was simulated for comparison purposes.

The geomechanical factors for matrix and fissure permeability, which were obtained from experimental results by Elsaig et al. (2016), were used in the model, as mentioned earlier. Furthermore, the geomechanical factor for hydraulic fracture, which was obtained from experimental results by McGinley et al. (2015), was used in the model.

\subsubsection{Impact of Geomechanical Factors (Matrix, Fissure, and propped) and Gas Slippage (MIP- 6H)}

To investigate the impact of geomechanical factors and gas slippage, the following six cases were considered ( $6 \mathrm{H}$ well) to determine the effective hydraulic fracture half-length by the production historymatching:

1. All geomechanical and slippage effects were included in the model.

2. All effects except for gas slippage were included in the model.

3. All effects and gas slippage effect except for the matrix geomechanical were included in the model.

4. All effects except for the matrix geomechanical and the gas slippage were included in the model.

5. The geomechanical factors only for matrix and fissure permeability were included in the model.

6. The geomechanical factors only for matrix permeability and propped fracture conductivity were included in the model.

The geomechanical factors for matrix permeability, fissure permeability, and the propped fracture conductivity and gas slippage were incorporated in the model. In this case, the geomechanical factor for matrix permeability, which was utilized from experimental results by Elsaig et al. (2016), was used in model, as mentioned earlier. However, the geomechanical factor for fissure permeability, which was obtained from experimental results by Cipolla et al. (2008) results, was used in model, as mentioned earlier. Furthermore, the geomechanical factor for hydraulic fracture, which was obtained from experimental results by McGinley et al. (2015), was used in model, as mentioned earlier. 


\subsubsection{Impact of Stress Shadowing and Geomechanical Factors (Matrix, Fissure, and propped) (Well MIP-6H).}

Fracture properties, including fracture half-length and fracture conductivity from the GOHFER calibrated model, were entered in reservoir simulation for well MIP-6H. In addition, the geomechanical factors for matrix permeability, fissure permeability, and the propped fracture conductivity were incorporated in the model. The geomechanical factors for matrix and fissure permeability which were obtained from experimental results by Elsaig et al. (2016) were used in the model as mentioned earlier.

Three different production profiles were generated to investigate the impact of geomechanical factors (stress-dependent matrix permeability, fissure permeability, and the propped fracture conductivity) and stress shadowing on gas production. One that includes both the stress shadowing and geomechanical factors, one that excluded the stress shadowing (from GOHFER) but included the geomechanical factors, and finally one that excluded both the stress shadowing and geomechanical factors

\subsubsection{Parametric Studies to Investigate the Impact of Fracture Half-Length Including Non-Uniform Fracture Half-Length on the Gas Recovery.}

\subsubsection{Fracture Half-Length}

Model for MIP-6H was utilized for parametric studies to investigate the impact of the hydraulic fracture half-length on the gas recovery (20-year simulated production) from Marcellus Shale. Geomechanical Factors were not included in the model.

\subsubsection{Non-Uniform Fracture Half-Length}

Model for MIP-6H was utilized for parametric studies to investigate the impact of the hydraulic fracture half-length on the gas recovery (20-year simulated production) from Marcellus Shale. Geomechanical Factors were not included in the model. Eleven non-uniform fracture half-length configurations were investigated, as illustrated in Figure 3.26. For cases 1, 2, and 3 small changes to the base model fracture half-length (100 ft.) were considered. For these cases, the two-fracture half-length (120 and $80 \mathrm{ft}$.) in different orders were assumed. For cases 4, 5, and 6, the changes to fracture half-lengths were increased. For these cases, the fracture half-length of 160 and $40 \mathrm{ft}$. in different orders were assumed. Finally, for cases 7, 8, and 9, fracture half-length of 180 and $20 \mathrm{ft}$. in different orders were assumed. For case 10, several fracture half-lengths, including $170 \mathrm{ft}$. at the beginning, followed by fracture half-lengths 
of $150,130,110,70,50$ and $30 \mathrm{ft}$. For case 11, the same fracture half-lengths as case 10 were assumed but in the reverse order.
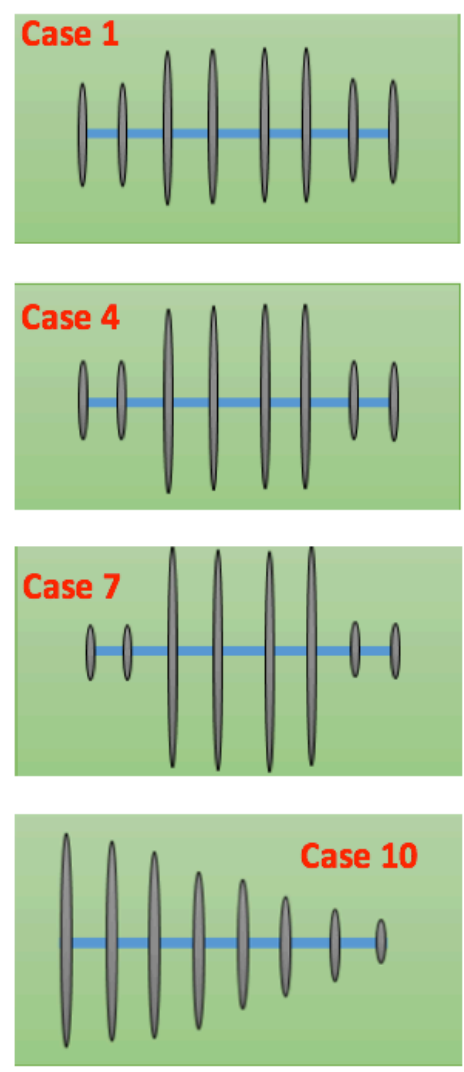
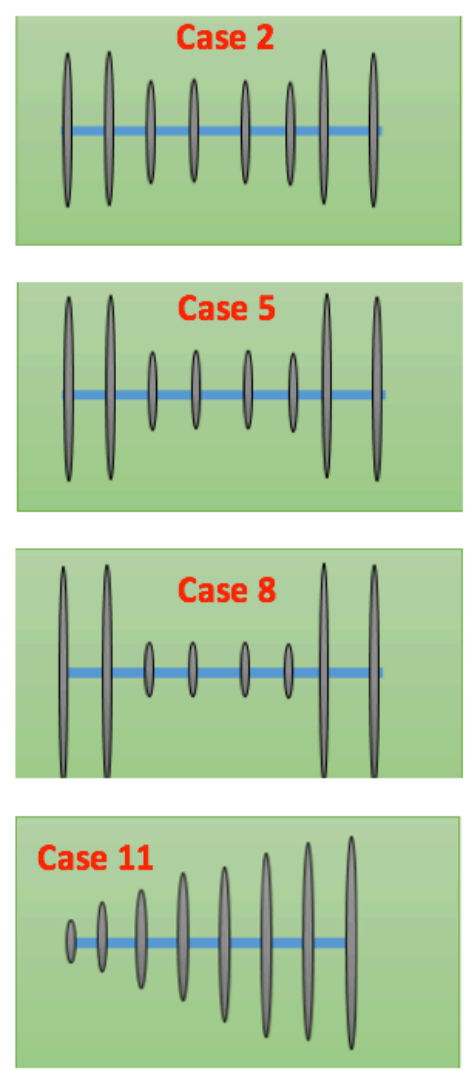
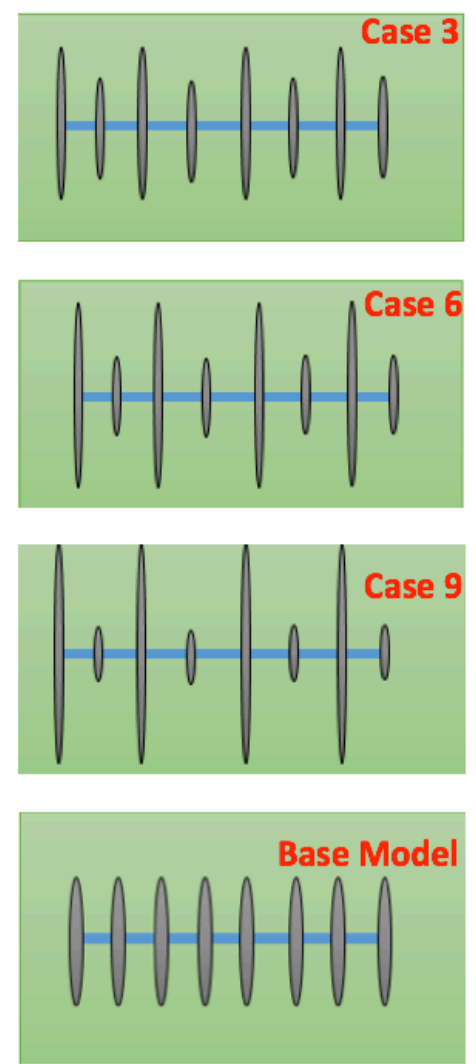

Figure 3.29: Illustrates Eleven Non-Uniform Fracture Half-Length Configurations.

\subsubsection{Parametric Studies to Investigate the Impact of the Geomechanical Factors on Gas Recovery.}

\subsubsection{Parametric Studies for Geomechanical Factor (Propped Fracture Conductivity) ( MIP-6H)}

The parametric studies, using matched models for well MIP-6H, were conducted to investigate the impact of the wellbore pressure, fissure permeability, matrix porosity, fracture half-length, and hydraulic fracture spacing on stress-dependent propped hydraulic fracture conductivity on production performance. Table 3.8 illustrates parameters and their ranges, which were used for parametric studies. The geomechanical factor (stress-dependent propped hydraulic fracture conductivity) was excluded from the model for MIP-6H and the entire production history (20-year simulated production) was predicted for comparison purposes. 
Table 3.8: Parameters and Their Values Used for Parametric Studies Geomechanical factor (Hydraulic fracture).

\begin{tabular}{|l|c|c|c|}
\hline Parameters & $\begin{array}{c}\text { Base } \\
\text { Case }\end{array}$ & Range & Unit \\
\hline Wellbore Pressure & 500 & $500-1500$ & $\mathrm{ft}$. \\
\hline Fissure Permeability & 0.002 & $0.004-0.008$ & $\mathrm{md}$ \\
\hline Matrix Porosity & $2.5 \%$ & $4.5 \%-6.5 \%$ & \\
\hline Fracture Half-Length & 260 & $160-350$ & $\mathrm{ft}$. \\
\hline $\begin{array}{l}\text { Fracture Stage Spacing without } \\
\text { increasing the number of stages }\end{array}$ & 300 & $300-220$ & $\mathrm{ft}$. \\
\hline
\end{tabular}

\subsubsection{Parametric Studies for Geomechanical Factors (Matrix, Fissure, and propped) (Well MIP-} 6H).

The parametric studies, using matched model for well MIP-6H, conducted to investigate the impact of fracture half-length, hydraulic fracture spacing, initial fracture conductivity, initial fissure permeability, and wellbore pressure on production performance. Table 3.9 illustrates Parameters and their values that were used for parametric studies. Furthermore, the geomechanical factors for matrix and fissure permeability, which were obtained from experimental results by Elsaig et al. (2016), were used in the model, as mentioned earlier. Furthermore, the geomechanical factor for hydraulic fracture, which was obtained from experimental results by McGinley et al. (2015), was used in the model.

Table 3.9: Parameters and Their Values Used for Parametric Studies Geomechanical Factors (Matrix, Fissure and Propped Fracture Conductivity).

\begin{tabular}{|l|c|c|c|}
\hline Parameters & Base Case & Range & Unit \\
\hline Fracture Half-Length & 300 & $350-450$ & $\mathrm{ft}$. \\
\hline $\begin{array}{l}\text { Fracture Stage Spacing } \\
\text { without increasing the } \\
\text { number of stages }\end{array}$ & 300 & $100-260$ & $\mathrm{ft}$. \\
\cline { 1 - 3 } $\begin{array}{l}\text { Fracture Stage Spacing with } \\
\text { increasing the number of } \\
\text { stages }\end{array}$ & 25 & 100 (24 Stages), 180 (14 Stages), & $\mathrm{ft}$. \\
\hline Initial Fracture conductivity & $260(10$ Stages) & md-ft. \\
\hline Initial Fissure Permeability & 0.001 & $5-20$ & $\mathrm{md}$ \\
\hline Wellbore Pressure & 500 & $0.002-0.006$ & psia \\
\hline
\end{tabular}

For each parameter, the model was used to generate the production profile (20-year simulated production) by both including (case 1 above) and excluding the geomechanical effects (cases 2, 3, and 4 above) for comparison. 


\subsubsection{Parametric Studies for Geomechanical Factors (Matrix, Fissure, and propped) and Gas Slippage (MIP-6H).}

The parametric studies, using the matched model for MIP-6H, were conducted to investigate the impact of fracture half-length, initial horizontal fracture conductivity, and fracture stage spacing on production performance. Table 3.10 illustrates parameters and their ranges, which were used for parametric studies. For each parameter, the model was used to generate the production profile (20-year simulated production) by both including (case 1 above) and excluding the geomechanical effect (case 6 above) for comparison. The geomechanical factor for matrix permeability, utilized from experimental results by Elsaig et al. (2016), was used in the model, as mentioned earlier. However, the geomechanical factor for fissure permeability, which was obtained from experimental results by Cipolla et al. (2008), was used in the model, as mentioned earlier. Furthermore, the geomechanical factor for hydraulic fracture, which was obtained from experimental results by McGinley et al. (2015), was used in the model, as mentioned earlier.

Table 3.10: Parameters and Their Values Used for Parametric Studies Geomechanical Factor (Fissure).

\begin{tabular}{|l|c|c|c|}
\hline Parameters & Base Case & Range & Unit \\
\hline Fracture Half-Length & 480 & $600-360$ & $\mathrm{ft}$. \\
\hline $\begin{array}{l}\text { Initial Horizontal Fracture } \\
\text { conductivity }\end{array}$ & 15 & $5-25$ & md-ft. \\
\hline $\begin{array}{l}\text { Fracture Stage Spacing with } \\
\text { increasing fractures }\end{array}$ & 300 & $\begin{array}{c}80 \text { (30 Stages), 140 } \\
\text { (18 Stages), 260 } \\
\text { (11 Stages) }\end{array}$ & $\mathrm{ft.}$ \\
\hline
\end{tabular}

\subsubsection{Parametric Studies to Investigate the Impact of the Reservoir and Treatment Parameters on the Degree of Stress Shadowing and the Gas Recovery from Marcellus Shale.}

\subsubsection{Parametric Studies for Well MIP-6H}

The parametric studies, using the MIP-6H well hydraulic fracture and reservoir simulation models, were conducted to investigate the impact of injection volume, simultaneous fracturing, sequential fracturing, and Poisson's ratio on the hydraulic fracture properties and gas recovery from the Marcellus Shale. Injection volume, illustrated in Table 3.1, was varied without changing the pump rate, proppant concentration, and the proppant type. Table 3.11 shows the amount of proppant mass per stage for different injection volumes. The fracture properties were predicted for each new treatment design by including and excluding the stress shadowing. 
Table 3.11: Parameters and Their Values Used for Parametric Studies.

\begin{tabular}{|l|c|c|c|}
\hline Parameters & Base Case & Range & Unit \\
\hline Proppant Mass per Stage & 400 & M-lbs \\
\hline $\begin{array}{l}\text { Fracture Stage Spacing with increasing the } \\
\text { number of stages }\end{array}$ & 300 (8 Stages) & $\begin{array}{c}250 \text { (10 Stages), 200 (12 Stages) } \\
150 \text { (16 stages), and 100 (23 } \\
\text { Stages) }\end{array}$ & $\mathrm{ft.}$ \\
\hline $\begin{array}{l}\text { Fracture Stage Spacing with decreasing the } \\
\text { number of stages }\end{array}$ & 300 (8 Stages) & $\begin{array}{c}350 \text { (7 stages), 400 (6 stages), } \\
\text { and 450 (5 stages) }\end{array}$ & $\mathrm{ft}$ \\
\hline Poisson's Ratio & 0.23 & $0.15-0.35$ & \\
\hline \multicolumn{2}{|c|}{ Sequential Fracturing and Simultaneous Fracturing } \\
\hline
\end{tabular}

\subsubsection{Parametric Studies for Well MIP-3H}

The sensitivity analysis, using the MIP-3H well hydraulic fracture and reservoir simulation models, was conducted to investigate the impact of cluster spacing and fracturing fluid volume on the hydraulic fracture properties and the gas recovery from the Marcellus Shale. The treatment design C, illustrated in Table 3.12, was used in this study as the base case for sensitivity analysis. This treatment design was selected based on the pump rate, which assures that fractures continue propagating, prevent screen out, and the amount of the proppant in the original design. The properties of the hydraulic fractures, both by including and excluding the stress shadowing, were predicted using the well MIP-3H hydraulic fracture model for different fluid volumes and cluster spacings. Subsequently, the gas recovery for each case was predicted using the well MIP-3H reservoir simulation model. The cluster spacings, which were used in this study are listed in Table 3.13. The fluid volumes, while maintaining the pump rate, proppant concentration, and the proppant type, that were used in this study are given in Table 3.14. 
Table 3.12: Pump Schedule C For MIP-3H (Base Case).

\begin{tabular}{|c|c|c|c|c|c|c|}
\hline \multicolumn{7}{|c|}{ NNE, MIP 3H Schedule C, 360,000 Lbs (35\% 100 Mesh) } \\
\hline Stage & Stage PPA & $\begin{array}{c}\text { Proppant } \\
\text { Type }\end{array}$ & Fluid Type & $\begin{array}{c}\text { Clean } \\
\text { Fluid (gal) }\end{array}$ & $\begin{array}{c}\text { Slurry Rate } \\
\text { (BPM) }\end{array}$ & $\begin{array}{c}\text { Proppant } \\
\text { Mass (Ibs) }\end{array}$ \\
\hline 1 & Rate & & SlickWater & 840 & 15 & \\
\hline 2 & Acid 15\% & & Acid 15\% HCL & 3000 & 15 & 0 \\
\hline 3 & Pad & & SlickWater & 42000 & 72 & 0 \\
\hline 4 & 0.25 & 100 & SlickWater & 12000 & 72 & 3000 \\
\hline 5 & 0.5 & 100 & SlickWater & 12000 & 72 & 6000 \\
\hline 6 & 0.75 & 100 & SlickWater & 15200 & 72 & 11400 \\
\hline 7 & 1 & 100 & SlickWater & 18900 & 72 & 18900 \\
\hline 8 & 1.5 & 100 & SlickWater & 28867 & 72 & 43300 \\
\hline 9 & 2 & 100 & SlickWater & 22500 & 72 & 45000 \\
\hline 10 & 0.5 & $40 / 70$ & SlickWater & 18800 & 72 & 9400 \\
\hline 11 & 0.75 & $40 / 70$ & SlickWater & 15067 & 72 & 11300 \\
\hline 12 & 1 & $40 / 70$ & SlickWater & 15100 & 72 & 15100 \\
\hline 13 & 1.5 & $40 / 70$ & SlickWater & 26467 & 72 & 39700 \\
\hline 14 & 2 & $40 / 70$ & SlickWater & 37800 & 72 & 75600 \\
\hline 15 & 2.5 & $40 / 70$ & SlickWater & 18900 & 72 & 47250 \\
\hline 16 & 3 & $40 / 70$ & SlickWater & 11350 & 72 & 34050 \\
\hline 17 & & Flush & SlickWater & 12000 & 72 & 0 \\
\hline & & & & 310,790 & & 360,000 \\
\hline
\end{tabular}

Table 3.13: Cluster Spacings and the Number of Fractures Used for Sensitivity Analysis.

\begin{tabular}{|c|c|}
\hline $\begin{array}{c}\text { Cluster } \\
\text { Spacing, ft. }\end{array}$ & $\begin{array}{c}\text { Number of } \\
\text { Fractures }\end{array}$ \\
\hline 30 & 200 \\
\hline 40 & 150 \\
\hline 50 (Base Case) & 120 \\
\hline 60 & 100 \\
\hline 80 & 75 \\
\hline 100 & 60 \\
\hline
\end{tabular}

Table 3.14: Fluid Volumes Used for Sensitivity Analysis.

\begin{tabular}{|l|c|c|c|c|c|}
\hline \multirow{2}{*}{$\begin{array}{l}\text { Fluid Volume per } \\
\text { Stage, Gallon }\end{array}$} & \multicolumn{4}{|c|}{ Cases } \\
\cline { 2 - 6 } & 95,783 & 184,315 & $\begin{array}{c}\mathbf{3 1 0 , 7 9 0} \\
\text { (Base Case) }\end{array}$ & 374,028 & 553,740 \\
\hline
\end{tabular}




\section{CHAPTER 4: RESULTS AND DISCUSSION}

\subsection{Result of Fracture Properties (Well MIP-6H)}

The results of fracture-modeling software are provided in Table 4.1 for well MIP-6H. The large fracture height is believed due to the lack of significant barriers which could limit the fracture height growth.

Table 4.1: Hydraulic Fracture Properties for Well MIP-6H.

\begin{tabular}{|c|c|c|c|c|c|c|c|c|}
\hline \multirow[t]{2}{*}{ Stages } & \multicolumn{2}{|c|}{ Average Fracture Width } & \multicolumn{2}{|c|}{ Fracture Height } & \multicolumn{2}{|c|}{ Fracture Half-Length } & \multicolumn{2}{|c|}{ Fracture Conductivity } \\
\hline & $\begin{array}{c}\text { Without Stress } \\
\text { Shadowing } \\
\text { Effects }\end{array}$ & $\begin{array}{c}\text { With Stress } \\
\text { Shadowing } \\
\text { Effects }\end{array}$ & $\begin{array}{c}\text { Without Stress } \\
\text { Shadowing } \\
\text { Effects }\end{array}$ & $\begin{array}{c}\text { With Stress } \\
\text { Shadowing } \\
\text { Effects }\end{array}$ & $\begin{array}{c}\text { Without Stress } \\
\text { Shadowing } \\
\text { Effects }\end{array}$ & $\begin{array}{c}\text { With Stress } \\
\text { Shadowing } \\
\text { Effects }\end{array}$ & $\begin{array}{c}\text { Without Stress } \\
\text { Shadowing } \\
\text { Effects }\end{array}$ & $\begin{array}{c}\text { With Stress } \\
\text { Shadowing } \\
\text { Effects }\end{array}$ \\
\hline & in & in & ft. & ft. & ft. & ft. & md-ft & md-ft \\
\hline 1 & 0.46 & 0.46 & 120 & 120 & 300 & 300 & 12 & 12 \\
\hline 2 & 0.46 & 0.38 & 120 & 100 & 300 & 280 & 18 & 10 \\
\hline 3 & 0.46 & 0.29 & 120 & 90 & 300 & 280 & 16 & 4 \\
\hline 4 & 0.44 & 0.40 & 120 & 100 & 300 & 280 & 13 & 8 \\
\hline 5 & 0.43 & 0.32 & 130 & 120 & 320 & 280 & 14 & 9 \\
\hline 6 & 0.43 & 0.31 & 140 & 130 & 320 & 300 & 17 & 9 \\
\hline 7 & 0.46 & 0.29 & 140 & 130 & 300 & 220 & 17 & 7 \\
\hline 8 & 0.44 & 0.23 & 140 & 70 & 300 & 180 & 15 & 3 \\
\hline
\end{tabular}

\subsection{Impact of Geomechanical Factor (Propped Fracture Conductivity)}

The geomechanical factor for hydraulic fracture, which was obtained from experimental results by McGinley et al. (2015), was only used in the model.

The results of history matching for MIP-6H using production data for the first 730 days are provided in Table 4.2. The history matching was performed by varying hydraulic fracture half-length, whereas the reservoir properties were held constant. Figure 4.1 illustrates the match between the simulation results (Red Line) and the actual field production data (Dashed Blue Line) for the first 730 days. Consequently, the matched model was used to predict the production for the next 730 days to verify the accuracy and reliability of the matched model. The predicted production rates are nearly identical to the actual data, as seen in Figure 4.1. This confirmed the reliability of the matched model. 
When geomechanical factor (Propped Fracture Conductivity) Fracture properties include in the reservoir model (the fracture half-length and fracture conductivity) predicted for the well (6H) by GOFHER software still resulted in significantly higher production than observed from the field data.

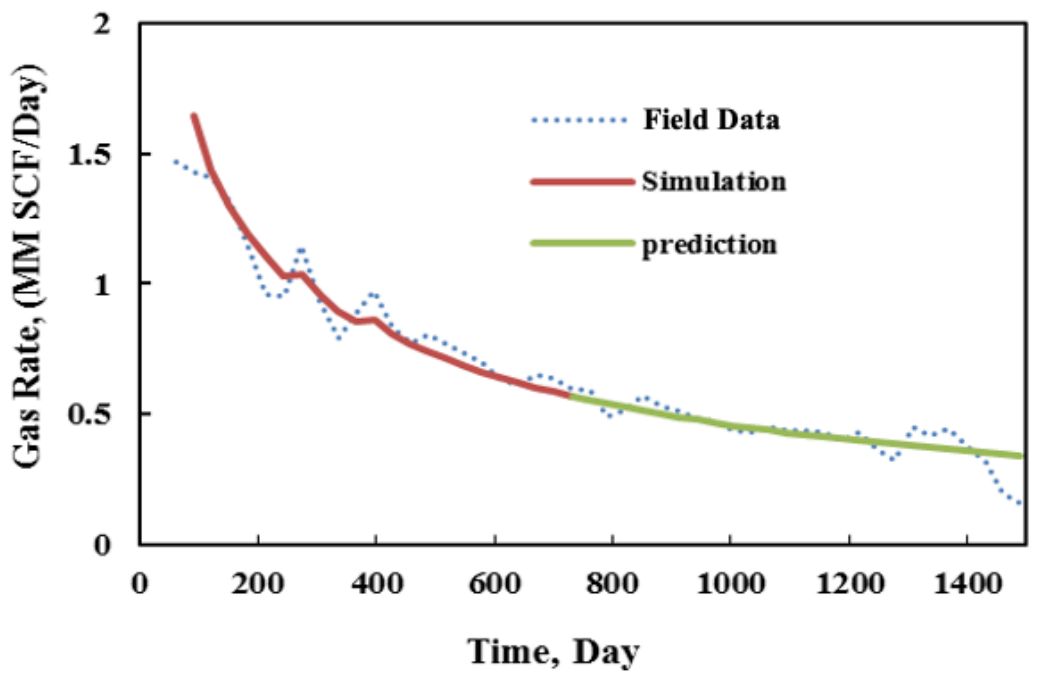

Figure 4.1: Predicted Production Rates for MIP-6H with Geomechanical Factor (Hydraulic Fracture) for Four Years.

Table 4.2: History Matching Parameters for MIP-6H With Geomechanical Factor.

\begin{tabular}{|c|c|}
\hline \multicolumn{2}{|l|}{ Elimsport Sample } \\
\hline Paramters & MIP-6H \\
\hline Number of Hydraulic Fractures & 8 \\
\hline Fracture Half-Length, $x_{f}(\mathbf{f t})$ & 200 \\
\hline Fracture Conductivity, $\mathrm{k}_{f} \mathrm{w}_{f},(\mathrm{mD}-\mathrm{ft})$ & 25 \\
\hline
\end{tabular}

To investigate the impact of stress-dependent propped fracture conductivity on the production, the geomechanical factor was excluded from the matched model for MIP-6H, and the entire production history was simulated for comparison purposes. Figures 4.2 and 4.3 illustrate the impact of the geomechanical factor on production rates and cumulative gas production (recovery).

It is evident from Figure 4.2 that the stress-dependent propped fracture conductivity has a significant impact on gas production initially and to a much lesser extent at late times. It should be noted that even though the decrease in fracture conductivity at early times is small, the production is impacted significantly because of higher gas flow rates (due to high reservoir pressure). While later, the impact of fracture conductivity on production is less significant because of the low gas flow rate(due to reservoir pressure 
depletion). Furthermore, at low Young's modulus, the stress-dependent propped hydraulic fracture conductivity could substantially reduce the initial production rate and ultimate gas recovery. Subsequently, the impact of stress-dependent propped hydraulic fracture conductivity must be taken into consideration for predicting shale gas production, particularly at the early stages of production.

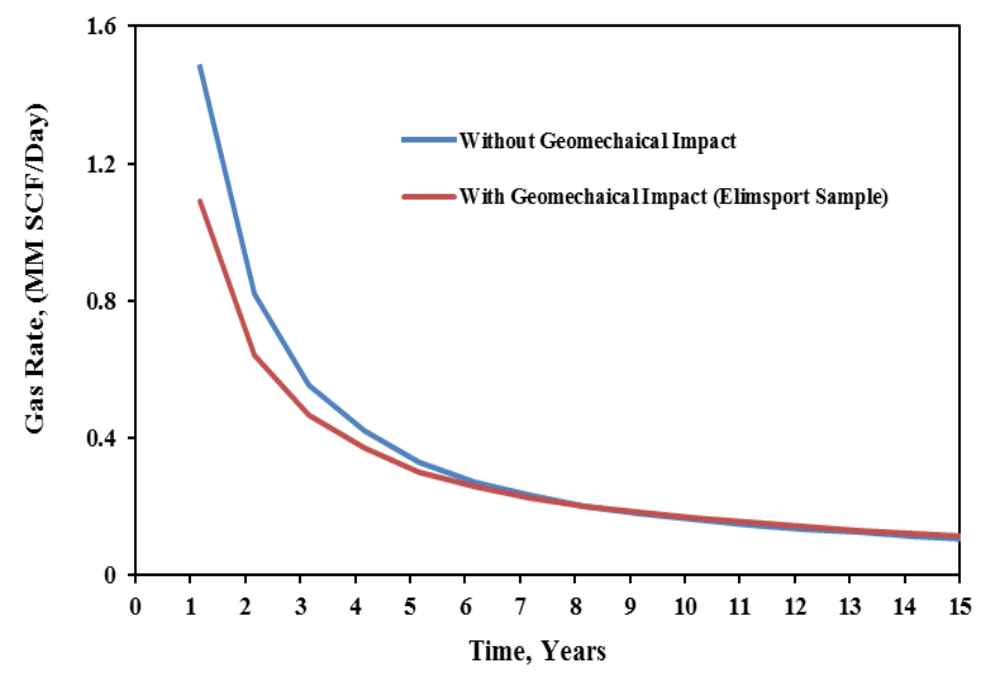

Figure 4.2: Gas Flow Rate for 15 Years with and without Considering Geomechanical Factor for Well MIP-6H (Elimsport Sample).

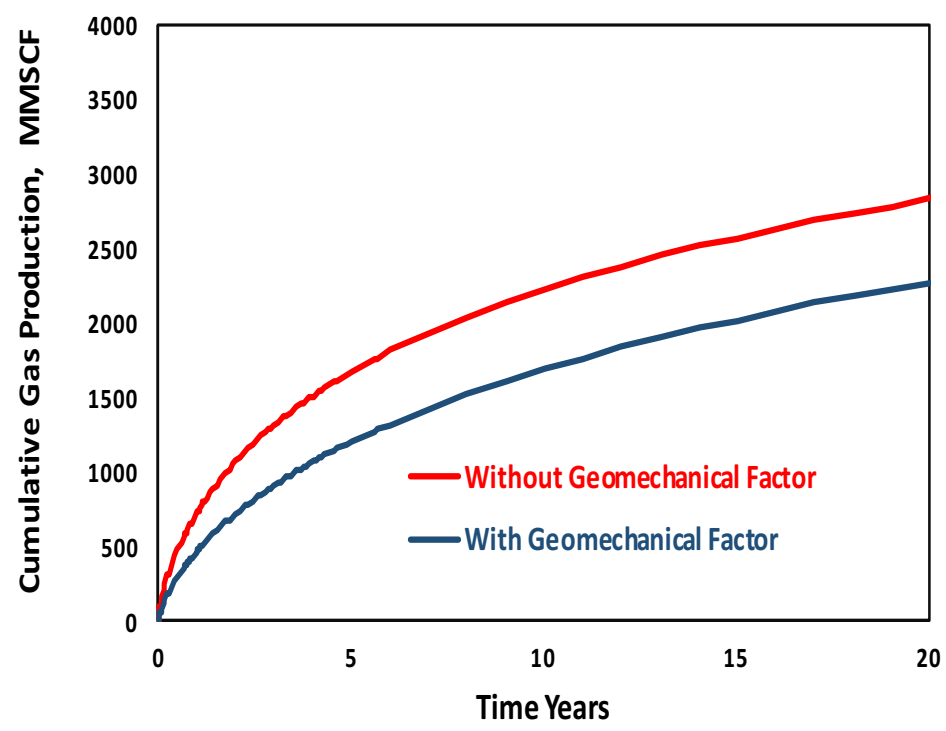

Figure 4.3: Cumulative Gas Production with and without Geomechanical Factor.

\subsection{Impact of Geomechanical Factors (Matrix, Fissure Permeability, and Propped Fracture}

\section{Conductivity)}

The geomechanical factors for matrix and fissure permeability, which were obtained from experimental results by Elsaig et al. (2016), were used in the model, as mentioned earlier. Furthermore, the 
geomechanical factor for hydraulic fracture, which was obtained from experimental results by McGinley et al. (2015), was used in the model.

Figure 4.4 illustrates the match between the simulation results (Red Line) and the actual field production data (Dashed Blue Line) from well MIP-6H for the first 730 days. The predicted production rates for the next 730 days are provided in Figure 9 and are compared against the actual production rates. As shown in Figure 4.4, the predicted production rates are nearly identical to the actual rates. This confirmed the reliability of the matched model. The values of the hydraulic fracture half-length obtained from history matching for all the cases are provided in Table 3.

Inclusion of the geomechanical factor (Matrix, Fissure Permeability Propped Fracture Conductivity) resulted in much longer hydraulic fracture half-lengths closer to the values predicted by Hydraulic Fracturing Models (GOFHER).

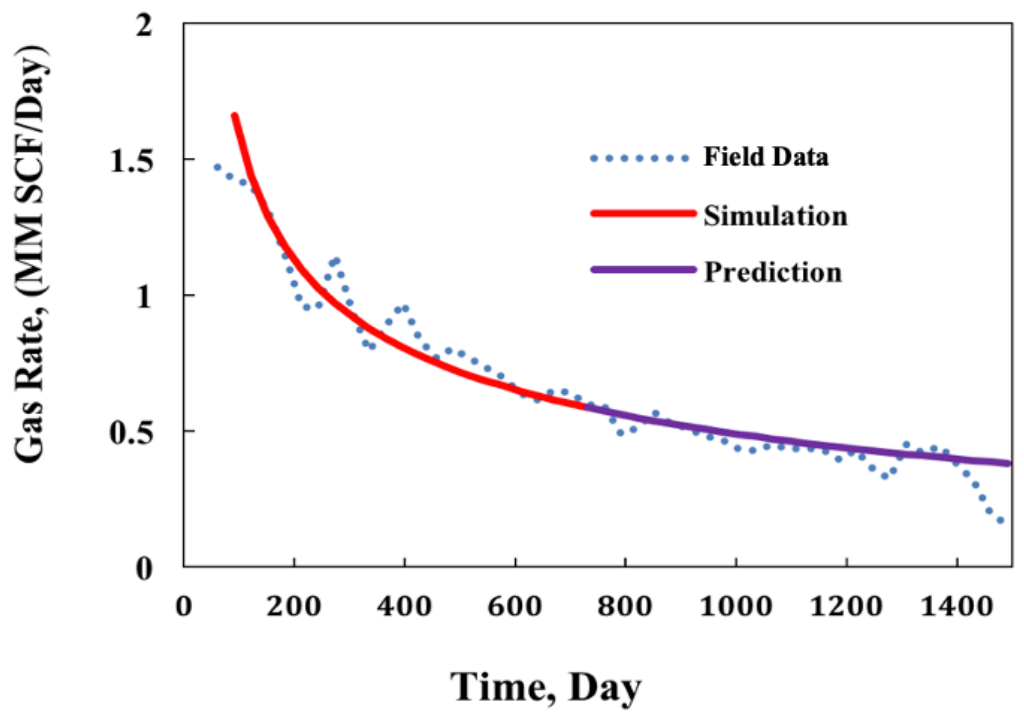

Figure 4.4: Predicted Production Rates for Well MIP-6H with Geomechanical Factors (Matrix, Fissure Permeability, and Hydraulic Fracture).

Table 4.3: Estimated Hydraulic Fracture Half-length for Well MIP-6H.

\begin{tabular}{|l|c|c|c|c|}
\hline Cases & 1 & 2 & 3 & 4 \\
\hline Fracture Half-Length, $\mathrm{x}_{\mathrm{f}}$ ft. & 300 & 240 & 180 & 280 \\
\hline
\end{tabular}

Figure 4.5 compares the predicted gas production rates, by the model, for well MIP-6H with and without the geomechanical factors. The gas flow rate decreases more rapidly when the geomechanical factors are included in the model. However, the geomechanical factors appear to diminish after about 15 
years. The geomechanical factors could substantially reduce the initial production rate and ultimate gas recovery. Subsequently, the impact of geomechanical factors must be considered for accurate prediction of the shale well production. This is particularly vital at the early stages of production.

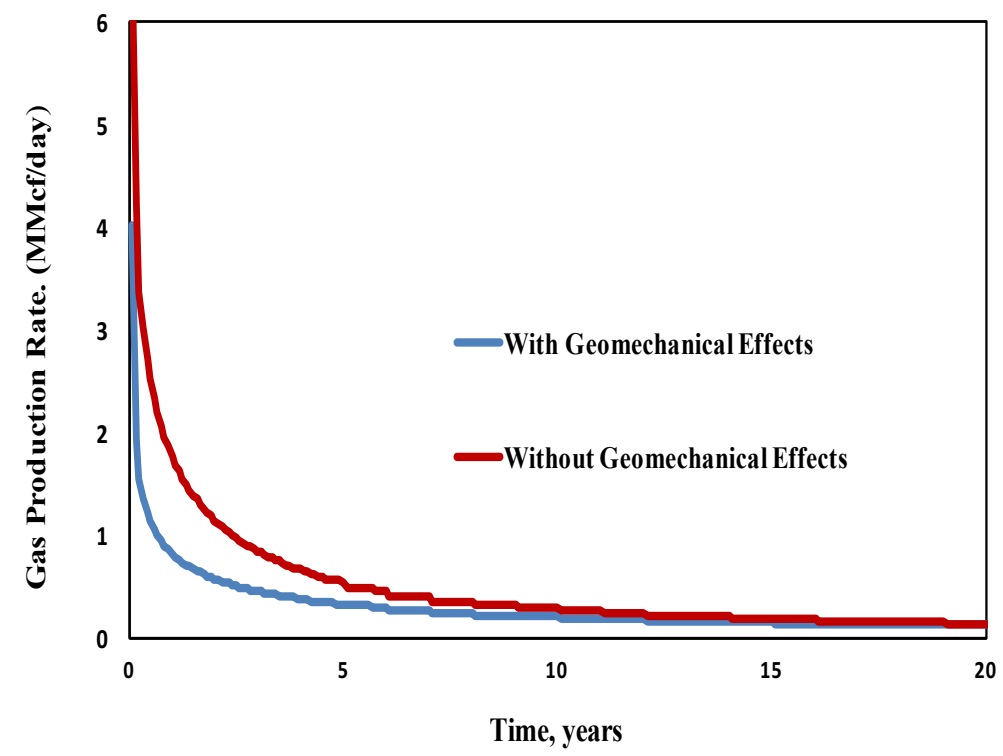

Figure 4.5: The Predicted 20-Year Gas Flow Rates for Well MIP-6H.

To investigate the impact of these geomechanical factors, each geomechanical factor was excluded from the matched model for MIP-6H for "case 1." Furthermore, the entire production history was simulated for comparison purposes. The results are illustrated in Figure 4.6. It is obvious from Figure 4.6 that the geomechanical factor associated with the fissure permeability has the most impact on the production. However, the geomechanical factor associated with matrix permeability has the least impact on gas production. This result could be related to a more stress-sensitive fissure when compared to the matrix or hydraulic fracture. Furthermore, it is clear from Figure 4.6 that the impact of the geomechanical factor associated with propped fracture conductivity occurs at a very early time of production. However, the impact of the geomechanical factor associated with matrix permeability is minor at a very early time of production. As production continues, the impact of the geomechanical factor associated with matrix permeability reduction becomes noticeable. also, the impact of the geomechanical factor associated with propped fracture conductivity becomes less prevalent than the impact of the geomechanical factor associated with the fissure permeability. Figure 4.7 illustrates the percentage reduction in gas recovery due to the geomechanical factors. 


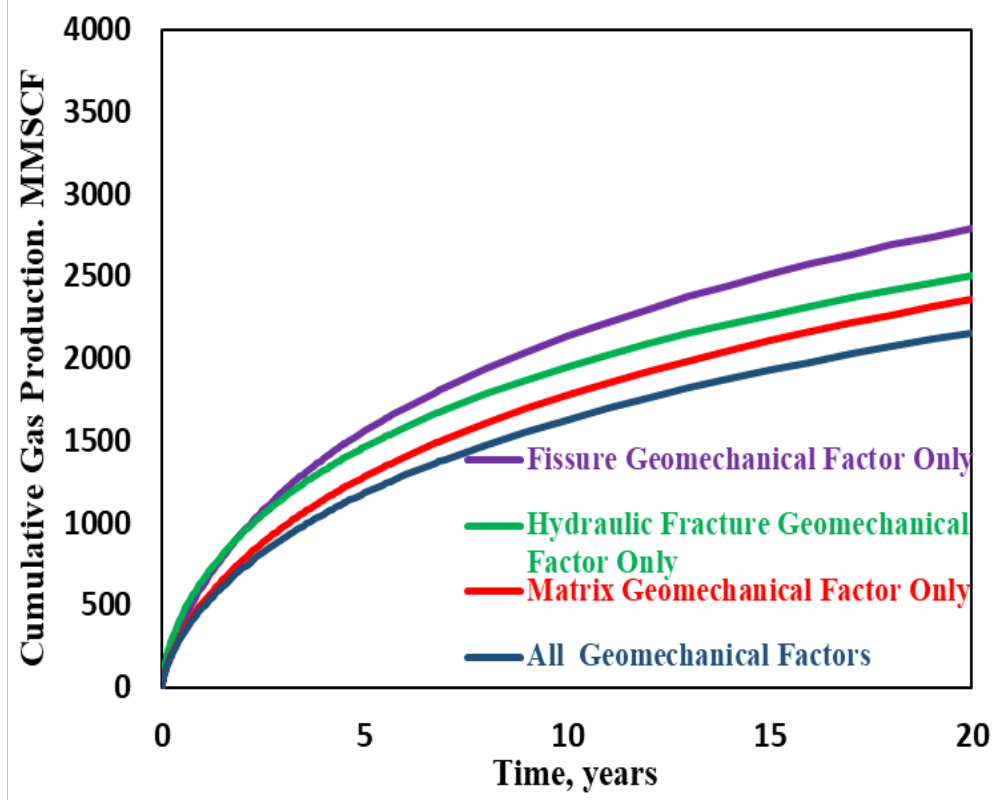

Figure 4.6: Cumulative Gas Production for Well MIP-6H.

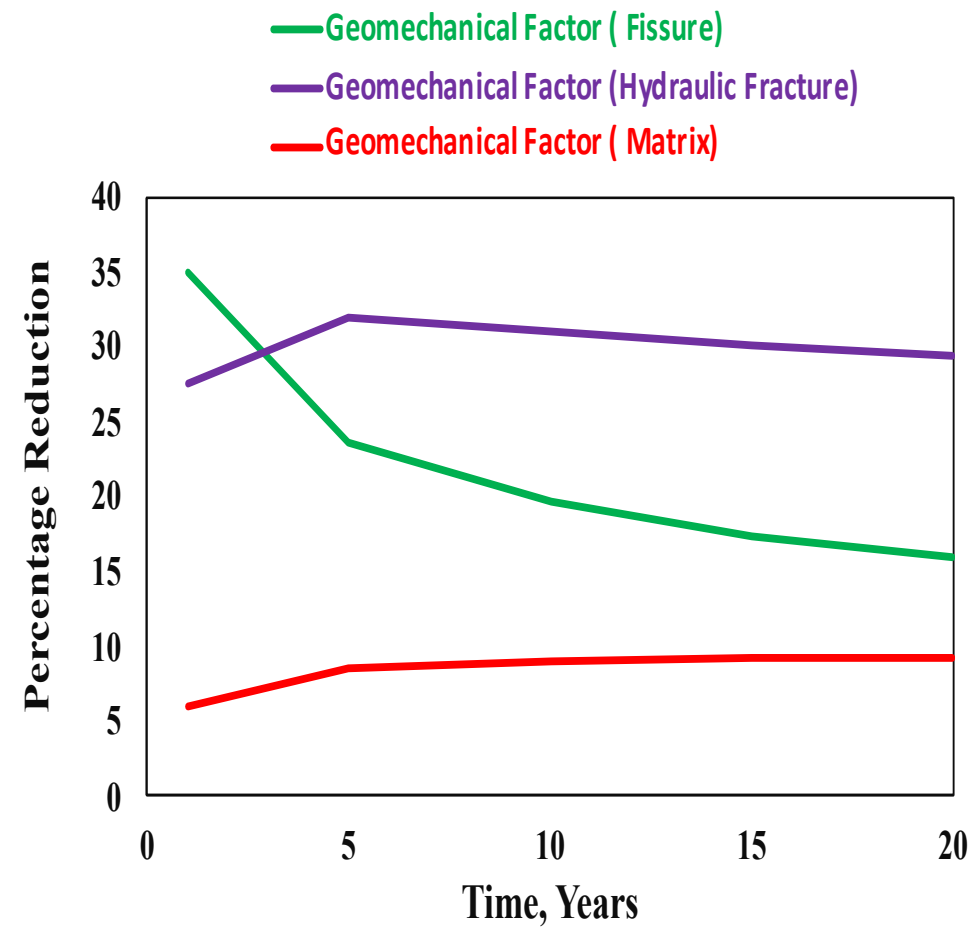

Figure 4.7: Percentage Reduction in Gas Recovery Due to Geomechanical Factors. 


\subsection{Impact of Geomechanical Factors and Gas Slippage (Well MIP-6H)}

The geomechanical factor for matrix permeability, utilized from experimental results by Elsaig et al. (2016), was used in the model, as mentioned earlier. However, the geomechanical factor for fissure permeability, which was obtained from experimental results by Cipolla et al. (2008), was used in the model as mentioned earlier. Furthermore, the geomechanical factor for hydraulic fracture, which was obtained from experimental results by McGinley et al. (2015), was used in the model.

The hydraulic fracture half-length for MIP-6H was the main variable which was determined by history matching the production data for the first 730 days. Figure 4.8 illustrates the match between the simulation results (Red Line) and the actual field production data (Dashed Blue Line) for case 1. Consequently, the matched model for case 1 was used to predict the production for the next 743 days to verify the accuracy and reliability of the matched model. The predicted production rates are nearly identical to the actual data, as seen in Figure 4.8. This confirmed the reliability of the matched model.

Table 4.4 summarizes the estimated effective fracture half-length for all the cases listed previously. As can be observed from Table 4.5, the inclusion of the geomechanical effects results in much longer hydraulic fracture half-lengths (Cases 1 and 2 vs. Case 6), which are closer to the values predicted by Hydraulic Fracturing Models. The predicted production rates are nearly identical to the actual data, as seen in Figure 4.8.

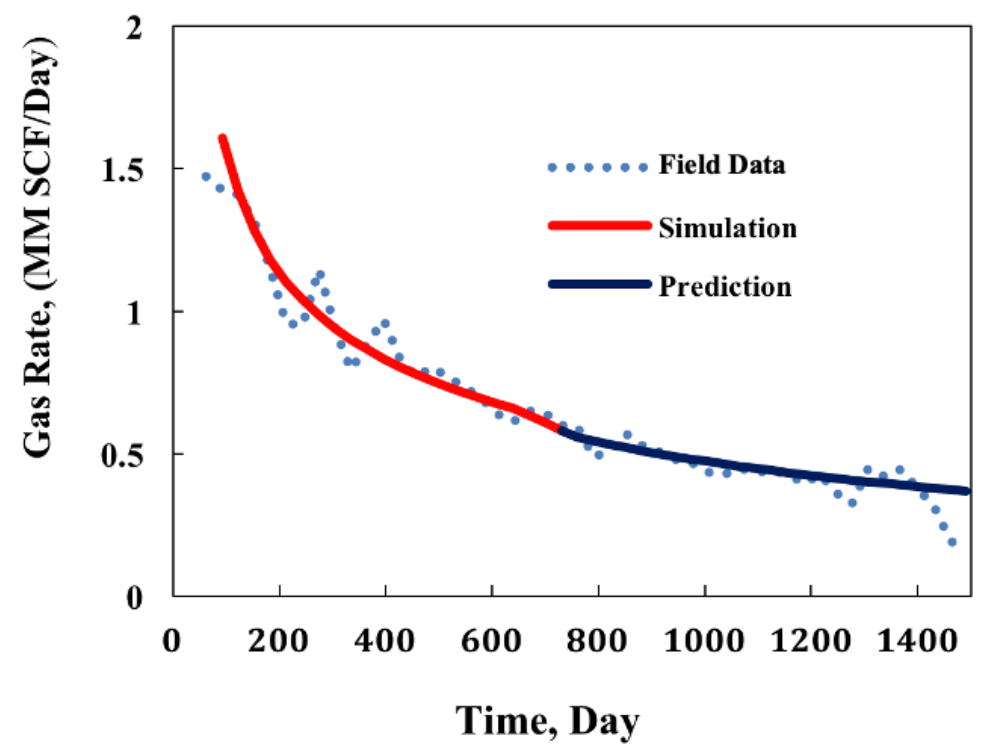

Figure 4.8: Comparison of the Predicted and Actual Production for Well MIP-6H (1473 days). 
Table 4.4: Estimated Fracture Half-length Obtained from History Matching.

\begin{tabular}{|l|c|c|c|c|c|c|}
\hline Cases & $\mathbf{1}$ & $\mathbf{2}$ & $\mathbf{3}$ & $\mathbf{4}$ & $\mathbf{5}$ & $\mathbf{6}$ \\
\hline Fracture Half-Length, ft., MIP-6H & 380 & 380 & 360 & 320 & 220 & 100 \\
\hline
\end{tabular}

When geomechanical factors (Matrix, Fissure Permeability, and Hydraulic Fracture) are taken into account, the accumulative gas production is definitely reduced because matrix, fissure, and hydraulic fracture permeability are decreased with the reduction of reservoir pressure. However, the production loss is extremely dependent on the correlation between matrix and fissure permeability with net stress. Furthermore, different core samples provide different results. Therefore, the correlation between matrix and fissure permeability with net stress plays a significant role in investigating how much is the impact of geomechanical factors on production performance.

Figure 4.9 compares the simulation results and the field water flow rates for well MIP-6H. The simulated results are based on the reduced initial water saturation of $60 \%$ for the hydraulic fracture and the natural fracture. Additionally, the endpoint of the relative permeability for water was reduced from 1 to 0.8 for hydraulic fracture and natural fracture.

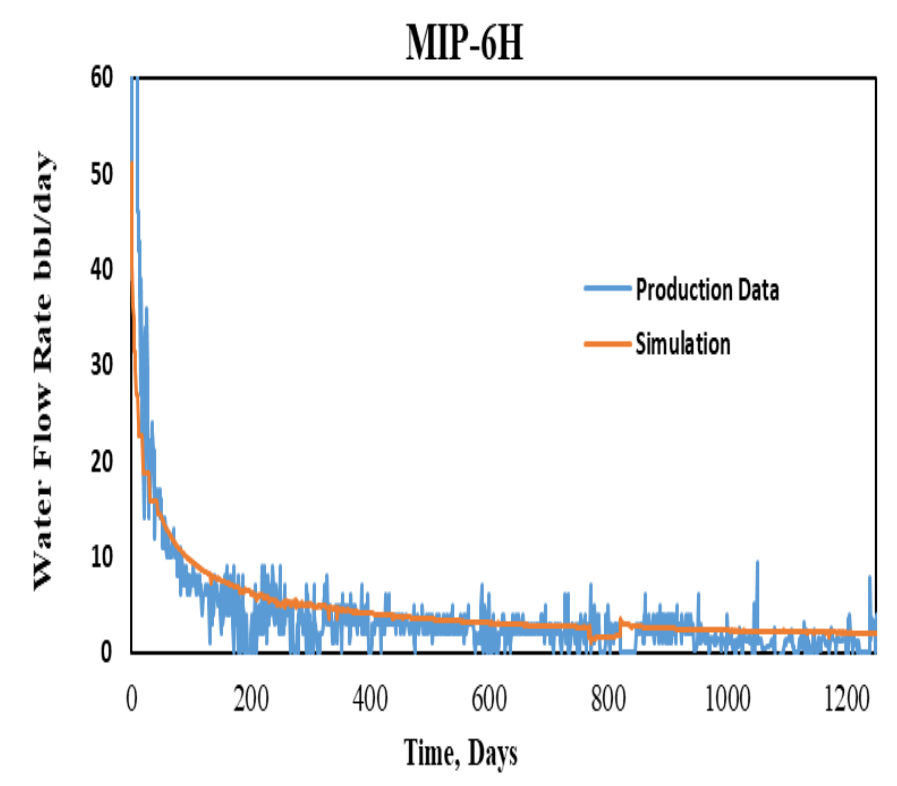

Figure 4.9: Production History for Well MIP-6H Water Production Rate.

Figure 4.10 compares the predicted gas production rates, by the model, for well MIP-6H with and without geomechanical effects. The gas flow rate decreases more rapidly when the geomechanical effects are included in the model. However, the geomechanical effects appear to diminish after about 15 years. The 
geomechanical effects could substantially reduce the initial production rate and ultimate gas recovery. Subsequently, the impact of stress-dependent matrix permeability, fissure permeability, and propped hydraulic fracture conductivity must be considered to accurately predict shale well production, particularly at the early stages of production.

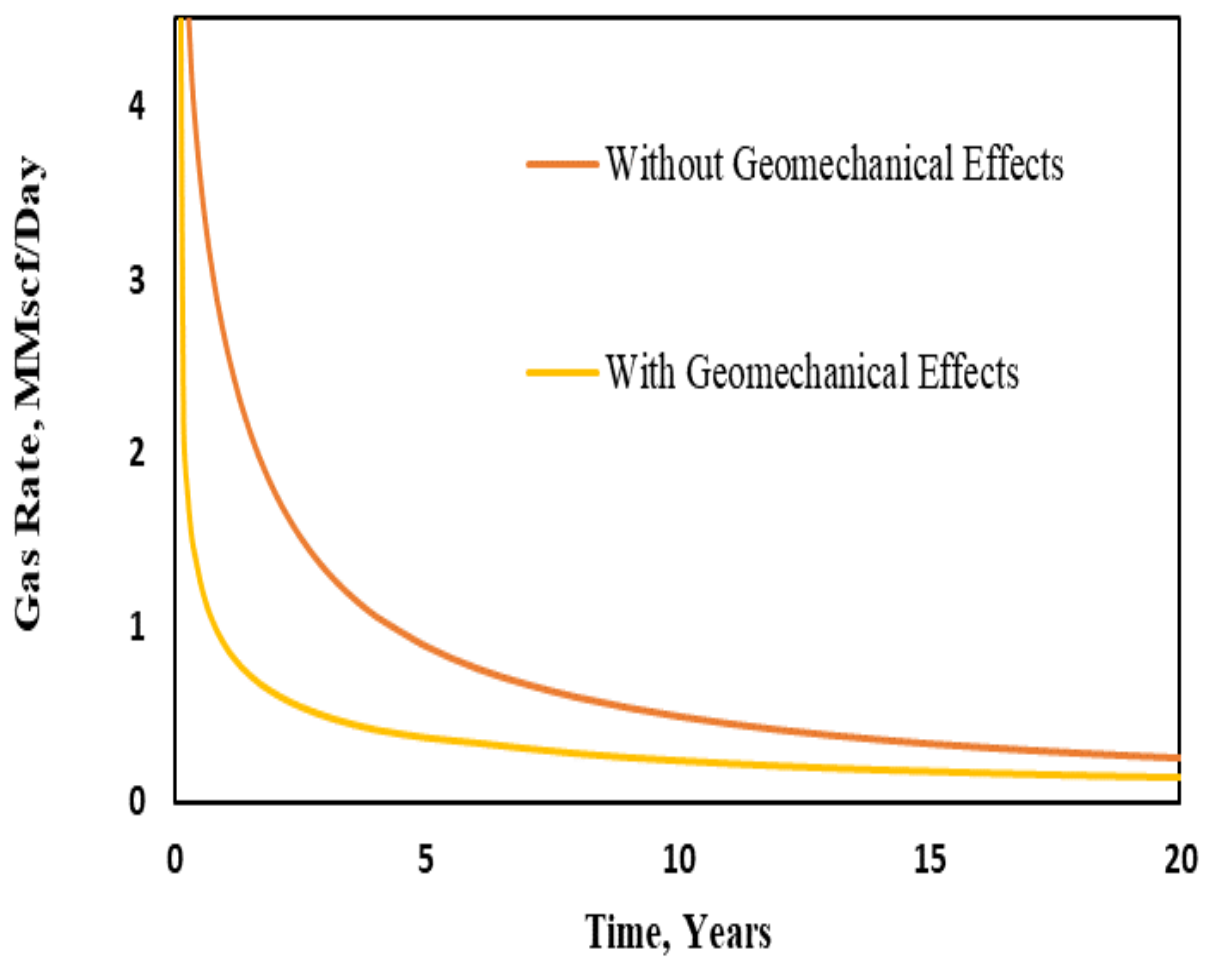

Figure 4.10: The Predicted 10-Year Gas Flow Rates for Well MIP-6H.

To investigate the impact of stress-dependent matrix permeability, fissure permeability, and propped fracture conductivity, each effect was excluded from the matched model for MIP-6H for (case 1), and the entire production history was simulated for comparison purposes. The results are illustrated in Figure 4.11. It is obvious from Figure 4.11 that the geomechanical factor associated with the fissure permeability has the most impact on the production and the geomechanical factor associated with matrix permeability has the least impact on gas production. This could be related to more stress-sensitive fissures as compared to the matrix or hydraulic fracture. The gas slippage did not show any significant impact on the predicted gas production rates. 


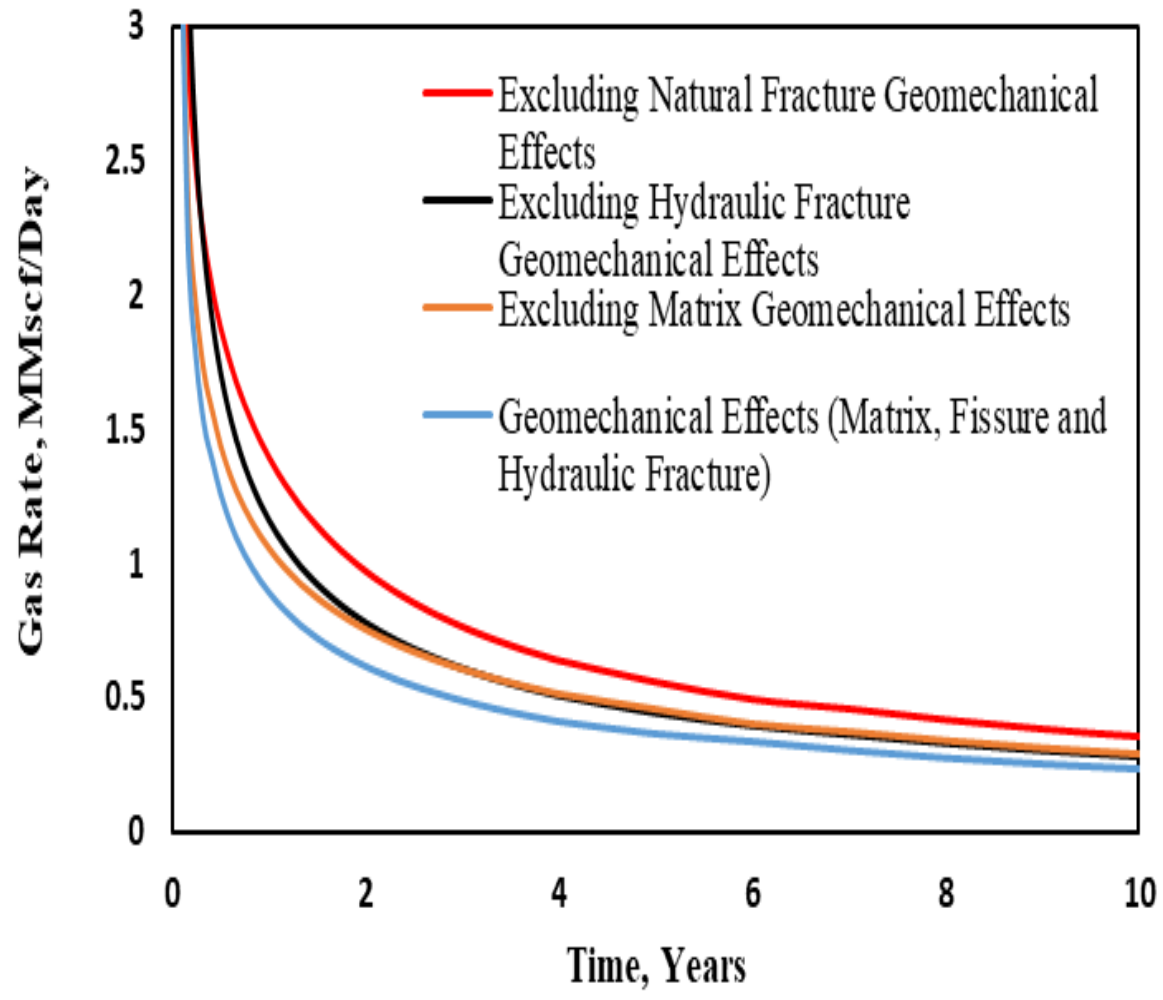

Figure 4.11: The Impact of Different Geomechanical Effects on the Predicted Gas Flow Rates.

\subsection{Impact of Stress Shadowing and Geomechanical Factors}

\subsubsection{Well MIP-6H}

The results of fracture-modeling software are provided in Table 4.5. Figure 4.12 compares three different production gas profiles and the actual production rates for well MIP-6H. The first production profile (orange) was generated using fracture properties predicted without stress shadowing effects (from GOHFER calibrated model), as illustrated in Figure 4.12, and by ignoring the geomechanical factors in the reservoir models. The second production profile (green) was generated using the same fracture properties, but the geomechanical factors were included in the reservoir models. The third production profile (red) was generated using fracture properties predicted with stress shadowing effects, as illustrated in Figure 4.12, and the geomechanical factors were included in the reservoir models. As can be observed from Figure 4.12, the inclusion of stress shadowing and geomechanical factors results in the closest prediction with the production data from well MIP-6H. Figure 4.13 illustrates the impact of stress shadowing on the predicted cumulative gas production for 20 years. 
Table 4.5: Fracture Properties with and without Stress Shadowing Effects for Well MIP-6H.

\begin{tabular}{|c|c|c|c|c|c|c|c|c|}
\hline \multirow[t]{3}{*}{ Stages } & \multicolumn{2}{|c|}{ Average Fracture Width } & \multicolumn{2}{|c|}{ Fracture Height } & \multicolumn{2}{|c|}{ Fracture Half-Length } & \multicolumn{2}{|c|}{ Fracture Conductivity } \\
\hline & $\begin{array}{c}\text { Without Stress } \\
\text { Shadowing } \\
\text { Effects }\end{array}$ & $\begin{array}{c}\text { With Stress } \\
\text { Shadowing } \\
\text { Effects }\end{array}$ & $\begin{array}{c}\text { Without Stress } \\
\text { Shadowing } \\
\text { Effects }\end{array}$ & $\begin{array}{c}\text { With Stress } \\
\text { Shadowing } \\
\text { Effects }\end{array}$ & $\begin{array}{c}\text { Without Stress } \\
\text { Shadowing } \\
\text { Effects }\end{array}$ & $\begin{array}{c}\text { With Stress } \\
\text { Shadowing } \\
\text { Effects }\end{array}$ & $\begin{array}{c}\text { Without Stress } \\
\text { Shadowing } \\
\text { Effects }\end{array}$ & $\begin{array}{c}\text { With Stress } \\
\text { Shadowing } \\
\text { Effects }\end{array}$ \\
\hline & in & in & ft. & ft. & ft. & ft. & md-ft & md-ft \\
\hline 1 & 0.46 & 0.46 & 120 & 120 & 300 & 300 & 12 & 12 \\
\hline 2 & 0.46 & 0.38 & 120 & 100 & 300 & 280 & 18 & 10 \\
\hline 3 & 0.46 & 0.29 & 120 & 90 & 300 & 280 & 16 & 4 \\
\hline 4 & 0.44 & 0.40 & 120 & 100 & 300 & 280 & 13 & 8 \\
\hline 5 & 0.43 & 0.32 & 130 & 120 & 320 & 280 & 14 & 9 \\
\hline 6 & 0.43 & 0.31 & 140 & 130 & 320 & 300 & 17 & 9 \\
\hline 7 & 0.46 & 0.29 & 140 & 130 & 300 & 220 & 17 & 7 \\
\hline 8 & 0.44 & 0.23 & 140 & 70 & 300 & 180 & 15 & 3 \\
\hline
\end{tabular}

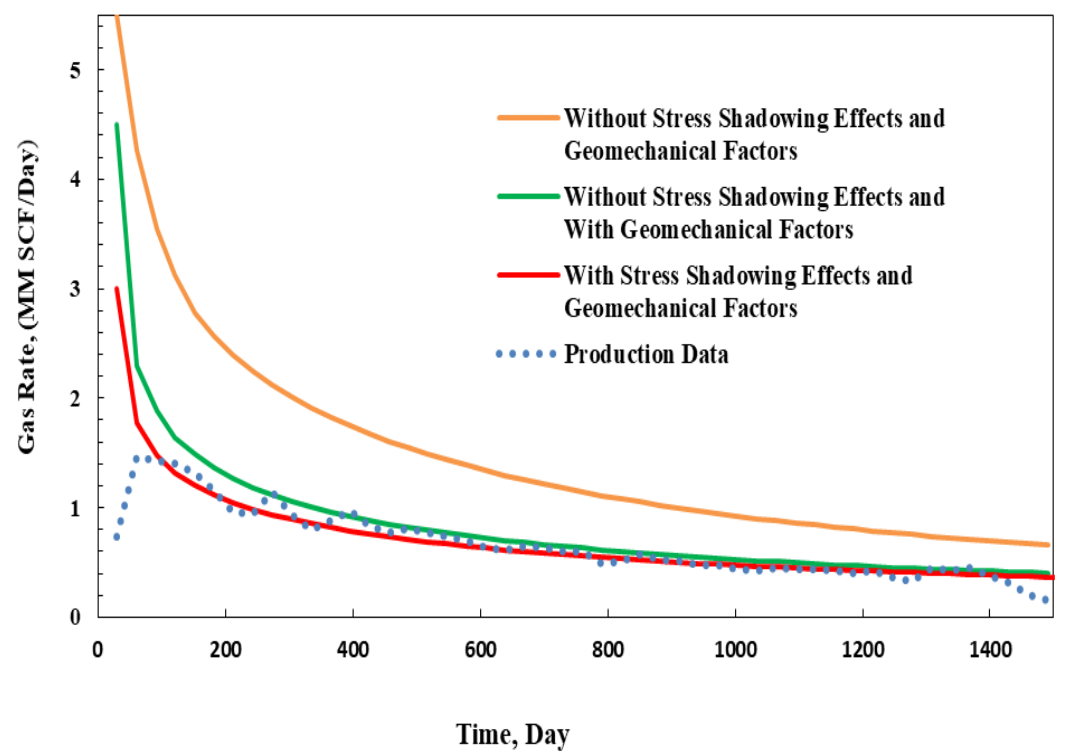

Figure 4.12: Gas Flow Rate with, without Stress Shadowing Effects, and without Geomechanical Factors for Well MIP-6 H. 


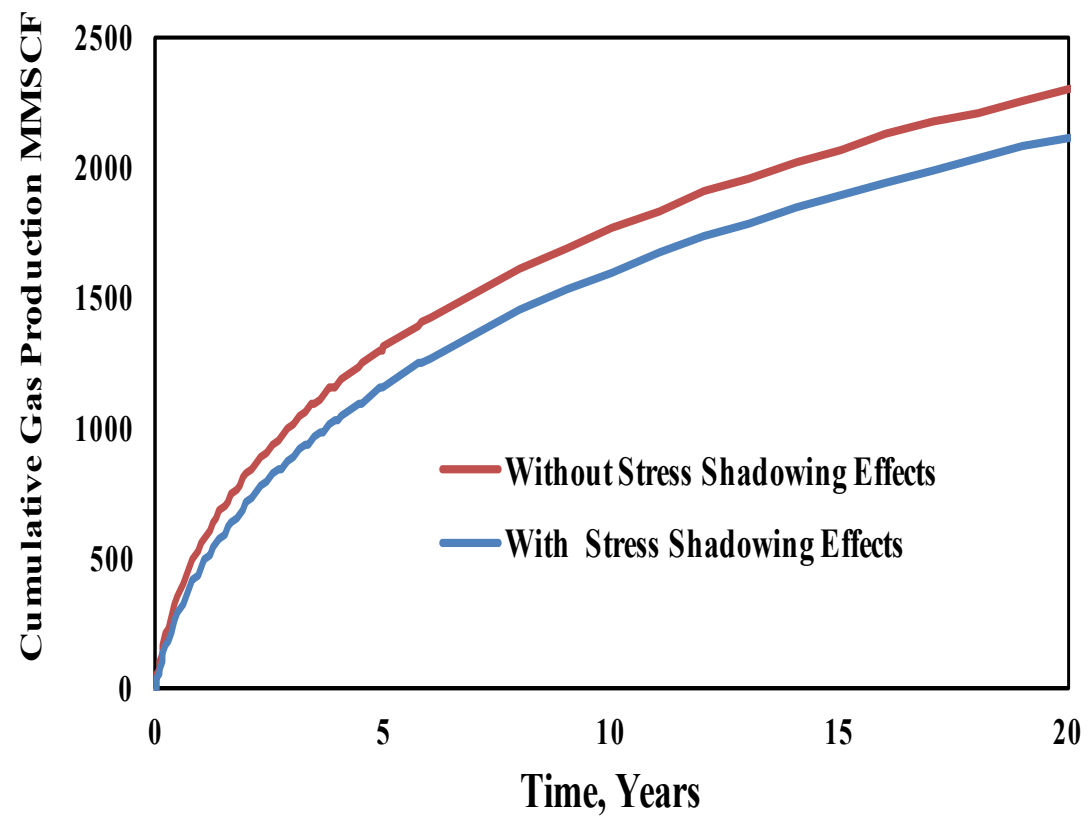

Figure 4.13: Impact of Stress Shadowing on Cumulative Gas Production.

\subsubsection{Well MIP-3H}

Figure 4.14 (a) illustrates the fracture height growth, obtained from microseismic interpretations, for different fracture stages in well MIP-3H. Figure 4.14 (b) shows the height asymmetry for different fracture stages in well MIP-3H. Figures 4.15 (a) and (b) illustrate the fracture length obtained from microseismic interpretations for different fracture stages in well MIP-3H. It is evident from Figure 4.16 that the fractures grow much more in an upward direction. The average half-length and height are $784 \mathrm{ft}$ and $432 \mathrm{ft}$. respectively from microcosmic interpretations. Figures 4.16 and 4.17 illustrate the predicted hydraulic fracture properties by GOPHER for 28 stages in well MIP-3H. The predicted fracture length and height for different stages are supported by microseismic study (StimMap Evaluation Report generated by Schlumberger).

Figure 4.18 illustrates the proppant concentration for different hydraulic fracture stages. It was evident that the proppant concentrate in the lower section of the fracture. Furthermore, Figure 4.18 shows that the fractures grew more in an upward direction, which is in agreement with the microseismic interpretations. 

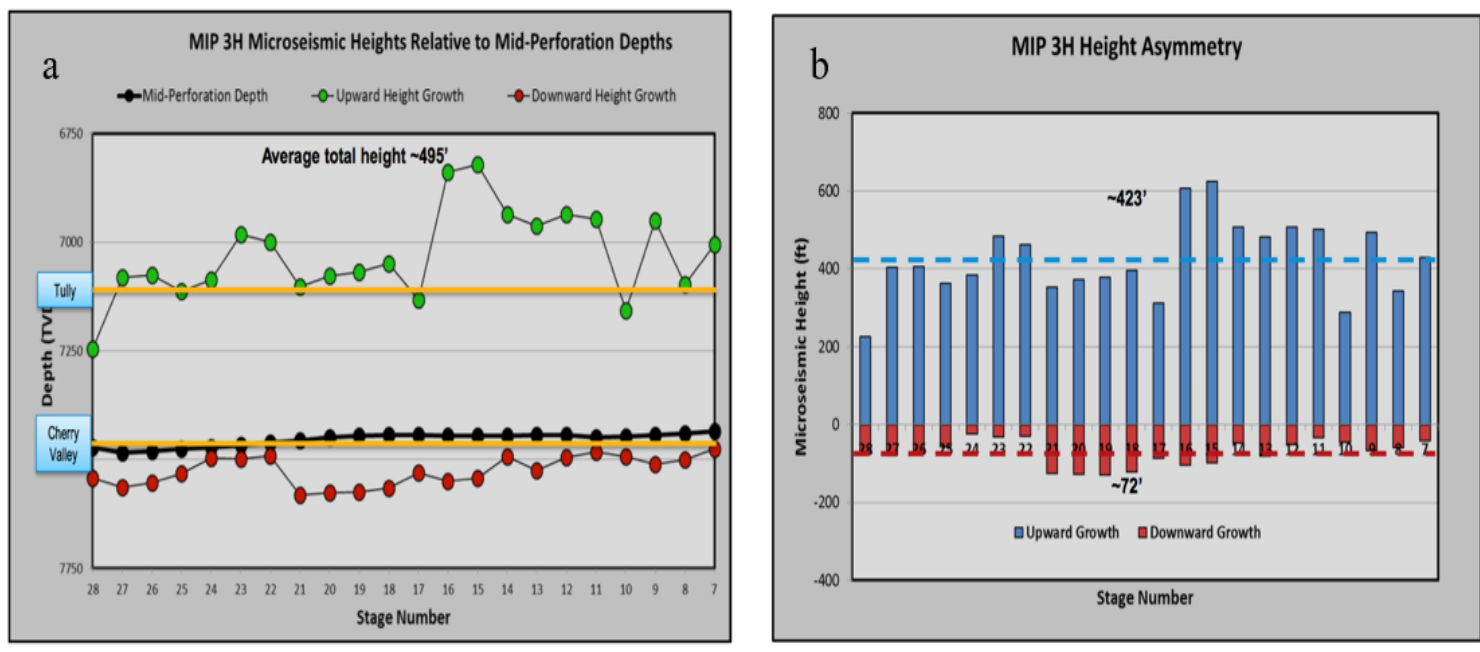

Figure 4.14: (a) Shows Upward vs. Downward Height Growth Per Stage (b) Illustrates the Height Asymmetry for Well MIP-3H (StimMap Evaluation Report Generated by Schlumberger).
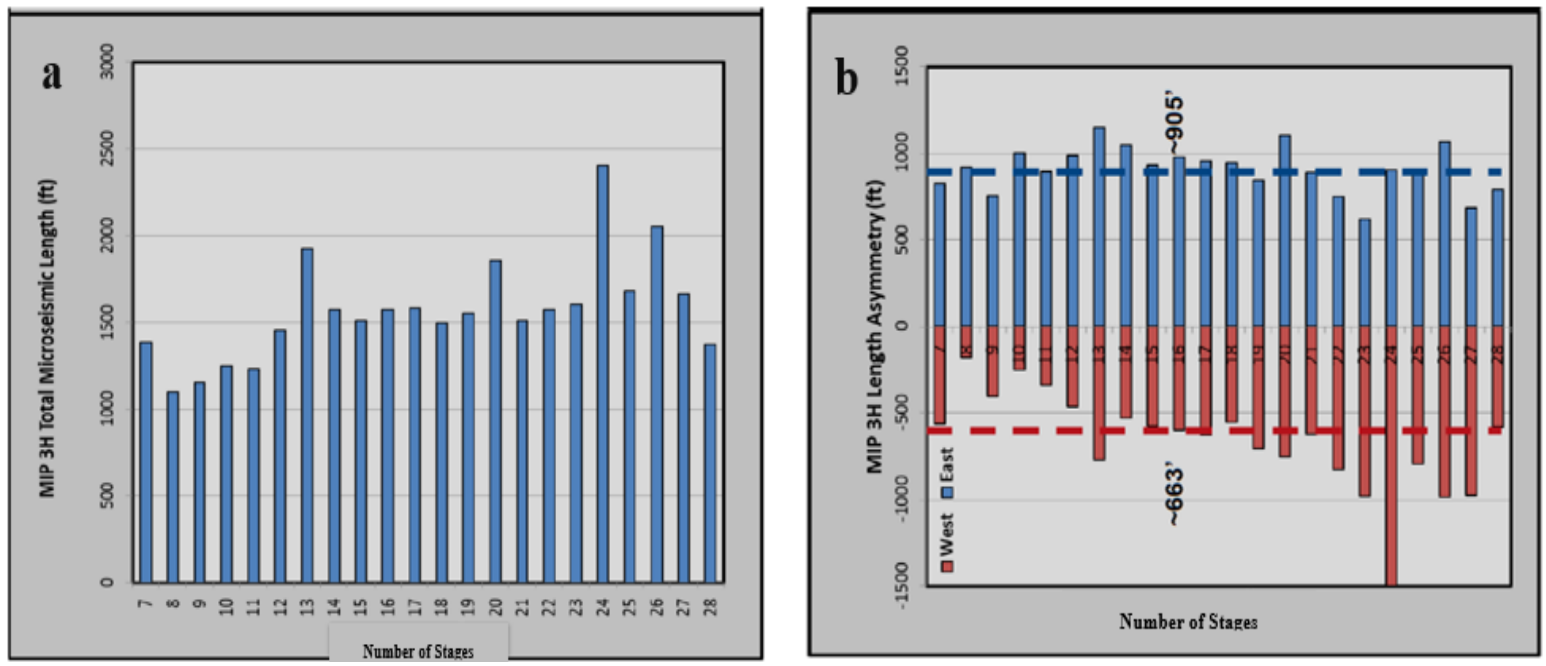

Figure 4.15: Illustrates the Fracture Length from Microseismic Interpretations (StimMap Evaluation Report generated by Schlumberger). 


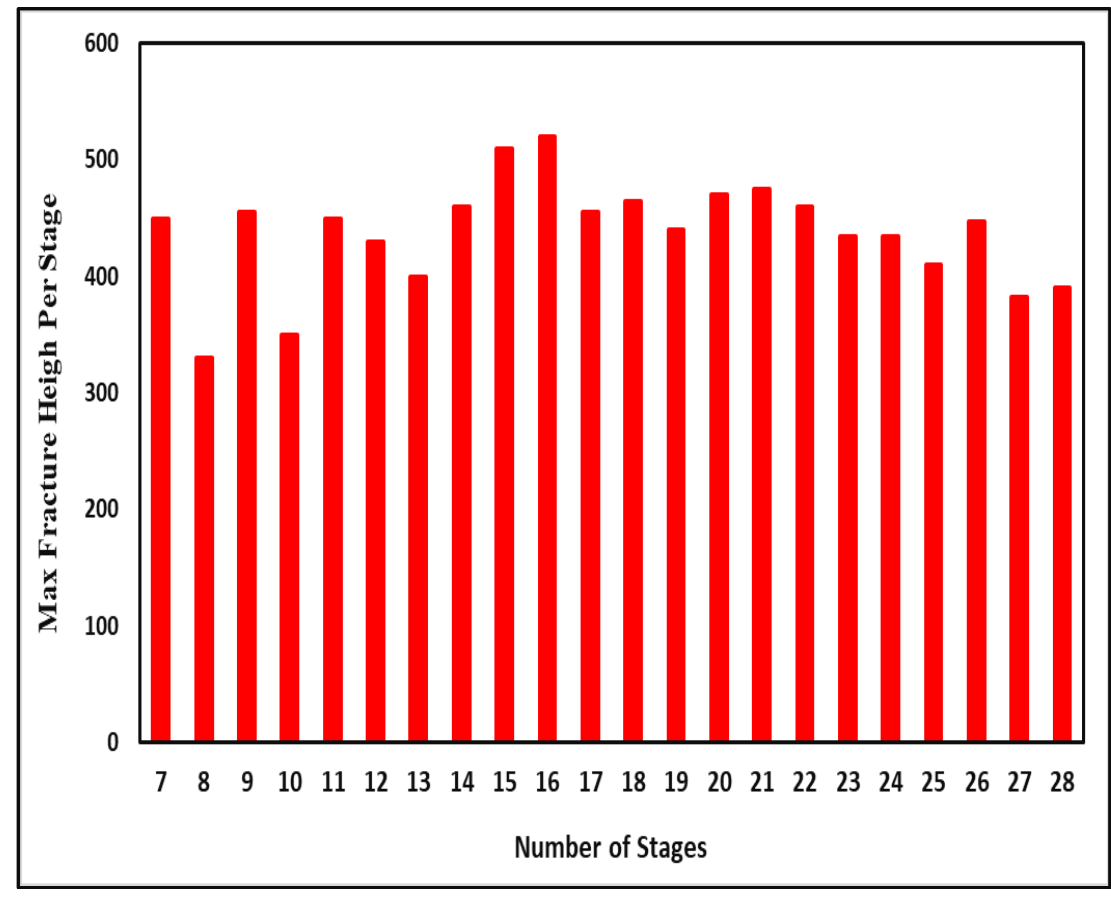

Figure 4.16: Max Fracture Height per Stage for Well MIP-3H from Fracture Modeling (GOHFER)

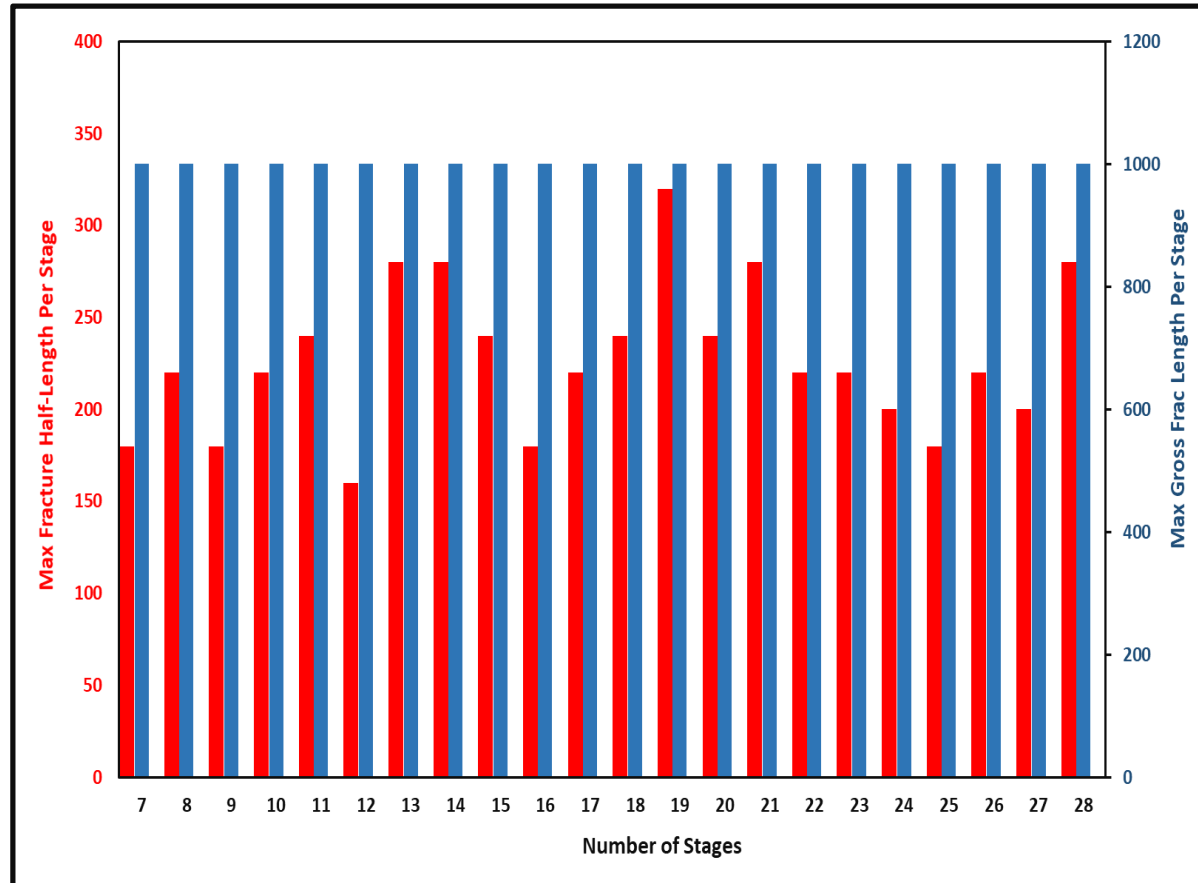

Figure 4.17: Max Half-Length per Stage and Max Gross Fracture Length per Stage for Well MIP3H from Fracture Modeling (GOHFER). 


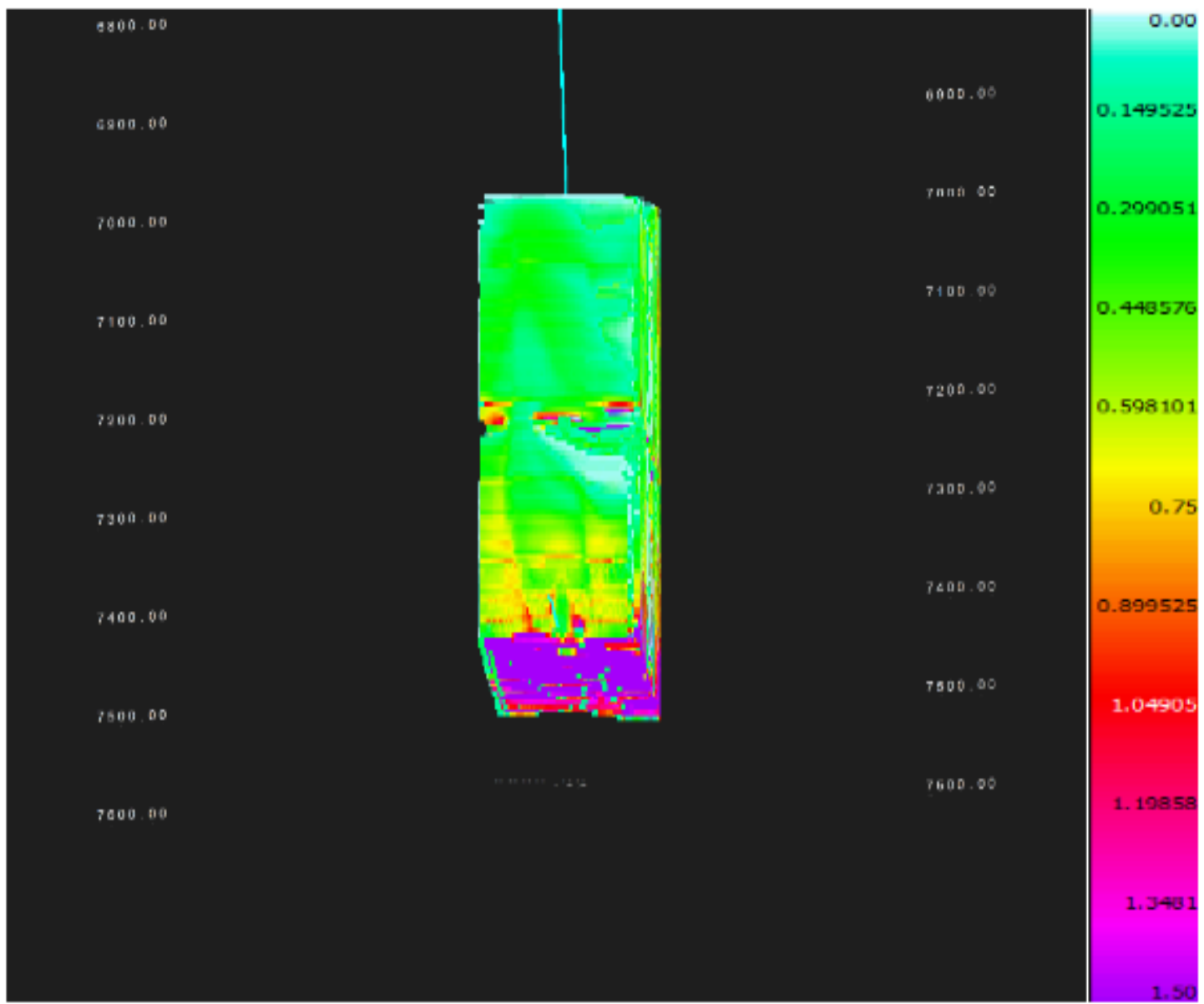

\section{Figure 4.18: Fracture Height for all Stages and High Proppant Concentration (Purple Color) at the bottom of Fracture for Well MIP-3H.}

Figure 4.19 illustrates the predicted average fracture conductivity in each cluster for stage 1. Stage 1 has 5 clusters. The clusters in the middle $(2,3$, and 4) have fracture conductivity lower than those on the ends ( 1 and 5) due to stress shadowing impact. Stress shadowing causes higher net pressure and lower fracture width. Therefore, less proppant are placed in the middle clusters (2, 3, and 4). Figure 4.20 also illustrates fracture half-length, fracture height, average fracture width, and proppant concentration for stage 1. Again, the clusters in the middle are shorter and narrower than those on the ends. This occurs in all stages ( 1 to 28$)$. When a stage has 4 clusters, center clusters ( 2 and 4$)$ have less proppant than outer clusters ( 1 and 4). Figure 4.21 illustrates the average, and maximum fracture conductivity, for stage 1 and stage 28 . It is evident that the average and maximum fracture conductivity in stage 28 is lower than in stage 1 due to the stress shadowing impact. 


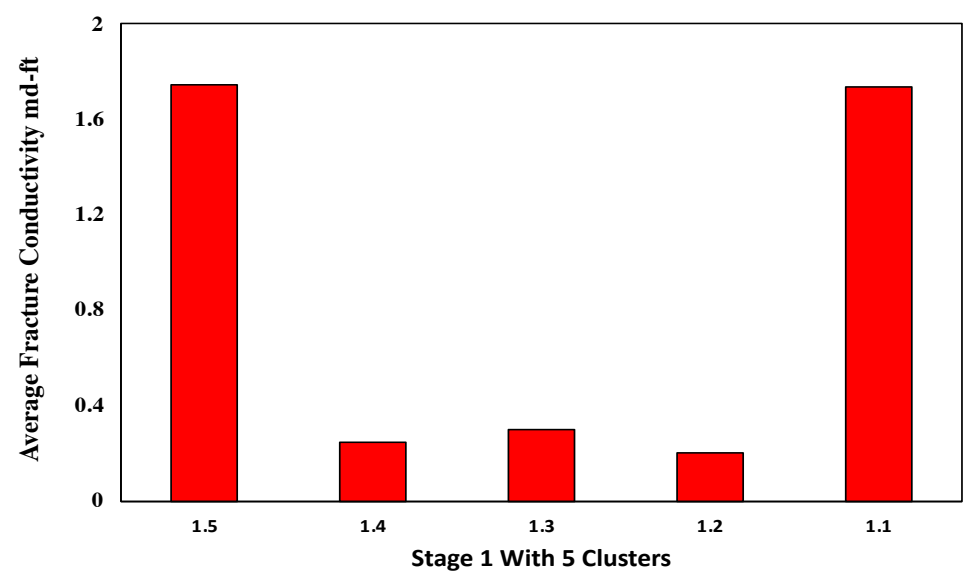

Figure 4.19: Illustrates Average Fracture Conductivity.
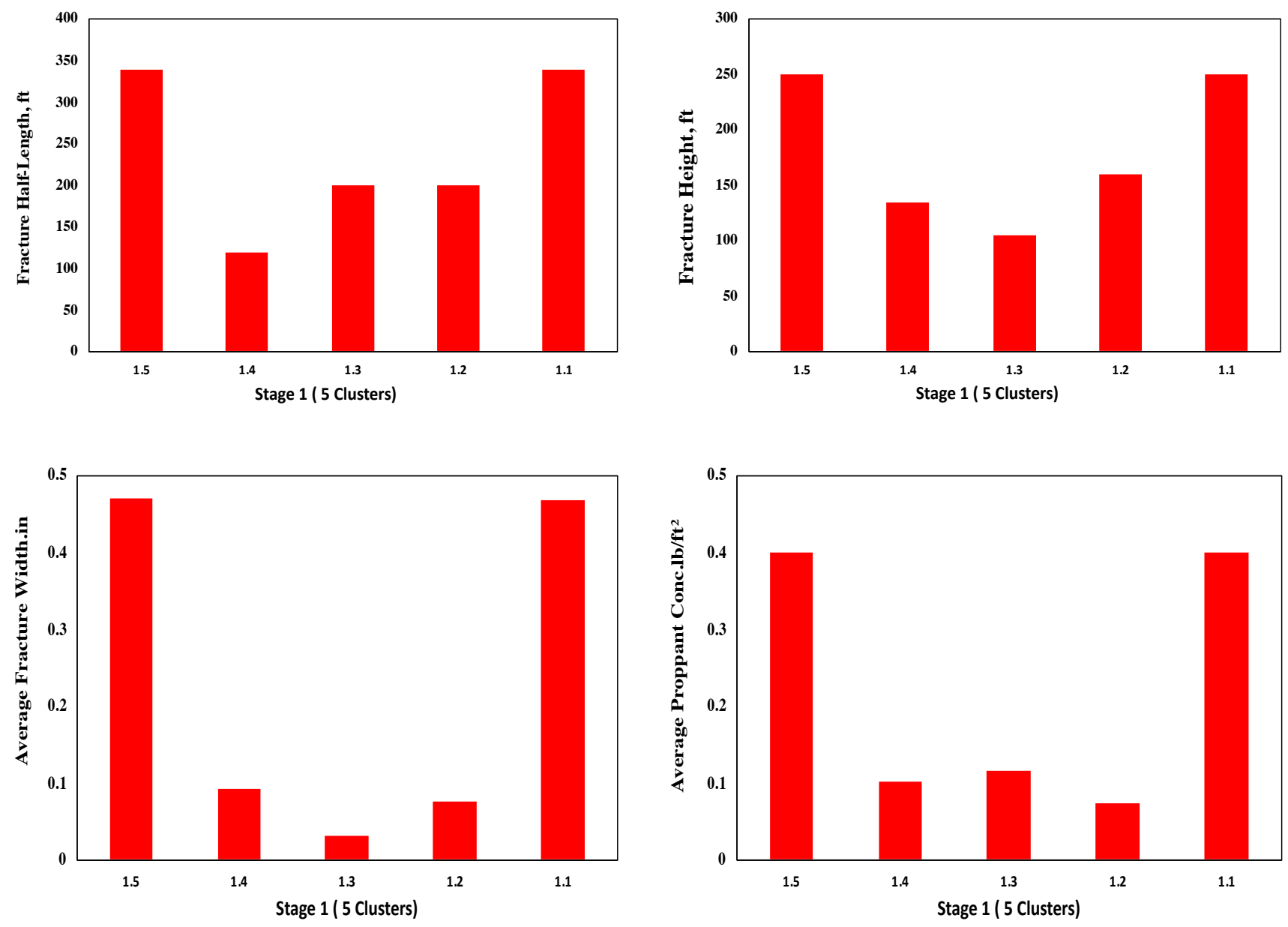

Figure 4.20: Illustrates Fracture Properties for Stage 1 with 5 Clusters. 

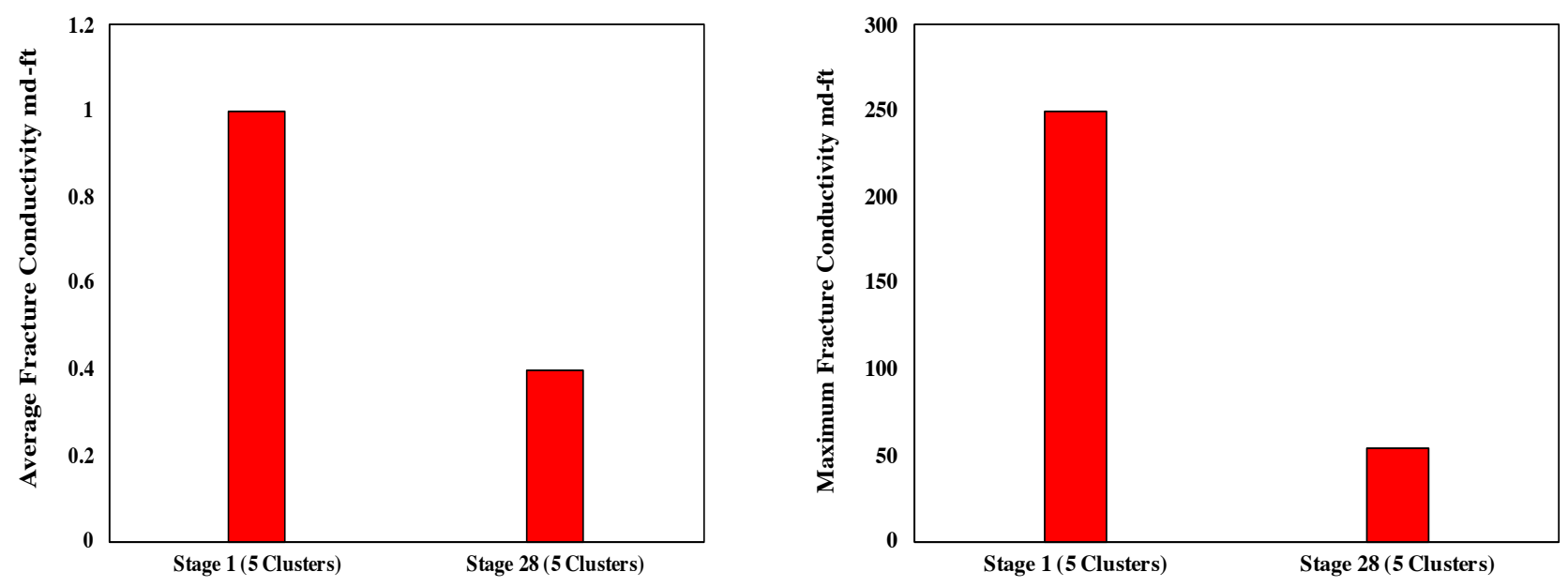

Figure 4.21: Shows the Average and Maximum Fracture Conductivity for Stages 1 and 28.

Figure 4.22 compares four different production gas profiles. The first production profile (orange) was generated using fracture properties predicted without stress shadowing and ignoring the geomechanical factors in the reservoir models. The second production profile (red) was generated by including the geomechanical factors in the reservoir models. The third production profile (green) was generated by including both stress shadowing and the geomechanical factors. The final production profile (blue) was generated without the adjustments for microseismic interpretations.

Furthermore, As illustrated in Figure 4.22, when the stress shadowing effects, the results of microseismic interpretations, and geomechanical factors were considered, the predicted production performance was found to be in close agreement with the production performance of the well under study 


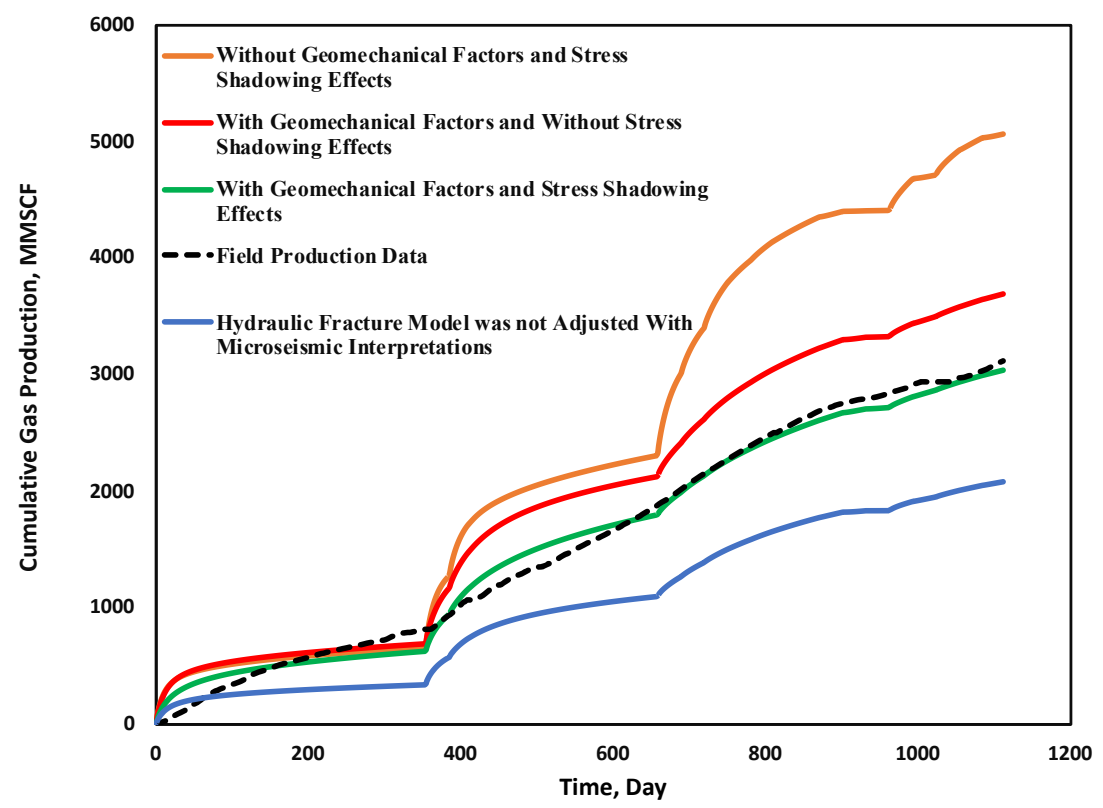

Figure 4.22: Cumulative Gas Production for Different Production Profiles for MIP-3H.

\subsection{Results of Parametric Studies for Fracture Half-length and Non-uniform Fracture Half-}

\section{Length.}

\subsubsection{Impact of Fracture Half-length}

Figure 4.23 illustrates the impact of fracture-half-length on cumulative production, which increases as the fracture half-length increases. Therefore, fracture half-length is a major contributor to gas recovery. The fracture half-length impact is much more significant during the early production.

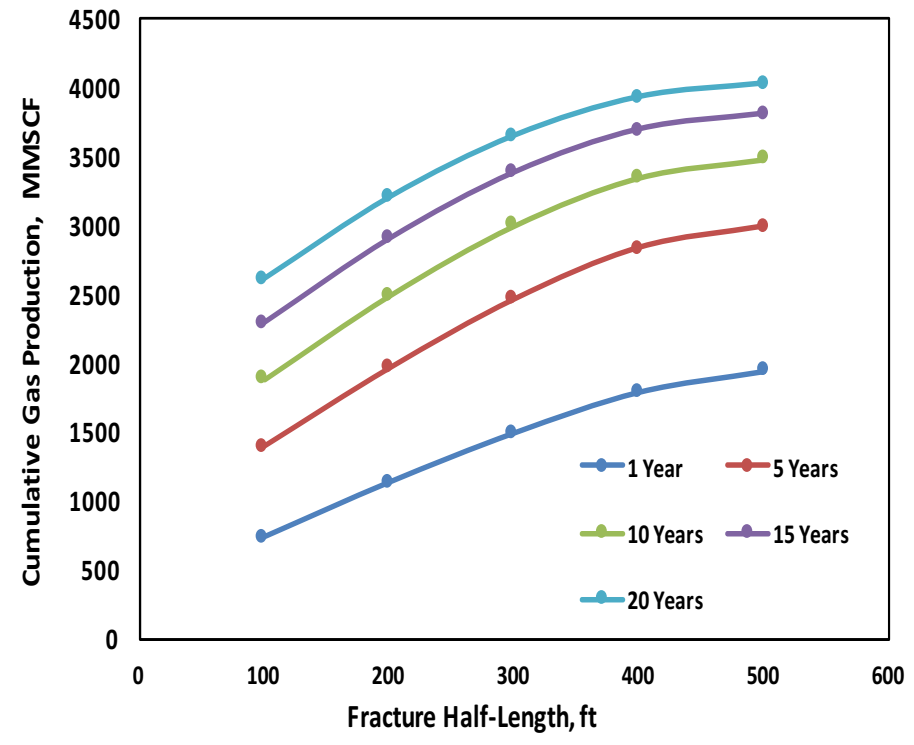

Figure 4.23: Illustrates Fracture Half-Length $X_{f}$ vs. Cumulative Gas. 


\subsubsection{Effect of Non-uniform Fracture Half-Length}

Table 4.6. summarizes the model predictions for all eleven cases and compares them against the base model predictions. As can be observed, case 10 provides the highest, and case 7 results in the lowest cumulative recovery. However, the impact of non-uniform fracture half-length is not very significant.

Table 4.6: Hydraulic Fracture Geometry.

\begin{tabular}{|c|c|c|c|c|c|c|c|c|c|c|}
\hline & \multicolumn{8}{|c|}{ Fracture Half-Length, $\mathrm{ft}$} & \multirow{2}{*}{$\begin{array}{c}\text { Cumulative } \\
\text { Gas } \\
\text { Production, } \\
\text { MMSCF }\end{array}$} & \multirow{2}{*}{$\begin{array}{c}\text { Deviation, } \\
\%\end{array}$} \\
\hline & Stage 1 & Stage 2 & Stage 3 & Stage 4 & Stage 5 & Stage 6 & Stage 7 & Stage 8 & & \\
\hline Base Model & 100 & 100 & 100 & 100 & 100 & 100 & 100 & 100 & 2618 & - \\
\hline Case 1 & 80 & 80 & 120 & 120 & 120 & 120 & 80 & 80 & 2594 & -0.93 \\
\hline Case 2 & 120 & 120 & 80 & 80 & 80 & 80 & 120 & 120 & 2639 & 0.80 \\
\hline Case 3 & 120 & 80 & 120 & 80 & 120 & 80 & 120 & 80 & 2621 & 0.10 \\
\hline Case 4 & 40 & 40 & 160 & 160 & 160 & 160 & 40 & 40 & 2520 & -3.73 \\
\hline Case 5 & 160 & 160 & 40 & 40 & 40 & 40 & 160 & 160 & 2660 & 1.62 \\
\hline Case 6 & 160 & 40 & 160 & 40 & 160 & 40 & 160 & 40 & 2632 & 0.52 \\
\hline Case 7 & 20 & 20 & 180 & 180 & 180 & 180 & 20 & 20 & 2456 & -6.20 \\
\hline Case 8 & 180 & 180 & 20 & 20 & 20 & 20 & 180 & 180 & 2650 & 1.24 \\
\hline Case 9 & 180 & 20 & 180 & 20 & 180 & 20 & 180 & 20 & 2632 & 0.51 \\
\hline Case 10 & 170 & 150 & 130 & 110 & 90 & 70 & 50 & 30 & 2565 & -2.04 \\
\hline Case 11 & 30 & 50 & 70 & 90 & 110 & 130 & 150 & 170 & 2565 & -2.03 \\
\hline
\end{tabular}

\subsection{Results of Parametric Studies with Geomechanical Factor (Propped Hydraulic Fracture) (MIP-6H)}

The geomechanical factor for hydraulic fracture which was obtained from experimental results by McGinley et al. (2015) was used in the model as mentioned earlier.

\subsubsection{Effect of Wellbore Pressure.}

Two values (1000 and $1500 \mathrm{psia}$ ) were considered for the constant wellbore pressure to investigate the impact of the stress-dependent propped hydraulic fracture conductivity on production. The comparison of constant hydraulic fracture permeability and stress-dependent hydraulic fracture permeability on cumulative gas production at 20 years is $16.85 \%$ for 1000 , and $10.8 \%$ for 1500 psia, as illustrated in Figures 4.24 and 4.25. It is obvious from a comparison between Figures 4.24 and 4.25 with Figure 4.3 (base case) that the impact of stress-dependent propped hydraulic fracture conductivity becomes more pronounced when wellbore pressure is lower. 


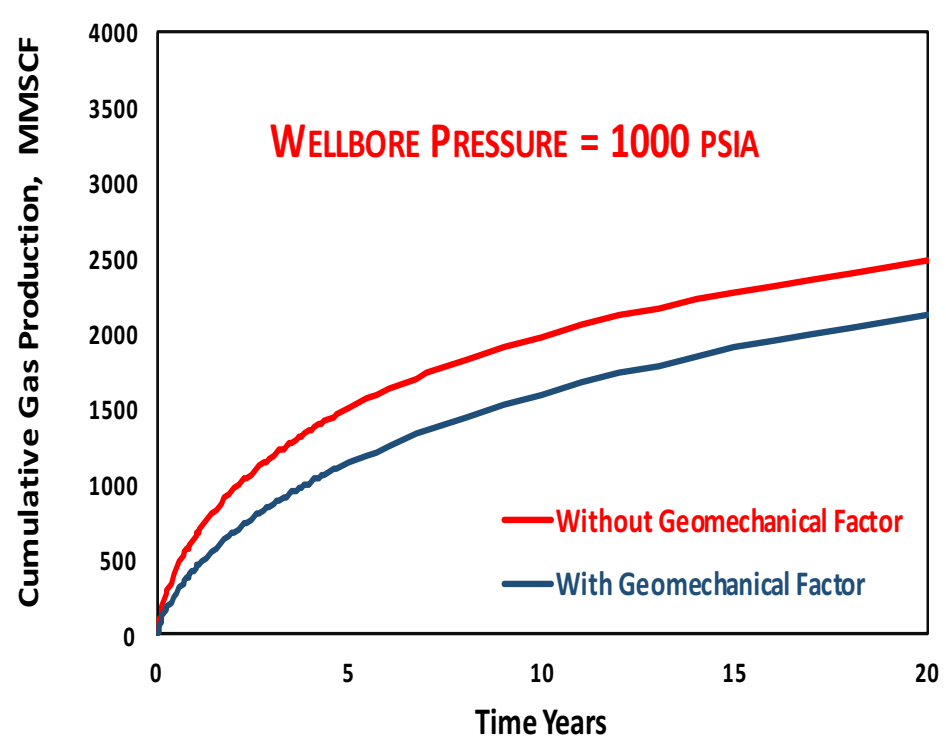

Figure 4.24: Cumulative Gas Production with and without Geomechanical Factor for Wellbore Pressure 1000 Psia.

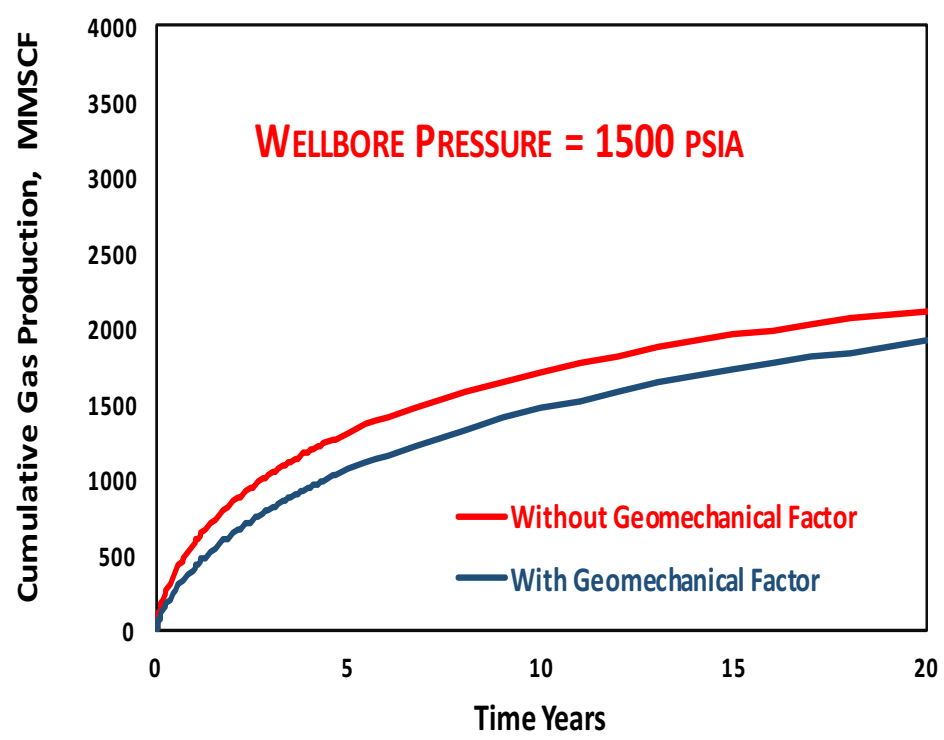

Figure 4.25: Cumulative Gas Production with and without Geomechanical Factor for Wellbore Pressure 1500 Psia.

\subsubsection{Effect of Fissure Permeability.}

Two values $(0.004$ and $0.006 \mathrm{md})$ were considered for the fissure permeabilities to investigate the impact of the stress-dependent propped hydraulic fracture conductivity on production. The comparison of constant hydraulic fracture permeability and stress-dependent hydraulic fracture permeability on cumulative gas production at 20 years is, $26.41 \%$ for $0.004 \mathrm{md}$, and $26.82 \%$ for $0.006 \mathrm{md}$, as seen in Figures 4.26 and 4.27. Therefore, It is observable from a comparison between Figures 4.26 and 4.27 with 
Figure 4.3 (Base Case) that as the fissure permeability increases, it does not influence the propped hydraulic fracture geomechanical factor.

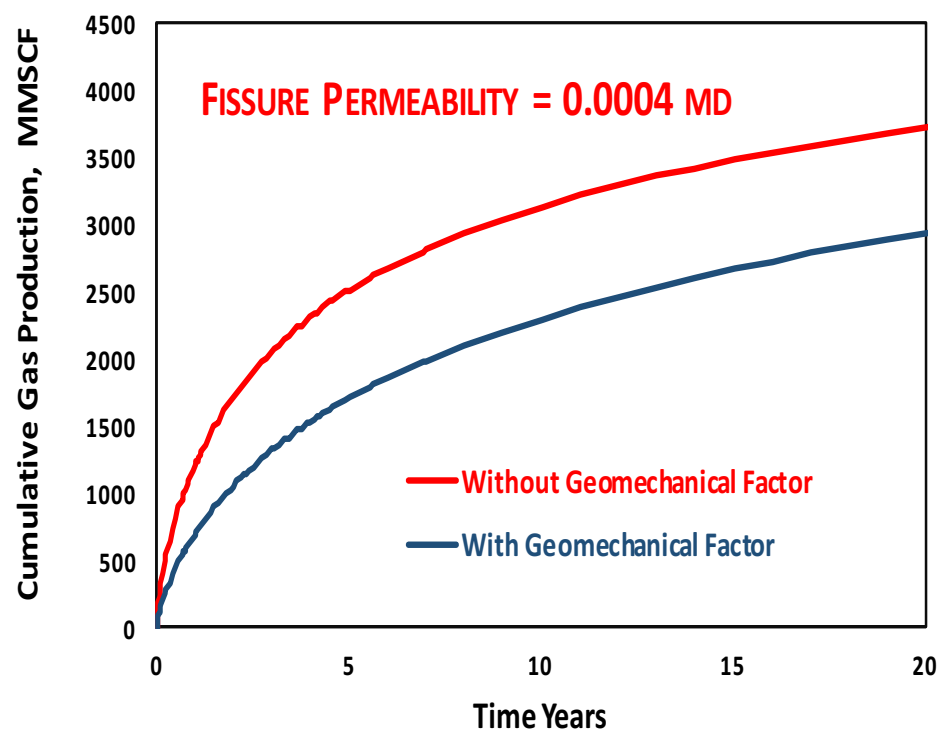

Figure 4.26: Cumulative Gas Production with and without Geomechanical Factor for Fissure Permeability 0.004md.

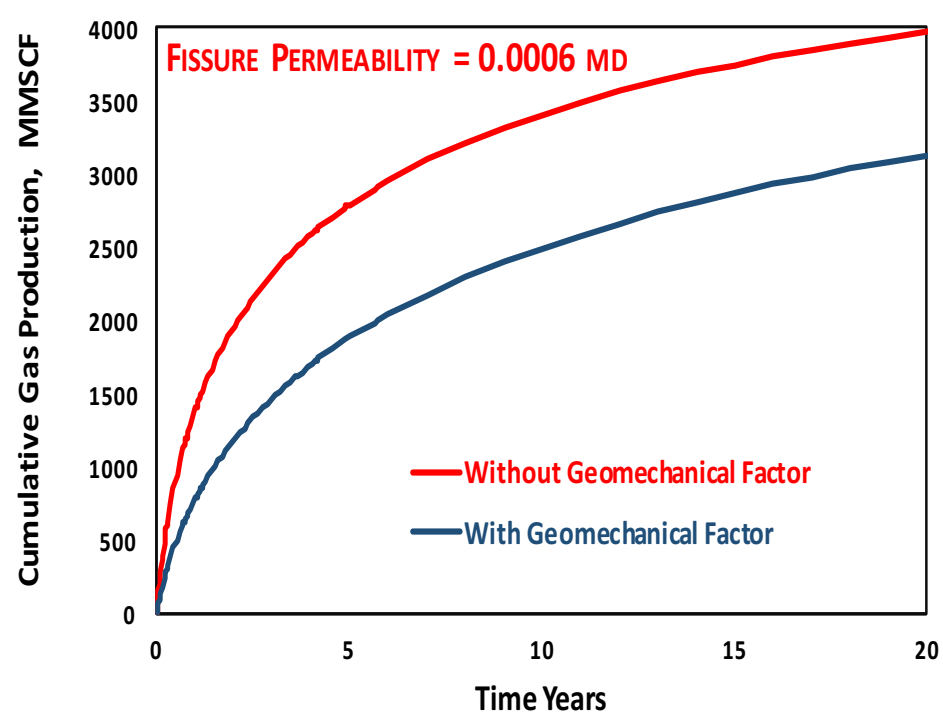

Figure 4.27: Cumulative Gas Production with and without Geomechanical Factor for Fissure Permeability 0.006md.

\subsubsection{Effect of Matrix Porosity.}

Two values $(2.5 \%$ and $6.5 \%)$ were considered for the matrix porosity to investigate the impact of the stress-dependent propped hydraulic fracture conductivity on production. The comparison of constant hydraulic fracture permeability and stress-dependent hydraulic fracture permeability on cumulative gas production at 20 years is $22.91 \%$ for the porosity of $2.5 \%$ and $26.78 \%$ for the porosity of $6.5 \%$, as 
illustrated in Figures 4.28 and 4.29. It is obvious from a comparison between Figures 4.28 and 4.29 with Figure 4.3 (base case) that increasing matrix porosity leads to production increase. Consequently, the impact of the stress-dependent propped hydraulic fracture conductivity increases with increasing matrix porosity.

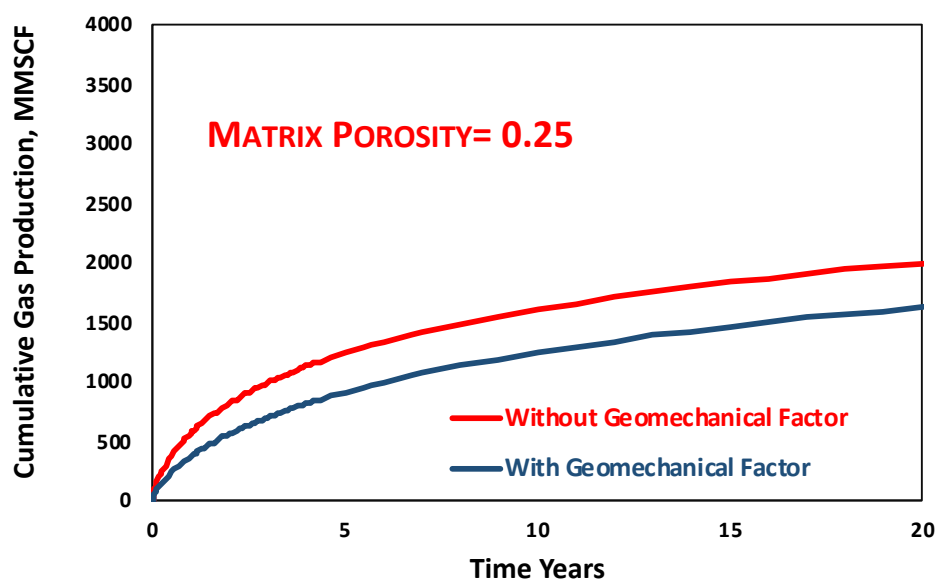

Figure 4.28: Cumulative Gas Production with and without Geomechanical Factor for Matrix Porosity 0.025.

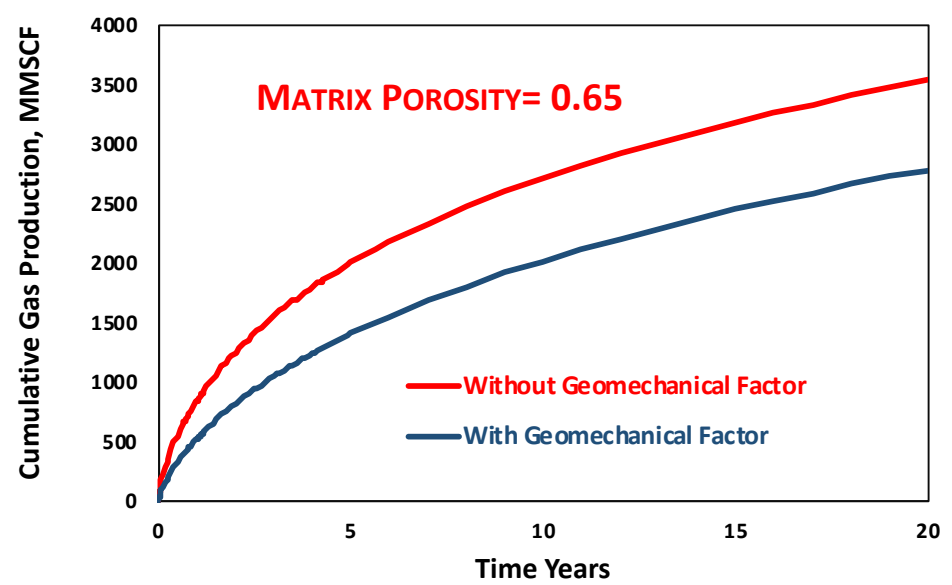

Figure 4.29: Cumulative Gas Production with and without Geomechanical Factor for Matrix Porosity 0.065.

\subsubsection{Fracture Half-Length.}

Two values (100 and $300 \mathrm{ft}$.) were considered for the fracture half-lengths to investigate the impact of the stress-dependent propped hydraulic fracture conductivity on production performance. The comparison of constant hydraulic fracture permeability and stress-dependent hydraulic fracture permeability on cumulative gas production at 20 years is $15.22 \%$ for $100 \mathrm{ft}$. and $31.16 \%$ for $300 \mathrm{ft}$. as seen in Figures 4.30 and 4.31. It is obvious from a comparison between Figures 4.30 and 4.31 with Figure 4.3 (Base Case) that the fracture half-length has a significant impact because the higher fracture half-length 
leads to higher pressure depletion causing more increase in stress. This makes the effect of the stressdependent propped hydraulic fracture conductivity on production more pronounced.

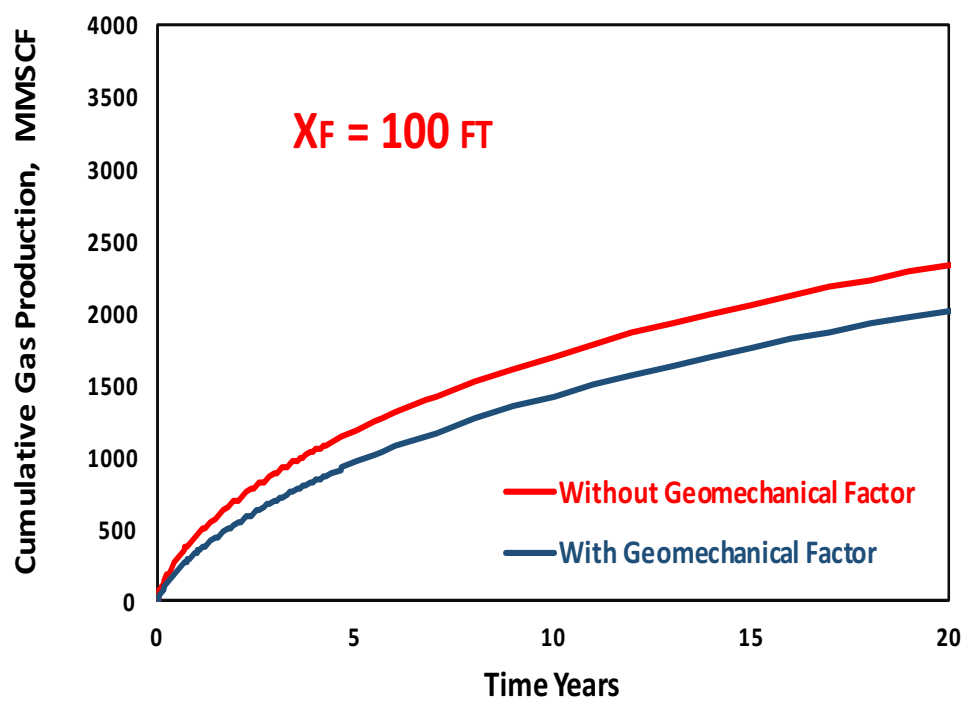

Figure 4.30: Cumulative Gas Production with and without Geomechanical Factor for Fracture Half-Length $100 \mathrm{ft}$.

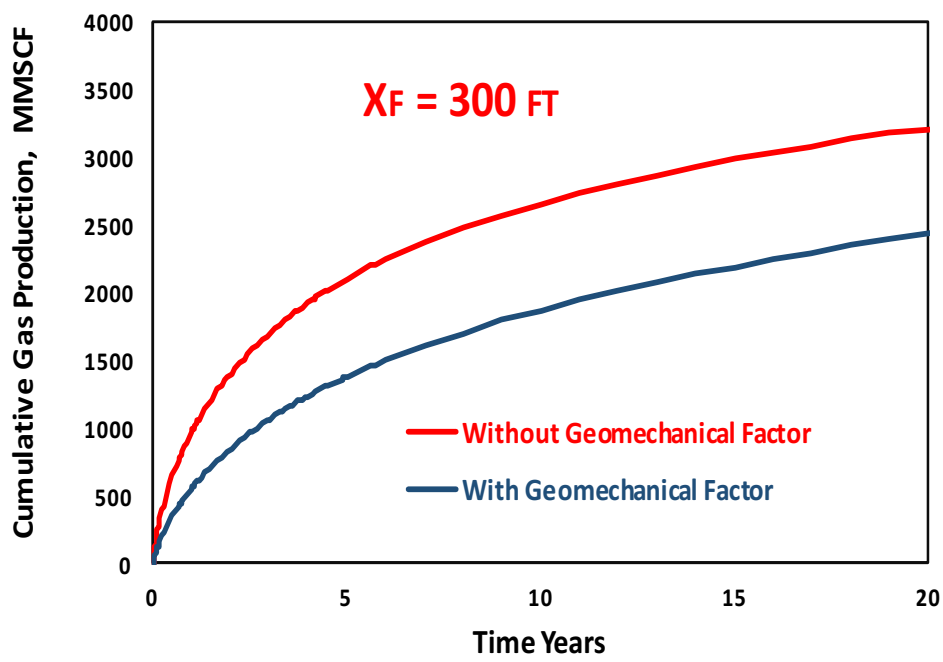

Figure 4.31: Cumulative Gas Production with and without Geomechanical Factor for Fracture Half-Length $300 \mathrm{ft}$.

\subsubsection{Effect of Hydraulic Fracture Spacing.}

During this study, the wells' fracture spacing was held constant to maintain verifiable results. Hydraulic fracture spacing was decreased from $260 \mathrm{ft}$., $180 \mathrm{ft}$., and $100 \mathrm{ft}$. to understand the impact of the stress-dependent propped hydraulic fracture conductivity on production. The comparison of constant hydraulic fracture permeability and stress-dependent hydraulic fracture permeability on cumulative gas 
production at 20 years is $14.5 \%$ for $100 \mathrm{ft}$., $19.19 \%$ for $180 \mathrm{ft}$., and $22.63 \%$ for $260 \mathrm{ft}$. as can be seen in Figure 4.17, 4.18, and 4.19 respectively. It is obvious from a comparison between Figure 4.32, 4.33, and 4.34 with Figure 4.3 (Base Case) that the impact of the stress-dependent propped hydraulic fracture conductivity decreases slightly with the closer hydraulic fracture spacing.

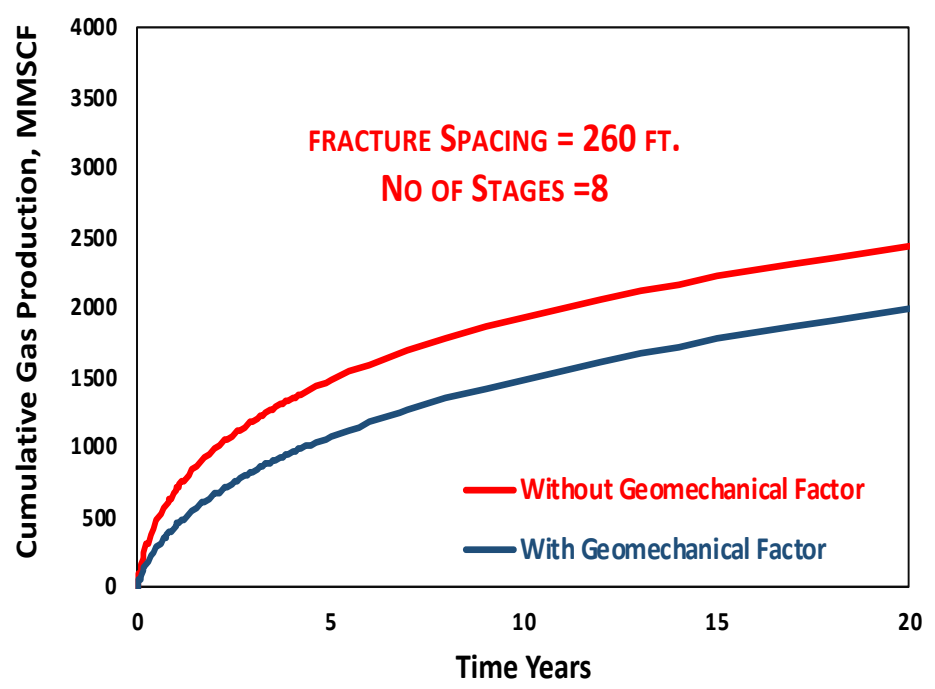

Figure 4.32: Cumulative Gas Production with and without Geomechanical Factor for Hydraulic Fracture Spacing 260 ft.

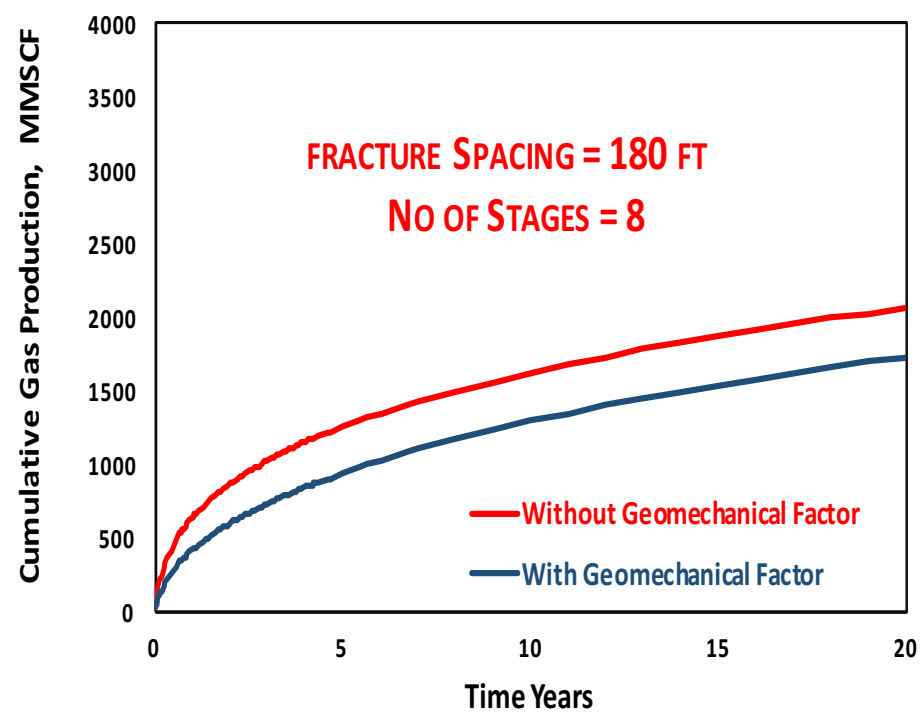

Figure 4.33: Cumulative Gas Production with and without Geomechanical Factor for Hydraulic Fracture Spacing $180 \mathrm{ft}$. 


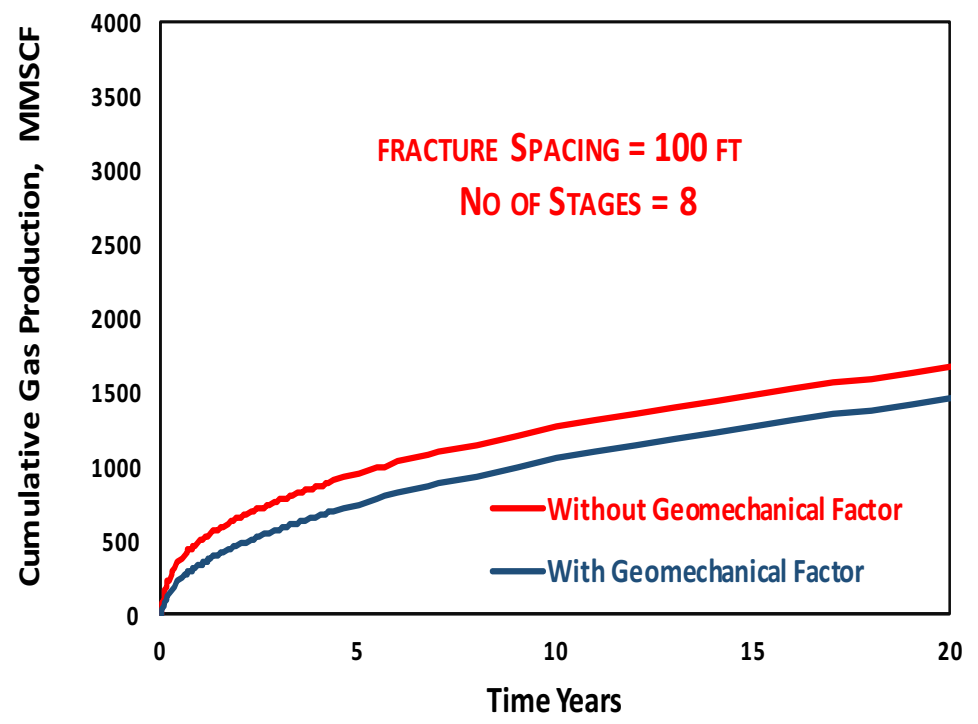

Figure 4.34: Cumulative Gas Production with and without Geomechanical Factor for Hydraulic Fracture Spacing 100 ft.

Figure 4.35 summarizes and compares the relative impact of critical parameters that influence the stress-dependent propped hydraulic fracture conductivity.

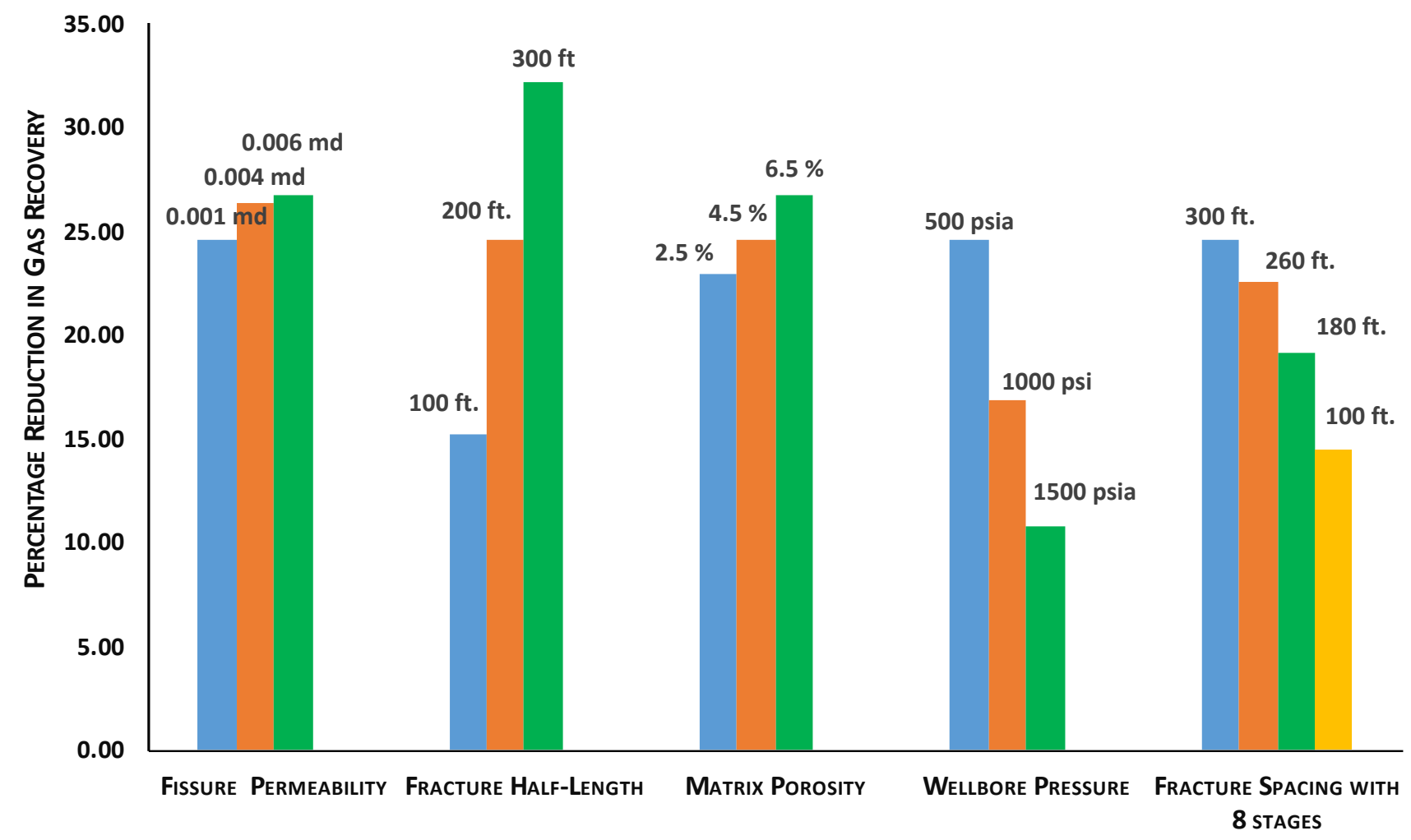

Figure 4.35: Critical Parameters that Influence the Stress-Dependent Propped Hydraulic Fracture Conductivity. 


\subsection{Results of Parametric Studies with Geomechanical Factors (Matrix, Fissure, and Hydraulic Fracture) for Well MIP-6H}

The geomechanical factors for matrix and fissure permeability, which were obtained from experimental results by Elsaig et al. (2016), were used in the model mentioned earlier. Furthermore, the geomechanical factor for hydraulic fracture, which was obtained from experimental results by McGinley et al. (2015), was used in the model.

\subsubsection{Fracture half-length.}

Figures 4.36, 4.37, and 4.38 illustrate the impact of the geomechanical factors associated with the matrix, fissure permeability, and propped fracture conductivity on cumulative gas production for various fracture half-lengths. Moreover, these Figures show a percentage reduction in gas recovery due to these geomechanical factors. It is evident from a comparison between Figures 4.36, 4.37, and 4.38 with Figure 4.6 (base case) that as the fracture half-length increases, the impact of the propped hydraulic fracture geomechanical factor becomes more significant. This occurs due to the expansion of the simulation reservoir volume (SRV), as illustrated in Figure 4.39. Figure 4.39 shows the pressure distribution after 2 years of production for different fracture half-lengths. As the fracture half-length increases, the simulation reservoir volume (SRV) increases. Simultaneously, results revealed that gas production increased more prominently in the hydraulic fracture than in the fissure and matrix. This shift occurred due to increasing the fracture half-length, which increased the movable hydrocarbon volume in the hydraulic fracture more than in the fissure and matrix. Thus, the geomechanical factors demonstrate which elements contribute more to overall gas production. Furthermore, Figure 4.40 illustrates the percentage reduction in gas recovery for different fracture half-lengths due to the geomechanical factors. It is clear from Figure 4.40 that the impact of the geomechanical factors associated with fissure and matrix decreases as half-length fracture increases. However, the effect of the geomechanical factor associated with propped hydraulic fracture increases. 

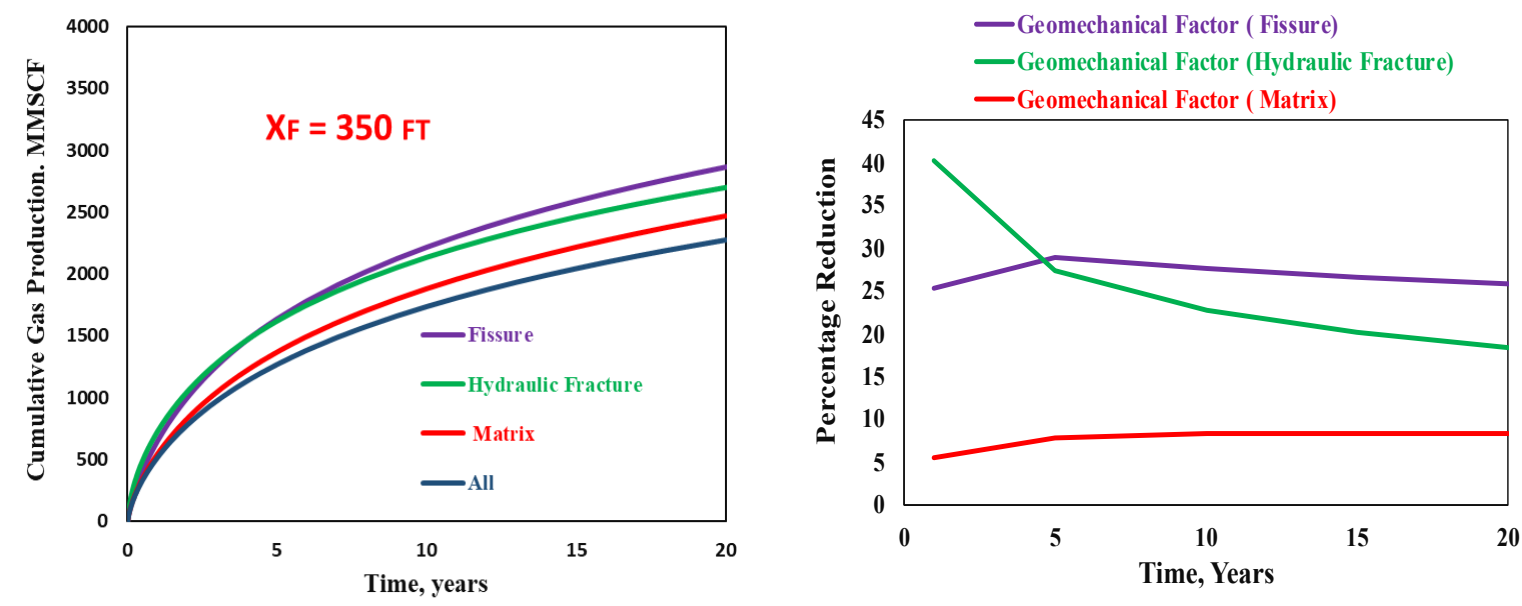

Figure 4.36: Cumulative Gas Production for Fracture Half-Length $350 \mathrm{ft}$ and Percentage Reduction in Gas Recovery Due to Geomechanical Factors.
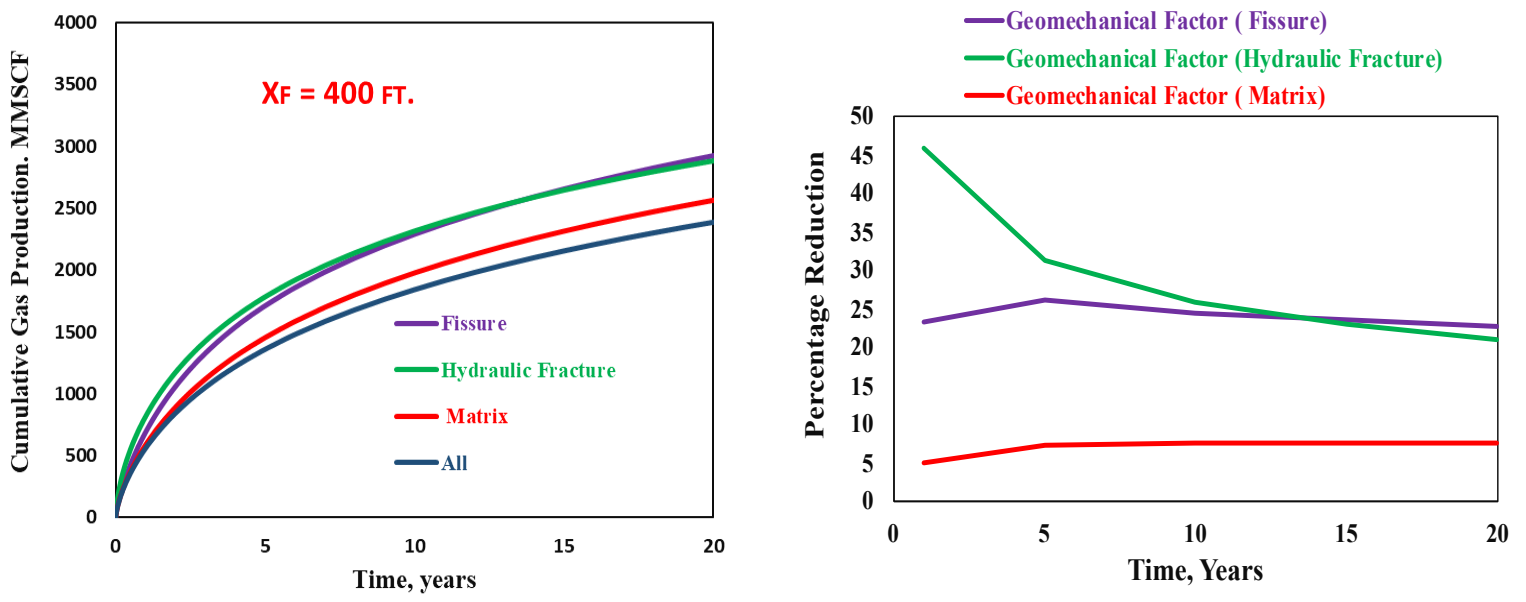

Figure 4.37: Cumulative Gas Production for Fracture Half-Length $400 \mathrm{ft}$ and Percentage Reduction in Gas Recovery Due to Geomechanical Factors.
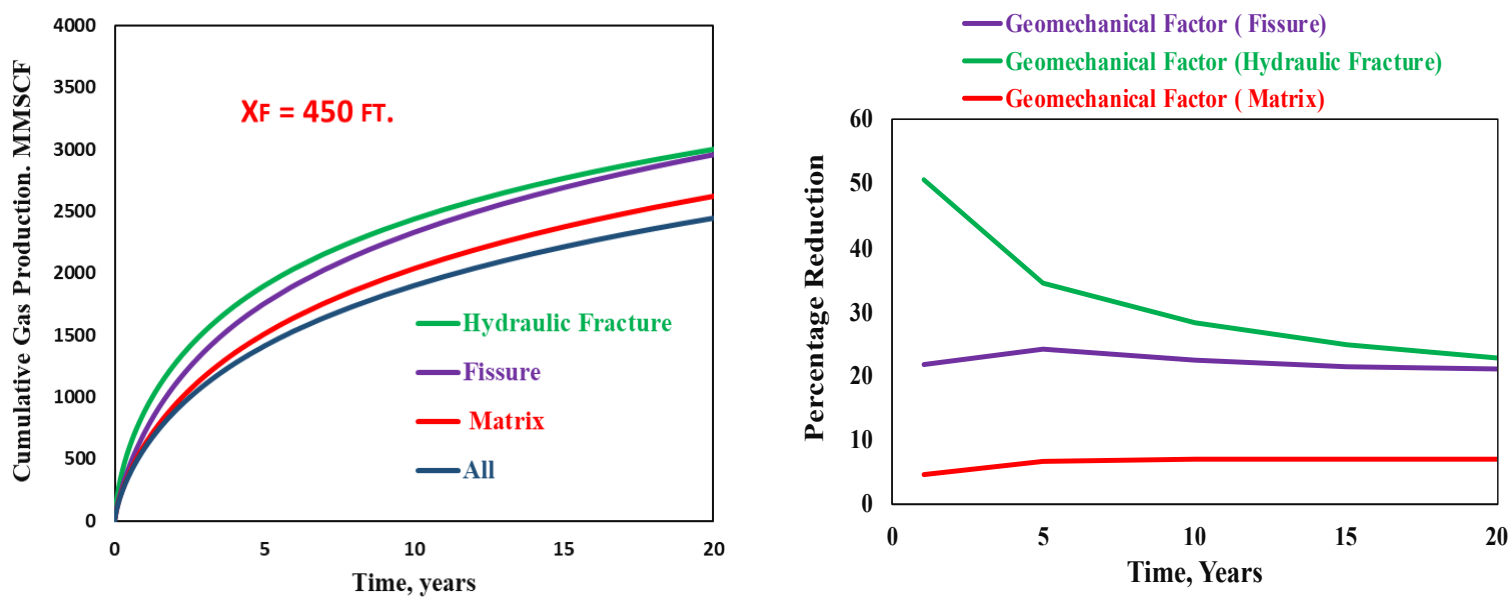

Figure 4.38: Cumulative Gas Production for Fracture Half-Length $450 \mathrm{ft}$ and Percentage Reduction in Gas Recovery Due to Geomechanical Factors. 

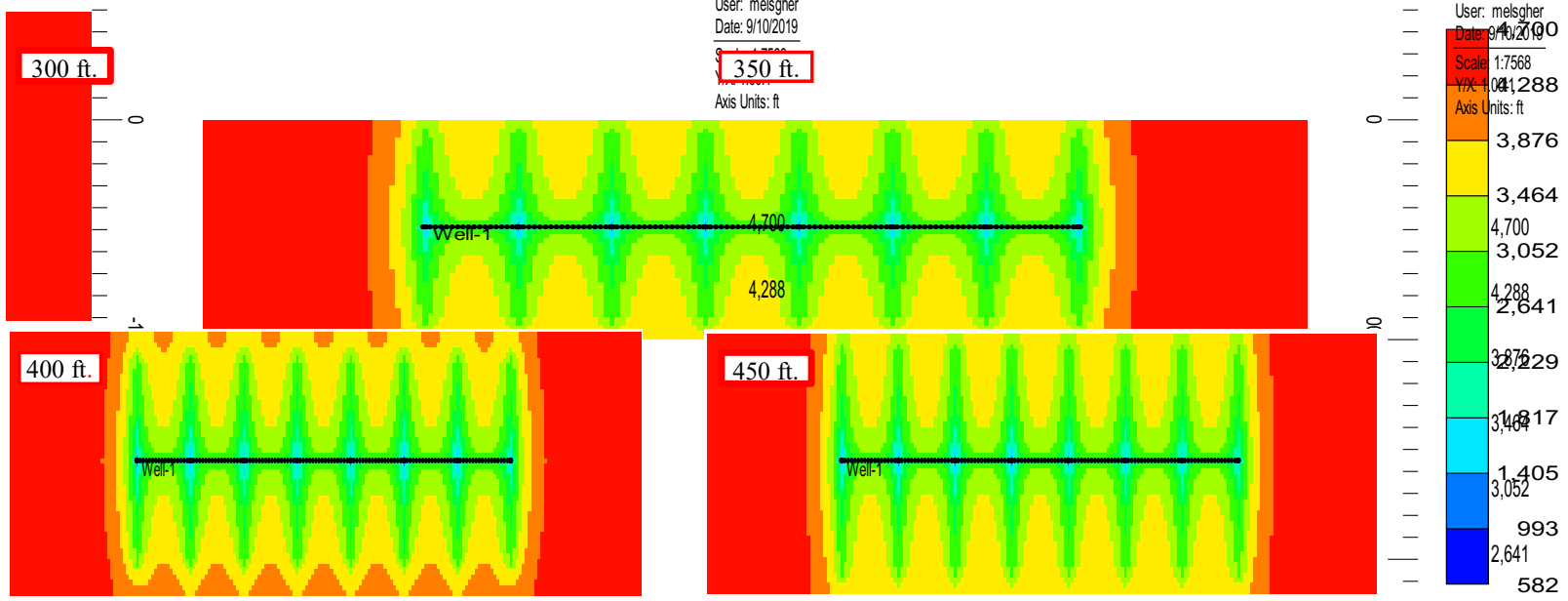

Figure 4.39: Pressure Distribution after 2 Years of Production for Different Fracture Half Lengths.
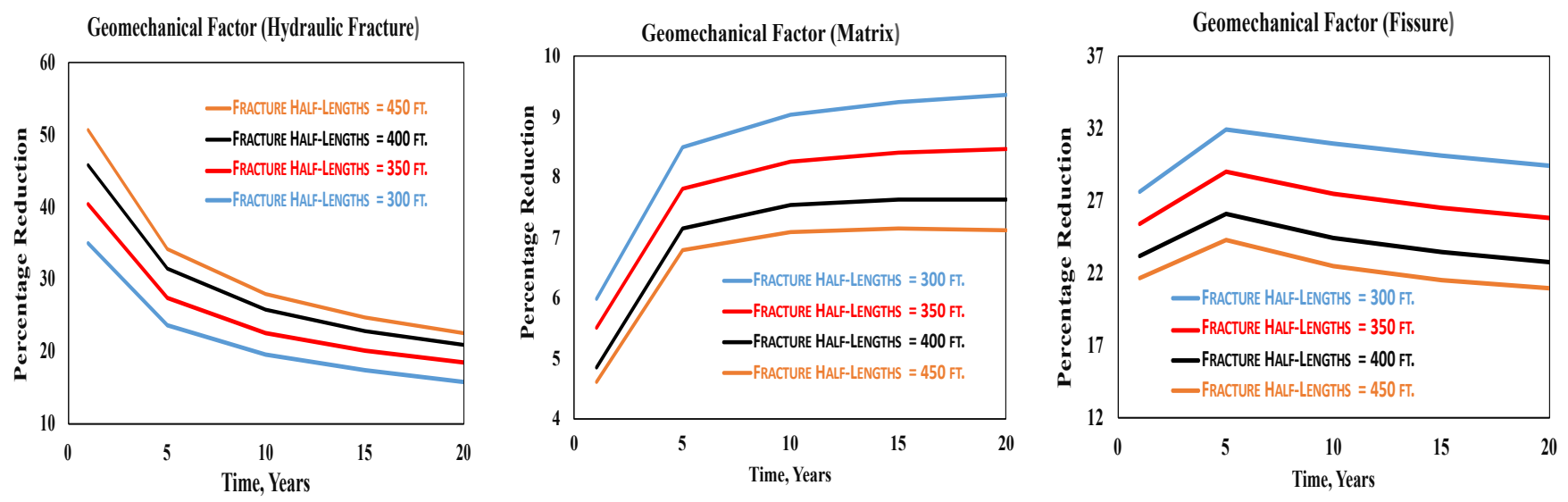

Figure 4.40: Percentage Reduction in Gas Recovery for Different Fracture Half Lengths Due to Geomechanical Factors.

\subsubsection{Fracture Conductivity}

Figures $4.41,4.42$, and 4.43 show the impact of the geomechanical factors on cumulative gas production for different fracture conductivities. Additionally, these Figures show a percentage reduction in gas recovery due to geomechanical factors. It is evident from a comparison between Figures 4.41, 4.42, and 4.43 with Figure 4.6 (base case) that as the initial fracture conductivity decreases, the impact of the propped hydraulic fracture geomechanical factor becomes more prominent. This change occurs because the fracture conductivity improved the contact efficiency between the reservoir and simulation reservoir volume (SRV). Additionally, increasing the fracture conductivity increases the movable hydrocarbon volume in fissure and matrix more than in the hydraulic fracture, as illustrated in Figure 4.44. Figure 4.44 shows the pressure distribution for different fracture conductivities after 2 years of production. The geomechanical factors determine which elements contribute more to overall gas production. It is clear from 
Figure 4.44 that when the fracture conductivity of the hydraulic fracture is large enough, there is a small pressure drop from the fracture tip to the wellbore. Therefore, the well begins to drain further and further out in the reservoir away from hydraulic fracture.

Figure 4.45 shows the percentage reduction in gas recovery for different fracture conductivities due to the geomechanical factors. It is clear from Figure 4.45 that as the fracture conductivity increases, the impact of geomechanical factors associated with fissure and matrix permeability increases. However, the effect of the propped hydraulic fracture geomechanical factor decreases.
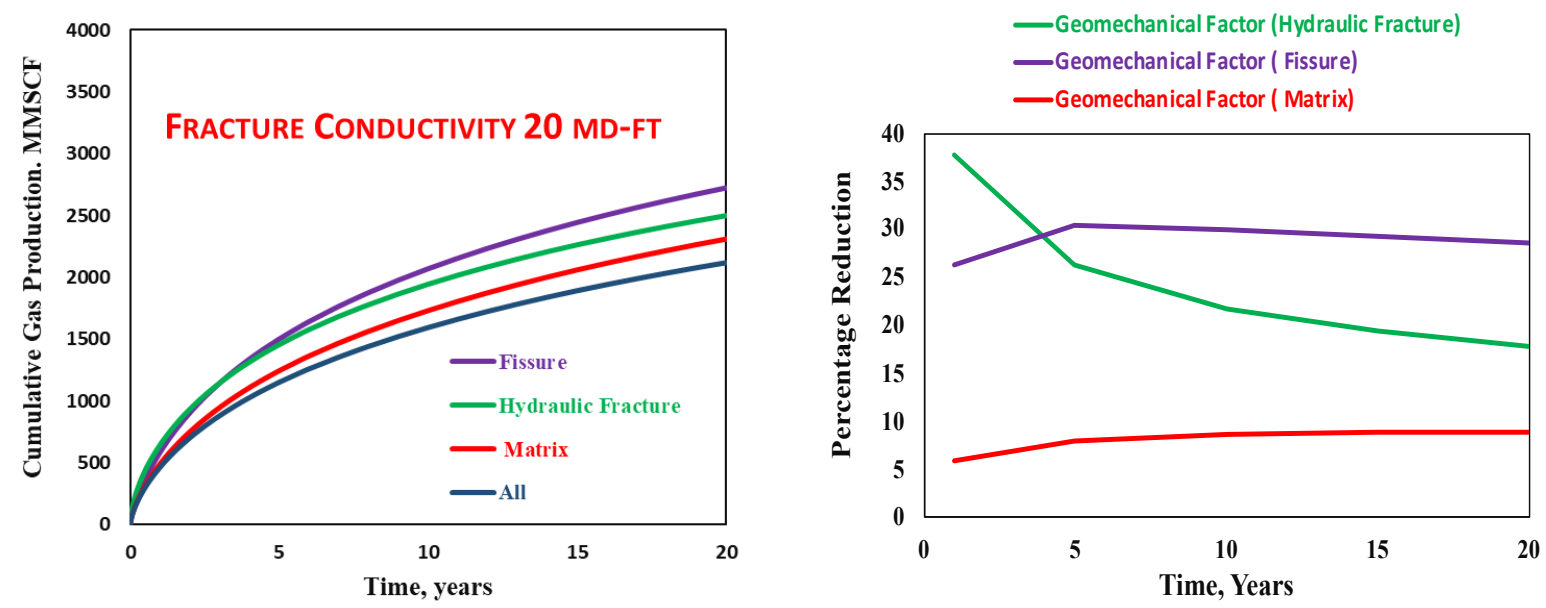

Figure 4.41: Cumulative Gas Production for Fracture Conductivity 20 md-ft and Percentage Reduction in Gas Recovery Due to Geomechanical Factors.
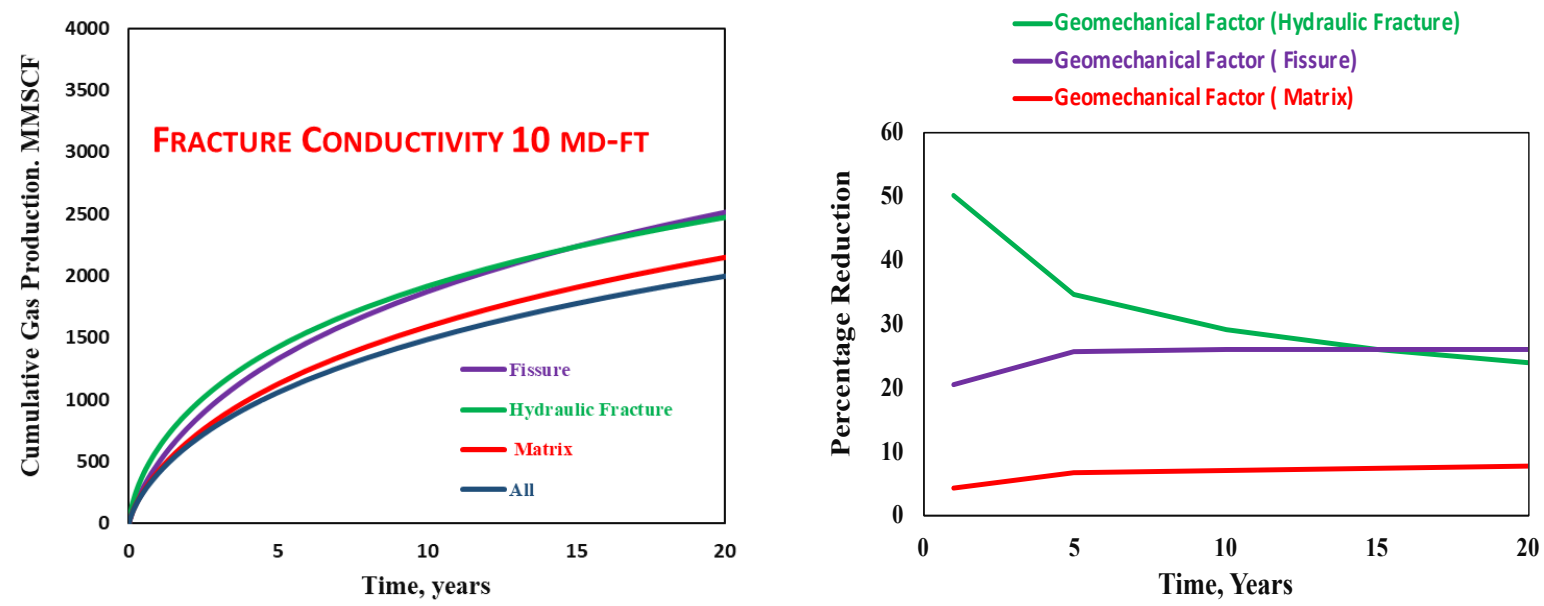

Figure 4.42: Cumulative Gas Production for Fracture Conductivity 10 md-ft and Percentage Reduction in Gas Recovery Due to Geomechanical Factors. 

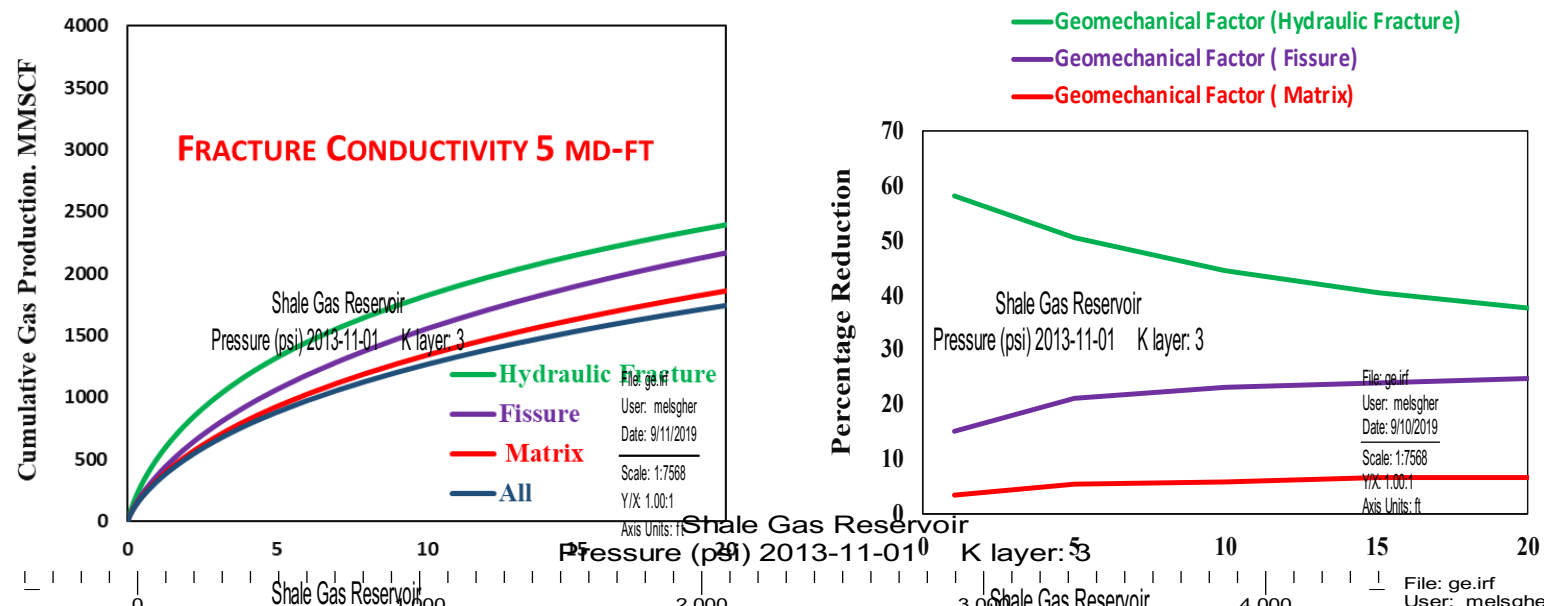

Figure 4.43: Cumulative Gas Production for Fracture Conductivity 5 md-ft and Percentage Reduction in Gas Recovery Due to Geomechanical Factors.
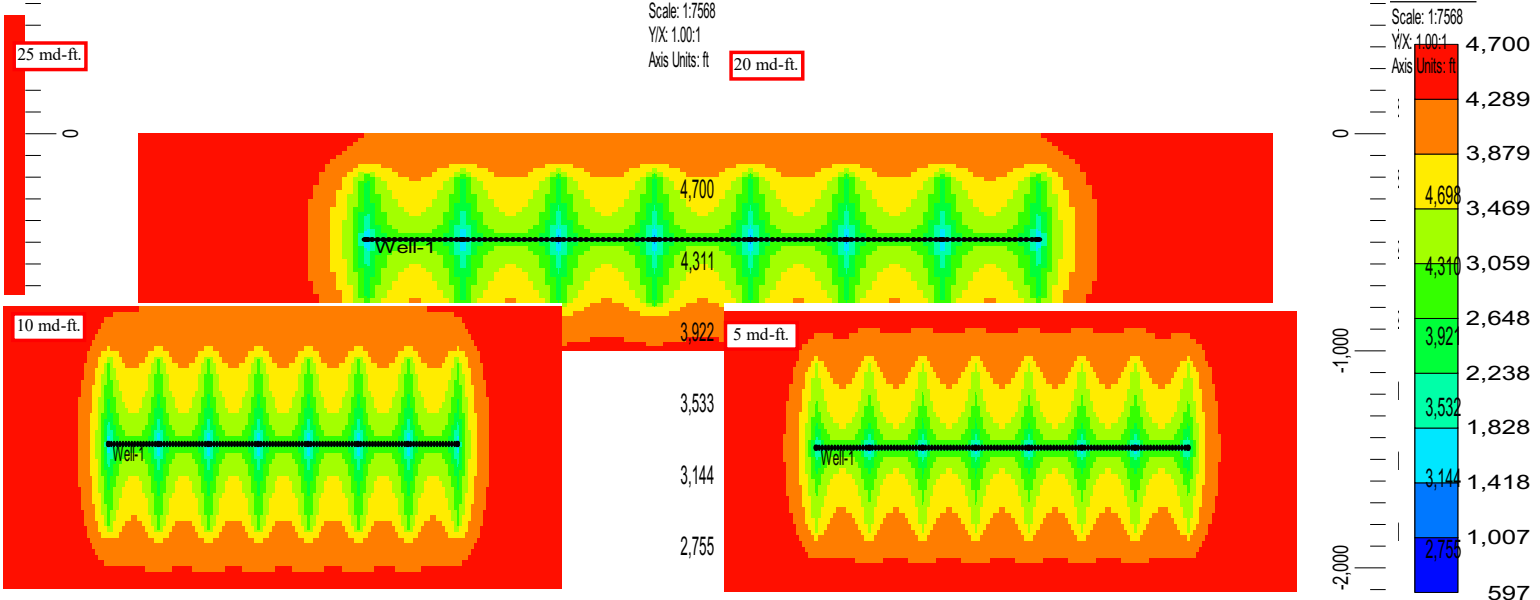

Figure 4.44: Pressure Distribution after 2 Years of Production for Different Fracture Conductivity.
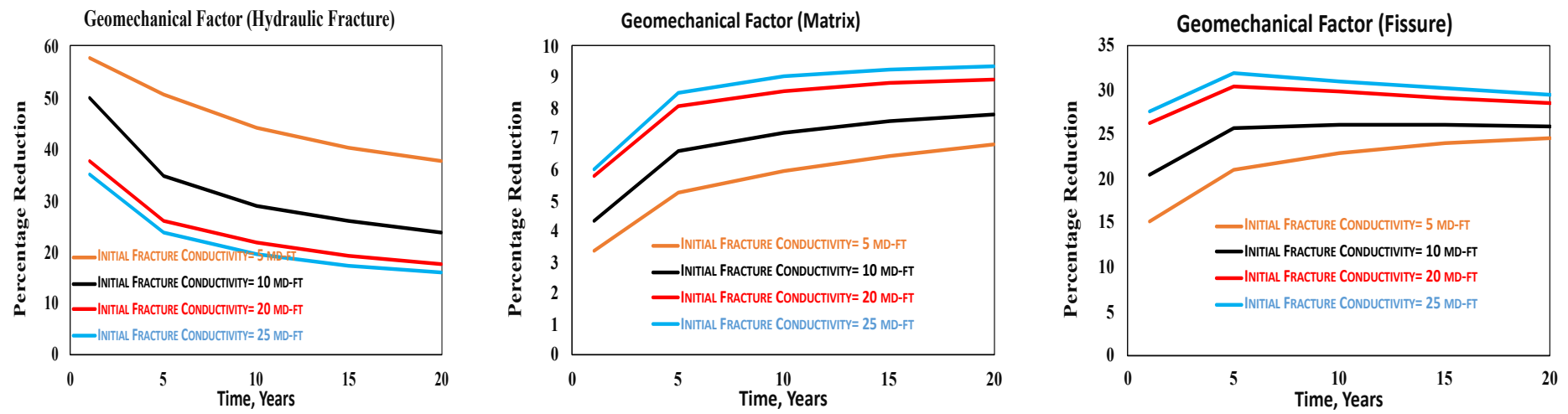

Figure 4.45: Percentage Reduction in Gas Recovery for Different Fracture Conductivities Due to Geomechanical Factors. 


\subsubsection{Fracture Stage Spacing}

Figures 4.46, 4.47, and 4.48 illustrate the impact of the geomechanical factors on cumulative gas production for different fracture stage spacings with keeping the same number of stages at 8 . It is obvious from a comparison between Figures 4.46, 4.47, and 4.48 with Figure 4.6 (base case) that the impact of the propped hydraulic fracture geomechanical factor approaches fissure geomechanical factor. This change ensues because gas production from the fissure decreases with more reduction than the matrix and fracture stages when the fracture stages spacing decreases. The geomechanical factors show a higher influence on the elements that contribute more to total gas production. Furthermore, the flow paths concentrate on a smaller portion of the lateral section. Consequently, the connection between the pay zone and the well decreased, leading to reduced production in all flow elements. Figure 4.49 shows the pressure distribution for different fracture stages after 2 years of production. Figure 4.50 shows a percentage reduction in gas recovery due to the geomechanical factors for different fracture stages spacing while maintaining the number of stages at 8 . It is evident from Figure 4.50 that as fracture spacing decreases, the impact of geomechanical factors decreases. Additionally, the gas production from the fissure decreases with more reduction than the matrix and fracture stages when the fracture stages spacing decreases. However, gas production from the fracture stages decreases with higher reduction than the matrix.
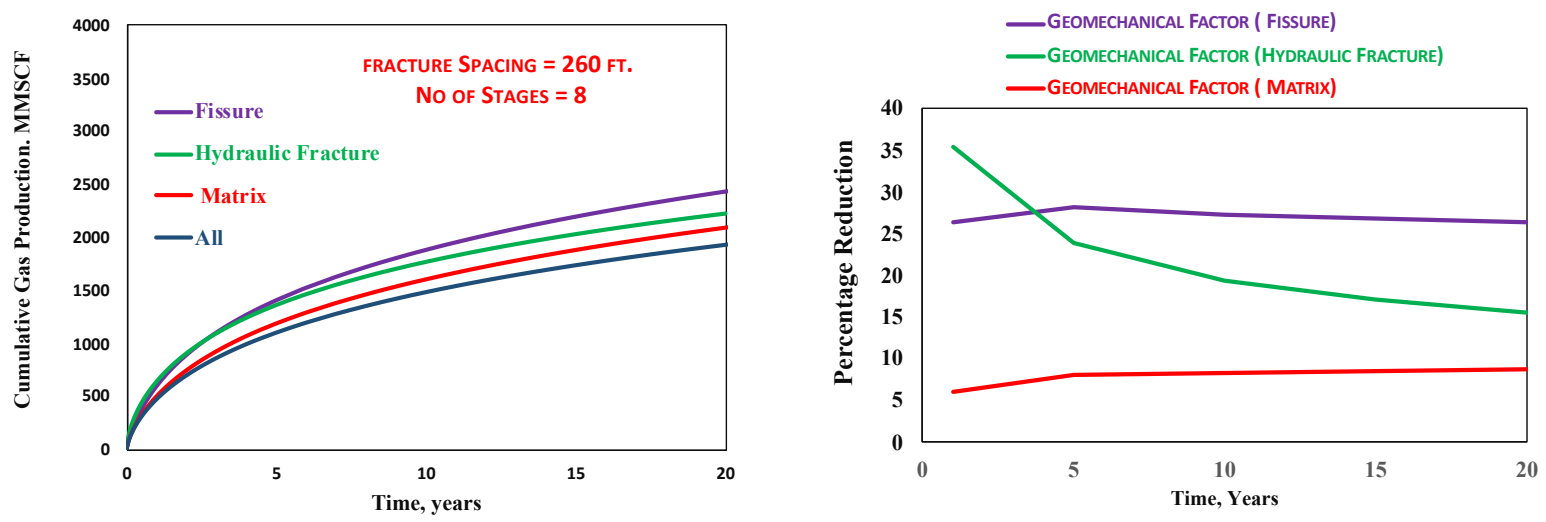

Figure 4.46: Cumulative Gas Production for Fracture Spacing of $260 \mathrm{ft}$. with 8 Stages and Percentage Reduction in Gas Recovery Due to Geomechanical Factors. 

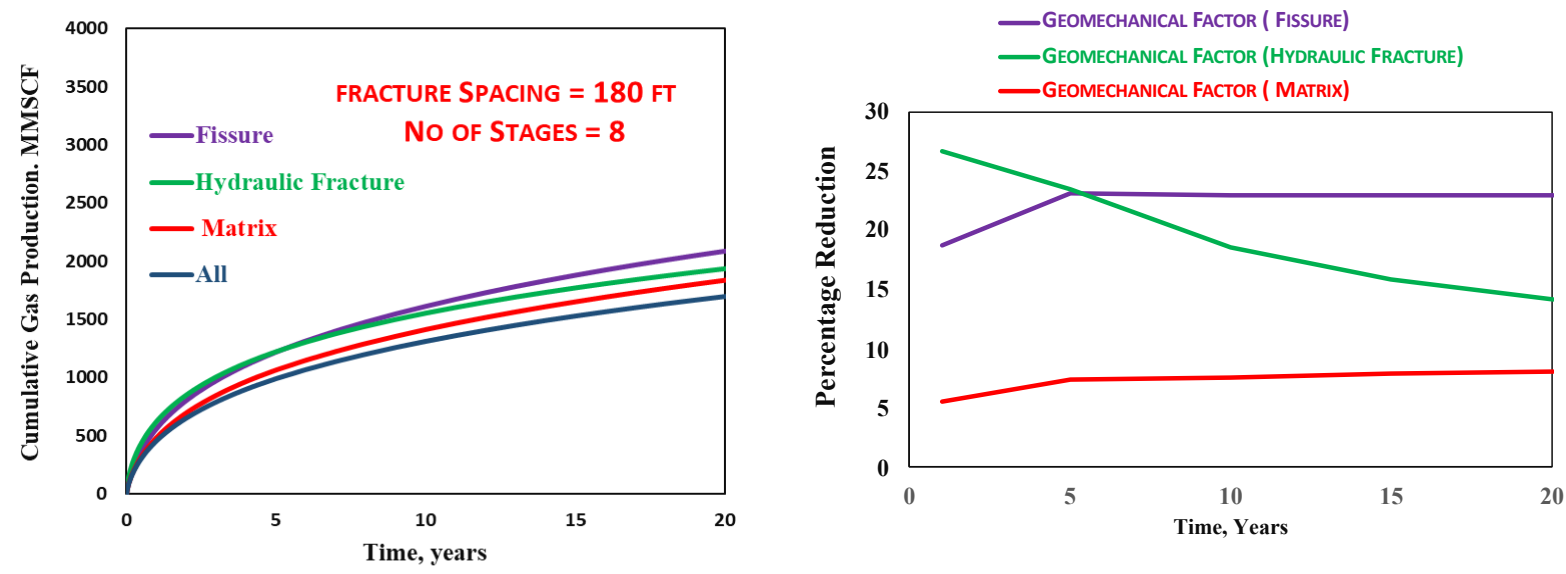

Figure 4.47: Cumulative Gas Production for Fracture Spacing of $180 \mathrm{ft}$. with 8 Stages and Percentage Reduction in Gas Recovery Due to Geomechanical Factors.
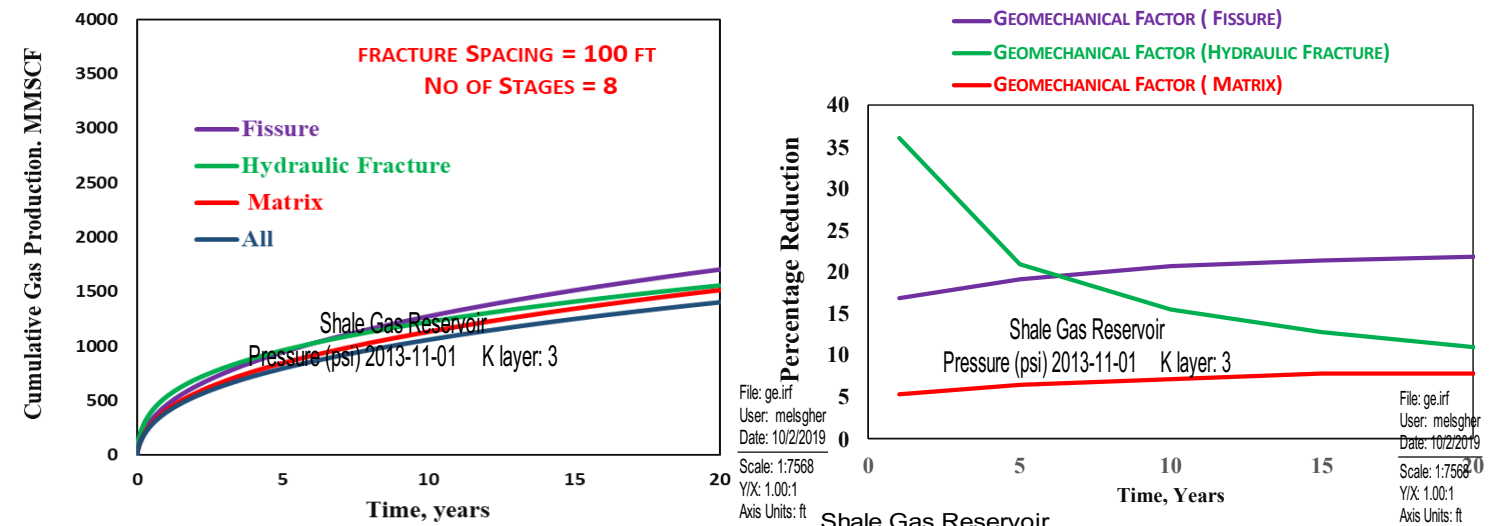

Figure 4.48: Cumulative Gas Production for Fracture Spacing of $100 \mathrm{ft}$. with 8 Stages and Percentage Reduction in Gas Recovery Due to Geomechanical Factors.
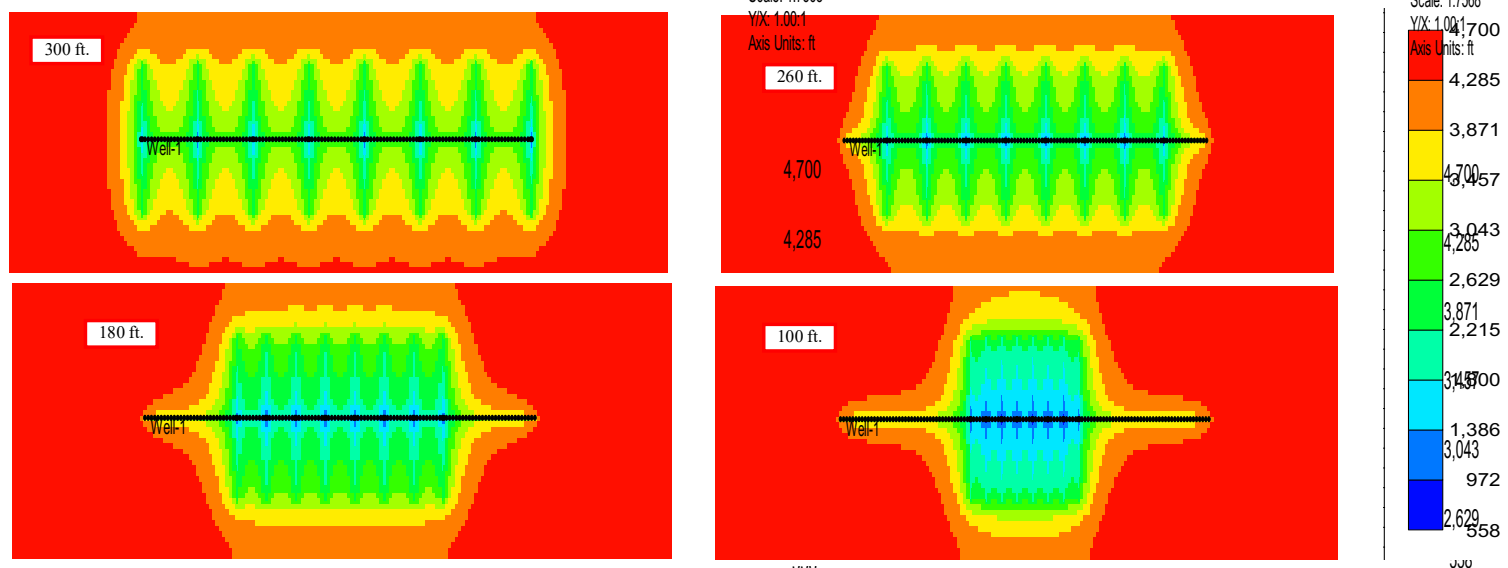

Figure 4.49: Pressure Distribution after 2 Years of Production for Different Fracture Spacing with 8 Stages. 

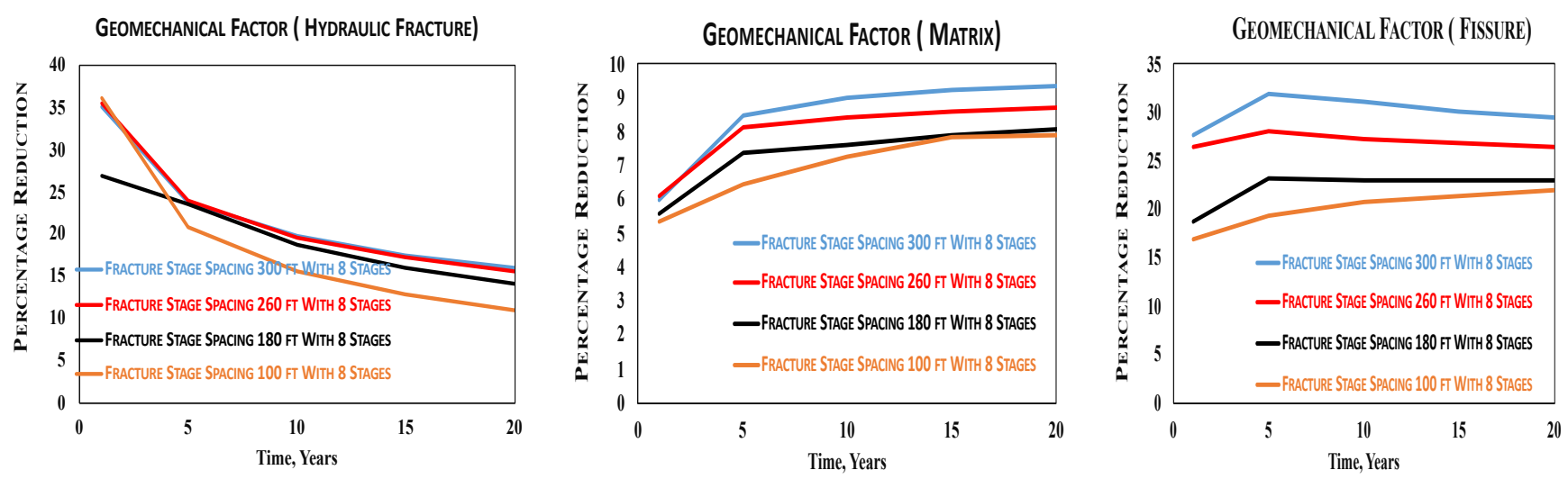

Figure 4.50: Percentage Reduction in Gas Recovery for Different Fracture Spacings with 8 Stages Due to Geomechanical Factors.

Figures 4.51, 4.52, and 4.53 illustrate the impact of the geomechanical factors on cumulative gas production for different fracture stage spacings while simultaneously changing the number of stages. It is evident from a comparison between Figures 4.51, 4.52, and 4.53 with Figure 4.6 (base case) that the cumulative gas production of the propped hydraulic fracture geomechanical factor approaches a similar level as that of the fissure geomechanical factor. This shift occurs because the gas production from the fracture stages increases with higher increment than the matrix and fissure when the fracture stages spacing decreases with the increasing number of fracture stages increases. Additionally, when the fracture spacing is reduced and the number of fracture stages is simultaneously increased, additional flow paths were created between the matrix, fissure, and the well through the various fractures stages which improved the contact efficiency between the reservoir and simulation reservoir volume (SRV) as illustrated in Figure 4.54. Figure 4.54 shows the pressure distribution after 2 years of production for different fracture stage spacings along with an increase in the number of stages. Therefore, the geomechanical factors show a greater influence on the elements contributing more to total gas production. Figure 4.55 shows a percentage reduction in gas recovery due to the geomechanical factors for different fracture stage spacing with increasing the number of stages. It is obvious from Figure 4.55 that as fracture spacing decreases, the impact of geomechanical factors associated with fissure and matrix permeability decreases. However, it does not influence the propped hydraulic fracture geomechanical factor, even though the gas production from the fracture stages increases with greater increment than the matrix and fissure. 

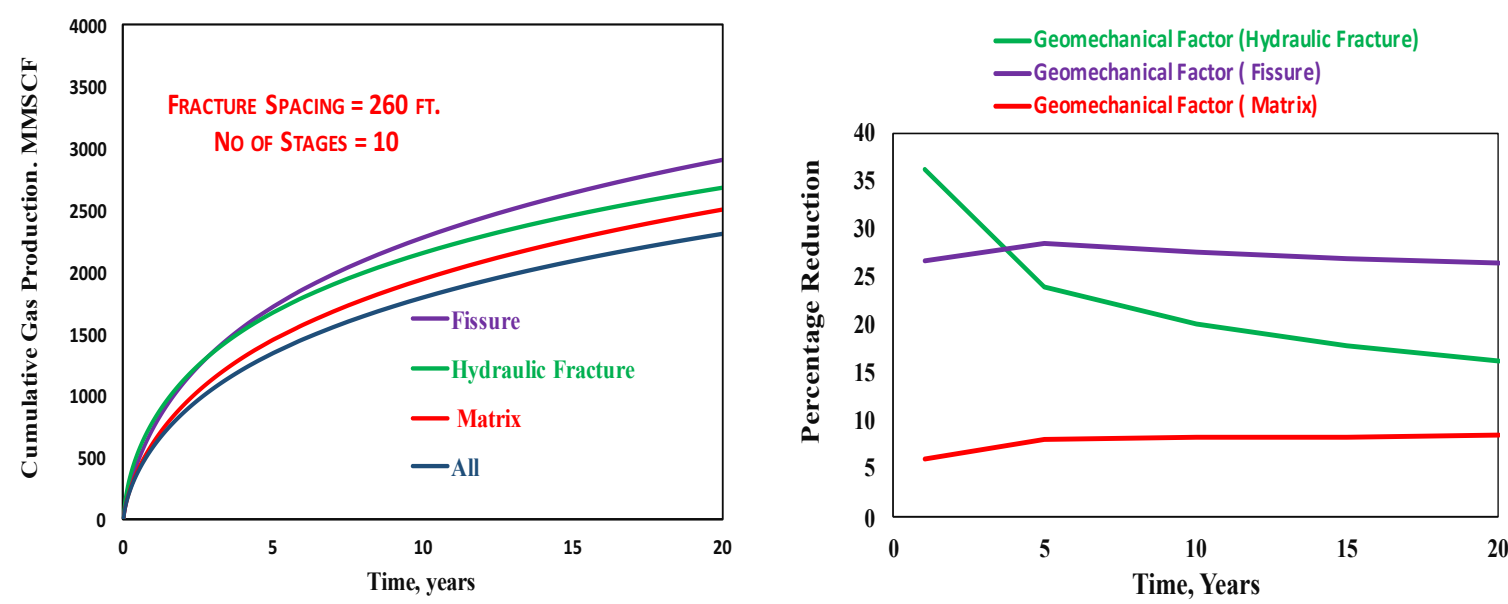

Figure 4.51: Cumulative Gas Production for Fracture Spacing of $260 \mathrm{ft}$. with 10 Stages and Percentage Reduction in Gas Recovery Due to Geomechanical Factors.
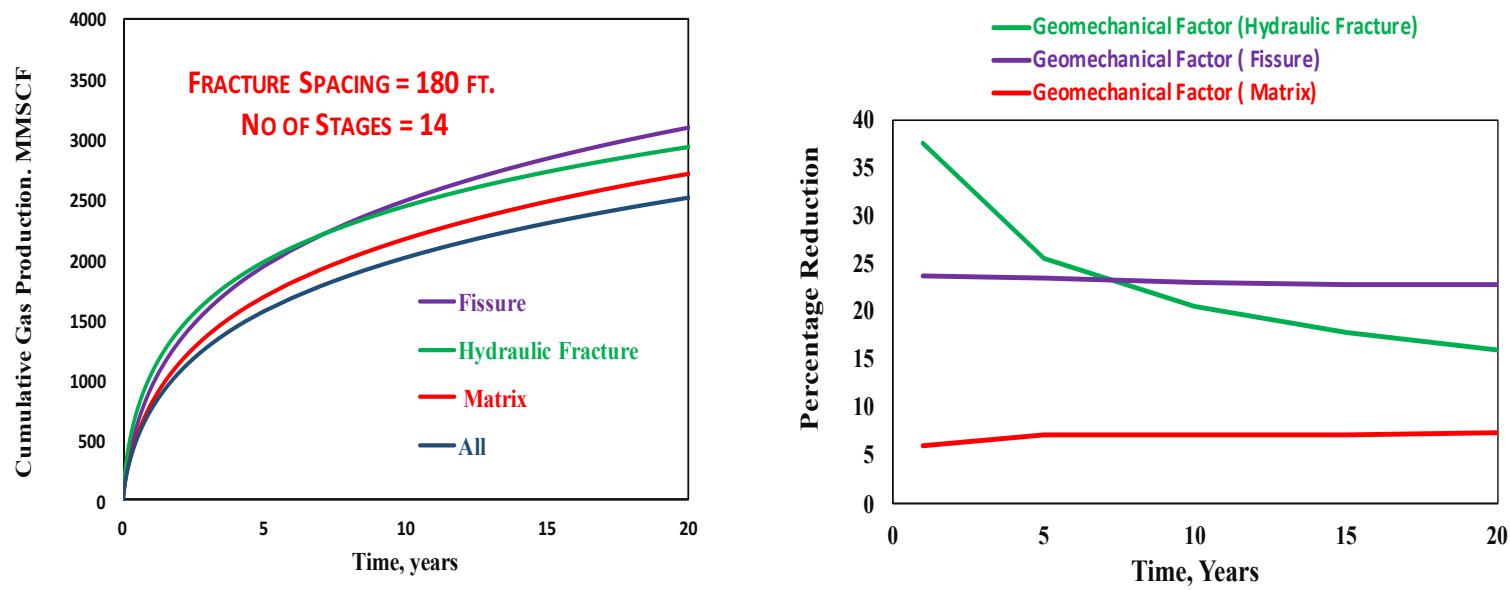

Figure 4.52: Cumulative Gas Production for Fracture Spacing of $180 \mathrm{ft}$. with 14 Stages and Percentage Reduction in Gas Recovery Due to Geomechanical Factors.
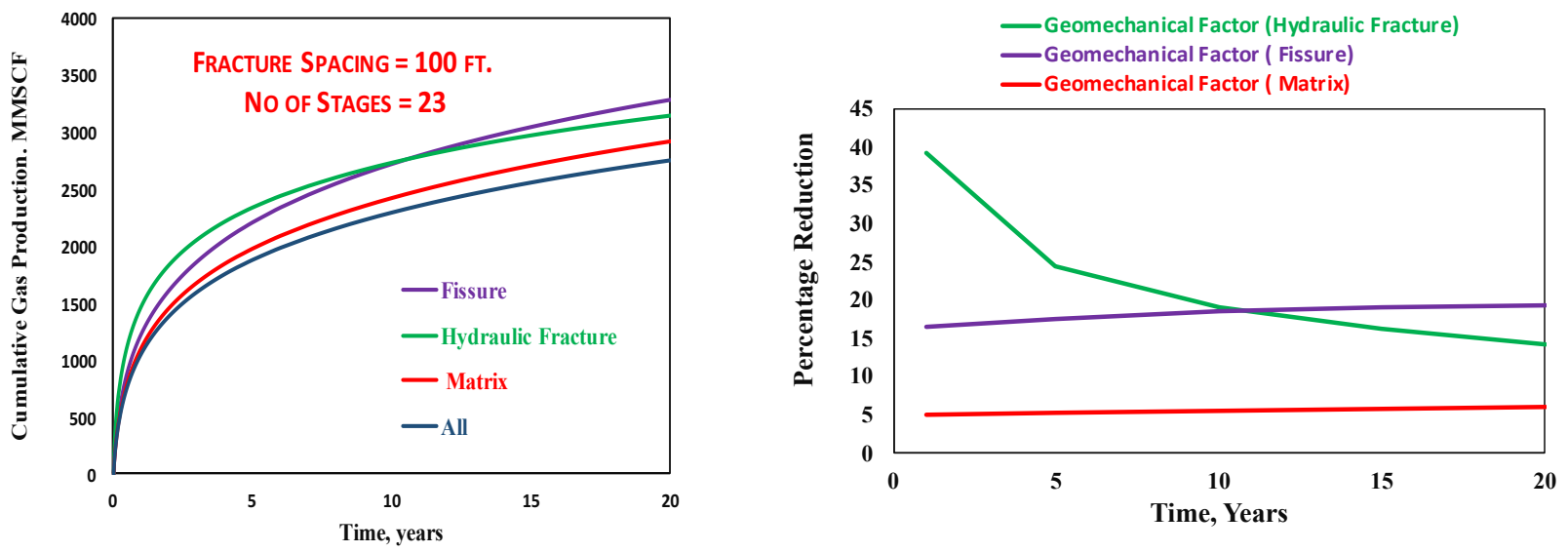

Figure 4.53: Cumulative Gas Production for Fracture Spacing of $100 \mathrm{ft}$. with 23 Stages and Percentage Reduction in Gas Recovery Due to Geomechanical Factors. 

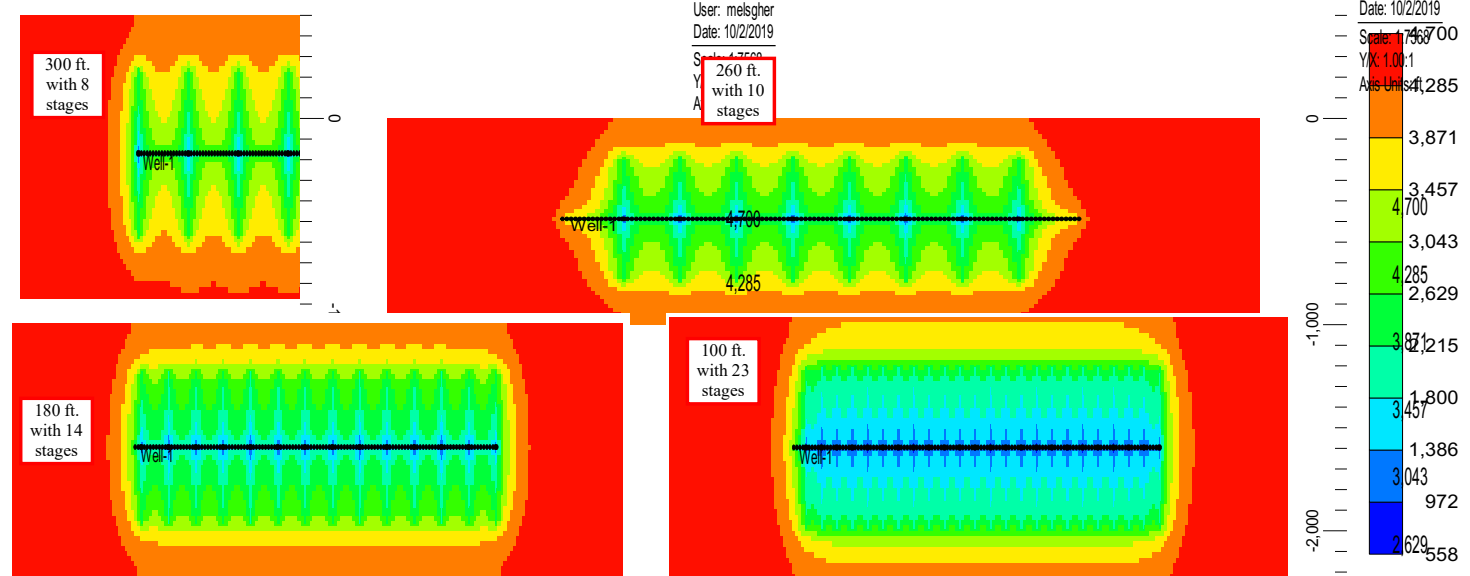

Figure 4.54: Pressure Distribution after 2 years of Production for Different Fracture Spacing with Increasing Number of Stages.
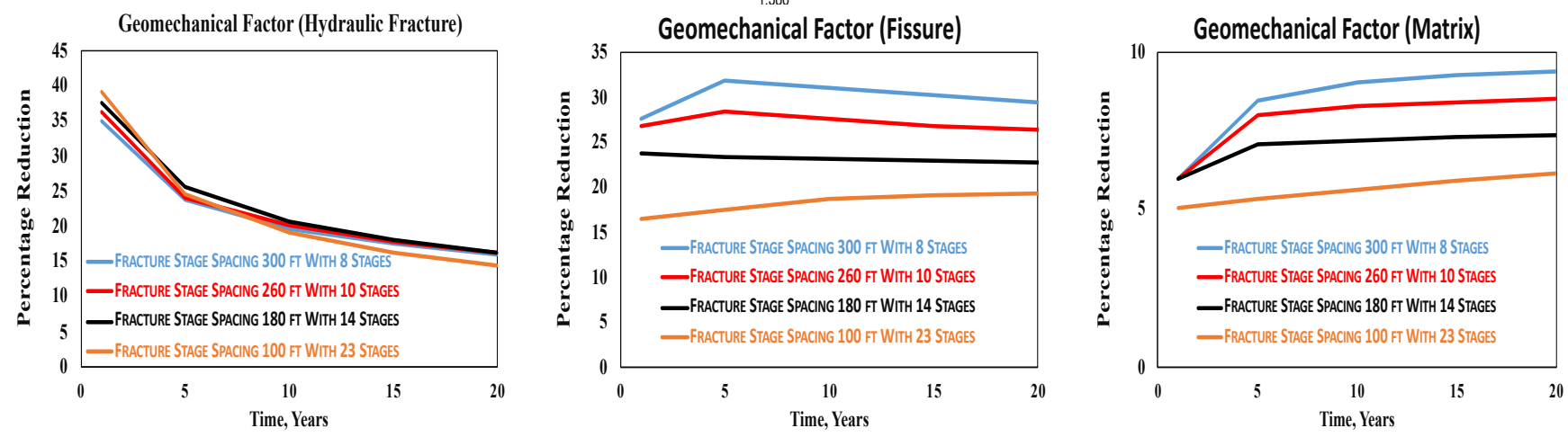

Figure 4.55: Percentage Reduction in Gas Recovery for Different Fracture Spacings and Stages Due to Geomechanical Factors.

\subsubsection{Fissure Permeability}

Figures 4.56, 4.57, and 4.58 illustrate the impact of geomechanical factors on cumulative gas production for different initial fissure permeabilities. It is obvious from a comparison between Figures 4.56, 4.57, and 4.58 with Figure 4.6 (base case) that as the initial fissure permeability increases, the impact of the matrix geomechanical factor becomes even less significant. This change occurs because the gas production from the fissure increases with a higher increment than the matrix and fracture stages. However, as the initial fissure permeability increases, it does not influence the propped hydraulic fracture geomechanical factor. Figure 4.59 shows the pressure distribution for different initial fissure permeabilities after 2 years of gas production. Furthermore, Figure 4.60 illustrates the percentage reduction in gas recovery for different fissure permeabilities due to the geomechanical factors. 

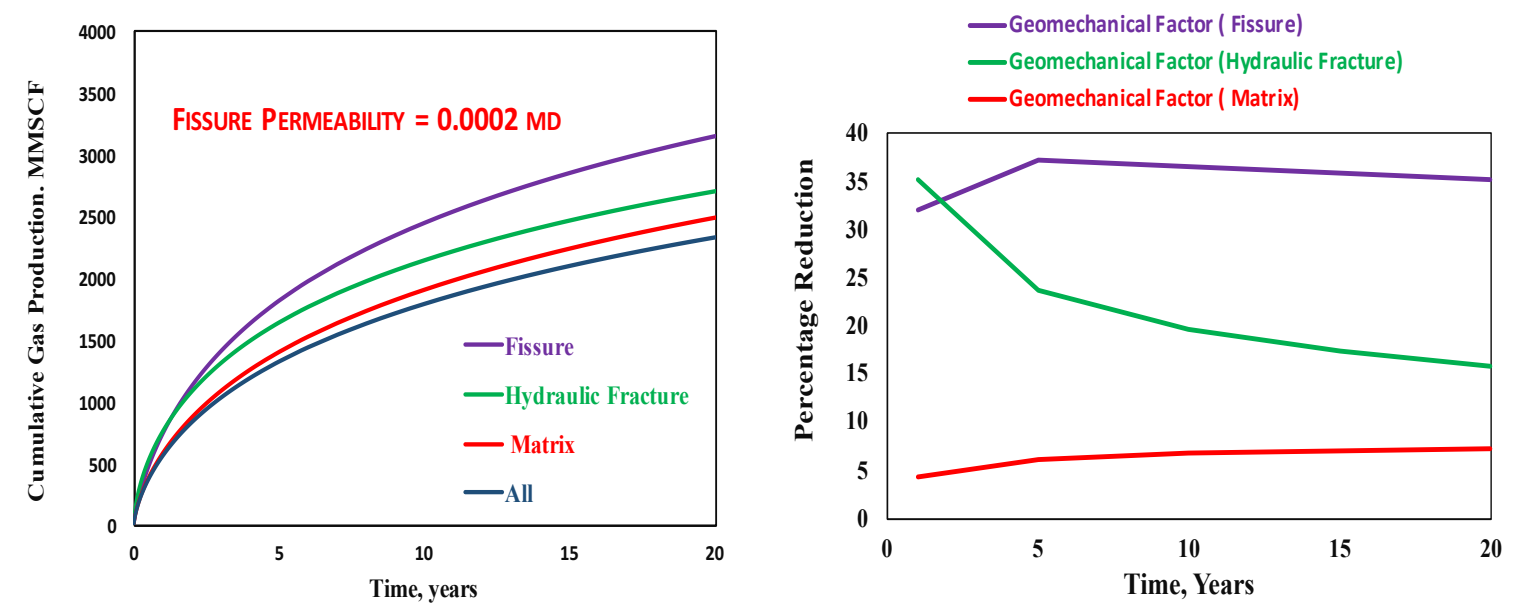

Figure 4.56: Cumulative Gas Production for Fissure Permeability 0.002 md. with 8 Stages and Percentage Reduction in Gas Recovery Due to Geomechanical Factors.
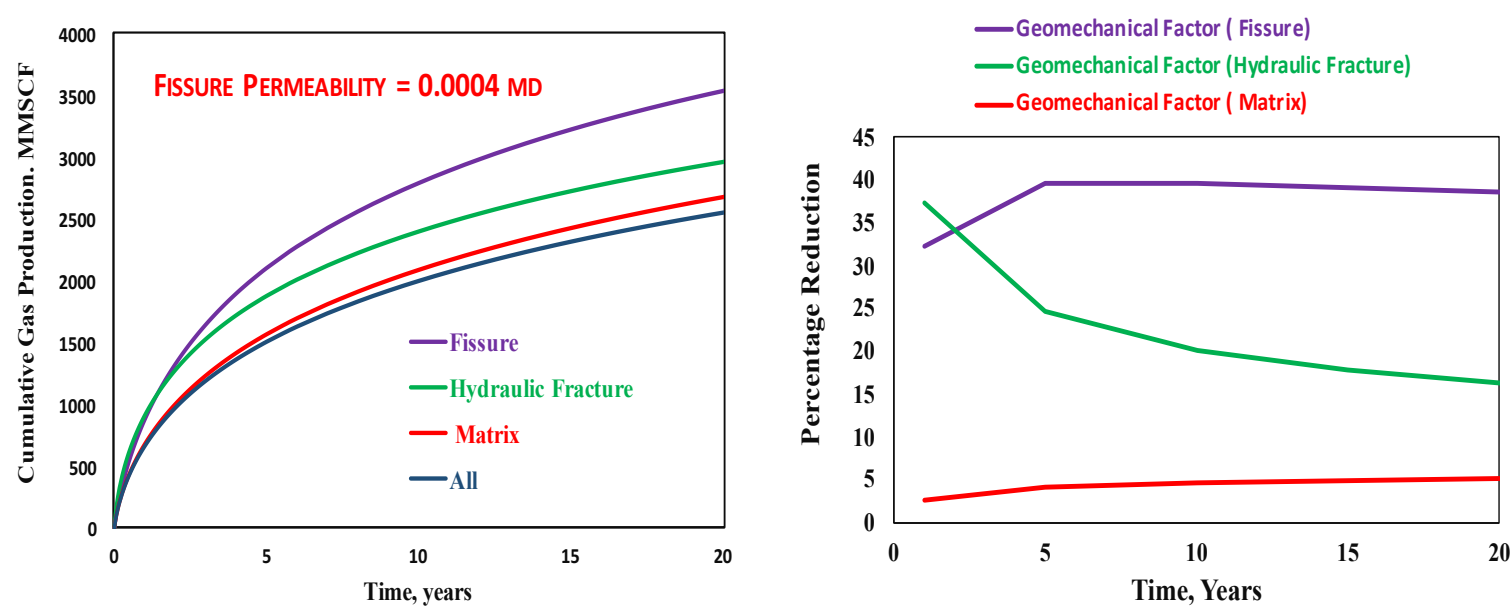

Figure 4.57: Cumulative Gas Production for Fissure Permeability 0.004 md. with 8 Stages and Percentage Reduction in Gas Recovery Due to Geomechanical Factors.
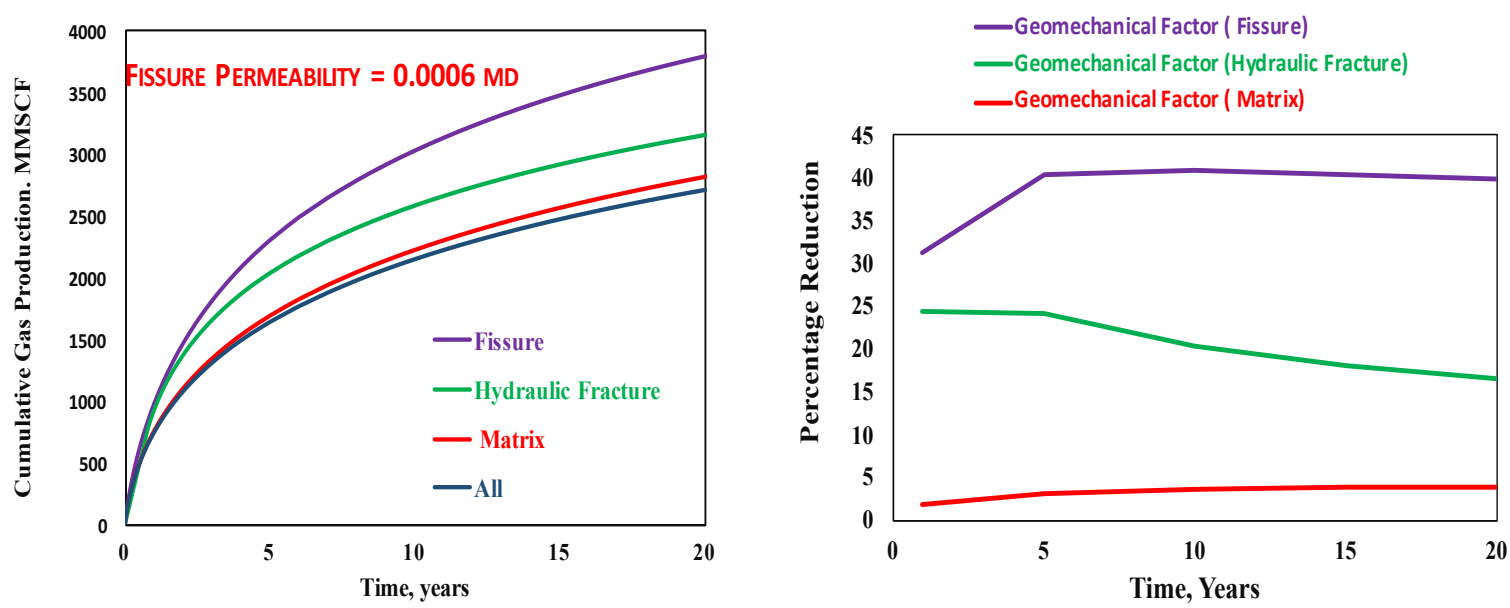

Figure 4.58: Cumulative Gas Production for Fissure Permeability 0.006 md. with 8 Stages and Percentage Reduction in Gas Recovery Due to Geomechanical Factors. 

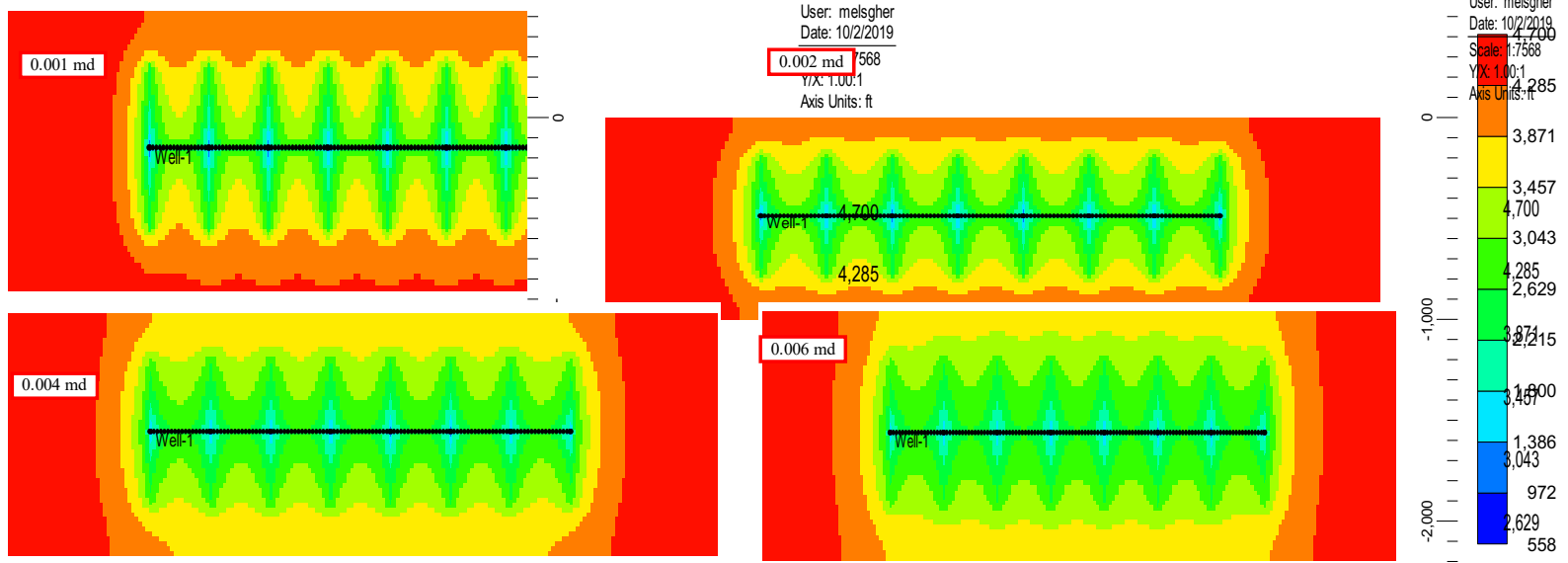

Figure 4.59: Pressure Distribution after 2 Years of Production for Different Fissure Permeabilities.
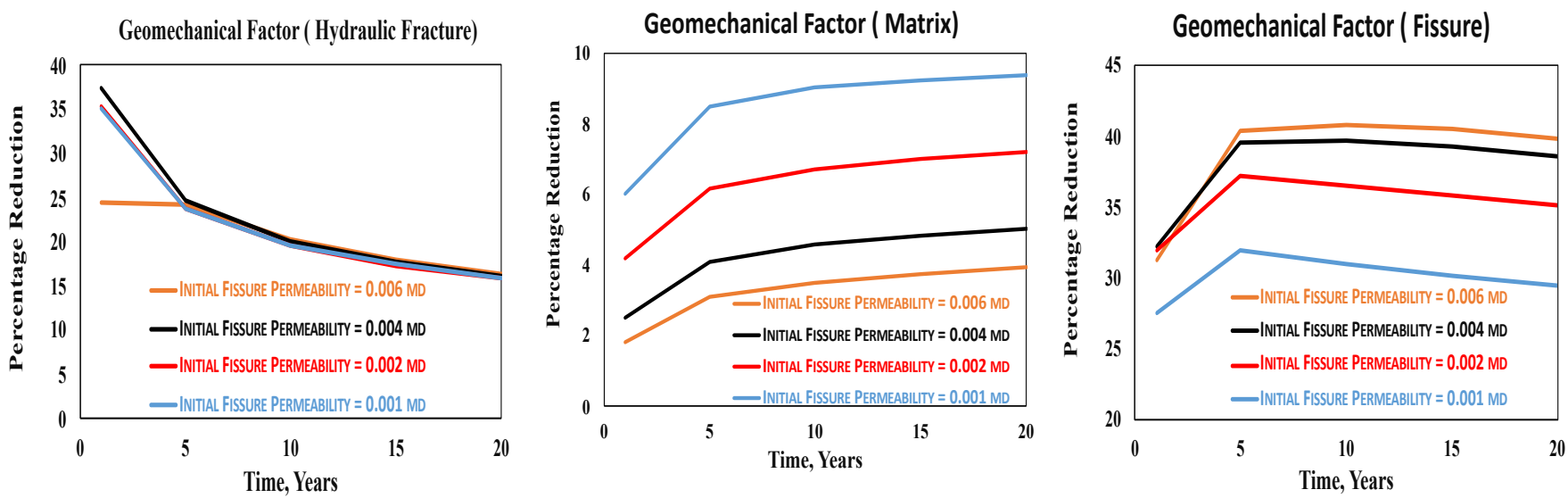

Figure 4.60: Percentage Reduction in Gas Recovery for Different Fissure Permeabilities Due to Geomechanical Factors.

\subsubsection{Wellbore Pressure}

Figures 4.61, 4.62, and 4.63 illustrate the impact of geomechanical factors on cumulative gas production for different wellbore pressures. It is clear from a comparison between Figures 4.61, 4.62, and 4.63 with Figure 4.6 (base case) that as the wellbore pressure decreases, the impact of the propped hydraulic fracture geomechanical factor approaches that of matrix geomechanical factor. This shift transpires because gas production from the fracture stages decreases with more reduction than the matrix. Increasing wellbore pressures lead to a reduction in production in all flow elements. Therefore, the geomechanical factors show a greater influence on the elements that contribute more to total gas production. Figure 4.64 shows the pressure distribution for wellbore pressure after 2 years of production. Figure 4.65 shows a percentage reduction in gas recovery due to the geomechanical factors for different wellbore pressure. It is evident from Figure 4.65 that as wellbore pressure increases, the impact of geomechanical factors decreases. Overall, increasing wellbore pressure does not have a significant impact on gas production loss. 

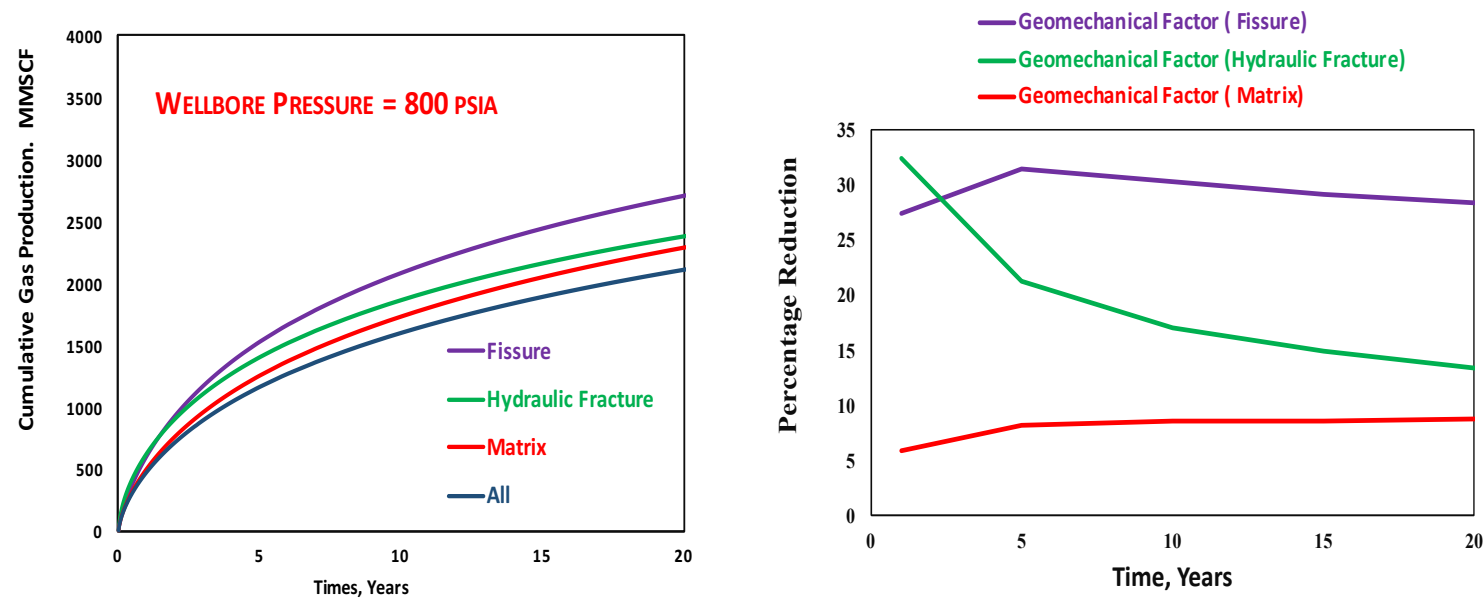

Figure 4.61: Cumulative Gas Production for Wellbore Pressure 800 Psia and Percentage Reduction in Gas Recovery Due to Geomechanical Factors.
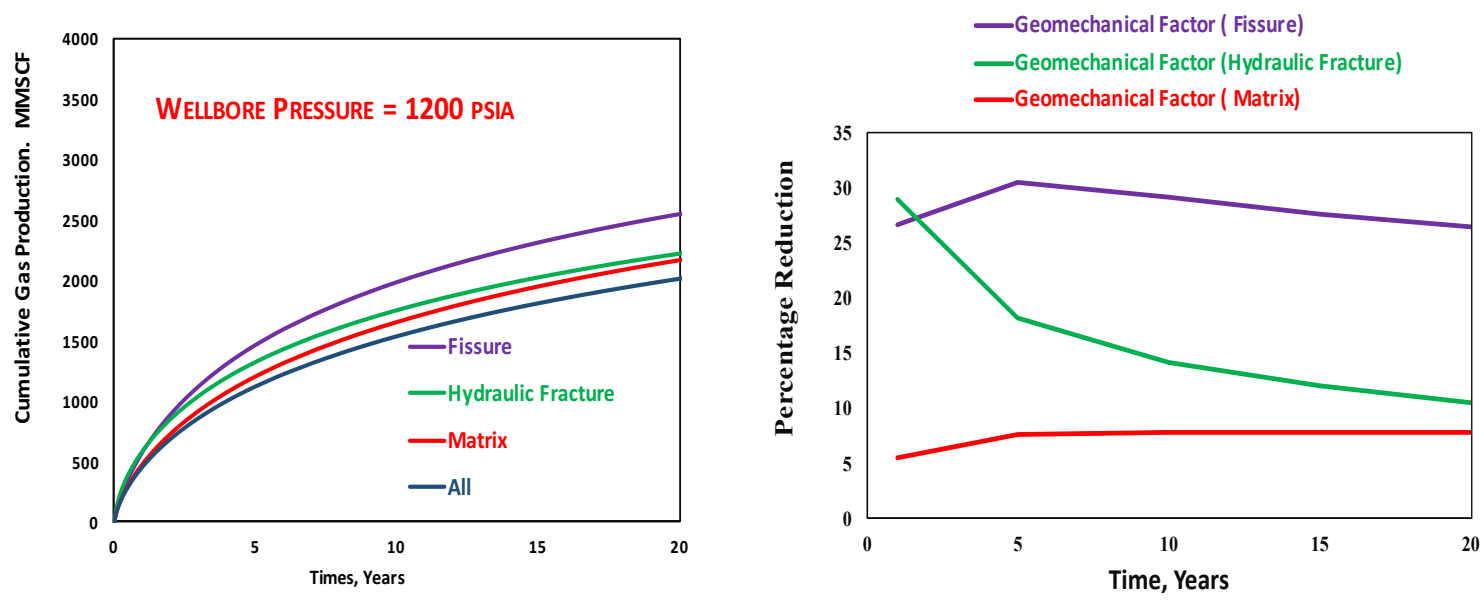

Figure 4.62: Cumulative Gas Production for Wellbore Pressure 1200 Psia and Percentage Reduction in Gas Recovery Due to Geomechanical Factors.
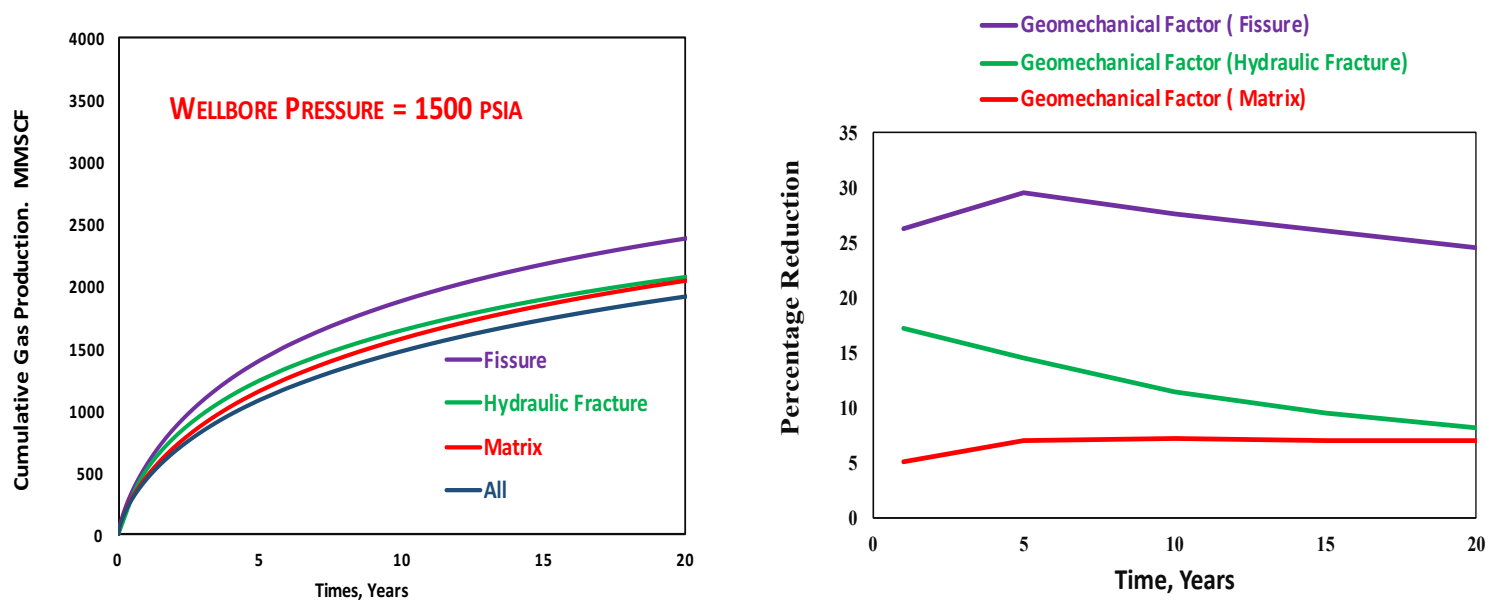

Figure 4.63: Cumulative Gas Production For Wellbore Pressure 1500 Psia and Percentage Reduction in Gas Recovery Due to Geomechanical Factors. 

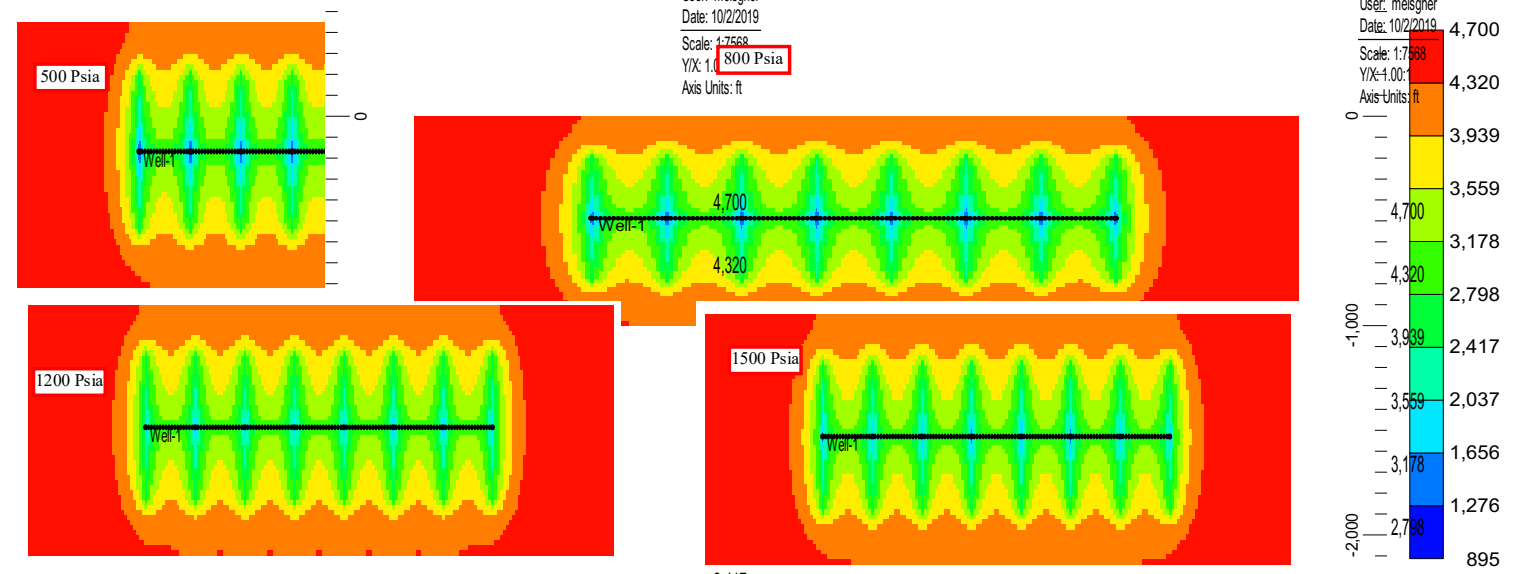

Figure 4.64: Pressure after 2 Years of Production for Various Wellbore Pressures.
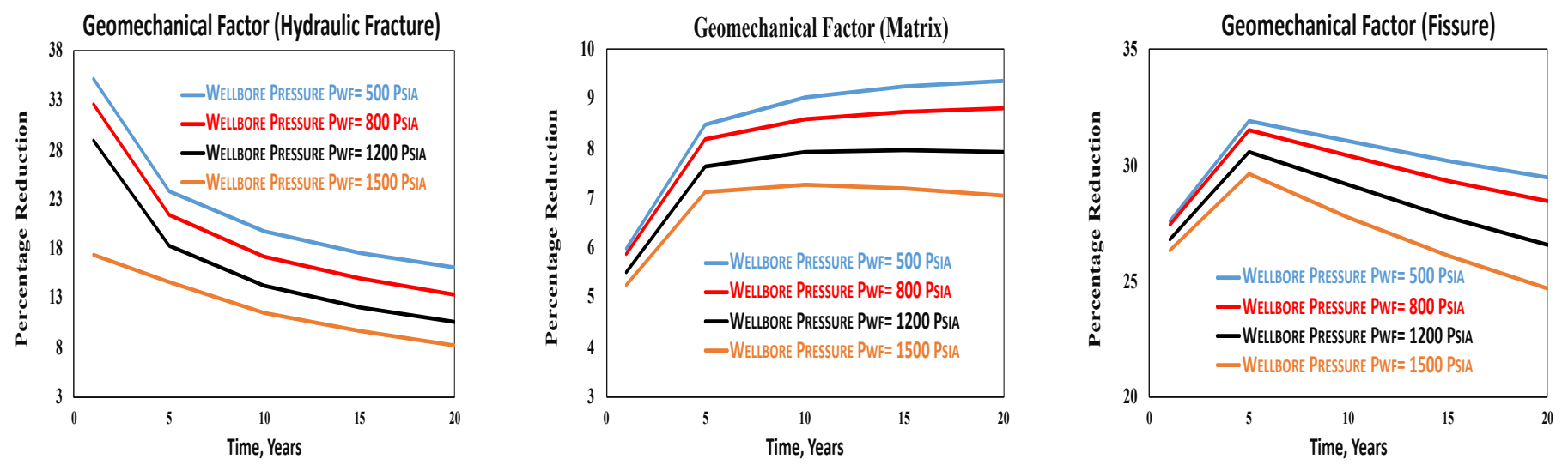

Figure 4.65: Percentage Reduction in Gas Recovery for Different Wellbore Pressures Due to Geomechanical Factors.

Figures 4.66, 4.67, and 4.68 summarize and compare the relative impact of critical parameters that influence geomechanical factors. It illustrates the percentage reduction in gas recovery due to geomechanical factors on cumulative gas production at 20 years. 


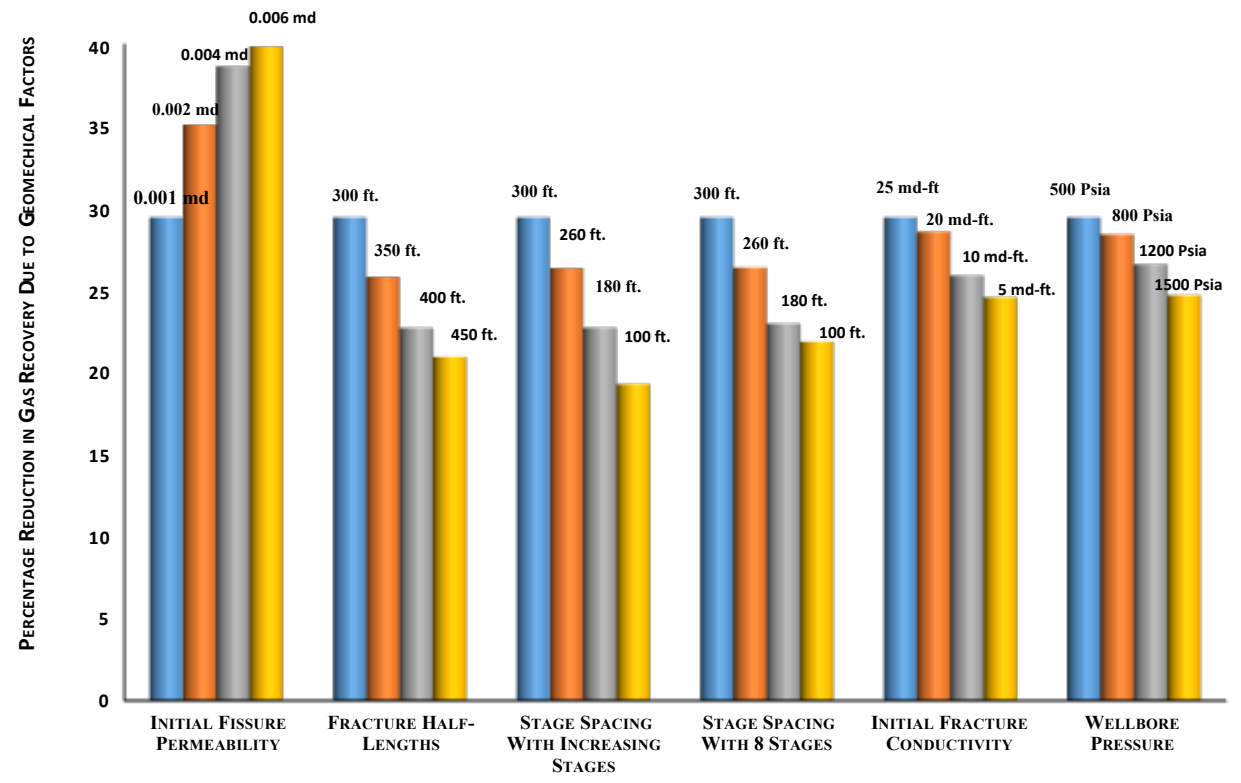

Figure 4.66: Critical Parameters That Influence The Impact Of Fissure Permeability Geomechanical Factors on Gas Recovery.

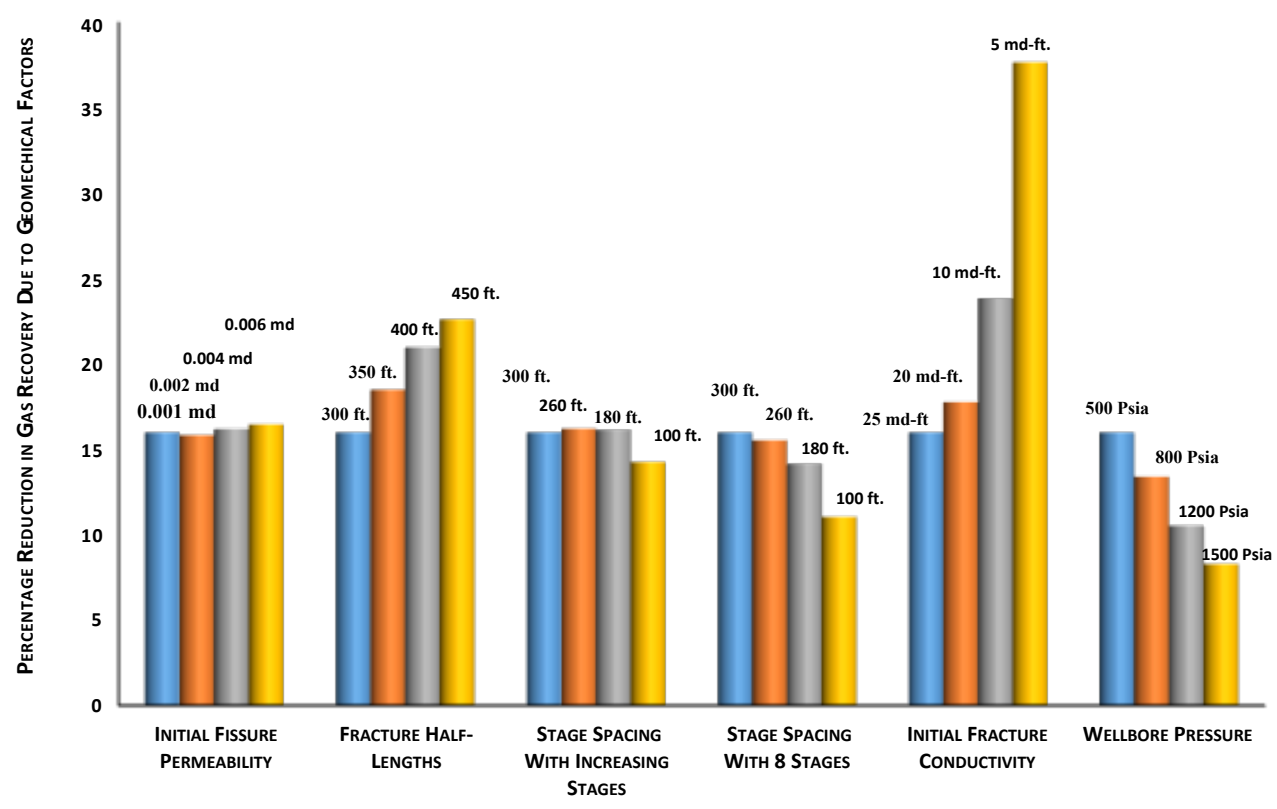

Figure 4.67: Critical Parameters That Influence Propped Fracture Conductivity Geomechanical Factors on Gas Recovery. 


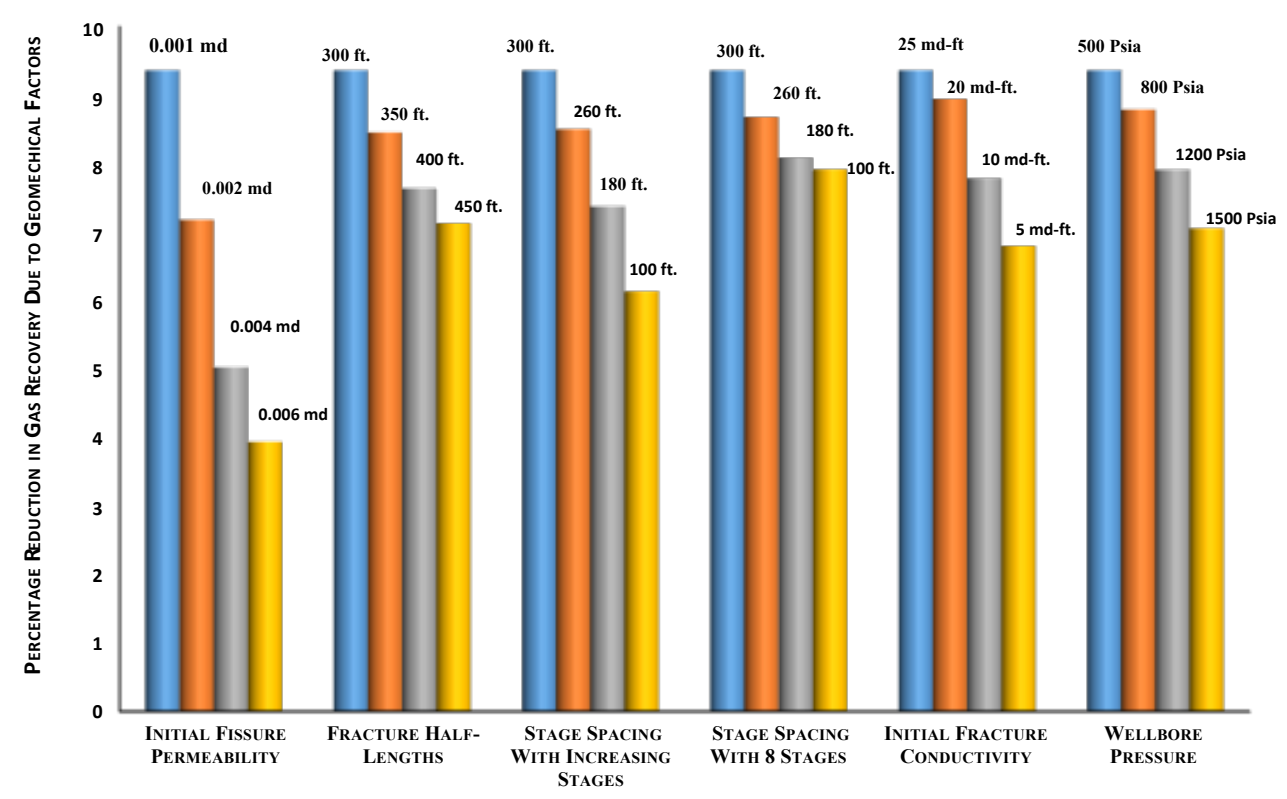

Figure 4.68: Critical Parameters That Influence Matrix Permeability Geomechanical Factors on Gas Recovery.

\subsection{Results of Parametric Studies with Geomechanical Factors (Matrix, Fissure, and Hydraulic Fracture) (MIP-6H)}

For the parametric studies, only the geomechanical factor associated with the fissure permeability was considered since it has the most impact on production.

The geomechanical factor for matrix permeability, utilized from experimental results by Elsaig et al. (2016), was used in the model, as mentioned earlier. However, the geomechanical factor for fissure permeability, which was obtained from experimental results by Cipolla et al. (2008), was used in the model, as mentioned earlier. Furthermore, the geomechanical factor for hydraulic fracture, which was obtained from experimental results by McGinley et al. (2015), was used in the model.

\subsubsection{Fracture Half-Lengths.}

The fracture half-length was changed to investigate on the production. For this purpose, we used the case 1 model (fracture half-length of $380 \mathrm{ft}$.). Figure 4.69 compares the cumulative production and production rates when the geomechanical effect are included and excluded. Figures 4.70 and 4.71 illustrate the similar results for fracture half-lengths of 260 and 500 feet. The 10-year cumulative production was decreased by $31.53 \%$ when the geomechanical effect was included in the model for 480 -ft fracture halflength. The reduction in cumulative production was $36.33 \%$ for 360 -ft fracture half-length and $28.10 \%$ for 600-ft fracture half-length. The results are summarized in Figure 4.72. 

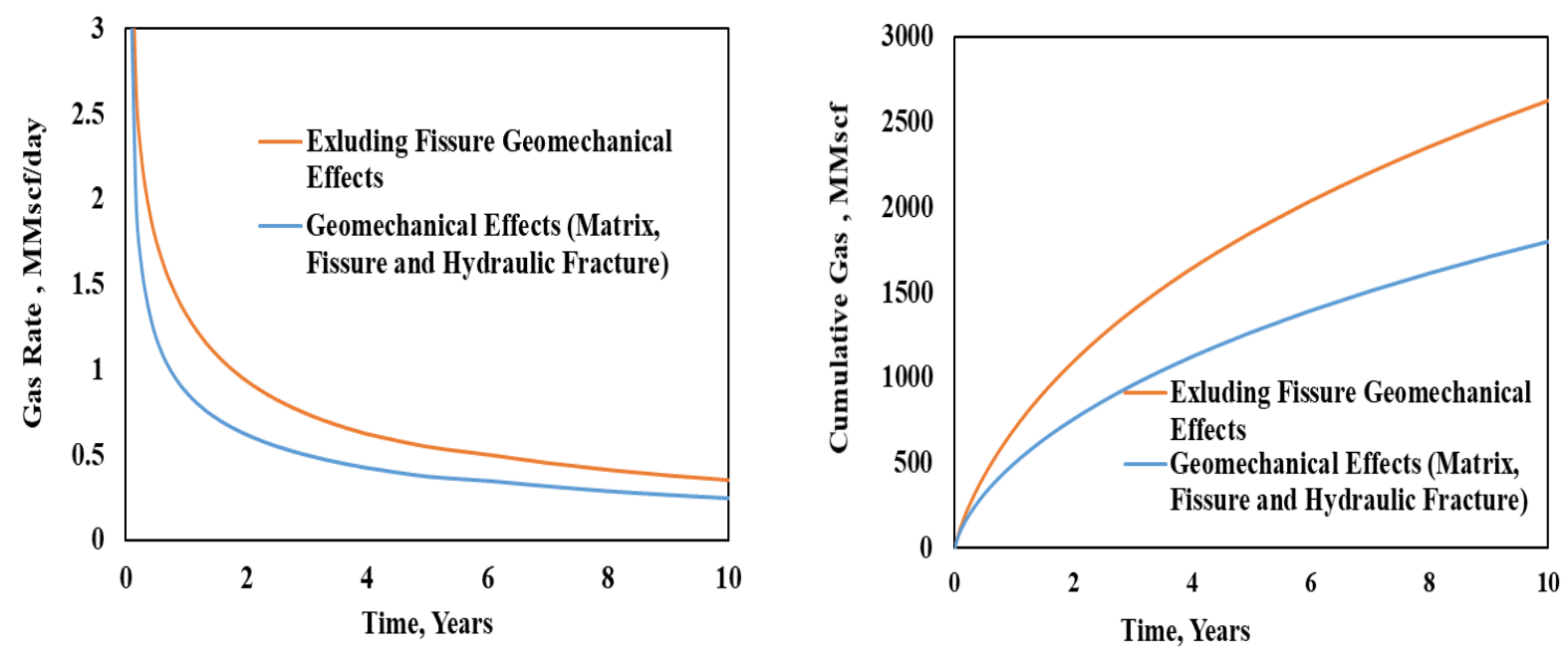

Figure 4.69: Effect of Fracture Half-length on the Cumulative Gas and the Production Rates (Case $1 \mathrm{Xf}=\mathbf{3 8 0} \mathrm{ft}$.).
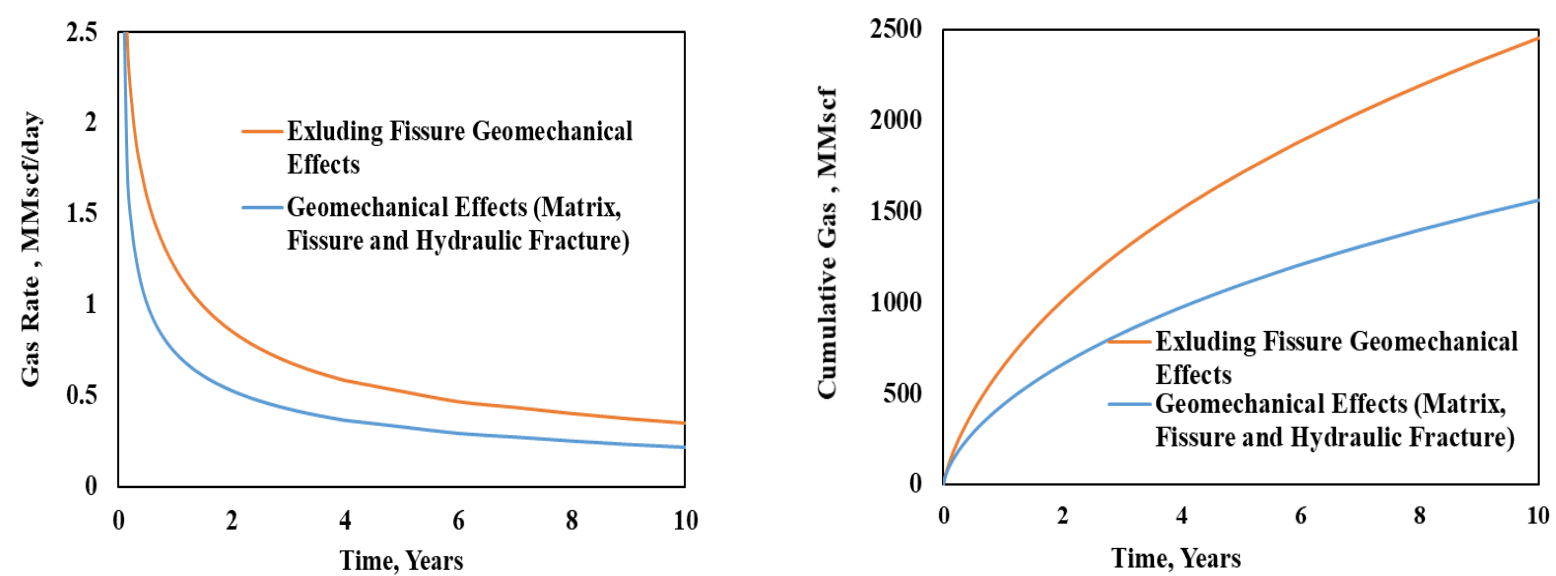

Figure 4.70: Effect of Fracture Half-length on the Cumulative Gas and the Production Rates $(X f=260$ ft. $)$.
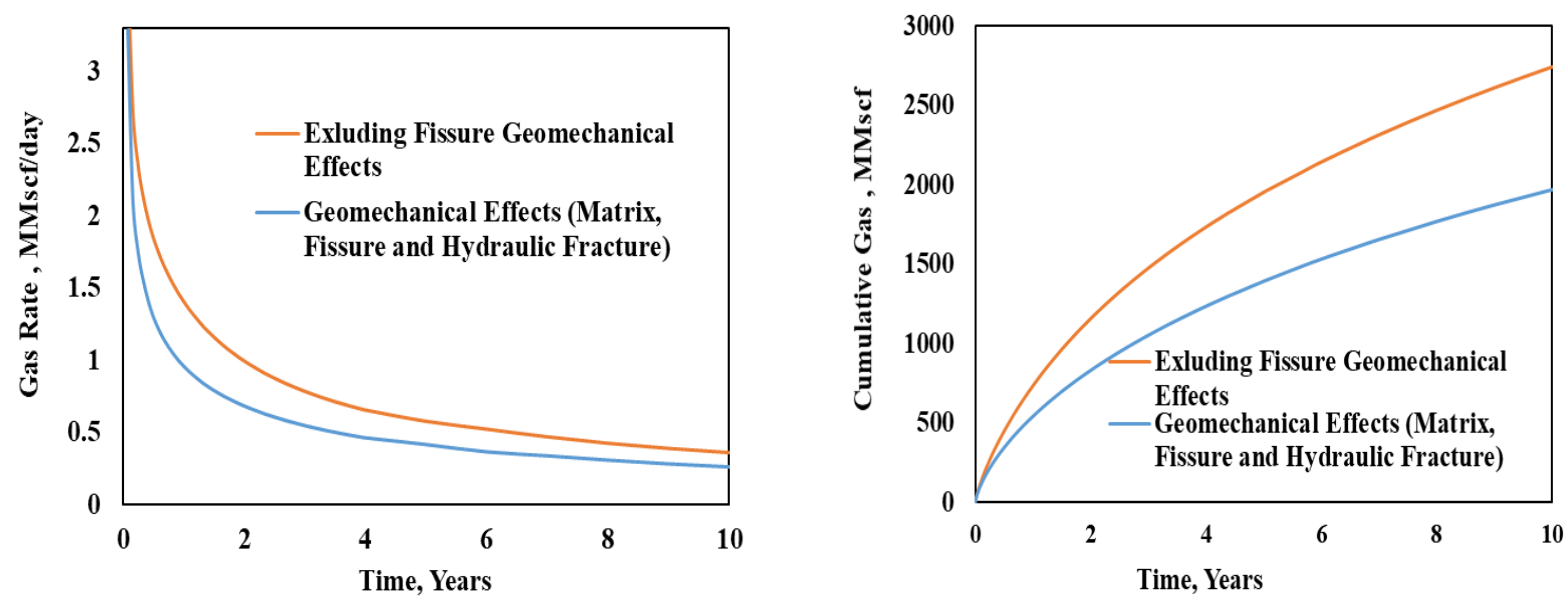

Figure 4.71: Effect of Fracture Half-length on the Cumulative Gas and the Production Rates $(\mathrm{Xf}=$ 500 ft.). 


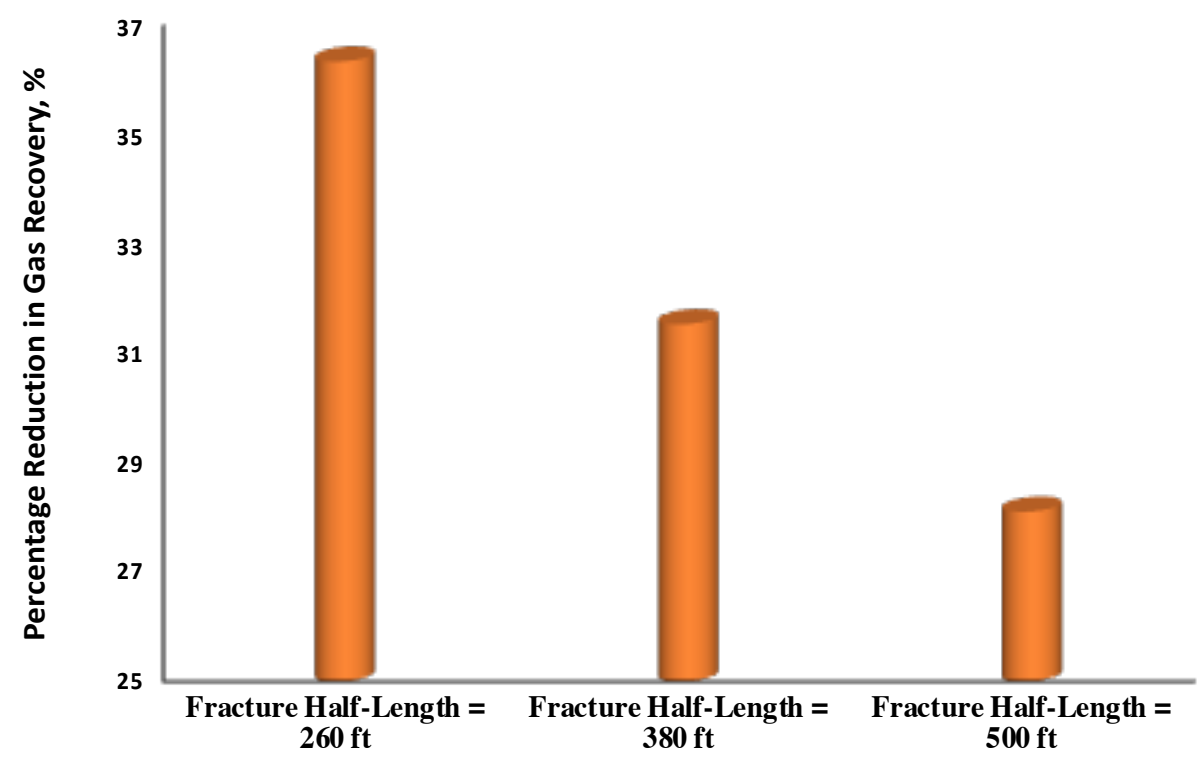

Figure 4.72: The Influence of Fracture Half-Length on the Stress-Dependent Fissure Permeability.

\subsubsection{Initial Fracture Conductivity.}

Initial fracture conductivity was changed to investigate its impact on geomechanical effects and production. Figures 4.73 and 4.74 illustrate the effect of the stress-dependent fissure permeability on the cumulative and the production rates for different values of initial fracture conductivity. The reduction in cumulative production was $28.34 \%$ for initial fracture conductivity $5 \mathrm{md}$-ft. and $33.52 \%$ for initial fracture conductivity $25 \mathrm{md}-\mathrm{ft}$. The results are summarized in Figure 4.75.
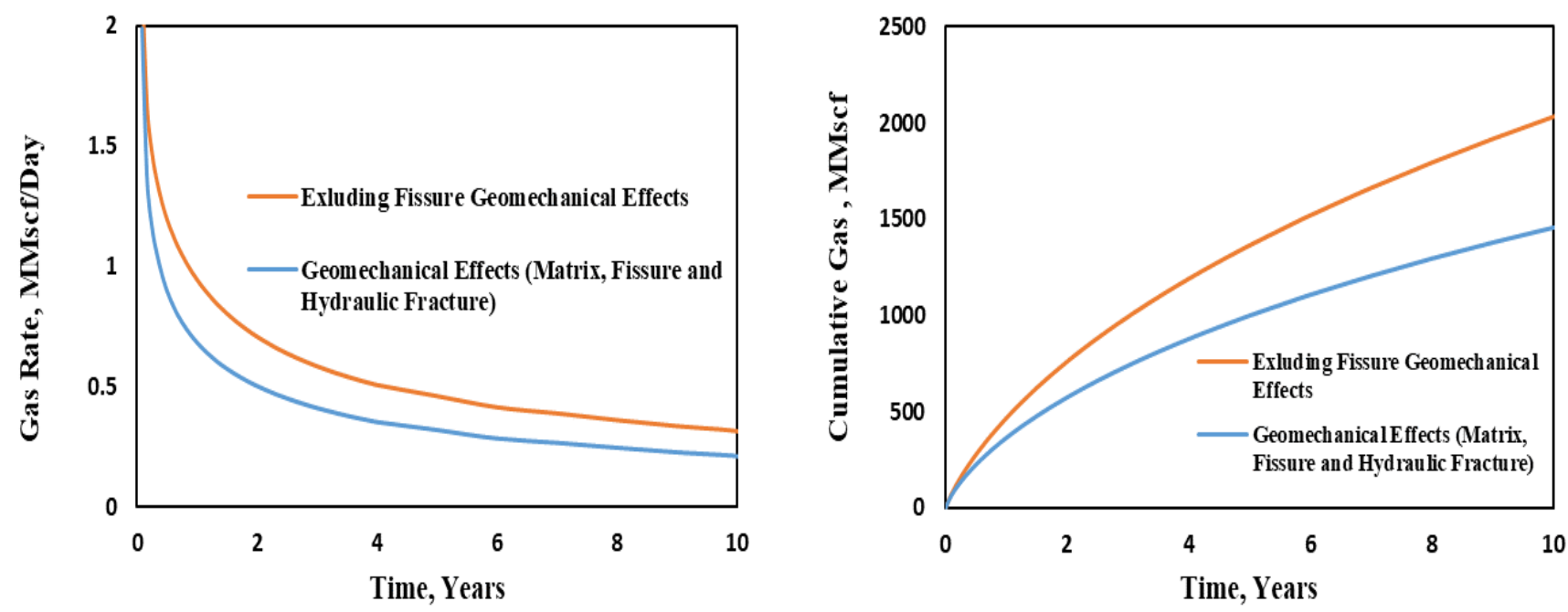

Figure 4.73: Impact Initial Fracture Conductivity (5 md-ft.) on the Cumulative Gas Production and Gas Rates. 

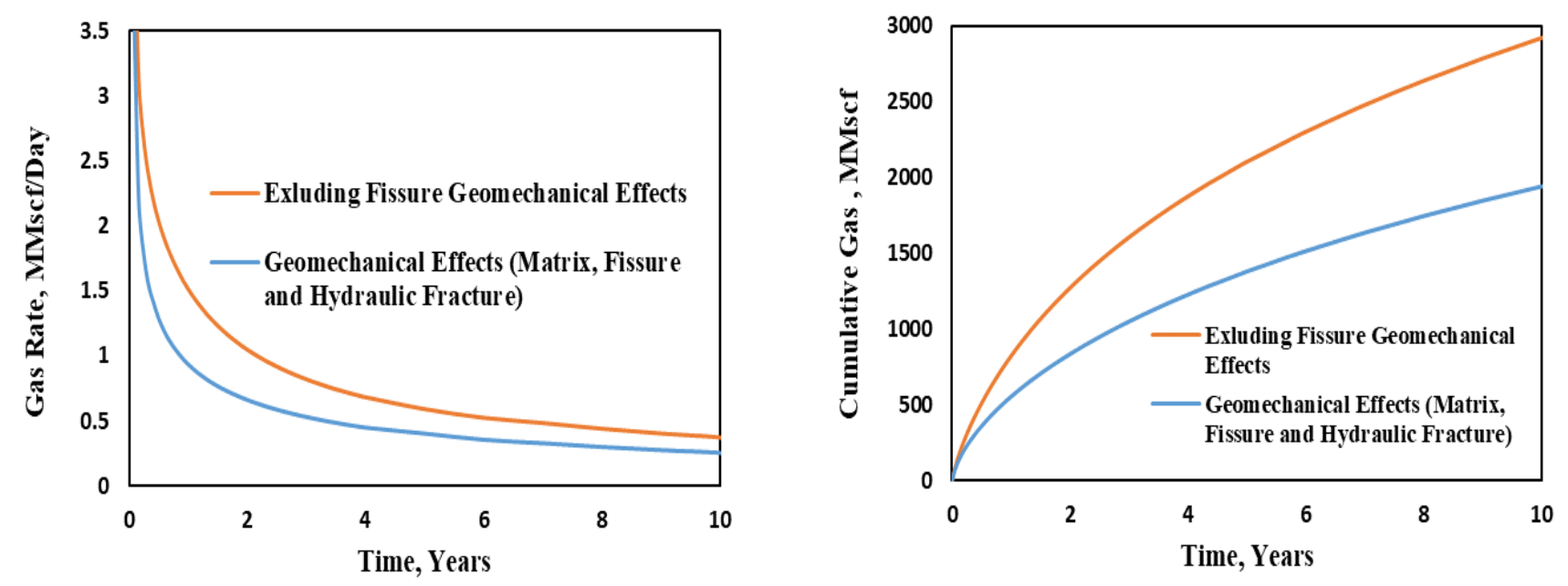

Figure 4.74: Impact Initial Fracture Conductivity (25 md-ft.) on the Cumulative Gas Production and Gas Rate.

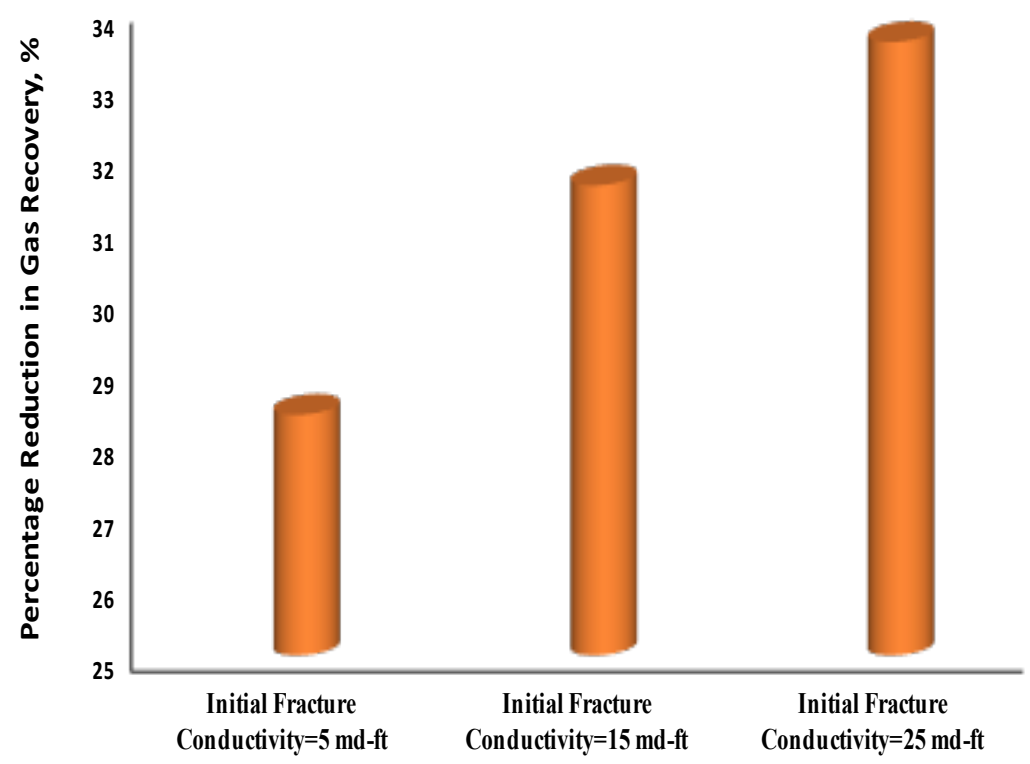

Figure 4.75: The Influence of Initial Fracture Conductivity on the Stress-Dependent Fissure Permeability.

\subsubsection{Hydraulic Fracture Spacing.}

Hydraulic fracture spacing was decreased to investigate its impact on geomechanical effects and production. Figures $4.76,4.77$, and 4.78 illustrate the effect of the stress-dependent fissure permeability on 
the cumulative and the production rates for different hydraulic fracture spacing. The reductions in cumulative production were $19.21 \%$ for fracture spacing of $80 \mathrm{ft}$. with 30 stages; $22.63 \%$ for fracture spacing of $140 \mathrm{ft}$. with 18 stages; and $29 \%$ for fracture spacing $260 \mathrm{ft}$. with 11 stages. The results are summarized in Figure 4.79.
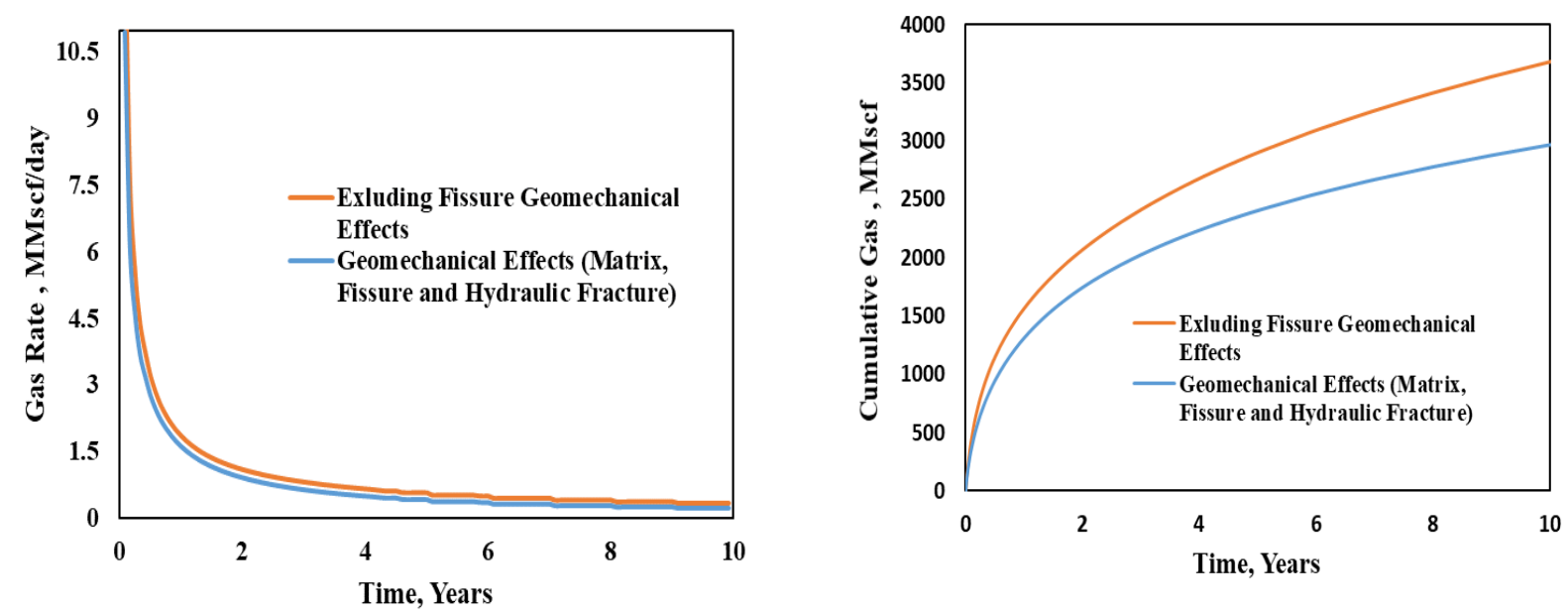

Figure 4.76: Impact of Fracture Stage Spacing on the Cumulative and Gas Rate (80 ft. with 30 Stages.).
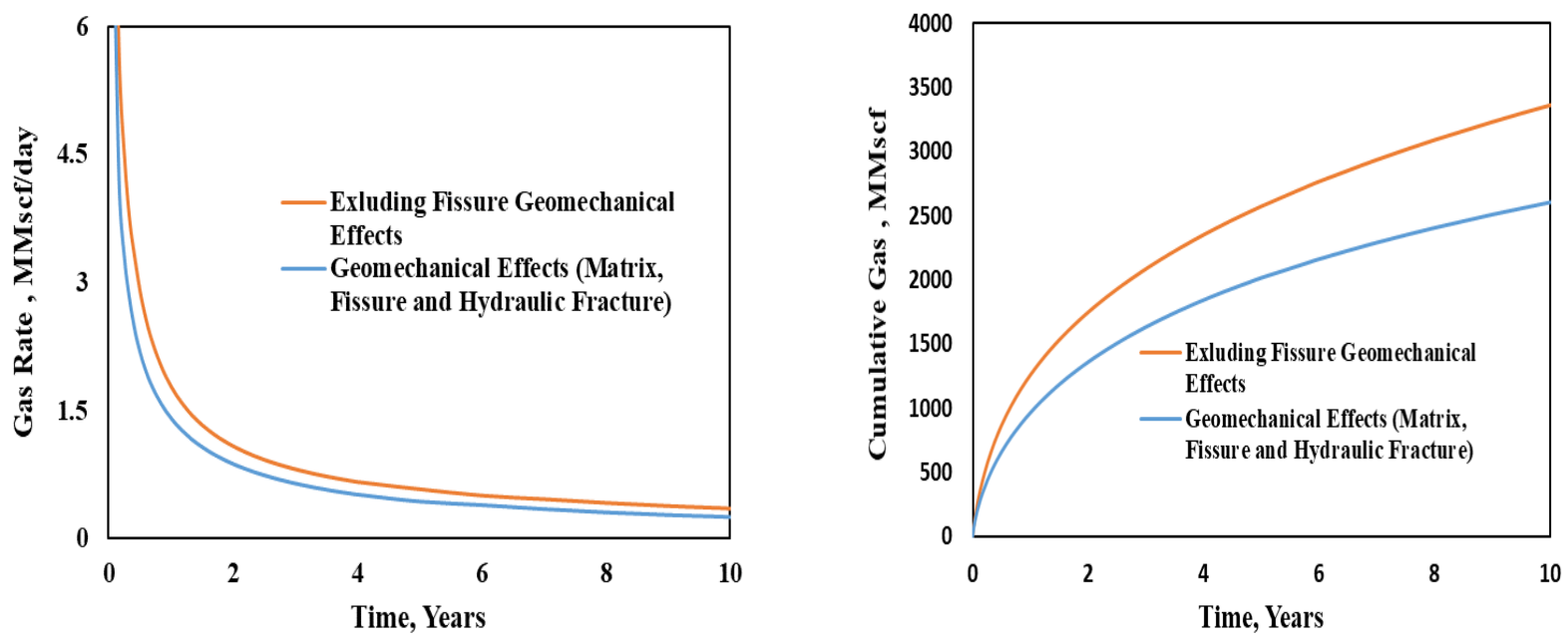

Figure 4.77: Impact of Fracture Stage Spacing on the Cumulative and Gas Rate (140 ft. with 18 Stages.). 

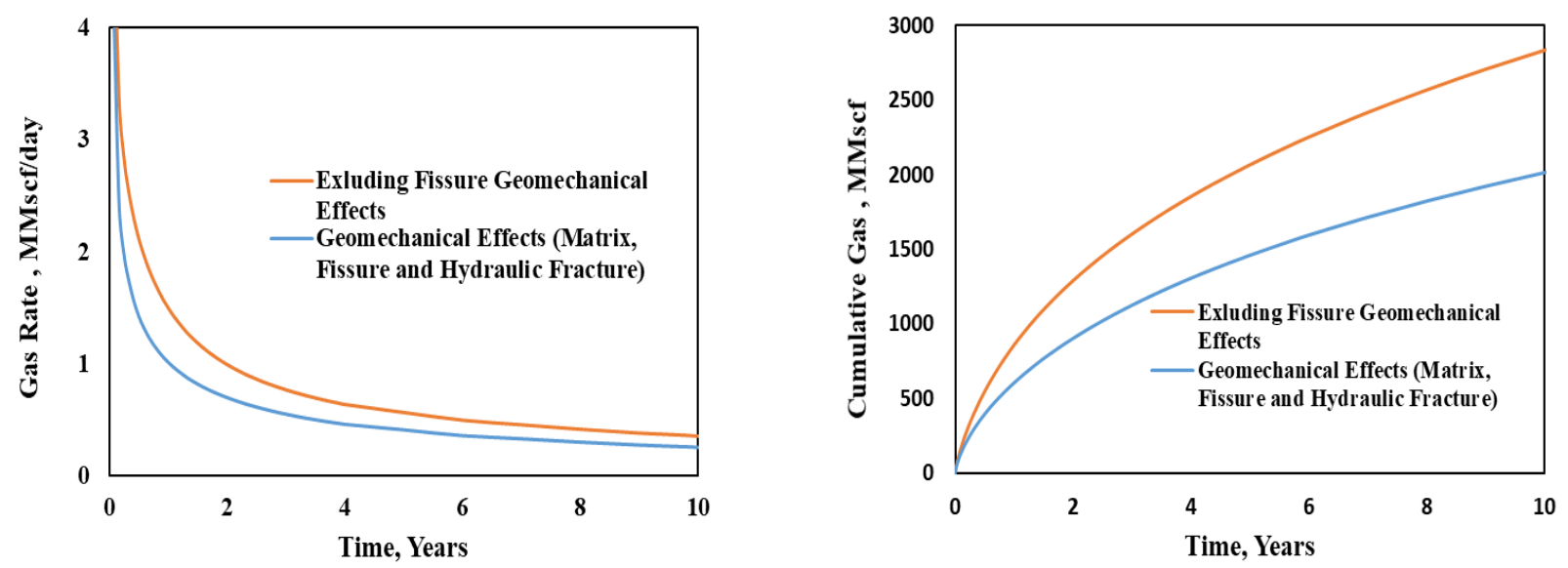

Figure 4.78: Impact of Fracture Stage Spacing on the Cumulative and Gas Rate (260 ft. with 11 Stages.).

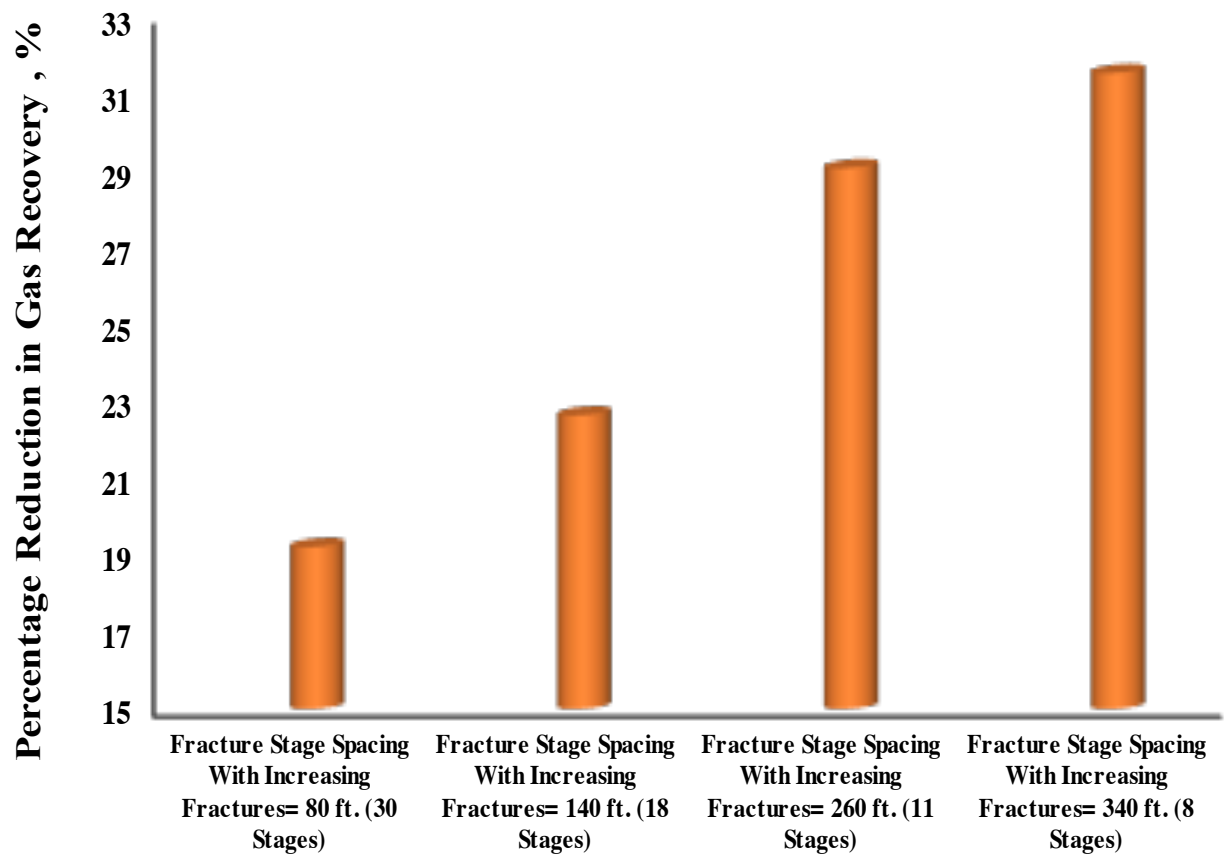

Figure 4.79: Effect of Fracture Spacing on the Stress-Dependent Fissure Permeability. 


\subsection{Results of Parametric Studies (Stress Shadowing)}

\subsubsection{Impact Fracture Spacing on Stress Shadowing and Gas Recovery (Well MIP-6H)}

The predicted hydraulic fracture properties, with and without stress shadowing effects, for different fracture spacing, indicate that the average fracture width and height decrease when stress shadowing effects are taken into consideration. Average fracture width decreases with the stress shadowing. When fracture spacing is wide, the change in fracture width becomes small because the impact of stress shadowing is less pronounced. Fracture height decreases with the stress shadowing due to increasing in-situ stress. Ignoring the stress shadowing effects results in vertical fracture growth. Fracture conductivity is enormously significant for flow into the wellbore from the reservoir, and it is reduced by stress shadowing effects, which will decrease gas production from each stage.

Figures 4.80 through 4.86 illustrate the impact of stress shadowing on 20-year cumulative gas production for different hydraulic fracture spacings. As can be observed from these figures, cumulative gas production decreases when stress shadowing effects are included. As mentioned previously, stress shadowing impacts the fracture properties. Therefore, cumulative gas production is impacted by stress shadowing. The closer the spacing, the more apparent is the impact of stress shadowing is on the production.

Furthermore, the loss in gas production caused by stress shadowing effects varies from 1.52 to $21 \%$ for the different fracture spacings. Stress shadowing can be avoided by increasing fracture spacing. However, this would reduce the drainage area for gas production, which results in lower gas recovery. Therefore, hydraulic fracture spacing should be optimized to determine the proper fracture spacing for the target gas recovery. Figure 4.87 compares the 20 -year cumulative gas production, with and without stress shadowing effects, for different fracture spacings. It is clear from Figure 4.87 that the cumulative gas production is negatively impacted by closer hydraulic fracture spacing. Figure 4.88 shows a percentage reduction in 20-year gas recovery due to the stress shadowing effects.

It is recommended that the stress shadow should be considered for the optimization of hydraulic fracture spacing. This is particularly important for Marcellus shale because of its low Young's modulus. 


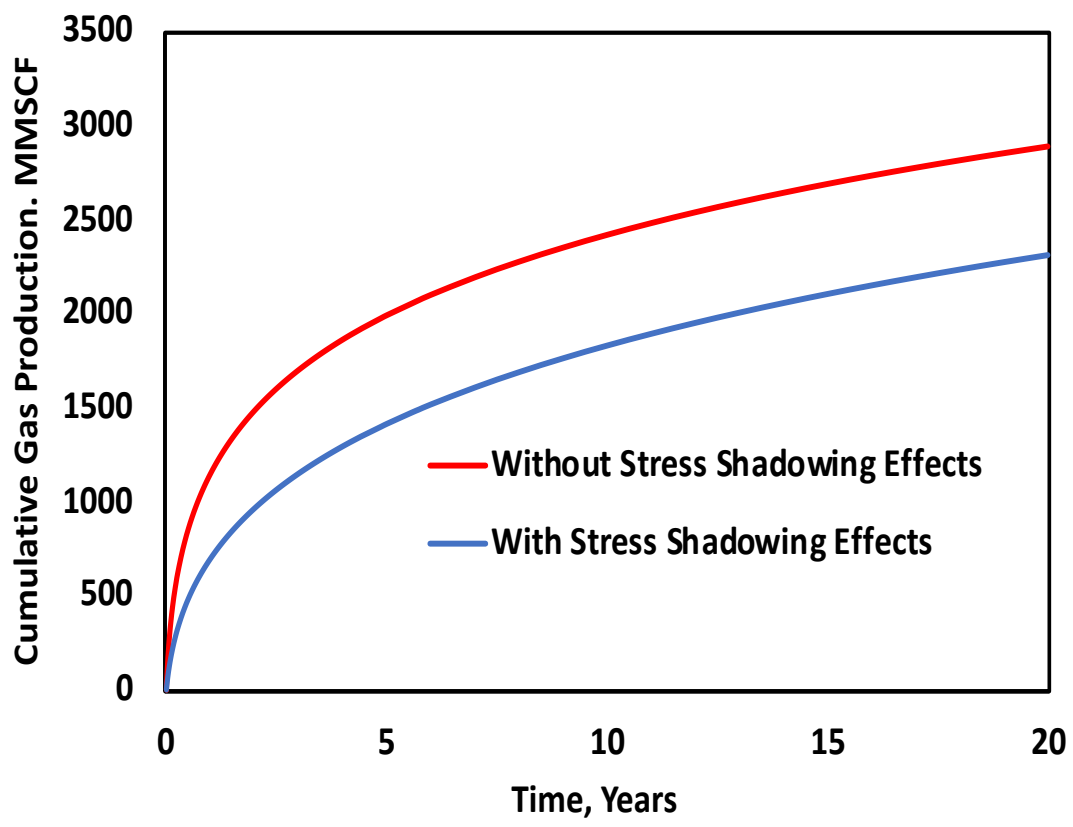

Figure 4.80: Impact of Stress Shadowing on Cumulative Gas Production for Hydraulic Fracture Spacing of $100 \mathrm{ft}$.

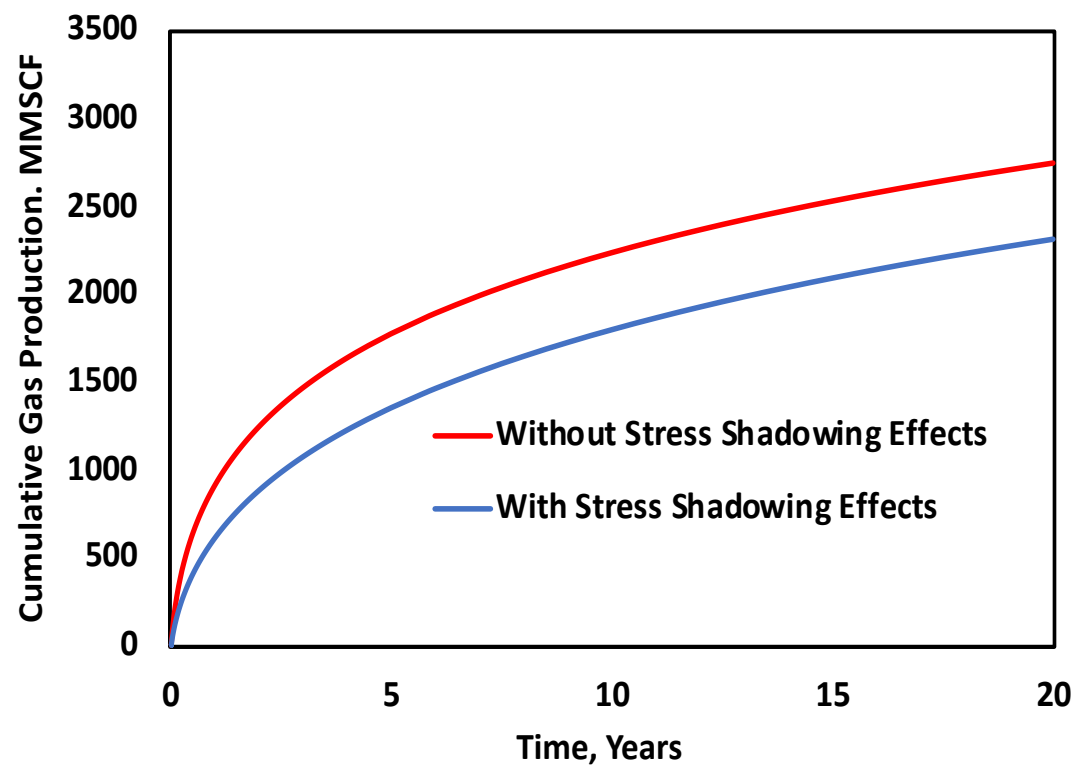

Figure 4.81: Impact of Stress Shadowing on Cumulative Gas Production for Hydraulic Fracture Spacing of $150 \mathrm{ft}$. 


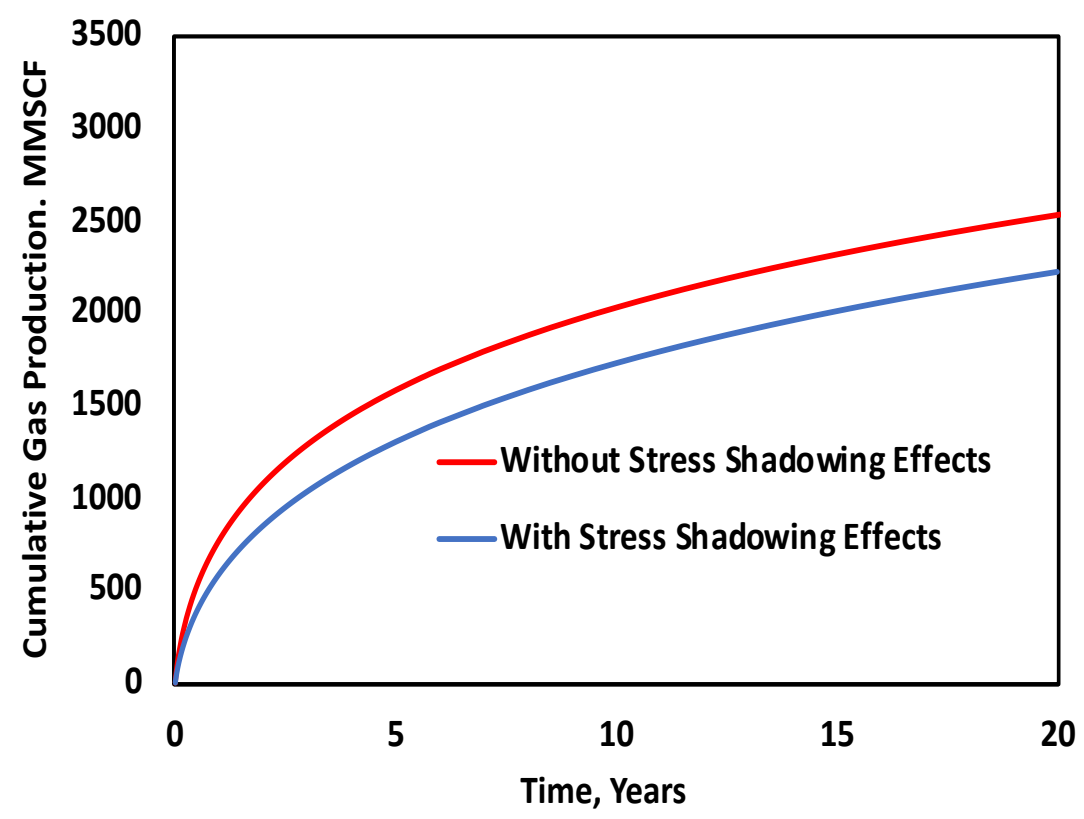

Figure 4.82: Impact of Stress Shadowing on Cumulative Gas Production for Hydraulic Fracture Spacing of $200 \mathrm{ft}$.

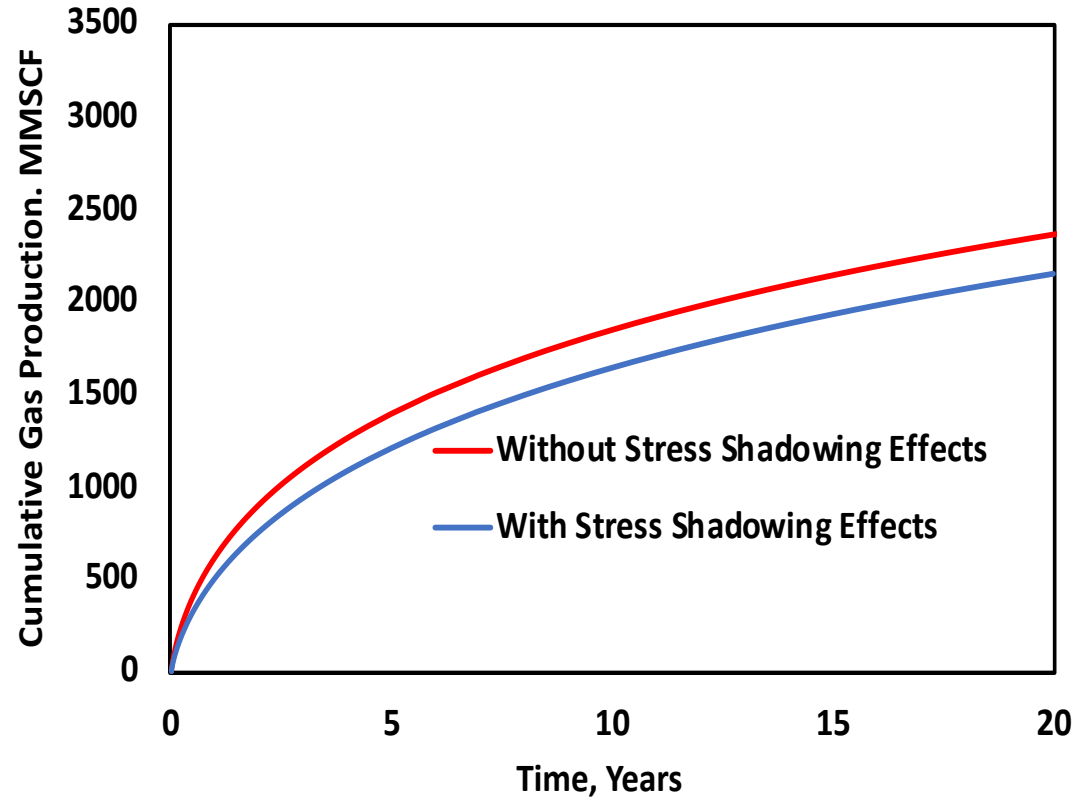

Figure 4.83: Impact of Stress Shadowing on Cumulative Gas Production for Hydraulic Fracture Spacing of $250 \mathrm{ft}$. 


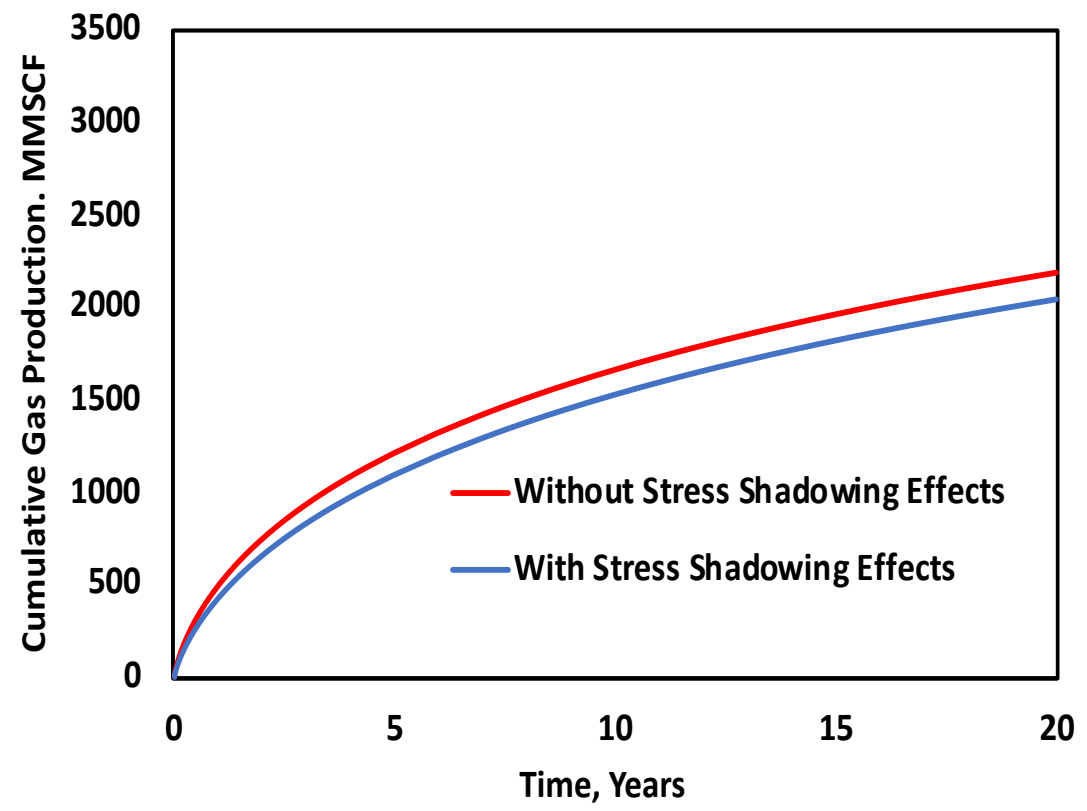

Figure 4.84: Impact of Stress Shadowing on Cumulative Gas Production for Hydraulic Fracture Spacing of $350 \mathrm{ft}$.

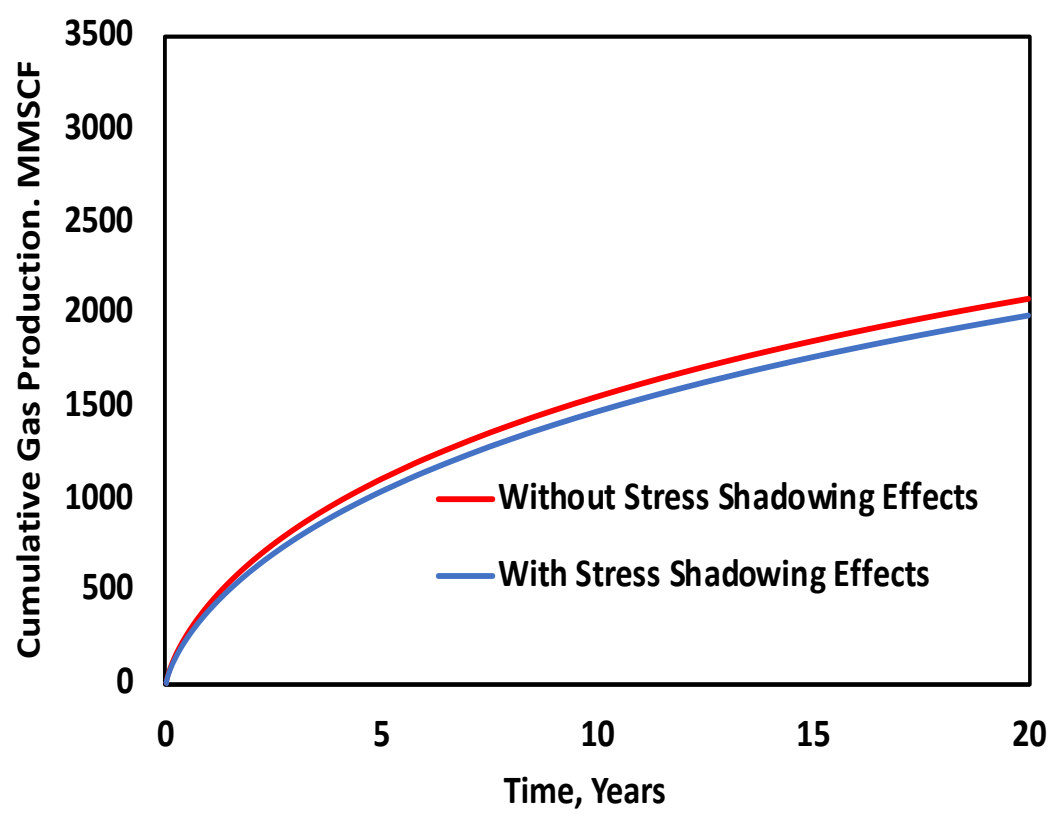

Figure 4.85: Impact of Stress Shadowing on Cumulative Gas Production for Hydraulic Fracture Spacing of $400 \mathrm{ft}$. 


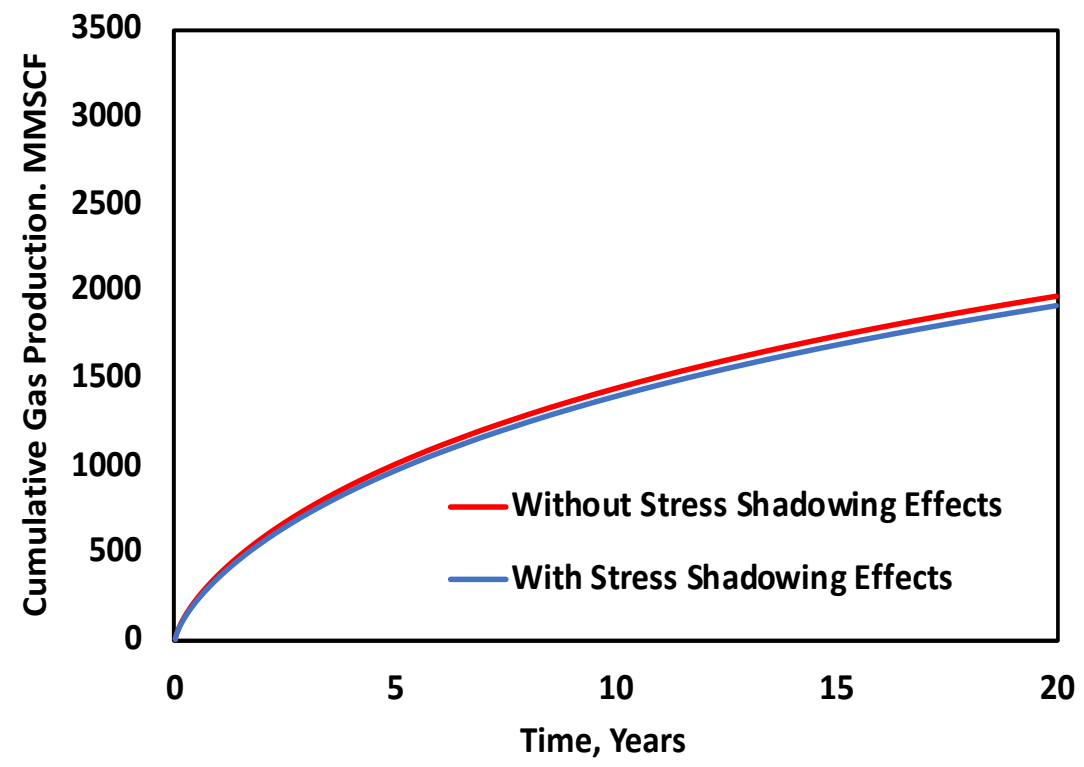

Figure 4.86: Impact of Stress Shadowing on Cumulative Gas Production for Hydraulic Fracture Spacing of $450 \mathrm{ft}$.

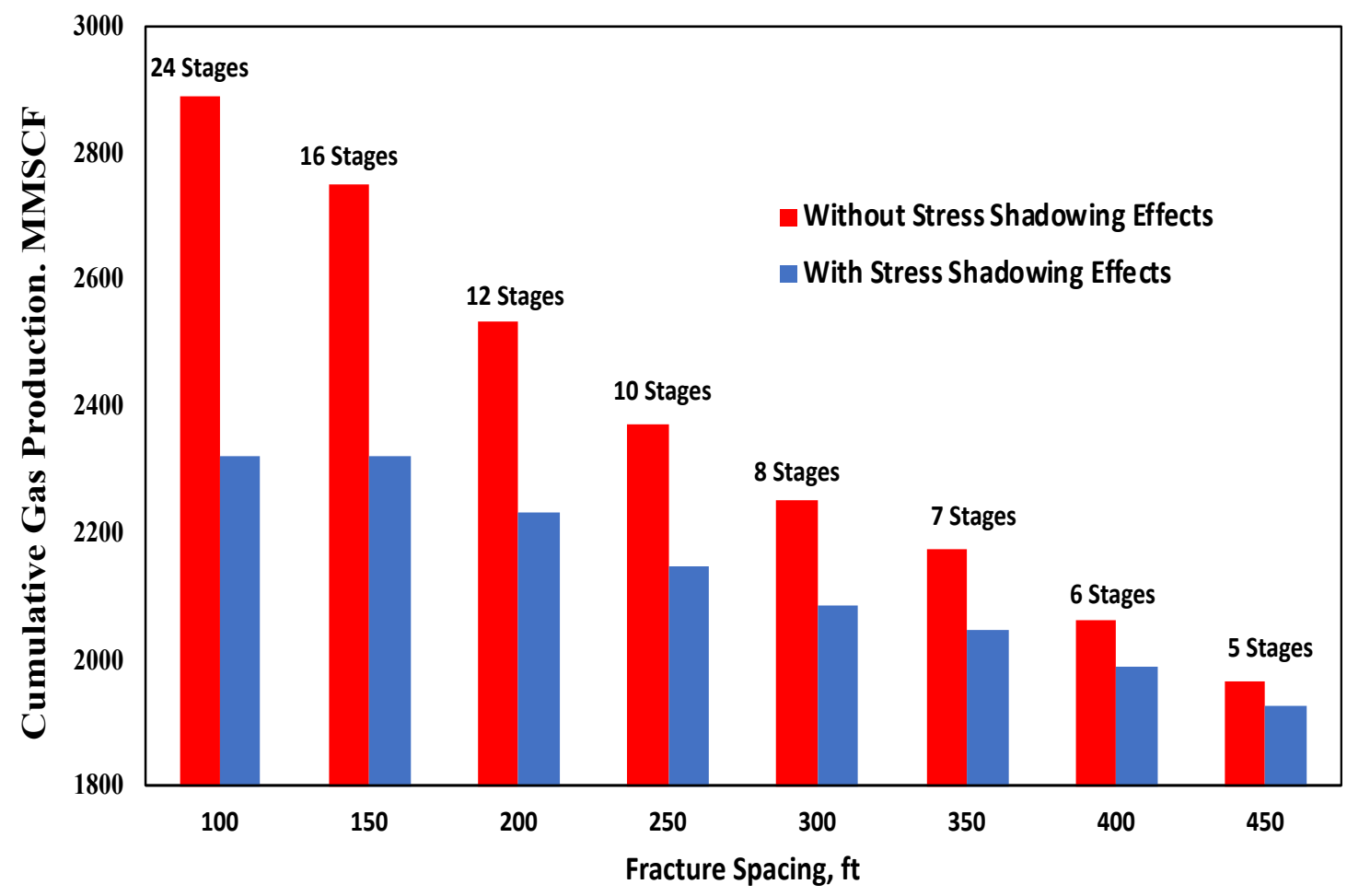

Figure 4.87: Cumulative Gas Production with and without Stress Shadowing Effects for 20 Years. 


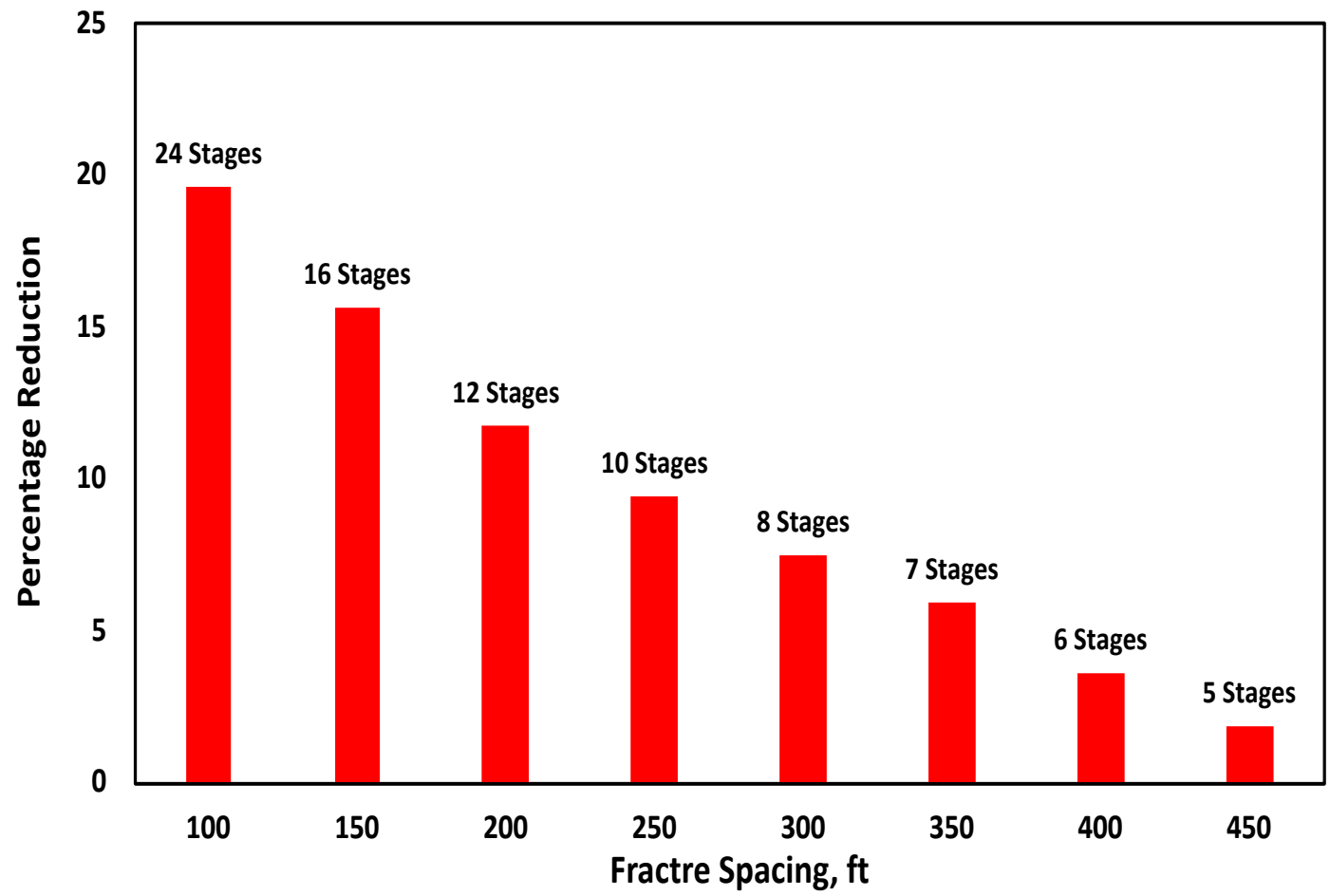

Figure 4.88: Percentage Reduction in 20-year Gas Recovery Due to the Stress Shadowing.

\subsubsection{Impact of the Treatment Size on Stress Shadowing and Gas Recovery (MIP-6H).}

Figures 4.89, 4.90, and 4.91 compare total fracture volumes with and without stress shadowing effects for different proppant mass per stage at stage spacing of $150 \mathrm{ft}$., $300 \mathrm{ft}$., and $450 \mathrm{ft}$. Total created fracture volumes for each case were obtained by multiplying fracture length, fracture height, and average fracture width for each stage. Subsequently, total fracture volumes were estimated by adding all stages together. It is very clear from Figures $4.89,4.90$, and 4.91 that when the proppant mass per stage increases the total fracture volume increase for a case without stress shadowing effects for stage spacing of $150 \mathrm{ft}$., $300 \mathrm{ft}$., and $450 \mathrm{ft}$. However, stress shadowing effects are a function of treatment size. It is clear from Figure 4.89 that when proppant mass per stage increases from $400 \mathrm{M}-\mathrm{lb}$, to $600 \mathrm{M}-\mathrm{lb}$, total fracture volume with stress shadowing (blue bar) does not increase significantly because of stress shadowing effects for stage spacing of $150 \mathrm{ft}$. Figure 4.92 combines the results illustrated in Figures 4.89, 4.90, and 4.91 for comparison purposes. As shown in Figure 4.92, the impact of stress shadowing is more pronounced at closer stage spacing.

Figure 4.93 illustrates the 20-year cumulative gas production, with and without stress shadowing, for different proppant mass per stage at stage spacing of $150 \mathrm{ft}$. As shown in Figure 4.93, the stress 
shadowing becomes more pronounced as the proppant mass per stage increases. For example, stress shadowing results in $18 \%$ reduction in gas recovery for $600 \mathrm{M}$-lbs. per stage but only $8 \%$ reduction for 100 M-lbs. per stage. Figures 4.94 and 4.95 illustrate similar cases for stage spacing of 300 and $450 \mathrm{ft}$. however, the impact of stress shadowing is less due to wider stage spacing. For example, at $300 \mathrm{ft}$. stage spacing (Figure 4.91), the reduction in gas recovery is $10 \%$ for $600 \mathrm{M}$-lbs and only $2 \%$ for $100 \mathrm{M}-\mathrm{lbs}$. The impact of stress shadowing at 450-ft stage spacing (Figure 4.95) is insignificant, and the reduction in gas recovery is negligible. Figure 4.96 combines the results illustrated in Figures 4.93, 4.94, and 4.95 for comparison purposes. As shown in Figure 4.96, the impact of stress shadowing is more apparent at closer stage spacing. Furthermore, the impact of stress shadowing at close stage spacing can be minimized by reducing the amount of proppant per stage.

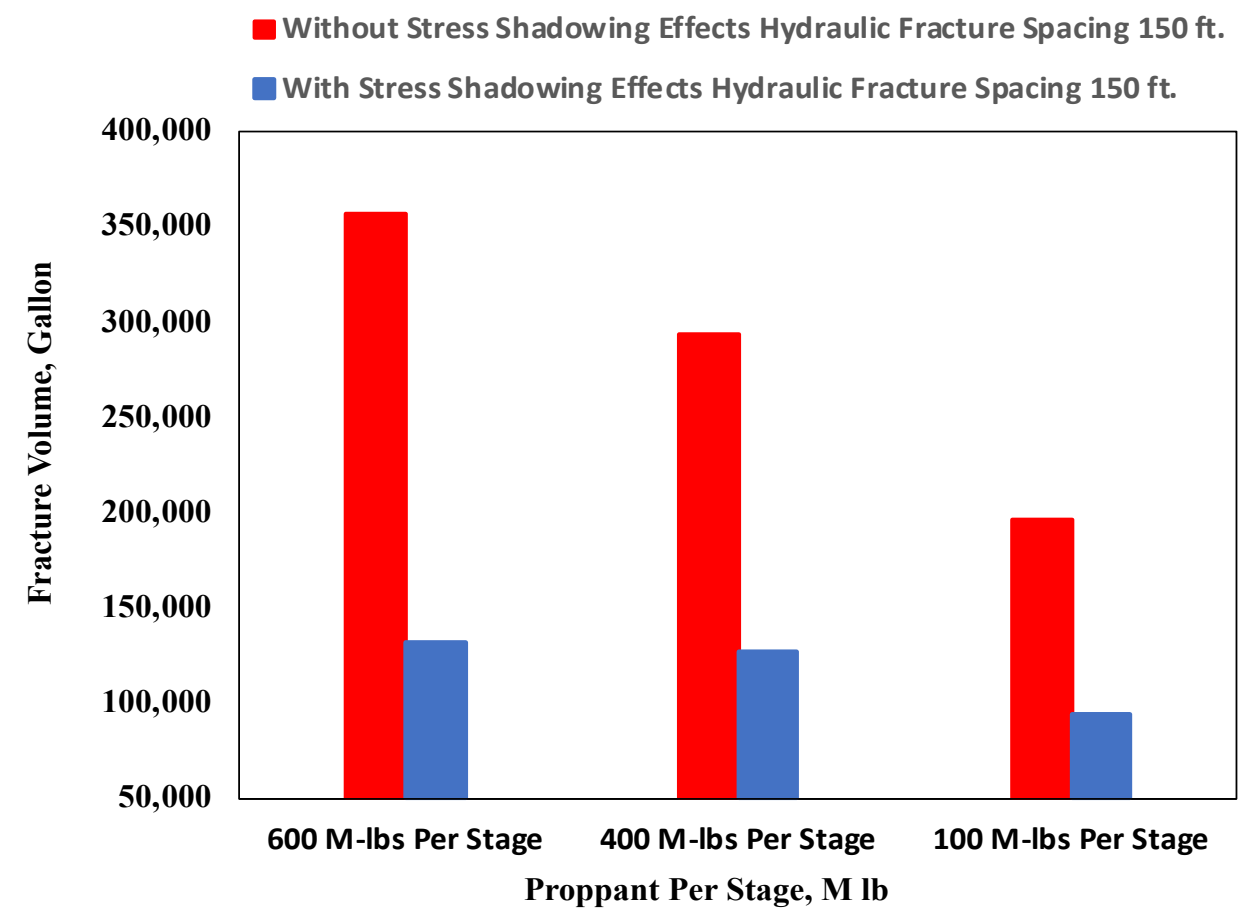

Figure 4.89: Impact of Stress shadowing on Fracture Volume for Different Treatment Sizes per Stage for Stage Spacing of $150 \mathrm{ft}$. 


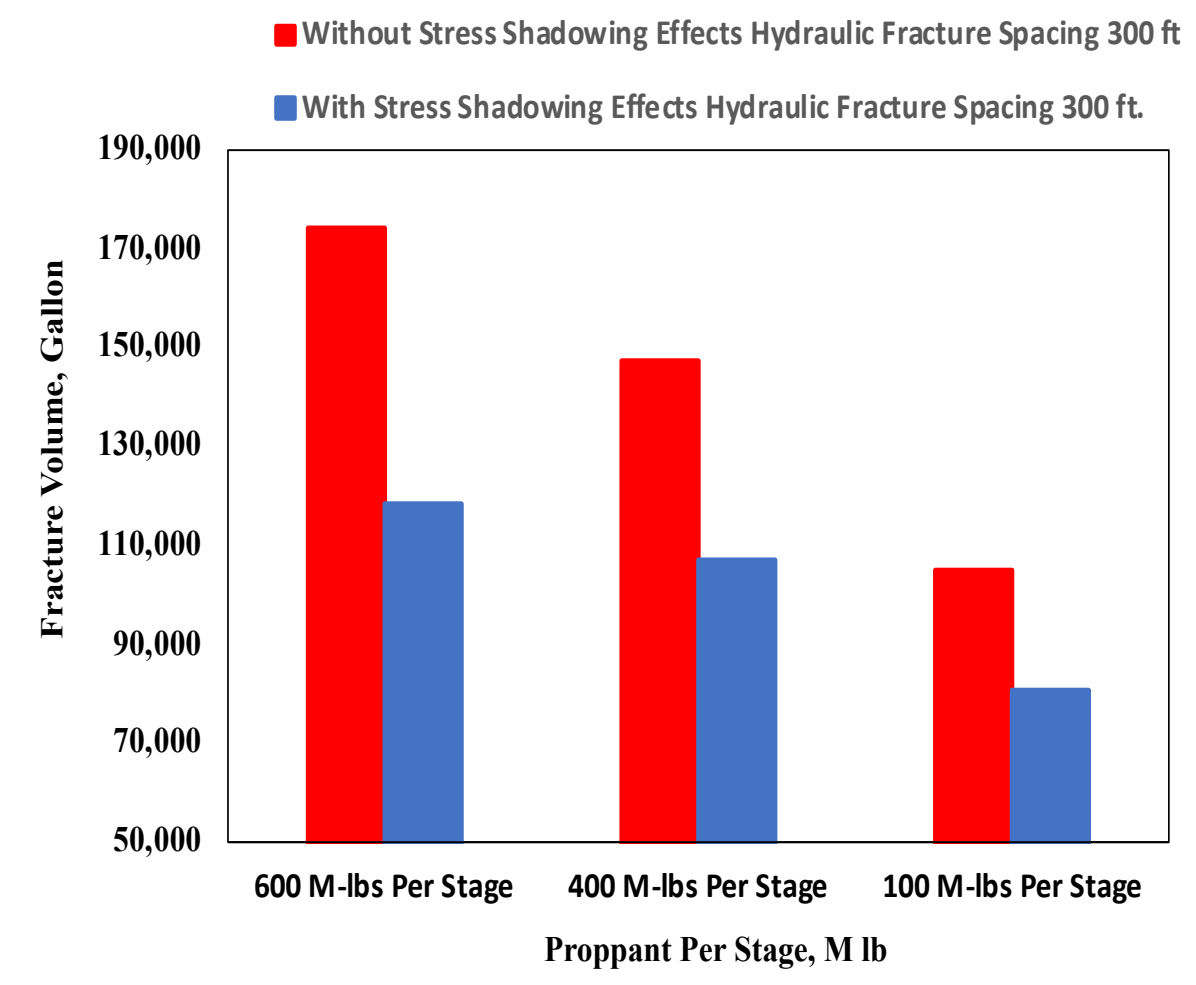

Figure 4.90: Impact of Stress shadowing on Fracture Volume for Different Treatment Sizes per Stage for Stage Spacing of $300 \mathrm{ft}$.

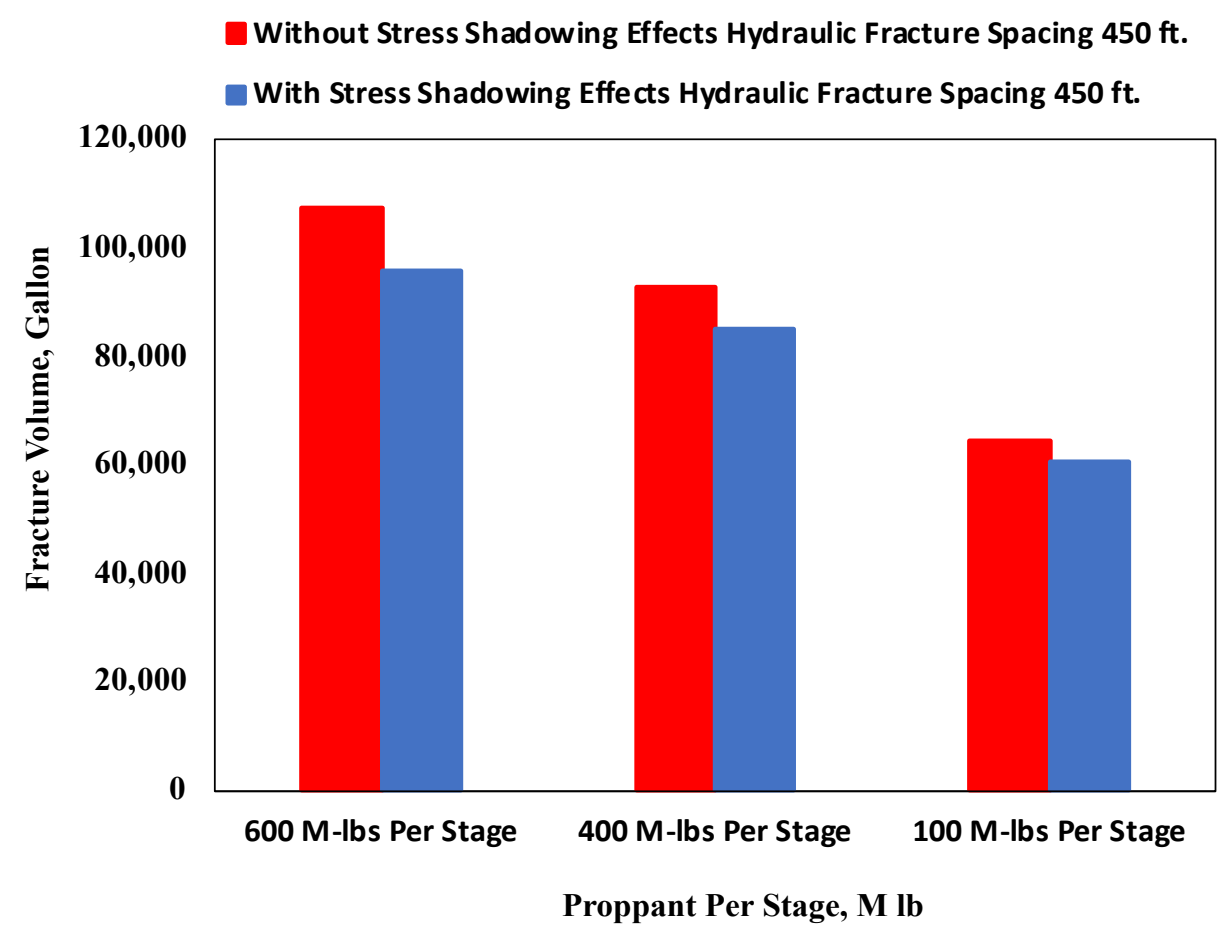

Figure 4.91: Impact of Stress Shadowing on Fracture Volume for Different Treatment Sizes per Stage for Stage Spacing of $450 \mathrm{ft}$. 


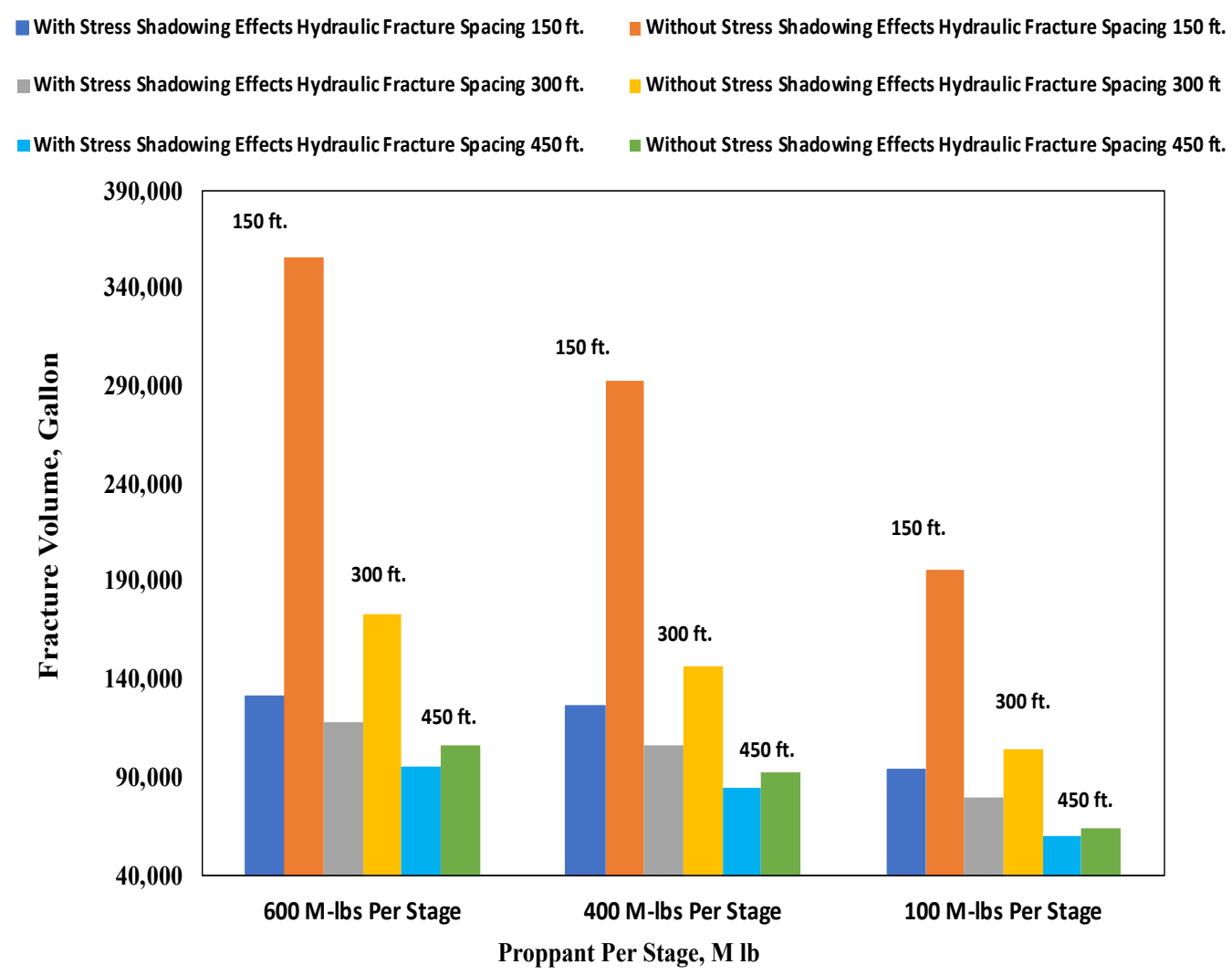

Figure 4.92: Impact of the Stress Shadowing on Fracture Volume for Various Stage Spacings and Treatment Sizes.

Without Stress Shadowing Effects Hydraulic Fracture Spacing 150 ft.

With Stress Shadow ing Effects Hydraulic Fracture Spacing $150 \mathrm{ft}$.

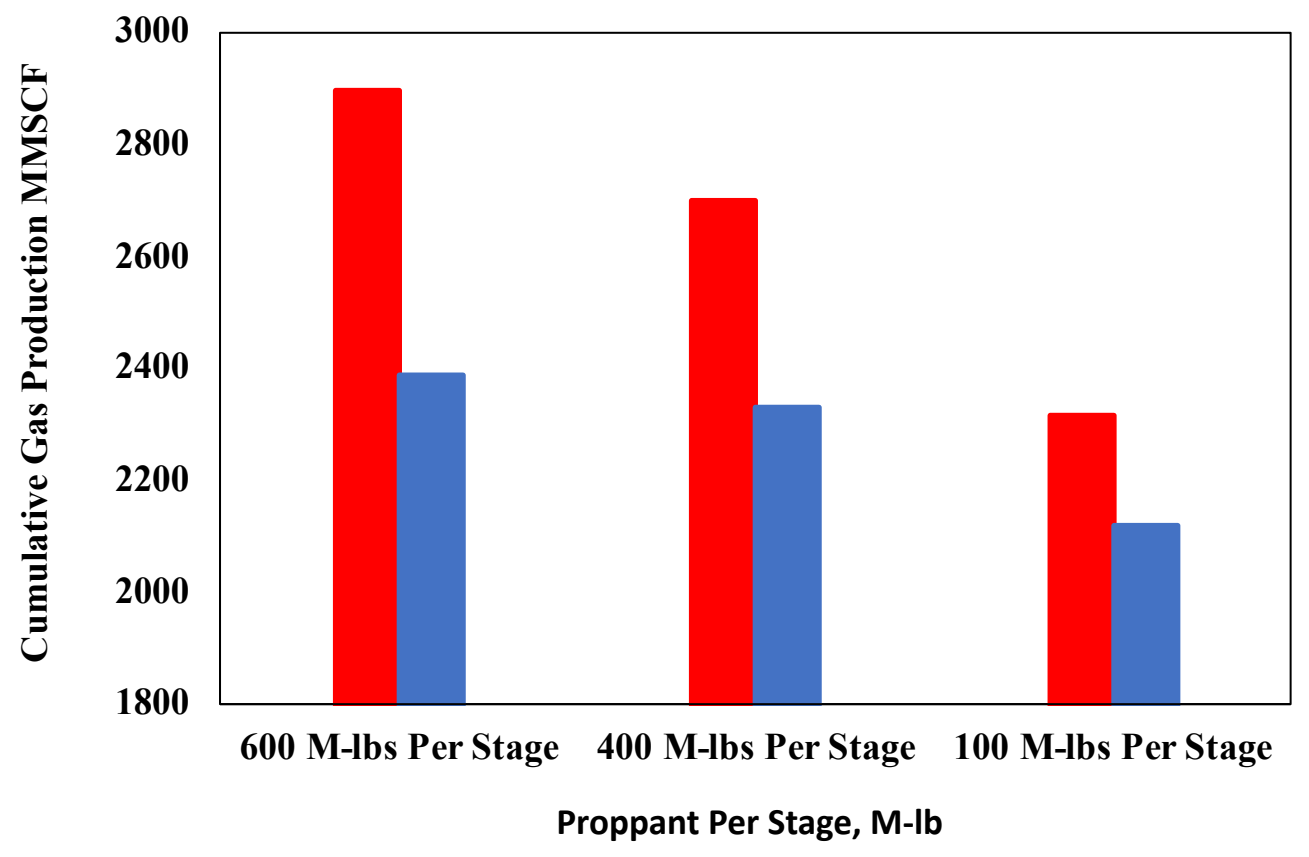

Figure 4.93: Impact of Stress Shadowing on Cumulative Gas Production for Different Treatment Sizes. 
-Without Stress Shadowing Effects Hydraulic Fracture Spacing $300 \mathrm{ft}$

-With Stress Shadowing Effects Hydraulic Fracture Spacing $300 \mathrm{ft}$.

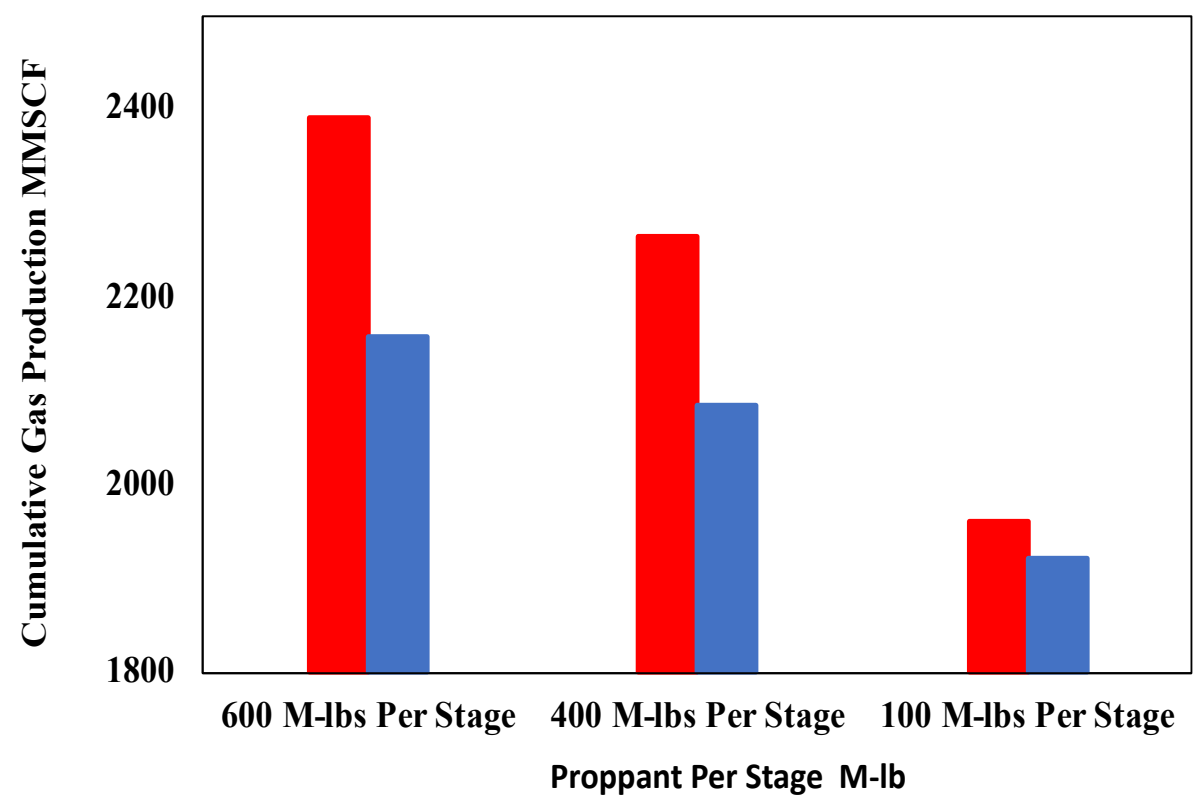

Figure 4.94: Impact of Stress Shadowing on Cumulative Gas Production for Different Treatment Sizes.

- Without Stress Shadowing Effects Hydraulic Fracture Spacing $450 \mathrm{ft}$.

-With Stress Shadowing Effects Hydraulic Fracture Spacing $450 \mathrm{ft}$.

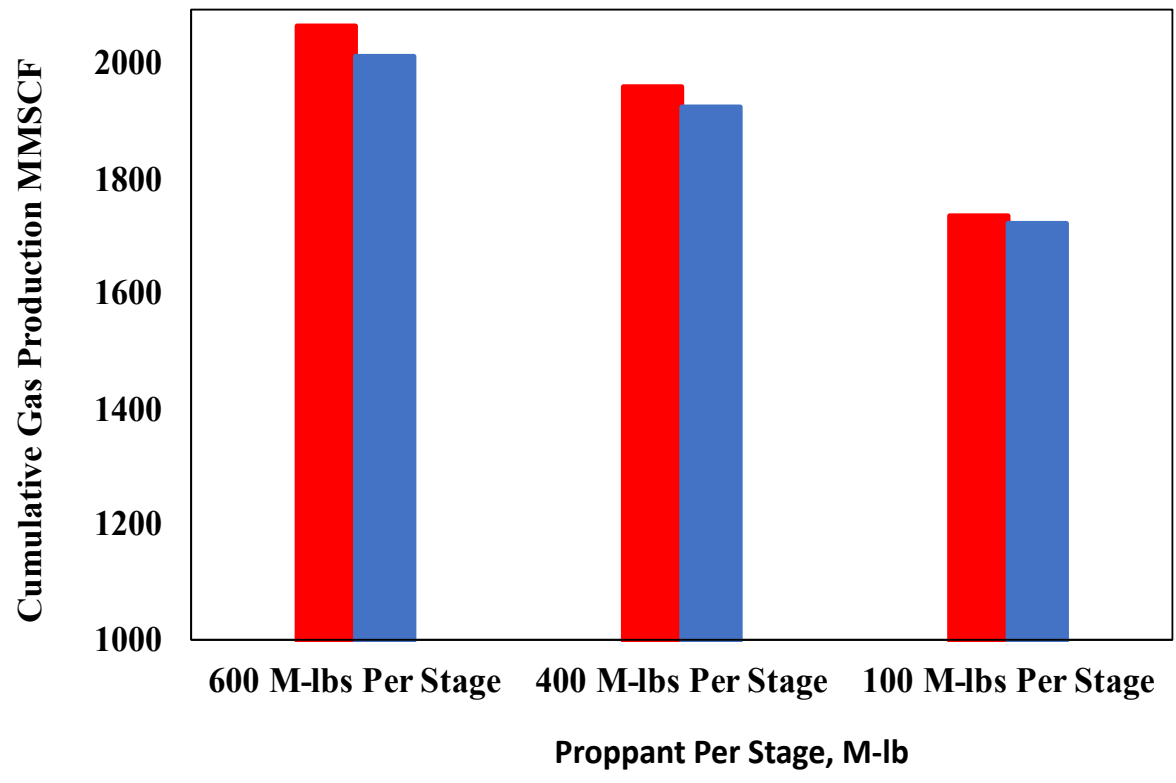

Figure 4.95: Impact of Stress Shadowing on Cumulative Gas Production for Different Treatment Sizes. 


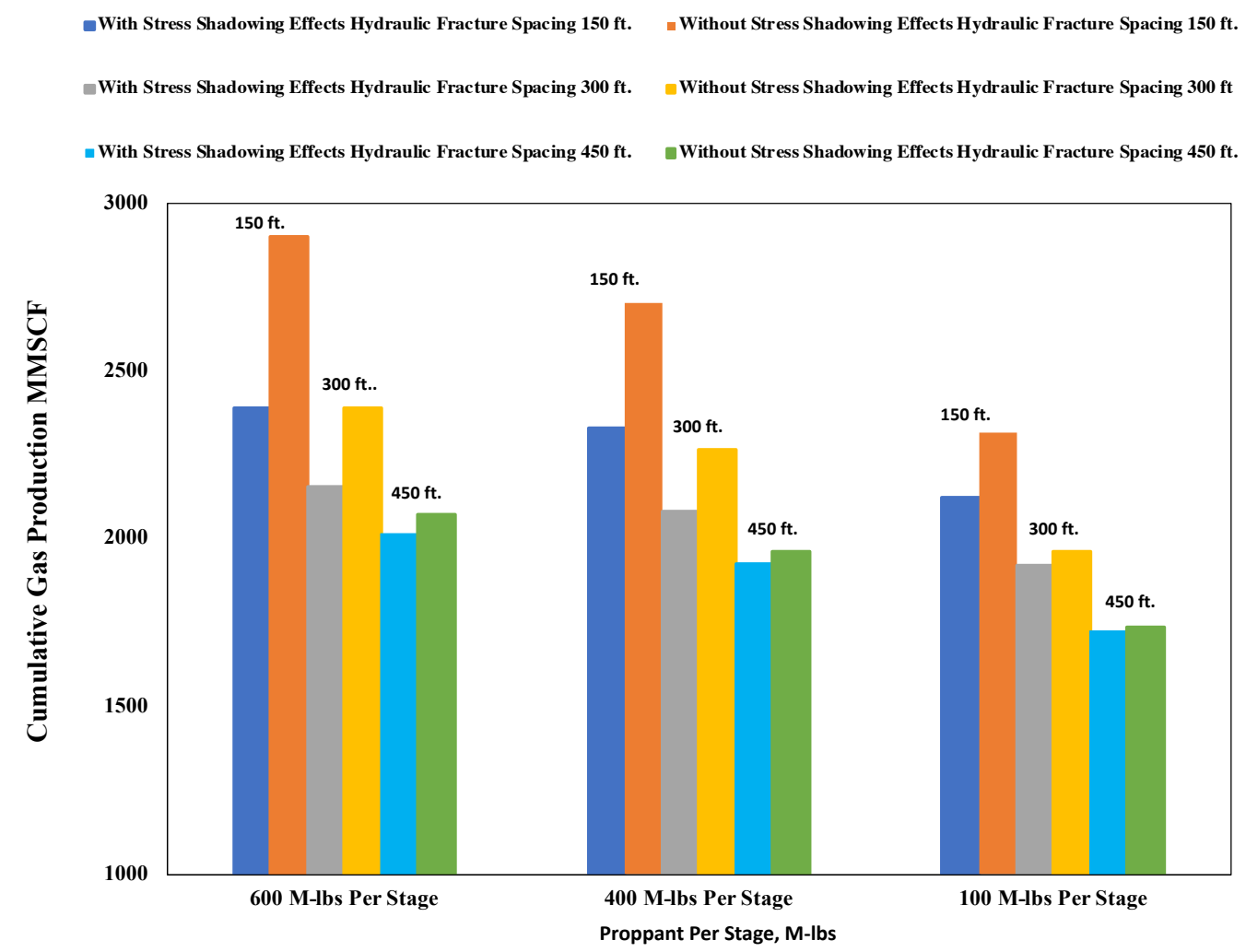

Figure 4.96: Impact of the Stress Shadowing on Gas Recovery for Various Stage Spacings and Treatment Sizes.

\subsubsection{Impact Treatment Sequencing on Stress Shadowing and Gas Recovery (Well MIP-6H)}

For sequential fracturing, the treatment design for each stage was assumed to be the same (See Table 3.1), and the stages were created from toe to heel. For simultaneous fracturing, the total amount of the fluid and the sand (eight times the sequential fracturing stage) is used as the input to the model. In this case, the stages are initiated and propagated at the same time with the same injection rate, and each stage takes fluid based on the stresses and friction values calculated within the model. As a result, the proppant is not distributed uniformly in different stages during simultaneous fracturing. Figures 4.97 (stage spacing of 150 $\mathrm{ft}$.), 4.98 (stage spacing of $300 \mathrm{ft}$.), and 4.99 (stage spacing of $450 \mathrm{ft}$.) compare the cumulative gas production for simultaneous and sequential fracturing. In all cases, the cumulative production for simultaneous fracturing is higher than for sequential fracturing. This can be attributed to the lower impact by the stress shadowing for simultaneous fracturing. Furthermore, as the stage spacing increases, the stress shadowing becomes less significant, and as a result, the differences between the sequential and simultaneous fracturing production profiles become insignificant. These types of analysis can provide a foundation for the design and optimization of the fracturing treatment in horizontal wells to achieve the desired fracture lengths, proppant placement, and production rates. 


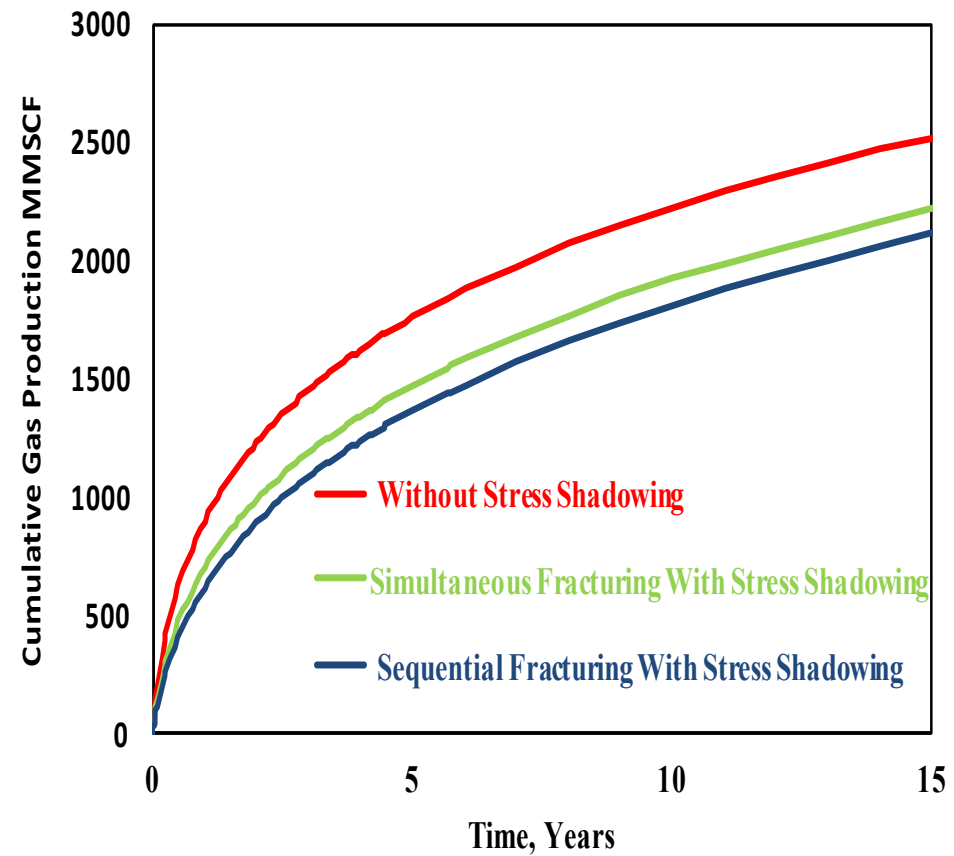

Figure 4.97: Cumulative Gas Production for Simultaneous and Sequential Fracturing for Stage Spacing $150 \mathrm{ft}$.

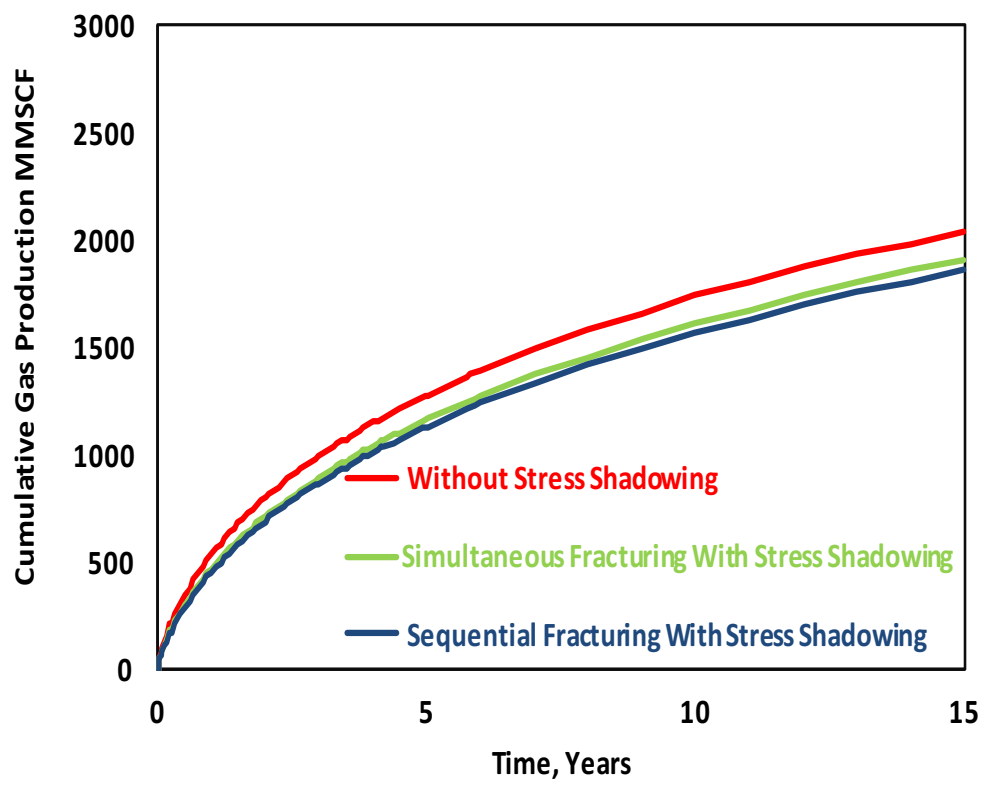

Figure 4.98: Cumulative Gas Production for Simultaneous and Sequential Fracturing for Stage Spacing $300 \mathrm{ft}$. 


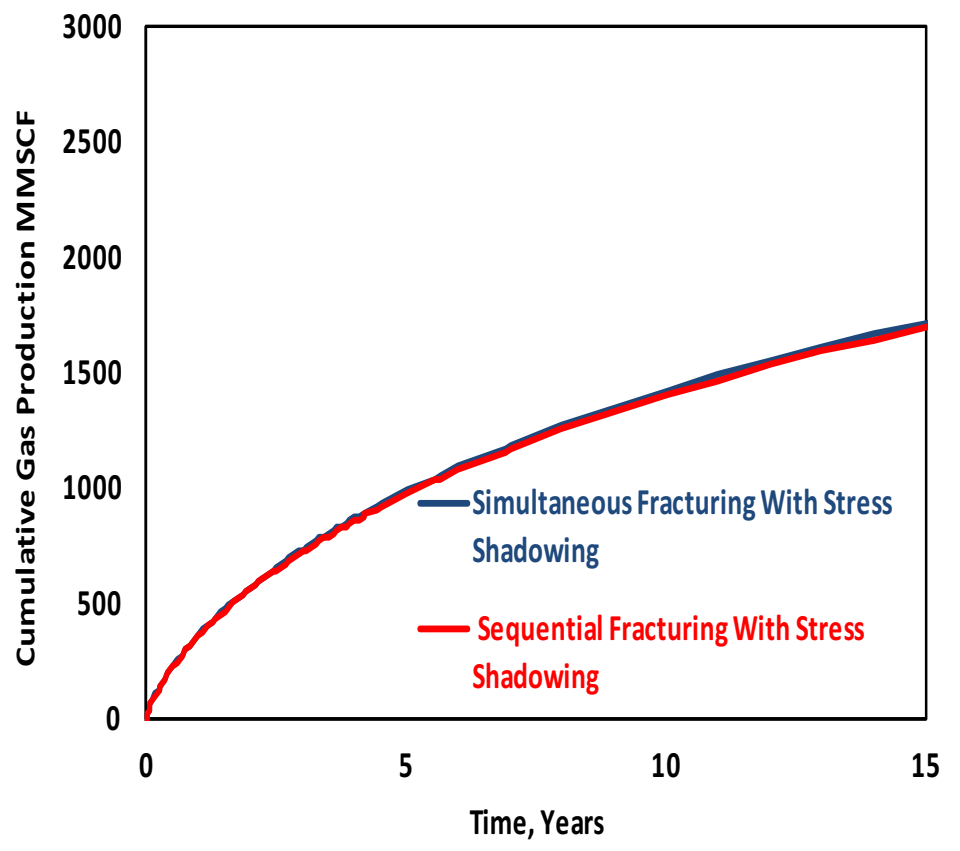

Figure 4.99: Cumulative Gas Production for Simultaneous and Sequential Fracturing for Stage Spacing $450 \mathrm{ft}$.

\subsubsection{Impact of the Poisson's Ratio on Gas Recovery (Well MIP-6H)}

To investigate the impact of rock mechanical properties on fracture properties and stress shadowing, Poisson's ratio for the pay zone (Marcellus Shale) was varied as provided in Table 3.11. Poisson's ratio is used primarily to estimate the minimum horizontal stress. The calculated minimum horizontal stress in the pay zone (Marcellus Shale) decreases as Poisson's ratio is decreased. Therefore the contrast between the pay zone and the upper zone, which acts as a barrier for vertical fracture extension, increases. This causes stimulation energy to concentrate in the pay zone, and as a result, the fracture properties are improved, leading to higher gas recovery. Figure 4.100 illustrates the impact of Poisson's ratio on the 15-year cumulative gas production for different stage spacings. It is interesting to note that for stage spacing of 150 $\mathrm{ft}$., the cumulative gas production for Poisson's ratios of 0.15 and 0.23 are approximately the same. This is attributed to higher impact by stress shadowing at this stage spacing which obscures the enhancement of the fracture properties. 
- Stage Spacing $150 \mathrm{ft}$. $\quad$ Stage Spacing $300 \mathrm{ft}$. $\quad$ Stage Spacing $450 \mathrm{ft}$.

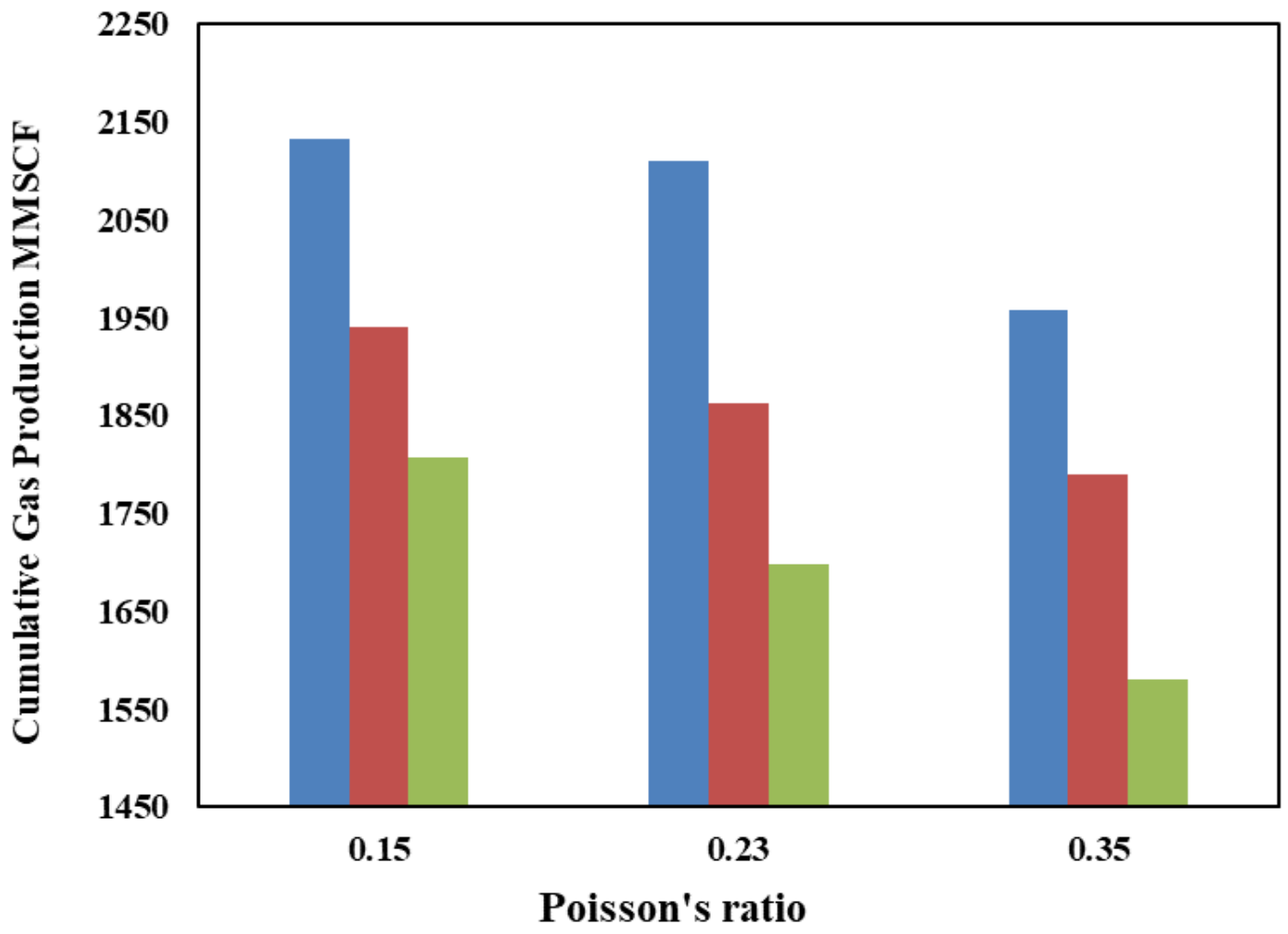

Figure 4.100: Impact of Poisson's Ratio on Cumulative Gas Production for Different Stage Spacing.

\subsubsection{Impact Stress Shadowing on Fracture Properties (Well MIP-3H)}

Figures 4.101 (A) and 4.101 (B) illustrate the slurry (mixture of proppant and fracturing fluid) volume and the injection rate for each cluster in stage 1 (base case) when a value of 1.2 is used for the transverse exponent. As can be observed from Figure 4.101 (A), the slurry volume is lower for the clusters in the middle $(2,3$, and 4$)$ than for those on the ends ( 1 and 5$)$ due to the stress shadowing. Therefore, less proppant is placed in the middle clusters $(2,3$, and 4$)$, resulting in inferior fracture properties (width, halflength, and height). Furthermore, the fracture height in Marcellus shale can be high due to the low in-situ stress contrast between the pay zone and its adjacent zones. However, the stress shadow can arrest the fracture height growth because of the increase in stress contrast. As can be seen from Figure 4.101 (B), the flow rate during the treatment for the heel (cluster 5) remains constant during the treatment while the flow rates for the other clusters decline due to stress shadowing. This occurs in all stages between the clusters. For stage 2 in addition to stress shadowing between clusters, there is also stress shadowing caused by the previously executed stage (stage 1). 
Figures 4.102 (A) and 4.102 (B) illustrate the slurry volume and the injection rate for each cluster in stage 1 (base case) when a value of 2 is used for the transverse exponent. It is clear from Figure 4.102 (A) that the slurry volume per cluster becomes almost uniform among the clusters because the degree of stress shadowing has been reduced. It is also clear from Figure 4.102 (B) that the injection rate remains constant during the treatment for all the clusters for the same reason.
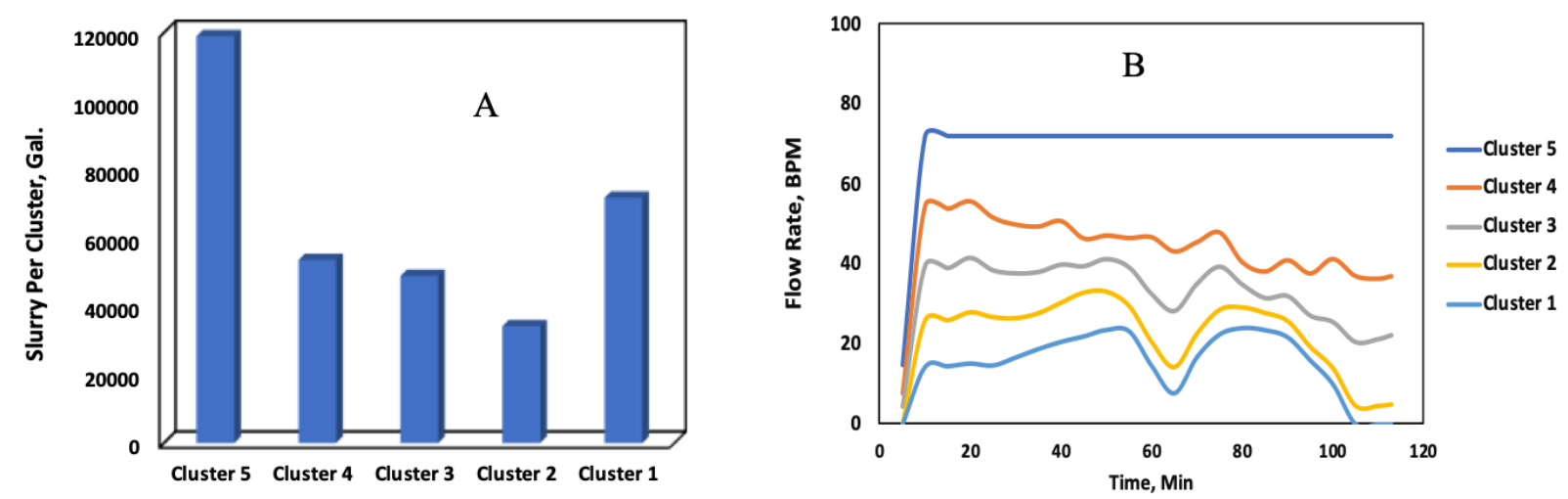

Figure 4. 101: Slurry and Flow Rate with Stress Shadowing Effects for Different Clusters in Stage 1.
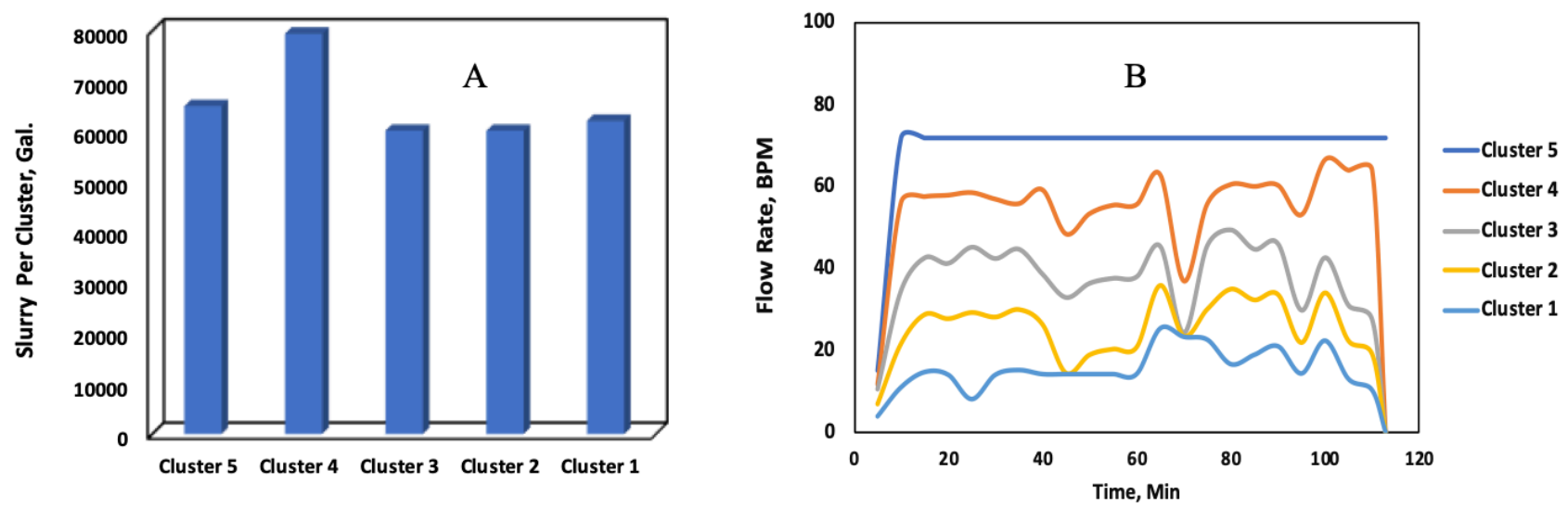

Figure 4. 102: Slurry and Flow Rate without Stress Shadowing Effects for Different Clusters in Stage 1.

\subsubsection{Impact Cluster Spacing on Stress Shadowing and Gas Recovery (MIP-3H)}

Figures 4.103, 4.104, and 4.105 compare the average fracture properties (width, half-length, and height) for different cluster spacings when the stress shadowing impact has been accounted between stages and clusters (transverse exponent of 1.2) and ignored between stages and clusters (transverse exponent of 2). The average fracture properties (width, half-length, and height) decrease when stress shadowing is 
considered. Figure 4.106 compares the predicted 10-year cumulative gas production for different cluster spacings. It is clear from Figure 4.106 that the stress shadowing negatively impacts the cumulative gas production as the cluster spacing was decreased. The closer the cluster spacing is, the more pronounced is the impact of stress shadowing. Figure 4.107 compares the change in cumulative gas production above and below the cumulative gas production for 50-ft cluster spacing (Base Case). It is obvious from Figure 4.107 that the increase in cumulative gas production for $40-\mathrm{ft}$ and $30-\mathrm{ft}$ cluster spacings are substantial when stress shadowing is ignored (Red Bars). However, the increase in cumulative gas production is not significant when the stress shadowing is considered (Blue Bars).

Figure 4.108 shows the change in the total fracture volume compared to fracture volume at $50-\mathrm{ft}$ cluster spacing (Base Case). The total fracture volume for each case was obtained by multiplying fracture length, fracture height, and average fracture width for each stage; subsequently, the total fracture volumes were estimated by summing up the fracture volumes for all the stages. It is obvious from Figure 4.108 that stress shadowing significantly impacts the fracture volume. This impact becomes more pronounced as the cluster spacing is decreased. Therefore, it is important for the optimization of the cluster spacing to take the stress shadow into consideration.

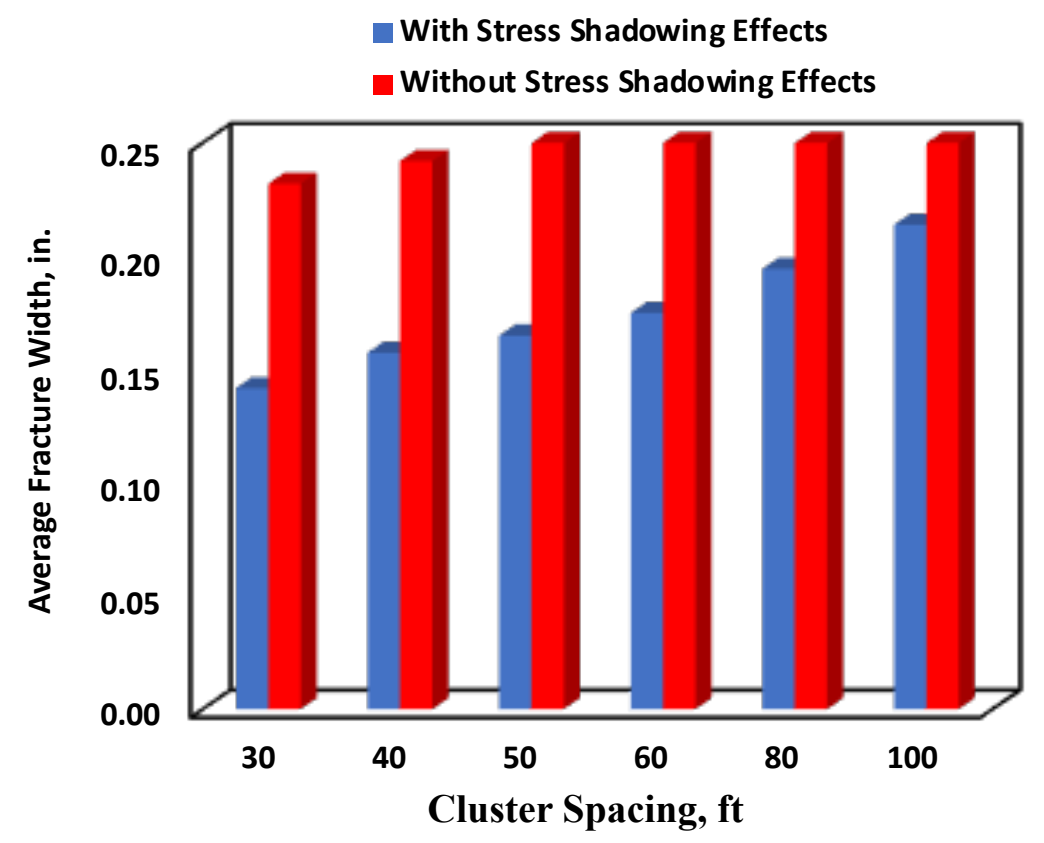

Figure 4. 103: Average Fracture Width with and without Stress Shadowing for Different Cluster Spacings. 


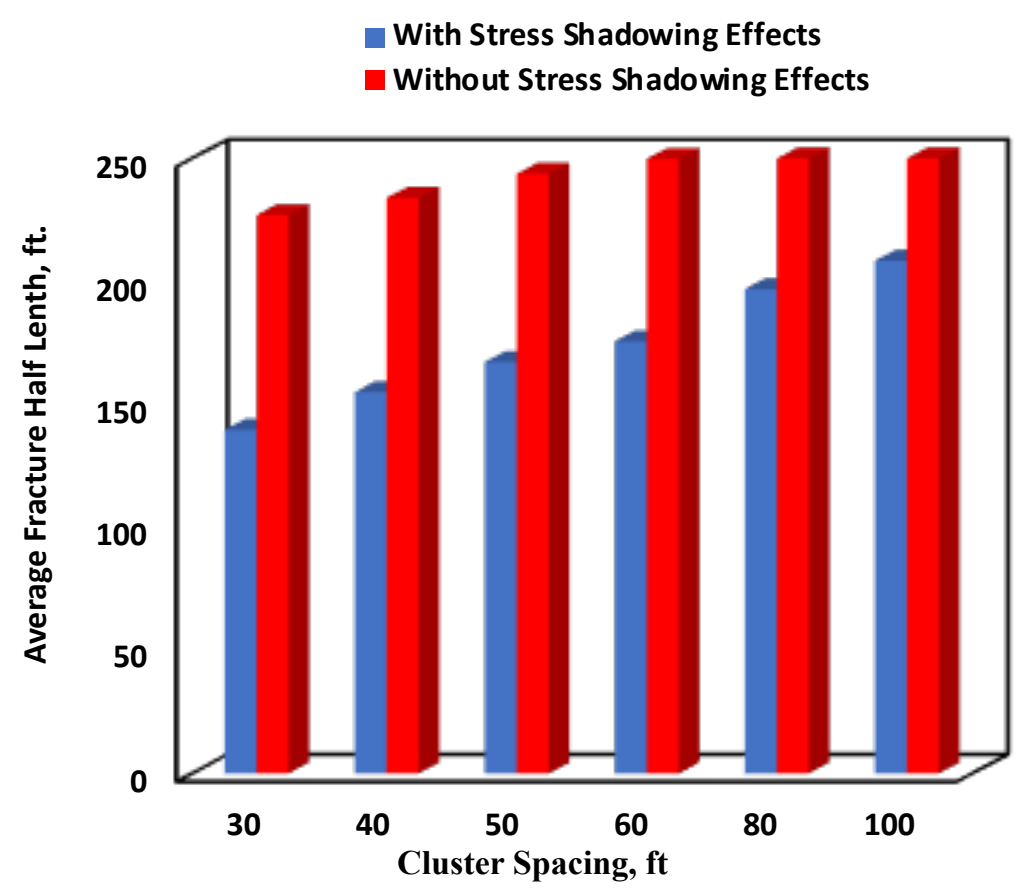

Figure 4. 104: Average Fracture Half-Length with and without Stress Shadowing for Different Cluster Spacings.

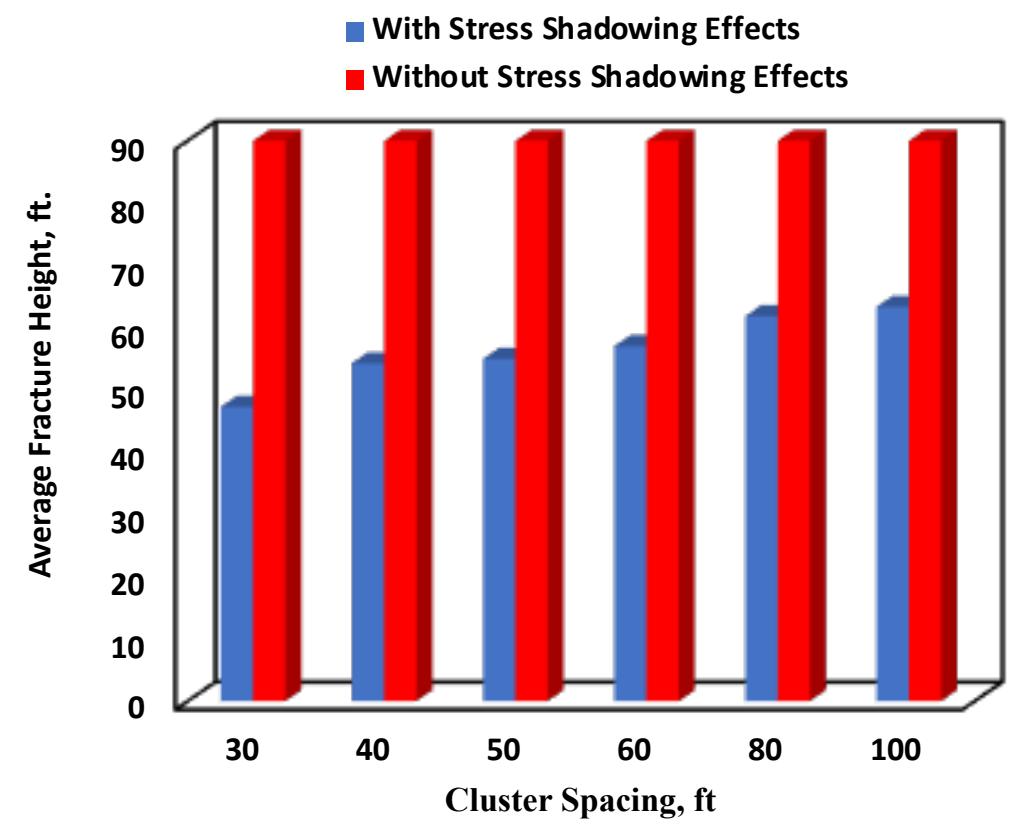

Figure 4. 105: Average Fracture Height with and without Stress Shadowing for Different Cluster Spacings. 


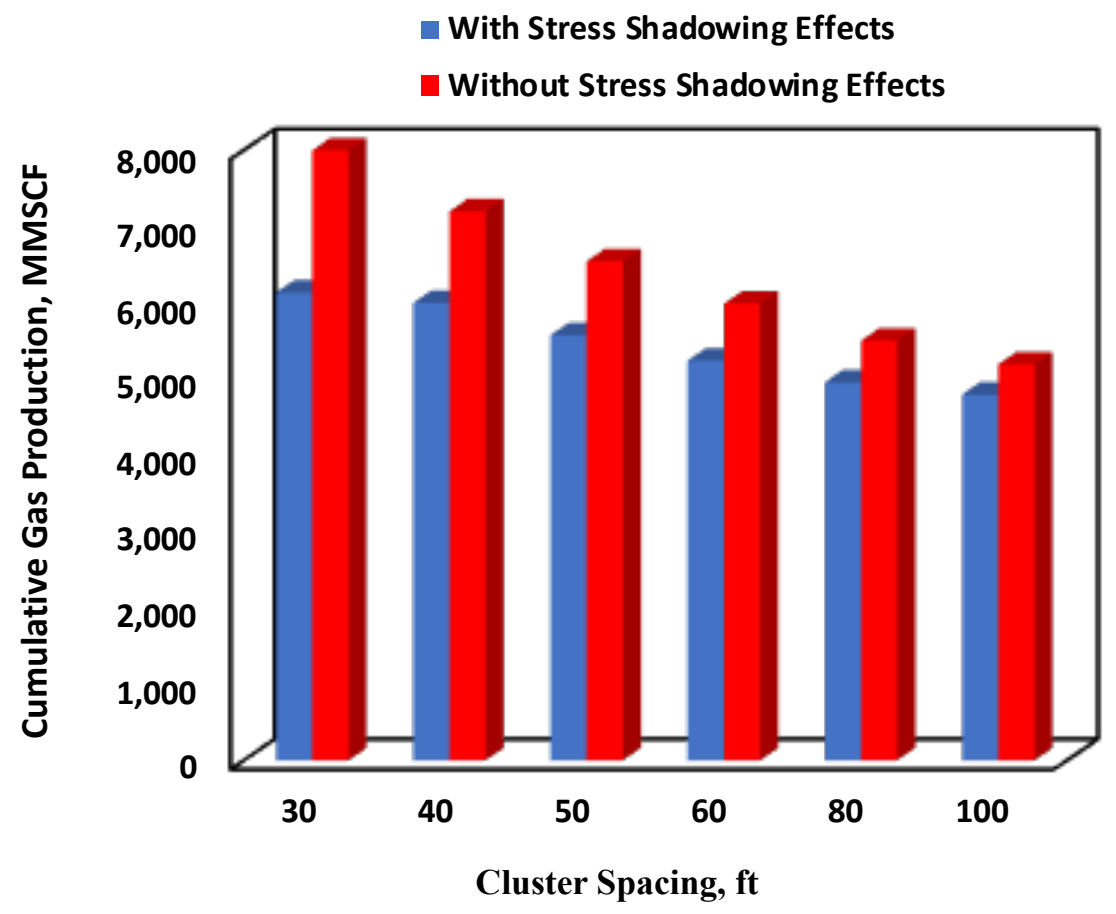

Figure 4. 106: 10-year Cumulative Gas Production with and without Stress Shadowing for Different Cluster Spacings.

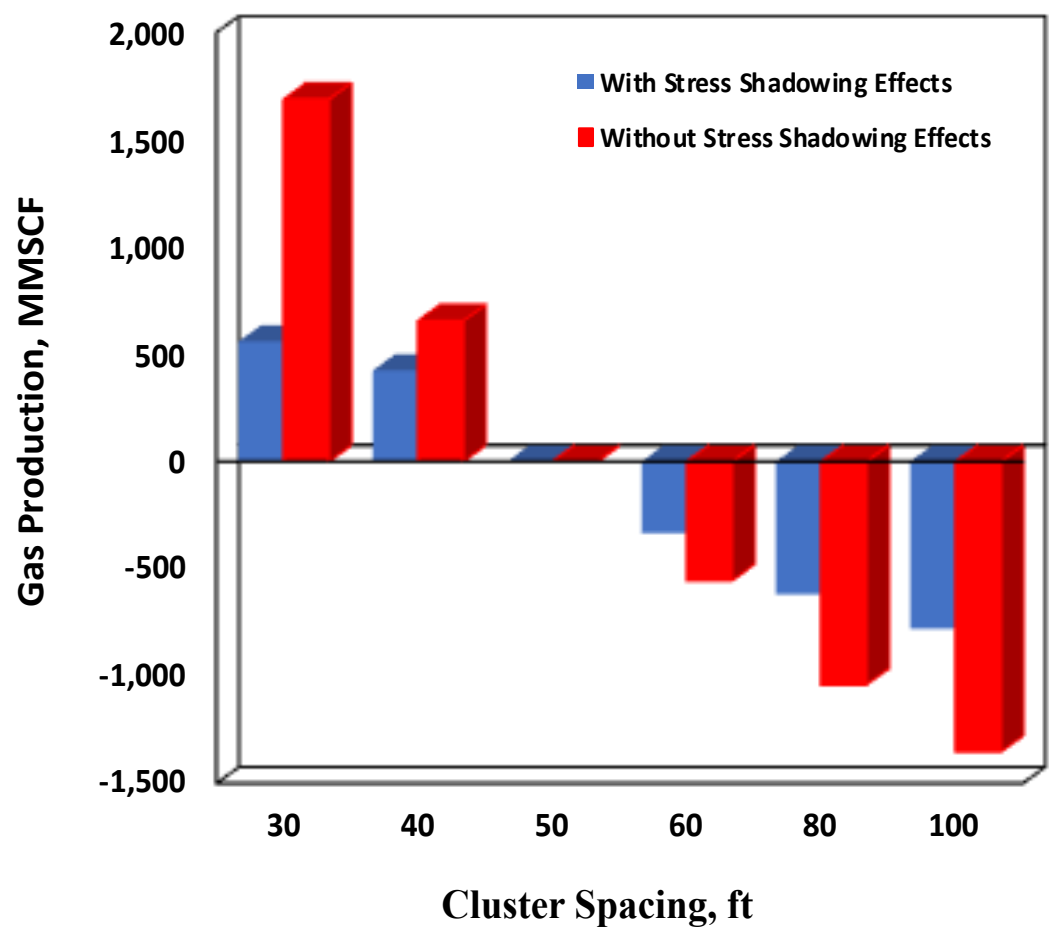

Figure 4. 107: Gas Production Change Compared to the Base Case for Different Cluster Spacings. 


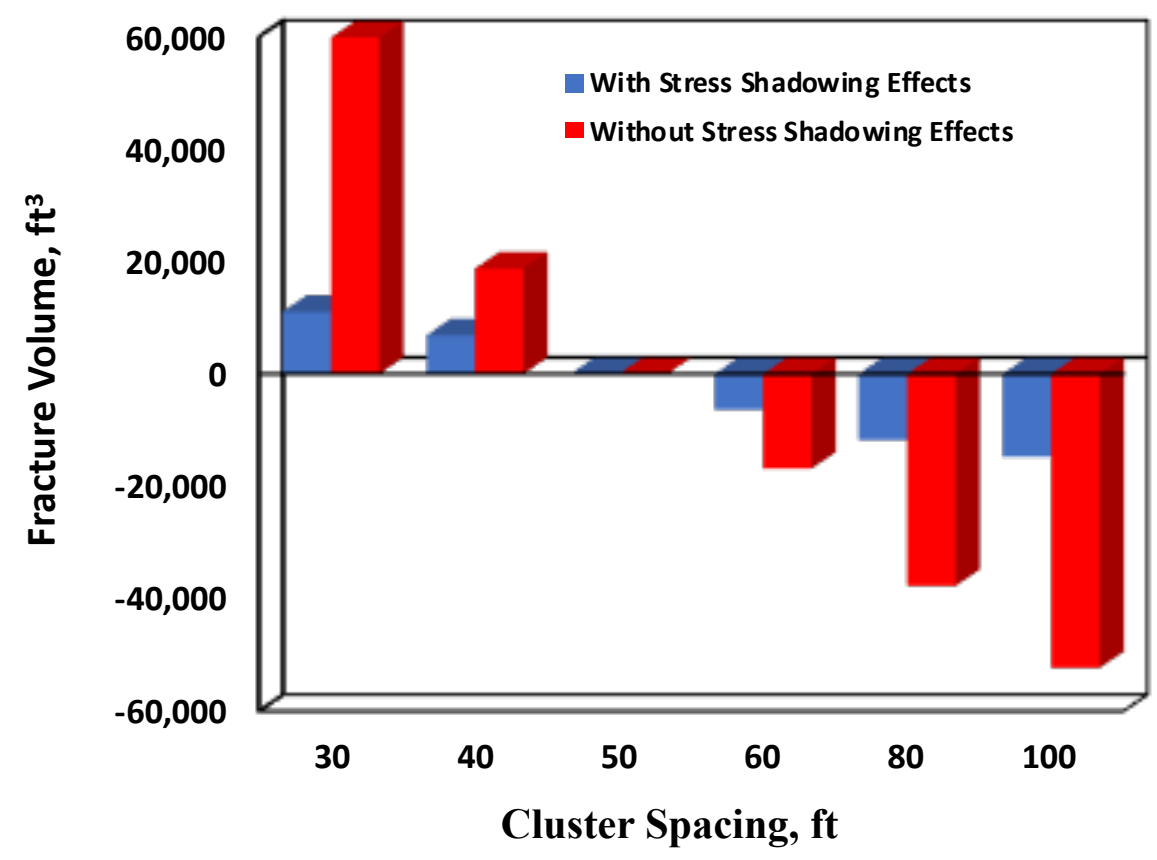

Figure 4. 108: Change in Total Fracture Volume Compared to the Base Case for Different Closer Cluster Spacings.

\subsubsection{Impact Cluster Spacing on Fracture Conductivity (Well MIP-3H)}

Fracture conductivity is essential for the flow from the reservoir into the wellbore. To investigate the impact of the stress shadowing on fracture conductivity, the average effective fracture conductivity with and without stress shadowing effects were predicted for different cluster spacings. Figure 4.109 compares the average effective fracture conductivity for different cluster spacings. It was evident from Figure 4.109 that the average effective fracture conductivity decreases when stress shadowing is taken into consideration. Furthermore, the average effective fracture conductivity without stress shadowing (Red Bars) is equally close to each for different cluster spacings. However, when the stress shadowing is considered (Blue Bars), the average effective fracture conductivity decreases as the cluster spacing decreases.

Figures 4.110 compares the average effective fracture conductivity and cumulative gas production for different cluster spacings. It is clear from Figure 4.110 that even though that the stress shadowing has caused a significant reduction in the fracture conductivity (Blue Bars), the cumulative production is not significantly impacted (Red Bars). Figure 4.111 compares the total fracture volume and cumulative gas production for different cluster spacings. It is clear from Figure 4.111 that the cumulative production is closely related to the total fracture volume. Therefore, it can be concluded that the total fracture volume has more of an impact on cumulative gas production than the fracture conductivity. 


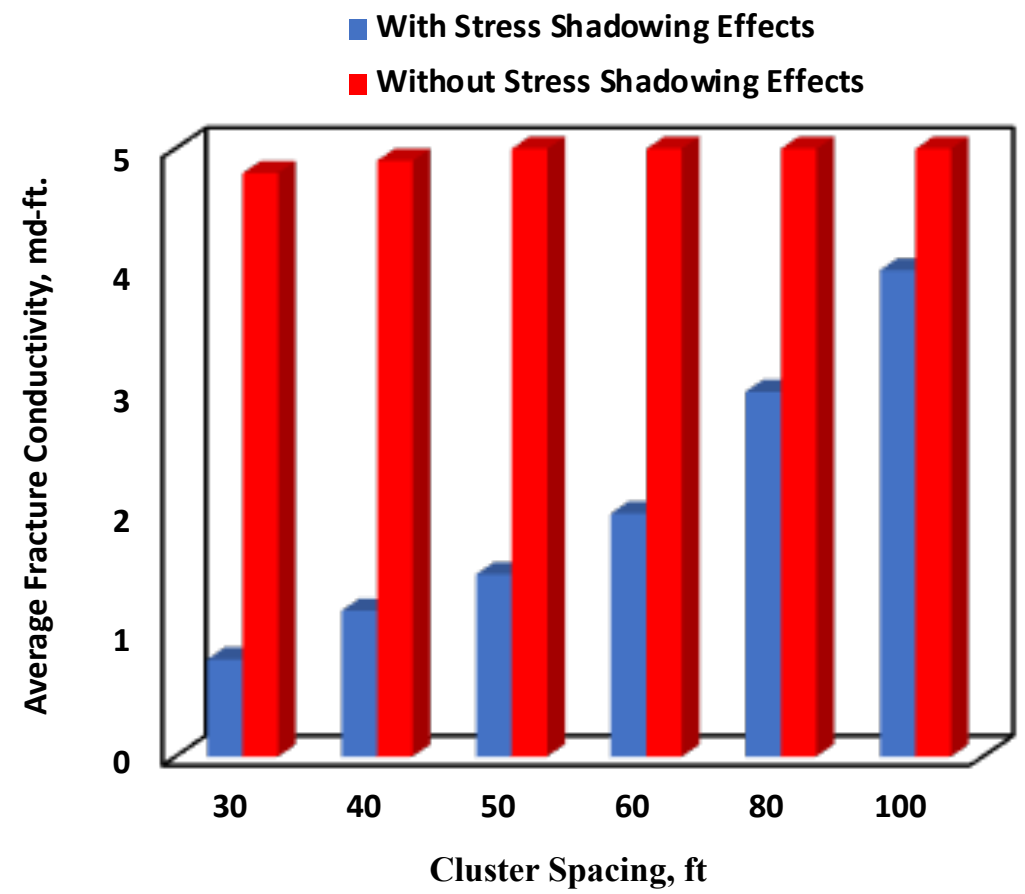

Figure 4. 109: Fracture Conductivity with and without Stress Shadowing for Different Cluster Spacings.

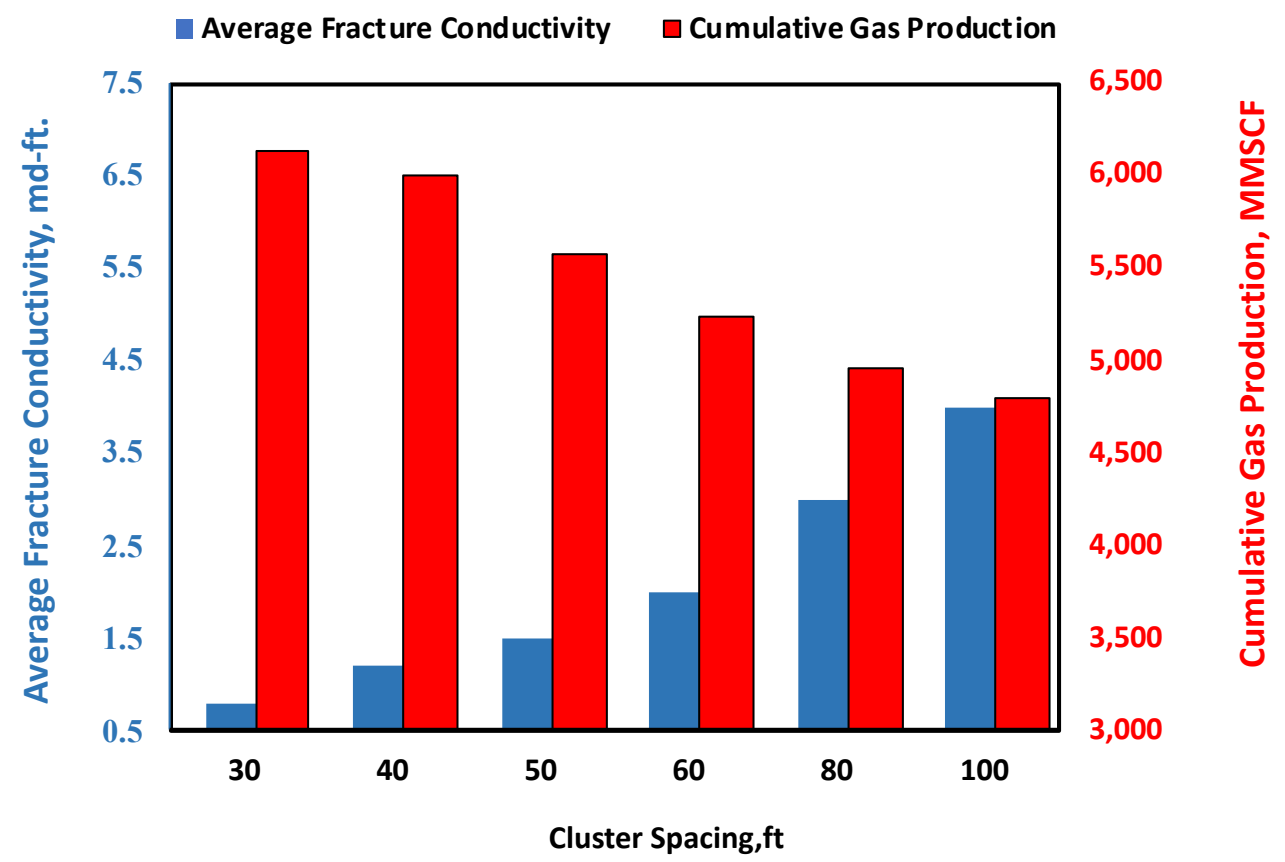

Figure 4. 110: Average Fracture Conductivity and 10-year Cumulative Gas Production for Different Cluster Spacings. 


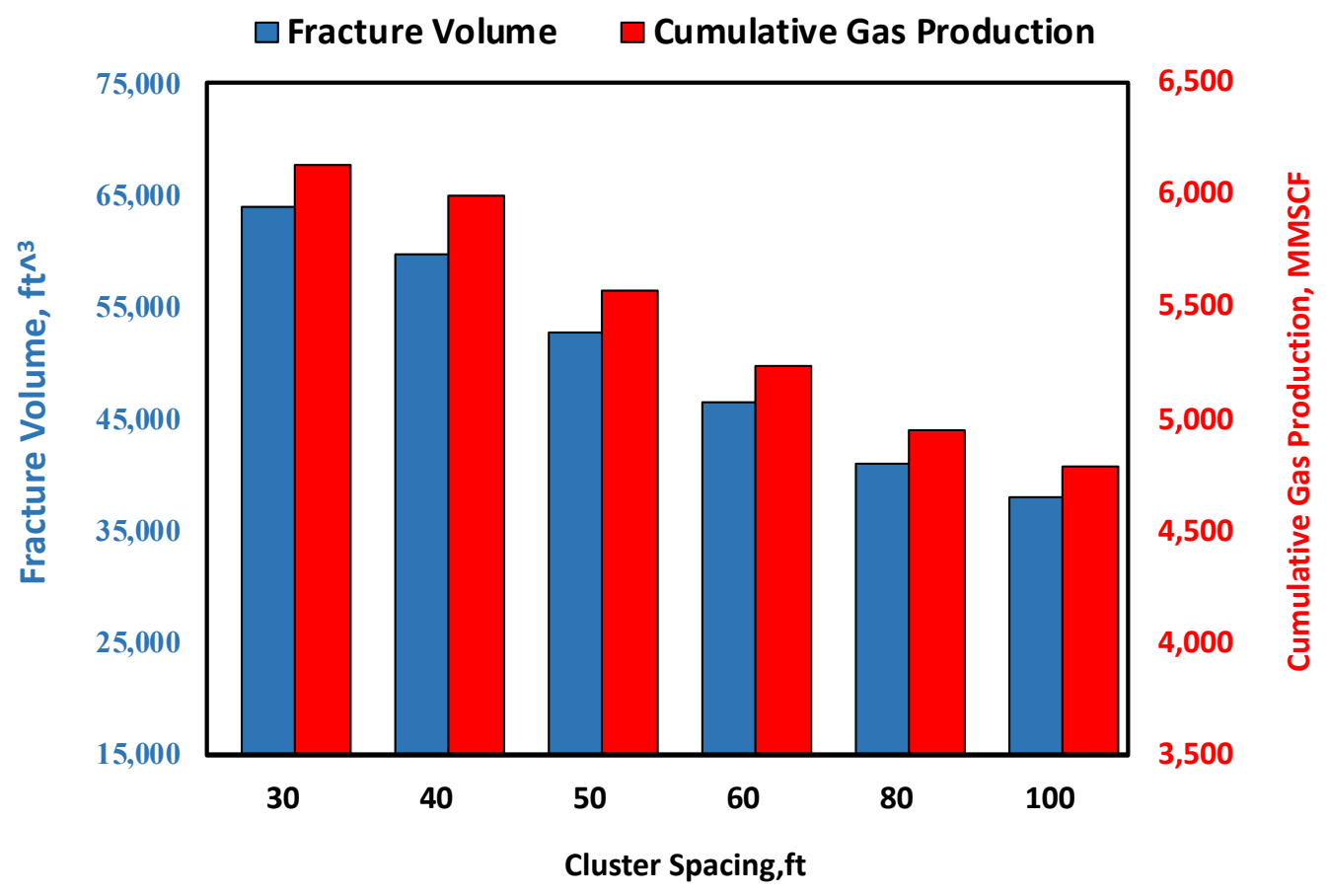

Figure 4. 111: Total Fracture Volume with Stress Shadowing and 10-year Cumulative Gas Production for Different Cluster Spacing.

\subsubsection{Impact Treatment Design on Stress Shadowing and Gas Recovery (MIP-3H)}

Figure 4.112 compares the total fracture volume for different fracturing fluid volumes per stage. The fracture volume is negatively impacted by the stress shadowing. Figure 4.113 shows the percentage reduction in 10-year gas recovery due to the stress shadowing for different treatment volumes per stage. It is obvious from Figure 4.112 that the stress shadowing impact becomes more pronounced as treatment volume increases. The optimal treatment volume appears to be 374,028 gal for the well under study. Stress shadowing at close cluster spacing can be minimized by reducing the fracturing fluid volume per stage. 


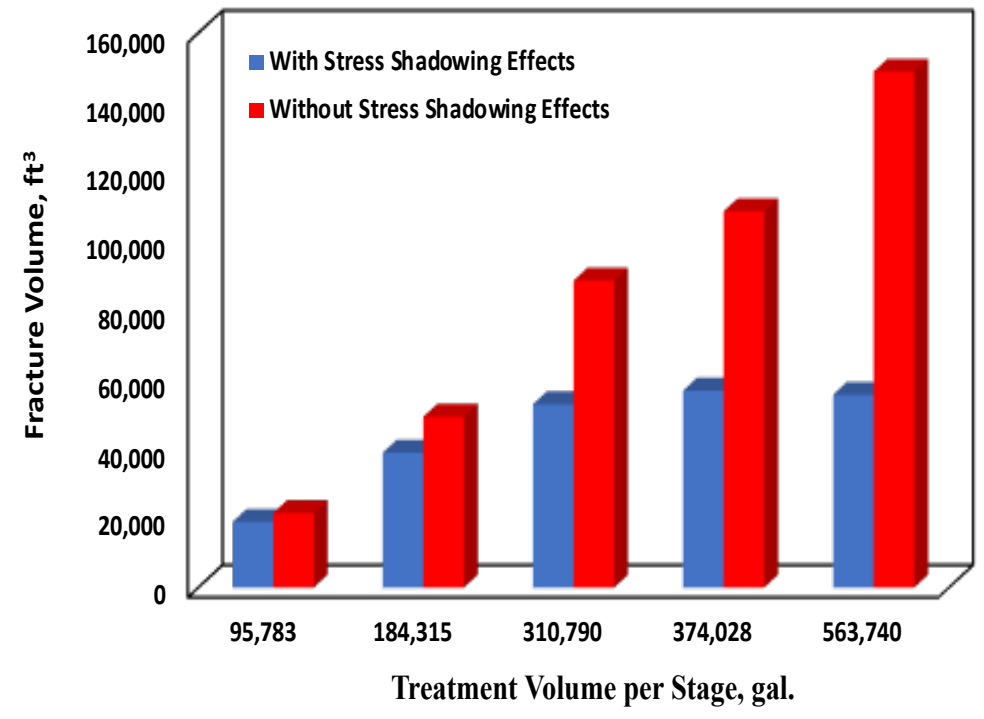

Figure 4. 112:Total Fracture Volume for Different Fracturing Fluid Volume per Stage.

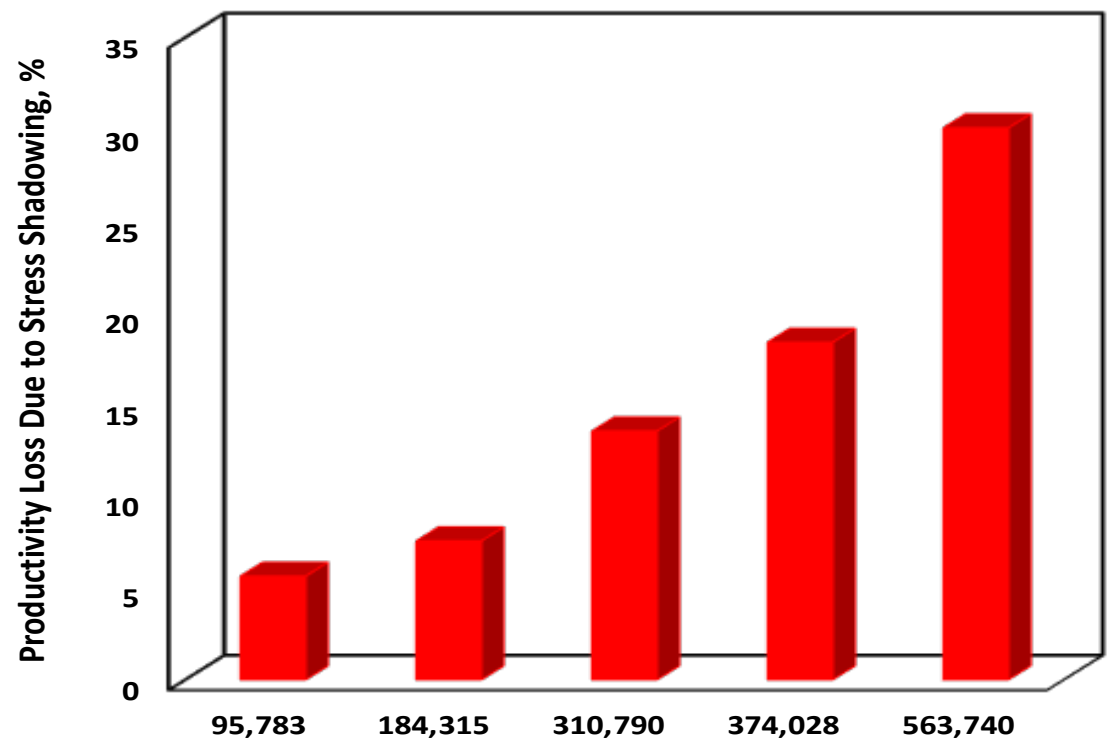

Treatment Volume per Stage, gal.

Figure 4. 113: Percentage Reduction in 10-year Gas Recovery Due to the Stress Shadowing Effects.

4.11. The Relationship between the Production Logging Tool Results (PLT) and Resistive Fractures (Fissures) and Fracture Conductivity per Stage along Horizontal Length.

Production Logging tool results (PLT) show widely varying contributions to production from the different stages for well MIP-3H, as seen in Figure 4.114. Figure 4.114 compares the production contribution per stage with continuous resistive fractures (Fissures). It was evident from Figures 4.114, 
$4.115,4.17$, and 4.18 that the production logging results could not be directly related to the hydraulic fracture properties or natural fracture distribution. As it is seen in Figure 4.116 that stages (5 and 15) have less fracture density. However, stage 5 produces more gas than stage 15. Furthermore, stage 10 has a high fracture density, but it is contributing about $7 \%$ of total gas production.

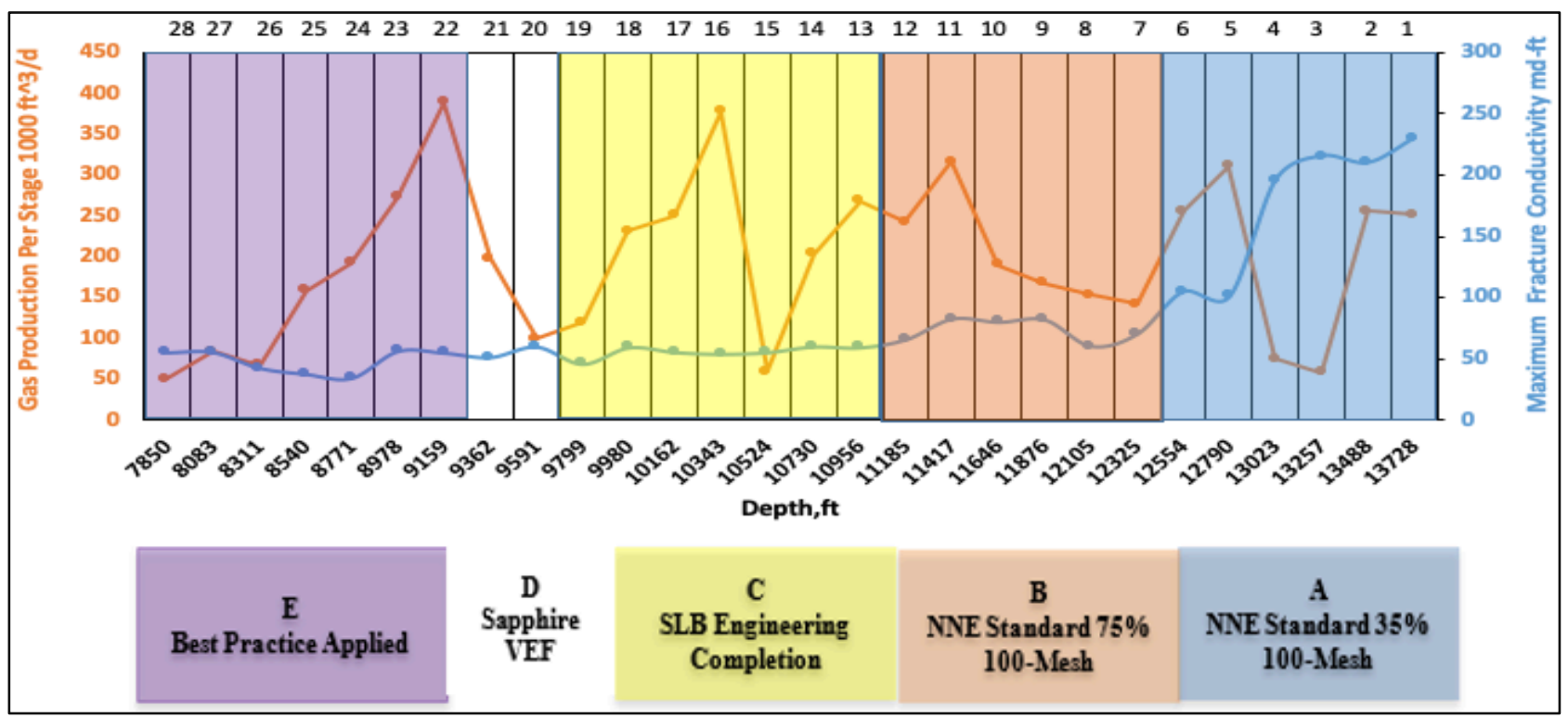

Figure 4.114: Illustrates Maximum Fracture Conductivity and Production Log Tool (PLT).

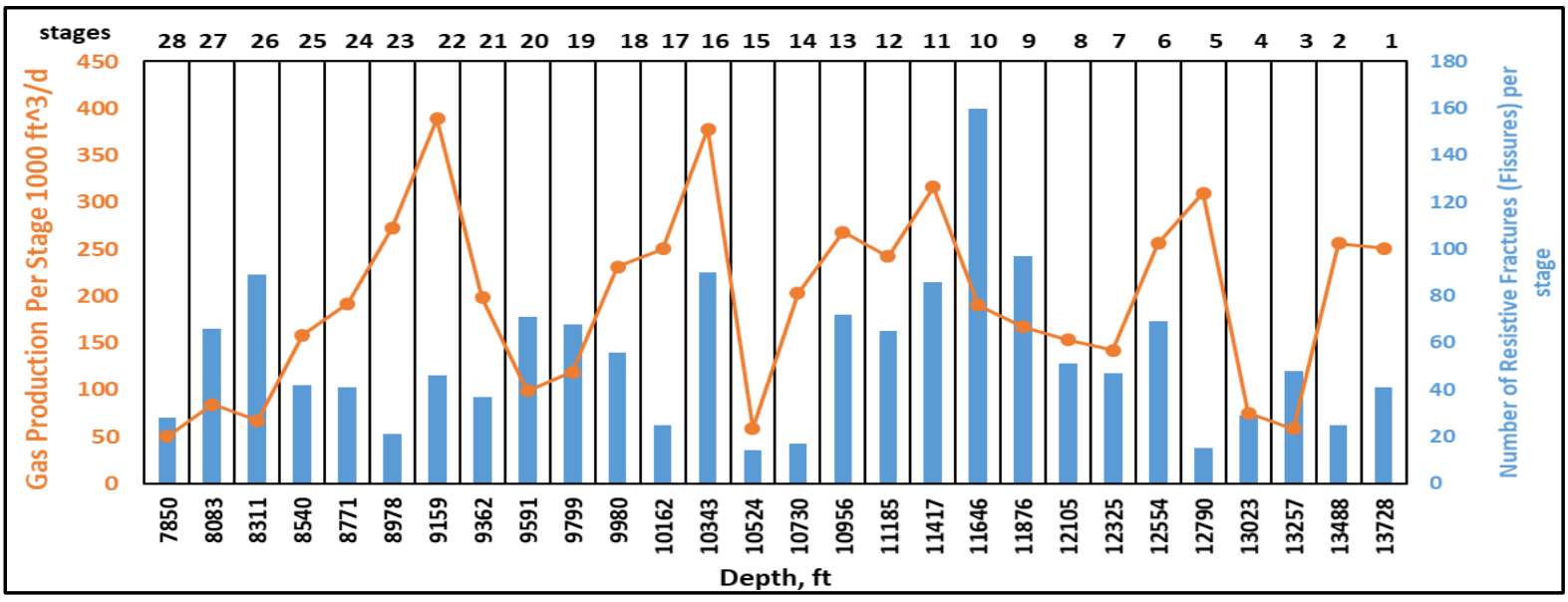

Figure 4.115: Illustrates the Relationship Between the Production Log Tool (PLT) and Resistive Fractures (Fissures) per Stage. 


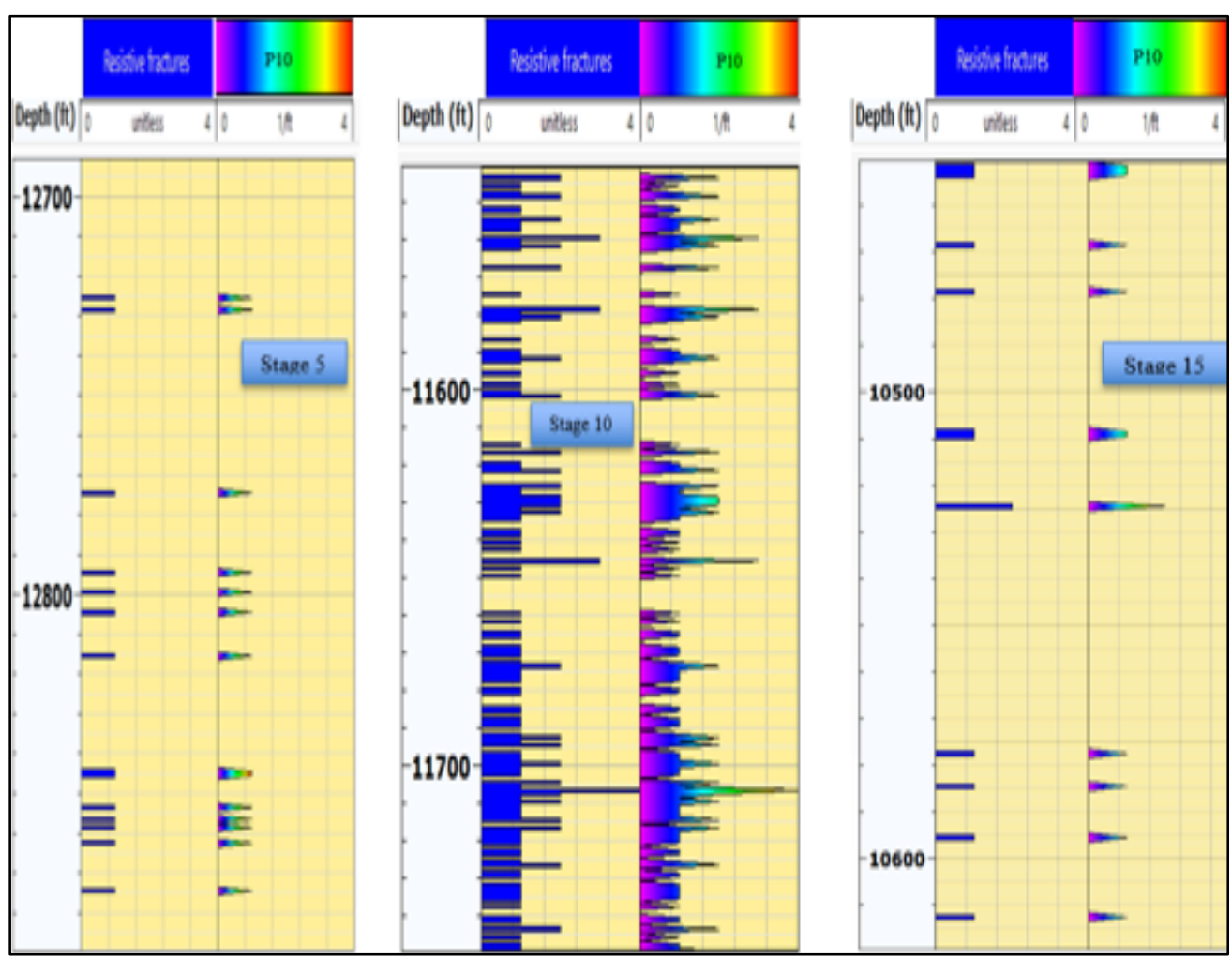

Figure 4.116: Shows Number of Resistive Continuous Fractures (Fissures) and Natural Resistive Continuous Fractures Density for Stages 5, 10, and 15.

\subsection{Comparison Gas Production Percentage per Section from the Production Logging Tool (PLT)}

Figure 4.117 shows the gas production percentage per section from the production logging tool (PLT). As it is mentioned early, the MIP-3H well was completed with 28 fracture stages from the toe to the heel in 5 sections, Section A (Stages 1-6), Section B (Stages 7-12), Section C (Stages 13-19), Section D (Stages 20-21), and section E (Stages 22-28). Section C (Stages 13-19) has the highest gas production because this section was designed based on the geomechanical properties from the well logs data obtained in the lateral. 


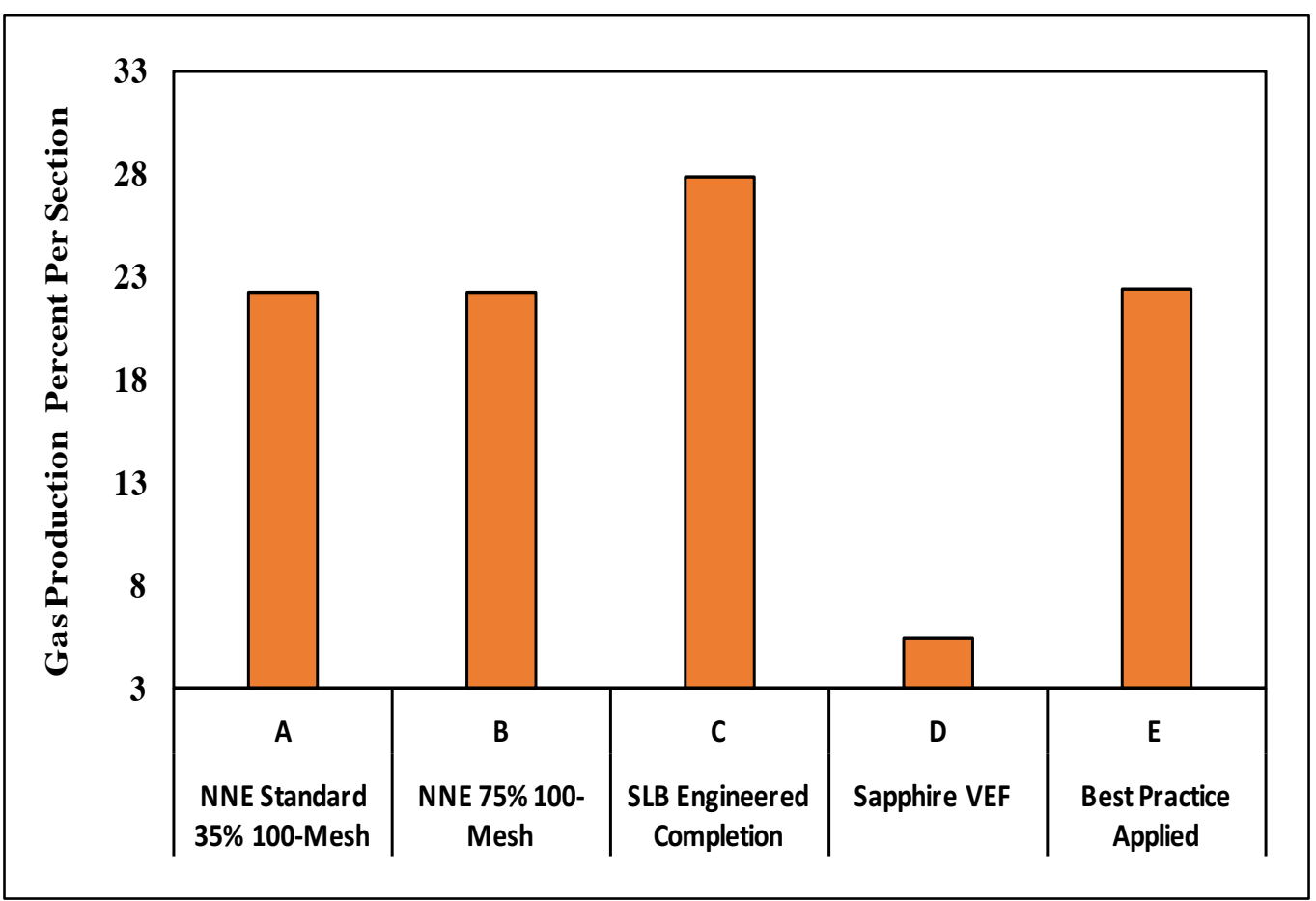

Figure 4.117: Shows the Gas Production Percentage by Section.

\subsection{The Relationship between the Total Organic Carbon (TOC) and Resistive Fractures (Fissures) and Production Logging Tool (PLT) per Stage along Horizontal Length}

The reservoirs which have high total organic carbon (TOC) tend to be ductile. At the same time, these reservoirs are more desirable because they are organic-rich. Average TOC per stage showed a weak positive relationship with a number of nature fractures (fissures) per stage, as seen in Figure 4.118. Furthermore, the average TOC per stage also showed a weak positive relationship with production logging tool results, as seen in Figure 4.119. Both production logging tool results and natural fracture (fissures) showed a fragile positive relationship with total organic carbon (TOC). However, production logging tool results showed a weaker relationship with total organic carbon (TOC) as compared to natural fracture (Fissures) with total organic carbon (TOC). 


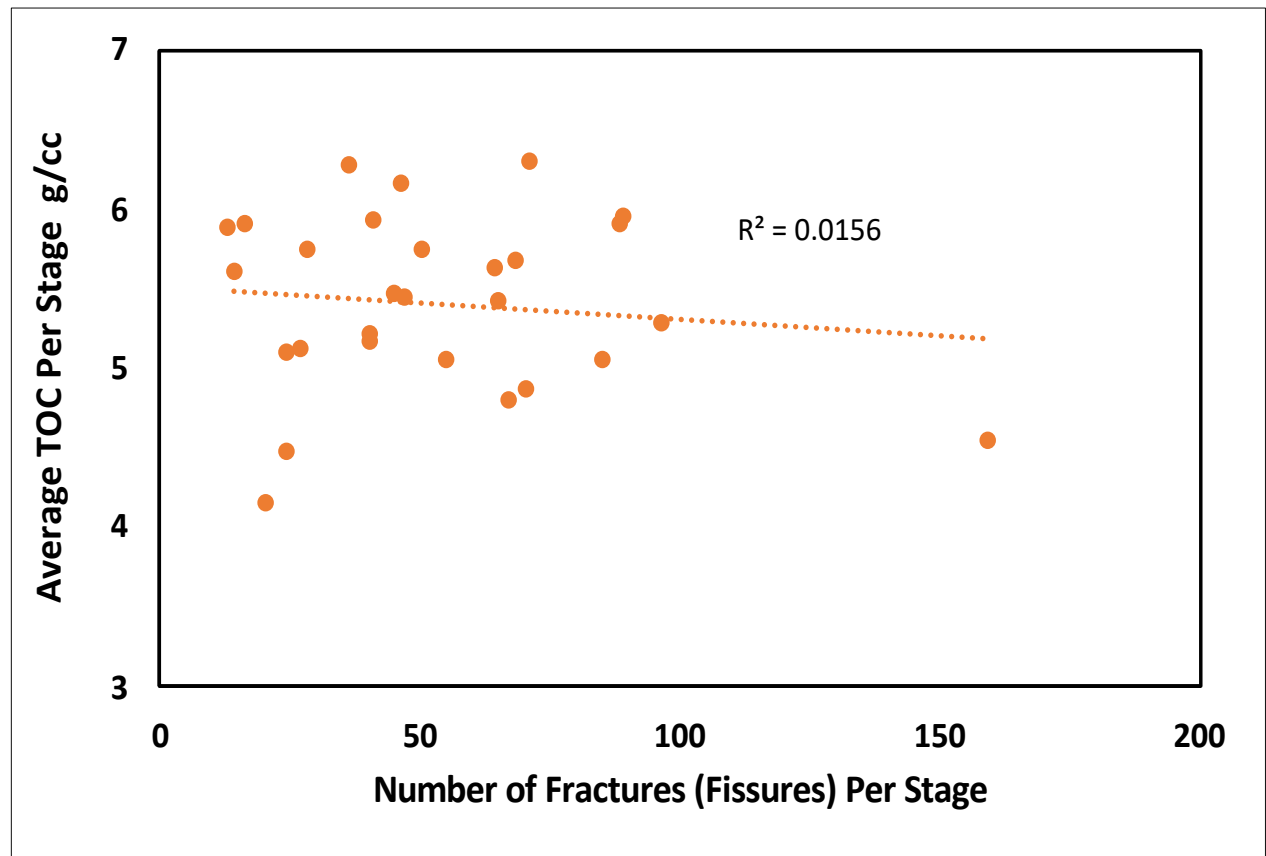

Figure 4. 118: Relationship Between Average (TOC) per Stage along Horizontal Length with Natural Fractures (Fissures) per Stage.

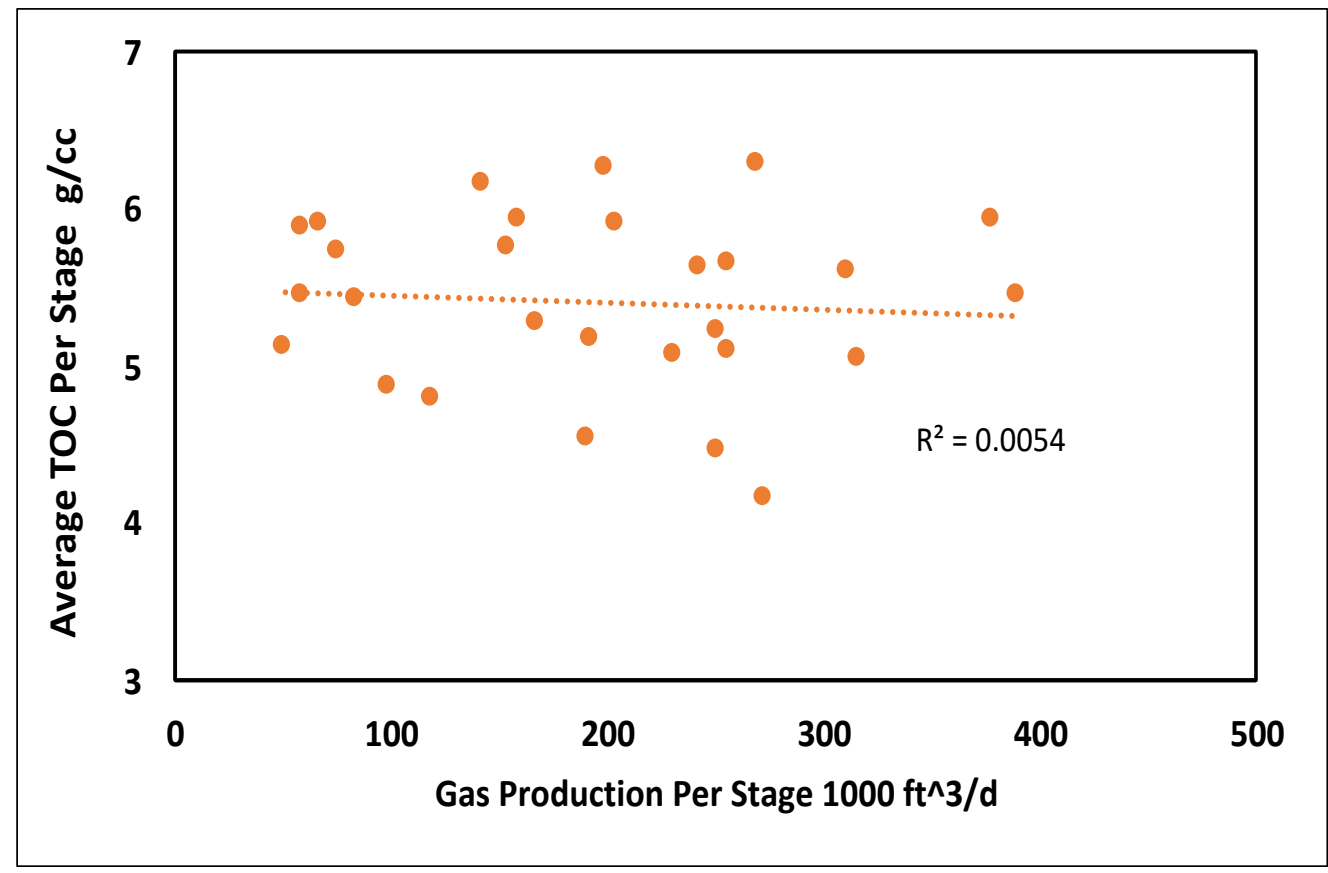

Figure 4.119: Relationship Between Average TOC per Stage along Horizontal Length with Production Logging Tool (PLT) per Stage. 


\section{CHAPTER 5: Conclusions and Recommendations}

\subsection{Conclusions}

\subsubsection{Horizontal Well MIP-6H}

A modeling study was implemented to evaluate the impact of geomechanical Factors and stress shadowing on gas production from horizontal wells with multiple hydraulic fractures completed in Marcellus Shale Well. The following conclusions can be drawn from this work:

1. The impact of Stress Shadowing and Geomechanical Factors must be considered for accurate prediction of the gas production from horizontal Marcellus shale with multiple hydraulic fracture stages.

2. The Geomechanical Factors and Stress Shadowing have negative impacts on gas production, particularly during the early stages of the production (1-5 years).

3. The fissure permeability and propped fracture conductivity geomechanical factors have a major impact on the production, while the matrix permeability geomechanical factor has only a minor impact on production.

4. The impact of the matrix and fissure permeability geomechanical factors decreases as the fracture half-length increases.

5. The impact of the propped fracture conductivity geomechanical factor increases as the fracture half-length increases. However, the effect of the propped fracture conductivity geomechanical factor increases as the initial fracture conductivity decreases.

6. As fracture spacing decreases while maintaining the number of stages at 8 , the impact of geomechanical factors decreases. The gas production from the fissure decreases with more reduction than the matrix and fracture stages. However, gas production from the fracture stages decreases with a more significant reduction than the matrix.

7. As fracture stages spacing decreases with increasing the number of fracture stages, the impact of the propped hydraulic fracture and matrix geomechanical factors decrease. However, it does not influence the propped hydraulic fracture geomechanical factor.

8. The gas production from the fracture stages increases with a greater increment than the matrix and fissure when fracture stages spacing decreases with increasing the number of fracture stages.

9. Initial fissure permeability has a major impact on the matrix permeability geomechanical factor. However, it does not influence the propped fracture conductivity geomechanical factor. 
10. As wellbore pressure increases, the impact of the geomechanical factors decreases.

11. When the wellbore pressure decreases, the impact of the propped hydraulic fracture geomechanical factor approaches that of the geomechanical matrix factor.

12. Gas slippage has an insignificant impact on gas production.

13. Fracture half-length has a significant impact on gas recovery.

14. The impact of non-uniform fracture half-length is not very significant.

15. Properties of Marcellus shale, including fracture closure stress, instantaneous shut-in pressure (ISIP), process zone stress (PZS), formation leak-off coefficient, and type, were estimated from DFIT analysis.

16. Pressure-dependent leak-off was observed from DFIT analysis. This indicates the presence of the natural fractures (fissure) intersected by the hydraulic fracture.

17. The stress profile was determined using vertical well log measurements (MIP-3H) and was calibrated using DFIT analysis.

18. Ignoring stress shadowing leads to higher estimated gas recovery.

19. The stress shadowing impact on the gas production diminishes as the spacing of the hydraulic fracture stage increases.

20. The stress shadowing impact on the gas production increases as the volume of the injected fluid and the sand amount per stage is increased.

21. The impact of the stress shadowing appears to be lower for simultaneous fracturing as compared to sequential fracturing.

22. The hydraulic fracture properties and gas recovery from Marcellus shale improve as Poisson's ratio decreases.

23. The improvement in the production performance of the Marcellus shale horizontal well, due to the lower Poisson's ratio, can be obscured by stress shadowing when the stage spacing is close.

24. The predicted fracture grows more upward in Marcellus Shale if the stress shadowing effects are ignored.

25. The higher is the fracture height. The more significant is the impact of stress shadowing in Marcellus Shale. 


\subsubsection{Horizontal Well MIP-3H}

1. The analysis of the FMI log indicated that the orientation of maximum and minimum horizontal stresses to be $\mathrm{N} 57^{\circ} \mathrm{E}$ and $\mathrm{N} 36^{\circ} \mathrm{W}$, respectively.

2. The stress regime in Marcellus shale (MIP-3H) was determined to be a normal fault based on the constructed stress polygon.

3. The middle clusters have shorter fracture half-length as compare to the end clusters because of stress shadowing.

4. Hydraulic fractures grew more in an upward direction from Marcellus Shale because low stress barriers between Marcellus shale and the zone above Marcellus Shale.

5. It is necessary to increase the stress in Onondaga Limestone to prevent downward hydraulic fracture growth.

6. Adjustment of the hydraulic fracture model with microseismic observation increased the accuracy and reliability of the predicted production performance.

7. The inclusion of geomechanical factor for fissure permeability and hydraulic fracture conductivity significantly improved the prediction of production performance.

8. There is no relationship between production logging tool results and natural fracture along the horizontal length for well under this study

9. Production logging tool results and natural fracture (Fissures) showed a weak positive relationship with total organic carbon (TOC). However, production logging tool results showed a more fragile relationship with total organic carbon (TOC) as compared to natural fracture (Fissures) with total organic carbon (TOC).

10. As the number of clusters per stage increases, the cumulative gas production will increase. However, this increase can be diminished by the impact of the stress shadowing as the cluster spacing decreases.

11. As the cluster spacing decreases, the impact of the stress shadowing become more pronounced

12. If the stress shadowing is ignored, the total fracture volume increases as the cluster spacing is lowered. However, the increase in the fracture volume becomes negligible when stress shadowing is considered.

13. Wider cluster spacing results in a lower total fracture volume but higher fracture conductivity.

14. The cumulative gas production appears to be impacted more by the total fracture volume than the fracture conductivity. 
15. As treatment volume per stage increases, the stress shadowing impact increases leading to lower gas recovery.

16. The impact of stress shadowing at narrow cluster spacing can be minimized by reducing the treatment volume.

\subsection{Recommendations Well MIP-6H}

1. Lateral heterogeneity of the reservoir properties affects fracture propagation. Therefore, It is recommended that horizontal well logs data are available along the horizontal length for accurate prediction of the gas production from a horizontal well with multiple hydraulic fractures completed in Marcellus Shale.

2. It is recommended to incorporate economic analysis for optimization hydraulic fracture spacing in Marcellus shale. 


\section{References}

Aadnoy, Bernt S., and J. Sebastian Bell. "Classification Of Drilling-induced Fractures And Their Relationship To In-situ Stress Directions." The Log Analyst 39 (1998):

Abass, H.H., Soliman, M.Y., Tahini, A.M. et al. 2009. Oriented Fracturing: A New Technique To Hydraulically Fracture an Openhole Horizontal Well.Proc., SPE Annual Technical Conference and Exhibition,New Orleans, Louisiana, USA, 4-7 October. SPE-124483-MS.

Adachi, J., Siebrits, E., Peircec, A., and J. Desroches, 2007, Computer simulation of hydraulic fractures, International Journal of Rock Mechanics \& Mining Sciences 44, pages: 739-757. Adachi, J.I. and E

Aboaba, A., and Cheng, Y. 2010. Estimation of fracture properties for a horizontal well with multiple hydraulic fractures in gas shale. SPE Paper 138524. SPE Eastern Regional Meeting, Morgantown, WV, October 12-14.

Alramahi, B., and Sundberg, M.I. 2012. Proppant embedment and conductivity of hydraulic fractures in shales. The 46th US Rock Mechanics/Geomechanics Symposium, 24-27 June 2012, Chicago, IL. ARMA 12-291.

Baihly, J. D., Altman, R. M., Malpani, R., \& Luo, F. (2010, January 1). Shale Gas Production Decline Trend Comparison over Time and Basins. Society of Petroleum Engineers.

Bell, J. S., \& D. I. Gough (1979). Northeast-southwest compressive stress in Alberta - Evidence from oil wells. Earth Planet. Sci. Lett., 45(2), 475-482.

Barree, R.D., and H. Mukherjee. "Determination of Pressure Dependent Leakoff and Its Effect on Fracture Geometry." Paper presented at the SPE Annual Technical Conference and Exhibition, Denver, Colorado, October 1996. doi: https://doi-org.wvu.idm.oclc.org/10.2118/36424-MS

Barree, R.D. (2018). GOHFER 3D User Manual. Retrieved June 2, 2019, from from Barree and Associates: https://www.barree.net/

Barree, R. D. (2015). "Stress Shadowing and Fracture Interference in GOHFER ${ }^{\circledR}$ Software. 10". Retrieved June 2, 2018, from Barree and Associates: https://www.barree.net/

Barree, Robert D., Barree, Valencia L., and David Craig. "Holistic Fracture Diagnostics: Consistent Interpretation of Prefrac Injection Tests Using Multiple Analysis Methods." SPE Prod \& Oper 24 (2009): 396-406. doi: https://doi-org.wvu.idm.oclc.org/10.2118/107877-PA

Bentek: August NatGas Production Nearly as High as July Record / Marcellus Drilling News. (2015, September 10). https://marcellusdrilling.com/2015/09/bentek-august-natgas-productionnearly-as-high-as-july-record/

Best, M.E., and Katsube, T.J. 1995. Shale permeability and its significance in hydrocarbon exploration, Geological Survey of Canada 14(3):165-170.

Boyce, M. L., Yanni, A. E., and Carr, T. R. 2010. Depositional Control of Organic Content in the Middle Devonian Marcellus Interval of West Virginia and Western Pennsylvania. Presented at the AAPG Hedberg Research Conference, Austin, Texas, USA, 5-10 December.

Briggs, K. 2014. The Influence of Vertical Location on Hydraulic Fracture Conductivity in the Fayetteville Shale. Master's Thesis: Texas A\&M University Petroleum Engineering. College Station, TX. Copyright 2014, Kathryn Elizabeth Briggs. 
Bruner, K.R., and Smosna, R., 2011, A comparative study of the Mississippian Barnett Shale, Fort Worth Basin, and Devonian Marcellus Shale, Appalachian Basin: Technical Report DOE/ NETL-2011/1478, National Energy Technology Laboratory (NETL) for the U.S. Department of Energy, $106 \mathrm{p}$.

Bustin, R. M., Bustin, A. M. M., Cui, A., Ross, D., \& Pathi, V. M. 2008. Impact of Shale Properties on Pore Structure and Storage Characteristics. Presented at the 2008 SPE Shale Gas Production Conference, Fort Worth, Texas, USA. 16-18 November. SPE-119892-MS.

Carr, T., Ghahfarokhi, P., Carney, B., Hewitt, J., \& Vargnetti, R. (2019, July 31). Marcellus Shale Energy and Environmental Laboratory (MSEEL) Results and Plans: Improved Subsurface Reservoir Characterization and Engineered Completions. Presented at the Unconventional Resources Technology Conference. doi:10.15530/urtec-2019-415.

Carter, K. M., Harper, J. A., Schmid, K. W., \& Kostelnik, J., 2011, Unconventional natural gas resources in Pennsylvania: The backstory of the modern Marcellus Shale play. Environmental Geosciences, 18(4), 217-257.

Cheng, Y., "Boundary Element Analysis of the Stress Distribution around Multiple Fractures: Implications for the Spacing of Perforation Clusters of Hydraulically Fractured Horizontal Wells", SPE 125769, SPE Eastern Regional Meeting, Charleston, WV, 23-25 September, 2009.

Cho, Y., Ozkan, E., Apaydin, O.G., 2013. Pressure-dependent natural-fracture permeability in shale and its effect on Shale-Gas well production. SPE Reserv. Eval. Eng. 16 (02): 216-228. SPE159801-PA

Chorn, L., N. Stegent, and J. Yarus, 2014, Optimizing Lateral Lengths in Horizontal Wells for a Heterogeneous Shale Play: Presented at the SPE/EAGE European Unconventional Resources Conference and Exhibition.

Cipolla, C.L., Warpinski, N.R., Mayerhofefr, M.J., and Lolon, E.P., and Vincent, M.C.2008. The Relationship between Fracture Complexity, Reservoir Properties, and Fracture Treatment design. Presented at the 2008 SPE Technical Conference and Exhibition. Denver, Colorado, USA, 21-24 September. SPE 115769-MS.

Cipolla, C.L., Lolon, E.P., Erdle, J.C., Rubin, B. 2010. Reservoir modeling in Shale-Gas reservoirs. SPE Res. Eval. Eng. 13 (4): 638-653. SPE-125530-PA.

Cipolla C., Weng X., Onda H., Nadaraja T., and Ganguly U. 2011a. New Algorithms and Integrated Workflow for Tight Gas and Shale Completions. Paper SPE 146872 presented at SPE Annual Technical Conference and Exhibition, Denver, Colorado, 30 October- 2 November.

Cipolla, C., Maxwell, S., Mack, M, and Downie, R. 2011b. A Practical Guide to Interpretation Microseismic Measurements. SPE 144067 presented at the SPE North American Unconventional Gas Conference and Exhibition, The Woodlands, Texas, USA, 14-16 June 2011.

Cipolla, C., Maxwell, S., and Mack, M. 2012. "Engineering Guide to the Application of Microseismic Interpretations.” Paper SPE 152165 presented at the SPE Hydraulic Fracturing Technology Conference held in The Woodlands, Texas, USA, 6-8 February. 
Cipolla, C., and Wallace, J., 2014. Stimulated Reservoir Volume: A Misapplied Concept? Paper SPE 168596, SPE Hydraulic Fracturing Technology Conference, The Woodlands, TX, February 4-6.

Cleary, Michael P. "Analysis Of Mechanisms And Procedures For Producing Favourable Shapes Of Hydraulic Fractures." Paper presented at the SPE Annual Technical Conference and Exhibition, Dallas, Texas, September 1980. doi: https://doiorg.wvu.idm.oclc.org/10.2118/9260-MS.

Cleary, Michael P. "Comprehensive Design Formulae For Hydraulic Fracturing." Paper presented at the SPE Annual Technical Conference and Exhibition, Dallas, Texas, September 1980. doi: https://doi-org.wvu.idm.oclc.org/10.2118/9259-MS.

Cleary, M.P., Kavvadas, Michael, and K.Y. Lam. "Development of a Fully Three-Dimensional Simulator for Analysis and Design of Hydraulic Fracturing." Paper presented at the SPE/DOE Low Permeability Gas Reservoirs Symposium, Denver, Colorado, March 1983. doi: https://doi-org.wvu.idm.oclc.org/10.2118/11631-MS

Craig, David P., Eberhard, Michael J., and Robert D. Barree. "Adapting High Permeability Leakoff Analysis to Low Permeability Sands for Estimating Reservoir Engineering Parameters." Paper presented at the SPE Rocky Mountain Regional/Low-Permeability Reservoirs Symposium and Exhibition, Denver, Colorado, March 2000. doi: https://doiorg.wvu.idm.oclc.org/10.2118/60291-MS.

CMG: GEM User's guide. Computer Modeling Group Ltd., 2019.

Davies, J. P., \& Davies, D. K.1999. Stress-Dependent Permeability: Characterization and Modeling. Presented at the 1999 SPE Annual Technical Conference and Exhibition. Houston, Texas, 36 October.SPE56813-MS.

Dontsove, E.V, Peirce, A.P. "An enhanced pseudo-3D model for hydraulic fracturing accounting for viscous height growth, non-local elasticity, and lateral toughness". Society of Petroleum Engineers Journal 4 May 2015. pp. 116-139

Economides, M. J., \& Nolte, K.G., 2000. Reservoir stimulation. John Wiley \& Sons, Ltd., 3rd Ed., 11 to $20-13$ pp.

Eissa, A., Kazi, A.: "Relation between static and dynamic Young's moduli of rocks," Int. J. Rock Mech. Min. Sci. Geomech. Abstr. Volume 25, Number 6, Pages 479- 482, 1988.

Elsaig, M., Aminian, K., Ameri, S., and Zamirian, M. 2016. Accurate Evaluation of Marcellus Shale Petrophysicl Properties. presented at the SPE Eastern Regional Meeting, Canton, Ohio, USA, 13-15 September 2016. SPE-184042-MS.

El Sgher, Mohamed, Kashy Aminian, and Samuel Ameri. 2019a. "The Impact of Stress Shadowing and Geomechanical Effects on Gas Production From Marcellus Shale." Paper presented at the SPE Western Regional Meeting, San Jose, California, USA, April 2019. doi: https://doiorg.wvu.idm.oclc.org/10.2118/195250-MS.

El Sgher, Mohamed, Kashy Aminian, and Samuel Ameri. 2019b. "The Stress Shadowing Impact on the Production Performance of Marcellus Shale." Paper presented at the SPE Annual Technical Conference and Exhibition, Calgary, Alberta, Canada, September 2019. doi: https://doi-org.wvu.idm.oclc.org/10.2118/196005-MS 
El sgher, Mohamed , Aminian, Kashy , and Samuel Ameri. 2018c. "The Impact of Stress on Propped Fracture Conductivity and Gas Recovery in Marcellus Shale." Paper presented at the SPE Hydraulic Fracturing Technology Conference and Exhibition, The Woodlands, Texas, USA, January 2018. doi: https://doi-org.wvu.idm.oclc.org/10.2118/189899-MS

Fan, L., Thompson, J.W. and Robinson, J.R. 2010. Understanding gas production mechanism and effectiveness of well stimulation in the Haynesville Shale through reservoir simulation. Presented at the Canadian Unconventional Resources and International Petroleum Conference, Calgary, Alberta, Canada, 19-21 October. SPE-136696-MS.

Fisher, K. and Warpinski, N., Pinnacle- A Halliburton Service, Hydraulic Fracture-Height Growth: Real Data, Society of Petroleum Engineers Paper, SPE 145949, 201.

Fisher, M.K., Heinze, J.R., Harris, C.D. et al. 2004.Optimizing Horizontal Completion Techniques in the Barnett Shale Using Microseismic Fracture Mapping.Proc.,SPE Annual Technology Conference and Exhibition, Houston, Texas, USA, 26-29 September. SPE-90051-MS.

Fracking: The Promise And The Problems. (2013, August 12). Thoughts of a Lapsed Physicist. http://www.lapsedphysicist.org/2013/08/12/fracking/

Fredd, C.N., McConnell S.B., Boney C.L. and England K.W. 2001. Experimental Study of Fracture Conductivity for Water-Fracturing and Conventional Fracturing Application. SPE J. 6 (3): 288-298. SPE-74138-PA.

Germanovich, L.N., Ring, L.M., Astakhov, D.K. et al. 1997. Hydraulic Fracture With Multiple Segments II: Modeling.Int. J. Rock Mech. Min. Sci.34 (3-4): 472.

Geertsma, J., de Klerk, F., 1969, A rapid method of predicting width and extent of hydraulically induced fractures, Journal of Petroleum Technology, Vol. 21, pages: 1571- 81 [SPE 2458]

Guzek, J.J. 2014. Fracture Conductivity of the Eagle Ford Shale. M.S. Thesis, Texas A\&M University, College Station, Texas (August 2014).

Guo, J.C., Lu, C., Zhao, J.Z. et al. 2008. Experimental Research on Proppant Embedment. J. China Coal Society 33 (6): 661-664. Chinese.

Gutierrez, M., Øino, L.E., Nygård, R. 2000. The stress-dependent permeability of a de-mineralized fracture in shale. Marine and Petroleum Geology.17 (8): 895-90.

Heller, R., Vermylen, J., Zoback, M., 2014. Experimental Investigation of Matrix Permeability of Gas Shales, AAPG Bull., 98 (5), 975-995.

Heidbach, Oliver; Rajabi, Mojtaba; Reiter, Karsten; Ziegler, Moritz (2016). World Stress Map Database Release 2016. GFZ Data Services.

Khristianovic S.A., Zheltov, Y.P., 1955, Formation of vertical fractures by means of highly viscous liquid. In: Proceedings of the fourth world petroleum congress, Rome, pages: 579-86.

Kresse, O., Weng, X., Gu, H. et al. 2013. Numerical Modeling of Hydraulic Fracture Interaction in Complex Naturally Fractured Formations. Rock Mech. Rock Eng. 46 (3): 555-558.

Huitt, J.L. and Mcglothlin, B.B. 1958. The Propping of Fractures in Formations Susceptible to Propping-sand Embedment. presented at the spring meeting of the Pacific Coast District, Division of Production, Los Anpeles, California, USA, May. SPE 58-115.

Lacy.L.L., Rickards A.R., Syed A.A. Embedment and Fracture Conductivity in Soft Formations Associated with HEC, Borate and Water-Based Fracture Designs. presented at the 1997 SPE 
Annual technical Conference and exhibition, San Antonio, Texas, USA, 5-8 October. SPE38590-MS.

Lesage, M., Hall, P., Pearson, J. R. A., \& Thlercelln, M. J. (1991). Pore-Pressure and Fracture Gradient Predictions. Journal for Petroleum Technology, 652-654. SPE 21607.

Lian, P., \& Cheng, L. 2012. The Characteristics of Relative Permeability Curves in Naturally Fractured Carbonate Reservoirs. Society of Petroleum Engineers.

Maxwell, Shawn. 2012 "Microseismic Imaging of Hydraulic Fractures: Snap, Crackle and Pops of Shale Reservoirs" CSEG Recorder March (2012): p. 9-11.

Maxwell, S.C., Weng, X., Kresse, O., and Rutledge, J., 2013. Modeling Microseismic Hydraulic Fracture Deformation. Paper SPE 166312, SPE Annual Technical Conference and Exhibition, New Orleans, LA, September 30-October 2.

McGinley, M., Zhu, D., Hill, A.D 2015. The effects of fracture orientation and anisotropy on hydraulic fracture conductivity in the Marcellus Shale. Presented at the SPE Annual Technical Conference and Exhibition, Houston, Texas, USA, 28-30 September 2015.SPE-174870-MS.

Miller, C. et al.: "Evaluation of Production Log Data from Horizontal Wells Drilled in Organic Shales" paper SPE 144326 presented at North American Unconventional Gas Conference and Exhibition, 2011.

Meyer, B. and Bazan, L. 2011. A Discrete Fracture Network Model for Hydraulically Induced Fractures-Theory, Parametric and Case Studies.Proc.,SPE Hydraulic Fracturing Technology Conference and Exhibition, The Woodlands, Texas, USA, 24-26 January. SPE-140514-MS.

Nordgren, R.P., 1972, Propagation of a vertical hydraulic fracture, SPE Journal, 12(8), pages: 30614, SPE 7834

Molenaar, M., Hill, D., and Koelman, V. 2011. Downhole Tests Show Benefits of Distributed Acoustic Sensing Oil Gas J. 109 (1): 82-85.

Morrill, J.C. 2011. Optimization of Hydraulic Fracture Spacing in Horizontal Wellbores in Unconventional Shale Reservoirs Master Thesis, Clorado School of Mines, Golden, Clorado .

Moss, D., \& M. D. Zoback, 1990. Utilization of observations of well bore failure to constrain the orientation and magnitude of crustal stresses - Application to continental, Deep Sea Drilling Project, and Ocean Drilling Program boreholes: Journal of Geophysical Research, v. 95, no. B6, June 10, p. 9305-9325.

Olson, J.E. 2008. Multi-Fracture Propagation Modeling: Applications to Hydraulic Fracturing in Shales and Tight Gas Sands. Proc., 42nd U.S. Rock Mechanics Symposium, San Francisco, California, USA, 29 June-2 July. ARMA-08-327.

Pope, C., Benton, T., and Palisch, T. 2009. Haynesville Shale-One operator's approach to well completions in this evolving play. SPE Annual Technical Conference and Exhibition, New Orleans, LA, 4-7 October. SPE-125079-MS.

Pedrosa, O. A., Jr. 1986. Pressure Transient Response in Stress-Sensitive Formation. Presented at the 56th California Regional Meeting of the Society of Petroleum Engineers, Oakland, California, USA, 2-4 April. SPE-15115-MS.

Perkins, T.K., Kern, L.R., 1961, Widths of hydraulic fractures, Journal of Petroleum Technology, 13(9), pages: 937-49 [SPE 89]. 
Paronish, Thomas J., Shuvajit Bhattacharya , and Timothy Carr. Integrated Geologic Analysis from Two Marcellus Shale Science Wells in Northeastern West Virginia. Poster presentation given at AAPG 2016 Annual Convention and Exhibition, Calgary, Alberta, Canada, June 19-22, 2016.

Rubin, B., 2010. Accurate Simulation of Non-Darcy Flow in Stimulated Fractured Shale Reservoirs. Presented at the SPE Western Regional Meeting, Anaheim, California, USA, May 27-29. SPE-132093-MS.

Raghavan, R., and Chin, L.Y. 2004. Productivity Changes in Reservoirs with Stress-Dependent Permeability. SPE Res Eval \& Eng 7(4): 304-315. SPE88870-PA.

Raghavan, R., \& Chin, L. Y. 2002. Productivity Changes in Reservoirs With Stress-Dependent Permeability.Society of Petroleum Engineers.

Roussel, N. P. and Sharma, M. M. 2011. Optimizing Fracture Spacing and Sequencing in HorizontalWell Fracturing. SPE Prod \& Oper 26 (2): 32-36. SPE-127986-PA.

Stegent, N. A., Wagner, A. L., Mullen, J. and Borstmayer, R. E. 2010. Engineering a Successful Fracture-Simulation Treatment in the Eagle Ford Shale. presented at the SPE Tight Gas Completion Conference held in San Antonio, Texas, USA, 2-3 November. SPE-136183-MS.

Suarez-Rivera, R., Deenadayalu, C., Gathogo, P., Chertov, M. and Kunjir, R. 2011. Improving Horizontal Completions on Heterogeneous Tight Shales. Paper CSUG/SPE 146998 presented at the Canadian Unconventional Resources Conference, Calgary, Alberta, Canada, 15- 17 November.

Serajian, V. and Ghassemi, A. 2011. Hydraulic Fracture Initiation from a Wellbore in Transversely Isotropic Rock. Paper ARMA 11-201 presented at the $45^{\text {th }}$ U Rock Mechanics/Geomechanics symposium, San Francisco, Califrnia,usa, 26-29- june.

Spain, D.R., I. Gil, H. Sebastian, P.S. Smith, J. Wampler, S. Cadwallader, M. Graff. 2015. GeoEngineered completion optimization: an integrated, multidisciplinary approach to improve stimulation efficiency in unconventional shale reservoirs. SPE 172921. Presented at the SPE Middle East Unconventional resources conference and exhibition held in Muscat, Oman, 2628 January.

Settari, A. and Cleary, M.P.: "Development and Testing of a Pseudo Three-Dimensional Model of Hydraulic Fracture Geometry (P3DH)," paper SPE 10505 presented at the 1982 SPE Symposium on Reservoir Simulation, New Orleans, Jan. 31-Feb. 3.

Schmoker, J. W. (1981). Determination of organic-matter content of Appalachian Devonian shales from gamma-ray logs. AAPG Bulletin, 65(7), 1285-1298.

Schlumberger. "StimMAP Evaluation Report MIP 3H and MIP 5H Marcellus Field." Northeast Natural Energy, Adrian Morales, Asbjoern Lund Johansen, 2016, 1-287.

Slocombe, R., A. Acock, K. Fisher, A. Viswanathan, C. Chadwick, R. Reischman, and E. Wigger, 2013, Eagle Ford completion optimization using horizontal log data: Presented at the Annual Technical Conference and Exhibition. New Orleans, Louisiana, USA 30 September-2 October, 2013SPE-166242-MS.

Soliman, M. Y., East, L. and Adams, D.: "GeoMechanics Aspects of multiple Fracturing of Horizontal and Vertical Wells," paper SPE 86992 presented at the 2004 SPE. 
Stegent, N. A., Wagner, A. L., Mullen, J. and Borstmayer, R. E. 2010. Engineering a Successful Fracture-Simulation Treatment in the Eagle Ford Shale. presented at the SPE Tight Gas Completion Conference held in San Antonio, Texas, USA, 2-3 November. SPE-136183-MS.

Singh, J.L. Miskimins. 2010. A numerical study of the effects of packer-induced stresses and stress shadowing on fracture initiation and stimulation of horizontal wells. Canadian unconventional resources and international petroleum conference (2010).

Terracina, J.M., Turner, J.M., Collins, D.H., and Sillars, S.E. 2010. Proppant selection and its effect on the results of fracturing treatments performed in shale formations. SPE Annual Technical Conference and Exhibition, 19-22 September 2010, Florence, Italy. SPE 135502.

Tao, Q., Ehlig-Economides, C. A., \& Ghassemi, A. 2009, January 1. Investigation of StressDependent Permeability in Naturally Fractured Reservoirs Using a Fully Coupled Poroelastic Displacement Discontinuity Model. Presented at SPE Annual Technical Conference and Exhibition, 4-7 October, New Orleans, Louisiana. SPE-124745-MS.

Ugueto, G. A., R.T. Huckabee, M.M. Molenaar, et al. 2016. Perforation cluster efficiency of cemented plug and perf limited entry completions: insights from fiber optics diagonstics. SPE-179124MS. Presented at the SPE Hydraulic Fracturing Technology Conference held in The Woodlands, Texas, 9-11 February.

Volk, L. J., Raible, C. J., Carroll, H. B. et al. 1981. Embedment of High Strength Proppant Into LowPermeability Reservoir Rock. SPE/DOE Low Permeability Symposium, Denver, CO. 27-29 May. SPE-9867-MS.

Weary, D.J., Ryder, R.T., and Nyahay, R. 2000. Thermal Maturity Patterns (CAI and \%Ro) in the Ordovician and Devonian Rocks of the Appalachian Basin in New York State. Open File Report 00-496, U.S. Department of the Interior U.S. Geological Survey, Albany, New York.

Wilson, T. H., Carr, T., Carney, BJ., Yates, M., MacPhail, K., Morales, A., Costello, I., Hewitt, J., Jordon, E., Uschner, N., Thomas, M., Akin, S., Oluwaseun, M., Asbjoern J., Hogarth, L., Anifowoshe, O., and Naseem, K. 2018. Marcellus Shale model stimulation tests and microseismic response yield insights into mechanical properties and the reservoir DFN. Interpretation, 6(2), T231-T243. Volume 6, Issue 2 (May 2018), Society Exploration Geophysicists. https://doi.org/10.1190/int-2016-0199.1.

Wutherich, K. D., and Walker, K. J., 2012. Designing Completions in Horizontal Shale Gas Wells Perforation Strategies. Paper SPE 155485 presented at the Americas Unconventional Resources Conference, Pittsburgh, Pennsylvania, 5-7 June.

Waters G., H. J. 2006. Use of Horizontal Well Image Tools To Optimize Barnett Shale Reservoir Exploitation. Paper SPE 103202. Presented at the SPE Annual Technical Conference and Exhibition, San Antonio, Texas, September 24-27.

Walsh, J.B. 1981. Effect of pore pressure and confining pressure on fracture permeability. International Journal of Rock Mechanics and Mining Sciences\& Geomechanics Abstracts 18 (5): 429-435.

Wang, H., \& Sharma, M. M. 2017. A New Variable Compliance Method for Estimating In-Situ Stress and Leak-off from DFIT data. Paper SPE 187348 presented at the SPE Annual Technical Conference and Exhibition held in San Antonio, TX, USA, 09-11 October. 
Yu, W. and Sepehrnoori, K. 2014. Simulation of Gas Desorption and Geomechanics Effects for Unconventional Gas Reservoirs. Fuel, 116:455-464.

Yu, W., \& Sepehrnoori, K. (2014). Sensitivity Study and History Matching and Economic Optimization for Marcellus Shale. Paper URTeC 1923491, Unconventional Technology Conference, Denver, CO, August 25-27 August 2014.

Zagorski, W. A., Emery, M., \& Ventura, J. L. (2017). Chapter 5: The Marcellus Shale Play: Its Discovery and Emergence as a Major Global Hydrocarbon Accumulation. 55-90. https://doi.org/10.1306/13572001M113349.

Zagorski, W. A., Wrightstone, G. R., \& Bowman, D. C. (2012). The Appalachian Basin Marcellus Gas PlayIts History of Development, Geologic Controls on Production, and Future Potential as a World-class Reservoir. In J. A. Breyer, Shale Reservoirs - Giant Resources for the 21st Century. American Association of Petroleum Geologists. https://doi.org/10.1306/13321465M973491

Zamirian. M, 2015. New Experimental Approach to Measure Petrophysical Properties of OrganicRich Shales.Ph.D. Dissertation, West Virginia University, Morgantown, WV (2015)

Zhang, J., Kamenov, A., Zhu, D., Hill, A.D. 2013. Laboratory Measurement of Hydraulic Fracture Conductivities in The Barnett Shale. SPE Hydraulic Fracturing Technology Conference, The Woodlands, Texas, USA, 2013. SPE-163839-PA.

Zoback, M.D., 2007. Reservoir Geomechanics: Earth Stress and Rock Mechanics Applied to Exploration, Production and Wellbore Stability. Cambridge University Press. 


\section{Appendix A}

\section{TREATING PRESSURE PLOTS FOR WELL MIP-6H}




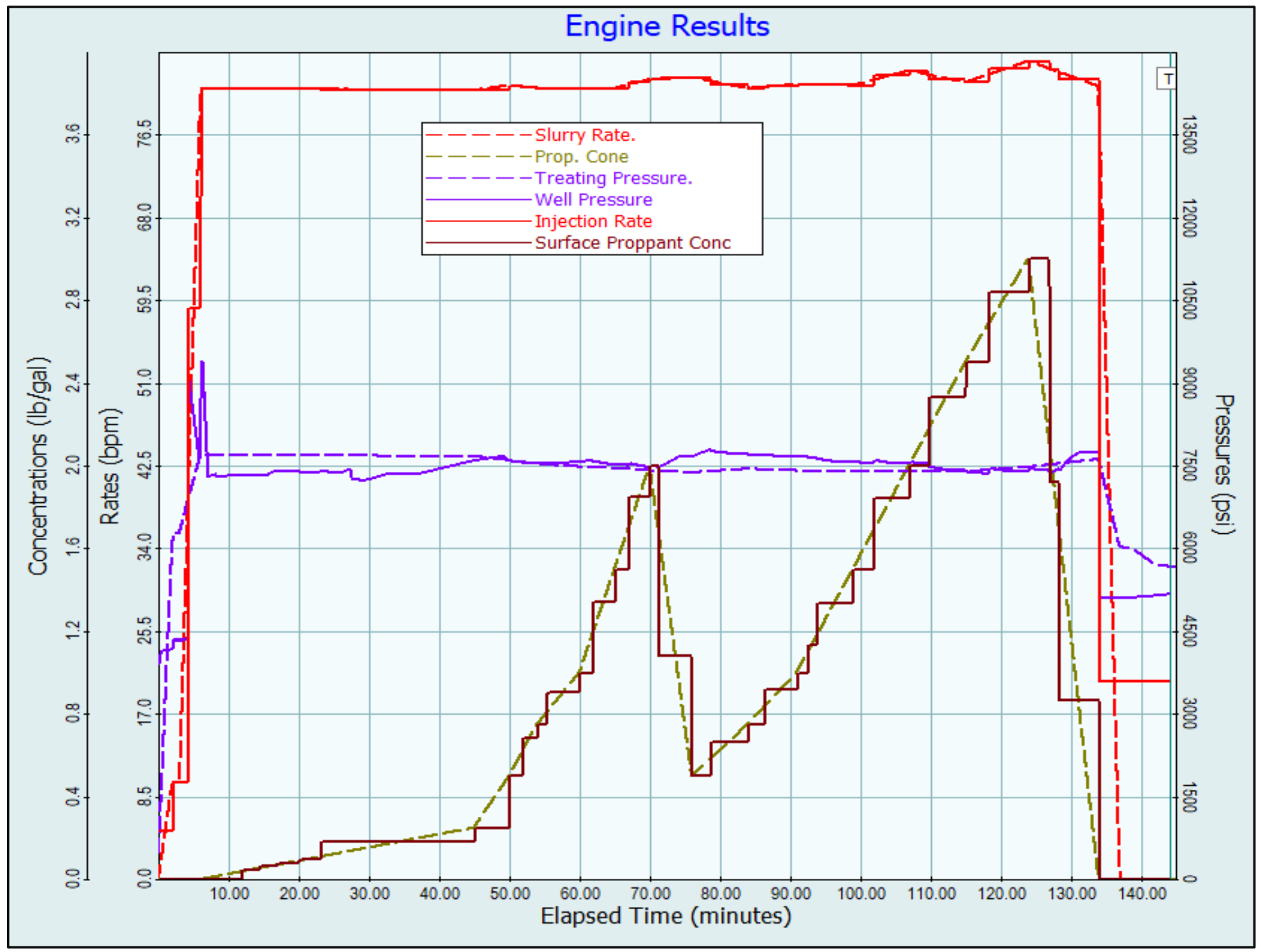

Figure A. 1: Sage 1 treatment data with a matched pressure between model and actual values. Dotted pressure curve represents the actual surface treating pressure (surface pressure in the plot legend), whereas the connected pressure curve represents the model surface treating pressure (well pressure in the plot legend). 


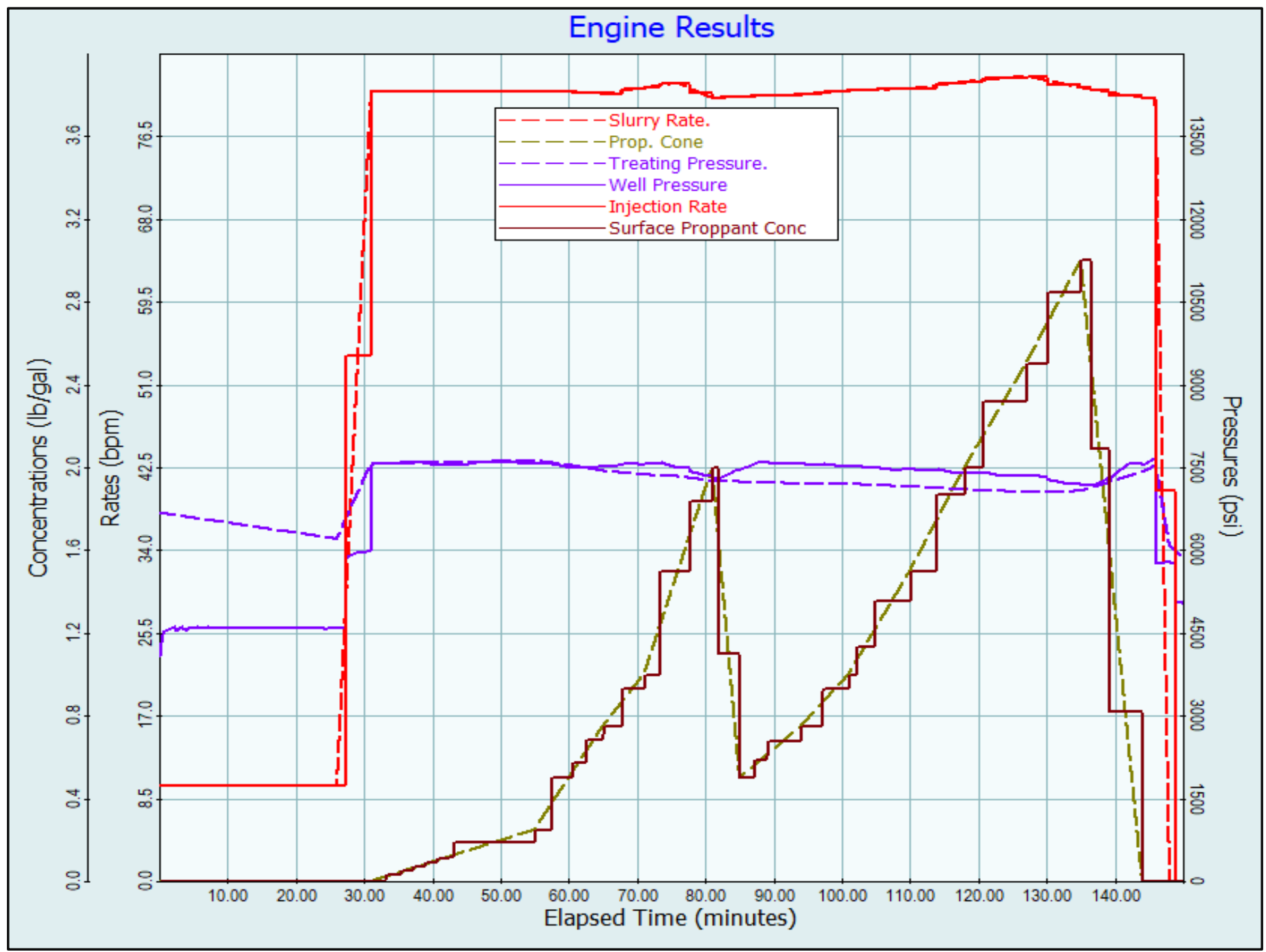

Figure A. 2: Sage 2 treatment data with a matched pressure between model and actual values. Dotted pressure curve represents the actual surface treating pressure (surface pressure in the plot legend), whereas the connected pressure curve represents the model surface treating pressure (well pressure in the plot legend). 


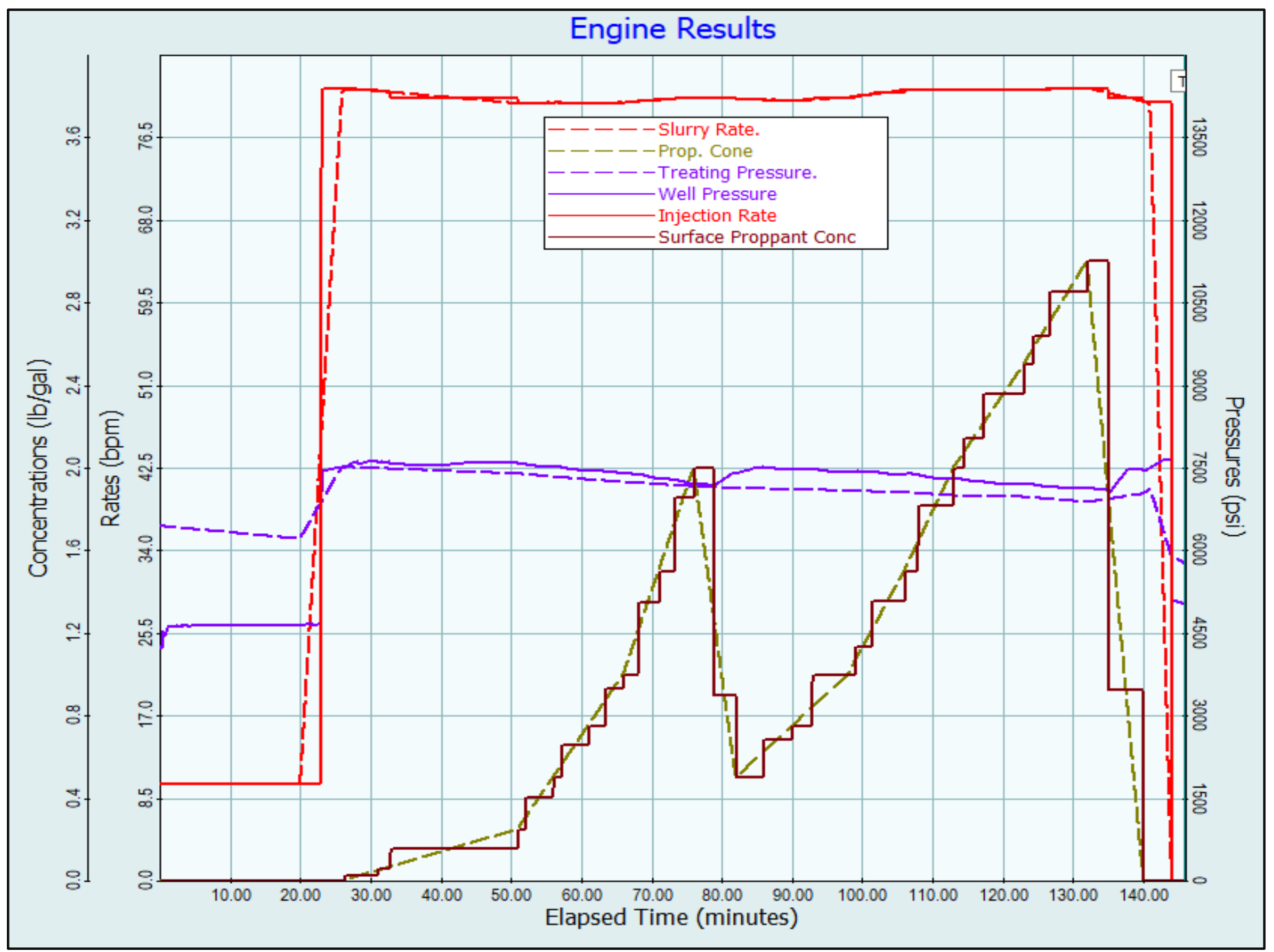

Figure A. 3: Sage 3 treatment data with a matched pressure between model and actual values. Dotted pressure curve represents the actual surface treating pressure (surface pressure in the plot legend), whereas the connected pressure curve represents the model surface treating pressure (well pressure in the plot legend). 


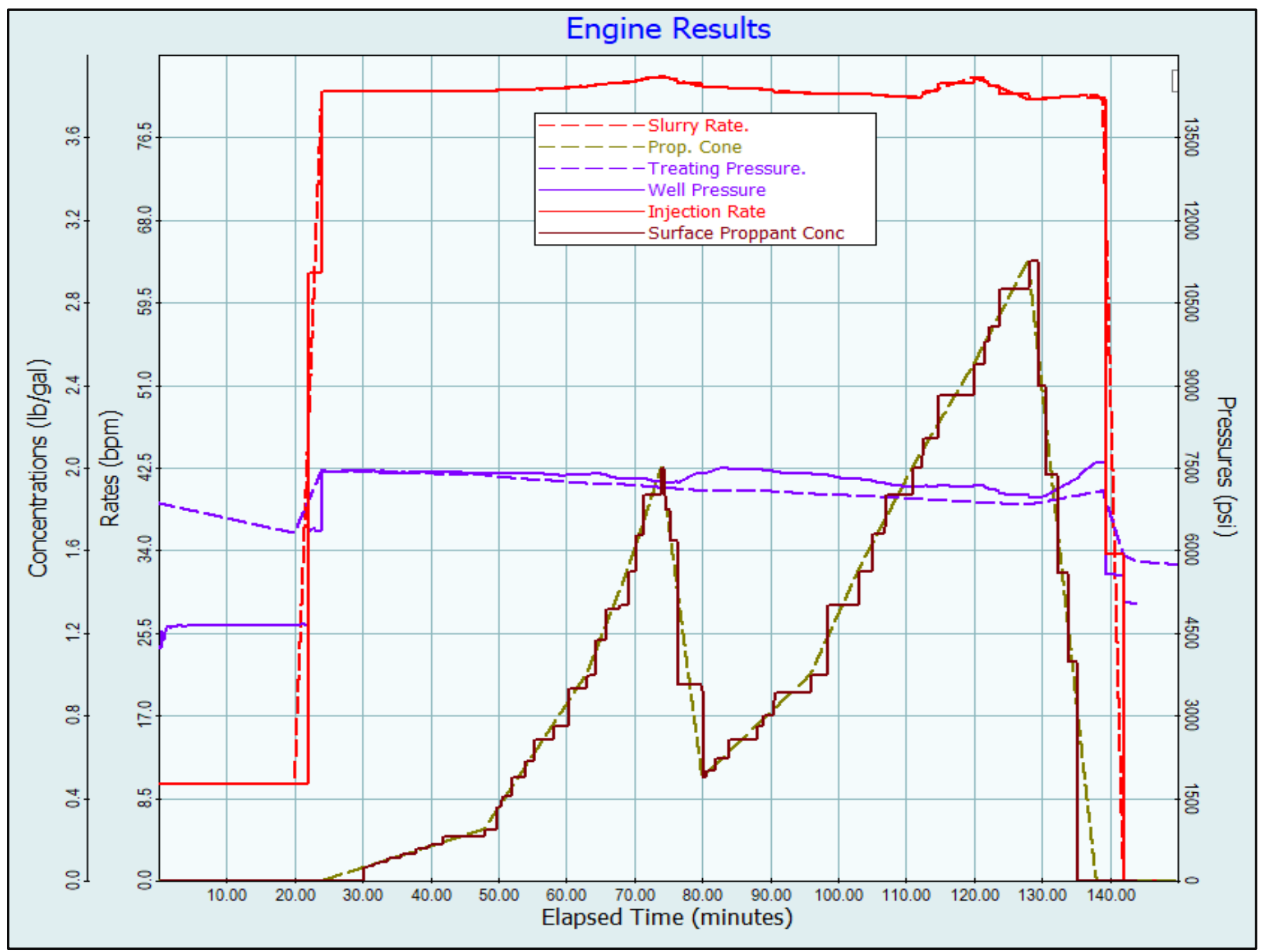

Figure A. 4: Sage 4 treatment data with a matched pressure between model and actual values. Dotted pressure curve represents the actual surface treating pressure (surface pressure in the plot legend), whereas the connected pressure curve represents the model surface treating pressure (well pressure in the plot legend). 


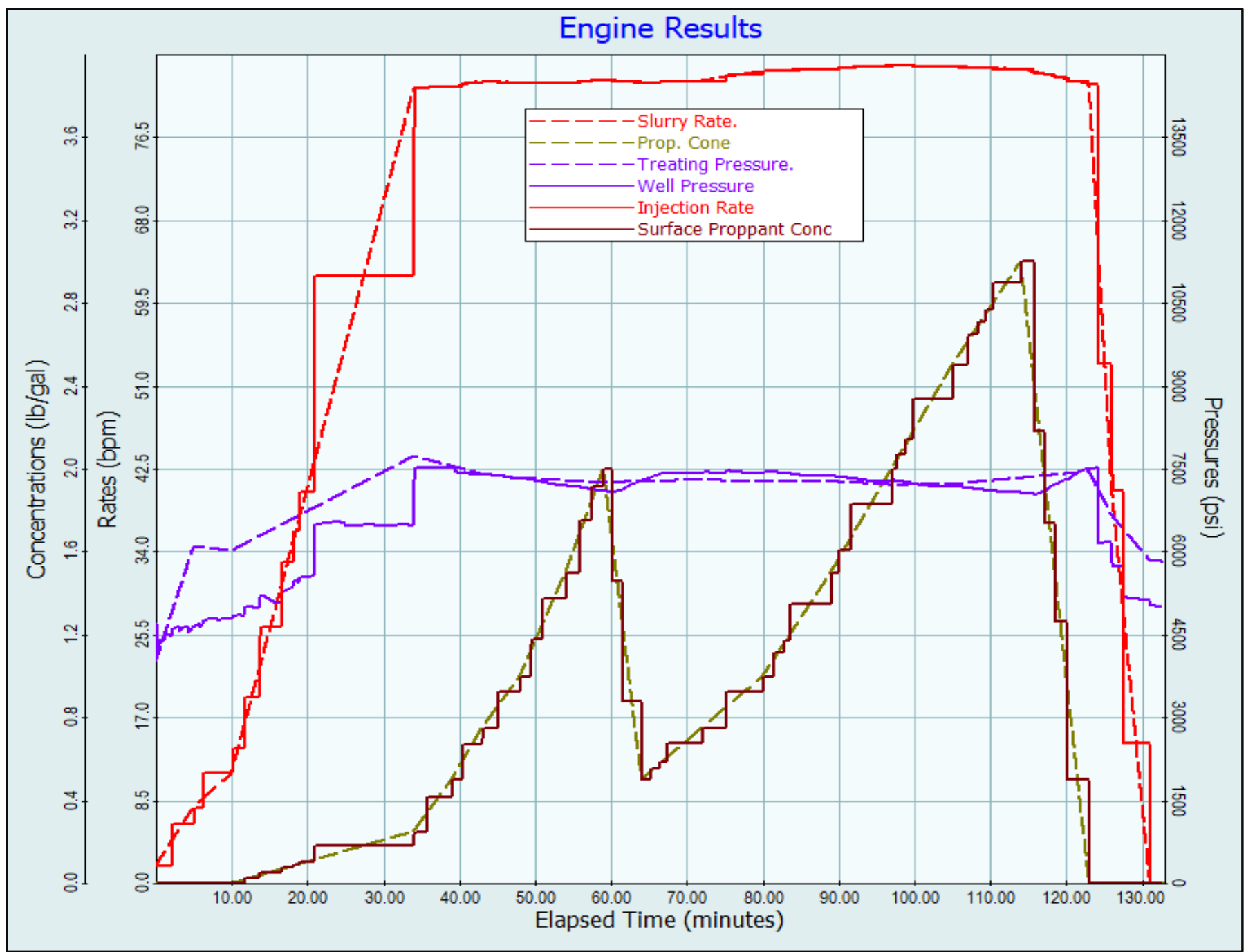

Figure A. 5: Sage 5 treatment data with a matched pressure between model and actual values. Dotted pressure curve represents the actual surface treating pressure (surface pressure in the plot legend), whereas the connected pressure curve represents the model surface treating pressure (well pressure in the plot legend). 


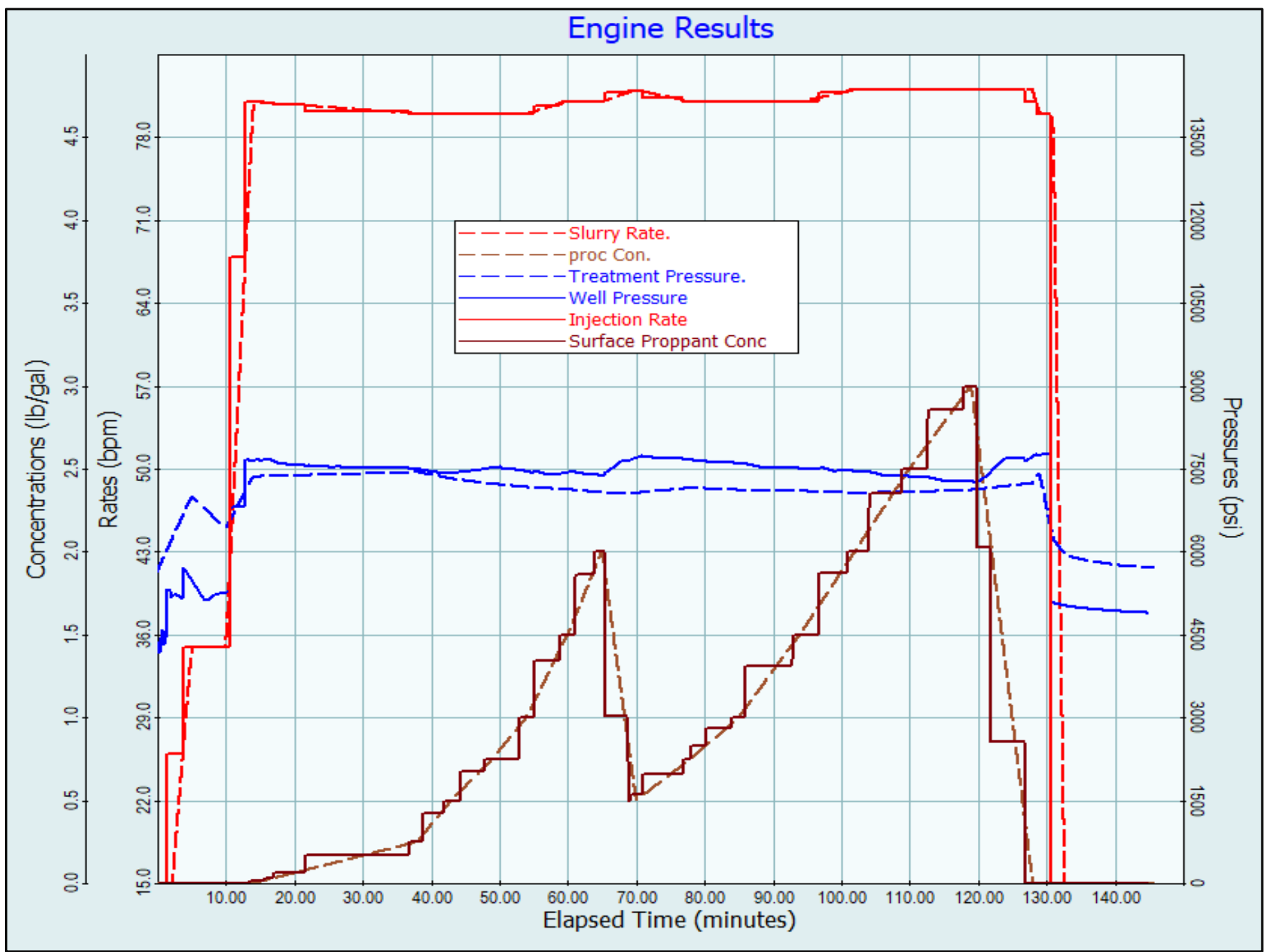

Figure A. 6: Sage 6 treatment data with a matched pressure between model and actual values. Dotted pressure curve represents the actual surface treating pressure (surface pressure in the plot legend), whereas the connected pressure curve represents the model surface treating pressure (well pressure in the plot legend). 


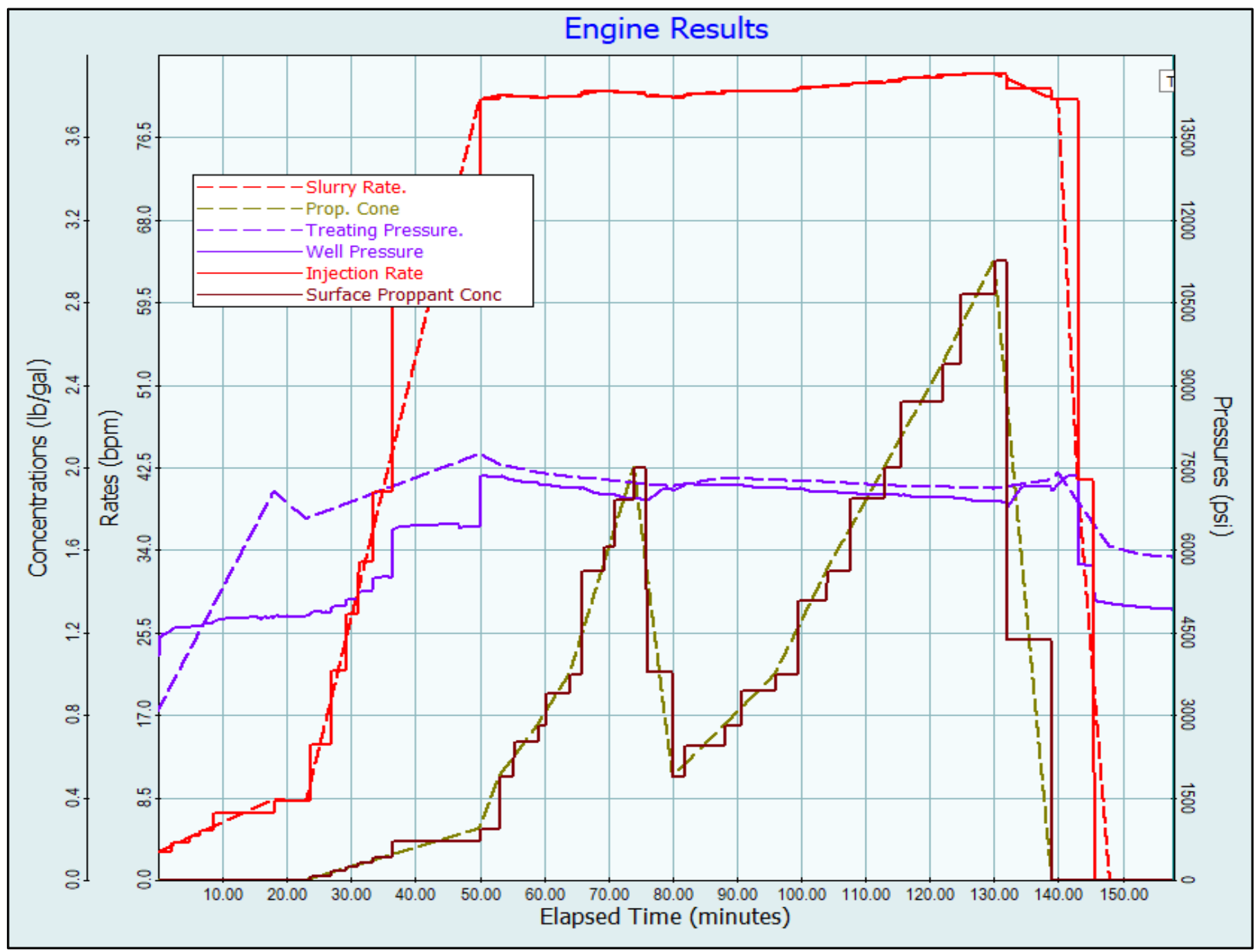

Figure A. 7: Sage 7 treatment data with a matched pressure between model and actual values.

Dotted pressure curve represents the actual surface treating pressure (surface pressure in the plot legend), whereas the connected pressure curve represents the model surface treating pressure (well pressure in the plot legend). 


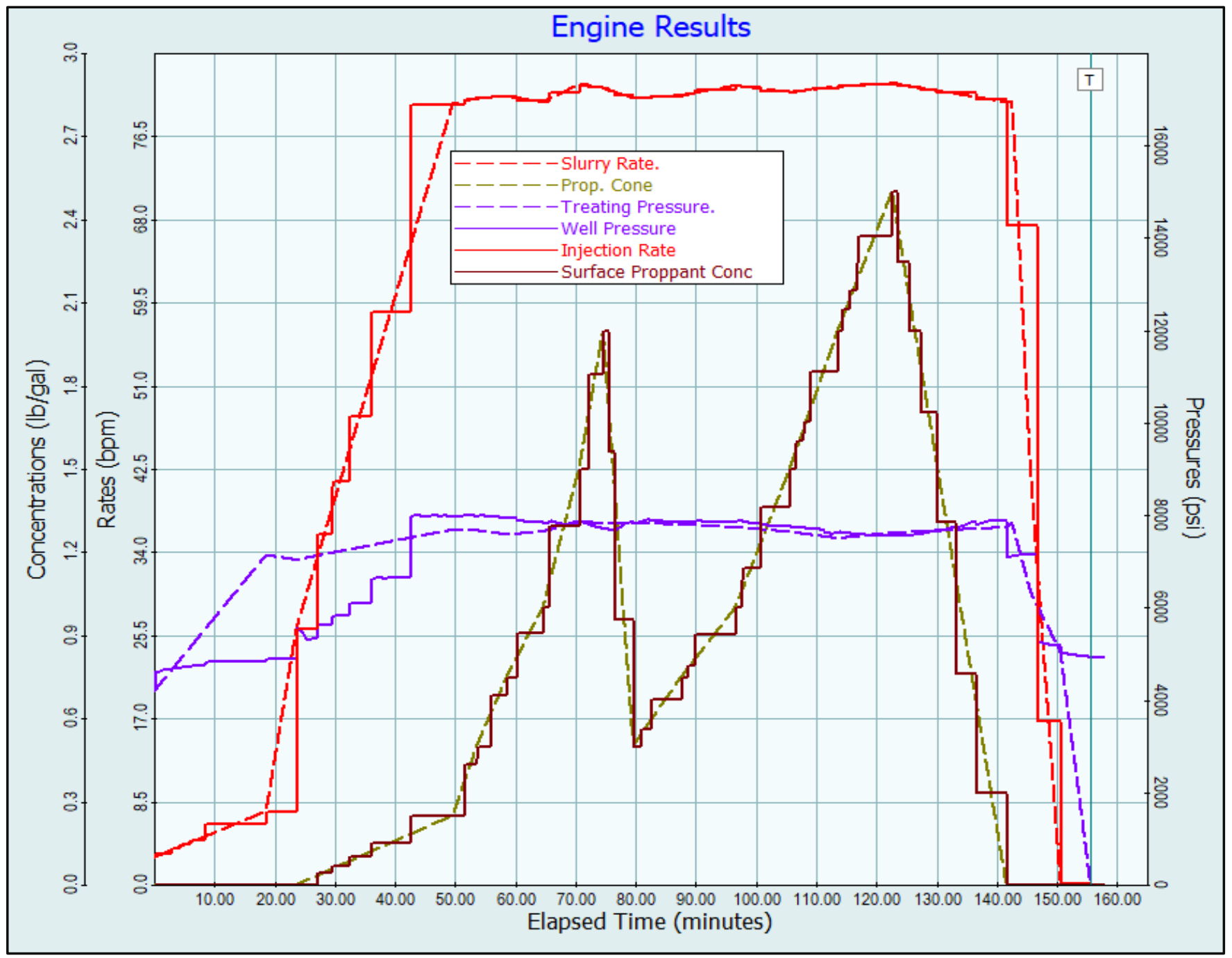

Figure A. 8: Sage 8 treatment data with a matched pressure between model and actual values. Dotted pressure curve represents the actual surface treating pressure (surface pressure in the plot legend), whereas the connected pressure curve represents the model surface treating pressure (well pressure in the plot legend). 
TREATING PRESSURE PLOTS FOR WELL MIP-3H 


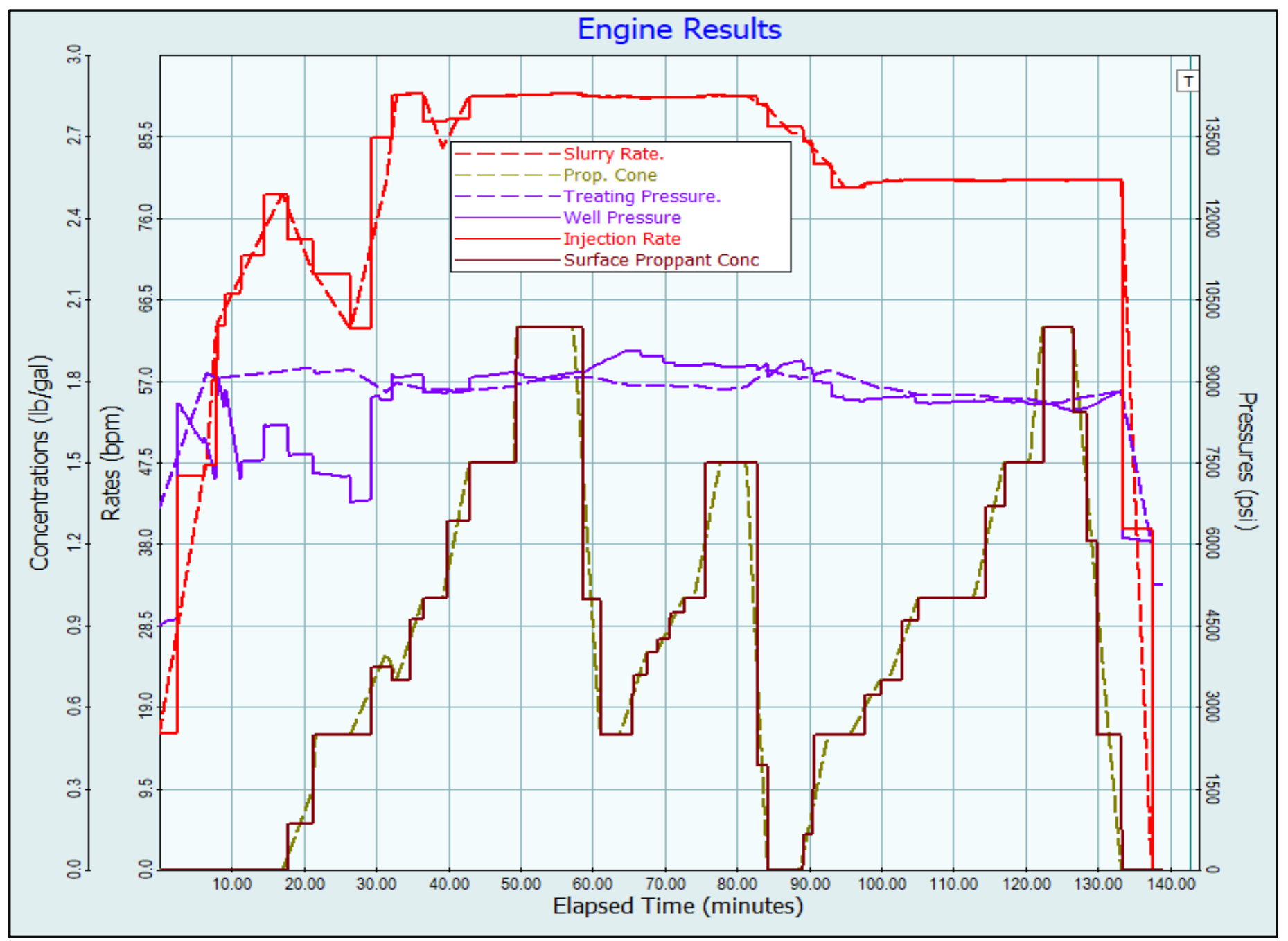

Figure A. 9: Sage 1 treatment data with a matched pressure between model and actual values. Dotted pressure curve represents the actual surface treating pressure (surface pressure in the plot legend), whereas the connected pressure curve represents the model surface treating pressure (well pressure in the plot legend). 


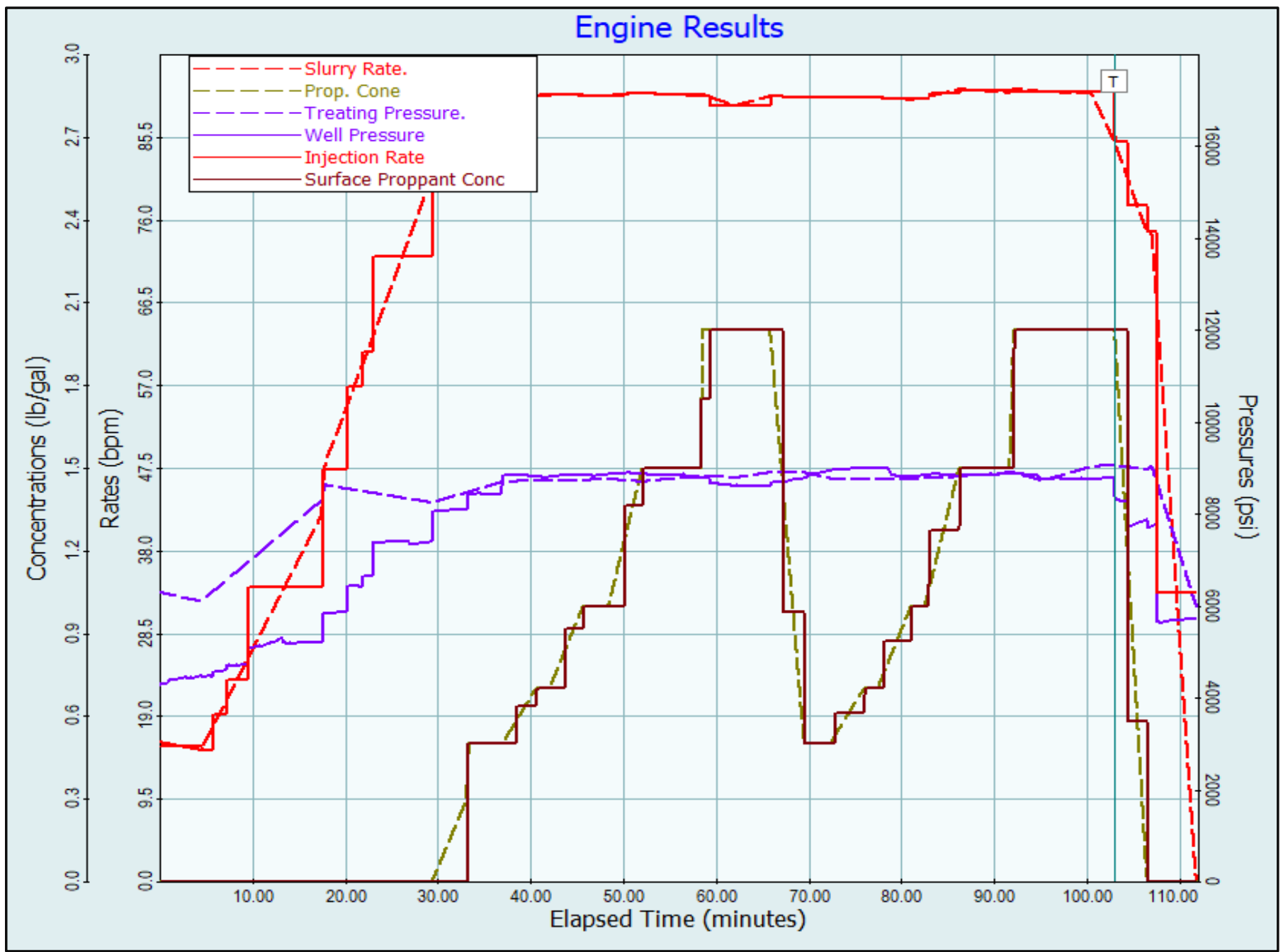

Figure A. 10: Sage 2 treatment data with a matched pressure between model and actual values. Dotted pressure curve represents the actual surface treating pressure (surface pressure in the plot legend), whereas the connected pressure curve represents the model surface treating pressure (well pressure in the plot legend). 


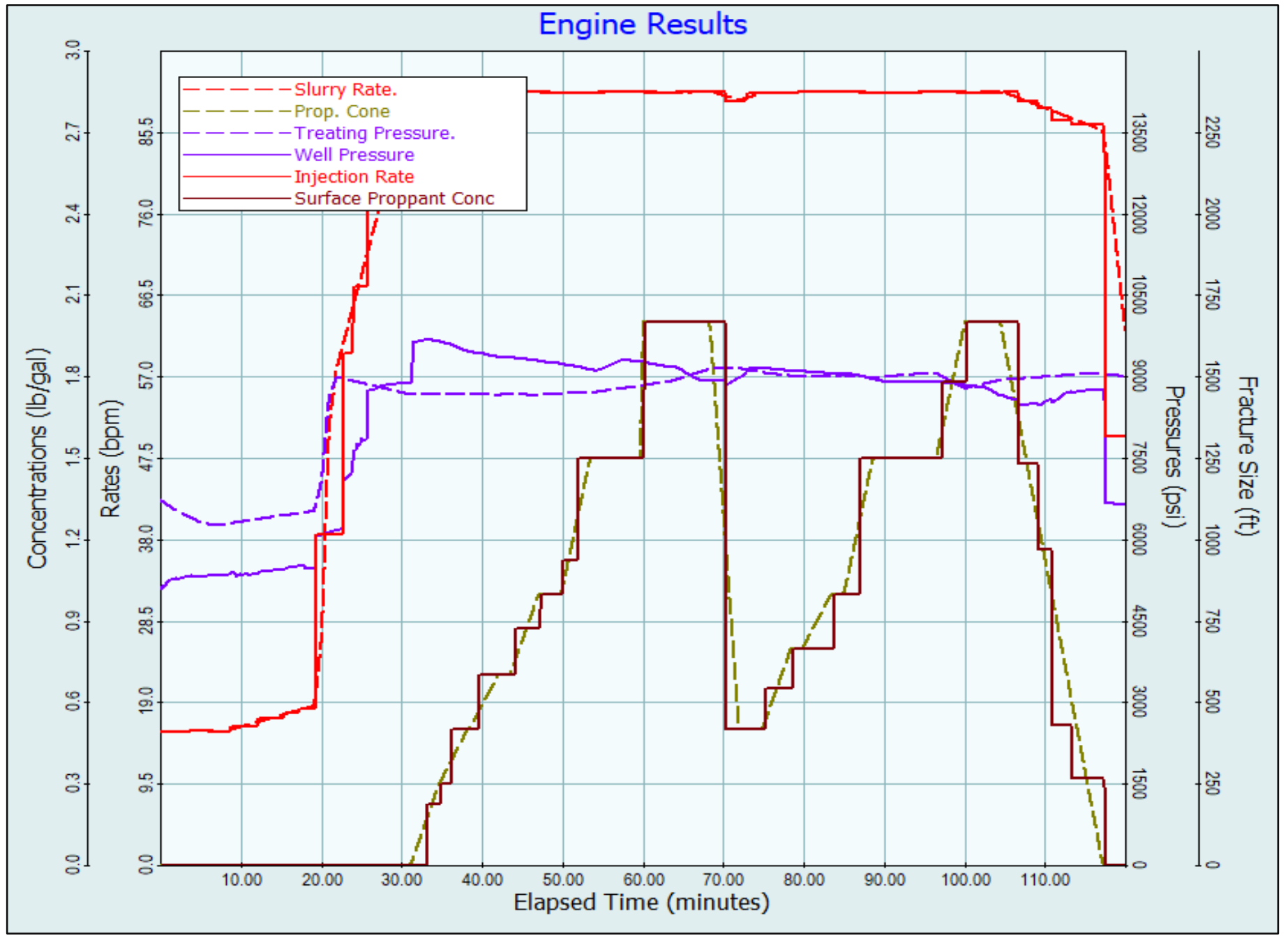

Figure A. 11: Sage 3 treatment data with a matched pressure between model and actual values. Dotted pressure curve represents the actual surface treating pressure (surface pressure in the plot legend), whereas the connected pressure curve represents the model surface treating pressure (well pressure in the plot legend). 


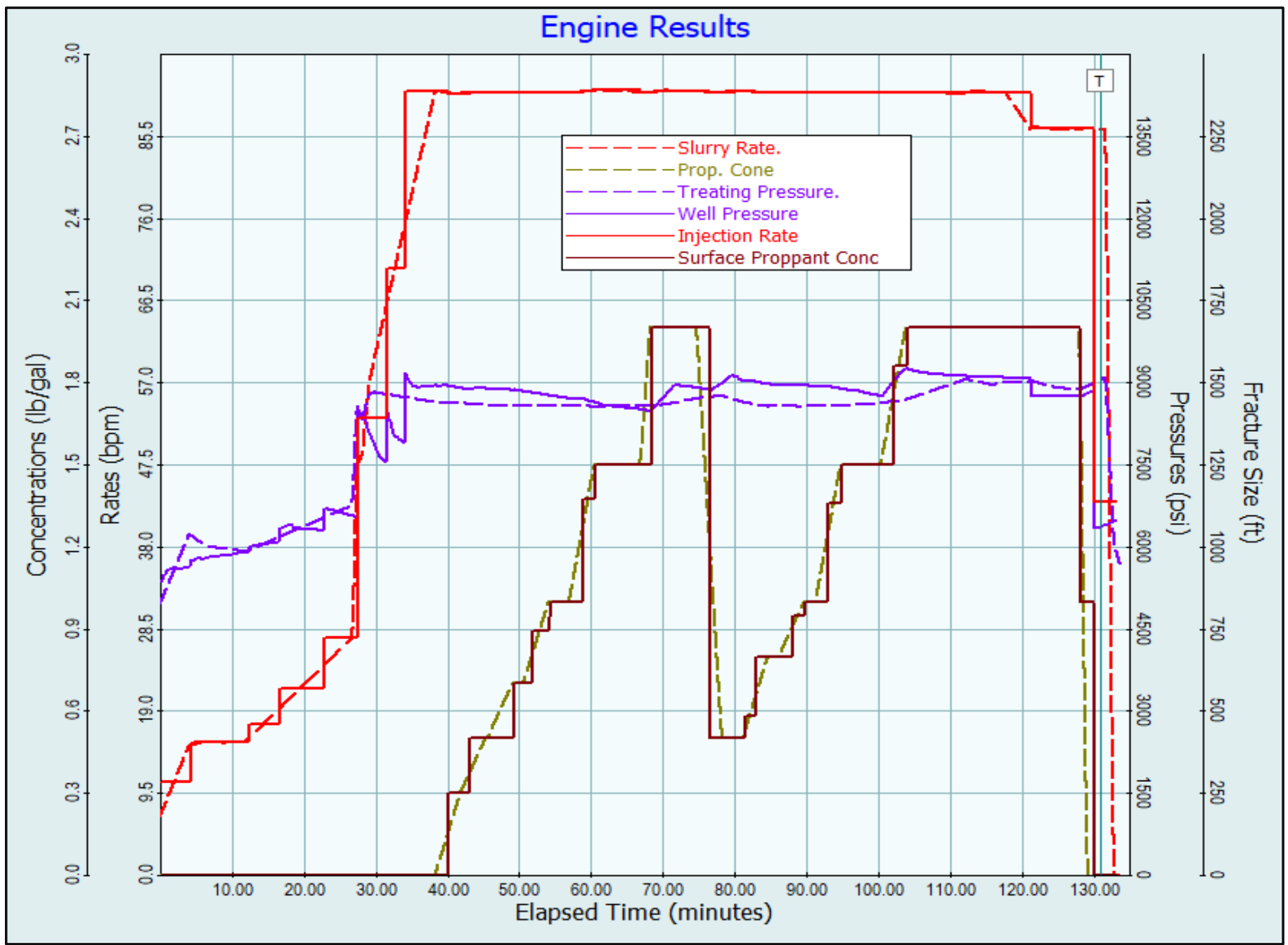

Figure A. 12: Sage 4 treatment data with a matched pressure between model and actual values. Dotted pressure curve represents the actual surface treating pressure (surface pressure in the plot legend), whereas the connected pressure curve represents the model surface treating pressure (well pressure in the plot legend). 


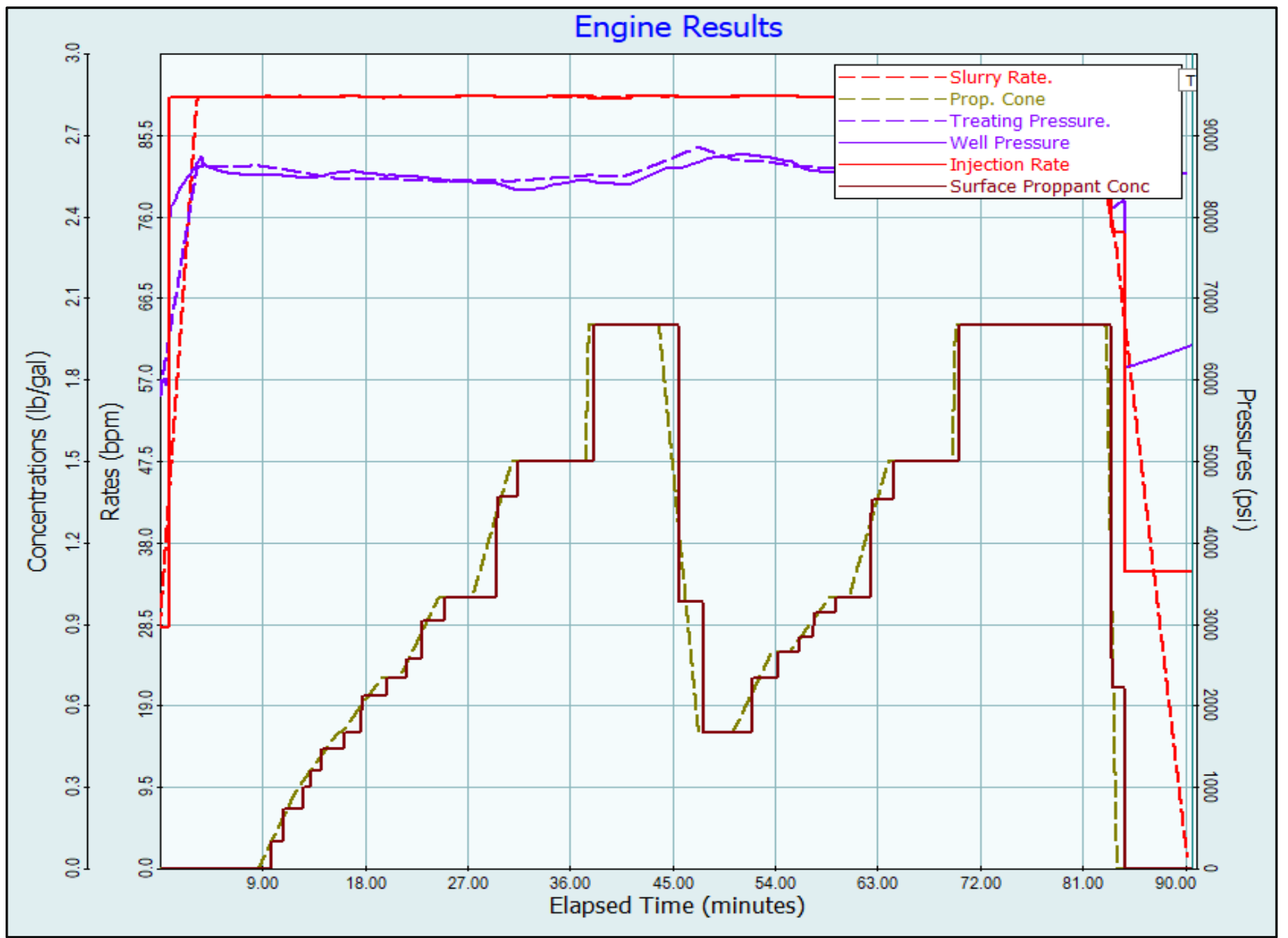

Figure A. 13: Sage 5 treatment data with a matched pressure between model and actual values. Dotted pressure curve represents the actual surface treating pressure (surface pressure in the plot legend), whereas the connected pressure curve represents the model surface treating pressure (well pressure in the plot legend). 


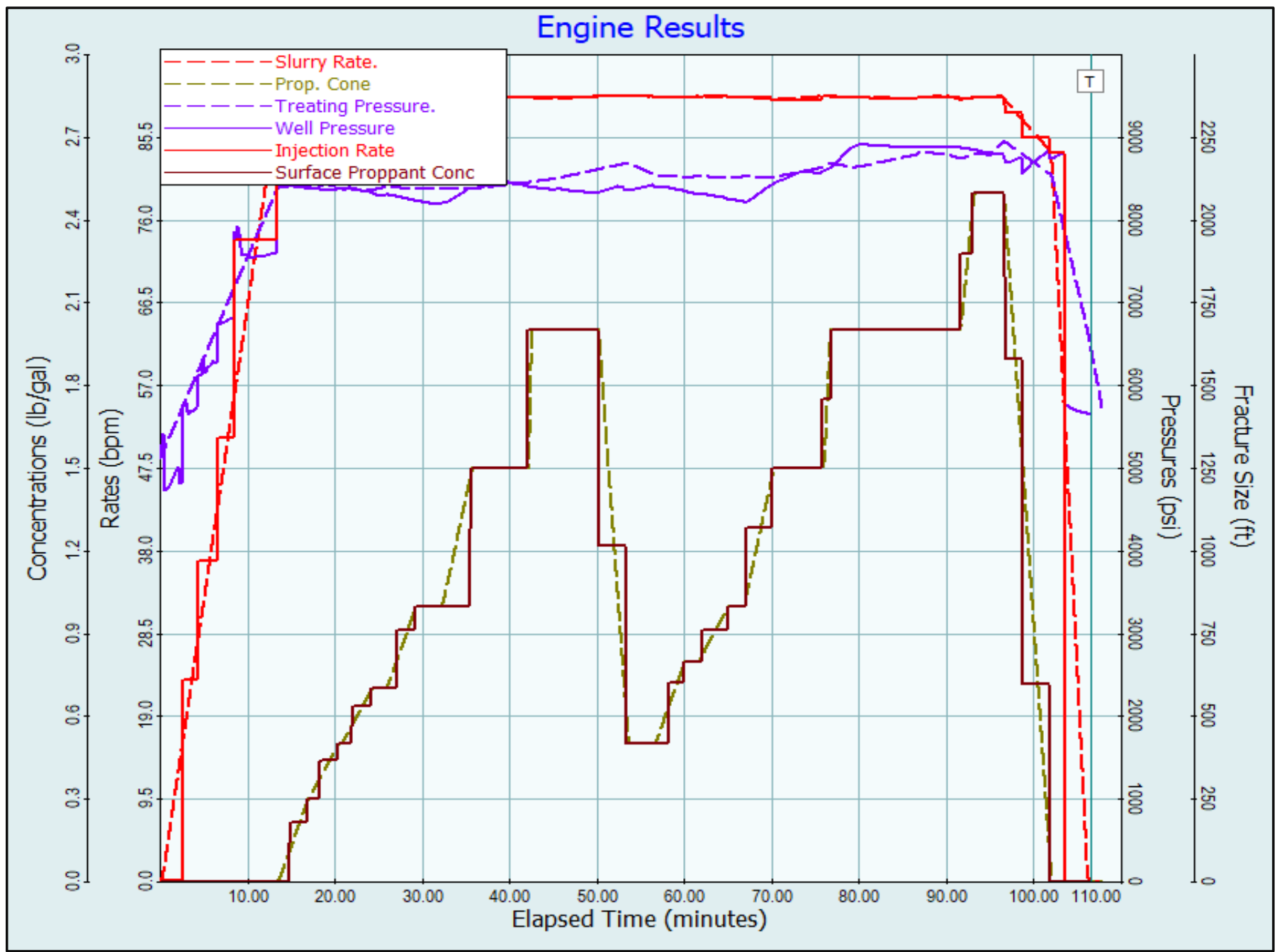

Figure A. 14: Sage 6 treatment data with a matched pressure between model and actual values. Dotted pressure curve represents the actual surface treating pressure (surface pressure in the plot legend), whereas the connected pressure curve represents the model surface treating pressure (well pressure in the plot legend). 


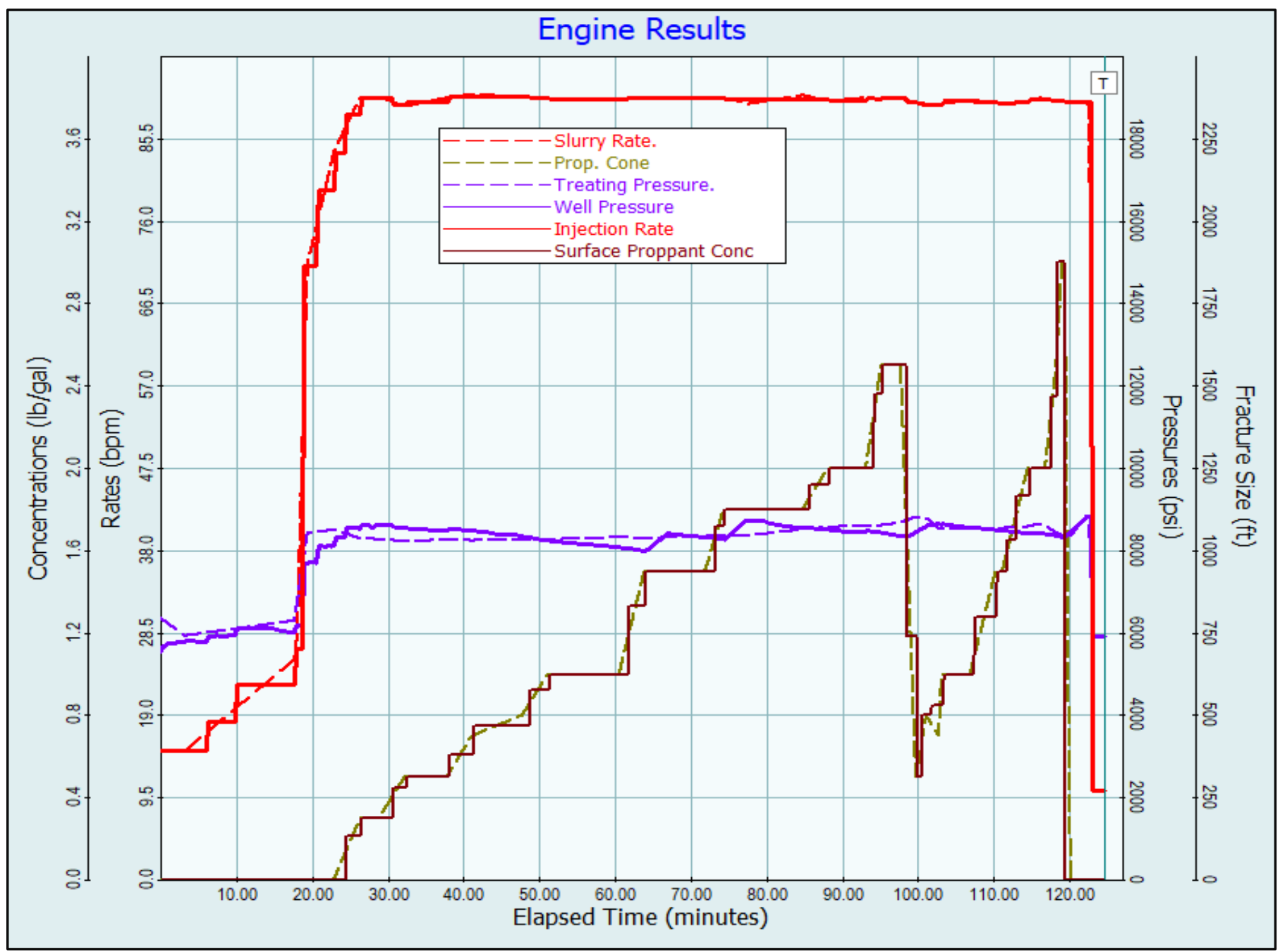

Figure A. 15: Sage 7 treatment data with a matched pressure between model and actual values. Dotted pressure curve represents the actual surface treating pressure (surface pressure in the plot legend), whereas the connected pressure curve represents the model surface treating pressure (well pressure in the plot legend). 


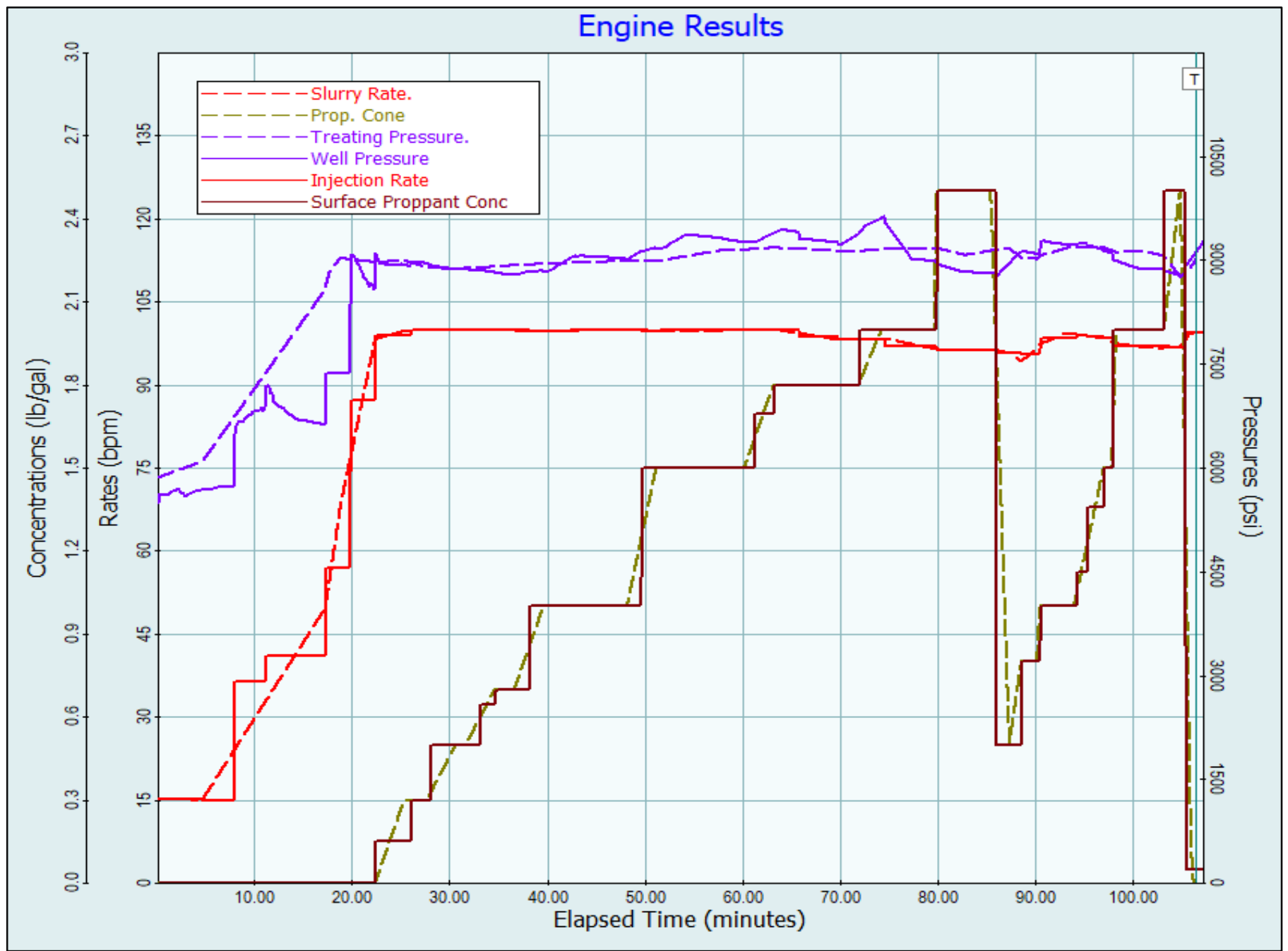

Figure A. 16: Sage 8 treatment data with a matched pressure between model and actual values. Dotted pressure curve represents the actual surface treating pressure (surface pressure in the plot legend), whereas the connected pressure curve represents the model surface treating pressure (well pressure in the plot legend). 


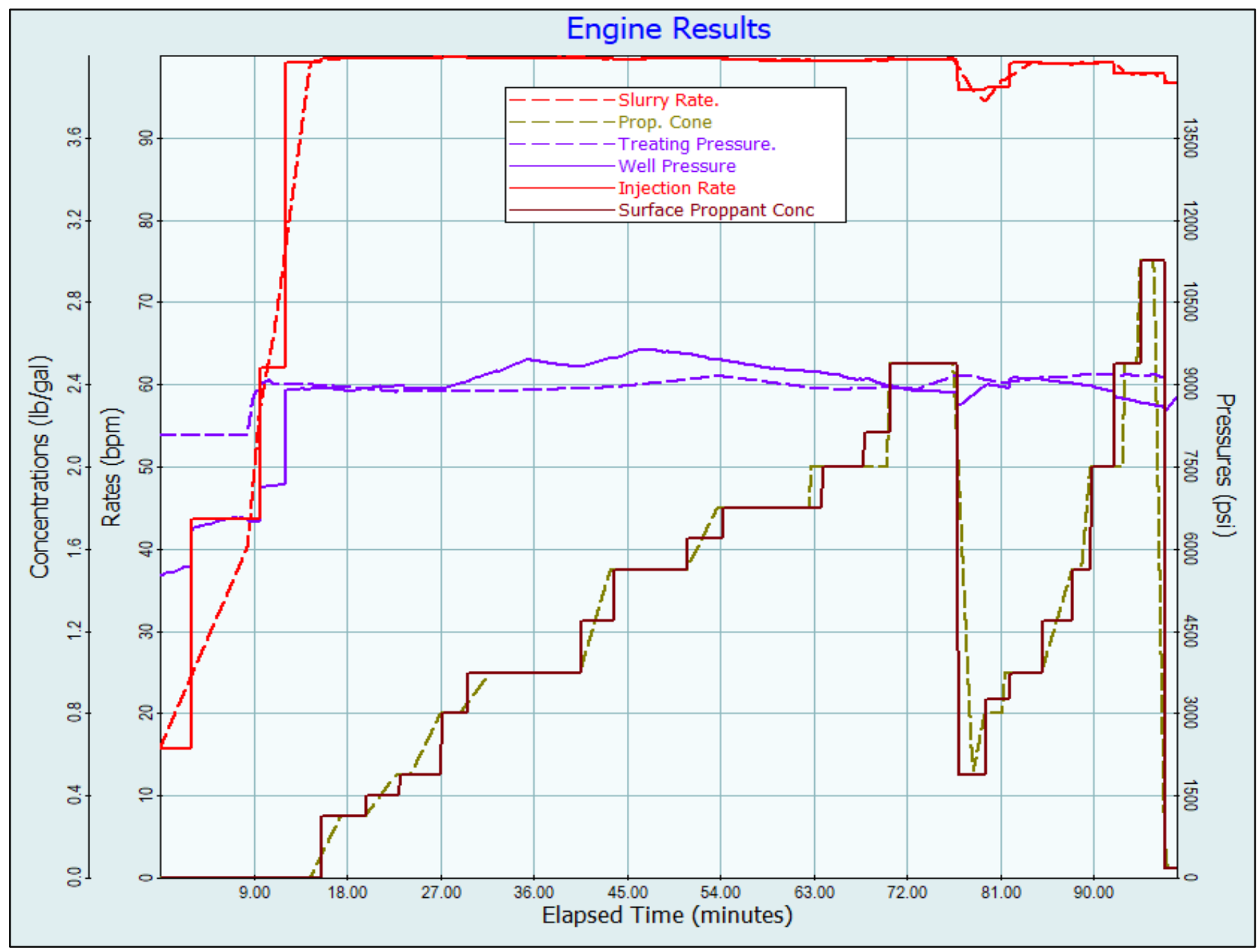

Figure A. 17: Sage 9 treatment data with a matched pressure between model and actual values. Dotted pressure curve represents the actual surface treating pressure (surface pressure in the plot legend), whereas the connected pressure curve represents the model surface treating pressure (well pressure in the plot legend). 


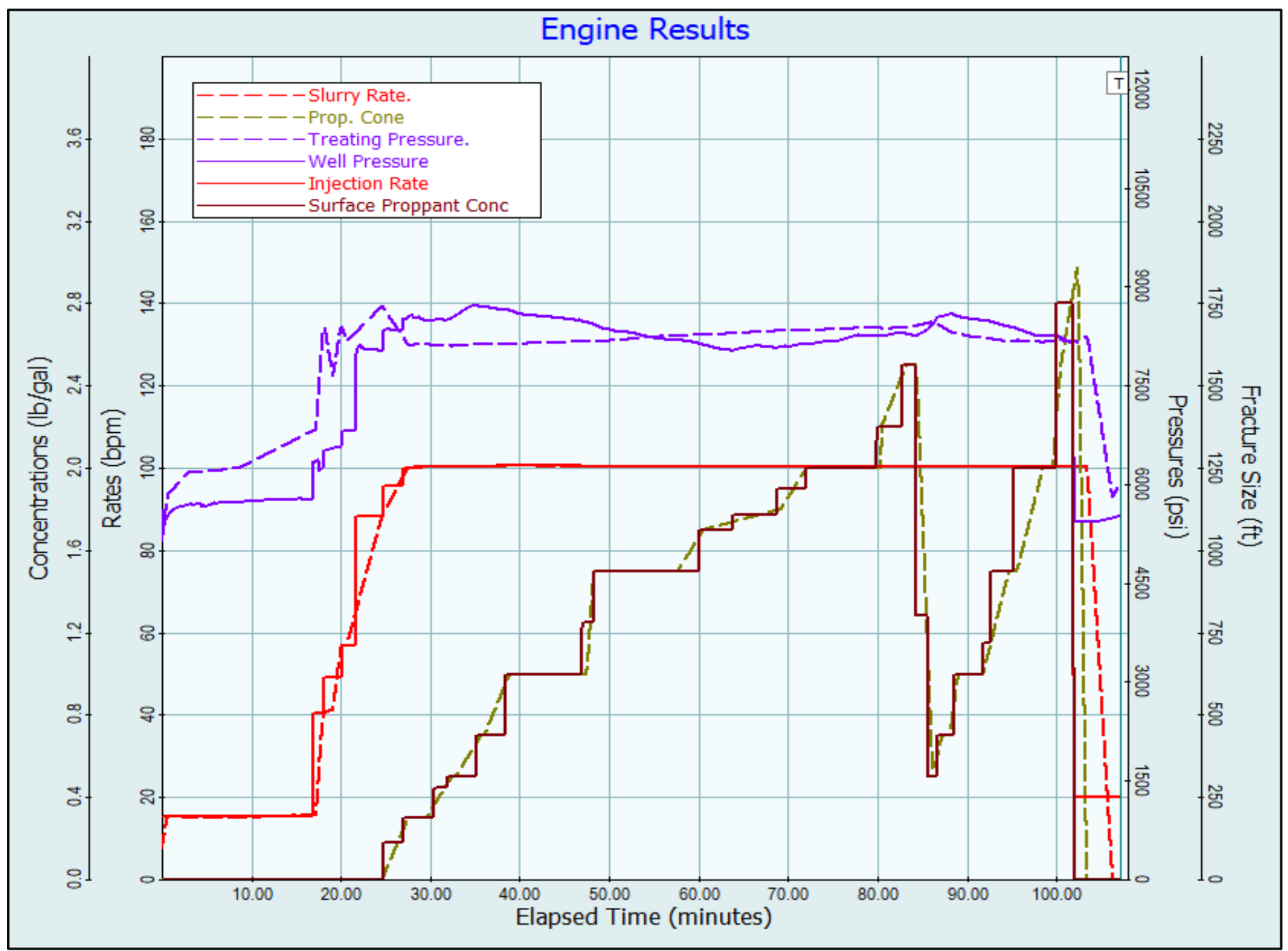

Figure A. 18: Sage 10 treatment data with a matched pressure between model and actual values. Dotted pressure curve represents the actual surface treating pressure (surface pressure in the plot legend), whereas the connected pressure curve represents the model surface treating pressure (well pressure in the plot legend). 


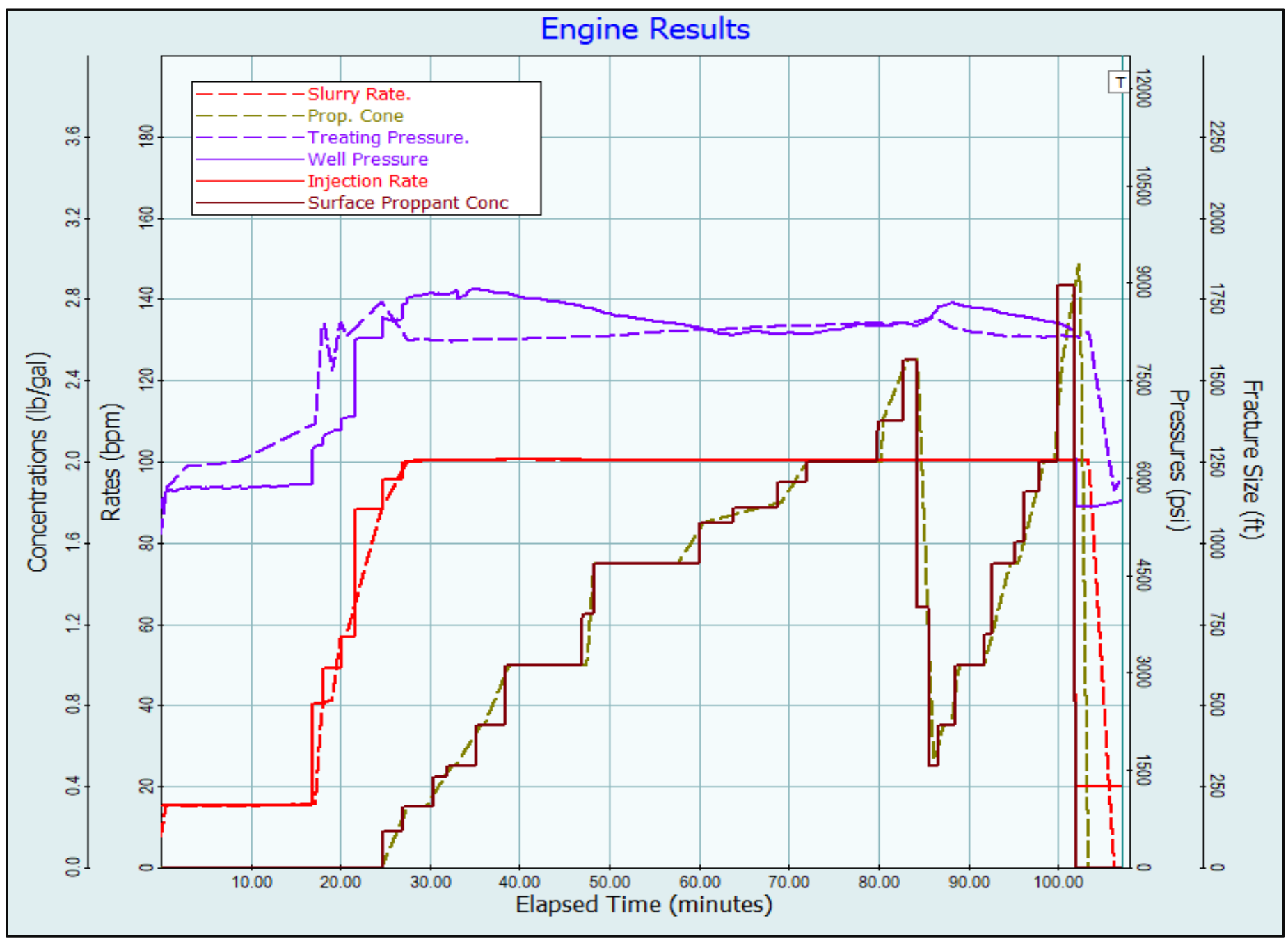

Figure A. 19: Sage 11 treatment data with a matched pressure between model and actual values. Dotted pressure curve represents the actual surface treating pressure (surface pressure in the plot legend), whereas the connected pressure curve represents the model surface treating pressure (well pressure in the plot legend). 


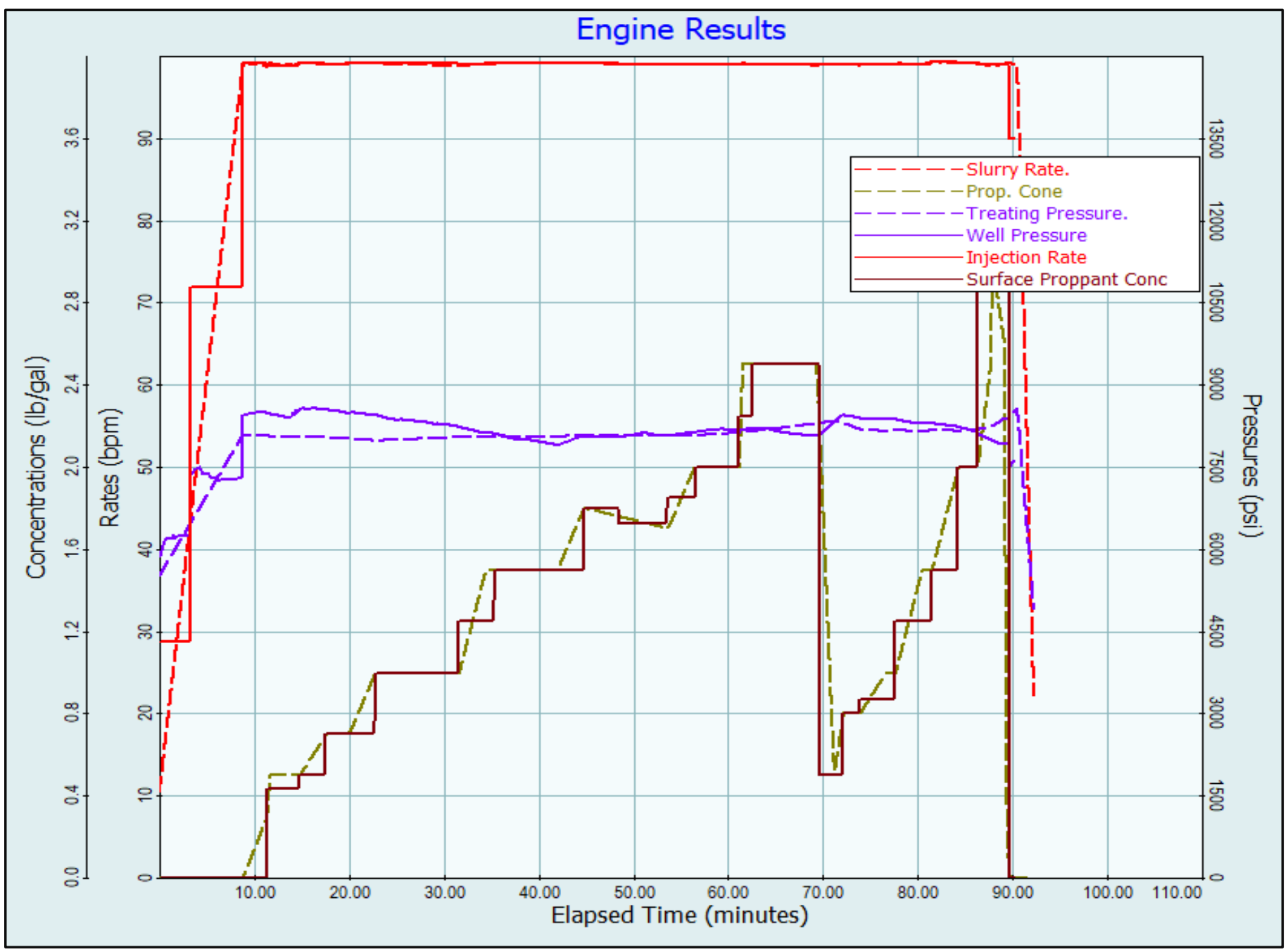

Figure A. 20: Sage 12 treatment data with a matched pressure between model and actual values. Dotted pressure curve represents the actual surface treating pressure (surface pressure in the plot legend), whereas the connected pressure curve represents the model surface treating pressure (well pressure in the plot legend). 


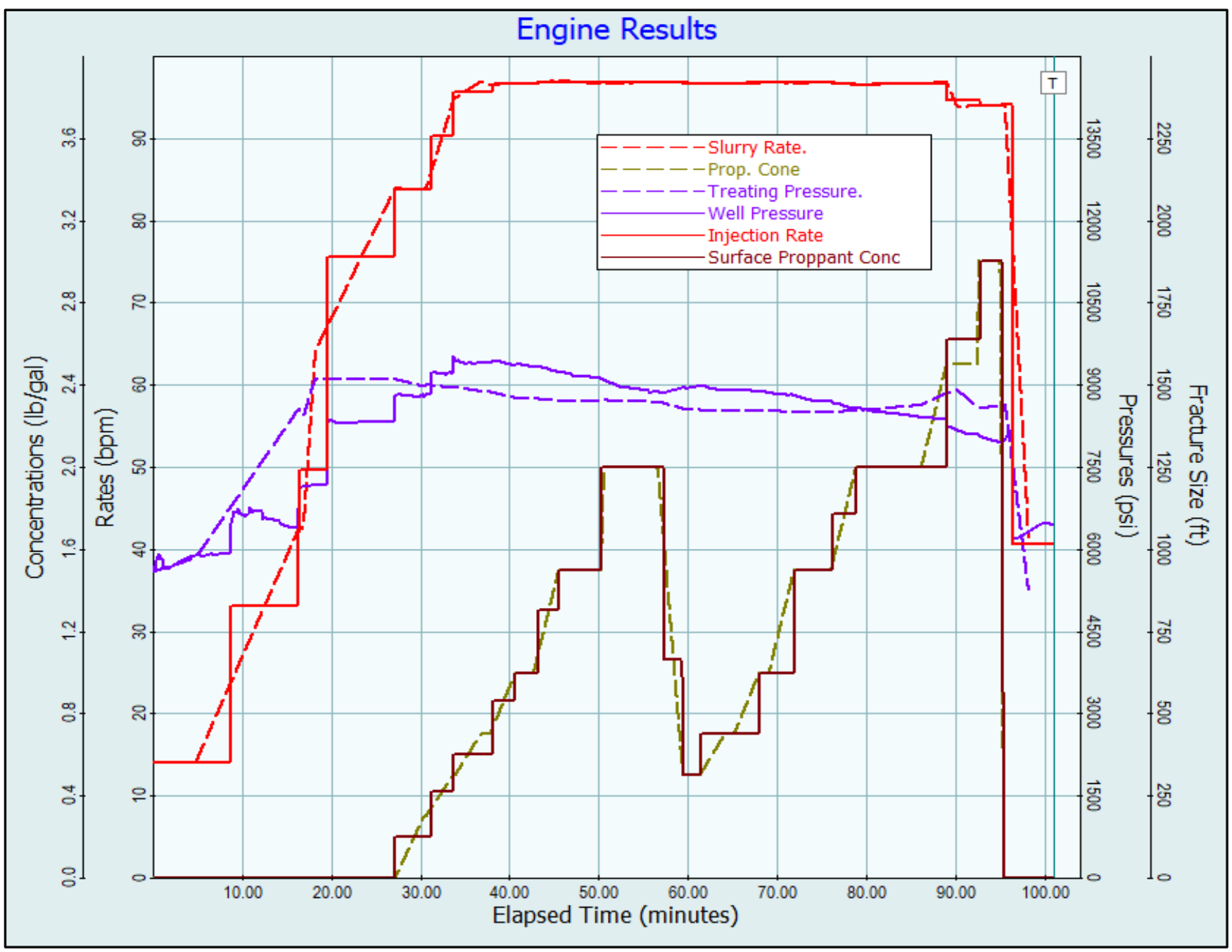

Figure A. 21: Sage 13 treatment data with a matched pressure between model and actual values. Dotted pressure curve represents the actual surface treating pressure (surface pressure in the plot legend), whereas the connected pressure curve represents the model surface treating pressure (well pressure in the plot legend). 


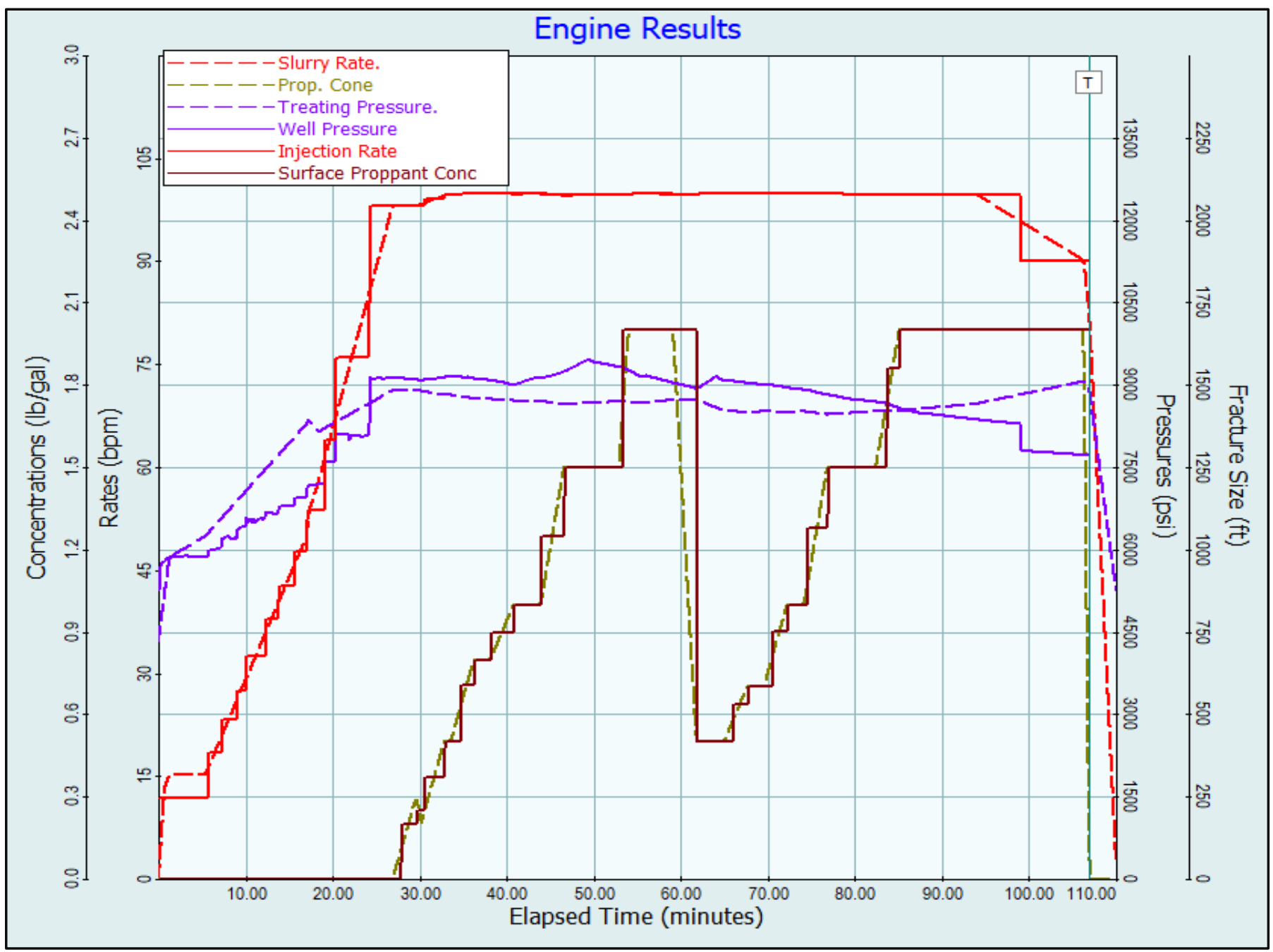

Figure A. 22: Sage 14 treatment data with a matched pressure between model and actual values. Dotted pressure curve represents the actual surface treating pressure (surface pressure in the plot legend), whereas the connected pressure curve represents the model surface treating pressure (well pressure in the plot legend). 


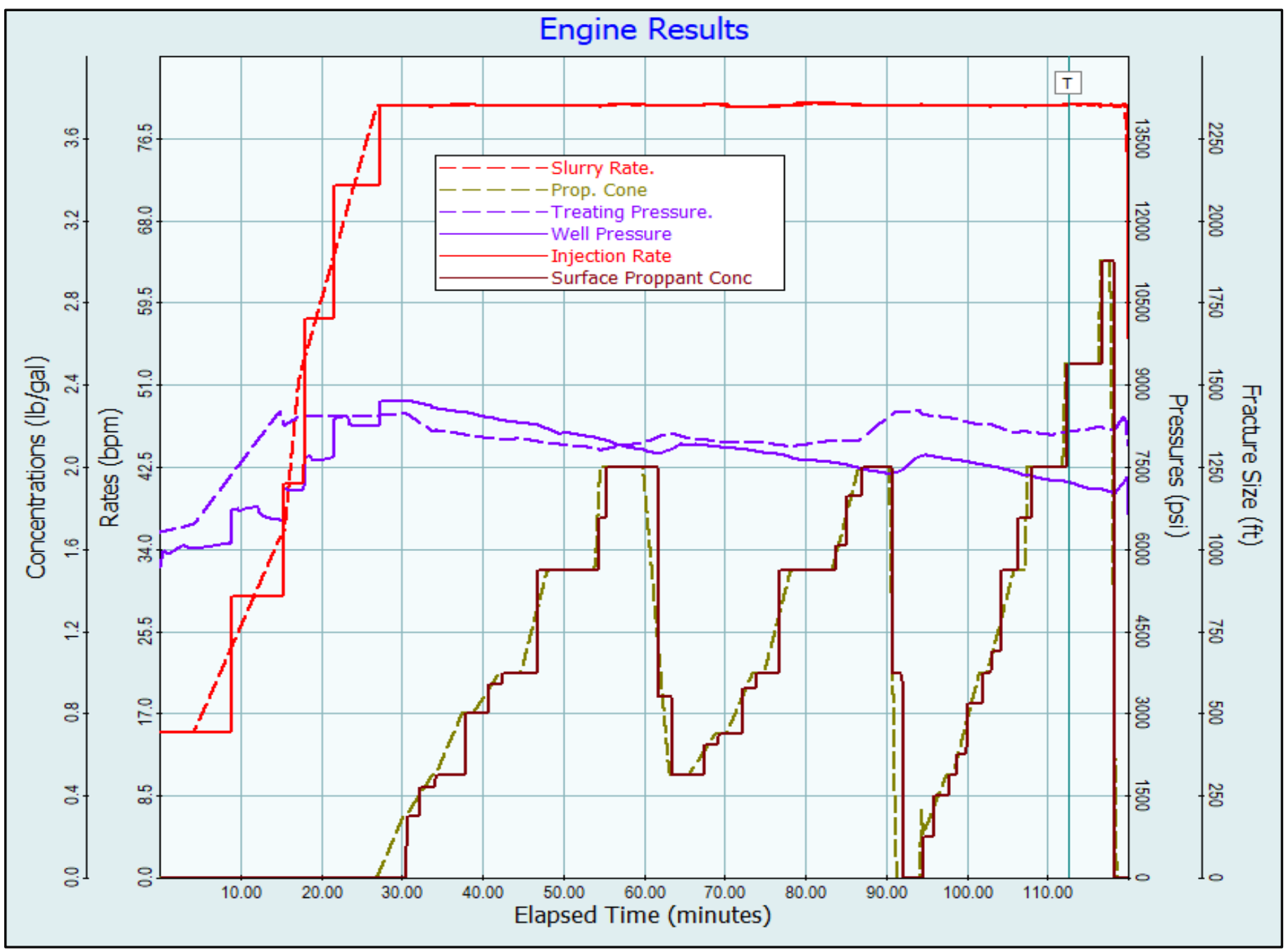

Figure A. 23: Sage 15 treatment data with a matched pressure between model and actual values. Dotted pressure curve represents the actual surface treating pressure (surface pressure in the plot legend), whereas the connected pressure curve represents the model surface treating pressure (well pressure in the plot legend). 


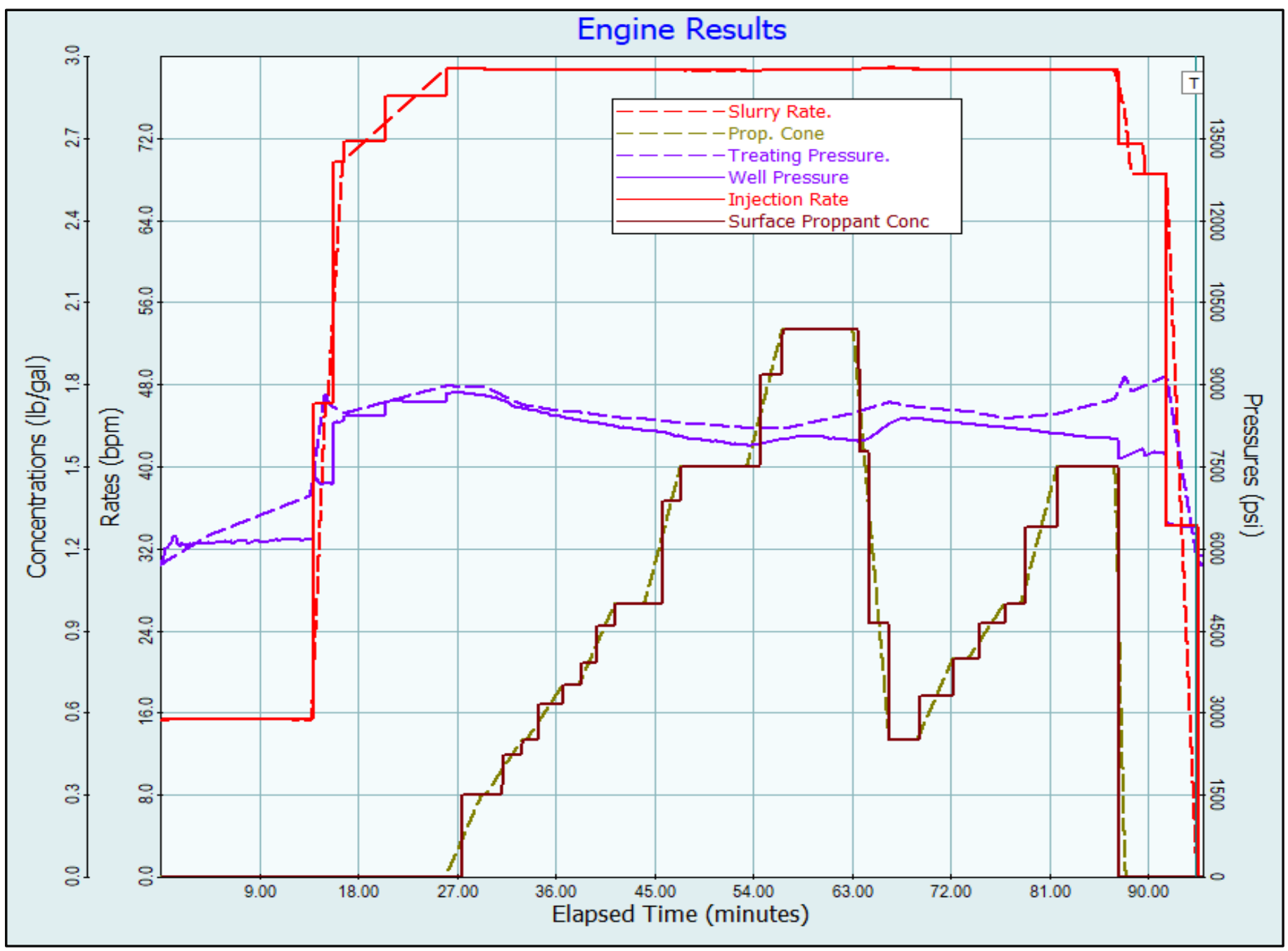

Figure A. 24: Sage 16 treatment data with a matched pressure between model and actual values. Dotted pressure curve represents the actual surface treating pressure (surface pressure in the plot legend), whereas the connected pressure curve represents the model surface treating pressure (well pressure in the plot legend). 


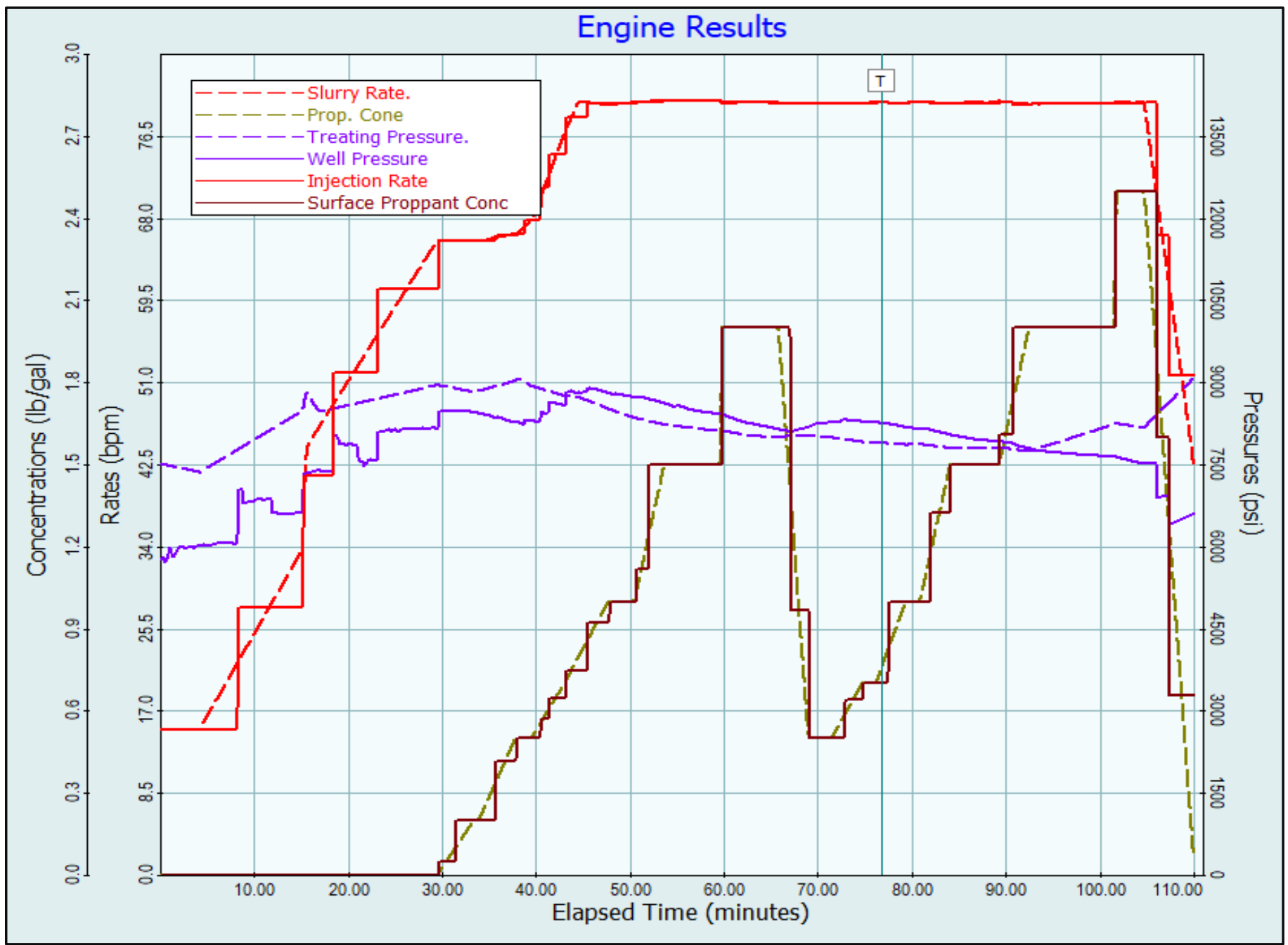

Figure A. 25: Sage 17 treatment data with a matched pressure between model and actual values. Dotted pressure curve represents the actual surface treating pressure (surface pressure in the plot legend), whereas the connected pressure curve represents the model surface treating pressure (well pressure in the plot legend). 


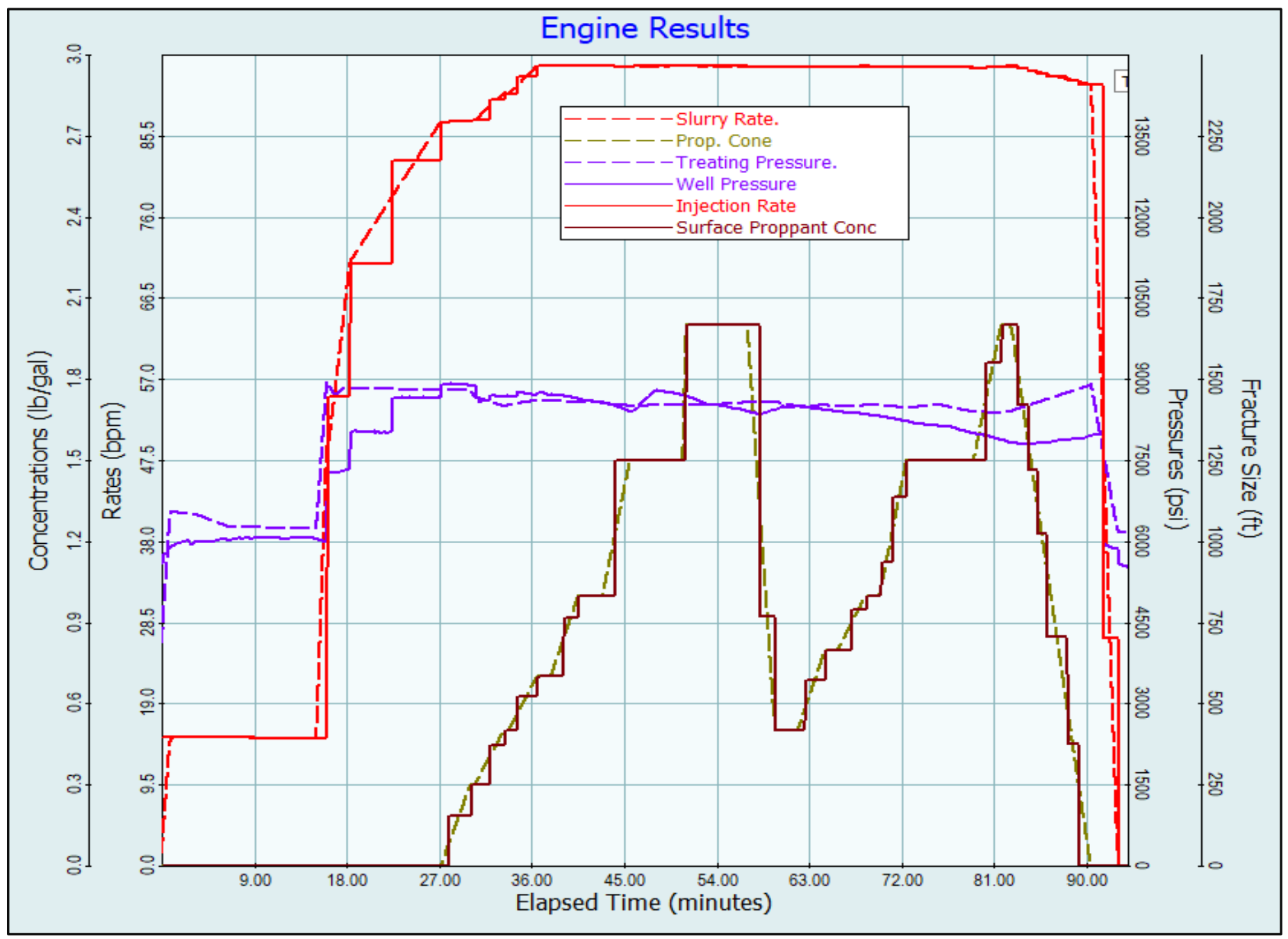

Figure A. 26: Sage 18 treatment data with a matched pressure between model and actual values. Dotted pressure curve represents the actual surface treating pressure (surface pressure in the plot legend), whereas the connected pressure curve represents the model surface treating pressure (well pressure in the plot legend). 


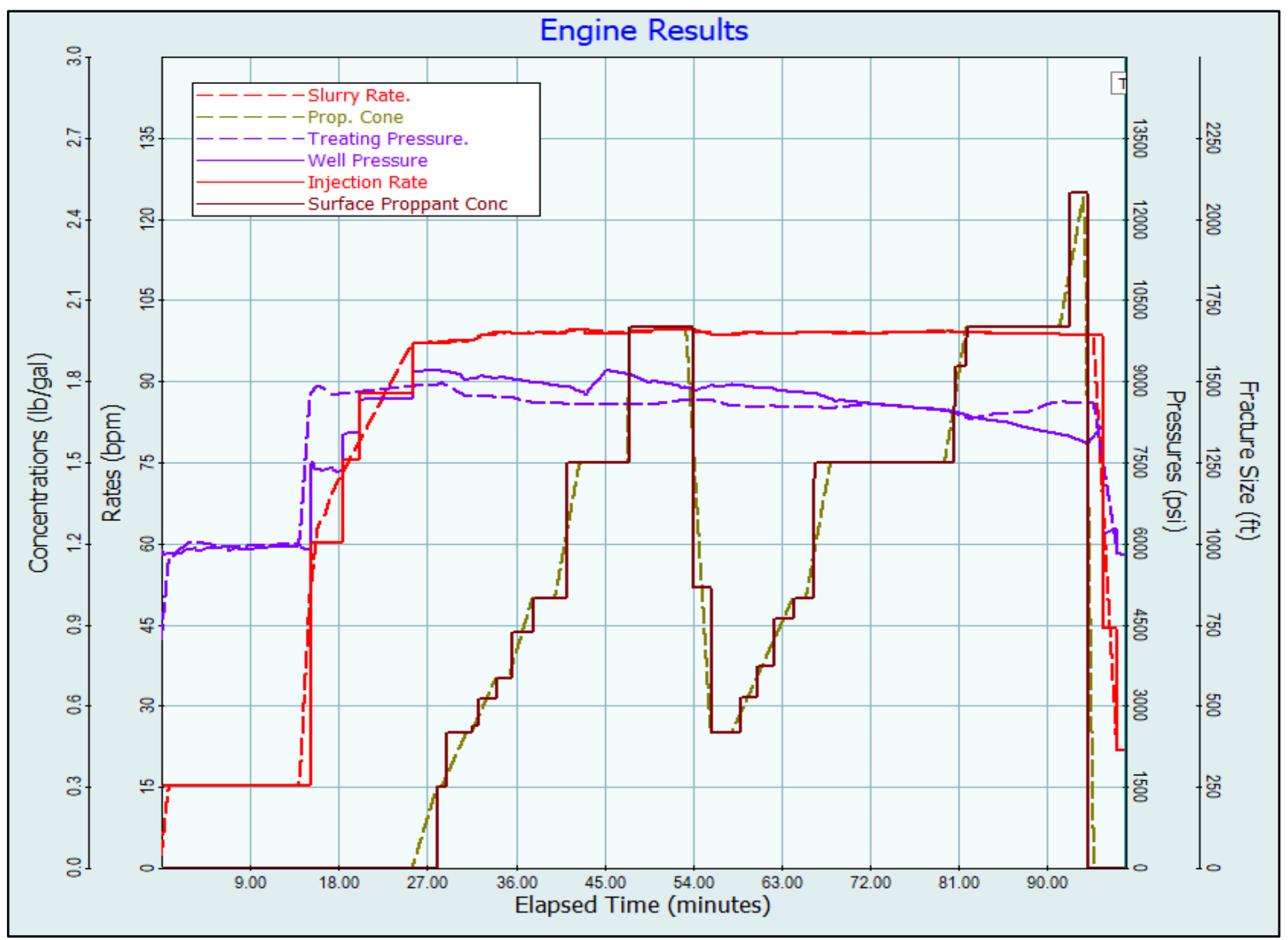

Figure A. 27: Sage 19 treatment data with a matched pressure between model and actual values. Dotted pressure curve represents the actual surface treating pressure (surface pressure in the plot legend), whereas the connected pressure curve represents the model surface treating pressure (well pressure in the plot legend). 


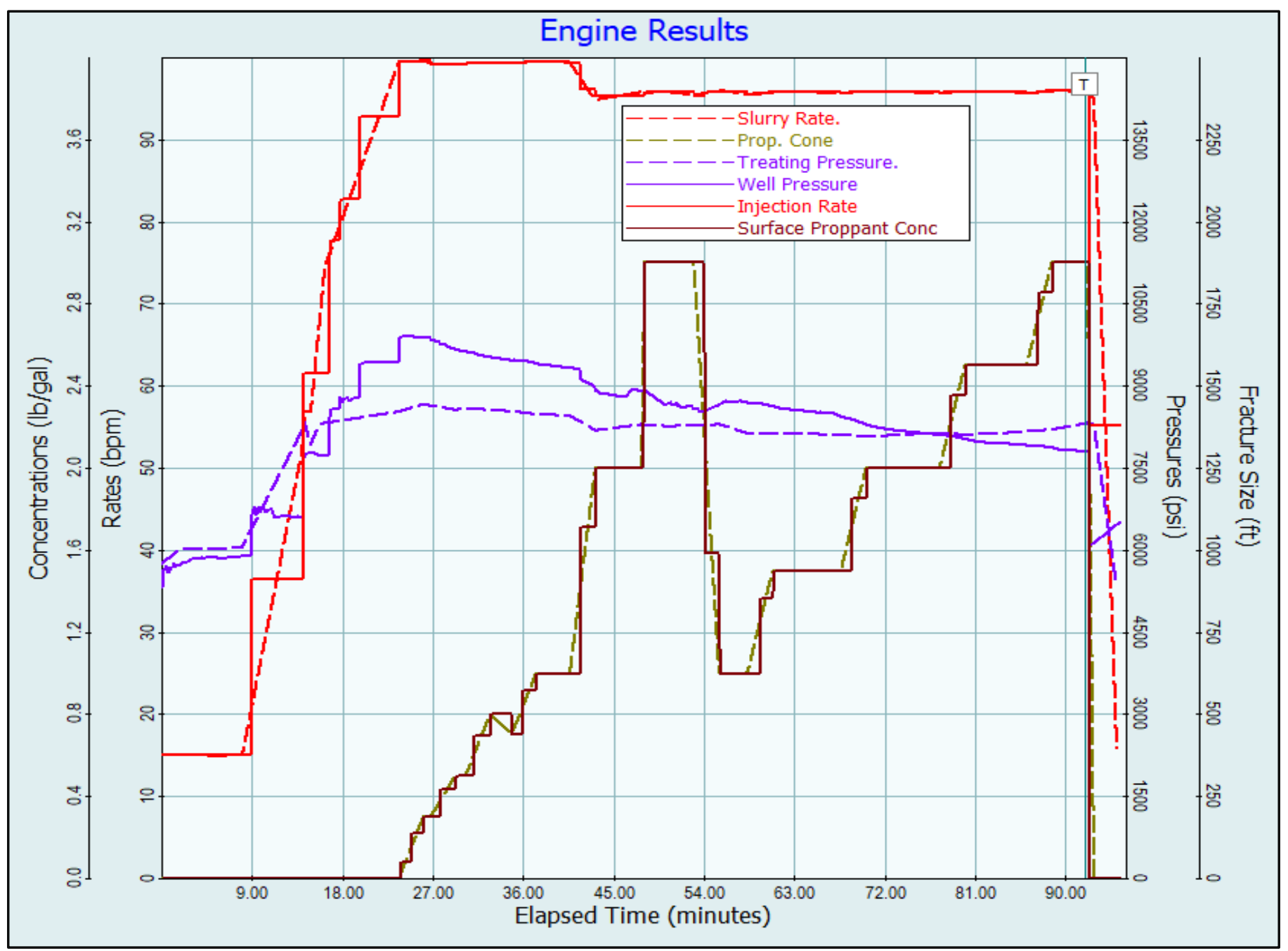

Figure A. 28: Sage 20 treatment data with a matched pressure between model and actual values. Dotted pressure curve represents the actual surface treating pressure (surface pressure in the plot legend), whereas the connected pressure curve represents the model surface treating pressure (well pressure in the plot legend). 


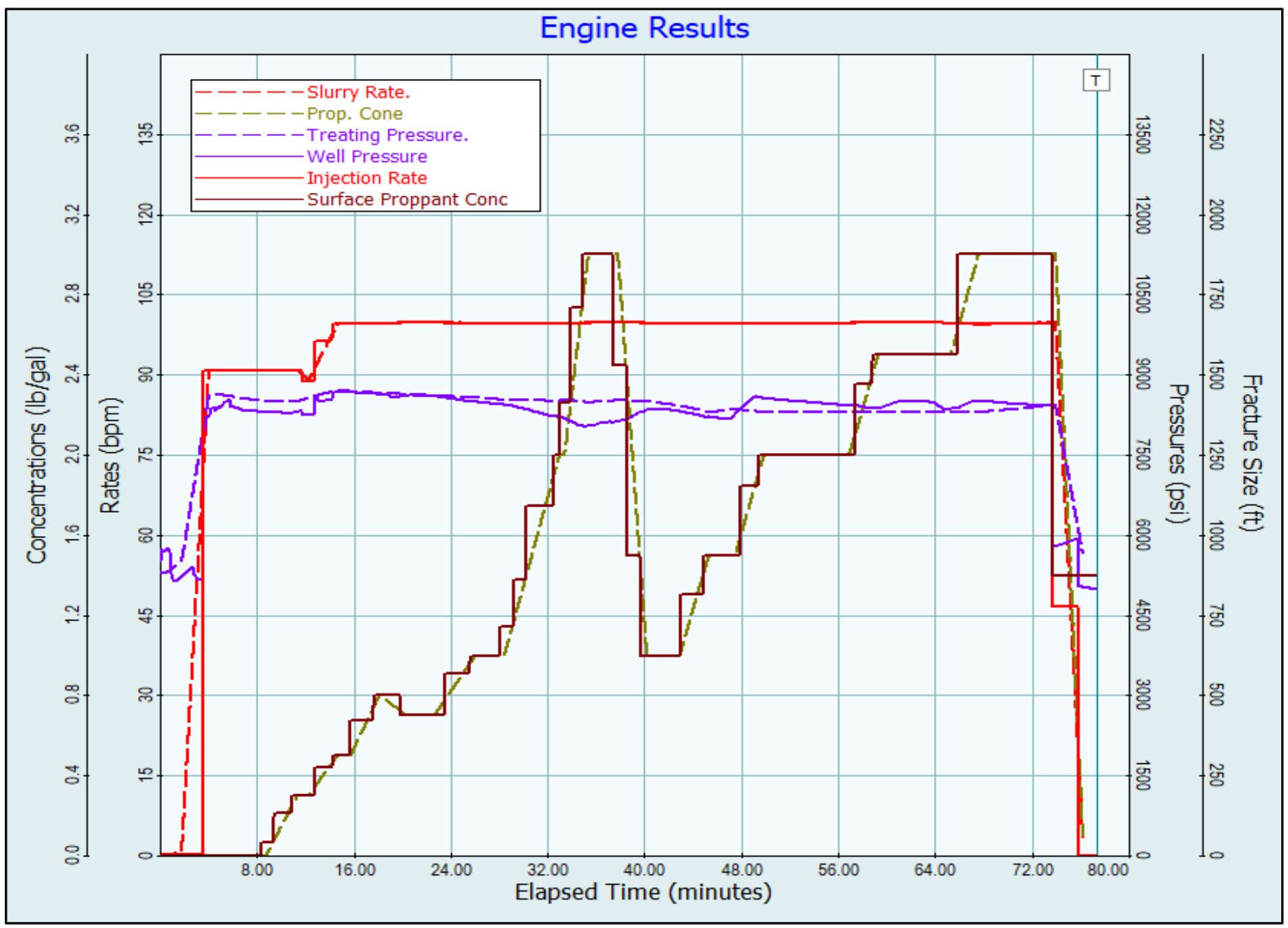

Figure A. 29: Sage 21 treatment data with a matched pressure between model and actual values. Dotted pressure curve represents the actual surface treating pressure (surface pressure in the plot legend), whereas the connected pressure curve represents the model surface treating pressure (well pressure in the plot legend). 


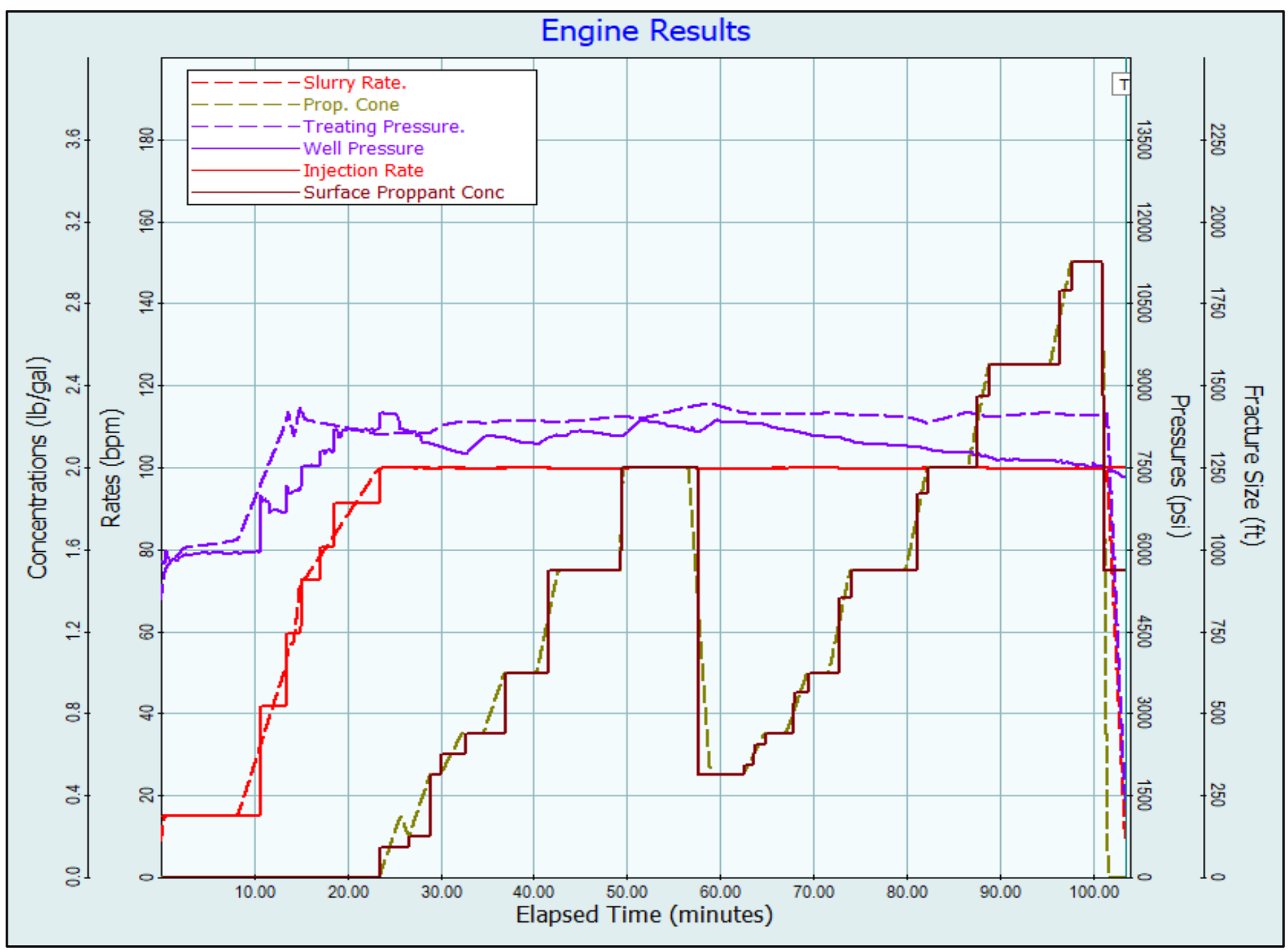

Figure A. 30: Sage 23 treatment data with a matched pressure between model and actual values. Dotted pressure curve represents the actual surface treating pressure (surface pressure in the plot legend), whereas the connected pressure curve represents the model surface treating pressure (well pressure in the plot legend). 


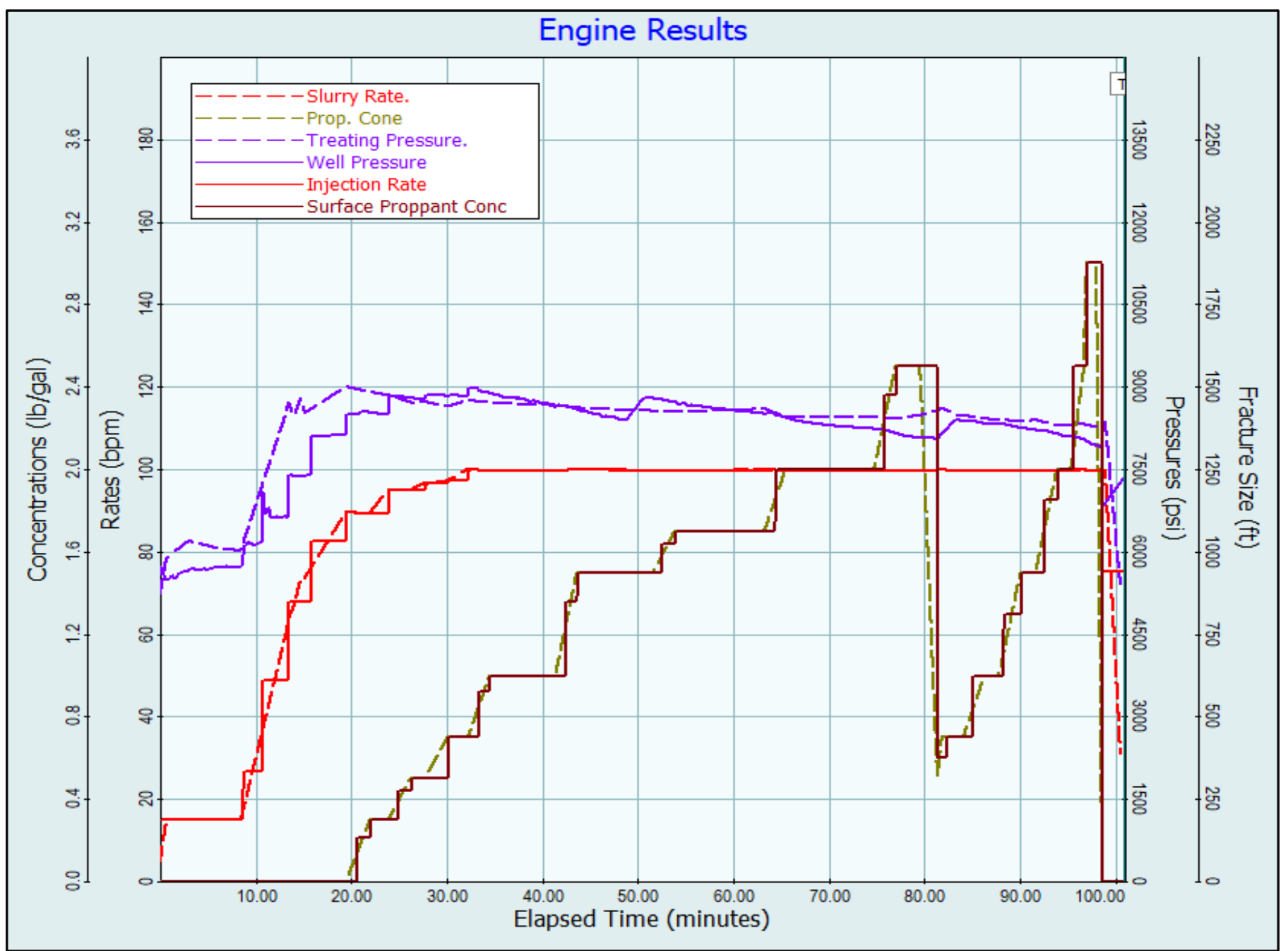

Figure A. 31: Sage 24 treatment data with a matched pressure between model and actual values. Dotted pressure curve represents the actual surface treating pressure (surface pressure in the plot legend), whereas the connected pressure curve represents the model surface treating pressure (well pressure in the plot legend). 


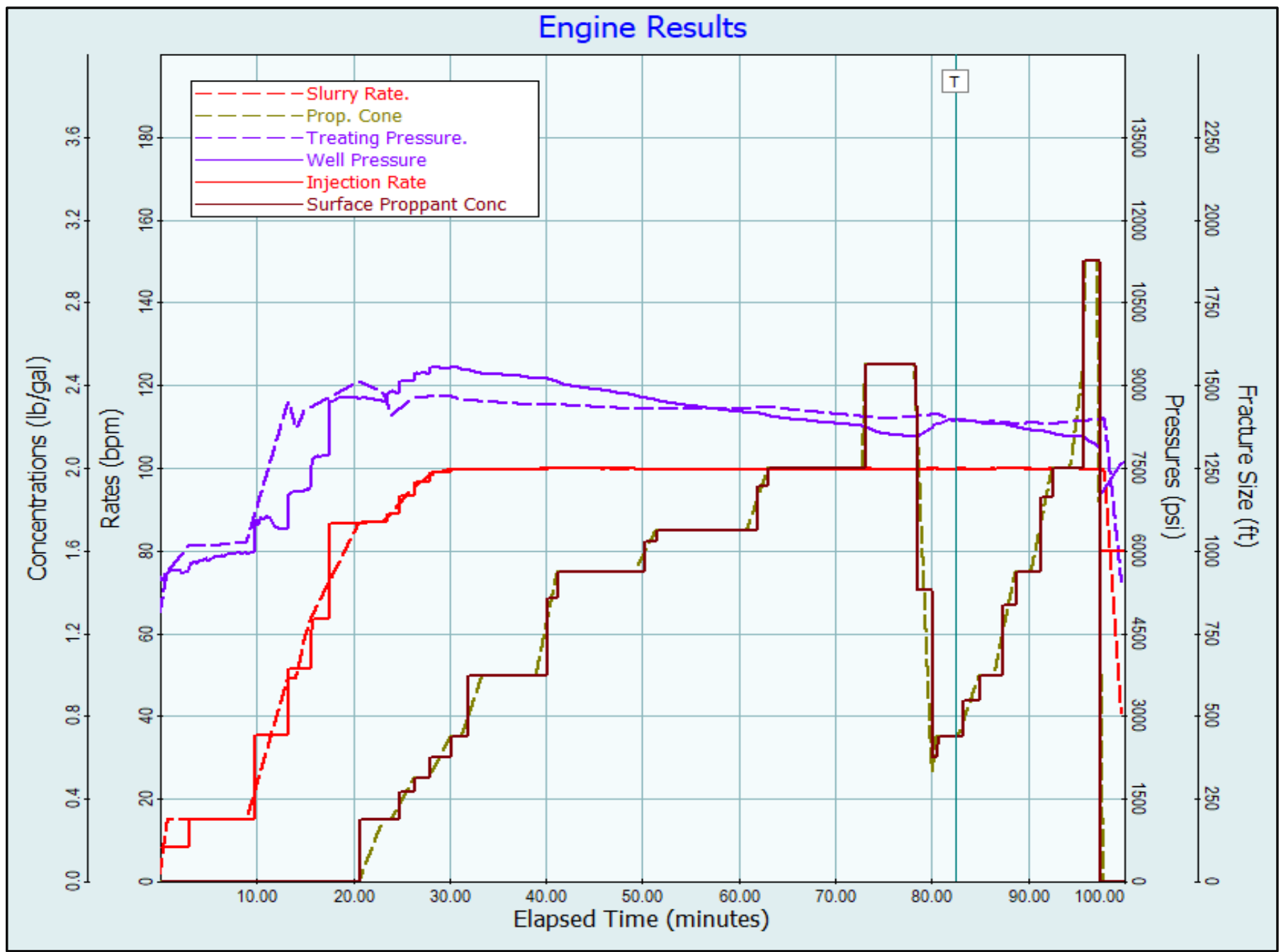

Figure A. 32: Sage 25 treatment data with a matched pressure between model and actual values. Dotted pressure curve represents the actual surface treating pressure (surface pressure in the plot legend), whereas the connected pressure curve represents the model surface treating pressure (well pressure in the plot legend). 


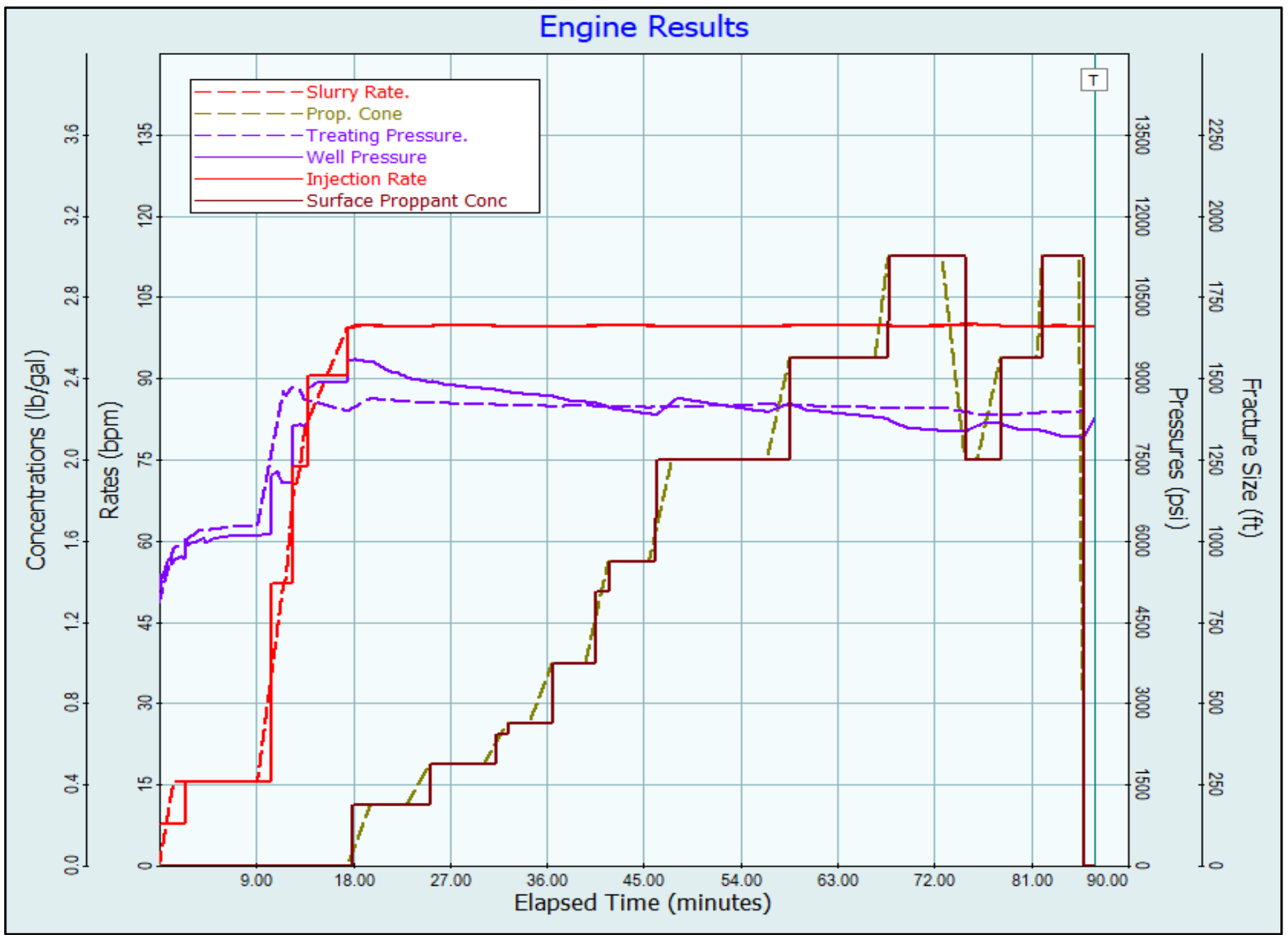

Figure A. 33: Sage 26 treatment data with a matched pressure between model and actual values. Dotted pressure curve represents the actual surface treating pressure (surface pressure in the plot legend), whereas the connected pressure curve represents the model surface treating pressure (well pressure in the plot legend). 


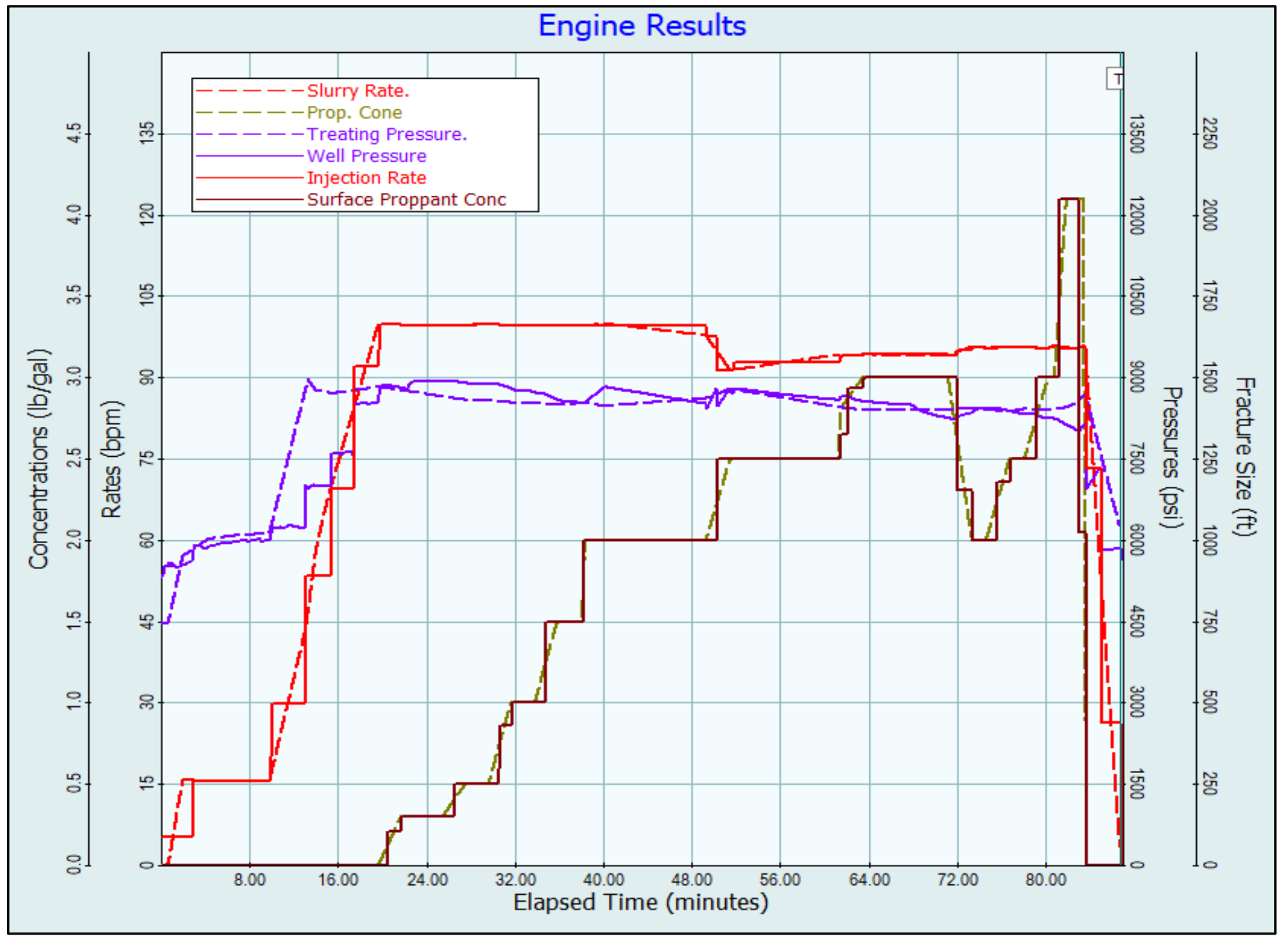

Figure A. 34: Sage 27 treatment data with a matched pressure between model and actual values. Dotted pressure curve represents the actual surface treating pressure (surface pressure in the plot legend), whereas the connected pressure curve represents the model surface treating pressure (well pressure in the plot legend). 


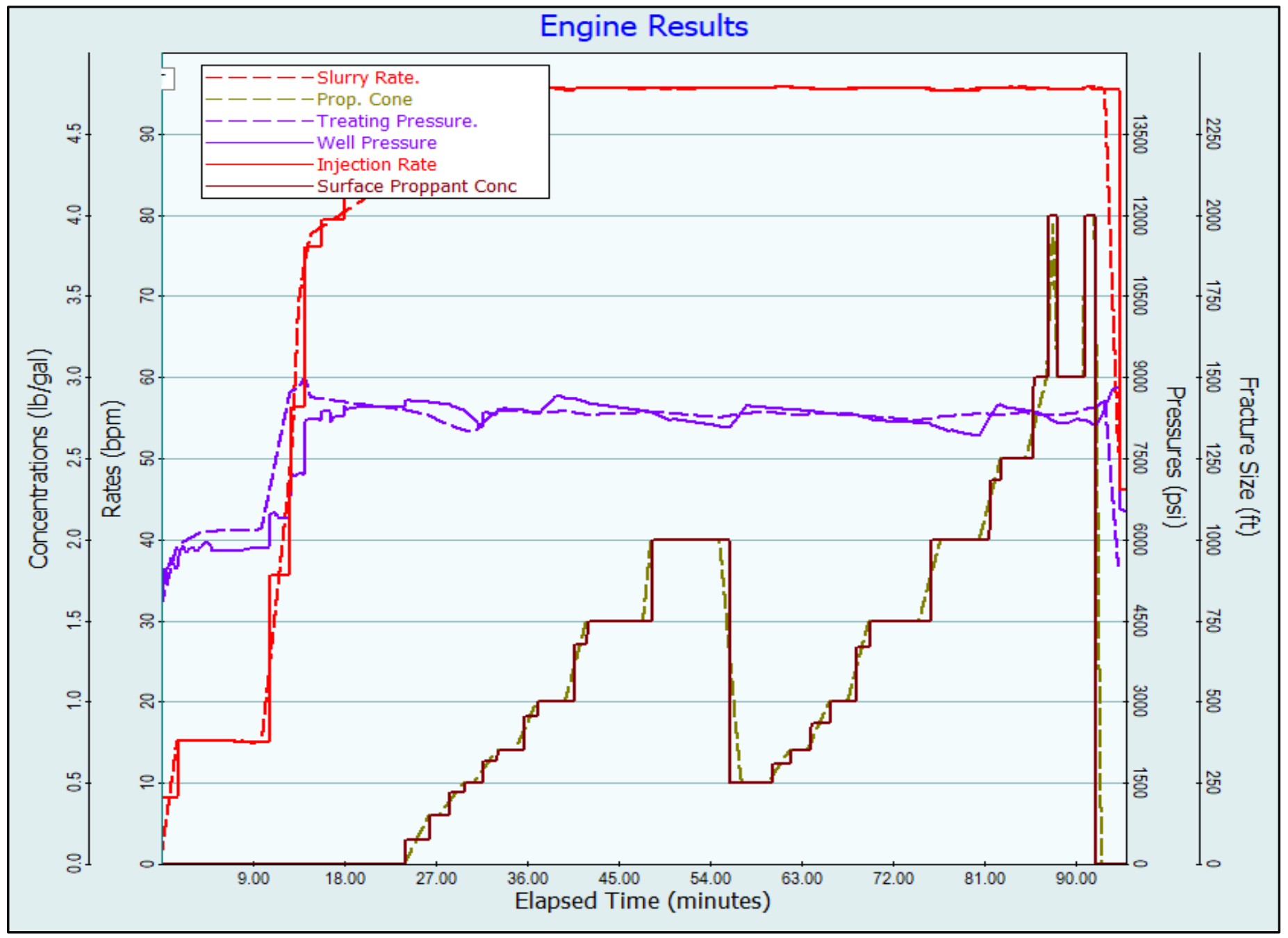

Figure A. 35: Sage 28 treatment data with a matched pressure between model and actual values. Dotted pressure curve represents the actual surface treating pressure (surface pressure in the plot legend), whereas the connected pressure curve represents the model surface treating pressure (well pressure in the plot legend) 